Katrin Boeckh / Oleh Turij (Hg.)

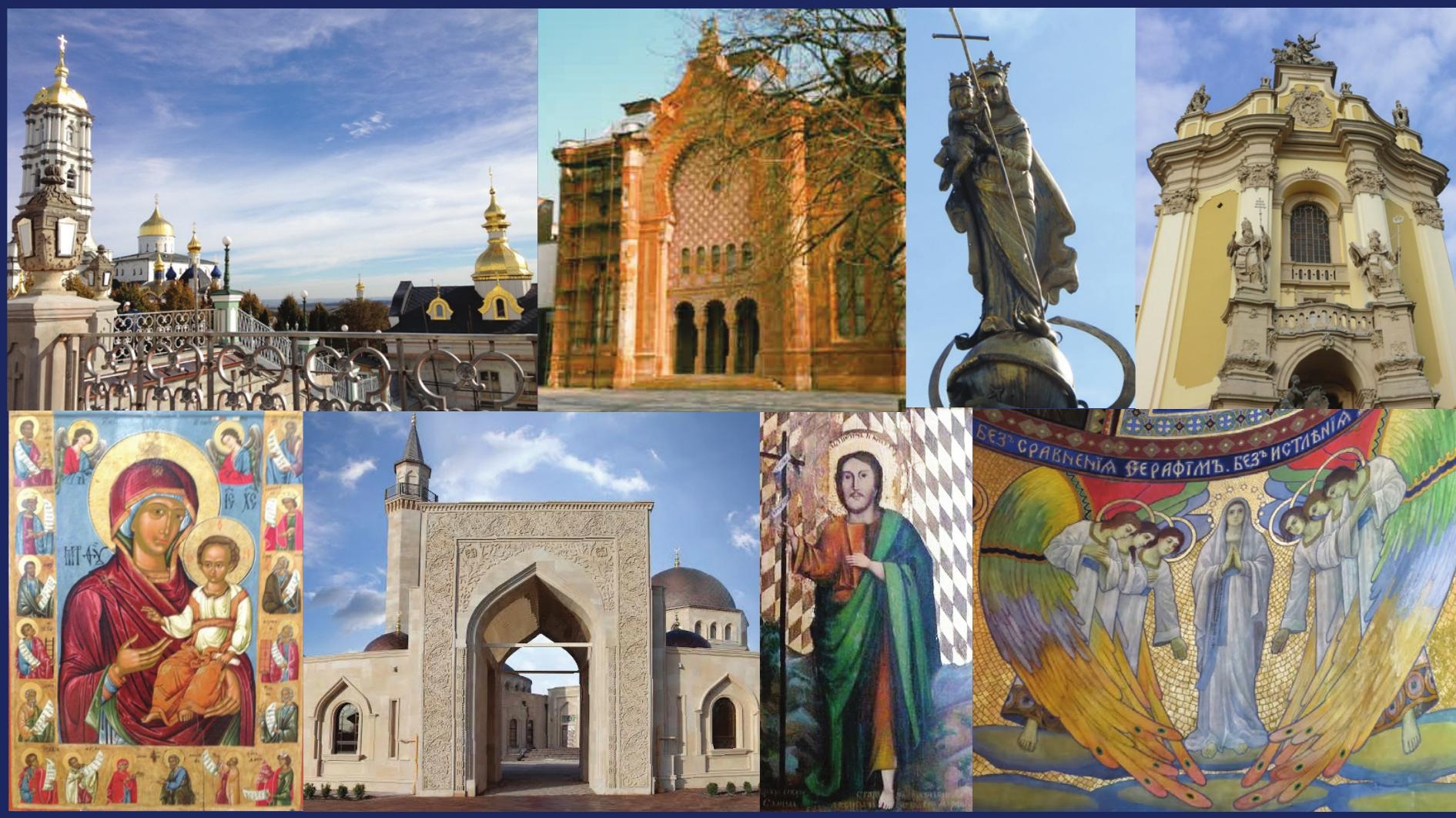

\title{
Religiöse Pluralität als Faktor des Politischen in der Ukraine
}




\section{DigiOst - Band 3}




\section{DigiOst}

Herausgegeben für

Collegium Carolinum, München

Herder Institut, Marburg

Institut für Ost- und Südosteuropaforschung, Regensburg

von

Martin Schulze Wessel

Peter Haslinger

Ulf Brunnbauer 
Katrin Boeckh / Oleh Turij (Hg.)

\author{
Religiöse Pluralität \\ als Faktor des Politischen \\ in der Ukraine
}

EiblionMedia

München - Berlin - Leipzig - Washington/D.C. 2015

DigiOst - Band 3 


\section{DigiOst, Band 3}

Herausgegeben vom

Institut für Ost- und Südosteuropaforschung

Landshuter Str. 4

D-93047 Regensburg

- www.ios-regensburg.de

im Auftrag des Fachrepositoriums für Osteuropastudien OstDok

- www.ostdok.de; www.ostdok.eu

Bereitgestellt und langzeitarchiviert durch die Bayerische Staatsbibliothek

URN: urn:nbn:de:bvb:12-ostdok-X-110-8

Empfohlene Zitierweise der digitalen Fassung

Katrin Boeckh / Oleh Turij (Hg.):

Religiöse Pluralität als Faktor des Politischen in der Ukraine. München 2015.

URL: http://nbn-resolving.de/urn/resolver.pl?urn:nbn:de:bvb:12-ostdok-x-110-8

\section{Umschlag}

Umschlaggestaltung: Christopher Triplett, KI-Media Marburg - London

(c) (i) (2) Creative Commons Namensnennung -

Weitergabe unter gleichen Bedingungen 4.0 International

Digitale Ausgabe auch über: Kubon \& Sagner Digital Library

http://digital.kubon-sagner.com/digiost/

„Biblion Media“ ist ein Imprint der Kubon \& Sagner GmbH

ISBN (Print) 978-3-86688-504-2

ISBN (eBook) 978-3-86688-505-9 


\section{Inhalt}

Katrin Boeckh / Oleh Turij

Einleitung: Religiöser Pluralismus, das Politische und die Ukraine $\ldots . \quad 1$

Kirchen und Staat

Andrij Juraš

Religiöser Pluralismus in der Ukraine.

Eine retrospektive, aktuelle und prospektive Analyse $\ldots \ldots \ldots \ldots \ldots .13$

Iryna Fenno

Die Umsetzung der Prinzipien der Gewissensfreiheit in der Ukraine $\quad$. 49

Martin-Paul Buchholz

Die Kirchen in der Ukraine vor der europäischen Frage $\ldots \ldots \ldots \ldots .65$

\section{Statements:}

Zwischen »Trennung « und symphonie«: Modelle und Praktiken

von Staat-Kirchen-Beziehungen in der gegenwärtigen Ukraine

Jurij Rešetnikov

Welches Modell der Beziehungen zwischen Staat und Kirchen

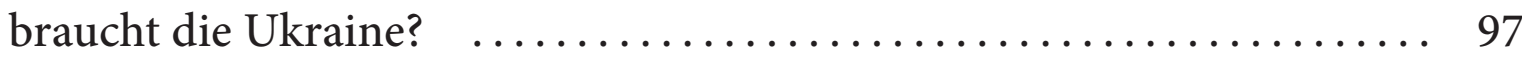

Myroslav Marynovych

Staatliche Favorisierung und Religionsfreiheit. Ein Statement $\ldots \ldots .107$ 
Inhalt

Religion und konfessionelle Vielfalt in der gegenwärtigen Gesellschaft

Oleh Turij

Historische Wurzeln interkonfessioneller Konflikte in der Ukraine:

Identifikationsprobleme der christlichen Kirchen $\ldots . \ldots \ldots \ldots \ldots . . .115$

Olga Popova

Religiosity and Economic Reforms in Transition Countries ........ 139

Maxim Gatskov / Ksenija Gatskova

Zum Anstieg der Religiosität in der postsowjetischen Ukraine:

Empirische Befunde und theoretische Erklärungsansätze $\ldots . \ldots \ldots .153$

Miriam Frey

Werte und Normen in der heutigen Ukraine im regionalen Kontext .. 189

Viktor Jelensky

Religionspluralismus, Religionsfreiheit und Entsäkularisierung:

der Fall Ukraine ...................................... 213

Kirchen in autoritären Regimen

Oleksandr Lysenko

Die Kunst des Möglichen: Die orthodoxe Kirche in der Ukraine

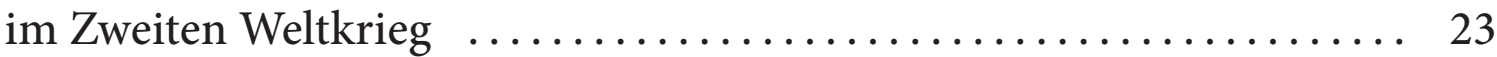

DigiOst 3 | vi 
Inhalt

Natalja Šlichta

»Verschieden « und »Identisch «: Orthodoxe und griechisch-

katholische Gläubige in der Ukrainischen Sowjetrepublik

nach dem Zweiten Weltkrieg $\ldots . \ldots . \ldots . \ldots . \ldots . \ldots . \ldots . . . .249$

Katrin Boeckh

Kirchen und staatliche Institutionen in der Ukraine.

Die Transformationen des Staatskomitees

für Religiöse Angelegenheiten (1917-2013) ............... 277

Die religiöse Dimension im historischen Gedächtnis

Thomas Wünsch

Die Heiligsprechung des Lemberger Franziskaners Johannes von

Dukla (ca. 1414-1484) durch Papst Johannes Paul II. im Jahr 1997:

Eine kirchenpolitische Maßnahme zur Europäisierung der Ukraine? 313

Yuriy Voloshyn

Die Erinnerung an die Schlacht von Poltava in der Zeitschrift

»Poltavskie Eparchial'nye Vedomosti« in den Jahren 1907 bis 1909 .. 333

Carola Söller

Gedenken - Mahnen - Aufarbeiten? Kirchen und

kommunistische Vergangenheit in der Ukraine und in Polen ...... 347

DigiOst 3 | vii 
Inhalt

Religiöse Minderheiten und religiöse Kultur

Viktoria Lyubashchenko

Die Rolle der protestantischen Kirchen im religiösen

und politischen Leben der Ukraine

Stefan Rohdewald

Vom ukrainischen »Antemurale Christianitatis « zur politischen Nation?

Geschichtsbilder der Ukraine und muslimische Krimtataren

395

Ljudmyla Boyarova

Zur religiösen Lexik in der modernen ukrainischen Standardsprache

Autorenverzeichnis

Abkürzungen

Register

DigiOst 3 | viii 


\section{Katrin Boeckh / Oleh Turij}

\section{Einleitung: Religiöser Pluralismus, das Politische und die Ukraine}

Die Publikation des vorliegenden Buches entstand in einer für die Ukraine kritischen Zeit. Die hier versammelten Texte wurden in den Monaten nach den dramatischen Massenprotesten auf dem Euro-Majdan ab November 2013 erstellt. Der Band erscheint nach der völkerrechtswidrigen Annexion der Krim am 18. März 2014 und nach der militärischen Einflussnahme in der Ostukraine durch Moskau. Vor dem Hintergrund der tragisch-revolutionären Wendung der politischen Landschaft der Ukraine steht jedoch der Untersuchungsgegenstand - die Kirchengemeinschaften in der Ukraine - in einem Kontinuum, das über die Zeitenwende 2013/14 hinweggeht, genauso wie er alle anderen und nicht wenigen Krisenzeiten überstanden hat, an und in denen die Ukraine und ihre Bewohner gelitten haben.

Zur Themenstellung des »religiösen Pluralismus als Faktor des Politischen in der Ukraine « führte die Beobachtung, dass die kirchenfeindliche Politik der kommunistischen Regimes in Osteuropa seit 1917 bzw. ab 1944/45 das Ziel, eine möglichst umfassende "Liquidierung« der Religionen herbeizuführen, nicht erreichte. Auffälliger Weise boten gerade Kirchen und Religionsgemeinschaften während des Sozialismus Dissidenten Rückzugsräume, Netzwerke und Meinungsforen, so dass auch Gläubige zu jenen Motoren gehörten, die sich für das Ende der sozialistischen Systeme einsetzten. In der Transformationszeit nach 1989/91 wurden - und dies auch zum großen Erstaunen »im Westen « - im östlichen Europa kirchliche und religiöse Zugehörigkeiten wieder als Massenphänomene sichtbar, was sich an einer Reihe von Umfragen ablesen lässt. In diesen zeigt sich, dass Kirchen und Religionen in den osteuropäischen Gesellschaften viel tiefer verankert sind als dies in Westeuropa der Fall ist. Und sie belegen ferner, dass es trotz der jahrzehntelangen Kirchenverfolgungen 
Boeckh / Turij, Einleitung: Religiöser Pluralismus, das Politische und die Ukraine

während der sowjetischen Zeit nicht gelungen ist, die Religionen als gesellschaftliche Kräfte auszurotten. Wie dies möglich war, ist hier kein expliziter Untersuchungsgegenstand, dennoch werden die Überlebensmechanismen der einzelnen Kirchen immer wieder zwischen den Zeilen der Beiträge und offen deutlich, etwa durch Schein-Mimikry der 1946 bzw. 1949 in den Untergrund gezwungenen unierten Kirche an die Orthodoxie, durch die Verbindung "unsowjetischer« Werte wie Patriotismus, die Menschenwürde und die Bedeutung des Einzelnen mit kirchlichen Überzeugungen oder durch eine Kultur der Offenheit, die beispielsweise im katholischen Bereich Ukrainer und Polen zusammenbrachte und sie auch rein geographisch auf ein Oberhaupt außerhalb der Sowjetunion - im Vatikan - verwies. Dies stellte eine Form freiwilliger Inter-Nationalität in Zeiten geschlossener Staatsgrenzen und geschlossener Gesellschaften innerhalb des »Ostblocks« dar.

Ein weiterer Befund ist, dass auch die historisch bedingte religiöse Vielfalt in der Ukraine nicht durch die sowjetischen Kirchenverfolgungen eingedämmt werden konnte. Vielmehr ist die große Anzahl verschiedener religiöser Gemeinschaften - 2014 waren es offiziellen Angaben zufolge 55 - ein Charakteristikum der Ukraine, das anderweitig in Osteuropa kaum zu finden ist. Die Religionspluralität steht daher im Vordergrund der vorliegenden Analysen, in denen das Agieren von Kirchen, Religionsgemeinschaften und deren Repräsentanten im öffentlichen Leben beleuchtet und die Interaktion und die gegenseitige Beeinflussung zwischen kirchlichen/religiösen und staatlichen Institutionen im Vordergrund stehen. Es sollen die Beziehungen zwischen den Kirchen in der Ukraine und der Staatsmacht in Vergangenheit und Gegenwart analysiert und Entwicklungsprozesse im Verhältnis dieser beiden Pole zueinander benannt werden. Dabei werden historische Kontinuitäten herausgearbeitet, die Veränderungen nach der Orangenen Revolution 2004/05 und der folgenden »blauen« Umwälzungen multiperspektivisch beschrieben, Rückschritte beleuchtet sowie Chancen und Hemmnisse ihrer Perspektive bis kurz vor dem Euro-Majdan 2013/14 ausgelotet.

DigiOst 3 | 2 
Boeckh / Turij, Einleitung: Religiöser Pluralismus, das Politische und die Ukraine

Das Thema ist für die Charakterisierung der gegenwärtigen politischen Lage in der Ukraine deswegen relevant, weil Kirchen und Religionen in Bezug auf die politische Orientierung von Individuen und Gesellschaften oft nicht nur kurzfristig die Meinungsbildung beeinflussen, sondern auch mittelfristige Einstellungen prägen und nicht selten langfristig Werte und Normen definieren. Außerdem lässt sich durch die Untersuchung von Kirchen und Religionsgemeinschaften der Grad der Demokratisierung eines Staats messen: zum einen anhand der Stärke der Regulierung des kirchlichen Bereiches durch die Politik, zum anderen anhand der Wirkungsmöglichkeiten von Glaubensgemeinschaften innerhalb des öffentlichen Lebens. Dass Glaubensgemeinschaften auch als politische Akteure in Erscheinung treten können, sieht man u.a. daran, dass sie die Formulierung, Verhandlung und Entscheidung von Macht- und Interessenfragen auf der Ebene der Tagespolitik (politics) beeinflussen und gleichzeitig selbst einen Teil des politischen Rahmenwerks bilden, in dem sich die Verfassungsrealität des Landes (polity) bewegt. Religions- und Konfessionsgemeinschaften sind auch deswegen als ein zentraler Teil des politischen Lebens zu betrachten, weil eine religiöse Zugehörigkeit das Zusammengehörigkeitsgefühl in einem Staatswesen stärkt, weil sie hilft, zivilgesellschaftliche Wirkung zu entfalten, und weil sie ihre Mitglieder zu einem Engagement auch außerhalb des kirchlichen Raumes motiviert.

Kirchen im »Politischen«: theoretische Annäherung

Das wissenschaftliche Ziel der vorliegenden Publikation besteht darin, einem Desiderat der allgemeinen Religions-, Kirchen- und Politikgeschichte unter Anwendung unterschiedlicher wissenschaftlicher Methoden abzuhelfen. Konzeptionell ordnen wir uns ein in die aktuell proklamierte Neuausrichtung der 
Boeckh / Turij, Einleitung: Religiöser Pluralismus, das Politische und die Ukraine

Politikgeschichte als einer "Kulturgeschichte des Politischen $",{ }^{1}$ wie sie etwa von Barbara Stollberg-Rilinger und anderen vertreten wird, die politische Geschichte neu denken möchten und Diskurse, Praktiken und Bedeutungszuschreibungen politischer Gegebenheiten dynamisch neu rekonstruieren wollen. Im vorliegenden Fall sollen dabei neue Aspekte der »Kulturgeschichte des Politischen « beschrieben werden, weil kollektiv verbindliche Entscheidungen und ihre Repräsentationen aus dem Bereich der Kirchen- und Religionsgeschichte einbezogen werden. Wie sehr religiöse Pluralität ein Gegenstand der Kulturgeschichte neueren Zuschnitts ist, ergibt sich aus den vielen sozial relevanten Manifestationen von Religion und Kirchen: Dazu gehören Verhandlungen um Kirchenbauten, juristische Auseinandersetzungen um die Rückgabe kirchlichen Eigentums über mehrere Kommunikationsebenen hinweg, öffentlichkeitswirksame Ereignisse wie Prozessionen, Wallfahrten, Heiligenverehrung etc. und die Sprache von Religionen und über Religionen. All dies reicht weit über den engeren kirchlichen Rahmen hinaus und bildet ein Wesenselement dessen, was Öffentlichkeit und »das Politische« ausmacht.

Untersuchungswürdig erscheint vor allem die Präsenz des Religiösen als soziales und intellektuelles Reservoir. Der ukrainische Fall ist besonders interessant, weil sich hier eine breite interkonfessionelle wie auch interreligiöse Konkurrenz abspielt, im Unterschied zum benachbarten Russland wird diese seit dem Ende der sowjetischen Herrschaft hier nicht generell verhindert oder bedroht, sondern wenigstens geduldet und auch gefördert.

Weiter soll die bisherige Kulturgeschichte des Politischen dadurch angereichert werden, dass wir nicht nur historisch und kulturologisch argumentieren, sondern auch multidisziplinär sondieren, da sozialwissenschaftliche Methoden ebenfalls zur Anwendung kommen und soziologische sowie ökonomische

1 Barbara Stollberg-Rilinger (Hg.): Was heißt Kulturgeschichte des Politischen?, Berlin 2005 (= Zeitschrift für Historische Forschung; Beiheft 35), 9-24.

DigiOst 3 | 4 
Boeckh / Turij, Einleitung: Religiöser Pluralismus, das Politische und die Ukraine

Determinanten für religiös motiviertes Handeln in das Gesamtbild miteinbezogen werden.

Den politischen Umbruch Ende der 80er, Anfang der 90er Jahre trieben Kirchen und ihre Repräsentanten als aktive Motoren und Unterstützer der Demokratiebewegung des Landes voran. Bezogen auf den Stand und Erfolg der Demokratisierung, der sich die ukrainischen Regierungen deklamatorisch und mit tatsächlichen Anstrengungen ab den 1990er Jahren unterwarfen, ist die innenpolitische Lage für Gläubige und Religionsgemeinschaften ein feiner Seismograph. Je mehr Handlungsfreiheit nämlich diesen zugestanden wird, als umso fortgeschrittener kann die Demokratisierung eines Landes eingeschätzt werden. Dies trifft auch zu in Bezug auf den politischen Freiraum, der einer religiösen Pluralität zugestanden wird, die mehr oder weniger staatlich geduldet oder gefördert werden kann. Hier, so wird im Folgenden beschrieben, blicken die Ukrainer auf eine lange Tradition der Existenz vieler Kirchen und Religionsgemeinschaften zurück, die über die Jahrhunderte hinweg alle landesherrschaftlichen Formen überlebten. Dabei waren sie aber auch immer wieder mit der Zurückdrängung - wie zu sowjetischer Zeit - und mit dem politischen Versuch in der post-sowjetischen Zeit, eine "homogene ukrainische Kirche" herzustellen, konfrontiert. Die intensivste Tendenz, eine »Einheitskirche« in der Ukraine zu etablieren, geht ausgerechnet auf die »orangene « Präsidentschaft von Viktor Juščenko (2005-2010) zurück, der als politischer Reformer westlichen Zuschnitts angetreten war. Nach dem Ende seiner »orangenen « Regierung wurde allenthalben beklagt, dass die Glaubens- und Gewissensfreiheit, während sie in der Verfassung von 1996 garantiert sind, in der Anwendung und Praxis in der Ukraine jedoch zu Sorge Anlass bereiten. Bereits in diesem Punkt wurde also klar, dass die Regierung von Viktor Janukovyč (2010-2014) wenigstens Demokratiedefizite aufwies, die sie kaum »Europa-tauglich" erscheinen ließ und unter der Bevölkerung die Unzufriedenheit mit seiner Politik noch verstärkte. Dabei waren es kirchliche Institutionen und Vertreter, die sich vor dem Euro-Majdan 2013/2014 an die Spitze der Westintegration der Ukraine

DigiOst 3 | 5 
Boeckh / Turij, Einleitung: Religiöser Pluralismus, das Politische und die Ukraine

stellten, indem sie in ihren Verlautbarungen "westliche Werte « wie die Einhaltung der Menschenrechte, bürgerliche Gleichheit und ähnliches unterstrichen und gesellschaftliche Diskussionen darüber anstießen, gleichzeitig aber dabei massive staatliche Behinderung erfuhren, als sie versuchten, eigene Kommunikationsstrukturen nach Brüssel aufzubauen.

Mit Blick auf die Ausgestaltung des Verhältnisses zwischen Staat und Kirche haben sich in Europa und darüber hinaus länderspezifische Modelle und Praktiken von Beziehungen zwischen Staat und Kirche sowie zwischen den Konfessionsgemeinschaften herausgebildet. Da das Prinzip der Trennung von Kirche und Staat im sowjetischen Kontext einseitig kirchenfeindlich ausgelegt wurde, ist die Diskussion über dieses Prinzip in der Ukraine wie in allen anderen post-sowjetischen Staaten viel tiefergehender als etwa in westeuropäischen Ländern, die ebenfalls diese Trennung befolgen, allerdings unter dem entgegengesetzten Vorzeichen der wohlwollenden Unterstützung von Kirchen.

Unabhängig von den Spezifika des »ukrainischen Weges« nach dem Ende der Sowjetherrschaft sind die gegenwärtigen Befunde für die Gesellschaft in der Ukraine jenen in anderen osteuropäischen Transformationsstaaten ähnlich: Die persönliche Religiosität hilft, sich auf die oft einschneidenden ökonomischen Reformen der postkommunistischen Staaten einzulassen und sie leichter durchzustehen. Ökonomische Untersuchungen legen den Schluss nahe, dass religiöse Personen mit ihrer Situation im Leben während der Wirtschaftsreformen in ihren Ländern zufriedener sind als nicht-religiöse Mitbürger. Empirisch lässt sich überzeugend nachweisen, dass Glaube und Religiosität in der postsowjetischen Ukraine in spezifischer Weise anwachsen, bedingt durch das ideologische Vakuum am Ende der kommunistischen Herrschaft, durch die Enttäuschung über fehlende Transformationserfolge, durch das Vertrauen zu den institutionellen Strukturen von Kirchen, aber auch durch bestehende Wertorientierungen und durch kulturelle Mechanismen ihrer Vertiefung. Dabei zeigen sich in der Ukraine, auch ohne Berücksichtigung der unterschiedlichen Religionen und Konfessionen, regional abgrenzbare Diversitäten bei der Ver- 
Boeckh / Turij, Einleitung: Religiöser Pluralismus, das Politische und die Ukraine

ankerung von individuellen Wert- und Normvorstellungen und bei kulturellen Praktiken, durch welche sich die Westukraine von den übrigen Landesteilen abhebt. Die in der gegenwärtigen Ukraine anzutreffende Entsäkularisierung weist ebenfalls regionale Eigenheiten auf und verbindet sich mit einer größeren Religiosität in der Westukraine. Soziologisch betrachtet wird klar, dass die Breite an religiösen Gemeinschaften in der Ukraine als solche von der Bevölkerung kaum wahrgenommen wird; politisch auftretendes Engagement begründet durch den kirchlichen Pluralismus im Land geht daher vor allem auf die führenden Repräsentanten der Religionsgemeinschaften zurück, während eine »Entsäkularisierung von unten « von ihren breiteren Mitgliederschichten betrieben wird. Trotz der unter Janukovyč vorgenommenen verstärkten Instrumentalisierung kirchlicher Strukturen wird den Glaubensgemeinschaften die Kraft zugesprochen, Hilfestellungen bei gesellschaftlichen Änderungen leisten zu können.

Eine wichtige Frage in diesem Zusammenhang lautet, welchen Beitrag die Kirchen in der Ukraine geleistet haben und leisten, um demokratische Strukturen zu etablieren und instand zu halten. Auch wenn Religionen selbst nicht dem demokratischen Prinzip verpflichtet sind, so sind sie doch vielfach im gesellschaftlichen und gesellschaftspolitischen Bereich ein Korrektiv gegen Willkür, Machtkonzentration und Intransparenz. Dies beobachten wir in einem Abschnitt über die Situation und das Handeln von Kirchen in jenen autoritären Regimen, die die Ukraine im 20. Jahrhundert überzogen, die sowjetische und die nationalsozialistische Diktatur. Beide ihrer Ideologie nach atheistisch ausgerichtet, kamen sie den Kirchen während des Zweiten Weltkrieges unter allerlei Einschränkungen entgegen. Diese standen nun im Dilemma, auf das staatliche Angebot einer limitierten Existenz einzugehen oder die institutionelle Zerschlagung zu riskieren. Die bestehenden Kirchenorganisationen in der Ukraine wählten erstere Option. Fällt dies moralisch oder strafrechtlich in die Kategorie der »Kollaboration«? Für die sowjetische Herrschaft nach dem Zweiten Weltkrieg war diese Frage auf jeden Fall zu bejahen - und die Antwort

DigiOst 3 | 7 
Boeckh / Turij, Einleitung: Religiöser Pluralismus, das Politische und die Ukraine

wurde zu einem erneuten Vorwand dafür, bis zu ihrem Ende wieder Druck auf Kirchen, ihre Repräsentanten und Angehörigen bis hin zu Gewalt auszuüben. Hilfestellungen dafür, dass dies nach außen hin nicht zu sichtbar wurde, gab dabei eine Reihe von staatlichen Institutionen, Räten und Komitees, die in enger Verbindung zu den Verfolgungsbehörden wie dem Innenministerium agierten. Erstaunlicherweise errang in der Transformationszeit ein solcher für Religionen und Kirchen zuständiger Rat deren Wertschätzung als politischer Ansprechpartner, den sie nicht verlieren wollten. Dies mag eines der wenigen Beispiele dafür sein, dass sich sowjetische Erbschaften positiv wenden ließen.

Erinnerungspolitik hat in der Ukraine insofern eine nicht zu unterschätzende Bedeutung, als durch deren staatliche Lenkung der ukrainische Regionalismus durch gemeinsame und übergreifende integrative Themen überwölbt werden sollte. Auf Integration muss auch das historische Gedächtnis und die Erinnerungspolitik, die von den Kirchen selbst betrieben wird, aus sein. Der Befund hier zeigt, das kirchliche und staatliche Erinnerung auch historisch gesehen eng miteinander verknüpft sind, aber Widersprüche aufweisen: Während einerseits die Erinnerung, die der polnische Papst Johannes Paul II. aktiv durch die Seligsprechung von Johannes von Dukla betrieb, zur Werbung im "Westen « für kirchliche Gegebenheiten in Ostmitteleuropa beitrug und diesen Raum gleichsam politisch nach Europa wieder zurückholte, sind noch längst nicht alle Fragen auf den Tisch gelegt worden, die sich mit den kirchlichen Verwicklungen in den autoritären Systemen der Vergangenheit beschäftigen.

Kleinere Kirchengemeinschaften haben in der Ukraine denselben Status wie Kirchengemeinschaften, die in Russland unter der Bezeichnung "traditionelle Religionen « firmieren. Charakteristisch für die Situation in der Ukraine ist im Unterschied zu Russland, dass viele von ihnen - dazu gehören die Protestanten und Katholiken - in der Ukraine seit langer Zeit präsent sind. Durch den politisch akzeptierten religiösen Pluralismus und die praktizierten und sich weiter intensivierenden konfessionellen Kontakte haben auch die kleineren Kirchen und Minderheitenreligionen eine gute Position in der ukrainischen 
Boeckh / Turij, Einleitung: Religiöser Pluralismus, das Politische und die Ukraine

Öffentlichkeit. Die Vielfalt der religiösen Landschaft erweist sich als günstiger Standortfaktor. Dazu kommt, dass auch sie in der großen Mehrheit grundsätzlich der ukrainischen Staatlichkeit gegenüber positiv eingestellt sind, dennoch aber - genauso wie alle anderen Kirchengemeinschaften - an Demokratiedefiziten wie Behördenwillkür und Korruption leiden. Dabei sind die christlichen wie auch die nicht-christlichen Minderheitenkirchen in der Ukraine gesellschaftlich integriert. In unseren Fallbeispielen ist aber an den protestantischen Christen zu beobachten, dass sie sich im politischen Leben eher zurückhalten als Mitglieder der größeren Kirchen, dass sie jedoch auch sensibler auf das politische Umfeld reagieren (müssen). Bezogen auf die muslimische Bevölkerung, hier die Krimtataren, deren Vertretungsorgane immer wieder ihr Bekenntnis zur Demokratie und zu westlichen Werten abgelegt haben, bestehen in der Ukraine integrative Nationsmodelle, die von einer politischen, keiner ethnischen Zugehörigkeit zur Staatsnation ausgehen und die Muslime mit einbeziehen. Nach der Flucht vieler Krimtataren in die Zentral- und Westukraine seit 2014 wird sich die Integration der Muslime in das christliche Umfeld noch weiter vertiefen.

Sprache gehört zu den elementaren Voraussetzungen für menschliches Handeln, sowohl im politischen wie im kirchlichen Bereich. Die Analyse zeigt, dass beide Sphären nicht unabhängig voneinander bestehen, dass aber vor allem die orthodoxe Kirche als jene mit den meisten Mitgliedern die religiöse Lexik im Ukrainischen prägte. Es ist davon auszugehen, dass auch mit einem steigenden religiösen Pluralismus die religiöse Lexik als ein Untersystem der ukrainischen Standardsprache keine großen Veränderungen erfahren wird.

Charakteristisch für die Ukraine ist jedenfalls, dass das innenpolitische Verhältnis zwischen Staat und Kirchen wohl weit stärker als in anderen europäischen Ländern durch außenpolitische Einflussnahmen und Rücksichten bestimmt wird. Die externe Einflussnahme auf das Geschehen in der Ukraine ist nicht explizit im Vordergrund der Beiträge, dennoch ist vielerorts subkutan das Konfliktpotential mit dem östlichen Nachbarn vernehmbar. Innensichten in die Zeit kurz vor dem Euro-Majdan und die damalige politische Lage lassen

DigiOst 3 | 9 
Boeckh / Turij, Einleitung: Religiöser Pluralismus, das Politische und die Ukraine

daher einen sensiblen Leser das sich dann entladende Szenario des kompletten Bruchs mit dem Regime in Kiev ab Oktober 2013 erahnen. Die immensen humanitären Investitionen dafür sind freilich noch nicht absehbar.

Die Herausgeber danken herzlich allen jenen, die dieses Projekt ermöglicht haben: dem Deutschen Akademischen Austauschdienst (DAAD), der die finanziellen Mittel für die dem Unternehmen zugrunde liegende Konferenz im Oktober 2013 in der Ukraine und für die Publikation bereitstellte, der Ukrainischen Katholischen Universität in L'viv/Lemberg für die freundliche Aufnahme während unserer Konferenz, Jurij Durkot und Benedikt Praxenthaler für die sorgfältige Übersetzung der ukrainischen Texte und nicht zuletzt sämtlichen Beitragenden in diesem Band, die zügig und - bei den ukrainischen Autoren - unter den schwierigen Bedingungen des Euro-Majdan 2013-2014 ihre Texte erstellt haben.

Wir verwenden in der Regel die wissenschaftliche Transliteration ukrainischer und russischer Namen sowie zumeist die ukrainischen Ortsnamen unter Ausnahme von Kiev, Odessa, Krim.

Wir widmen den Band dem Gedenken an Bohdan Sol'čanyk (25.7.198520.2.2014), Dozent der Ukrainischen Katholischen Universität L'viv, von Heckenschützen auf dem Majdan erschossen.

Regensburg, L'viv

Katrin Boeckh, Oleh Turij 
Kirchen und Staat 
Katrin Boeckh - 978-3-86688-505-9 


\section{Andrij Jurǎ̌}

\section{Religiöser Pluralismus in der Ukraine. Eine retrospektive, aktuelle und prospektive Analyse}

Die These der unikalen polykonfessionellen Situation, das heißt eines bemerkenswerten religiösen Pluralismus in der Ukraine, ist weit verbreitet. Wenn aber viele vor 15 bis 20 Jahren diese Situation als eine Art Anomalie oder vorübergehende Erscheinung angesehen haben, so versuchen heute die Gesellschaft insgesamt und insbesondere die Religionsforscher dieses Phänomen mit weniger Emotionen und größerer Systematik zu betrachten. Die Diskussionen werden dabei nicht nur unter dem Blickpunkt moralischer Wertungen und Präferenzen geführt (Ist es gut oder schlecht? Welchen Einfluss hat es auf die ukrainische politische und andere Realität?), sondern es geht um den Anfang für eine umfassende Analyse dieses Phänomens: um die rein theoretische Forschung, um die historischen Vorbedingungen, um die Berücksichtigung der im modernen Kontext sichtbaren Erscheinungsformen, aber auch der Determinanten des religiösen Pluralismus, die entweder im Laufe der vergangenen geschichtlichen Epochen oder in der Gegenwart dessen Charakter in der Ukraine bestimmten oder gar für das Aufkommen oder die Existenz dieses Phänomens verantwortlich waren. Bei einem aufmerksamen Blick auf den modernen religiösen Pluralismus in der ukrainischen Gesellschaft muss folgende Frage beantwortet werden: Ist es ein rein ukrainisches ethnisches, endogenes Phänomen, das sich »innerhalb« der ukrainischen ethnischen Gemeinschaft herausgebildet hat, oder ist es eine »äußere« (exogene) Erscheinung vor dem ukrainischen ethnischen Hintergrund, die unter dem Einfluss von verschiedenartig gerichteten heterogenen politischen, ethnischen und historischen Faktoren entstanden ist, welche in diversen historischen Epochen mit dem ukrainischen ethnischen Element zusammengewirkt und zur Entstehung des heute zu beobachtenden konfessionellen Pluralismus beigetragen haben? In 
Juraš, Religiöser Pluralismus in der Ukraine

dem vorgeschlagenen Kontext ist es nicht möglich, eine eindeutige Antwort darauf zu geben. Die Behauptung, dass der ukrainische religiöse Pluralismus ein komplexes Phänomen ist, zu dessen Grundlagen und Determinanten sowohl der rein ukrainische ethnische Hintergrund als auch äußere Faktoren gehören, scheint aber plausibel. Wir haben also mit einem mehrschichtigen Phänomen zu tun, das nicht durch ein einziges Paradigma oder nur eine Charakteristik definiert werden kann. Deswegen wird es hier aus verschiedenen Perspektiven betrachtet.

\section{Erster Blickpunkt: Die ausschließlich auf den ukrainischen ethnischen Hintergrund ausgerichtete religiös-konfessionelle Pluralität}

Um den Forschungsgegenstand zu präzisieren, wird hier ein einheitliches Konzept der religiös-konfessionellen Entwicklung der ukrainischen Ethnie von vorchristlicher Zeit bis zur Gegenwart vorgeschlagen. Als Grundlage für die Analyse dient der Begriff, der hier als konfessioneller Status der ukrainischen ethnischen Gemeinschaft in verschiedenen Zeitperioden bezeichnet wird. Entscheidend dabei ist die Tatsache, welche Religionsgemeinschaften die konfessionelle Situation in der ukrainischen Gesellschaft in einem konkreten historischen Zeitraum geprägt haben. Aus unserer Sicht ist es ratsam, die entsprechenden Tendenzen von den Anfängen der Ausbildung jener Identität, die wir heute als ukrainisch bezeichnen, zu verfolgen. 
Juraš, Religiöser Pluralismus in der Ukraine

Erste Periode: Das Heidentum als Staatsreligion oder das Zeitalter bedingter Monokonfessionalität (bis 988)

Beachtenswerter Weise können selbst die Einwohner der Rus', die bis zur offiziellen Übernahme des Christentums im Jahr 988 in großer Mehrheit eine heidnische Weltanschauung hatten, nicht eindeutig als monokonfessionelle Ethnie bezeichnet werden. Erstens gab es auch in dieser Zeit viele Einflüsse anderer Konfessionen und Ethnien. Es ist bekannt, dass in der Kiever Rus', besonders in ihrem südlichen Teil, zahlreiche religiöse Minderheiten lebten, die enge Kontakte zur slavischen Bevölkerung pflegten. In den griechischen Siedlungen auf der Krim und im nördlichen Schwarzmeerraum dominierte die Orthodoxie, also das östliche Christentum mit byzantinischem Ritus. In Kiev selbst bestand offiziell seit der Mitte des 9. Jahrhunderts die byzantinische Kirche des Heiligen Ilias, die nicht nur für ausländische Christen (Kaufleute und Söldner, die dem Großfürsten dienten), sondern auch für einheimische Christen geöffnet war. Folgende geschichtliche Fakten zur Christianisierung eines kleineren Teils der autochthonen slavischen Bevölkerung der Rus' vor 988 können als gesichert gelten:

- die erste Taufe der Einwohner Kievs während der Herrschaft von Askold und Dir (in den 860er Jahren);

- die Vertretung der Rus' bei der Unterzeichnung des Vertrags mit Konstantinopel unter Fürst Igor (941) durch adelige slavische Christen;

- die Taufe der Fürstin Ol'ga 955 oder 957;

- die mögliche Taufe des Fürsten Jaropolk (in den 970er Jahren).

Außer der unmittelbaren Bekanntschaft mit dem byzantinischen Christentum waren die Einwohner der Rus' auch über dessen andere Zweige bestens informiert. Gotische Stämme, die zwischen dem 2. und 4. Jahrhundert das gesamte Gebiet zwischen Dnistr und Donec' bevölkerten und später nach 
Juraš, Religiöser Pluralismus in der Ukraine

Westen abwanderten, machten die Rus' mit dem Arianismus bekannt, der am stärksten verbreiteten und einer der einflussreichsten Bewegungen des ersten christlichen Jahrtausends. Die armenischen Kolonisten in Kiev und im nördlichen Schwarzmeerraum hielten sich unbeirrt an ihren eigenen Ritus und an ihre eigene kirchliche Tradition.

Zweifellos versuchten auch westliche Kaufleute, Botschafter und Missionare, den Einwohnern der Rus' die Vorteile der christlichen Kirche nach westlichem Muster nahezubringen. Die ersten belegten Kontakte der Rus' mit der römischen Kirche werden in der Chronik von Tietmar von Merseburg auf 959 datiert, als Fürstin Ol'ga den deutschen Kaiser Otto I. bat, Bischöfe und Priester in die Rus' zu entsenden. Vom 8. bis zum 10. Jahrhundert gab es in den meisten Städten der Kiever Rus' zahlreiche Kaufleute persischer Herkunft, die sich an Manichäismus, Paulikianismus oder Nestorianismus hielten und diesen Glauben verbreiteten.

Außer verschiedenen christlichen Konfessionen waren auch der Islam, der sich damals im Nordkaukasus bereits etabliert hatte, sowie der Judaismus, der zur offiziellen Religion im Reich der Chasaren - einem gefährlichen Nachbarn des Kiever Staates - erhoben wurde, an der Verbreitung ihrer Einflüsse in der Kiever Rus' interessiert.

Weiter muss betont werden, dass nicht die Einflüsse verschiedener Konfessionen die relative Monokonfessionalität der ersten vorchristlich-heidnischen Periode der konfessionellen Geschichte der Ukraine entscheidend geprägt haben. Der Hauptgrund für diese Einschätzung liegt darin, dass das vorchristliche religiöse System der Slaven nur mit vielen Vorbehalten als selbstständiges konfessionelles System bezeichnet werden kann. Der heidnische Glaube der vorchristlichen Rus' kann eher als urtümliches religiöses System eingestuft werden, das Elemente und Merkmale eines genuinen konfessionellen Systems noch nicht zu entwickeln vermochte. Das bedeutet, dass die heidnischen Vorstellungen der Slaven damals keine Glaubensdoktrin und kein System der Gottesdienste sowie keine geordnete Hierarchie aufwiesen. Deswegen können 
Juraš, Religiöser Pluralismus in der Ukraine

sie nur als unstrukturierte und nicht institutionalisierte Form betrachtet werden, deren Hauptbestimmung darin lag, das geistige Vakuum im Vorfeld der Übernahme oder der Entstehung eines vollwertigen Systems von Religion und Kirche, dass heißt also wirklich einer Konfession, auszufüllen. Wenn man also nur von einer relativen Herausbildung - im konfessionellen Sinne - eines in der Bevölkerung vorherrschenden religiösen Systems sprechen kann, ist die These einer realen und vollwertigen Monokonfessionalität der Kiever Rus' offensichtlich nicht formulierbar.

\section{Zweite Periode: Das Frühchristentum im Zeitalter des Doppel- glaubens und des religiösen Wettbewerbs (988 bis Anfang des 12. Jahrhunderts)}

Obwohl alle anderen erwähnten Richtungen mit Ausnahme des östlichen Christentums, die in der Kiever Rus' existierten oder mit ihr im Kontakt waren, wie schon früher keinen wesentlichen Einfluss auf das religiöse Leben der Rus' hatten und keine wirklichen Konkurrenten für das als offizielle Religion legitimierte östliche Christentum waren, kann von einer allgemeinen und sofortigen Realisierung der von dieser radikalen konfessionellen Reform gesetzten Ziele nicht die Rede sein. Eine erwartete klare Wende in der religiösen Selbstidentifizierung aller östlichen Christen trat nach der »Taufe« im Jahr 988 nicht ein. Weil die neue Religion schnell und oberflächlich angenommen wurde, blieben zahlreiche Einwohner der Rus' lange Zeit ihrem früheren Glauben, dem nicht konstituierten Heidentum, treu. Fast anderthalb Jahrhunderte existierte in vielen Gebieten der Kiever Rus', insbesondere in den von der Hauptstadt entfernten Regionen, eine besondere Art der religiösen Selbstverortung, die mit dem Begriff Doppelglaube bezeichnet wurde und zunächst in mechanischer, später in organischer Verflechtung von ideologischen und rituellen Elementen der alten Religion und des neuen christlichen Glaubens bestand. 
Juraš, Religiöser Pluralismus in der Ukraine

Merkmale und Formen des religiösen Synkretismus können in diesem Fall klar beobachtet werden.

Wenn wir die erste Periode als bedingt monokonfessionell bezeichnet haben, so kann die zweite Periode als die einer schwachen oder eingeschränkten Monokonfessionalität definiert werden.

Im Laufe dieser Periode - nach der Annahme des Christentums und bis zu dessen endgültiger Etablierung, der Tilgung des weit verbreiteten Doppelglaubens und der vollständigen Inkorporation von einzelnen atavistischen Elementen des Heidentums durch die altrus'ische Orthodoxie - konnte die formal nun monokonfessionelle Bevölkerung allerdings nicht mit einem soeben neu eingeführten religiösen System zufrieden gestellt werden. Dafür sorgten sowohl der Widerstand des konservativen Teils dieser Gesellschaft als auch die Schwäche der hierarchischen und administrativen Struktur der neuen Religion.

Dritte Periode: Orthodoxie als nicht kompetitive religiöse Dominante: das Zeitalter wirklicher Monokonfessionalität (Anfang des 12. bis Mitte des 17. Jahrhunderts)

Mit der endgültigen Etablierung der Orthodoxie, welche zum Hauptregulator des geistigen Lebens der gesamten Bevölkerung wurde, und als das Heidentum eine immer seltenere Ausnahme als verbreitete Praxis wurde, begann in der Kiever Rus' eine nächste und eine singuläre Periode der ukrainischen Religionsgeschichte: die tatsächliche Monokonfessionalität, als jegliche nicht orthodoxe Konfessionen keinerlei wirkliche Einflüsse auf das religiöse Leben der mittelalterlichen ukrainischen Bevölkerung hatten. Auch wenn es einzelne oppositionelle Strömungen gab, so spiegelten sie entweder die diffusen Stimmungen im orthodoxen Milieu selbst wider, rüttelten dabei aber nicht am Wesen dieser Konfession, oder sie stellten einen schwachen Nachhall der in Bezug auf die ukrainische Orthodoxie äußerlichen Konflikte innerhalb des Christentums und 
Juraš, Religiöser Pluralismus in der Ukraine

der theologischen Auseinandersetzungen dar. In diesem Zeitraum übernahm die Orthodoxie nicht nur die Rolle der alleinigen Konfession für die bis dahin schon etablierte ukrainische Ethnie, sie wurde außerdem zu einem äußerst wichtigen Faktor für deren politische und nationale Selbstidentifizierung. Diese dritte Periode in der Geschichte der konfessionellen Transformation in der Ukraine kann im Kontext unserer Analyse als eine Art Eckstein betrachtet werden, gleichsam als »Idealzustand«, von dem man später allmählich und immer stärker abgewichen ist. Dies hat sich letztlich in der aktuellen Situation manifestiert, als die Ukraine die Merkmale eines monokonfessionellen Staates endgültig eingebüßt hat.

Vierte Periode: Der klassische Protestantismus und Kämpfe um die Kirchenunion: das Zeitalter der frühen Polykonfessionalität (Mitte des 16. bis Ende des 17. Jahrhunderts)

Die Anfänge der Prozesse, die zum allmählichen Verlust der konfessionellen Homogenität in der Ukraine geführt haben, können auf die Mitte des 16. Jahrhunderts datiert werden. Damals entstanden in den verschiedenen Regionen der Ukraine, die zum polnisch-litauischen Staat gehörten, insbesondere in den westlichen Gebieten, als Reaktion auf die gesamteuropäischen Tendenzen im kirchlichen und religiösen Leben die ersten protestantischen (lutherischen, calvinischen, unitarischen, sozinianischen usw.) Gemeinden. Über die Verbreitung der protestantischen Bewegung in der Ukraine zeugen die von Mychajlo Hruševs'kyj angeführten Zahlen: ${ }^{1}$ Für diese Zeit sind 103 protestantische Gemeinden belegt. Es gibt Grund, anzunehmen, dass deren tatsächliche Anzahl aber wesentlich größer war und zumindest das Doppelte betrug.

1 Грушевський: 3 історії релігійної думки, 52-54.

DigiOst $3 \mid 19$ 
Juraš, Religiöser Pluralismus in der Ukraine

Aber sogar diese Zahl beweist, dass an der Grenze zwischen dem 16. und 17. Jahrhundert die ersten nicht-orthodoxen Religionsgemeinden in der Ukraine als System entstanden sind und sich über alle wichtigen Zentren der rechtsufrigen Ukraine verbreitet haben.

In Bezug auf die Römisch-Katholische Kirche, mit der die ukrainische Orthodoxie über die gesamte Geschichte in Berührung stand, konnte eine solche Frage nicht aufkommen, da diese Konfession eindeutig als Phänomen wahrgenommen wurde, das ausschließlich zur polnischen nationalen geistigen Tradition gehörte und nach allgemein verbreiteter Auffassung allem Ukrainischen entgegen stand.

Die Verstärkung der Einflüsse der Jesuiten auf das öffentliche Leben in der Rzeczpospolita unter Stephan Bathóry und Sigismund III. Wasa führte zu grausamen Verfolgungen der protestantischen Führer, deren protestantischen Gemeinden bis Ende des 17. Jahrhunderts vollständig verkümmerten. Allerdings war die massive protestantische Bewegung in der West-, Nord- und Zentralukraine, die Mitte des 16. Jahrhunderts entstanden war und Anfang des 17. Jahrhunderts ihre Blütezeit erreicht hatte, der erste ernsthafte Versuch, die Monokonfessionalität der ukrainischen Ethnie zu sprengen.

Die Anfänge protestantischer Religionsgemeinden in der Ukraine um die Mitte des 16. Jahrhunderts waren die erste tatsächliche Transformation im religiösen Bereich, die eine partielle Verschiebung der konfessionellen Prioritäten bei einem Teil der ukrainischen Gesellschaft verursachte und die vierte Periode in der Geschichte der konfessionellen Transformation einleitete. Das Wesen dieser Periode bilden zwei Versuche einer radikalen Veränderung der Monokonfessionalität der ukrainischen Bevölkerung: der eben erwähnte protestantische und der katholische. Der letztere wurde in einer Form realisiert, die für die ukrainische Bevölkerung näher und verständlicher war, die Bewahrung des traditionellen Glaubens voraussetzte (die Einführung der Union) und deswegen erfolgreicher war und auch die weiteren Ereignisse in der Ukraine stark beeinflusste.

DigiOst 3 | 20 
Juraš, Religiöser Pluralismus in der Ukraine

Wenn die Anfänge der vierten Periode mit der Gründung der ersten protestantischen Gemeinden Mitte des 16. Jahrhunderts verbunden sind, so bilden die Verbreitung der Kirchenunion nach 1596 und die Blütezeit des Protestantismus im ersten Viertel des 17. Jahrhunderts deren Kulmination. Als Ende dieser Periode können mit gutem Grund die letzten Jahrzehnte des 17. Jahrhunderts betrachtet werden. Dies war die Zeit des totalen Niedergangs des Protestantismus, der Etablierung der Kirchenunion in Galizien und Transkarpatien, also die Periode der endgültigen Herausbildung von dominanten Einflusszonen der Unierten (der Begriff "griechisch-katholische Kirche« wurde erst ab dem ersten Viertel des 18. Jahrhunderts verwendet) und der orthodoxen Kirche.

Die vierte Periode (etwa 150 Jahre) umfasst also einen wichtigen und den womöglich turbulentesten Zeitabschnitt in der Kirchengeschichte der Ukraine. Die von der Mehrheit der ukrainischen Bischöfe geplante und realisierte Vereinigung mit Rom im Jahr 1596 war die erste radikale Transformation der konfessionellen Orientierung des nationalen Charakters. Es war somit ein Schritt, der bei Einleitung und unmittelbarer Umsetzung der Transformationsidee auf Dominanz von innerukrainischen Gründen und Mechanismen setzte. Der Vereinigungsprozess (die Union) setzte nach den Vorstellungen seiner Initiatoren - der ukrainischen Bischöfe und der polnischen Patrone - die konfessionelle Neuorientierung der ganzen Bevölkerung voraus.

Obwohl diese strategischen Maximalpläne weder damals noch später umgesetzt wurden (gegen die Vereinigung mit Rom hatten sich zwei von sieben der damaligen ukrainischen Bischöfe ausgesprochen, ${ }^{2}$ die auf die Ablehnung der Union durch fast alle Mönche, die Mehrheit des weißen Klerus und der ukrainischen Bevölkerung Rücksicht genommen hatten), führten die durch die Unionspolitik des Kiever Metropoliten und der Mehrheit der Bischöfe verursachten Veränderungen zur ersten realen und immens wichtigen Trans-

2 Субтельний: Україна. Історія, 95.

DigiOst 3 | 21 
Juraš, Religiöser Pluralismus in der Ukraine

formation im religiösen Bereich, die, wenngleich sehr schmerzhaft, umfassende Auswirkungen auf die gesamte Gesellschaft hatte.

Wenn die Entstehung des Netzes von protestantischen Gemeinden Mitte des 16. Jahrhunderts als Einpflanzung einiger nicht traditioneller Merkmale in das konfessionelle Bild der Ukraine und als erster Versuch, die konfessionelle Homogenität der ukrainischen Bevölkerung durch Übernahme von ausländischem, für die damals bereits etablierte ukrainische geistige Tradition meistens fremdem Religionsgut zu sprengen, betrachtet werden kann, so bedeutet die Einführung der Kirchenunion in den 1590er Jahren eine tatsächliche Spaltung der vorher in Bezug auf ihre Religion einheitlichen ukrainischen Ethnie in zwei antagonistische (zumindest für damalige Zeit) konfessionelle Gruppen: Orthodoxe und unierte Katholiken. Dazu trugen auch die Deklarationen der Leiter der Unionsbewegung über die formalen und unbedeutenden Änderungen bei.

Dass dieser Prozess äußerst schmerzhaft und dramatisch war, zeugen die Ereignisse nicht nur im geistlich-religiösen Bereich, sondern auch im gesellschaftlichen Leben der Ukraine im 17. Jahrhundert schlechthin; sie waren alle direkt oder indirekt mit dem Kampf zwischen der orthodoxen und unierten Strömung um Einfluss und Dominanz in der ukrainischen Bevölkerung verbunden.

Mit der Synode von Brest hat die ukrainische Bevölkerung tatsächlich und unwiederbringlich ihren monokonfessionellen Status eingebüßt. Allerdings haben sich die zum damaligen Zeitpunkt gebildeten konfessionellen Gruppen zahlenmäßig, territorial und sozial noch nicht klar und endgültig konstituiert.

Fast zwei Jahrhunderte lang dauerte der unversöhnliche Kampf zweier Kirchen und ihrer weltlichen Anhänger. Zunächst überwogen die Einflüsse der unierten Kirche in der Dnipro-Ukraine und in Wolhynien, die beiden Diözesen in Galizien blieben dagegen noch etwa 100 Jahre orthodox (die Diözese von Przemyśl wechselte erst 1692, und die Diözese von L'viv erst 1700 zur Union).

Der endgültige Wechsel zur Kirchenunion der beiden westukrainischen Eparchien ist von sehr großer Bedeutung. Erstens wurden damit in groben Umrissen die mehrheitlichen Einflussgebiete der Orthodoxen und der Grie- 
Juraš, Religiöser Pluralismus in der Ukraine

chisch-Katholischen Kirche definiert, die mit einigen Veränderungen bis heute bestehen. Zweitens hat er endgültig die doppelte Konfessionalität der ukrainischen Bevölkerung geprägt. Diesen Zeitraum - das letzte Jahrzehnt des 17. und der Anfang des 18. Jahrhunderts - halten wir deswegen für den Abschluss einer sehr wichtigen vierten Periode in der Geschichte der ukrainischen konfessionellen Transformation.

Die Verteilung der Einflusszonen von Orthodoxie und Katholizismus im 17. und später auch insbesondere im 18. Jahrhundert wurde stark von damaligen innerukrainischen und zwischenstaatlichen politischen Gegebenheiten und Ereignissen beeinflusst. Der polnische Staat unterstützte bis zu einem gewissen Grad die unierte Kirche, die ukrainischen Kosaken förderten die Orthodoxie, auch Bohdan Chmel'nyc'kyj stärkte ihr vehement den Rücken im ukrainisch-polnischen Krieg von 1648-1654, was auch den religiösen Hintergrund bei der Vereinigung der linksufrigen Ukraine mit Russland im Jahr 1654 verantwortete; ab Mitte des 18. Jahrhunderts kam es zudem zu antipolnischen Aufständen in der rechtsufrigen Ukraine. Das alles zeugt noch einmal von der traditionellen Rolle politischer und staatlicher Faktoren nicht nur für die politische, sondern auch für die Kirchengeschichte der Ukraine.

Fünfte Periode: Der politische und religiöse Niedergang: das Zeitalter der orthodox-katholischen Doppelkonfessionalität (Anfang des 18. Jahrhunderts bis Ende des 19. Jahrhunderts)

Die nächste, fünfte Periode der konfessionellen Transformation dauerte weniger als 200 Jahre. Die konfessionelle Neuorientierung ging hier hauptsächlich in eine Richtung; es handelte sich um die staatlich geförderte Bekehrung der Griechisch-Katholischen Kirche in der rechtsufrigen Ukraine zur Orthodoxie (letztes Viertel des 18. Jahrhunderts), im westlichen Wolhynien (die endgültige Aufhebung der Union bis 1839) und im Chełm-Land (1875). Gleichzeitig 
Juraš, Religiöser Pluralismus in der Ukraine

gewann das System der konfessionellen Prioritäten der ukrainischen Gemeinschaft, polarisiert auf der Achse »orthodox-griechisch-katholisch «, immer mehr an Eindeutigkeit. Es entstand eine reale Doppelkonfessionalität.

Die gewaltsame Unterbrechung des ukrainischen politischen Zusammenlebens durch die Nachbarstaaten (zunächst durch Russland und Polen, später durch Russland und Österreich-Ungarn) führte zum natürlichen Rückgang der national-religiösen Auseinandersetzungen und verursachte weitgehend eine Verteilung der konfessionellen Prioritäten bei der ukrainischen Ethnie, die sich Ende des 18. Jahrhunderts herausbildete. Das Verhältnis zwischen zwei konfessionellen Gruppen der Ukrainer, das sich bis zu diesem Zeitpunkt herauskristallisiert hatte (die griechisch-katholischen Ukrainer in Galizien, Wolhynien und Transkarpatien machten etwa ein Fünftel der gesamten ukrainischen Ethnie aus), ${ }^{3}$ ist nicht nur während des gesamten nächsten Jahrhundert (bis zum letzten Viertel des 19. Jahrhunderts) fast unverändert geblieben, sondern ist bis heute ein essentieller historischer Faktor, der die Verteilung der konfessionellen Prioritäten innerhalb der ukrainischen Bevölkerung beeinflusst.

Mit dem Erlahmen des aktiven ukrainischen gesellschaftlichen Kirchenlebens Ende des 18. Jahrhunderts, das zweifellos ein nahrhafter Boden für die nationalen bzw. interkonfessionellen Auseinandersetzungen war, kann fast ein vollständiges Erlöschen des Kampfes zwischen den Kirchen registriert werden. Somit wurde nahezu für ein Jahrhundert sowohl in der West- als auch in der Ostukraine eine Situation konserviert, die sich bis zum Ende des 18. Jahrhunderts herausgebildet hatte und durch folgende Besonderheiten gekennzeichnet war: Erstens genoss die orthodoxe Kirche, die in der Ukraine 1686 unter die Hoheit des Moskauer Patriarchats geriet, eine bedingungslose Unterstützung in den meisten ukrainischen Gebieten, die an das Russische Reich gefallen waren; sämtliche Diözesen und Pfarreien der unierten Kirche wurden allmählich aufgelöst. Zweitens konnte sich in Galizien und Transkarpatien

3 Ebenda.

DigiOst 3 | 24 
Juraš, Religiöser Pluralismus in der Ukraine

die Griechisch-Katholische Kirche einer genauso eindeutigen Unterstützung erfreuen und zur vollständigen Auflösung der Orthodoxie beitragen (das letzte Kloster, das die Union nicht annahm, das Skyt Manjava in den Vorkarpaten, wurde 1785 geschlossen). In Österreich-Ungarn hatte die Orthodoxie nur in der doppelethnischen (ukrainischen und rumänischen), aber monokonfessionellen (orthodoxen) Bukowina einen legitimen Status.

Sechste Periode: Die Ukraine in der neuesten Zeit: das Zeitalter der modernen Polykonfessionalität (Ende des 19. Jahrhunderts 1988 - bis heute)

Der nächste Faktor in der ukrainischen Kirchengeschichte nach Einleitung und praktischer Etablierung der Kirchenunion brachte vielleicht nicht so gravierende Veränderungen, leitete jedoch eine recht symptomatische Transformation der religiösen Orientierung in der modernen Ukraine und somit die sechste Periode in der Geschichte der konfessionellen Transformation ein. Es handelt sich um das Entstehen des Protestantismus Mitte des 19. Jahrhunderts, seine aktive Verbreitung im letzten Viertel des 19. Jahrhunderts und seine zweite Welle Anfang des 20. Jahrhunderts.

Der Unterschied zwischen diesen beiden Wellen war nicht nur ein inhaltlicher; ihre Entstehung hatte unterschiedliche Gründe, und sie manifestierten sich nach außen in einigen ziemlich symptomatischen Formen. Wenn sich die lutherisch-calvinisch-unitaristische Bewegung im 16. und 17. Jahrhundert meistens in den westlichen Regionen der Ukraine verbreitet hatte, entstanden die baptistischen Gemeinden und die Gemeinden der Pfingstler im 19. und 20. Jahrhundert vor allem in der Süd- und Zentralukraine. Im Unterschied zur frühen protestantischen Bewegung, die durch die Begeisterung des ukrainischen und polnischen Adels an europäischen Trends entstanden war, stützte sich der 
Juraš, Religiöser Pluralismus in der Ukraine

ukrainische Protestantismus Ende des 19. und Anfang des 20. Jahrhunderts überwiegend auf die spontane Initiative der einfachen Bevölkerungsschichten.

Die Bewegung, die in den 1850er Jahren durch kleine Gruppen initiiert wurde, zählte 1884 bereits fast 100.000 Anhänger, ${ }^{4}$ was zu einem massiven Widerstand der offiziellen russischen Orthodoxie und einer heftigen Reaktion in der gesamten Gesellschaft führte. Nachdem 1905 das offizielle Verbot für Sekten aufgehoben wurde, verbreitete sie sich noch schneller, marschierte allmählich Richtung Westen (nach Wolhynien und Podolien) und fand neue Anhänger auch im Einflussbereich der Griechisch-Katholischen Kirche (westliches Podolien, südliche Vorkarpaten). Bis 1917 verwandelte sich der Protestantismus in eine machtvolle religiöse Strömung, die nicht weniger als eine Million Anhänger zählte und somit die drittgrößte nach der Orthodoxie und der Griechisch-Katholischen Kirche war. ${ }^{5}$

Die zweite Welle der protestantischen Bewegung in der Ukraine war in Bezug auf ihre Etablierung, den Einfluss auf religiöse Prozesse und die Transformation der konfessionellen Prioritäten viel erfolgreicher als die erste. Sie hat nicht nur die Sympathien eines großen Teils der Bevölkerung (fünf bis sieben Prozent) gewonnen, sondern auch sehr robuste Gemeinden gegründet, die seit ihrem Ursprung eine durchgehende Geschichte haben. Als Faktor, der die Transformation des konfessionellen Status der Bevölkerung geändert und zur Entstehung des modernen ukrainischen Polykonfessionalismus geführt hat, steht der neuzeitliche und zeitgenössische ukrainische Protestantismus nach der Einführung der Kirchenunion an der zweiten Stelle.

Die ziemlich starke Verbreitung des Protestantismus in der Ukraine um die Jahrhundertwende zum 20. Jahrhundert leitete die letzte Periode der konfessionellen Transformation ein. Ihr Anfang ist aber nicht die Mitte des 19. Jahrhunderts, als die neue protestantische Bewegung nur deklariert wurde, sondern

4 Жабко-Потапович: Христове Світло в Україні, 139.

5 Ebenda. 
Juraš, Religiöser Pluralismus in der Ukraine

das Ende des 19. Jahrhunderts, als bereits ein ganzes System protestantischer Gemeinden in großen Teilen der ukrainischen Gebiete existierte. Für diese Periode sind generell folgende Tendenzen kennzeichnend:

- die innere qualitative Veränderung der Orthodoxie und der Griechisch-Katholischen Kirche als traditionelle ukrainische Konfessionen, ihre Neuorientierung auf die dominierende Unterstützung der proukrainischen religionsnationalen Ideologien (und nicht heterogenen Auslandsorientierungen wie früher): Die eindeutige Dominanz der national-patriotischen Elemente in der sozialgesellschaftlichen Position der Griechisch-Katholischen Kirche und die Anfänge der ukrainozentrischen autokephalen orthodoxen Jurisdiktionen;

- lokale konfessionelle Neuorientierungen (in Transkarpatien und Galizien) und globale religionspolitische Umwälzungen, verursacht durch gewalttätige Unterbrechung der religiösen und kirchlichen Tradition durch den Staat;

- das Etablieren des Protestantismus als reale und gewichtige Komponente der konfessionellen Struktur der Bevölkerung.

Sehr wichtig im Kontext der soeben erwähnten Tendenzen waren die Ereignisse in den Jahren 1988-1990. Diese haben den künstlichen Charakter der staatlich gestützten Beziehung zwischen konfessionellen Prioritäten und dem konfessionellen Status der ganzen Gesellschaft (typisch für die gesamte Sowjetunion, aber in der Ukraine am deutlichsten spürbar) sowie die Verfehlungen der früheren staatlichen Konfessionspolitik (mit dem totalen Verbot einzelner Konfessionen und Kirchen), die auf strenger Reglementierung und diversen Verboten basierte, belegt. Die Ereignisse dieser Zeit wurden zum Ausgangspunkt für weitere grundlegende konfessionelle Neuorientierungen und eine allgemeine Erneuerung des religiösen Lebens, die in der heutigen Etappe einen polykonfessionellen und pluralistischen Charakter bekräftigt haben.

Wir führen in dieser letzten Periode bewusst viele kirchliche und konfessionelle Transformationsprozesse und Ereignisse zusammen, die in verschiedenen 
Juraš, Religiöser Pluralismus in der Ukraine

Regionen der Ukraine (während dieser Periode gehörte die ganze Ukraine oder ihre Teile zu Russland, Österreich-Ungarn, zur Sowjetunion, zu Polen, zur Tschechoslowakei, zu Ungarn, Rumänien, Deutschland; unabhängig war sie eigentlich nur zwischen 1917 und 1920 sowie nach 1991) stattgefunden haben und durch unterschiedliche Faktoren verursacht sowie von ungleicher Reaktion und Rolle der damaligen lokalen Macht begleitet wurden. Dafür sprechen einige Überlegungen. Die meisten wichtigen Prozesse der sechsten Periode der konfessionellen Transformation haben Folgendes gemeinsam:

Erstens wurden sie entweder vom Staat eingeleitet oder durch den Staat gefördert und trugen aus diesem Grund einen »unnatürlichen « Charakter. Das betrifft nicht nur Russland und später die Sowjetunion, sondern auch die rigorose konfessionelle Politik Österreich-Ungarns, Polens und der Tschechoslowakei.

Zweitens hatten diese Prozesse keinen gravierenden Einfluss auf die konfessionellen Prioritäten in der Ukraine, sie konnten eine bestimmte Konfession nur etwas fördern - und das auch nur auf lokaler Ebene - oder ihre Entwicklung bremsen. Sogar der mit Gewalt vollzogene brutale Bruch mit der kirchlich-konfessionellen Tradition (in den 1930er Jahren und 1944 im Falle der Ukrainischen Autokephalen Orthodoxen Kirche, 1945 bei den Pfingstlern und 1946 bzw. 1949 bei der Ukrainischen Griechisch-Katholischen Kirche) war eine vorübergehende Erscheinung, was ein weiteres Mal von künstlichen und somit nur kurzfristigen Änderungen durch staatliche Eingriffe zeugte.

Drittens förderten diese Prozesse direkt (wie bei der breiten Etablierung von nicht orthodoxen Konfessionen) oder indirekt (wie bei der Staatspolitik des Atheismus, die zur Abkehr eines großen Teils der Bevölkerung von religiöser - meistens orthodoxer - Tradition führte und Bedingungen für missionarische Tätigkeit schuf sowie später auch die Etablierung der für die Ukraine nicht traditionellen Konfessionen in den Regionen mit ehemals dominierenden orthodoxen Einflüssen ermöglichte), aber auf jeden Fall die Konsolidierung der Polykonfessionalität der ukrainischen Ethnie, einer wichtigen Tendenz, welche 
Juraš, Religiöser Pluralismus in der Ukraine

die wichtigsten Inhalte der konfessionellen Transformationen der letzten 120 Jahre bestimmte.

In der Ursachenforschung für Transformationsprozesse im religiösen Bereich, die in der sechsten Periode stattgefunden haben, müssen drei für ihren Verlauf spezifische Unterperioden ausgewiesen werden:

Erste Unterperiode: Die letzten Jahrzehnte des 19. Jahrhunderts bis zum Ende der 1920er Jahre in der Ostukraine und bis 1939/1940 in der Westukraine

Als Grenze zwischen den ersten zwei Unterperioden kann für die östliche (sowjetische) Ukraine die brutale Aufhebung der sogenannten Ukrainisierungspolitik Ende der 1920er bis Anfang der 1930er Jahre durch die Sowjetunion (darunter fallen die Auflösung der Ukrainischen Autokephalen Orthodoxen Kirche sowie maximale Einschränkungen für die Russische Orthodoxe Kirche und sämtliche protestantischen Kirchen) und für die Westukraine die Inkorporation von Galizien, Westwolhynien, Transkarpatien und der Bukowina in die Sowjetunion (1939 und in den 1940er Jahren) gesehen werden. Die eingehende Analyse des konfessionellen Lebens in der Ukraine in der ersten Unterperiode lässt Folgendes feststellen: Trotz der Bedeutung von außerkirchlichen, vor allem politischen Faktoren, war ihre Rolle bei der Einleitung und Umsetzung der konfessionellen Transformationsprozesse sekundär oder jedenfalls vollständig durch verschiedene Fusionsformen des religiösen und politischen Bereichs bedingt. Das heißt, in jener Zeit waren diese Prozesse meistens die Folge einer natürlichen Evolution der religiösen Beziehungen in der Ukraine, weil alle Religionsgemeinschaften damals noch eine relative Freiheit genießen konnten.

A. Der erste wichtige kritische Punkt ist der Versuch, die konfessionellen Prioritäten in Galizien während der Okkupation von 1914-1915 durch die 
Juraš, Religiöser Pluralismus in der Ukraine

russische Armee zu ändern. Damals hat der wolhynische Erzbischof Eulogius, dem die Synode der Russischen Orthodoxen Kirche die Obhut über die geistigen Bedürfnisse der ukrainischen Bevölkerung in der Region aufgetragen hat, eine breit umworbene Aktion mit Rückendeckung der neuen Verwaltung gestartet, um die Anhänger der Griechisch-Katholischen Kirche zum Wechsel zur Orthodoxie zu bewegen. In fast neun Monaten russischer Präsenz in Galizien sind damals fast 200 griechisch-katholische Gemeinden zur Orthodoxie übergetreten, was etwa zehn Prozent aller Gemeinden ausmachte. ${ }^{6}$ Bei den Ursachen für dieses ziemlich verbreitete Vorgehen haben externe Gründe, nämlich die Förderung durch die neuen Machthaber, eine wichtige Rolle gespielt. Allerdings wäre es übertrieben, diesen Prozess nur als machtpolitisch manipuliert und künstlich provoziert zu betrachten. In vielen Fällen wurde er zum konkreten Ausdruck des pro-orthodoxen, zum damaligen Zeitpunkt wirklich moskaufreundlichen Potenzials, das traditionell in Galizien existierte und hier als »Moskophilie« bezeichnet wurde. Unter Berücksichtigung dieser Gegebenheiten gibt es gute Gründe anzunehmen, dass der 1914-1915 vollzogene Wechsel einiger galizischer Kirchengemeinden zur Orthodoxie auch durch objektive Faktoren verursacht wurde, die wirkliche Stimmungen eines Teils (etwa zehn bis 15 Prozent) der ukrainischen Bevölkerung Galiziens widerspiegelten.

Nach dem Abzug der russischen Armee aus Galizien wurden die neugegründeten Gemeinden sehr schnell wieder aufgelöst. Immerhin zeugte dieser erfolglose Versuch, einen massiven Wechsel der griechisch-katholischen Gemeinden zur Orthodoxie zu organisieren, von den Divergenzen bei den strategischen konfessionellen Orientierungen der Ukrainer in Galizien. Zwar waren die meisten von ihnen überzeugte Anhänger der Griechisch-Katholischen Kirche, doch große Teile der Bevölkerung wurden in der Kirchenunion nur durch die

6 Власовський: Нарис історії Української Православної Церкви, 249.

DigiOst 3 | 30 
Juraš, Religiöser Pluralismus in der Ukraine

klare Religionspolitik der polnischen (bis 1772), dann österreichischen (von 1772 bis 1914) und ab 1920 wieder polnischen Behörden gehalten.

B. Die pro-orthodoxe Bewegung in Transkarpatien in der ersten Hälfte des 20. Jahrhunderts setzte einen weiteren bedeutsamen konfessionellen Transformationsprozess in der besagten Periode in Gang. Als 1903 die ersten orthodoxen Gemeinden in Transkarpatien entstanden und ihre Organisation in einzelnen Orten (beispielsweise wechselten im Städtchen Iza von 500 Höfen nur 64 nicht zur Orthodoxie $)^{7}$ in Österreich-Ungarn als nationaler Verrat interpretiert wurde, konnte noch niemand ahnen, dass bereits 1921 die Volkszählung in der Tschechoslowakei, die offizielle Zahlen der orthodoxen Bevölkerung im Land mit allen möglichen Mitteln zu reduzieren versuchte, 60.986 orthodoxe Ukrainer oder etwa 15 Prozent der gesamten ukrainischen Bevölkerung anführte. ${ }^{8}$

Die Volkszählung von 1930 zeigte eine noch tiefere Transformation: 135.000 Ukrainer oder fast ein Drittel von deren Gesamtzahl, ${ }^{9}$ organisiert in $130 \mathrm{Ge}$ meinden (zwölf davon in ukrainischen Siedlungen in der Slowakei), bekannten sich zur Orthodoxie. Logisch war auch der weitere Anstieg von Anhängerzahlen der orthodoxen Kirche und von Gemeinden bis Ende der 1930er Jahre, die nach ständigen Auseinandersetzungen um deren Jurisdiktion Bischof Damaskin als Vertreter des serbischen Patriarchats in seine Obhut nahm.

Die massive Neuorientierung der Ukrainer griechisch-katholischen Glaubens in Transkarpatien hin zur Orthodoxie ist ein aufschlussreicher und wichtiger Prozess der religiösen Transformation im 20. Jahrhundert, dessen Dynamik auch der unverhohlene Widerstand des Staates nicht aufhalten konnte. Der Erfolg in Transkarpatien war im Vergleich zu Galizien durch einige Gründe bedingt:

7 Закарпатський: Православна Церква на Закарпатті, 148.

8 Оксіюк: Великий подвижник Православ'я на Закарпатті, 95.

9 Закарпатський: Православна Церква на Закарпатті, 157. 
Juraš, Religiöser Pluralismus in der Ukraine

- Erstens war der tschechoslowakische Staat, unter dessen Protektorat in der Zwischenkriegszeit Transkarpatien geriet, wesentlich toleranter.

- Zweitens war die Bevölkerung in Transkarpatien wesentlich konservativer, viele traten der Kirchenunion - Transkarpatien kann ab der zweiten Hälfte des 17. Jahrhunderts als bedingt monokonfessionelle griechisch-katholische Region bezeichnet werden - nur formell bei (ähnliche Prozesse konnten im rumänischen Siebenbürgen beobachten werden, wo nach der nominellen allgemeinen Akzeptanz und Annahme der Kirchenunion von 1699-1700 weniger als ein halbes Jahrhundert später die orthodoxe Bewegung einsetzte, die mit Wiederherstellung und staatlicher Anerkennung der orthodoxen Hierarchie in dieser Region endete), tatsächlich bleiben sie aber der alten orthodoxen Tradition treu.

- Drittens hatten die ukrainischen nationalen Ideen einen viel geringeren Einfluss in Transkarpatien in der Zeit, als die pro-orthodoxe Bewegung sowohl in Transkarpatien in der ersten Hälfte des 20. Jahrhunderts, als auch in Galizien 1914-1915 vornehmlich Konzepte für eine nationale und kulturelle Einheit mit Russland produzierte, gegen die sich die Ukrainer auflehnten, die sich ihrer eigenen nationalen Identität bewusst waren und zu den überzeugten Anhängern der Griechisch-Katholischen Kirche gehörten.

Gemeinsam für die beiden erwähnten Bewegungen war, dass sie von der Existenz bedeutender pro-orthodoxer Sympathien unter der lokalen ukrainischen griechisch-katholischen Bevölkerung zeugten. Darüber hinaus hatten sie einen wesentlichen Einfluss (direkt in Transkarpatien und indirekt in Galizien) auf die weiteren Entwicklungen in den betreffenden Regionen.

C. In der Ostukraine wurden die Transformationsprozesse Anfang und Mitte der 1920er Jahre, als die Kirche, vom Staat getrennt, noch eine relative Freiheit genießen konnte (der Staat befand sich zwar in einem Konfrontationsverhältnis 
Juraš, Religiöser Pluralismus in der Ukraine

zur Religion, deklarierte aber noch nicht seinen nachdrücklichen Wunsch, die Religion grundsätzlich auszulöschen), von zwei Faktoren bestimmt:

- von der allmählichen Etablierung protestantischer Denominationen, obgleich ohne sichtbare Extensität;

- von der Teilung der orthodoxen Kirche, die aber insgesamt die größten Mitgliederzahlen aufwies. Außer den drei größten Hauptkirchen - der Russischen Orthodoxen Kirche mit Patriarch Tichon, der Ukrainischen Autokephalen Kirche und der Lebendigen Kirche - gab es damals noch bis zehn kleinere, meist territoriale, de facto autokephale Kirchen in der Ukraine.

Die letzteren Transformationen setzten der Homogenität der russischen Orthodoxie in der Ukraine ein Ende. Es war die Religion der überwiegenden Mehrheit der ukrainischen Bevölkerung und somit der wichtigste Faktor für deren konfessionelle Selbstbestimmung. Diese Transformationen waren zwar ein sehr bedeutender Moment im damaligen Kirchenleben, trugen jedoch einen rein innerkonfessionellen (innerorthodoxen) Charakter. Sie führten zu Gründungen neuer Kirchen und Umverteilung der Prioritäten und Einflüsse zwischen Kirchen derselben Konfession, beeinflussten aber nicht entscheidend das generelle Kräfteverhältnis zwischen den Konfessionen. Deswegen können diese Veränderungen und Neuorientierungen innerhalb der Orthodoxie jurisdiktionelle Veränderungen - nicht als Transformationen im Bereich der zwischenkonfessionellen Beziehungen, die der eigentliche Gegenstand dieser Abhandlung sind, angesehen werden.

Zum Abschluss der Analyse von Transformationsprozessen während der ersten Unterperiode kann man zu dem signifikanten Fazit kommen, dass bei einer relativ freien Entwicklung jegliche religiös bedingten Prozesse in der Ukraine zur Vertiefung und Erweiterung der Polykonfessionalität führen. 
Juraš, Religiöser Pluralismus in der Ukraine

Zweite Unterperiode: Ab Ende der 1920er Jahre in der Ostukraine und ab 1939-1940 in der Westukraine bis 1988

Im Gegensatz zu den Transformationen vor 1939-1940 in der Westukraine und vor Ende der 1920er Jahre in der Ostukraine, die durch die inneren kirchlichen Mechanismen verursacht wurden, wurden die meisten konfessionellen und kirchlichen Transformationen nach 1929 in der Sowjetukraine (in der Westukraine nach der Eingliederung dieser Gebiete in die Sowjetunion) unter Zwang und von äußeren (politischen) Faktoren ausgelöst. Erstens muss man aus dieser Position heraus vor allem das für die gesamte Sowjetherrschaft typische Schrumpfen der Anzahl von Religionsgemeinden betrachten, was indirekt, aber sehr stark Prozesse konfessioneller Transformation beeinflusst hat. Zweitens war die staatliche Einmischung in die Tätigkeit der religiösen Organisationen ebenfalls ein wichtiger Faktor für die Beziehungen zwischen den Konfessionen in der Sowjetzeit, der die damalige und zukünftige Umverteilung der konfessionellen Sympathien und Prioritäten beeinflusste. Der staatliche Druck auf die Religionsgemeinschaften war freilich unterschiedlich; die Tätigkeit einiger Kirchen wurde nur reglementiert, die anderen wurden harten Repressalien ausgesetzt, wieder andere wurden verboten. Privilegierte Gemeinschaften genossen in der Sowjetzeit bessere Bedingungen, was ihre Entwicklung förderte und die potentiellen Möglichkeiten für die Zukunft schuf. Dies betrifft in erster Linie die religionspolitische Situation in der Sowjetukraine nach dem Zweiten Weltkrieg, als die Hauptrolle in den strategischen Überlegungen des Staates und deren Umsetzung der Russischen Orthodoxen Kirche zugeordnet wurde. Die Tätigkeit der Römisch-Katholischen Kirche und der meisten protestantischen Kirchen wurde dagegen vom Staat strengstens kontrolliert, viele Kirchen durften gar nicht mehr offiziell existieren (die Ukrainische Autokephale Orthodoxe Kirche, die Ukrainische Griechisch-Katholische Kirche, die Pfingstler, die Zeugen Jehovas, einige baptistische Kirchen usw.). Diese Abstufung und Selektivität der staatlichen Prioritäten im Religionsbereich waren typisch für 
Juraš, Religiöser Pluralismus in der Ukraine

die Nachkriegszeit. Vor dem deutschen Angriff auf die Sowjetunion dagegen, von 1929 bis 1941 in der Ostukraine, wurden die Beziehungen zwischen dem Staat und allen Religionsgemeinschaften durch den allgemeinen Kurs auf deren Auflösung auf allen Ebenen und unabhängig von der Konfession geprägt. Wenn es vor dem bolschewikischen Umsturz von 1917 in zehn orthodoxen Eparchien mit einer ukrainischen Bevölkerungsmehrheit fast 12.000 orthodoxe Kirchen gab, ${ }^{10}$ so blieben davon bis Mitte 1930er Jahre nur wenige übrig, nicht mehr als hundert in der gesamten Sowjetukraine. ${ }^{11}$ Die massivsten Kirchenschließungen gab es von Ende der 1920er bis Mitte der 1930er Jahre. Dieses erzwungene Schrumpfen war nicht nur für die orthodoxe Kirche, sondern auch für alle anderen Konfessionen ein typisches Bild. Die Anzahl der Mitglieder und der Gotteshäuser des Baptistenbundes in der Ukraine verringerte sich im Vergleich zur Zeit vor der Revolution, ${ }^{12}$ als der Staat, dessen offizielle Religion die Orthodoxie war, allen Andersgläubigen mehr als kühl gegenüberstand, um das Dreifache.

Diese Tatsachen sprechen dafür, dass die wichtigste Transformation der konfessionellen Orientierung der ukrainischen Bevölkerung in der Ostukraine seit Ende der 1920er Jahre im formellen Verzicht auf Glauben und folglich auf konfessionelle Zugehörigkeit bestand. Übrigens kann sowohl die formelle als auch die inhaltliche Etablierung des Atheismus, der de facto ein philosophisch-weltanschauliches System ist, das nach formellen und informellen Merkmalen einer Religion nahe steht, mit einigen Vorbehalten als Ausdruck der für die moderne Ukraine typischen konfessionell-weltanschaulichen Pluralismus betrachtet werden.

10 Полный православный богословскій энциклопедическій словарь, т. 1, 547, 852; т. 2, 1331, 1824, 1839, 2139, 2272, 2275, 2364.

11 Степанов: Свидетельство обвинения, 265-267.

12 Жабко-Потапович: Христове Світло в Україні, 142. 
Juraš, Religiöser Pluralismus in der Ukraine

Heute kann man argumentieren, dass die Reaktion der Gesellschaft auf die gewaltsame Unterbrechung der kirchlich-religiösen Tradition widersprüchlich und deren Folgen nicht eindeutig waren. Vor allem muss betont werden: Obwohl der große Teil der Bevölkerung nur äußerlich das vom Staat aufgezwungene Muster der Beziehungen zur Religion annahm (das heißt, man stritt nur formell seine Zugehörigkeit zur jeglichen Konfession ab und gab genauso formell seine konfessionelle Identität auf), verursachte diese Staatspolitik bei einem anderen Teil der Bevölkerung einen inhaltlichen Religionsnihilismus. Sie führte einerseits zu völligen Aufgabe der kirchlichen Tradition in allen Formen, andererseits zum spürbaren Formalismus bei der Erfüllung von religiösen Pflichten und Riten in der heutigen Zeit des politischen und weltanschaulichen Liberalismus, als die Rückkehr zur religiösen und konfessionellen Praktiken nicht nur zu einem möglichen, sondern in bestimmten Situationen zu einem unentbehrlichen Element der Identifikation auf persönlicher und kollektiver Ebene wurde. Für den anderen, größeren Teil der Bevölkerung der Ukraine hat die Religion als jahrhundertelang entwickeltes System kultureller und weltanschaulicher Prinzipien überhaupt nicht an Kraft und Bedeutung eingebüßt. Davon zeugen die moderne religiöse Renaissance und die Rückkehr zu den religiösen Werten, welche die Ukraine während des Zweiten Weltkrieges erlebt hat und die stark die gesamte Nachkriegszeit beeinflusst haben.

Nachdem das organisierte religiöse Leben in der Ukraine Ende der 1930er Jahre fast vollständig zum Erliegen gekommen war, setzte unter der deutschen Besatzung eine allgemeine Wiedergeburt der vormaligen kirchlichen Strukturen ein. Ein wichtiges und originelles Element der Konfessionsstruktur wurde die wiedergeborene Ukrainische Autokephale Orthodoxe Kirche. Zu deren Neutralisierung musste das Moskauer Patriarchat seinen recht zahlreichen wieder entstandenen Pfarreien einen Autonomiestatus verleihen.

Einen besonderen Stempel haben die zahlreichen Religionsgemeinden in den inkorporierten westukrainischen Gebieten den zwischen- und innerkonfessionellen Beziehungen in der Ukraine zwei Jahre vor dem deutschen 
Juraš, Religiöser Pluralismus in der Ukraine

Überfall auf die Sowjetunion und während des gesamten Krieges aufgedrückt. Es handelt sich um etwa 2.500 griechisch-katholische Gemeinden und Klöster in Galizien und Transkarpatien ${ }^{13}$ und ungefähr um die gleiche Zahl orthodoxer Gemeinden im westlichen Wolhynien, in der Bukowina und teilweise in Transkarpatien. Für orthodoxe Gemeinden gab es keine besonderen Fragen bezüglich ihrer zukünftigen Konfession und Jurisdiktion; ihre Inkorporierung in das Moskauer Patriarchat war von Vornherein eine entschiedene Sache. Was dagegen die konfessionelle Neuorientierung der griechisch-katholischen Gemeinden anbelangt, so hat der Sowjetstaat nicht sofort gewagt, konkrete Schritte zu unternehmen.

Erst nach Kriegsende und mit maximaler Rückendeckung der Regierung und des Nachrichtendienstes - also unter allen möglichen Formen von Druck und Gewalt - hat eine »Initiativgruppe« von hochrangigen griechisch-katholischen Priestern, die vom Regime eingesetzt worden war, den Wechsel zur Orthodoxie auf einer Pseudo-Synode in L'viv am 8. März 1946 eingeleitet. Hier hätten, wie die »Initiativgruppe« darlegte, von 1.270 Priestern, die Anfang 1946 in den galizischen Gemeinden tätig waren, 986 den Wunsch nach Vereinigung mit der russischen orthodoxen Kirche geäußert. ${ }^{14}$ Etwas mehr als ein Jahr später ${ }^{15}$ haben insgesamt fast 1.160 (über 90 Prozent) Vertreter des griechisch-katholischen weißen Klerus ihre Loyalität und Vereinigung mit der Orthodoxie deklariert.

In Transkarpatien ging die Verdrängung der griechisch-katholischen Gemeinden unauffälliger vonstatten: 1947 erklärten 73 griechisch-katholische Gemeinden ihre Absicht, zur Orthodoxie zu wechseln. ${ }^{16}$ Weitere 130 Gemeinden haben diesen Schritt 1948 vollzogen. Am 5. April 1949 haben 14 bekannte

13 Гордієнко: Сталінізм і Українська Греко-Католицька Церква, 83.

14 Доклад о деятельности центра Инициативной группы, 73.

15 Додатковий список духовенства, що возз'єдналося з Православною Церквою, 31.

16 Панас: Історія Української Церкви, 146. 
Juraš, Religiöser Pluralismus in der Ukraine

Vertreter des Klerus eine Konferenz einberufen, die den Beschluss der L'viver Synode von 1946 wiederholt und zur vollständigen Vereinigung mit der Orthodoxie und zur Auflösung der Griechisch-Katholischen Kirche aufgerufen hat. Bis Christi Himmelfahrt wurden sämtliche griechisch-katholischen Gemeinden in Transkarpatien in die Russische Orthodoxe Kirche integriert.

In der Geschichte der konfessionellen Transformationen in der Ukraine im 20. Jahrhundert ist die Neuorientierung von etwa vier Millionen Gläubigen der Griechisch-Katholischen Kirche in der Westukraine und ihre meist unter Gewalt vollzogene Inkorporierung in die Orthodoxie nach dem Zweiten Weltkrieg das zweitwichtigste Ereignis (nach dem Versuch, die religiöse Tradition in der Ostukraine mit Gewalt zu unterbrechen), das die Situation in der Ukraine insgesamt beeinflusst, das Kräfteverhältnis zwischen den Konfessionen in der betreffenden Region grundsätzlich verändert hat und zur wichtigsten historischen Vorbedingung für die moderne Situation wurde. Hier geht es einerseits um die gleichsam triumphale Rückkehr der Ukrainischen Griechisch-Katholischen Kirche, die in vielerlei Hinsicht ihre Vorkriegszahlen übertroffen und den überzeugende Wunsch der meisten Menschen in den Regionen ihrer historischen Verbreitung nach Wiederbelebung ihrer bekannten und historisch ererbten religiösen Ausdrucksformen gezeigt hat. Andererseits geht es auch um die Beibehaltung der starken Positionen der orthodoxen Kirchen in Galizien und insbesondere in Transkarpatien.

Es ist aber zu betonen, dass die erwähnten Veränderungen mit massiven Eingriffen des Staates in die Belange der Kirche (durch die Verhaftung und Ermordung der griechisch-katholischen Bischöfe und durch Repressalien gegen einige hundert Priester und Mönche, welche die Vereinigung mit dem Moskauer Patriarchat nicht akzeptiert haben) vollzogen wurden, der nicht nur als Verbündeter der russischen orthodoxen Kirche bei der Integration von vier griechisch-katholischen Diözesen aufgetreten ist, sondern diese Transformationsprozesse mit eingeleitet hat. Die orthodoxe Kirche und der Staat haben die These über die Notwendigkeit einer Rückkehr zur Monokonfessionalität 
Juraš, Religiöser Pluralismus in der Ukraine

in der ukrainischen - im weiteren Sinne der ostslavischen - Bevölkerung aufgestellt. Durch gewaltsame Unterbrechung der konfessionellen Tradition der Griechisch-Katholischen Kirche und flächendeckende Einschränkungen der protestantischen Konfessionen in der Nachkriegszeit in der Ukraine mit gleichzeitig liberaler Behandlung der Orthodoxie, die hier damals nur durch Gemeinden des Moskauer Patriarchats vertreten war, ist es dem Sowjetstaat und der russischen Orthodoxie für eine Zeitlang gewissermaßen gelungen, mit Hilfe von Repressalien die Idee der künstlichen Monokonfessionalität zu realisieren. Allerdings war diese Monokonfessionalität kurzlebig und lebensunfähig.

Der erste schwere Stoß gegen die nach dem Krieg erreichte formale Monokonfessionalität und Dominanz der Orthodoxie, die vom Staat relativ liberal behandelt wurde, war Ende der 1950er und Anfang der 1960er der Verzicht der Sowjetregierung unter Nikita Chruščev auf die Strategie der vorherigen fünfzehn Jahre gegenüber der Religion. Dann aber wurden die Ablehnung und Bekämpfung jeglicher Religion, auch der Orthodoxie, wieder zur Grundlage der staatlichen Religionspolitik erhoben. Als Folge der praktischen Maßnahmen hat sich die Zahl der Religionsgemeinden mehr als halbiert. Diesmal war die orthodoxe Kirche, die damals über das am besten entwickelte Netz von örtlichen Kirchengemeinden verfügte, die größte Leidtragende. Während des etwa dreijährigen Feldzuges gegen die Kirche hat die Russische Orthodoxe Kirche die meisten Klöster und Priesterseminare sowie die Hälfte der Pfarreien verloren.

Mit dem Machtantritt Leonid Brežnevs wurde die gewaltsame staatliche Repressionspolitik gegenüber den Kirchen eingestellt. Mitte der 1960er Jahre wurde die Situation fast 25 Jahre eingefroren. Obwohl der Orthodoxie ein äußerst schwerer Stoß versetzt worden war, blieb sie in der Zeit, in der die Ukrainische Griechisch-Katholische Kirche verboten war und der Protestantismus unter strenger staatlicher Kontrolle leben musste, die einflussreichste Konfession.

Der zweite gewichtige Schlag gegen das Kräfteverhältnis, das vom Staat künstlich herbeigeführt und durch Gewalt beibehalten wurde, folgte Ende der 
Juraš, Religiöser Pluralismus in der Ukraine

1980er Jahre, als der Staat durch objektive Faktoren gezwungen war, die Politik der totalen Reglementierung der Religion aufzugeben.

Es ist also kein Zufall, dass sich die für den totalitären Sowjetstaat erwünschte formale Homogenität nach dem Wechsel der Gläubigen der Ukrainischen Griechisch-Katholischen Kirche zur Orthodoxie nicht länger zu halten vermochte, als der Staat nicht mehr imstande war, die Situation unter völliger Kontrolle zu halten und alle Formen der Unzufriedenheit im Keime zu ersticken. Mit dem Zusammenbruch des totalitären politischen Systems setzte auch der schnelle Niedergang und die spontane Korrektur des durch das kommunistische Regime aufgebauten Systems konfessioneller Prioritäten und Beziehungen ein, es schalteten sich konfessionelle und außerkonfessionelle Faktoren und Mechanismen geschichtlicher, ethischer, nationaler, theologischer und traditionalistischer Art ein, welche die natürliche Entwicklung und die Selbstregulierung des konfessionellen Systems von jedem Staat bestimmen.

\section{Dritte Unterperiode: Vom Ende der 1980er Jahre bis heute}

Das Ende der 1980er Jahre, genauer das Jahr 1988, als endgültiger Wendepunkt im Verhältnis des Staates zur Religion, was sich durch den schrittweisen Verzicht auf die staatliche Gewaltanwendung gegen den religiösen Gemeinden manifestiert hat, betrachten wir als den Umbruch, der die zweite von der dritten Unterperiode der letzten, sechsten inhaltlich polykonfessionellen Periode in der Geschichte der konfessionellen Transformation der Ukraine trennt. Diese Unterperiode umfasst alle Ereignisse der nahen Zeitgeschichte, die einerseits in der Forschung gut bekannt sind, andererseits einer gesonderten Abhandlung bedürfen würde, was jedoch den Rahmen dieses Beitrags sprengen würde. 
Juraš, Religiöser Pluralismus in der Ukraine

\section{Zweiter Blickpunkt: Die Ebene der religiös-konfessionellen Pluralität im allgemeinen polyethnischen ukrainischen gesellschaftlichen Kontext}

Außer der erwähnten statistisch dominierenden Pluralität vor einem ukrainisch-ethnischen Hintergrund kann man über weitere wichtige Elemente des religiösen Pluralismus in der Ukraine sprechen, die aus Einflüssen anderer ethnischer Faktoren resultieren:

- Die Römisch-Katholische Kirche ist sowohl historisch als auch in moderner Zeit traditionell mit dem polnischen ethnischen Hintergrund verflochten, in Transkarpatien mit der slowakischen und ungarischen Minderheit.

- Die protestantischen Gemeinden (der deutschen und schwedischen Lutheraner, der ungarischen reformatorischen Kirche, der koreanischen Baptisten usw.) haben ebenfalls einen eindeutigen ethnischen Hintergrund.

- Zwei Abzweigungen der russischen Altorthodoxie (die Hierarchie von Belaja Krinica und die sogenannten Priesterlosen) sind ausschließlich mit den russischen ethnischen Gemeinden verbunden.

- Derselbe russische ethnische Hintergrund dominiert ebenfalls deutlich bei einigen kleinen oder alternativen orthodoxen Kirchen: bei einigen Zweigen der Wahren Orthodoxen Kirche und bei der Russischen Orthodoxen Kirche im Ausland usw.

- Die ethnische Zugehörigkeit der Muslime (Tataren auf der Krim und in der Ostukraine, Aserbaidschaner und andere kleine Gruppen in Kiev und anderen Städten) und der Juden muss nicht extra betont werden.

Die mit geschichtlichen Herausbildungsprozessen verbundene moderne ukrainische Polykonfessionalität bedeutet auch das Entstehen eines spezifischen »Identifizierungscodes« der meisten Mitglieder der ukrainischen Bevölkerung. Damit ist das permanente Gefühl der Anwesenheit »anderer « gemeint, das sich 
Juraš, Religiöser Pluralismus in der Ukraine

jahrhundertelang herausgebildet und etabliert hat. Dieses mentale Bild konnte nicht spontan oder augenblicklich entstehen. Der ursprünglichen Feindseligkeit des späten Mittelalters ist die Bevölkerung allmählich entwachsen und hat sich zunächst auf den bewussten Wunsch hin bewegt, die andere konfessionelle Identität zu verstehen, um mit ihr konfliktlos zu koexistieren, und schließlich hin zu ihrer Anerkennung und Respektierung, um nicht nur zu koexistieren, sondern auch mit ihr zusammenzuarbeiten und einen sozialen Zusammenhalt zu erreichen. Der Schluss, dass religiöser Pluralismus in der ukrainischen Gesellschaft anderen Formen von Pluralität und Variabilität, beispielsweise dem politischen oder weltanschaulichen Pluralismus, vorausging, scheint daher stringent.

Auch wenn wir die Existenz oder gar ein spezifisches Diktat des religiösen Pluralismus feststellen, können wir auf keinen Fall behaupten, dass diese Mission von allen Mitgliedern der Gesellschaft eindeutig unterstützt wird. Es wird immer Gruppen geben, die sich gewissermaßen nach religiösem Universalismus oder nach Homogenität sehnen und deren Abwesenheit dramatisch empfinden. Ihre vermeintliche Opposition zum Polykonfessionalismus erscheint als eine idealistische »Rückkehr in das ursprüngliche Paradies«, in dem alles klar definiert und verständlich war, und das Problem der Wahl gar nicht existierte. Dieses »erträumte Paradies«, das sich zu einer Art Legende oder einem Mythos entwickelt hat, scheint für viele Menschen in der Ukraine die illusorische Monokonfessionalität in der Zeit der »Taufe« der Rus' unter Fürst Volodymyr und einigen Jahrhunderten danach zu sein, die in diesem Beitrag als dritte monokonfessionelle Periode bezeichnet wird.

Ein indirektes Echo der Denkweise in Kategorien der konfessionellen Homogenität oder des konfessionellen Universalismus (Monokonfessionalität) sind in der modernen Ukraine das Entstehen und die Entwicklung einer entsprechenden Ideologie und sogar eine gesellschaftliche Nachfrage nach einer Vereinigung und einer entsprechenden Rhetorik. Man muss sich gar nicht an detaillierte Meinungsumfragen wenden, um festzustellen, dass die Zahl von Anhängern einer ukrainischen Einheitskirche wächst. Konsequenterweise können Politiker diese 
Juraš, Religiöser Pluralismus in der Ukraine

Tatsache nicht ignorieren. Als Höhepunkt für den Versuch, eine »Einheitskirche« zu etablieren, ist die Amtszeit Viktor Juščenkos anzusehen. Allerdings konnte auch dieser nicht von einer gesamtnationalen Universalreligion träumen, in der sämtliche Kirchen der ostchristlichen Tradition zusammengeführt würden. Gleichwohl wollte er in der Praxis diese Idee im »kleineren Maßstab « realisieren und zumindest die orthodoxen Denominationen unter einem maximalen Konsens über die Ideologie dieses Prozesses mit der Griechisch-Katholischen Kirche vereinen. Aber selbst diese »eingeschränkte« oder »lokale« Vereinigungsplattform konnte nicht umgesetzt werden.

Das Echo solcher Ideen kann man übrigens auch in der Politik anderer ukrainischer Präsidenten finden. Während der zweiten Amtszeit von Leonid Kučma hat sich die Idee herauskristallisiert, die formale und nicht nur faktische - wie es heute praktisch der Fall ist - Autonomie für die Ukrainische Orthodoxe Kirche zu erlangen und alle Orthodoxen in dieser Idee zu vereinen. Dieselbe Erkenntnis und der Wunsch, die sogenannten traditionellen Konfessionen zumindest teilweise zu fusionieren, haben auch die Amtszeit von Viktor Janukovyč geprägt. Jeder Beobachter kann die erstaunliche Evolution der Religionspolitik von Janukovyč bestätigen: von seiner eindeutigen Selbstidentifizierung mit einer einzigen Konfession (der Ukrainischen Orthodoxen Kirche Moskauer Patriarchats) bis hin zum Wunsch, ein diversifiziertes Konfessionsmodell aufzubauen. Dies wurde im Rahmen der Feierlichkeiten zum 1025-jährigen Jubiläum der »Taufe« der Ukraine-Rus' und zum 22. Jahrestag der Unabhängigkeit des Landes im Jahr 2013 deutlich.

Nach den Überlegungen über den gegenwärtigen Kontext der Pluralität in der ukrainischen Gesellschaft im religiösen Bereich wäre es wichtig, noch einen Aspekt zu analysieren, der zum letzten Punkt dieses Beitrags führt: der prospektiven Analyse. Obwohl die Tiefe und der Einfluss von pluralistischen Konfessionsmodellen und ihre Wirkung auf das etablierte Bild der Ukrainer in der Geschichte, ihre Psychologie und Weltanschauung noch nicht genug 
Juraš, Religiöser Pluralismus in der Ukraine

anerkannt werden, muss man in diesem Kontext einige grundsätzlich wichtige Aspekte betonen, die noch einmal von der europäischen Dimension der ukrainischen Realität sowohl in der Geschichte als auch in der Gegenwart zeugen.

Wie oben dargestellt, erreichte der im späten Mittelalter etablierte religiöse und konfessionelle Pluralismus in den ukrainischen Gebieten im 17. und 18. Jahrhundert seinen Höhepunkt. In allen diesen alten Perioden stand die ukrainische Bevölkerung nicht nur nach dem äußerlichen Erscheinungsbild der pluralistischen Absichten, sondern auch nach dem Charakter und Niveau der Verinnerlichung der pluralistischen Realität im konfessionellen Bereich durch die Gesellschaft in der Vorhut gesamteuropäischer Tendenzen und war nicht nur vielen Nachbarn (für einige war die Ablehnung der Pluralität und Variabilität die einzig akzeptierte Norm) voraus, sondern auch vielen Nationen, die heute als Muster der Toleranz und Liberalität jeglicher Art gelten.

Die konfessionelle Teilung innerhalb der ukrainischen Gemeinschaft, also der konfessionelle oder religiöse Pluralismus, ist autark, das heißt, er entwickelt sich und übt seinen Einfluss im Rahmen des ganzen Systems der ukrainischen Gesellschaft aus, nicht nur auf der religiös-konfessionellen Ebene. Es hat sich beispielsweise erwiesen, dass Russland der religiösen Variabilität grundsätzlich feindlich gegenüber steht. Die polnische Gesellschaft konnte nach einigen Experimenten in der Geschichte (unter anderem mit dem Protestantismus) die Idee des religiösen Pluralismus auch nicht ganz akzeptieren. Ungarn, Rumänien und teilweise Belarus haben sich nach ziemlich schmerzhaften und nicht eindeutigen Entwicklungen auf eine vorsichtige und begrenzte Akzeptanz des bikonfessionellen Modells geeinigt (Katholizismus und reformatorische Kirche in Ungarn, orthodoxe und Griechisch-Katholische Kirche in Rumänien, Orthodoxie und Katholizismus in Belarus). Im gesamten osteuropäischen Gebiet hat nur die Ukraine sowohl in der Vergangenheit als auch in der modernen Zeit die konfessionelle Pluralität als Norm übernommen (Orthodoxie mit mehreren Denominationen, Römisch-Katholische und Griechisch-Katholische Kirche, einige einflussreiche Zweige des sogenannten späten Protestantismus), 
Juraš, Religiöser Pluralismus in der Ukraine

was ihre Zugehörigkeit zum gesamteuropäischen Wertesystem, zu dessen Grundbausteinen Pluralismus und Toleranz gehören, nicht nur im religiösen Bereich, sondern auch auf der Ebene der psychologischen Einstellungen und weltanschaulichen Grundsätzen bekräftigt. Die Akzeptanz und Übernahme pluralistischer Prinzipien im religiösen Bereich stellt eine breitere mentale Plattform der ukrainischen Ethnie dar, die keine grundsätzlich feindliche Einstellung zu Europa generell und zu »europäischen Grundregeln« für gesellschaftliche Beziehungen birgt.

Die Hauptschlussfolgerung dieses Beitrags wird von der konsolidierten Position sämtlicher wichtiger Religionsgemeinschaften in der Ukraine, die sich im Allukrainischen Kirchenrat zusammengeschlossen haben, bekräftigt. Sie besteht darin, dass die Kirchen den Wunsch der Ukrainer nach der europäischen Integration prinzipiell unterstützen und fördern. Mit dieser Position solidarisch zeigt sich sogar die Mehrheit der Führung der Ukrainischen Orthodoxen Kirche des Moskauer Patriarchats, die es gewagt hat, diesen prinzipiellen Standpunkt gegen die klare gegensätzliche Meinung der kanonischen Führung in Moskau und der zwar einflussreichen, aber nicht besonders zahlreichen Opposition in den eigenen Reihen öffentlich zu deklarieren. Dieses Beispiel ist nicht nur eine weitere Veranschaulichung der vorher aufgestellten Thesen, sondern auch ein Grund für die Artikulation einer realistischen Hoffnung: Erstens ist die Suche nach einer für die moderne ukrainische Gesellschaft so notwendigen Integrationsidee theoretisch und praktisch möglich, und zweitens muss diese Suche in gleichsam »europäischer« Richtung auf der Basis von Akzeptanz und der Übernahme pluralistischer Modelle, vor allem im konfessionellen Bereich, geführt werden.

Wenn in der Gesellschaft zwei oder sogar mehr Sprachen aktiv funktionieren, wenn gesellschaftliche Prozesse durch unterschiedliche, manchmal antagonistische Kulturtraditionen beeinflusst werden, kann die Akzeptanz und Übernahme europäischer Werte wie Toleranz und Pluralismus in allen Sphären zum einflussreichsten Faktor der nationalen Konsolidierung werden. 
Juraš, Religiöser Pluralismus in der Ukraine

Dabei ist die Akzeptanz und Übernahme von Normen und Prinzipien der religiösen Toleranz als »europäisches Axiom« eine der Aufgaben, welche die Ukraine schon vor langem gemeistert hat.

Der religiöse Pluralismus, von vielen in der Ukraine als überflüssiges und unnützes Erbe gesehen, das die gesellschaftliche Entwicklung angeblich störe und auf der Basis des Universalismus neu formatiert werden müsse, zeigt sich tatsächlich als Instrument, um zahlreiche Ziele zu erreichen. Es gibt auch keine realen pragmatischen oder rationellen Vorbedingungen dafür, dass es zu einer schnellen oder unumgänglichen Aufhebung oder nur zu einem Rückgang des religiösen Pluralismus in der Ukraine käme. Ein Blick auf die interkonfessionelle Ebene lässt zur Feststellung gelangen, dass es heute keine reale Initiative bzw. Plattform dafür gibt, deren Umsetzung realistisch oder glaubwürdig wäre. Es geht vor allem um Einigkeit zwischen der orthodoxen und der griechisch-katholischen Gemeinschaft.

Ohne die Begrifflichkeiten dieses Aspekts eingehender zu besprechen (beispielsweise, ob man unter religiösem Pluralismus nur die Existenz unterschiedlicher Konfessionen oder auch einzelner Gruppen und Kirchen innerhalb einer Konfession versteht), aber in der Annahme, dass die Teilungen innerhalb einer Konfessionen wie parallele Jurisdiktionen in der Orthodoxie ein Argument für die Idee und Praxis des religiösen Pluralismus ist, muss man zum Schluss kommen, dass die jurisdiktionelle Teilung innerhalb der Orthodoxie auch sicherlich bestehen bleiben wird. Auch wenn durch den Druck der »Vereinigungsidee« und durch eine eventuelle Unterstützung dieses Prozesses durch bestimmte politische Kreise ein gewisses Vereinigungsszenario innerhalb der ukrainischen Orthodoxie möglich ist, werden die Gruppen der Unzufriedenen und folglich auch die kleineren oder größeren jurisdiktionellen Teilungen erhalten bleiben. Die einflussreiche kritische Masse der radikalen Opponenten der Vereinigung, die sich organisatorisch gegen diese Tendenz wehren kann, ist in beiden Lagern vorhanden. Und das bedeutet, dass der konfessionelle und 
Juraš, Religiöser Pluralismus in der Ukraine

religiöse Pluralismus in der heutigen Ukraine eine Realität für die nähere und sogar für die fernere Zukunft bleiben wird.

\section{Literatur}

Власовський, Іван: Нарис історії Української Православної Церкви. Нью Йорк 1957.

Гордієнко, Володимир: Сталінізм і Українська Греко-Католицька Церква. In: Українське відродження і національна церква. Київ 1990, 83-85. Грушевський, Михайло: 3 історії релігійної думки. In: Грушевський, Михайло: Духовна Україна. Київ 1994, 5-136.

Доклад о деятельности центра Инициативной группы. In: Львовский церковный собор. Документы и материалы. 1946-1981. Москва 1982. Додатковий список духовенства, що возз'єдналося з Православною Церквою. In: Православний Вісник 1 (1949), 31-32.

Жабко-Потапович, Лев: Христове Світло в Україні. Чікаго 1991.

Закарпатський, П.: Православна Церква на Закарпатті. In: Православний вісник (1948) № 3, 71-81, № 4, 99-113, № 5, 146-157.

Оксіюк, Йосип: Великий подвижник Православ’я на Закарпатті. In: Православний вісник 3 (1948), 94-95.

Панас, Кость: Історія Української Церкви. Львів 1992.

Полный православный богословскій энциклопедическій словарь. В 2 т. Москва 1992.

Степанов (Русак), Владимир: Свидетельство обвинения. В 3 т. Москва 1993.

Субтельний, Орест: Україна. Історія. Київ 1991. 
Juraš, Religiöser Pluralismus in der Ukraine

\title{
Abstract
}

\author{
Andrij Juraš \\ Religious Pluralism in Ukraine: Retrospective, Actual, \\ and Future Analysis
}

Modern Ukrainian poly-confessionalism is viewed through the prism of this phenomenon's formation and historical preconditions in Ukrainian ethnic territories, as well as through a general multiethnic Ukrainian social context. More precisely, the article defines the confessional status of Ukrainian society and clarifies the mechanisms of the main confessional transformations. Furthermore, it discusses the role of modern poly-confessionality in Ukraine with regards to the implementation of the Euro-integrational processes and the prospects of its development. 


\section{Iryna Fenno}

\section{Die Umsetzung der Prinzipien der Gewissensfreiheit in der Ukraine}

Die Gewissensfreiheit ist eine Kategorie, die den Stellenwert der Religion in der Gesellschaft widerspiegelt. Sie reflektiert die Genese der Religion und der religiösen Institute, Prozesse der Institutionalisierung der Religion, die Beziehungen zwischen Staat und Kirche, die Bedeutung der Religion in der Gesellschaft sowie das religiöse Leben und den Zustand der Religionsfreiheit. Theoretische Überlegungen zum philosophischen Aspekt der Gewissensfreiheit als einer der wichtigsten Werte und Freiheiten führen zwangsläufig zur Analyse der praktischen Umsetzung dieser Freiheit. Aus der rechtlichen Sicht ist Gewissensfreiheit ein Grundrecht, das zusammen mit anderen Rechten und Freiheiten vor allem durch das Grundgesetz, aber auch durch andere Gesetze und Normen gewährleistet wird.

Der Beitrag im Folgenden weist darauf hin, dass die Religionsfreiheit auch im öffentlichen Leben der Ukraine einen äußerst sensiblen Faktor darstellt. Dabei war kurz vor der Flucht und Absetzung des Präsidenten Janukovyč nach den Protesten auf dem Euro-Majdan 2014 in seiner Religionspolitik eine immer stärker spürbare Verschlechterung zwischen der Regierung auf der einen Seite und den Kirchen in der Ukraine auf der anderen Seite zu beobachten. Dazu werden im einzelnen Kritikpunkte religiöser Repräsentanten vorgestellt, auf die die Politik allerdings nicht mehr reagieren wollte.

\section{Rechtliche Lage}

Nach der Proklamation der staatlichen Unabhängigkeit wurden in der Ukraine gesetzlich geregelte Bedingungen für ein durch den Staat garantiertes Recht 
Fenno, Die Umsetzung der Prinzipien der Gewissensfreiheit in der Ukraine auf Gewissensfreiheit geschaffen. In Artikel 35 der ukrainischen Verfassung von 1996 heißt es:

"Jeder hat das Recht auf freie Weltanschauung und Religion. Dieses Recht beinhaltet die Freiheit, sich zu einer beliebigen bzw. zu keiner Religion zu bekennen, religiöse Kult- oder sonstige religiöse Tätigkeiten individuell bzw. kollektiv unbehindert auszuüben. Die Realisierung dieses Rechts kann durch Gesetz nur zum Schutz der öffentlichen Ordnung, der Gesundheit und der Sittlichkeit der Bevölkerung oder zum Schutz der Rechte und der Freiheiten anderer Menschen eingeschränkt werden.»

1991 wurde das Gesetz »Über die Gewissensfreiheit und religiöse Organisationen « verabschiedet, in dem in Artikel 3 »jedem Bürger der Ukraine das Recht auf Gewissensfreiheit garantiert wird «.

Das US Department of State stellt in seinem Jahresbericht über die Gewissensfreiheit für $2012^{1}$ fest, dass in der Ukraine rechtliche und politische Grundlagen vorhanden sind, um Glaubensfreiheit zu gewährleisten und die Existenz eines breiten Netzes von religiösen Organisationen zu ermöglichen. Die jüngsten statistischen Daten ${ }^{2}$ zeigen folgendes Bild:

»Das Religionsnetz in der Ukraine ist zum 1. Januar 2013 durch 55 Glaubensrichtungen vertreten, dazu gehören 36.995 religiöse Organisationen, darunter 87 Zentralen und 295 Verwaltungen, 35.460 Religionsgemeinden mit 31.313 Priestern, 500 Klöster mit 6.834 Mönchen, 370 Missionen, 81 Bruderschaften, 202 religiöse Bildungseinrichtungen mit 19.752 Auszubildenden sowie 13.157

1 International Religious Freedom Report for 2012.

2 Інформаційний звіт Міністерства культури України »Про стан і тенденції розвитку релігійної ситуації та державно-конфесійних відносин в Україні«.

DigiOst $3 \mid 50$ 
Fenno, Die Umsetzung der Prinzipien der Gewissensfreiheit in der Ukraine

Sonntagsschulen. 384 Kirchenzeitungen berichten über das religiöse Leben.

Für Gottesdienste werden 23.814 Kirchen und Gebetshäuser genutzt.«

Die regionale Verbreitung:

Die Zahlen über die Verbreitung und Verteilung der Religionsgemeinden und -einrichtungen belegen, dass deren Dichte in den westlichen Regionen größer ist, im Osten und im Süden dagegen geringer: in acht Gebieten der Westukraine (Wolhynien, Transkarpatien, Ivano-Frankivs'k, L'viv, Rivne, Ternopil', Chmel'nyc'kyj, Černivci) sind insgesamt 39 Prozent der religiösen Gemeinschaften konzentriert, in neun Oblasti im Norden und in der Zentralukraine (Vinnycja, Žytomyr, Kiev, Kirovohrad, Poltava, Sumy, Čerkasy, Černihiv und Kiev-Stadt) sind 31 Prozent der Organisationen registriert, und in zehn Gebieten im Süden und im Osten des Landes (in der Autonomen Republik Krim, in Dnipropetrovs'k, Donec'k, Zaporižžja, Luhans'k, Mykolajiv, Odessa, Charkiv, Cherson und in der Stadt Sevastopol') sind 30 Prozent der religiösen Organisationen ansässig.

\section{Die konfessionelle Verbreitung:}

Die Orthodoxie ist die dominierende Konfession in der Ukraine, Anfang 2013 zählte sie 19.107 Gemeinden, was 51,6 Prozent von deren Gesamtzahl ausmachte. Die Katholiken waren zum 1. Januar 2013 mit 5.029 Gemeinden vertreten, die 13,6 Prozent aller Gemeinden ausmachten. Die Protestanten zählten 10.613 Gemeinden und erreichten damit 28,7 Prozent an der Gesamtzahl. Ethnisch geprägte Konfessionen werden in der Ukraine von 1.806 Gemeinden repräsentiert, die 4,9 Prozent sämtlicher Gemeinden ausmachen (Muslime: 3,3 Prozent, Juden: 0,8 Prozent und andere).

Der kurze Überblick über das Spektrum der Religionsgemeinschaften in der Ukraine spiegelt nicht alle praktischen Aspekte, die mit der Umsetzung des Rechts auf Gewissensfreiheit verbunden sind, wider. Insgesamt zeugt aber der religiöse Pluralismus in der Ukraine davon, dass dieses Recht gewährleistet 
Fenno, Die Umsetzung der Prinzipien der Gewissensfreiheit in der Ukraine

ist und dass hier Bedingungen für das Funktionieren verschiedener religiöser Organisationen geschaffen worden sind.

\section{Gewissensfreiheit und ihre Umsetzung: zur Perzeption}

Uns interessiert im Folgenden vor allem, welche Prinzipien der Gewissensfreiheit in die Praxis umgesetzt werden und welche Probleme es dabei gibt. Die Forschung definiert folgende Grundprinzipien für die Gewissensfreiheit: 1. staatliche Garantien für das Recht auf Gewissensfreiheit; 2. Gleichheit der Bürger unabhängig von ihrer Einstellung zur Religion; 3. Gleichheit aller religiösen Organisationen vor dem Gesetz; 4. Trennung der Kirche vom Staat; 5. weltlicher Charakter der Bildung; 6. Verantwortung der religiösen Organisationen für Gesetzesverstöße; 7. das Recht auf Eigentum; 8. das Recht auf Ausübung von Gottesdiensten, religiösen Riten, Zeremonien und Prozessionen in den vom Gesetz geregelten Fällen.

Es ist interessant zu sehen, wie die Einwohner des Landes die Gewissensfreiheit sehen, insbesondere wenn man dabei Umfragen von Anhängern verschiedener Konfessionen aus mehreren Jahren vergleicht. Die Umfragen des Razumkov-Zentrums ${ }^{3}$ vermitteln folgendes Bild: Die Anzahl der Befragten, die überzeugt sind, dass es in der Ukraine uneingeschränkte Gewissensfreiheit und Gleichheit der Konfessionen gibt, ist zwischen 2010 und 2013 um 10,5 Prozentpunkte gesunken und befindet sich mit 65,4 Prozent etwa auf dem Niveau des Jahres 2000. Der höchste Wert (75,9 Prozent) wurde hier im Jahr

3 Релігія і влада в Україні: проблеми взаємовідносин (07.03.2014). Die Umfrage wurde vom 28. Februar bis 6. März 2013 durchgeführt. Es wurden 2010 Erwachsene (18+) befragt, theoretische Abweichung liegt bei 2,3 Prozent. Die Resultate werden mit den Umfrageergebnissen vom August 2000 und November 2010 verglichen.

DigiOst $3 \mid 52$ 
Fenno, Die Umsetzung der Prinzipien der Gewissensfreiheit in der Ukraine

2010 erreicht. Die Anzahl von Befragten, die diese Frage nicht beantworten konnten, bleibt dagegen über die Jahre konstant (13 bis 13,5 Prozent):

Umfrage des Razumkov-Zentrums:

Sind Sie mit der Behauptung, dass es in der Ukraine uneingeschränkte Gewissensfreiheit und Gleichheit der Konfessionen vor dem Gesetz gibt, einverstanden? (in Prozent der Befragten)

\begin{tabular}{lccc} 
& Einverstanden & Nicht einverstanden & Schwer zu sagen \\
\hline 2000 & 66,3 & 20,6 & 13,1 \\
\hline 2010 & 75,9 & 10,5 & 13,6 \\
\hline 2013 & 65,4 & 21,0 & 13,5 \\
\hline
\end{tabular}

Mit der Aussage, dass es in der Ukraine Gewissensfreiheit und Gleichheit der Konfessionen vor dem Gesetz nur deklariert, aber nicht praktiziert werden, war 2013 fast jeder dritte Befragte einverstanden (8,5 Prozentpunkte mehr im Vergleich zu 2010):

Umfrage des Razumkov-Zentrums:

Sind Sie mit der Behauptung, dass in der Ukraine Gewissensfreiheit und Gleichheit der Konfessionen vor dem Gesetz nur deklariert, aber nicht praktiziert werden, einverstanden? (in Prozent der Befragten)

\begin{tabular}{lccc} 
& Einverstanden & Nicht einverstanden & Schwer zu sagen \\
\hline 2000 & 38,7 & 42,1 & 19,2 \\
\hline 2010 & 24,4 & 52,1 & 23,6 \\
\hline 2013 & 32,9 & 34,4 & 22,6 \\
\hline
\end{tabular}


Fenno, Die Umsetzung der Prinzipien der Gewissensfreiheit in der Ukraine

Im Jahr 2013 waren 32,3 Prozent der Befragten überzeugt, dass die Religionsgemeinschaften und Kirchen ihre Rechte und Freiheiten in unerlaubter Weise ausnutzen (2010 waren es 27,6 Prozent):

Umfrage des Razumkov-Zentrums:

Sind Sie mit der Behauptung, dass die Religionsgemeinschaften und Kirchen ihre Rechte und Freiheiten in unerlaubter Weise benutzen, einverstanden? (in Prozent der Befragten)

\begin{tabular}{lccc} 
& Einverstanden & Nicht einverstanden & Schwer zu sagen \\
\hline 2000 & 37,6 & 38,2 & 24,2 \\
\hline 2010 & 27,6 & 43,9 & 28,6 \\
\hline 2013 & 32,3 & 40,2 & 27,5 \\
\hline
\end{tabular}

Die Verteilung der Ergebnisse nach der Konfession zeigt folgendes Bild: 71,4 Prozent der Anhänger der Ukrainischen Orthodoxen Kirche (unter der Jurisdiktion des Moskauer Patriarchats) (UOK [MP]) sprachen 2013 von uneingeschränkter Gewissensfreiheit (2010 waren es 86,1 Prozent). Unter den Anhängern der Ukrainischen Orthodoxen Kirche - Kiever Patriarchat (UOK-KP) waren 73,4 Prozent derselben Meinung, bei der Ukrainischen Griechisch-Katholischen Kirche (UGKK) waren es 73,6. Im Vergleich zu anderen großen Konfessionen ist bei den Anhängern der UGKK die Überzeugung, dass es in der Ukraine uneingeschränkte Gewissensfreiheit gibt, seit $2010 \mathrm{am}$ wenigsten (nur um 2,7 Prozent) gesunken.

Die Anhänger der UOK-KP dachten 2013 am ehesten (38,9 Prozent), dass Gewissensfreiheit und Gleichheit der Konfessionen vor dem Gesetz nur deklariert, aber nicht praktiziert würden, gefolgt von den Anhängern der UGKK (34,8 Prozent) und der UOK (MP) (26,4 Prozent).

Wie die Umfrage von 2013 zeigt, sind die Anhänger der UGKK am wenigsten (21,2 Prozent) überzeugt, dass die Religionsgemeinschaften und Kirchen ihre 
Fenno, Die Umsetzung der Prinzipien der Gewissensfreiheit in der Ukraine

Rechte und Freiheiten in unerlaubter Weise ausnutzen, gefolgt von der UOK (MP) (25,1 Prozent) und UOK-KP (32,8 Prozent). Im Vergleich zu 2010 haben die Anhänger der UGKK ihre Meinung kaum geändert, bei der UOK (MP) und UOK-KP ist die Zahl der Skeptiker um 1,9 bzw. 3,6 Prozentpunkte gestiegen.

Bei allen drei Fragen kann man feststellen, dass sich die Lage bei der Umsetzung der Gewissensfreiheit in den letzten drei Jahren verschlechtert hat.

\section{Veränderungen des Gesetzes der Gewissensfreiheit}

Wenn wir über die Umsetzung der Prinzipien der Gewissensfreiheit in der Ukraine sprechen, sind drei Ebenen auszusondern, die zusammen in vollem Umfang den ganzen Bereich widerspiegeln:

1. Der Bereich der Staatspolitik und der Beziehungen zwischen Staat und Kirche. Davon, wie die Beziehungen zwischen Staat und Kirche funktionieren, wie effizient und stabil die Politik des Staates bei Schaffung von günstigen Bedingungen für das Funktionieren der religiösen Organisationen in einem polykonfessionellen Staat ist, hängt ab, ob Faktoren vermieden werden können, die zu Spannungen in den interkonfessionellen Beziehungen führen würden, ob die Gleichheit sämtlicher Religionsgemeinschaften vor dem Gesetz garantiert und die Trennung der Kirche vom Staat gewährleistet werden kann.

2. Die institutionelle Ebene, also die Ebene der Religionsgemeinschaften. Hier geht es darum, welche Bedingungen für das Funktionieren einer Religionsgemeinschaft als juristische Person in verschiedenen Bereichen geschaffen werden, und darum, wie es mit Rechtsschutz, Eigentumsfragen und Besteuerung steht.

3. Die individuelle Ebene. Hier kommen das Recht der Bürger, ihre religiöse oder nicht-religiöse Einstellung frei und ohne Zwang zu definieren, sowie ihre Gleichheit unabhängig von dieser Einstellung zur Geltung. Es geht also um die Aufhebung der Diskriminierung nach dem Religionsmerkmal. 
Fenno, Die Umsetzung der Prinzipien der Gewissensfreiheit in der Ukraine

Einige wichtige Veränderungen der staatlichen Politik in den letzten Jahren zeitigten direkte Auswirkungen sowohl auf die Umsetzung der Prinzipien der Gewissensfreiheit als auch auf die Beziehungen zwischen Staat und Kirche insgesamt:

A. Veränderungen in der Struktur der staatlichen Exekutive, die einen direkten Bezug zur Regulierung im Bereich der Religion haben und die Richtung der Staatspolitik bestimmen:

- Der Posten des Vizepremiers für humanitäre Frage wurde abgeschafft und seine Kompetenzen zwischen anderen Vizepremiers aufgeteilt.

- Durch das Dekret des Präsidenten »Über die Optimierung der zentralen Exekutivgremien« Nr. 1085 vom 9. Dezember 2010 wurde das Staatskomitee der Ukraine für Nationalitäten und Religionen abgeschafft. Seine Kompetenzen wurden an das Department für Religionen und Nationalitäten (unter der Leitung von Mychajlo Moškola) im Kulturministerium übertragen.

- Beim Ministerkabinett gibt es eine noch 2008 als Beratungsgremium gegründete Kommission für die Gewährleistung der Rechte religiöser Organisationen. Allerdings tagte sie in der Regierungszeit Mykola Azarovs (2010-2014) zum ersten Mal erst im Oktober 2012 unter dem Vorsitz von Vizepremier Rajisa Bohatyrova.

\section{B. Gesetzgebung}

Es wurden Änderungen zum Gesetz »Über die Gewissensfreiheit und religiöse Organisationen " verabschiedet, die in den religiösen Kreisen und unter Experten kontroverse Diskussionen auslösten. Bezeichnend sind hier vor allem nicht nur die Änderungen selbst, sondern die Art und Weise, wie die Meinung religiöser Kreise und von Experten berücksichtigt oder besser gesagt ignoriert wurde. Dies sind einige vielsagende Beispiele für die Reaktion auf diese Änderungen. So heißt es in der Erklärung des All-Ukrainischen Rats für Kirchen und Religiöse Organisationen: 
Fenno, Die Umsetzung der Prinzipien der Gewissensfreiheit in der Ukraine

»[...] Wir halten den Gesetzesentwurf Nr. 10221, der durch das Justizministerium vorbereitet und von der Verchovna Rada verabschiedet wurde, für einen Schritt, der zur Destabilisierung der religiösen Situation in der Gesellschaft führen, das Niveau der Glaubensfreiheit in der Ukraine verschlechtern und wesentliche Hindernisse für die geistige und soziale Mission der Kirchen und religiösen Organisationen schaffen wird. $\aleph^{4}$

Das Oberhaupt der Ukrainischen Griechisch-Katholischen Kirche Svjatoslav Ševčuk sagte in einem Interview für die Zeitung »Den'«:

»Die Tatsache, dass der Präsident die Änderungen zum Gesetz «Über die Gewissensfreiheit und religiöse Organisationen` unterzeichnet hat, lässt die Kirchenoberhäupter von einer Krise in den Beziehungen zwischen Staat und Kirche reden [...]. Es wird gesprochen, aber es gibt keinen Dialog. [...] Im Moment sieht es danach aus, dass das Paradigma in den Beziehungen zwischen Kirche und Staat zerstört worden ist. $\aleph^{5}$

In einem Appell der Synode der UGKK an den Präsidenten, die Regierung und das Parlament in Bezug auf die letzten Gesetzesinitiativen heißt es:

»Wir stellen fest, dass das voreilige Verabschieden des erwähnten Gesetzesentwurfes im Widerspruch zu früher getroffenen Absprachen das Vertrauen in den Dialog zwischen Staat und Kirche unterminiert und dessen Umsetzung unübersehbare Folgen für die Beziehungen zwischen Staat und Kirche sowie zwischen verschiedenen Konfessionen haben kann. $\ll^{6}$

4 Звернення глав конфесій до Президента України щодо ветування змін до Закону про свободу совісті.

5 Глава УГКЦ: »Сьогодні в державно-церковних відносинах - криза«.

6 Звернення Синоду УПЦ КП до Президента, Уряду та Парламенту щодо останніх законодавчих ініціатив.

DigiOst 3 | 57 
Fenno, Die Umsetzung der Prinzipien der Gewissensfreiheit in der Ukraine

Ähnliche Positionen werden auch im »Offenen Brief der Bürgerinitiativen, Menschenrechtler und Wissenschaftler « vom 30. Oktober 2012, im »Bericht des US State Departments über die Glaubensfreiheit in der Welt 2012«, der im Mai 2013 präsentiert wurde, und im Jahresbericht der Menschenrechtsbeauftragten des ukrainischen Parlaments Valerija Lutkovs'ka im Juni 2013 vertreten.

Was den Inhalt der beschlossenen Änderungen im Gesetz »Über die Gewissensfreiheit und religiöse Organisationen « anbelangt, so sind hier folgende Aspekte besorgniserregend:

1. Das Prozedere für die Registrierung der religiösen Organisationen wurde komplizierter gemacht, nun geht es um eine »doppelte Registrierung«: Die Veränderungen zu den Artikeln 13 und 14 sehen zum einen eine staatliche Registrierung einer Religionsgemeinde, die für den Status einer juristischen Person notwendig ist. Dafür sind laut Gesetz »Über die Registrierung von juristischen Personen und natürlichen Personen als Unternehmer« das Justizministerium und seine territorialen Vertretungen zuständig. Zum anderen muss die Satzung registriert werden, abhängig vom Vereinstyp ist dafür entweder eine Gebiets-Verwaltung (bzw. die Stadtverwaltungen in Kiev und Sevastopol') oder ein zentrales Exekutivgremium, das die Religionspolitik des Staates realisiert, also das Kulturministerium, zuständig.

2. Die Verstärkung der staatlichen Kontrolle über die Befolgung von Gesetzen über die Gewissensfreiheit und religiöse Organisationen.

Die Änderungen zu Artikel 29 bestimmen, dass das Befolgen der Gesetze über die Gewissensfreiheit, Weltanschauung, Glaubensfreiheit und religiöse Organisationen zentrale staatliche Exekutivgremien, die für die Ausarbeitung und Umsetzung der Staatspolitik im Bereich der Religion zuständig sind, andere zentrale Exekutivgremien, die Staatsanwaltschaft, lokale Behörden sowie 
Fenno, Die Umsetzung der Prinzipien der Gewissensfreiheit in der Ukraine

lokale Selbstverwaltungsorgane im Rahmen ihrer Kompetenzen überwachen sollen. Dabei sind die Kompetenzen der Staatsanwaltschaft nicht klar definiert.

3. Problematisch ist auch die im Gesetz formulierte Forderung, dass "öffentliche Gottesdienste, religiöse Riten, Zeremonien und Prozessionen jedes Mal von der zuständigen lokalen Staatsverwaltung, dem Exekutivgremium eines Gemeinde- oder Stadtrates genehmigt werden müssen. Das Ersuchen um eine solche Genehmigung muss spätestens zehn Tage vor dem geplanten Termin für Gottesdienst, Ritus, Zeremonie oder Prozession, dringende Fälle ausgenommen, eingereicht werden «(Artikel 21). Auf diese Problemstellen, die gegen das Gesetz »Über die Freiheit von friedlichen Versammlungen « verstoßen, wird im Bericht der Menschenrechtsbeauftragten hingewiesen; Valerija Lutkovs'ka schlägt vor, sie »mitteilungspflichtig, aber nicht genehmigungspflichtig« zu machen. ${ }^{7}$

Im Bericht des Kulturministeriums »Über den Zustand und die Tendenzen der Entwicklung der Situation im religiösen Bereich und in den Beziehungen zwischen Staat und Kirche in der Ukraine $«^{8}$ wurden für das Jahr 2012 insgesamt 25 Verstöße gegen das Gesetz über die Gewissensfreiheit und religiöse Organisationen festgestellt. 2011 wurden zum Vergleich zwei solcher Fälle registriert, 2010 waren es 14. Ein Verstoß wurde gegen das Gesetz über den Zivildienst im Gebiet Černihiv registriert. Allerdings handelt es sich hier allesamt um Verstöße aus der Zeit vor dem Inkrafttreten des neu novellierten Gesetzes »Über die Gewissensfreiheit und religiöse Organisationen«.

7 Щорічна доповідь Уповноваженого Верховної Ради України з прав людини про стан дотримання прав і свобод людини і громадянина, 2013 рік, 222.

8 Інформаційний звіт Міністерства культури України »Про стан і тенденції розвитку релігійної ситуації та державно-конфесійних відносин в Україні«.

DigiOst 3 | 59 
Fenno, Die Umsetzung der Prinzipien der Gewissensfreiheit in der Ukraine

Laut Bericht gibt es die meisten Verstöße gegen das Gesetz, die Gerichtsklagen zur Folge hatten, bei Eigentumsfragen und bei der Registrierung von Satzungen der Religionsgemeinschaften, unter anderem sind sie in den Gebieten Vinnycja, Ternopil', Zakarpattja, Černihiv und der Autonomen Republik Krim verbreitet. Keine Verstöße wurden dagegen in den Gebieten Volyn', Zaporižžja, Mykolajiv, Luhans'k, Poltava, Kirovohrad und Cherson registriert. 2012 wurden die meisten Verstöße im Gebiet Vinnycja beobachtet (20), je zwei Verstöße entfallen auf die Autonome Republik Krim und Ternopil', ein Fall wurde im Gebiet Černihiv registriert. Von den genannten Verstößen wurden sieben durch religiöse Organisationen mit registrierten Satzungen begangen, drei von Organisationen ohne Registrierung, fünf von Amtsträgern der religiösen Organisationen und ebenfalls fünf von ausländischen Bürgern, die eine gesetzwidrige religiöse Tätigkeit in der Ukraine praktiziert haben. ${ }^{9}$

Die typischen Fälle sind Verstöße gegen Artikel 24 über die religiöse Tätigkeit der ausländischen Geistlichen in einer Religionsgemeinde ohne Genehmigung durch Behörden (begangen von Bürgern der Slowakei, der Schweiz, Argentiniens, Ägyptens und Israels durch gesetzwidrige religiöse Tätigkeit in den Religionsgemeinden der Adventisten des Siebenten Tages, in der orientalisch geprägten Gemeinde "Sri Chinmoy«, der Ukrainischen Griechisch-Katholischen Kirche sowie in den muslimischen und jüdischen Gemeinden) sowie gegen Artikel 21, was das Zelebrieren von öffentlichen Gottesdiensten ohne offizielle Genehmigung der lokalen Behörden bedeutet (Zeugen Jehovas, Pfingstkirche »Neues Leben «, jüdische messianische Gemeinden in Vinnycja und Mohyliv-Podils'kyj).

Die Spannungen zwischen den Konfessionen und mit den lokalen Behörden werden vor allem durch Konflikte über Eigentumsfragen ausgelöst. Dies ist damit verbunden, dass Gemeinden Kirchengebäude und Grundstücke aus dem kommunalen oder staatlichen Besitz als Eigentum oder zur Pacht bekommen,

9 Ebenda.

DigiOst $3 \mid 60$ 
Fenno, Die Umsetzung der Prinzipien der Gewissensfreiheit in der Ukraine

oder auch mit der Eigentumsproblematik bei dem Wechsel der Gemeinde zur anderen Konfession (Jurisdiktion). Ferner gibt es Konfliktsituationen, die mit der Registrierung der Satzungen (Statuten) der religiösen Gemeinden durch Behörden zu tun haben.

\section{Schlussfolgerungen}

Insgesamt kann festgestellt werden, dass in der Ukraine im Großen und Ganzen Bedingungen zur Realisierung des Rechts auf Gewissensfreiheit vorhanden sind, allerdings sind hier in den letzten Jahren einige Komplikationen aufgetreten, die durch folgende Faktoren verursacht worden sind:

1. Das Fehlen eines ständigen Dialogs zwischen den staatlichen Behörden und dem All-Ukrainischen Rat für Kirchen und Religiöse Organisationen, dessen Position bei den Gesetzesänderungen im Bereich der Religion nicht berücksichtigt wurde. Außerdem konnte das ukrainische Parlament das Konzept der Beziehungen zwischen Staat und Kirche in der Ukraine nicht verabschieden.

2. Die Novellierung des Gesetzes über die Gewissensfreiheit widerspricht den Prinzipien der Gewissensfreiheit selbst.

3. Die Eigentumsfragen und das Problem der Rückgabe von Kircheneigentum bleiben ungelöst, was Spannungen vor Ort verschärft. 
Fenno, Die Umsetzung der Prinzipien der Gewissensfreiheit in der Ukraine

\section{Literatur}

Глава УГКЦ: „Сьогодні в державно-церковних відносинах - криза«, unter http://news.ugcc.org.ua/news/glava_ugkts_sogodn\%D1\%96_v_derz havnotserkovnih_v\%D1\%96dnosinah_kriza_65224.html (08.03.2014).

Звернення глав конфесій до Президента України щодо ветування змін до Закону про свободу совісті, unter http://vrciro.org.ua/index. php?option=com_content\&task=view\&id=186\&Itemid=31 (08.03.2014).

Звернення Синоду УПЦ КП до Президента, Уряду та Парламенту щодо останніх законодавчих ініціатив, unter http://www.irs.in.ua/index. php?option $=$ com_content $\&$ view $=$ article $\&$ id $=1134 \% 3 \mathrm{~A} 1 \&$ catid $=50 \% 3 \mathrm{Az}$ $\mathrm{v} \&$ Itemid $=78 \&$ lang $=\mathrm{uk}(08.03 .2014)$.

Інформаційний звіт Міністерства культури України »Про стан і тенденції розвитку релігійної ситуації та державно-конфесійних відносин в Україні« (Короткий виклад), unter http://mincult.kmu.gov.ua/mincult/ uk/publish/article/327651;jsessionid=C3A44E0C71766DF76E718C94498 F73A5 (08.03.2014).

»Релігія і влада в Україні: проблеми взаємовідносин«. Інформаційні матеріали до Круглого столу на тему: »Державно-конфесійні відносини в Україні станом на 2013 рік: рух до партнерства держави і Церкви чи до кризи взаємин?« 22 квітня 2013p., unter http://www.razumkov.org. ua/upload/Przh_Religion_2013.pdf (07.03.2014).

Щорічна доповідь Уповноваженого Верховної Ради України з прав людини про стан дотримання прав і свобод людини і громадянина, 2013 рік. International Religious Freedom Report for 2012, unter http://www.state.gov/j/ $\mathrm{drl} / \mathrm{rls} /$ irf/religiousfreedom/\#wrapper (03.03.2014). 
Fenno, Die Umsetzung der Prinzipien der Gewissensfreiheit in der Ukraine

\section{Abstract}

\section{Iryna Fenno}

\section{The Realization of the Principles of Freedom of Consciousness in Ukraine}

Since Ukraine's independence, conditions for the implementation of the principles of freedom of conscience have emerged. This can be seen in legislations that formalize the right of freedom of conscience (Constitution of Ukraine and the Law of Ukraine »On Freedom of Conscience and Religious Organization «), and by the implementation of the necessary conditions for the operation of religious organizations in a multi-religious environment (primarily ensuring the equality of all religious organizations). This article pays close attention to the complexities that are involved in the implementation of the principles of freedom of conscience. These complexities are manifested at the level of state-confessional relations, institutional, and individual levels. The author analyzes data from 2012 concerning violations of the law on freedom of conscience. 
Katrin Boeckh - 978-3-86688-505-9 


\section{Martin-Paul Buchholz}

\section{Die Kirchen in der Ukraine vor der europäischen Frage}

Die Ukraine ist mit $603.700 \mathrm{~km}^{2}$ das flächenmäßig größte Land Europas. Vier Jahre nach ihrer staatlichen Unabhängigkeit trat die Ukraine dem Europarat bei, doch erst seit der Orangenen Revolution im Jahre 2004 ist dieses Land in der außerukrainischen Wahrnehmung aus dem Schatten Russlands und der postsowjetischen Staaten herausgetreten und hat eine aktive Europa-Politik entwickelt. ${ }^{1}$ Die »europäische Frage« ist demnach keine von außen herangetragene, sondern bezieht sich auf eine innereuropäische Positionierung dieses Landes und seiner politischen wie gesellschaftlichen Akteure und erfordert - durch den Ausschluss der geographischen Definition - eine begrifflich weiter gefasste Füllung des Begriffes »Europa».

Während die politischen Repräsentanten der Ukraine oft in den Blick genommen wurden, weiß man über andere gesellschaftspolitische Akteure dieses Landes - und als solche sind auch die Kirchen zu betrachten - in der westeuropäischen Öffentlichkeit eher wenig. Daher soll die Problematik der einzelnen Europabezugspunkte für Kirche, Staat und Gesellschaft im Folgenden skizziert werden, um auf die Dichotomie der Ansichten der kirchlichen Vertreter in der Ukraine einerseits und des europäisch-institutionellen Selbstverständnisses aufmerksam zu machen. Zudem soll anhand konkreter Beispiele aus der neuesten Geschichte der Ukraine kurz gezeigt werden, wie Kirchen versuchen, sich produktiv in die Europa-Politik der Ukraine einzubringen, wo sie ihre Aufgaben sehen und wie sie versuchen, diesen gerecht zu werden. Das soll kurz

1 Siehe hierzu Schneider-Deters: Die Ukraine. Machtvakuum zwischen Russland und der Europäischen Union, 83-130 und die Beiträge in Besters-Dilger / Woldan (Hgg.): Die Ukraine auf dem Weg nach Europa.

DigiOst 3 | 65 
Buchholz, Die Kirchen in der Ukraine vor der europäischen Frage

insbesondere anhand des All-Ukrainischen Rats für Kirchen und Religiöse Organisationen gezeigt werden, der in seiner Eigenschaft als interkonfessionelles ukrainisches Organ eine Besonderheit in der Religionslandschaft Europas darstellt. Allgemein kann nur ein grober Überblick über die Problemstellung gegeben werden; einzelne Europabezüge bei den jeweiligen ukrainischen Konfessionen sind noch an anderer Stelle gesondert zu untersuchen.

\section{Der Weg zu einer selbstständigen Außenpolitik}

Es war die Ukraine, die mit ihrer Unabhängigkeitserklärung im August 1991 einen entscheidenden Anstoß für die Auflösung der Sowjetunion gab. ${ }^{2}$ Als nunmehr unabhängiger Staat musste die Ukraine nicht nur eine eigene staatliche Verwaltung aufbauen und versuchen, die unterschiedlichen Regionen und partikularen Interessen auf ihrem Territorium zusammenzuhalten, sondern sich danach auch außenpolitisch positionieren und dies nicht nur zu westeuropäischen Staaten, die schon zu Zeiten der Sowjetunion als Ausland galten, sondern auch zu den anderen ehemaligen Sowjetrepubliken und darunter vor allem Russland, das nun nach dem Zerfall der Sowjetunion ebenfalls als eigenständiger Staat existierte. Für Russland und die Ukraine bedeutete dies, dass man das jeweilige andere Land als Ausland betrachtete, obwohl man vorher Jahrzehnte lang zusammengehört hatte. Neue Beziehungen zu den westlichen Staaten aufzunehmen war für die Ukraine nicht mit Konflikten verbunden, ${ }^{3}$ dagegen gestalteten sich die bilateralen Beziehungen zu Russland schwierig. Sie waren bereits zu Beginn überlagert vom Konflikt über das Erbe der sowje-

2 Kappeler: Russland und die Ukraine, 13.

3 Wenn es auch keine Konfliktpunkte gab, so wurde die Ukraine jedoch vom Westen anfangs ignoriert, und erst mit dem Verzicht auf atomare Waffen seitens der Ukraine 1994 begann der Westen die Unabhängigkeit des neuen Staates zu unterstützen. Hierzu: Simon: Die Ukraine auf dem Weg - Wohin?, 11-17. 
Buchholz, Die Kirchen in der Ukraine vor der europäischen Frage

tischen Schwarzmeerflotte, die sich nun auf ukrainischem Territorium befand, und der sowjetischen Nuklearwaffen. Die Ukraine unterhält nicht nur wichtige Wirtschaftsbeziehungen zu Russland, sie ist auch im energiepolitischen Bereich eng mit seinem Nachbarn im Osten verbunden, da aus Russland das benötigte Gas für die Energieversorgung des Landes importiert wird. Eine Hinwendung der Ukraine nach Westen wurde von Russland, welches die Ukraine noch immer als »Bestandteil seines strategischen Vorfelds « ${ }^{4}$ betrachtet, oft als Provokation empfunden, und Moskau drohte in einem solchen Fall mit Konsequenzen, was sich insbesondere jüngst in den Verhandlungen der Ukraine mit der EU um ein Assoziierungsabkommen zeigte. ${ }^{5}$

\section{Die Ukraine: Ein Land zwischen der EU und Russland}

Die europäische Frage ergibt sich für die Ukraine schon aus den geopolitischen Gegebenheiten, wie sie sich im Zuge der EU-Osterweiterung herauskristallisiert haben. Mit der fünften und gleichzeitig größten EU-Erweiterung 2004 fand eine Osterweiterung der EU bis an die ukrainische Grenze statt, welche die Ukraine endgültig zwischen die EU und Russland zwängte.

Die politische Führung der Ukraine schwankte je nach politischer Machtkonstellation zwischen einer Annäherung an Russland und an den Westen. Nach der Unabhängigkeitserklärung der Ukraine spielte die Europa-Politik unter dem ersten Präsidenten Kravčuk (1991-1994) keine übergeordnete Rolle. Ab 1994 begann mit der Amtszeit von Präsident Leonid Kučma (1994-2004) eine »deklarative Europa-Politik« der Ukraine. ${ }^{6}$ In präsidialen Erlassen und

4 Kappeler: Russland und die Ukraine, 14.

5 Dazu genauer: Malygina: Die Ukraine vor dem EU-Gipfel in Vilnius.

6 Schneider-Deters: Die Ukraine. Machtvakuum zwischen Russland und der Europäischen Union, 83-84. 
Buchholz, Die Kirchen in der Ukraine vor der europäischen Frage

Gesetzen wurde immer wieder auf eine Strategie für die europäische Integration der Ukraine verwiesen. ${ }^{7}$ Die ukrainische Politik interessierte sich für eine EU-Integration und erklärte die EU-Mitgliedschaft der Ukraine sogar zum politischen Ziel, bot aber durch das autokratische System im eigenen Land, die Ablehnung von Demokratisierungsprozessen und den Mangel an Reformen im Inneren der EU einen Grund, diese Bestrebungen zu ignorieren und dem Land keine Beitrittsperspektive zur EU zu eröffnen. ${ }^{8}$ Erst unter Präsident Juščenko wurde ab dem Jahre 2005 die Annäherung an die EU - die ja inzwischen die ukrainischen Grenzen erreicht hatte - zu einem Hauptziel der ukrainischen Außenpolitik und auch politisch von Kiev vorangetrieben. ${ }^{9}$

Der Orangenen Revolution im Jahre 2004/2005, als man in der Ukraine gegen die Wahlfälschungen protestierte und die Präsidentschaftswahl tatsächlich wiederholt werden musste, wodurch Juščenko das Amt des Präsidenten antreten konnte, ist es zu verdanken, dass die Ukraine aus dem Schatten Russlands getreten und in der westeuropäischen Wahrnehmung angekommen ist. Die geopolitische Schlüsselfunktion, welche die Ukraine im postkommunistischen Osteuropa durch ihre geographische Lage zwischen der EU und Russland einnimmt, wurde in der westeuropäischen Öffentlichkeit weitestgehend ignoriert und erst durch die ernsthaften Bestrebungen der Ukraine zu einer europäischen Integration wahrgenommen. ${ }^{10}$

Im Zuge der - zumindest zwischenzeitlichen - Annäherung der Ukraine an die EU ist die Haltung gesellschaftlicher Akteure zu den Grundprinzipen der EU auch in politischer Hinsicht relevant. Zu den gesellschaftspolitischen Akteuren, die häufig in Politik und Medien vernachlässigt werden, gehören auch die Kirchen.

7 Ebenda.

8 Simon: Die Ukraine auf dem Weg - wohin?, 21-22, und Schneider-Deters: Die Ukraine. Machtvakuum zwischen Russland und der Europäischen Union, 83.

9 Besters-Dilger / Woldan (Hgg.): Die Ukraine auf dem Weg nach Europa.

10 Umland: Weißer Fleck. Die Ukraine in der deutschen Öffentlichkeit. 
Buchholz, Die Kirchen in der Ukraine vor der europäischen Frage

Die Kirchen in Osteuropa standen nach dem Zusammenbruch des Kommunismus vor einer dreifachen Aufgabe: Sie mussten sich in einer neuen, modernen, demokratischen, pluralen Welt zurechtfinden und gleichzeitig die vergangene Epoche reflektieren, in der sie nur bedingt agieren konnten und als gesellschaftlicher Akteur nicht anerkannt waren. Zudem mussten sie sich nach einem staatlich verordneten Atheismus neu institutionalisieren. Im Gegensatz zur Zeit der Sowjetunion sind die Kirchen heute im öffentlichen Raum in der Gesellschaft wieder präsent und auch von staatlicher Seite her anerkannt, und sie genießen sogar großes Vertrauen im Lande. ${ }^{11}$

\section{Europa ist mehr: Europabezüge}

Die »europäische Frage« lässt sich in mehrfacher Hinsicht betrachten. Als Europakriterien könnte man die Ausprägung der Trennung von Kirche und Staat, die Haltung zu den Menschenrechten und die Lehrmeinung der Kirchen über die Zugehörigkeit zu Europa untersuchen, wie Igor Gordyi dies in einem Aufsatz vorschlug. ${ }^{12}$ In den offiziellen Dokumenten der größten Konfessionen lassen sich hingegen vier umfassendere Europabezüge finden. Im Folgenden wird dafür zwischen einem kulturellen, einem politischen, einem pluralen und einem Europa der Werte unterschieden. Diese vier Untersuchungsfelder unterschiedlicher Kategorien bieten sich an, da diesen ein expliziter bzw. auch impliziter Europabegriff zugrunde liegt, der nachvollzogen werden kann, wenn man die offiziellen Dokumente liest, in denen sich Kirchen und religiöse Orga-

11 Vgl. die regelmäßig durchgeführten Vertrauensumfragen in der Ukraine u.a.: »Наибольшим доверием в Украине пользуется церковь«. Weitere Umfragedaten des Razumkov-Zentrums in: Релігія і влада в Україні: Проблеми взаємовідносин.

12 Gordyi: Die Kirchen und die Europäisierung der Ukraine. 
Buchholz, Die Kirchen in der Ukraine vor der europäischen Frage

nisationen in der Ukraine immer wieder zu bestimmten aktuellen Ereignissen zu Wort gemeldet haben.

Zuerst sollen die Fragen nach einem kulturellen Europabegriff und einer kulturellen Zugehörigkeit zu Europa als gemeinsamen Geschichtsraum untersucht werden. Die ukrainischen Kirchen haben sich zu dieser kulturellen Zugehörigkeit zu Europa bekannt. ${ }^{13}$ Die Russische Orthodoxe Kirche (ROK) hält jedoch nach wie vor daran fest, dass die Ukraine zur "historischen Rus'» gehört und die Ukrainische Orthodoxe Kirche mit Moskau verbunden sei. ${ }^{14}$ Das Moskauer Patriarchat stellt damit nicht die Zugehörigkeit der Ukraine zu Europa in Frage, sondern verortet die Ukraine und damit auch die Ukrainische Orthodoxe Kirche in einem Kulturraum, dessen Grenzen mit der Westgrenze der Ukraine identisch sind. Europa wird dabei nicht zwangsläufig auf seinen westlichen Teil reduziert, dieser jedoch von einem orthodox geprägten Kulturraum abgegrenzt, der laut der ROK aus dem Erbe der Christianisierung der Kiever Rus' entstand. ${ }^{15}$

Als nächstes stellt sich die Frage nach einem politischen Europabegriff. Europa ist nach dem Zweiten Weltkrieg, durch die verschiedenen Wirtschaftszusammenschlüsse und Verträge, zu einer politischen- und wirtschaftlichen Institution geworden, deren wichtigste Abteilungen heute in Brüssel und Strasbourg untergebracht sind. Die grundsätzliche Haltung zu Europa mit seinen Institutionen und seinen vielfältigen Verflechtungen nationalstaatlicher Einzelbereiche und damit auch die Haltung zu einer Annäherung der Ukraine

13 »Обращение Церквей и религиозных организаций к украинскому народу«.

14 Zur historischen Rus' gehören nach Ansicht des Moskauer Patriarchats alle Staaten, die aus der Kiever Rus' hervorgegangen sind: Russland, die Ukraine und Belarus. Siehe hierzu: „Определение Освященного Архиерейского Собора Русской Православной Церкви «О единстве Церкви» (2008) und Gordyi: Die Kirchen und die Europäisierung der Ukraine, $301 \mathrm{ff}$.

15 »Определение Освященного Архиерейского Собора Русской Православной Церкви 〈О единстве Церкви» (2008).

DigiOst $3 \mid 70$ 
Buchholz, Die Kirchen in der Ukraine vor der europäischen Frage

an die EU, spielt auch für die religiösen Institutionen des Landes eine Rolle. Kirchliche Lobbyarbeit auf europäischer Ebene gehört zum europäischen Alltagsgeschäft. Kirchen besitzen Büros und Vertretungen in Brüssel und Strasbourg. Der EU-Präsident trifft sich jährlich mit Kirchenvertretern, und die Kirchen äußern sich zur Politik der europäischen Institutionen, geben Ratschläge und Warnungen und versuchen darüber hinaus, eigene Interessen durchzusetzen.

Die Kirchenoberhäupter wollen auf bevorstehende Veränderungen im politischen Bereich vorbereitet sein und ihre Meinungen dazu in aktuelle Debatten einfließen lassen. Einzelne Kirchen der Ukraine haben sich in der Vergangenheit auch zu einem gemeinsamen Wirtschaftsraum, zur EU-Integration und sogar zum Assoziierungsabkommen zwischen der EU und der Ukraine geäußert.

Ein weiterer Bezugspunkt für die Haltung der Kirchen zu Europa ist die Reaktion auf ein plurales Europa, das durch und durch heterogen veranlagt nur durch gegenseitige Toleranz als minimalen Konsens auf der Ebene der Einzelakteure existieren kann. Hierunter fällt der Bereich der Ökumene und als konkretes Ereignis in der ukrainischen Geschichte, das auf eine negative Haltung einer Kirche, nämlich der Ukrainischen Orthodoxen Kirche des Moskauer Patriarchates (UOK [MP]) schließen lässt, der Papstbesuch im Jahre 2001. Johannes Paul II. war damals von Präsident Kučma in die Ukraine eingeladen worden. Angehörige des Moskauer Patriarchates riefen dazu auf, den Besuch zu boykottieren und das Höhlenkloster in Kiev, das der Papst bei seinem Besuch in Kiev besuchen sollte, für den Gast aus Rom zu sperren. ${ }^{16}$

Ebenfalls unter dem Aspekt des pluralen Europas ist die Haltung zu alternativen Lebensweisen wie z. B. gleichgeschlechtlichen Partnerschaften zu

16 Hierzu: Durkot: Zwischen Zwist und Dialog. Ukrainische Kirchen und Konfessionen nach dem Papstbesuch. 
Buchholz, Die Kirchen in der Ukraine vor der europäischen Frage

untersuchen, was im Folgenden unter dem Themenkomplex der Antidiskriminierungsdebatte skizziert werden soll.

Europa soll dabei nicht nur als geographischer und kultureller Raum betrachtet werden, zu welchem die Ukraine ohne Frage gehört und in welchem sich auch die ukrainischen Kirchen verorten. Europa ist auch mehr als eine politische- oder Wirtschaftsgemeinschaft und Pluralität. Europa soll vielmehr auch als Wertegemeinschaft verstanden werden, was für eine europäische Identität viel greifbarer ist. Dies legt die neue, allerdings nicht ratifizierte, EU-Verfassung im zweiten Artikel als »Ziele und Werte der Union" fest, welche für das gesamte Handeln der EU verpflichtend sein sollen:

"Die Werte, auf die sich die Union gründet, sind die Achtung der Menschenwürde, Freiheit, Demokratie, Gleichheit, Rechtsstaatlichkeit und die Wahrung der Menschenrechte einschließlich der Rechte der Personen, die Minderheiten angehören. Diese Werte sind allen Mitgliedstaaten in einer Gesellschaft gemeinsam, die sich durch Pluralismus, Nichtdiskriminierung, Toleranz, Gerechtigkeit, Solidarität und die Gleichheit von Frauen und Männern auszeichnet. ${ }^{17}$

Dieser Wertekatalog gilt für die EU und damit nicht für alle Staaten Europas. Als weitere Grundlage für eine europäische Wertegemeinschaft kann die europäische Menschenrechtskonvention angesehen werden, die in dem Verfassungsentwurf bereits berücksichtigt ist. Diese wurde vom Europarat, in welchem auch die Ukraine vertreten ist, verabschiedet; sie ist daher für wesentlich mehr europäische Staaten verbindlich.

17 Einzusehen unter: http://eur-lex.europa.eu/de/editorial/abc_c02_r1.htm. 
Buchholz, Die Kirchen in der Ukraine vor der europäischen Frage

Die Haltung zu einem Europa der Werte, ${ }^{18}$ das ein Bekenntnis zu Menschenrechten, Demokratisierung und Rechtsstaatlichkeit einfordert, ist für die einzelnen Konfessionen in deren Grundsatzdokumenten zu untersuchen. Interessant ist dabei die Überprüfung der Kompatibilität einzelner Schlüsselbegriffe, denn auch in den Dokumenten der ukrainischen Kirchen geht es immer wieder um Werte und Werteverfall, ohne dass diese explizit aufgelistet werden.

Es handelt sich bei den in der EU-Verfassung genannten Werten um eben jene, die von Seiten der EU auch immer wieder von der Ukraine eingefordert werden. So hatte am 18. Oktober 2012 der EU-Kommissionspräsident José Manuel Barroso die anstehenden Wahlen und den Umgang der Ukraine mit politischen Gefangenen zum Test für die Verwurzelung der europäischen Werte in der Ukraine erklärt. ${ }^{19}$ Der Umgang mit politischen Gefangenen verweist auf den Fall Tymošenko, ${ }^{20}$ der nicht nur von der EU, sondern auch von der UGKK mit fehlender Rechtsstaatlichkeit verbunden wird. ${ }^{21}$

Die ROK hatte im Jahre 2000 mit ihrer Sozialdoktrin ihre grundsätzliche Haltung zum Verhältnis zwischen Kirche und Staat und auch zu den Grundrechten verdeutlicht und 2008 mit dem Dokument »Die Grundlagen der Lehre der Russischen Orthodoxen Kirche über die Würde, die Freiheit und

18 Zur Wertedebatte siehe auch: Schockendorf: Die Bedeutung europäischer Werte für die Ukraine.

19 Ukraine-Analysen 108 vom Oktober 2012: Chronik 18.10.2012.

20 Julija Tymošenko war von Januar bis September 2005 und von Dezember 2007 bis März 2010 ukrainische Ministerpräsidentin unter Präsident Juščenko. Nach dem Amtsantritt von dessen Nachfolger im Jahre 2010 wurden mehrere Strafverfahren gegen sie eingeleitet, die u. a. von Seiten der EU als politisch motiviert gewertet werden. Hierzu Schneider-Deters: Die Ukraine. Machtvakuum zwischen Russland und der Europäischen Union, 337-379.

21 Siehe hierzu: »Глава УГКЦ звернувся до судді Кірээва з проханням про зміну міру запобіжного заходу для Юлії Тимошенко« und »Глава УГКЦ Патриарх Свяиосоав раскритиковал »советскую систему правосудия« в Украине«. 
Buchholz, Die Kirchen in der Ukraine vor der europäischen Frage

die Menschenrechte ${ }^{22}$ die Haltung zu den Menschenrechten noch einmal spezifiziert, auf die in der Sozialdoktrin nur kurz eingegangen worden war. Das Kiever Patriarchat reagierte auf die Sozialdoktrin der ROK und gab in den Jahren 2001 und 2004 ebenfalls zwei Grundsatzdokumente heraus, in denen $\mathrm{zu}$ aktuellen gesellschaftlichen Problemen Stellung genommen wurde: »Kirche und Welt am Übergang zum dritten Jahrtausend « (2001) und » Über die geistige Wiedergeburt der ukrainischen Gesellschaft in den Zeiten der Globalisierung « (2004). ${ }^{23}$ Auch diese beiden Dokumente besitzen als Grundsatzdokumente einen besonderen Stellenwert und greifen die Themenfelder auf, die von der ROK ebenfalls diskutiert worden waren. Beide Kirchen äußern sich in den Dokumenten auch zum Verhältnis der Kirche zur Politik und erteilen jeglichem politischen Engagement der Kirchen eine Absage. Die anderen Konfessionen der Ukraine gaben zwar keine Grundsatzdokumente zu diesen Fragen heraus, weshalb ihre Einstellung für die Öffentlichkeit schwer zu verifizieren ist, doch sind auch von diesen zu den genannten Punkten, die zu einem Europa der Werte gehören, ergänzt durch eine grundsätzliche Trennung von Kirche und Politik, offizielle Äußerungen veröffentlicht worden.

Die herausgegebenen und genannten Dokumente bieten bereits ein Beispiel für ein dichotomes Werteverständnis zwischen den orthodoxen Kirchen auf der einen und westeuropäischen Institutionen auf der anderen Seite. Wenn sich auch keine Widersprüche bei der Betonung der Werte finden, so stimmen doch inhaltliche Wertedefinitionen nicht zwangsläufig überein. Insbesondere das Dokument zu den Menschenrechten rief heftige Reaktionen bei den westeuro-

22 Uertz / Schmidt (Hgg.): Die Grundlagen der Lehre der Russischen Orthodoxen Kirche über die Würde, die Freiheit und die Menschenrechte.

23 »Про духовне відродження українського суспільства в умовах глобалізації світу« und »Церква і світ на початку третього тисячоліття«. 
Buchholz, Die Kirchen in der Ukraine vor der europäischen Frage

päischen Kirchen hervor, wie an der Reaktion der Gemeinschaft Evangelischer Kirchen in Europa (GEKE) ${ }^{24}$ zu erkennen war. ${ }^{25}$

Trotz Überschneidungen, die es zwischen den einzelnen Ebenen für die Europabezüge immer wieder gibt - so sind beispielsweise Gesetzesentwürfe in Strasbourg über ein Antidiskriminierungsgesetz vom Thema der Menschenrechte nicht zu abstrahieren - , lassen sich doch explizite wie implizite Europavorstellungen und Haltungen zur europäischen Politik identifizieren, die auch gesondert untersucht werden können. Daher soll als zweiter Punkt die Positionierung der Kirchen in einem politischen Europa genauer betrachtet werden.

\section{Die religiöse Landschaft der Ukraine und die interreligiöse Zusammenarbeit}

Die ukrainische Kirchengeschichte war in den 90er Jahren geprägt von Kirchenspaltungen und internen -kämpfen, die letztlich dazu geführt haben, dass man heute anstelle der Russischen Orthodoxen Kirche gleich drei orthodoxe Kirchen vorfindet: Die Ukrainische Orthodoxe Kirche des Moskauer Patriarchats (UOK [MP]), die Ukrainische Orthodoxe Kirche des Kiever Patriarchats (UOK-KP) und die Ukrainische Autokephale Orthodoxe Kirche (UAOK). Unter diesen befinden sich gleich zwei nicht kanonische Kirchen, die UOK-KP und die UAOK, welche von der Weltorthodoxie nicht als eigenständige Kirche anerkannt werden, was nicht ohne Folge blieb für den interreligiösen Dialog innerhalb der Ukraine. Alle drei orthodoxen Kirchen verstehen sich als ukrainische Na-

24 Die GEKE ist ein Verbund von evangelischen Kirchen in Europa, der fast alle lutherischen, reformierten und methodistischen Kirchen Europas einschließt. Ihre Gründung geht zurück auf das Jahr 1973.

25 Hallensleben: Russische Beiträge zur westlichen Menschenrechtsdebatte, 25-27. 
Buchholz, Die Kirchen in der Ukraine vor der europäischen Frage

tionalkirchen. Neben diesen sieht sich auch die griechisch-katholische Kirche, deren Gründung auf die Kirchenunionen von Brest (1595/96) und Užhorod (1646) zurückgeht, als ukrainische Nationalkirche. ${ }^{26}$

Doch auch protestantische Gemeinden haben sich in der Ukraine nach dem Zerfall der Sowjetunion neu im öffentlichen Raum etabliert, und ihre Gemeindezahlen übersteigen in der Gemeindestatistik in manchen Regionen jene der orthodoxen Gemeinden. ${ }^{27}$ Vor dem Hintergrund dieser zersplitterten kirchlichen Landschaft wurde 1996 auf Initiative des damaligen ukrainischen Präsidenten Leonid Kučma der All-Ukrainische Rat für Kirchen und Religiöse Organisationen gegründet. Mit diesem Gremium sollte ein Ansprechpartner für den Staat auf religiöser/kirchlicher Ebene gefunden werden. ${ }^{28}$ Die Mitglieder des Rates sind Vertreter verschiedener Konfessionen, von denen dann in der Regel das Oberhaupt im Rat sitzt oder zumindest gemeinsame Verlautbarungen mitunterschreiben muss. ${ }^{29}$ In der ersten Zusammensetzung des Rates von 1996 saßen neben zwei muslimischen und einem jüdischen neun christliche Vertreter, darunter auch die drei orthodoxen Kirchen der Ukraine.

Anfangs noch aus 13 Vertretern bestehend, einschließlich dem Vorsitzenden des Staatskomitees für Religiöse Angelegenheiten (Державний Комітет України у Справах Релігій), stand der Rat noch unter Beobachtung und Kontrolle des Staates. Anfangs erinnerte die Initiierung des Rates durch den Staat und die Mitarbeit in demselben an die sowjetischen Überwachungsmechanismen

26 Zur Geschichte der ukrainischen Kirchen nach den Zusammenbruch der Sowjetunion siehe: Heyer: Kirchengeschichte der Ukraine im 20. Jahrhundert sowie Драбинко: Православие в посттоталитарной Украине und Bremer: Nation und Religion in der Ukraine.

27 Zur kirchlichen Situation in der Ukraine siehe auch die Studien des Razumkov-Zentrums: http://www.razumkov.org.ua.

28 Für genauere Informationen zum Rat siehe: Васин: Украина - промоутер межрелигиозного согласия на международной арене.

29 Genauere Informationen, auch zu den Mitgliedern des Rates, in: Діалог Релігій в Україні. 
Buchholz, Die Kirchen in der Ukraine vor der europäischen Frage

über die Kirchen. Das Staatskomitee für Religiöse Angelegenheiten berief die Sitzungen des Rates ein, es war für die organisatorisch-technische Durchführung derselben und für die Veröffentlichung aller Dokumente verantwortlich. Die Befürchtung einer Ausweitung der staatlichen Kontrolle bewahrheitete sich nicht, doch kann von einer aktiven Arbeit bzw. Zusammenarbeit kaum gesprochen werden, da alle Initiativen vom Staatskomitee für Religion ausgingen und bei allen Fragen eben dieses einbezogen werden musste. ${ }^{30}$ So wurden denn auch in den ersten Jahren kaum gemeinsame Dokumente verabschiedet. Seit 2004 ist die staatliche Mitarbeit im Religionsrat durch eine Gesetzesänderung und die Auflösung des Staatskomitees für Religiöse Angelegenheiten nicht mehr gegeben. Im Jahre 2004 begann eine rege Aktivität der Mitglieder des All-Ukrainischen Rats für Kirchen und Religiöse Organisationen. Das Bewusstsein, mit dem Rat ein Gremium zu haben, das als Ansprechpartner für den Staat gilt und das nun nicht mehr von diesem kontrolliert wurde, wodurch die Möglichkeit gegeben war, sich zu gesellschaftspolitischen Belangen zu äußern und sich in diese einzubringen, mochte ein Übriges dazu beigetragen haben, dass die Zahl der Dokumente, die nun der Rat herausgab, kontinuierlich anstieg. Die Kirchen begannen ihren Einflussbereich aktiv zu nutzen und traten von nun an selbstständig in den Dialog mit den staatlichen Institutionen. In dieser Phase eines neuen Selbstbewusstseins gaben die Kirchen durch effektive Arbeit des Religionsrates vermehrt Themen vor, die diskutiert wurden und zu denen man Dokumente veröffentlichte. Die Anzahl der öffentlichen Verlautbarungen stieg bis in die Gegenwart kontinuierlich an. Mit 19 Kirchen und religiösen Verbänden repräsentiert der Rat heute etwa 90 Prozent aller Konfessionen. Der Rat wandte sich seit der Orangenen Revolution verstärkt immer wieder mit Aufrufen und Stellungnahmen bei aktuellen Themen oder für Grundsatzfragen an die Gesellschaft und die Regierung, in einigen Fällen auch direkt an den

30 Васин: Украина - промоутер межрелигиозного согласия на международной арене.

DigiOst 3 | 77 
Buchholz, Die Kirchen in der Ukraine vor der europäischen Frage

Präsidenten der Ukraine. Darüber hinaus wirkte der Rat bei der Erörterung einiger Gesetzesakte mit.

Die Intensität des Dialogs zwischen Staat und Kirche nahm allerdings mit Amtsantritt von Viktor Janukovyč im Februar 2010 ab. Bezeichnend war, dass der Präsident den Kirchenrat im ersten Jahr seiner Amtszeit gänzlich ignorierte. Das zweite Treffen mit den Vertretern der Kirchen wurde vom Präsidenten einberufen, als diese gerade zu einer Reise nach Brüssel aufbrechen wollten. ${ }^{31}$ Die Beziehungen zum ukrainischen Staatsoberhaupt wurden dadurch ebenfalls nicht verbessert. Der Vorfall zeigt jedoch, dass nicht nur die Kirchen die Europa-Politik der Ukraine beobachten, sondern auch die staatliche Seite den Annäherungsbemühungen der Kirchen an die europäischen Institutionen hohe Aufmerksamkeit schenkt.

\section{Die Reisen nach Brüssel}

Spätestens mit dem »Kirchenartikel « ${ }^{32}$ des Vertrags von Lissabon kann nicht mehr behauptet werden, dass die europäischen Institutionen die Kirchen und

31 Die Reise nach Brüssel sollte vom 21. bis 23. März 2012 stattfinden. Unter anderem war ein Treffen mit dem Präsidenten des Europäischen Rates geplant. Nachdem die Kirchenoberhäupter bei einem Treffen mit dem stellvertretenden Ministerpräsidenten der Ukraine von der bevorstehenden Fahrt berichtet und um Unterstützung für die Reise gebeten hatten, wurde zwei Tage vor Beginn der Reise ein Treffen mit dem Präsidenten am ersten Tag der geplanten Reise einberufen. Dazu: »Экстренная встреча В. Януковича с представителями ВСЦиРО срывает их визит в Брюссель«.

32 Am 1. Dezember 2009 ist mit dem Inkrafttreten des Vertrags von Lissabon der so genannte "Kirchenartikel « (Art. 17) in den Vertrag über die Arbeitsweise der Union eingefügt worden. Mit dem dritten Absatz dieses Artikels wird die Union zu einem regelmäßigen Dialog mit den Kirchen und Religionsgemeinschaften

DigiOst $3 \mid 78$ 
Buchholz, Die Kirchen in der Ukraine vor der europäischen Frage

religiösen Gemeinschaften in Europa ignorieren würden. ${ }^{33}$ Nicht zuletzt in dem Bemühen, die Bevölkerung Europas an der europäischen Integration teilhaben zu lassen, wurde die Rolle der Religion in Europa neu gewürdigt: In der Präambel des Vertrags über die europäische Union wurde das religiöse Erbe Europas mit aufgenommen. ${ }^{34}$

Umgekehrt lässt sich die Anteilnahme der Kirchen an Veränderungen in Europa und an der Politik der EU nicht nur anhand der Präsenz kirchlicher Vertreter in Brüssel ablesen. Interesse an den Entscheidungen der europäischen Institutionen und den Diskussionen, die in diesen geführt werden, zeigen auch die Kirchen der Ukraine. Keine der Kirchen der Ukraine unterhält jedoch in Brüssel oder Strasbourg eine Vertretung. ${ }^{35}$ Eine Partizipation an der kirchlichen Lobbyarbeit bei den europäischen Institutionen ist für die Kirchen der Ukraine bisher nicht in Sicht.

$\mathrm{Zu}$ Beginn des Jahres 2013 reisten die Vertreter des All-Ukrainischen Rats für Kirchen und Religiöse Organisationen nach Brüssel, um dort mit Politikern der EU zu sprechen, einen Dialog mit den europäischen Institutionen zu begründen und den All-Ukrainischen Rat als positives europäisches Beispiel des interreligiösen Dialoges vorzustellen. Die Organisation der Reise war mit Unterstützung der Konrad-Adenauer-Stiftung durchgeführt worden, welche auch die Kosten für die Fahrt übernahm. Die Unterstützung der ukrainischen Regierung erfuhren die Reisepläne keineswegs. Die Reise war ursprünglich

innerhalb ihrer Grenzen verpflichtet. Hierzu: Schnabel: Anhörung zur Ausgestaltung des Dialogs zwischen EU und Kirchen, 11-12.

33 Hierzu genauer: Belafi: »In Anerkennung ihrer Identität und ihres besonderen Beitrags « - Der Dialog der EU mit den Kirchen und Religionsgemeinschaften als Grundlage und Kernstück europäischer Religionspolitik, 153-173.

34 Droege: Zur Genese des europäischen Religionsverfassungsrechts, 142.

35 Die UOK (MP) hat lediglich als Teil der ROK dort eine Vertretung. Die ROK besitzt in Brüssel ein Büro, beschränkt sich dort aber darauf, die EU-Politik zu beobachten. Offizielle Auftritte und Stellungnahmen wurden bisher vom Außenamtssprecher des Moskauer Patriarchates durchgeführt. 
Buchholz, Die Kirchen in der Ukraine vor der europäischen Frage

für den März 2012 vorgesehen und konnte dann kurzfristig nicht zustande kommen, weil der ukrainische Präsident durch die Einberufung eines Treffens mit den Oberhäuptern der Konfessionen die Reise immerhin um ein ganzes Jahr verzögerte.

Im Rahmen des Besuches in Brüssel, der vom 6. bis 7. März 2013 stattfand, trafen die Kirchenvertreter unter anderem den EU-Kommissar für Erweiterung und Europäische Nachbarschaftspolitik, Štefan Füle. ${ }^{36}$ Die Vertreter des Kirchenrates machten bei dem Treffen in Brüssel mit dem EU-Kommissar deutlich, dass sie eine Unterzeichnung des Assoziierungsabkommens zwischen der EU und der Ukraine, die für den November 2013 vorgesehen war, unterstützen, ebenso sprachen sie sich für die Visumserleichterungen für ukrainische Bürger aus. Für diese solle es einfacher sein, die Staaten der EU besuchen zu können.

Einstimmig traten auch alle Delegierten des Rates bei den Gesprächen in Brüssel - bei denen zeitweise der ukrainische Botschafter zugegen war - dafür ein, dass die Zukunft der Ukraine auf den Grundlagen europäischer Werte und demokratischer Standards errichtet werden solle. Gleichzeitig riefen sie die EU auf, die Ukraine mit den heutigen Herausforderungen nicht alleine zu lassen.

In dem Communiqué, welches nach der Reise auf der Sitzung des Kirchenrates am 11. April 2013 verabschiedet wurde, ${ }^{37}$ bezeichneten die Mitglieder des Rates die Reise als erfolgreich. Sie betonten ihre Unterstützung zur verstärkten Zusammenarbeit zwischen der Ukraine und der EU und definierten ihre eigene Aufgabe in diesem Prozess: Im Fortschreiten der Vertiefung der Beziehungen zwischen der EU und der Ukraine sehen die Kirche für sich vornehmlich eine bestimmte konkrete Aufgabe, nämlich die traditionellen moralischen, fami-

36 »Делегация Всеукраинского Совета Церквей встретилась с еврокоммиссаром Штефаном Фюле«.

37 »Итоговое коммюнике ВСЦиРО по поводу визита делегации Совета в Брюссель (6-7 марта 2013 г.)«. 
Buchholz, Die Kirchen in der Ukraine vor der europäischen Frage

liären und andere geistige Werte zu unterstützen, die für sie die Grundlagen der europäischen Zivilisation bilden.

\begin{abstract}
"Als religiöse Akteure halten wir es für unsere Pflicht im Kontext der Vertiefung der Beziehungen zwischen der Ukraine und der EU, die traditionellen moralischen, familiären und anderen geistigen Werte zu bezeugen und zu unterstützen, entspringen sie doch dem Allerhöchsten. Gerade auf diesen Werten gründete sich die europäische Zivilisation. «38
\end{abstract}

Ein weiteres Bekenntnis zur europäischen Integration erfolgte am 30. September 2013, als die Vertreter der größten Konfessionen ein Dokument verabschiedeten, in welchem sie ihre befürwortende Haltung untermauerten. Das ukrainische Volk sei schon lange ein Teil der europäischen Zivilisation. Die Wechselbeziehungen mit der geistigen Kultur Europas und der europäische Bildungs- und Rechtstradition seien für die ukrainische Gesellschaft und Staatlichkeit mitbestimmend gewesen. ${ }^{39}$

Die Kirchenoberhäupter ${ }^{40}$ äußerten sich in dem Dokument ebenfalls zu den russisch-ukrainischen Beziehungen und betonten noch einmal, dass die

38 Wortlaut im Original: »Як релігійні діячі ми вважаємо своїм обов’язком у контексті поглиблення відносинміж Україною і ЄС свідчити та підтримувати традиційні моральні, сімейні та інші духовні цінності, адже вони походять від Всевишнього. Саме на цих цінностях було сформовано європейську цивілізацію.« Übersetzung des Verfassers. »Итоговое коммюнике ВСЦ и РО по поводу визита делегации Совета в Брюссель (6-7 марта 2013 г.)«.

39 »Обращение Церквей и религиозных организаций к украинскому народу«. 40 Unterschrieben hatten das Dokument die Kirchenoberhäupter der UOK (MP), UOK-KP, UGKK sowie Vertreter der Ukrainischen Lutherischen Kirche, der Deutschen evangelisch-lutherischen Kirche der Ukraine, der All-Ukrainischen Union der Evangelikalen Baptisten, der Ukrainischen Kirche der Christen des Evangelikalen Glaubens, der Präsident der Union Jüdischer Religiöser Organisationen und der Vorsitzende der geistlichen Administration der Muslime der Ukraine. 
Buchholz, Die Kirchen in der Ukraine vor der europäischen Frage

Befürwortung der europäischen Union keine negativen Auswirkungen auf das Verhältnis zu Russland habe. Auch Russland sei schließlich in Kultur und Geschichte eng mit Europa verbunden. ${ }^{41}$ Die zukünftige Entwicklung sehen die Kirchenvertreter für die Ukraine im Kreis der freien europäischen Nationen. Das Dokument war zwar nicht vom All-Ukrainischen Rat für Kirchen und Religiöse Organisationen herausgegeben und verabschiedet worden, kann aber als interreligiöses Dokument gelten, das die Unterstützung aller Mitglieder des Rates besitzt. ${ }^{42}$

Am 30. September 2013 fand die zweite Reise einer Delegation mit Vertretern der ukrainischen Kirchen nach Brüssel statt, an der auch der Kiever Patriarch und das Oberhaupt der UGKK teilnahmen. ${ }^{43}$ Vom 30. September bis zum 2. Oktober ging es bei dem Besuch in Brüssel um aktuelle Fragen des internationalen Dialogs, die Rolle der religiösen Organisationen in der Europäischen Union, die europäischen Perspektiven für die Ukraine und damit auch um das Assoziierungsabkommen zwischen der Ukraine und der EU. Betont wurde zudem die Bedeutung der Zusammenarbeit in Europa als Projekt der Friedenssicherung. ${ }^{44}$

41 „Обращение Церквей и религиозных оргаеизаций к украинскому народу«.

42 Das Dokument war kurzfristig verfasst worden und eine Zusammenberufung des Kirchenrates für eine dortige Erörterung hätte viel Zeit in Anspruch genommen. Das Dokument sollte vor der Brüssel-Reise der Delegierten des Rates präsentiert werden. Die Unterschriften unter dem Dokument sind nach Angaben des Institutes für Religionsfreiheit in Kiev ebenfalls nur aus zeitlichen Gründen nicht vollständig (Anfrage an den Verwaltungsdirektor des Institutes für Religionsfreiheit Maksym Vasyn vom 12.11.2013).

43 Ursprünglich geplant als Reise für den All-Ukrainischen Kirchenrat, konnten aus organisatorischen Gründen nicht alle Mitglieder des Rates an der Reise teilnehmen.

44 Genauere Informationen über die Brüssel-Reise unter: »Иерархи украинских церквей обсудили с евродепутатами отношения Украины и $\mathrm{EC}$ « und »Украинские релиниозные деятели прибыли в Брюссел для диалога о европерспективах Украины«. 
Buchholz, Die Kirchen in der Ukraine vor der europäischen Frage

Einhergehend mit der positiven Einstellung zur europäischen Integration steht Europa jedoch nicht als ausschließliches Erfolgsmodell. Viel sei noch zu verbessern im vereinigten Europa wie auch in der Ukraine selbst - insbesondere im religiösen Bereich und im Bereich der Moral und der familiären Werte, die eines besonderen Schutzes bedürften. So äußerte sich der Kiever Patriarch Filaret: »Uns gefällt nicht alles in der Ukraine, wie uns auch nicht alles in Europa gefällt, aber dann, wenn das Assoziierungsabkommen zwischen der Ukraine und der EU abgeschlossen wird, wird es einfacher, das zu verbessern, was eine Verbesserung erfordert. « ${ }^{45}$

\section{Die Antidiskriminierungsdebatte}

Ein Thema, welches als Beispiel für die Reaktionen und die Anteilnahme der ukrainischen Kirchen an der europäischen Politik auf der Hand liegt und welches einhergeht mit der Kritik der ukrainischen Kirchen am Werteverfall in Europa, ist die Antidiskriminierungsdebatte. Als im Jahre 2010 im Europarat wieder über ein Antidiskriminierungsgesetz abgestimmt werden sollte, mit dem auch sexuelle Minderheiten besser vor Diskriminierung geschützt werden sollten, wandten sich die Vertreter des Kirchenrates in einem Brief an den ukrainischen Präsidenten. Ein erster Brief wurde bereits am 18. Januar verfasst und an den Präsidenten und den Außenminister geschickt, jedoch nicht öffentlich gedruckt. Am 19. April 2010 folgte der zweite Brief, diesmal als offener Brief an den Präsidenten. ${ }^{46}$

45 Übersetzung des Verfassers nach: »Иерархи украинских церквей обсудили с евродепутатами отношения Украины и ЕС«.

46 Обращение ВСЦ и РО к Президенту Украины против аморальных инициатив в ПАСЕ (19 квітня 2010 р. № 022/10) in: Всеукраїнська Рада Церков i релігійних організацій. Збірник офіційних документів 1996-2011. Київ 2011. 
Buchholz, Die Kirchen in der Ukraine vor der europäischen Frage

Der Kampf gegen Diskriminierung - so heißt es hier - sei ein Angriff auf die traditionellen moralischen und familiären Werte, die von dem Großteil der ukrainischen Bevölkerung anerkannt seien. Die Vertreter der Kirchen verwiesen in dem Schreiben auf ihre Deklaration »Über die negative Einstellung zur Homosexualität und den Versuch der Legalisierung sogenannter gleichgeschlechtlicher Ehen $« .{ }^{47}$ Bereits im Jahre 2007 hatten die Kirchen diese Deklaration über ihre Haltung zur Homosexualität veröffentlicht. Sie hatten damals klar gemacht, dass man Homosexualität nicht hinnehmen dürfe. Der Rat rief in Anbetracht der in Kürze geplanten Sitzung des Europarates den Präsidenten auf, zu handeln, verbunden mit der Aufforderung, dafür zu sorgen, dass dieses Gesetz von den Vertretern der Ukraine keine Zustimmung erhält. Die Mehrheit der Bevölkerung - laut dem Brief sogar 90 Prozent - sei gegen ein solches Gesetz. Drei Forderungen werden in dem Dokument gestellt:

- Dem Außenministerium und dem Botschafter der Ukraine den Auftrag zu geben, im Europarat unmissverständlich gegen den Gesetzesentwurf aufzutreten,

- den Mitgliedern der ständigen ukrainischen Delegation im Europarat zu raten, gegen die Gesetzesinitiative zu stimmen, und

- den Außenminister zu beauftragen, einen Rat ins Leben zu rufen, der über die Zusammenarbeit zwischen dem Außenministerium und dem Kirchenrat beraten solle.

47 ДЕКЛАРАЦИЯ Всеукраинского Совета Церквей и религиозных организаций »О негативном отношении к явлению гомосексуализма и попыткам легализации так называемых однополых браков (регистрации однополых партнерств)« (Декларация принята в г. Киеве на заседании Всеукраинского Совета Церквей и религиозных организаций от 15 мая 2007 года), in: Всеукраїнська Рада Церков і релігійних організацій. Збірник офіційних документів 1996-2007, 92-93. 
Buchholz, Die Kirchen in der Ukraine vor der europäischen Frage

Insbesondere im letzten Punkt wird der Wunsch deutlich, an politischen Prozessen, die Europa und nicht nur die Ukraine betreffen, aktiv teilzunehmen und den Standpunkt der Kirchen vor der Politik zu verteidigen. Der Protest gegen das Antidiskriminierungsgesetz forderte auch auf Seiten der ukrainischen Regierung eine Reaktion. Die Haltung zur Antidiskriminierungsdebatte war auch in den Gesprächen über die Visumserleichterungen besprochen worden, und die ukrainische Regierung hatte offiziell nichts gegen das Gesetz einzuwenden. Regierungsvertreter bedauerten, dass die Kirchen die Beziehungen der Ukraine zur EU nur erschweren würden. ${ }^{48}$

\section{Im Zuge des Assoziierungsabkommens}

Ein wichtiger Punkt der EU-Ukraine Politik, der in den Jahren 2012 und 2013 immer wieder diskutiert wurde, ist das Assoziierungsabkommen zwischen der EU und der Ukraine, welches der Ukraine einen Zugang zum europäischen Binnenmarkt eröffnen würde. ${ }^{49}$ Die Unterzeichnung wurde seitens der EU mit Bedingungen verknüpft. In den Bereichen Demokratisierung, Rechtsstaatlichkeit und Menschenrechte müsse die Ukraine Fortschritte machen.

Die Kirchenvertreter hatten bei ihrem Besuch in Brüssel in den Gesprächen mit den Abgeordneten und dem Präsident des europäischen Rates explizit ihre Haltung zum Assoziierungsabkommen deutlich gemacht. Das Assoziierungsabkommen sei wichtig für die Entwicklung der Ukraine. Im Vorfeld war das Assoziierungsabkommen nicht in den kirchlichen Dokumenten genannt worden. Hingegen lassen sich aber die Forderungen seitens der EU an die

48 »Министр сожалеет, что Церковь не поддерживает закон, запрещающий дискриминацию геев«.

49 Hierzu ausführlich Schneider-Deters: Die Ukraine. Machtvakuum zwischen Russland und der Europäischen Union, 533ff. und Langbein: A la carte. Die Ukraine und der Freihandel mit der EU, 359-371. 
Buchholz, Die Kirchen in der Ukraine vor der europäischen Frage

Ukraine als Voraussetzung für die Unterzeichnung in kirchlichen Stellungnahmen finden. So griffen die Kirchen die Forderungen nach Verbesserungen im Bereich Demokratie und Rechtsstaatlichkeit auf.

Im Bereich Rechtsstaatlichkeit wurde die Unterzeichnung seitens der EU konkret mit Hafterleichterungen bzw. der Freilassung der ehemaligen Premierministerin Julija Tymošenko in Verbindung gebracht, deren Verhaftung die EU für politisch motiviert hielt. ${ }^{50}$

Der Fall Tymošenko, mit dem die EU die Verhandlungen mit der Ukraine sogar an einer bestimmten Person festmachte, wurde auch von den Kirchenoberhäuptern kommentiert. Der Prozess und das Urteil von 2011 würden die Beziehungen zu Europa stark belasten. ${ }^{51}$ Ein Jahr später, im April 2012, baten die Kirchenoberhäupter in einem Brief an den Präsidenten öffentlich für die Freilassung der ehemaligen Premierministerin. ${ }^{52}$

Für den Bereich Demokratisierung ist ein Wandel im kirchlichen Bereich zu bemerken, wenn man das Jahr 2004 als Ausgangspunkt nimmt. Bei den Wahlen im Jahre 2004 hatte die UOK (MP) noch aktiv den Präsidentschaftskandidaten und heutigen Präsidenten Viktor Janukovyč unterstützt. ${ }^{53}$ In den Präsidentschaftswahlen im Jahre 2010 und den Parlamentswahlen im Jahre 2012 riefen die Kirchen die Bevölkerung einheitlich dazu auf, das aktive Wahl-

50 Hierzu Schneider-Deters: Die Ukraine. Machtvakuum zwischen Russland und der Europäischen Union, 519ff., 550ff.

51 »Церковь не одобрила приговор Ю. Тимошенко«.

52 »Предстоятели украинских Церквей просят Виктора Януковича освободить Юлию Тимошенко«. Das Dokument wurde offiziell nicht von der UOK (MP) unterstützt. Alle Unterzeichner wurden kurz darauf zum Präsidenten einberufen, der ihnen persönlich erklärte, dass eine Begnadigung nicht vorgesehen sei.

53 Siehe hierzu ausführlich die Dissertation von Igor Gordyi: Ukrainische Kirchen und die Orangene Revolution. 
Buchholz, Die Kirchen in der Ukraine vor der europäischen Frage

recht wahrzunehmen, und sie bekräftigten, dass die Kirchen keinen Kandidaten unterstützen, sondern sich aus der Wahl heraushalten würden. ${ }^{54}$

Die Zusammenarbeit mit Europa und die Unterzeichnung des Assoziierungsabkommens mit der EU - so wird aus den Äußerungen der Kirchenvertreter in Brüssel deutlich - wird von den Kirchenvertretern als Ausgangsbasis für Verbesserungen innerhalb der Ukraine gesehen, auch wenn die Kirchen diese schon seit längerem von der ukrainischen Politik einfordern. Die EU hatte die Erfüllung ihrer Forderungen jedoch als Ausgangsbasis für die Zusammenarbeit und die Unterzeichnung des Assoziierungsabkommens gedacht.

\section{Fazit}

Eine Vereinnahmung der Kirche von Seiten des Staates, wie man es für Russland oft konstatiert hat, lässt sich für die Ukraine nicht feststellen. Die Kirchen und religiösen Organisationen haben im All-Ukrainischen Rat für Kirchen und Religiöse Organisationen ein unabhängiges Gremium gefunden, mit welchem sie sich an Gesellschaft und Politik wenden können, um auf ihre Anliegen aufmerksam zu machen.

Die vier Untersuchungsebenen für Europabezüge weisen einige Schnittmengen auf, doch lassen sich folgende Muster erkennen: Eine Befürwortung der EU-Integration und einer Annäherung an die EU steht der Ablehnung der dort anerkannten Vielfalt der Lebensmodelle diametral gegenüber. Die Ablehnung gleichgeschlechtlicher Partnerschaften und eines Antidiskriminierungsgesetzes wirft die Frage nach der Haltung zu den Menschenrechten auf. Die Befür-

54 Siehe hierzu: »Обрашение ВСЦ и РО к украинскому народу по случаю второго тура выборов Президента Украины« vom 01.02.2010, in: Всеукраїнська рада церков і релігійних организацій. Збірник офіційних документів 1996-2011. 
Buchholz, Die Kirchen in der Ukraine vor der europäischen Frage

wortung europäischer Werte bedarf noch einer genaueren Untersuchung des Wertebegriffes, wie er von den Kirchen vertreten wird.

Die Kirchen bezeichnen sich als eine der größten Kräfte in der Ukraine, zusammen mit der Bevölkerung, deren Standpunkte sie ihrem Selbstverständnis nach vertreten, auch wenn es um das Streben nach einer europäischen Zukunft der Ukraine geht. Sie reagieren nicht nur auf die Entwicklung innerhalb Europas mit Stellungnahmen und Kommentaren, sie versuchen auch die Entwicklung mitzugestalten durch Empfehlungen, Appelle und Warnungen, die sie an verschiedene Institutionen in Politik und Gesellschaft richten.

Anhand der offiziellen Dokumente der Kirchen seit der Unabhängigkeit der Ukraine lässt sich feststellen, dass die europäische Frage in ihrem ganzen Facettenreichtum für die ukrainischen Kirchen erst dann entstand, als diese politisch an Relevanz gewann. Andere politische Themen wurden in den Jahren vor 2004 in Politik und Gesellschaft diskutiert, zu welchen sich die Kirchen äußerten und Stellung bezogen. Spätestens aber seit dem Amtsantritt Viktor Juščenkos war die EU-Integration eines der wichtigsten außenpolitischen Ziele. Die aktuelle Debatte um das Assoziierungsabkommen bestimmte ebenfalls die ukrainische Politik in Bezug auf Europa. Seit diesem Zeitpunkt äußern sich auch die Kirchen verstärkt zu politischen Themen und Werten. Die europäische Integration ist ein neues Thema für die ukrainischen Kirchen, das explizit erst seit 2010 diskutiert wird.

Der All-Ukrainische Kirchenrat hat sich in Bezug auf die europäische Frage und die damit verbundenen Themen, zu denen er sich geäußert hat, nicht an eine Trennung von Kirche und Staat bzw. Politik gehalten, sondern auch politische Empfehlungen abgegeben. Er begründet dies nicht aus politischen Ambitionen heraus, sondern aus der Sorge um das eigene Land und die ukrai- 
Buchholz, Die Kirchen in der Ukraine vor der europäischen Frage

nische Bevölkerung, da er in seinem Selbstverständnis »die Gläubigen, welche die dominierende Mehrheit der ukrainischen Gesellschaft darstellen, vertritt. « ${ }^{55}$

Für die ukrainischen Kirchen ist der Weg nach Europa verbunden mit Demokratisierung und der Würdigung von Vielfalt und Religionsfreiheit, was die Entwicklung innerhalb der Ukraine positiv beeinflussen solle. ${ }^{56}$ Die negativen Aspekte, die mit der Annäherung an Europa verbunden sind, wie die Gefahr des dortigen - also eines westeuropäischen - moralischen Werteverfalls $s^{57}$ können durch positive Impulse wie durch das Vorbild der ukrainischen Kirchen - so deren Hoffnung - vermindert werden. Beiden Seiten, sowohl den Kirchen der Ukraine als auch den europäischen Institutionen, die mit diesen kommunizieren, steht mit der Annäherung der Ukraine an Europa und der europäischen Integration insbesondere bei der Diskrepanz in den Wertepräferenzen ein beidseitiger Transformationsprozess bevor. Beide Seiten werden sich mit der Position des jeweils anderen auseinandersetzen müssen.

Der All-Ukrainische Kirchenrat kann als positives Beispiel für einen innereuropäischen interreligiösen Dialog auch für die EU gelten, der dazu beitragen kann, die europäische Gemeinschaft auch interkonfessionell zu festigen und die Menschen in Europa dadurch einander näher zu bringen.

55 Übersetzung des Verfassers nach: »Иерархи украинских церквей обсудили с евродепутатами отношения Украины и ЕС«.

56 »Иерархи украинских цекрвей обсудили с евродепутатами отношения Украины и EC«und »Украинские религиозные леятели всртетились с президентом Европейского Совета ван Ромпеем«.

57 »Главы Церквей и конфессий заявили о своей позиции относительно евроинтеграции Украины«. 
Buchholz, Die Kirchen in der Ukraine vor der europäischen Frage

\section{Literatur}

Васин, Максим: Украина - промоутер межрелигиозного согласия на международной арене. Herausgegeben am 25.01.2012 vom Institut für Religionsfreiheit in Kiev. Als PDF unter: http://www.irs.in.ua (26.01.2014).

Всеукраїнська рада церков і релігійних организацій. Збірник офіційних документів 1996-2007. Київ 2007.

Всеукраїнська рада церков і релігійних организацій. Збірник офіційних документів 1996-2011. [CD] Київ 2011.

Главы Церквей и конфессий заявили о своей позиции относительно евроинтеграции Украины (30.09.2013), unter http://risu.org.ua/ru/index/ all_news/ukraine_and_world/international_relations/53846/(29.11.2013).

Глава УГКЦ звернувся до судді Кірээва з проханням про зміну міру запобіжного заходу для Юлії Тимошенко (10.08.2011), unter http://risu.org.ua/ ua/index/all_news/community/religion_and_policy/43751/(29.11.2013).

Глава УГКЦ Патриарх Свяиосоав раскритиковал »советскую систему правосудия« в Украине (15.10.2011), unter http://risu.org.ua/ru/index/ all_news/state/church_state_relations/44880/(29.11.2013).

Делегация Всеукраинского Совета Церквей встретилась с еврокоммиссаром Штефаном Фюле (07.03.2013), unter http://risu.org.ua/ru/index/ all_news/ukraine_and_world/international_relations/51521/(29.11.2013).

Діалог Релігій в Україні. Konrad-Adenauer-Stiftung 2012.

Драбинко, Александр: Православие в посттоталитарной Украине (вехи истории). Киев 2002.

Иерархи украинских цекрвей обсудили с евродепутатами отношения Украины и ЕC (01.10.2013), unter http://risu.org.ua/ru/index/all_news/ ukraine_and_world/international_relations/53858/(29.11.2013).

Итоговое коммюнике ВСЦ и РО по поводу визита делегации Совета в Брюссель (6-7 марта 2013 г.), unter http://vrciro.org.ua/index. php?option=com_content\&task=view\&id=205\&Itemid=1 (29.11.2013). 
Buchholz, Die Kirchen in der Ukraine vor der europäischen Frage

Министр сожалеет, что Церковь не поддерживает закон, запрещающий дискриминацию геев (13.02.2013), unter http://risu.org.ua/ru/index/all_ news/state/legislation/51289/ (29.11.2013).

Наибольшим доверием в Украине пользуется церковь (11.02.2013), unter http://www.irs.in.ua/index.php?option=com_content\&view=article\&id=1 $179 \% 3 \mathrm{~A} 1 \&$ catid=34\%3Aua\&Itemid=61\&lang=ru (29.11.2013).

Обращение Церквей и религиозных организаций к украинскому народу (30.09.2013), unter http://www.irs.in.ua/index.php?option=com_cont ent $\&$ view $=$ article $\&$ id $=1281 \% 3 \mathrm{~A} 1 \&$ catid $=50 \% 3 \mathrm{Azv} \&$ Itemid $=78 \&$ lang $=\mathrm{ru}$ (29.11.2013).

Определение Освященного Архиерейского Собора Русской Православной Церкви »О единстве Церкви« (2008), unter http://www.mospat.ru/ archive/41636/ (29.11.2013).

Про духовне відродження українського суспільства в умовах глобалізації світу«, unter http://www.old.risu.org.ua/ukr/resourses/religdoc/uockp_ doc/uockp_councildeclaration2004/ (29.11.2013).

Предстоятели украинских Церквей просят Виктора Януковича освободить Юлию Тимошенко (03.04.2012), unter http://risu.org.ua/ru/index/ all_news/community/religion_and_policy/47600/ (29.11.2013).

Релігія і влада в Україні: Проблеми взаємовідносин. Изд. Разумков Центр Київ 2013.

Украинские религиозные леятели всртетились с президентом Европейского Совета ван Ромпеем (01.10.2013), unter http://www.irs.in.ua/index. php?option $=$ com_content\&view $=$ article\&id $=1285: 1 \&$ catid $=35$ : world\&Ite $\mathrm{mid}=62$ \&lang $=\mathrm{ru}(29.11 .2013)$.

Украинские релиниозные деятели прибыли в Брюссел для диалога о европерспективах Украины (30.09.2013), unter http://www.irs.in.ua/index. php?option $=$ com_content $\&$ view $=$ article\&id $=1283 \% 3$ A $1 \&$ catid $=35 \% 3$ Awo rld\&Itemid=62\&lang=ru (29.11.2013). 
Buchholz, Die Kirchen in der Ukraine vor der europäischen Frage

Церковь не одобрила приговор Ю. Тимошенко (12.10.2011), unter http:// risu.org.ua/ru/index/all_news/community/religion_and_policy/44842/ (29.11.2013).

Церква і світ на початку третього тисячоліття, unter http://risu.org.ua/ua/ index/resourses/church_doc/uockp_doc/34099/ (29.11.2013).

Экстренная встреча В. Януковича с представителями ВСЦиРО срывает их визит в Брюссель (20.03.2012), unter http://risu.org.ua/ru/index/all_ news/state/church_state_relations/47377/ (29.11.2013).

Belafi, Matthias: »In Anerkennung ihrer Identität und ihres besonderen Beitrags « - Der Dialog der EU mit den Kirchen und Religionsgemeinschaften als Grundlage und Kernstück europäischer Religionspolitik. In: Werkner, Ines-Jacqueline / Liedheger, Antonius (Hgg.): Europäische Religionspolitik. Wiesbaden 2013, 153-173.

Besters-Dilger, Juliane / Woldan, Alois (Hgg.): Die Ukraine auf dem Weg nach Europa. Die Ära Juschtschenko. Frankfurt am Main 2011.

Bremer, Thomas (Hg.): Religion und Nation. Die Situation der Kirchen in der Ukraine. Wiesbaden 2003.

Droege, Michael: Zur Genese des europäischen Religionsverfassungsrechts. In: Werkner, Ines-Jacqueline / Liedheger, Antonius (Hgg.): Europäische Religionspolitik. Wiesbaden 2013, 141-151.

Durkot, Juri: Zwischen Zwist und Dialog. Ukrainische Kirchen und Konfessionen nach dem Papstbesuch. Veröffentlichung der Konrad-Adenauer-Stiftung (KAS-AI 8/01, S. 4-18), unter http://www.kas.de/wf/doc/kas_268544-1-30.pdf (26.01.2014).

Gordyi, Igor: Ukrainische Kirchen und die Orange Revolution. Diss. Universität Wien 2008.

Gordyi, Igor: Die Kirchen und die Europäisierung der Ukraine. In: Besters-Dilger, Juliane / Woldan, Alois (Hgg.): Die Ukraine auf dem Weg nach Europa. Die Ära Juschtschenko. Frankfurt am Main 2011, 293-311. 
Buchholz, Die Kirchen in der Ukraine vor der europäischen Frage

Hallensleben, Barbara: Russische Beiträge zur westlichen Menschenrechtsdebatte. In: Glaube in der 2. Welt 37 (2009) Heft 10, 25-27.

Heyer, Friedrich: Kirchengeschichte der Ukraine im 20. Jahrhundert. Göttingen 2003.

Kappeler, Andreas: Russland und die Ukraine. Verflochtene Biographien und Geschichten. Wien/Köln/Weimar 2012.

Langbein, Julia: A la carte. Die Ukraine und der Freihandel mit der EU, in: Sapper, Manfred / Weichsel, Volker (Hgg.): Die Ukraine im Wandel. Stabile Instabilität in einem Zwischenland. Bonn 2010, 359-371.

Malygina, Katerina: Die Ukraine vor dem EU-Gipfel in Vilnius. Einflussversuche externer Akteure, abrupter Kurswechsel der Regierung und die Volksversammlung zugunsten der europäischen Integration. In: Ukraine-Analysen Nr. 124 (2013), 2-5.

Schnabel, Patrik Roger: Anhörung zur Ausgestaltung des Dialogs zwischen EU und Kirchen. in: EKD-Europa-Informationen 137.

Schneider-Deters, Winfried: Die Ukraine: Machtvakuum zwischen Russland und der Europäischen Union. Berlin 2012.

Schockendorf, Andreas: Die Bedeutung europäischer Werte für die Ukraine (Rede vom 06.09.2010), unter http://www.kas.de/ukraine/de/ publications/20618/ (26.01.2014).

Simon, Gerhard: Die Ukraine aufdem Weg - wohin? In: Simon, Gerhard (Hg.): Die neue Ukraine. Gesellschaft - Wirtschaft - Politik(1991-2001). Köln 2002,5-27.

Uertz, Rudolf / Schmidt, Lars Peter (Hgg.): Die Grundlagen der Lehre der Russischen Orthodoxen Kirche über die Würde, die Freiheit und die Menschenrechte. Auslandsbüro der Konrad-Adenauer-Stiftung e.V. Moskau 2008.

Ukraine-Analysen 108 (2012).

Umland, Andreas: Weißer Fleck. Die Ukraine in der deutschen Öffentlichkeit. In: Osteuropa. Heft 9. September 2012, 127-133.

Werkner, Ines-Jacqueline / Liedheger, Antonius (Hgg.): Europäische Religionspolitik. Wiesbaden 2013. 
Buchholz, Die Kirchen in der Ukraine vor der europäischen Frage

\section{Internetseiten}

www.irs.in.ua

www.risu.org.ua

http://vrciro.org.ua/

http://www.razumkov.org.ua

http://www.mospat.ru

http://eur-lex.europa.eu
Seite des »Institute for Religious Freedom»

Relihijno-informacijna služba Ukraïny

Website des All-Ukrainischen Rats für Kirchen

und Religiöse Organisationen

Seite des Razumkov-Zentrums

Website des Moskauer Patriarchates

Seite der Europäischen Union

\section{Abstract}

\section{Martin-Paul Buchholz}

The Churches in the Ukraine and the European Question

In today's Ukrainian politics and society, Europe is not only considered as a geographical notion, but is also salient in discussions around topics such as culture, politics, pluralism, and values. This demonstrates Europe's relevance to Ukraine's political agenda, as well as public discussions. On another note, churches have established themselves after the fall of the Soviet Union as sociopolitical actors in Ukraine. Churches also contribute to discussions around these key European issues, expressing their own opinions, requests, and appeals. In Ukraine, the »All-Ukrainian Council of Churches and Religious Organizations « represents an independent panel and interacts with the state, society, and European institutions when religious interests are at stake. In the European context, this Council is a unique model for an inter-religious dialogue. 


\section{Statements: \\ Zwischen »Trennung « und »Symphonie«: \\ Modelle und Praktiken von Staat-Kirchen-Beziehungen in der gegenwärtigen Ukraine}


Katrin Boeckh - 978-3-86688-505-9 


\section{Jurij Rešetnikov}

\section{Welches Modell der Beziehungen zwischen Staat und Kirchen braucht die Ukraine?}

Eine Analyse von existierenden Modellen für die Beziehungen zwischen Staat und Kirchen in verschiedenen Ländern der Welt führt schnell zu dem Schluss, dass es hier weder ein einheitliches Modell noch zwei bis drei Basismodelle gibt, genauso wenig wie eine konventionelle wissenschaftliche Typologie dafür. Jedes Land baut seine Beziehungen mit den religiösen Organisationen im Kontext seiner konkreten Situation und etablierten Traditionen. Die Entwicklung des einen oder anderen Modells der Beziehungen zwischen Staat und Kirche wird von mehreren Faktoren beeinflusst, und jedes konkrete Modell solcher Beziehungen in einem Land wird von dem gesamten gesellschaftlichen System, am stärksten jedoch vom politischen System und den Prioritäten der politischen Macht geprägt. Obwohl der Begriff »Modell der Beziehungen zwischen Staat und Kirche« zur Definition der Art der Regulierung dieser Beziehungen verwendet wird und obwohl sich die Schlüsselelemente in mehreren Ländern wiederfinden und einander ähneln, können sich die konkreten Merkmale der Beziehungen zwischen Staat und Religionsgemeinschaften in verschiedenen Ländern unterscheiden. Für die Analyse dieser Beziehungen sind das Verständnis und die Berücksichtigung der komplizierten und dynamischen soziokulturellen Prozesse in jeweiligen Ländern erforderlich. Eine solche Analyse ist notwendig, um positive und negative Tendenzen bei der praktischen Umsetzung verschiedener Modelle sowie die für die Ukraine unter Einbeziehung von eigenen Erfahrungen verwertbaren Elemente auszumachen. Auf der Grundlage dieser Analyse sollen Richtlinien für weitere Entwicklung der Beziehungen zwischen Staat und Kirche in der Ukraine erarbeitet werden.

Die Erfahrungen anderer Länder können nicht mechanisch auf die Ukraine übertragen werden. Trotzdem sind sie nützlich, weil man hier nicht nur die 
Rešetnikov, Modell der Beziehungen zwischen Staat und Kirchen

positiven Momente übernehmen, sondern auch Fehler vermeiden kann. Es geht also darum, diese Erfahrungen zu analysieren und kreativ zu verarbeiten und sie für weitere Reformen im sozialen Bereich in der Ukraine unter Berücksichtigung der lokalen Besonderheiten zu nutzen.

Obwohl es in der Wissenschaft keine einheitliche Typologie der Beziehungsmodelle zwischen Staat und Kirche gibt, kann man die von bekannten ausländischen Religionsforschern wie Silvio Ferrari und Jelena Mirošnikova vorgeschlagene Klassifizierung grundsätzlich übernehmen. Es werden drei Modelle der Beziehungen zwischen Staat und Kirche ausgesondert: das Trennungsmodell, das Kooperationsmodell und das Identifikationsmodell (das Modell der Staatskirche). ${ }^{1}$ Der bestimmende Faktor ist die Möglichkeit und das Ausmaß der Zusammenarbeit des Staates mit Religionsinstitutionen und das Festhalten am Prinzip der Gleichheit von religiösen Organisationen vor dem Gesetz bzw. die Festlegung von Privilegien für einige.

Das Trennungsmodell, das in seiner reinen Form nicht nur die Trennung der Kirche vom Staat proklamiert (dies ist auch für das Kooperationsmodell typisch), sondern auch die Möglichkeit einer Zusammenarbeit zwischen staatlichen und kirchlichen Organisationen bestreitet, ist heute in Europa eher eine Ausnahme. Sogar Frankreich, das gewissermaßen als Standard für ein Trennungsmodell betrachtet wird, lässt sowohl die Seelsorge in der Armee und in den Strafvollzugsanstalten als auch die staatliche Förderung für private katholische Schulen zu. Somit ist klar, dass es in Frankreich nicht um die Trennung der Kirche vom Staat im atheistischen Sinne geht.

Für viele postkommunistische, besonders für postsowjetische Staaten, die Anfang der 1990er Jahre unabhängig wurden und mehrheitlich das sowjetische Modell der antagonistischen Trennung der Kirche vom Staat geerbt haben, ist heute die Suche nach einem eigenen optimalen Modell für die Beziehungen zwi-

1 Бурьянов: Характер и пределы регулирования в сфере свободы совести в демократическом государстве. 
Rešetnikov, Modell der Beziehungen zwischen Staat und Kirchen

schen Staat und Kirche kennzeichnend, was zu einigen Umgestaltungsprozessen in diesem Bereich führt. Man kann beobachten, dass sich die Beziehungen zwischen Staat und Kirche in der Russischen Föderation vom Trennungsmodell in Richtung Identifikationsmodell transformieren. Es handelt sich um die Russische Orthodoxe Kirche, die potentiell nicht nur de facto, sondern auch de jure einen besonderen Status bekommen kann, aber ebenfalls um den Islam und im geringeren Maße um das Judentum und den Buddhismus. Diese Religionen werden in der Präambel des Gesetzes »Über die Gewissensfreiheit und religiöse Vereinigungen " genannt. ${ }^{2}$ Die neuesten Veränderungen in den Gesetzen der Russischen Föderation wie beispielsweise das Gesetz »Über die Bildung in der Russischen Föderation« aus dem Jahr 2012 zeugen von der Abkehr vom "reinen" Trennungsmodell hin zu einem anderen Modell, das die Möglichkeit einer Zusammenarbeit zwischen staatlichen und religiösen Institutionen voraussetzt. ${ }^{3}$

Die reale Polykonfessionalität in der Ukraine, die Spaltung der Orthodoxie, das Fehlen einer Kirche, die im gesamten Land dominieren und gleichmäßig in den Regionen vertreten würde und dort einen entsprechenden Einfluss hätte, machen ein solches Szenario für die Ukraine unmöglich. Aus diesem Grund scheint es, dass ein Kooperationsmodell, in dem die Religionsgemeinschaften vom Gesetz gleich behandelt werden, für die Ukraine besser geeignet wäre.

Die gesellschaftlich-politische Entwicklung in der Ukraine um die Jahrtausendwende hat einen wesentlichen Einfluss auf die Beziehungen zwischen Staat und Kirche ausgeübt. Die Demokratisierung des öffentlichen Lebens und die Etablierung des ideologischen und politischen Pluralismus haben nicht nur die Rolle der Religionsgemeinschaften in der heutigen ukrainischen

2 Федеральный закон Российской Федерации № 125-Ф3 „О свободе совести и о религиозных объединениях".

3 Федеральный закон Российской Федерации № 273-Ф3 »Об образовании в Российской Федерации«. 
Rešetnikov, Modell der Beziehungen zwischen Staat und Kirchen

Gesellschaft gestärkt, sondern auch die Notwendigkeit markiert, das sowjetische Modell der Staatspolitik gegenüber Religion und Kirche aufzugeben und nach neuen Organisationsmodellen der Beziehungen zwischen Staat und Kirche unter Berücksichtigung der Erfahrungen anderer, insbesondere europäischer Länder zu suchen. Die intensive Entwicklung der Gesellschaft in einem polykonfessionellen ukrainischen Staat macht die Suche nach einem optimalen und effizienten Modell der Beziehungen zwischen dem Staat und den Religionsgemeinschaften notwendig.

Heute, nach zwanzig Jahren der Unabhängigkeit und der Entwicklung der Beziehungen zwischen Staat und Kirche unter neuen demokratischen Bedingungen, besteht Bedarf an einer Strategie für die weitere Harmonisierung der Beziehungen zwischen Staat und Kirche, insbesondere unter Berücksichtigung der Möglichkeiten einer praktischen Zusammenarbeit. Dieser Bedarf wird nicht nur durch wesentliche quantitative Veränderungen der Religionsszene in der Ukraine sowie durch das erreichte qualitativ neue Niveau bedingt, was die Zusammenarbeit mit dem Staat in verschiedenen Bereichen auf die Tagesordnung setzt, sondern auch durch weitere demokratische Entwicklungen im Land im Zusammenhang mit der Orientierung auf die europäische Integration, was eine Anpassung der nationalen Gesetzgebung an das internationale, insbesondere europäische Recht erfordert.

Die Erforschung der Beziehungen zwischen Kirche und Staat in geschichtlicher Perspektive, die Analyse der entsprechenden internationalen Erfahrungen, die Ausarbeitung auf dieser Grundlage von Vorschlägen über die verbesserten Mechanismen sind objektiv an der Zeit. Gleichzeitig kann die verzögerte Definierung eines optimalen Modells zur künstlichen Verlangsamung der künftigen Harmonisierungsprozesse in den Beziehungen zwischen Staat und Kirche führen und somit auch zu einem sozialpolitischen Destabilisierungsfaktor werden.

Der verfassungsrechtliche Begriff »Trennung der Kirche vom Staat« muss einer eingehenden Untersuchung unterzogen werden. In vielen grundlegenden internationalen, insbesondere europäischen Rechtsnormen ist nicht von der 
Rešetnikov, Modell der Beziehungen zwischen Staat und Kirchen

"Trennung der Kirche vom Staat", sondern von der »Trennung von Kirche und Staat « die Rede. Der Unterschied zwischen diesen Begriffen ist nicht terminologischer, sondern vielmehr inhaltlicher Natur. Das Trennungsprinzip bedeutet gleichberechtigte Beziehungen zwischen Staat und Kirche, Autonomie von Staat und Kirche in ihren eigenen Kompetenzbereichen; es bedeutet auch, dass sich der Staat mit keiner Religion oder Religionsgemeinschaft identifiziert und sich den verschiedenen religiösen Institutionen gegenüber neutral verhält. Dieser Ansatz bedeutet in der Regel nicht, dass die Zusammenarbeit und gegenseitige Unterstützung zwischen Staat und religiösen Organisationen unmöglich wären. Wichtig ist jedoch, dass diese Institutionen dabei unabhängig voneinander bleiben. In vielen Ländern finanziert der Staat direkt oder indirekt religiöse Organisatioen, indem er deren gemeinnützigen Vereinen oder Bildungseinrichtungen Zuwendungen gewährt. Wenn in den USA das Trennungsprinzip die Nichteinmischung des Staates in die inneren Angelegenheiten der Kirchen bedeutet, so hat es in Frankreich eine andere Bedeutung, nämlich dass die Kirchen sich nicht in die Belange des Staates einmischen. Diese Beispiele zeigen, wie breit die Grenzen für dessen praktische Anwendung sein können. In der postsowjetischen Lesart dagegen bedeutet das Prinzip der Trennung der Kirche vom Staat, dass die Zusammenarbeit zwischen den Akteuren eigentlich unmöglich ist.

Die ukrainischen Gesetze folgen dem Prinzip der Trennung der Kirche vom Staat und der Schule von der Kirche, was in der postsowjetischen und postatheistischen Lesart als Unmöglichkeit einer Zusammenarbeit zwischen Staat und Religionsgemeinschaften in verschiedenen Bereichen gedeutet wird. Dies verkörpert das Trennungsmodell der Beziehungen zwischen Staat und Kirche. Gleichzeitig zeigt das reale Leben, dass eine solche Zusammenarbeit möglich und angebracht ist. Somit steht hier die Frage einer neuen gesetzlichen Regulierung auf der Tagesordnung, die den Übergang vom Trennungsmodell zum Kooperationsmodell markieren würde. Die existierenden Gesetze bremsen die Weiterentwicklung dieser gesellschaftsrelevanten Zusammenarbeit, 
Rešetnikov, Modell der Beziehungen zwischen Staat und Kirchen

und das ukrainische Parlament hat kein Potential, um sie zu reformieren. Es entsteht eine nachteilige Situation, in der die objektiven gesellschaftlichen Prozesse ausgebremst werden und die einzelnen Gesetzesänderungen keinen Systemcharakter haben. Deswegen ist die Erarbeitung und Verabschiedung eines Konzepts für die Entwicklung der Beziehungen zwischen Staat und Kirche in der Ukraine notwendig. Dieses Konzept soll nicht nur die wünschenswerte Richtung für diese Entwicklung vorgeben, sondern auch die Gesetzesänderungen vorbereiten.

Nach der Unabhängigkeit wurden mindestens drei Entwürfe eines solchen Konzepts vorbereitet: Die »Grundprinzipien der Beziehungen zwischen Staat und Kirche«, die der vor-synodalen Kommission der Ukrainischen Griechisch-Katholischen Kirche 1996 vorgelegt wurden, ${ }^{4}$ die Grundlagen der Beziehungen zwischen Staat und Kirche in der Ukraine, die vom Institut für Gesetzesvorschläge und Rechtsexpertise 2003 ausgearbeitet wurden; ${ }^{5}$ sowie der Entwurf für das Konzept der Beziehungen zwischen Staat und Konfessionen in der Ukraine des Ukrainischen Zentrums für politische und wirtschaftliche Forschung (Razumkov-Zentrum), das unter Beteiligung des All-Ukrainischen Rats für Kirchen und Religiöse Organisationen ebenfalls 2003 zustande kam. ${ }^{6}$ Der letzte Entwurf hat die größte Unterstützung der Religionsgemeinschaften gefunden. Aus diesem Grund hat das Staatskomitee für Nationalitäten und Religionen in den Jahren 2008-2009 einen Gesetzesentwurf unter dem Titel »Das Konzept der Beziehungen zwischen Staat und Konfessionen in der Ukraine « vorbereitet. ${ }^{7}$

Obwohl der Entwurf des Razumkov-Zentrums 2004 die Zustimmung des Parlamentsausschusses für Kultur und Geistiges gefunden hat, wurde weder

4 Принципи взаємовідносин між державою та церквою, 52-58.

5 Основи (концепція) державно-церковних відносин в Україні. Концепція Інституту законодавчих передбачень і правової експертизи.

6 Проект Концепції державно-конфесійних відносин в Україні.

7 Концепія державно-конфесійних відносин в Україні. Проект. 
dieser noch ein anderer Entwurf in das Parlament eingebracht. ${ }^{8} \mathrm{Da}$ auch der letzte Entwurf bereits einige Jahre alt ist, müssen die Entwürfe überarbeitet und an die aktuelle Situation angepasst werden. Die Erarbeitung und Verabschiedung des Entwicklungskonzeptes für Beziehungen zwischen Staat und Kirche in der Ukraine bleibt also an der Tagesordnung.

Aus der Sicht des Verfassers wäre es wichtig, auf das Verfassungsprinzip der Trennung der Kirche vom Staat und der Schule von der Kirche hinzuweisen, das gewünschte Modell der Beziehungen zwischen Staat und Kirche zu definieren, weitere Schritte zur endgültigen Überwindung von negativen Folgen der totalitären Politik der ehemaligen Sowjetunion gegenüber Religion und Kirche zu planen und insbesondere Richtlinien für die Rückgabe des ehemaligen Eigentums der Kirchen an Religionsgemeinschaften zu erarbeiten. Ferner sollten die Beziehungen zwischen Staat und Kirche institutionalisiert werden. So muss im Gesetz ein für Religionsangelegenheiten zuständiges Staatsgremium mit Sonderstatus auf der zentralen Exekutivebene mitsamt territorialen Vertretungen wie auch ein Beratungsgremien unter Beteiligung von Staat und Kirchen auf der Regierungsebene (etwa eine Kommission zur Sicherung der Rechte von Religionsgemeinschaften) sowie bei einzelnen Ministerien und Ämtern und in den lokalen Verwaltungen (Öffentliche Beiräte für die Zusammenarbeit mit Kirchen und religiösen Organisationen) definiert werden.

Ferner sollte man die Möglichkeit für die Zusammenarbeit zwischen dem Staat und religiösen Institutionen in verschiedenen Bereichen sowie die wichtigsten Punkte einer solchen Zusammenarbeit festlegen (zum Beispiel im Bildungsbereich, wo ein obligatorischer Ethik-Unterricht auf alternativer Basis eingeführt, das Recht von Religionsgemeinschaften auf Gründung allgemeinbildender Schulen gewährleistet und die staatliche Anerkennung von Abschlüssen kirchlicher Bildungseinrichtungen garantiert werden sollen, oder im sozialen

8 Європейська договірна модель врегулювання державно-церковних відносин: історичний і сучасний світовий досвід для України, 986-1000. 
Rešetnikov, Modell der Beziehungen zwischen Staat und Kirchen

Bereich, wo das Institut für Militär- und Gefangenenseelsorge eingeführt werden soll). Es sollte auch auf die dafür notwendigen Gesetzesänderungen hingewiesen werden. Es scheint daher angebracht, sowohl eine öffentliche Diskussion als auch eine Diskussion unter Experten über die möglichen Bestandteile eines solchen Konzepts und über ihre konkreten Inhalte zu führen.

\section{Literatur}

Бурьянов, Сергей: Характер и пределы регулирования в сфере свободы совести в демократическом государстве, unter http://elib.org.ua/ internationallaw/ua_readme.php?subaction $=$ showfull\&id $=1095960093 \&$ archive $=\&$ start_from $=\& u$ cat $=1 \&$ category=1 (01.03.2014).

Киричук, Олександра: Європейська договірна модель врегулювання державно-церковних відносин: історичний і сучасний світовий досвід для України. In: Історія релігій в Україні. Науковий щорічник. Книга I. Львів 2009, 986-1000.

Концепія державно-конфесійних відносин в Україні. Проект. (Im Archiv des Verfassers befindlich.).

Основи (концепція) державно-церковних відносин в Україні. Концепція Інституту законодавчих передбачень і правової експертизи, unter http:// old.risu.org.ua/ukr/study/research_conference/churchstateconception/ conception_02/(02.03.2014).

Принципи взаємовідносин між державою та церквою. In: Права людини в Україні. Інформаційно-аналітичний бюлетень Українсько-Американського Бюро захисту прав людини 15 (1996), 52-58.

Проект Концепції державно-конфесійних відносин в Україні, unter http:// old.risu.org.ua/ukr/study/research_conference/churchstateconception/ conception_01/(02.03.2014). 
Rešetnikov, Modell der Beziehungen zwischen Staat und Kirchen

Федеральный закон Российской Федерации № 125-Ф3 „О свободе совести и о религиозных объединениях«, 26.9.1997, unter http://constitution. garant.ru/act/right/171640/ (01.03.2014).

Федеральный закон Российской Федерации № 273-Ф3 „Об образовании в Российской Федерации«, 29.12.2012, unter http://www.rg.ru/2012/12/30/ obrazovanie-dok.html (01.03.2014).

\section{Abstract}

Jurij Rešetnikov

Which Model for State-Church Relations Does Ukraine Need?

The article analyzes the process of searching for a suitable model for statechurch relations in Ukraine. The author argues that Ukraine needs a new conception for the development of state-church relations and suggests some elements for this conception. 
Katrin Boeckh - 978-3-86688-505-9 


\section{Myroslav Marynovych}

\section{Staatliche Favorisierung und Religionsfreiheit. Ein Statement}

Im Folgenden soll über den Versuch der Bevorzugung einer Glaubensgemeinschaft durch den Staat und über die Religionsfreiheit allgemein gesprochen werden. Diese Thematik wird aber in einen etwas ungewöhnlichen Kontext gestellt werden, nämlich aus dem Blickpunkt der modernen Konzepte des »Nullsummenspiels« (das bedeutet: »ich gewinne, du verlierst «, »ich bin rechtgläubig, du bist Häretiker« usw.). Dies ist der absolute Gegensatz, der keinerlei Kompromisse zulässt und den »Mehrwert« behandelt: Wie steht es um diese Konzepte bei den Kirchen in der Ukraine?

22 Jahre Unabhängigkeit der Ukraine weisen eine fantastische Dynamik von Veränderungen, Abstürzen und Aufstiegen auf. Zunächst können wir den Untergang der stalinistischen »Eismasse« sehen, in der das gesamte religiöse Leben in der ganzen Sowjetunion, unter anderem in der Ukraine, gleichsam »eingefroren « wurde. Unter dem Einfluss der Perestrojka kalbte diese Eismasse kleine »Eisberge«, die dann miteinander kollidierten. Dies ist das Reich des »Nullsummenspiels«.

Einerseits waren die religiösen Bestrebungen in der Ukraine sehr intensiv. Andererseits war es aber infolge der Kollisionen von »Religionseisbergen «, das heißt von Gemeinden verschiedener Kirchen, sehr schwer, einen Frieden unter den Religionen zu stiften. Zu jener Zeit galt für die Sicherheit jeder einzelnen Gemeinde eine sehr spezifische Formel: »Ich werde mich nur dann in Sicherheit wähnen, wenn ich meinen Gegner vernichtet habe, wenn meine Gegner verschwunden sind oder mein Territorium verlassen haben.« Aus diesem Grund konnte man damals Äußerungen hören, die exakt in das Schema des »Nullsummenspiels« passten, etwa: »Die Uniaten sind Todfeinde des ukrainischen Volkes« oder, wie es manchmal in der Westukraine zu vernehmen war: 
Marynovych, Staatliche Favorisierung und Religionsfreiheit

„Orthodoxe, ab hinter den Zbruč!« (also hinter die Grenze, welche die Westukraine von dem größeren Teil des Landes trennte). Zum Nullsummenspiel passte auch die pejorative Bezeichnung von Protestanten als »Sekte«.

Der Staat war zu jener Zeit ratlos, weil ihm sein Lieblingsspielzeug abhanden gekommen war: die gezähmte Kirche, die er ab und zu für politische Zwecke nutzen konnte. Die Bemühungen des Staates, dieses Spielzeug zurückzugewinnen, scheiterten immer wieder, weil in der Ukraine anstelle einer zugelassenen Kirche eine ganze Menge von Kirchengemeinschaften und Konfessionen entstanden war, und es war äußerst schwierig für den Staat, eine davon auszuwählen.

Freilich versuchte man es immer wieder. Jeder ukrainische Präsident favorisierte in seiner Amtszeit eine bestimmte Kirche. Nach einiger Zeit stieß eine derartige Politik jedoch auf so heftigen Widerstand, dass es große Nachteile für die Staatsmacht brachte. Jeder Präsident kam dann sukzessive zum Schluss, dass es für den Staat besser und sicherer sei, keine bestimmte Kirche zu favorisieren, sondern das Ziel zu verfolgen, alle mehr oder weniger gleich zu behandeln.

Die Orangene Revolution stellte gewissermaßen einen Wendepunkt dar. Damals hatte die Inbrunst der religiösen Konflikte nachgelassen, die Gemeinden begannen zu realisieren, dass die Existenz einer Nachbargemeinde nicht zur unabwendbaren Katastrophe führt. Die Forderung, den Gegner auszulöschen, ist also nach und nach der Erkenntnis gewichen, dass eine Zusammenarbeit von beiderseitigem Nutzen sein kann.

Freilich gab es auch konfessionelle Konflikte, doch die Statistik zeigt, dass sie allmählich abklangen. Die Orangene Revolution wurde unter mehreren Gesichtspunkten zu einem Einschnitt. Es wurde das Phänomen der gemeinsamen Erklärungen verschiedener Konfessionen zu sozialen Problemen geboren. Orthodoxe, Katholiken und Protestanten traten mit einer Reihe von gemeinsamen Erklärungen (das kann mit Dokumenten belegt werden) hauptsächlich zu gesellschaftlichen Themen auf, etwa zur Entscheidungsfreiheit bei den Wahlen. 
Marynovych, Staatliche Favorisierung und Religionsfreiheit

Vor der Orangenen Revolution hatte man sich ein gemeinsames Vorgehen verschiedener Kirchen im sozialen Bereich, etwa bei der Wohltätigkeit, kaum vorstellen können. Die Bemühungen einiger Laienorganisationen und Bürgerinitiativen, eine solche Zusammenarbeit in die Wege zu leiten, waren auf Widerstände gestoßen, weil hier wieder das Problem der Verunsicherung aufkam - gemeinsame Aktionen konnten die Kirchen ihre Gläubigen kosten. Während der Orangenen Revolution auf dem Majdan entstand vielleicht zum ersten Mal das Phänomen einer Partnerschaft.

Noch ein aussagekräftiges Beispiel für die Veränderungen ist der All-Ukrainische Rat für die Kirchen und Religiösen Organisationen (ukr. Всеукраїнська рада Церков та релігійних організацій). In der Amtszeit Leonid Kučmas war diese Institution kaum handlungsfähig, weil die Kirchen Bedenken hatten, dass man das Gremium instrumentalisieren würde, um sie unter Druck zu setzen. Nach der Orangenen Revolution konnte sich der Kirchenrat aber zu einer effizienten Institution etablieren. Ich habe mehrmals gehört, dass die Kirchen eine solche Plattform für den Dialog mit dem Staat brauchen. Die Arbeit des Gremiums zeugt also auch von der veränderten Mentalität innerhalb der Kirchen.

Auf jeden Fall bildete sich in der Ukraine bis 2010 das Phänomen einer bewussten »friedlichen Koexistenz« verschiedener Konfessionen heraus, die endlich begriffen haben, dass ein gemeinsames koordiniertes Handeln für alle von Vorteil sein kann. So begann die Logik des »Mehrwerts« zu funktionieren.

Im selben »orangenen « Jahr 2004 hat das damalige Oberhaupt der Ukrainischen Griechisch-Katholischen Kirche Ljubomyr Huzar seinen Pastoralbrief »Ein Volk Gottes im Land auf den Kiever Hügeln (Один Божий народ у краї на Київських горах) « veröffentlicht, in dem er die Eckpunkte für die Wiederherstellung der einheitlichen Kiever Kirche formuliert hat. Wer dieses Dokument genau liest, wird dort den Leitsatz des »Mehrwerts auf Kiever Art« finden. Anders gesagt, wird dort das »inklusive« Vereinigungsmodell ans Herz gelegt, wenn die historischen Zweige der vormals einheitlichen Kiever Kirche, die 
Marynovych, Staatliche Favorisierung und Religionsfreiheit

heute in verschiedenen konfessionellen Gruppen existieren, ihre Verbindungen zu den eigenen historischen Zentren - Moskau, Rom, Konstantinopel - nicht kappen, sondern durch das Miteinander einen neuen Wert gewinnen.

Es ist interessant, dass dieser Vorschlag ziemlich positiv von allen orthodoxen Kirchen aufgenommen wurde. Ich kann das am Beispiel des 2009 durch Renovabis organisierten Runden Tisches in Freising bestätigen. Die Veranstalter haben Vertreter der Ukrainischen Griechisch-Katholischen Kirche und der Ukrainischen Orthodoxen Kirche des Moskauer Patriarchats zur Diskussion eingeladen. Es hat sich herausgestellt, dass die Idee der Kiever Kirche, anders als die Veranstalter vermutet haben, zu keinen feindseligen Kontroversen geführt hat. Im Gegenteil: Archimandrit Kyrylo Hovorun, der die Delegation der Ukrainischen Orthodoxen Kirchen leitete, formulierte es so: »Wir stehen der Idee einer Kiever Kirche wohlwollend gegenüber, sehen sie aber anders als die Griechisch-Katholische Kirche.«

Diese positive Suche nach Initiativen dauerte bis 2010 an, also bis zum Machtwechsel in der Ukraine. Was danach kam, war ein Versuch des neuen Präsidenten, die Situation zugunsten einer Kirche entscheidend zu ändern. Anderthalb Jahre lang gab es kein Treffen zwischen Viktor Janukovyč und dem All-Ukrainischen Kirchenrat, der Präsident zog es vor, nur mit einer Kirche, der Ukrainischen Orthodoxen Kirche des Moskauer Patriarchats, zu sprechen. Andere Kirchen betrachteten diese Situation mit großer Besorgnis, weil sie an die Rückkehr zum alten Modell des Nullsummenspiels erinnerte, nach dem Motto: »Ich kenne nur eine «richtige Kirche, mit den anderen spreche ich nicht «.

Dies galt nicht nur für christliche Kirchen, sondern auch für religiöse Gemeinschaften insgesamt. Der neue Präsident brach mit der Tradition, die von früheren Staatsoberhäuptern gepflegt wurde, nämlich das jüdische Chanukka-Fest zu besuchen. Diese Tradition war ein wichtiges Zeugnis dafür, dass der ukrainische Präsident nicht nur für Christen, sondern auch für Nicht-Christen da ist. Sie wurde aber aufgegeben, so dass der Präsident de facto nur zu einer Konfession Beziehungen pflegte.

DigiOst 3 | 110 
Marynovych, Staatliche Favorisierung und Religionsfreiheit

Etwas später änderte sich aber die Situation. Vor dem Hintergrund der allgemeinen Abkühlung der politischen Beziehungen zwischen Kiev und Moskau, deren Gründe ich hier ausklammern möchte, distanzierte sich Janukovyč von der anfänglichen Bevorzugung einer Kirche. Man muss hier der Ukrainischen Orthodoxen Kirche Respekt zollen, dass sie von diesen festen Umarmungen des Staates nicht immer begeistert war. Diejenigen, die sich auf das russische Modell der Beziehungen zwischen Kirche und Staat hin orientierten, freuten sich zwar über die anfänglichen Änderungen der Präsidialpolitik. Die anderen aber betrachteten sie mit Vorsicht und Bedenken, wohl wissend, dass die Situation in der Ukraine eine andere ist. Deswegen wäre es falsch zu behaupten, dass die Ukrainische Orthodoxe Kirche ihre ursprüngliche Bevorzugung durch den Präsidenten offiziell befürwortete.

Am 26. Juli 2013 sagte Präsident Janukovyč in Kiev bei der Eröffnung der festlichen Veranstaltungen aus Anlass der 1025-Jahr-Feier der Christianisierung der Rus' kurz vor dem Besuch von Präsident Putin und Patriarch Kyrill etwas, was früher undenkbar gewesen wäre: »Für den Staat sind alle Kirchen und religiösen Gemeinden gleich. Wir respektieren die Wahl unserer Bürger und garantieren jedem sein Verfassungsrecht auf Glaubensfreiheit. Wir werden nicht zulassen, dass einige politische Kräfte die religiösen Gemeinschaften zu ihren partikularen Zwecken instrumentalisieren. Das gilt auch für Zentren im Ausland, die manchmal versuchen, über religiöse Organisationen die innenpolitische Lage in der Ukraine zu beeinflussen. Es geht ja um die nationale Sicherheit des Staates. « Für mich ist dies ein wichtiger Moment in der Amtsführung von Janukovyč, der mit dem Nullsummenspiel angefangen hat, dann aber die Gleichheit aller Konfessionen - zumindest deklarativ - anerkannte.

Diese Prozesse in der Ukraine zeugen davon, dass hier sowohl die Kirchen in ihren Beziehungen untereinander, als auch der Staat in seinem Verhältnis zu den religiösen Gemeinschaften wichtige Erfahrungen gesammelt haben. In der Ukraine hat sich eine relativ nachhaltige Tradition der Zusammenarbeit entwickelt, bei der jede Partei einen »Mehrwert« gewinnt. 
Marynovych, Staatliche Favorisierung und Religionsfreiheit

\section{Abstract}

Myroslav Marynovych

\section{A Statement on State Favoritism and Religious Freedom}

With the emergence of new political situations at the beginning of the 1990s, conflicts between Ukrainian churches arose, fed by the attempts of each Ukrainian president to favour one of the churches. Following the Orange Revolution in 2004-2005, churches began to rethink their position; they realized that mutual cooperation would be beneficial for all of them. They established common institutions that became a platform for a variety of churches and denominations in Ukraine. As such, they also guarantee that religious freedom in Ukraine is respected. 


\section{Religion und konfessionelle Vielfalt in der gegenwärtigen Gesellschaft}


Katrin Boeckh - 978-3-86688-505-9 


\section{Oleh Turij}

\section{Historische Wurzeln interkonfessioneller Konflikte in der Ukraine: Identifikationsprobleme der christlichen Kirchen}

\section{Bedingungen}

Bereits zu Beginn der Christianisierung stießen auf dem Territorium der Ukraine die Einflüsse des christlichen (sowie des nicht-christlichen) Ostens und Westens aufeinander und verflochten sich miteinander. Die Unterschiede zwischen verschiedenen religiösen Traditionen führten hier oft zu dauerhaften und scharfen Konflikten; andererseits ergaben sich dadurch nicht selten Anstöße zur Suche nach Versöhnung und Einigung. Diese historischen, geopolitischen, ethno-kulturellen und weiteren Besonderheiten übten in den vergangenen Jahrhunderten einen wesentlichen Einfluss auf die Entwicklung der Religiosität in der Ukraine aus. Sie finden auch heute noch ihren Ausdruck in der Vielfalt der christlichen Kirchen und Konfessionen und in ihren komplizierten Beziehungen zueinander. ${ }^{1}$

Ein unmittelbarer Faktor, der die Entwicklung des religiösen Lebens in der heutigen Ukraine beeinflusst, ist die Tragödie des 20. Jahrhunderts - die Ära des Terrors und der Gewalt. Nach einer ungefähren Schätzung sind in der Ukraine des 20. Jahrhunderts etwa 17 Millionen Menschen allein durch Willkür und Gewalt umgekommen. Da man in der Sowjetunion über diese Barbarei öffentlich oder auch in Privatgesprächen nicht reden konnte, fanden

1 Einen knappen Überblick zu der Geschichte des Christentums und anderen Religionen in der Ukraine sowie die neueste Bibliographie zeichnet Himka: Religious Communities in Ukraine. Dazu siehe auch Turij: Das religiöse Leben und die zwischenkonfessionellen Verhältnisse in der unabhängigen Ukraine. 
Turij, Historische Wurzeln interkonfessioneller Konflikte

diese Katastrophe und die dafür ursächlichen Ereignisse keinen Widerhall im Bewusstsein der Gesellschaft. Die Toten wurden nicht betrauert, die Gewalt und das Unrecht wurden nicht vergeben, die psychischen und geistigen Wunden sind geblieben.

Ein Bestandteil der Gewaltherrschaft in der Ukraine war die Verfolgung der Religion und die Verbreitung des Atheismus. Da das kommunistische Regime seine totalitäre Herrschaft festigen wollte, duldete es keine Strukturen, die andere und insbesondere humanistische Werte vertraten. Der Kampf mit der Religion wurde zur Staatsideologie, für deren Durchsetzung keine Bemühungen zu schade waren und für welchen nicht lange nach Mitteln gesucht wurde: zerstörte, niedergebrannte, entweihte Gotteshäuser; erschossene, inhaftierte und in Lager deportierte orthodoxe, katholische und andersgläubige Geistliche und Laien; verfolgte, in den Untergrund getriebene und vernichtete Kirchen (wie die Ukrainische Autokephale Orthodoxe Kirche zu Beginn der 1930er Jahre oder die Ukrainische Griechisch-Katholische Kirche 1946 in Galizien und 1949 in Transkarpatien). All dies waren auch leidvolle Erfahrungen der Bevölkerung in der Ukraine während des realen Sozialismus.

Jene religiösen Gemeinschaften, die vom kommunistischen Regime formell zugelassen waren, mussten sich jahrzehntelang auf eine enge, private Sphäre beschränken, sofern in einem System der totalen ideologischen Kontrolle und Indoktrinierung überhaupt von einer Privatsphäre die Rede sein kann. Ganze Generationen waren im Verlauf der sowjetischen Herrschaft der Glaubensfreiheit beraubt. Dies führte zu einem Schwinden jahrhundertealter Glaubenstraditionen, zu einer fortschreitenden Geistlosigkeit und einer Vertiefung der Demoralisierung der Gesellschaft.

Ein weiterer Aspekt der sowjetischen Religionspolitik, vor allem nach ihrer wesentlichen Korrektur durch Stalin während des Zweiten Weltkrieges, war die Instrumentalisierung und Ausnutzung der legal wirkenden kirchlichen Strukturen zum Zweck der ihrem Wesen nach atheistischen Innen- und Außenpolitik. Eine besondere Rolle wurde der Russischen Orthodoxen Kirche (ROK) 
Turij, Historische Wurzeln interkonfessioneller Konflikte

zugedacht, die als »Verteidiger des sozialistischen Vaterlandes«, Mitgestalter der »neuen historischen Gemeinschaft - des Sowjetvolkes« und als Sprachrohr der »sowjetischen Friedenspolitik" in der internationalen Arena zu dienen hatte.

Der erreichte modus vivendi mit dem kommunistischen Regime brachte der ROK Gewinn: Er lähmte die Versuche der Autokephalie, weitete das »kanonische Territorium« aus, vermehrte die Zahl der Kirchen und Gläubigen auf Kosten der liquidierten Ukrainischen Griechisch-Katholischen Kirche, bestimmte die Überführung einer Reihe von orthodoxen Bistümern und Kirchen, die früher niemals zu ihr gehört hatten, unter die Jurisdiktion des Moskauer Patriarchats, und stärkte den Einfluss der ROK in der Weltorthodoxie und der christlichen Ökumene. Allerdings zeigten diese »Errungenschaften« während der Krise des Sowjetsystems und Gorbačevs Perestrojka in den ausgehenden 1980er Jahren die Kehrseite der Medaille. Die ROK, bei einem Teil ihrer Geistlichkeit und der Gläubigen in Misskredit geraten, wurde seitens der Dissidenten und der national-demokratischen Bewegung zum Objekt der Kritik. Das Auftauchen der Ukrainischen Griechisch-Katholischen Kirche aus dem Untergrund und die Entstehung von Gemeinden der Ukrainischen Autokephalen Orthodoxen Kirche im Jahre 1989 kündigten den Verlust der früheren Monopolstellung der ROK an. Ein gleichzeitiges unerwartetes Anwachsen der Religiosität unter den Bedingungen der neuen Religionsfreiheit wurde von einer Verschärfung der religiösen Konflikte in der Ukraine begleitet, welche die internationalen ökumenischen Beziehungen ernsthaft komplizierten. Die Unabhängigkeitserklärung der Ukraine 1991 schuf einen zusätzlichen neuen staatspolitischen Kontext für die Aktivitäten aller Kirchen auf ihrem Gebiet.

Hauptmerkmal der Periode von Gorbačevs Perestrojka und der ukrainischen »Wiedergeburt « vom Ende der 1980er bis zu den 1990er Jahren war die rasche Liberalisierung aller gesellschaftlicher Bereiche, begleitet von heftigen politischen, ökonomischen, kulturellen und ideologischen Veränderungen. Ein euphorischer Übergang von den entideologisierten Mustern der Einmütigkeit 
Turij, Historische Wurzeln interkonfessioneller Konflikte

hin zu einem stürmischen Pluralismus von Meinungen, Ansichten und Überzeugungen charakterisierte alle Aspekte des ukrainischen Lebens. ${ }^{2}$

Im Laufe der ersten Jahre der Unabhängigkeit setzte auch ein nie da gewesener Aufschwung des religiösen Lebens ein. Waren im Jahre 1985 in der Sowjetukraine 16 Konfessionen registriert, so übersteigt ihre Zahl heute 100. Die Zahl der religiösen Gemeinschaften (Pfarreien, Gemeinden und Gemeinschaften mit lokaler Bedeutung) wuchs in dieser Periode auf das Sechsfache an (von 62.000 auf 345.000), mit weiter steigender Tendenz. ${ }^{3}$ Einer der Hauptgründe für die rasante Entwicklung war, dass sich die Ukraine schon zuvor durch eine hohe Religiosität der Bevölkerung auszeichnete, auch dank ihres westlichen Teils, der erst nach dem Zweiten Weltkrieg unter die Sowjetherrschaft geriet, in dem die Gläubigen konsequent der atheistischen Propaganda Widerstand leisteten. ${ }^{4}$

\section{Identität}

Das Erlangen der neuen gesellschaftlichen und religiösen Freiheit in der Ukraine Ende der 1980er/Anfang der 1990er Jahre war nicht nur durch eine stürmische und dynamische Entwicklung der Kirchen und der religiösen Gemeinschaften gekennzeichnet, sondern auch durch die Verschärfung von alten und der Entstehung von neuen Konflikten und Spannungen in der religiösen Sphäre, welche die innenpolitische Situation und die internationalen ökumenischen Beziehungen ernsthaft belasteten. Sowohl in Westeuropa als auch in der Uk-

2 Gudziak: Ukrainian Religious Life During the First Five Years of Independence, 49-72.

3 Hier und im Folgenden werden die statistischen Angaben des Staatskomitees für Nationalitäten und Religionen angegeben: www.scnm.gov.ua bzw. www.risu.org. ua/ukr/resourses/statistics/.

4 Єленський: Релігія і »перебудова«, 11; Паращевін: Релігія та релігійність в Україні, 13-16. 
Turij, Historische Wurzeln interkonfessioneller Konflikte

raine hält man die "globalen« und »geopolitischen« Umstände für die Quelle dieser Spannungen, doch spielen unserer Meinung nach die Schwierigkeiten der größten Kirchen der Ukraine mit ihrer eigenen Identität die wichtigere Rolle. Das Fehlen einer positiven Antwort auf die Frage: »Wer sind wir? « ruft Versuche hervor, die eigene Identität $\mathrm{zu}$ bezeichnen und $\mathrm{zu}$ stärken, indem man sich von den anderen mittels der Formel »Wir sind nicht die!« oder, was oft noch kategorischer klingt, »Nur wir - und nicht die! « absetzt.

Das Problem der Identität berührt, so paradox es klingen mag, am schärfsten jene Kirchen, die laut der offiziellen Terminologie als »traditionell« oder »historisch « bezeichnet werden: die griechisch-katholischen, römisch-katholische und orthodoxen Kirchen. Dieses Problem hat drei grundlegende voneinander abhängige Dimensionen: eine staatliche, nationale und ekklesiale. Dabei werden die Schwierigkeiten mit der kirchlichen Identität, obwohl sie eigener Natur sind, meines Erachtens von der gesellschaftlichen Undefinierbarkeit mitbestimmt, deren charakteristische Züge vom Fehlen einer lang andauernden Tradition selbstständiger staatlicher Existenz gekennzeichnet werden. Dazu gehören die Eklektik der staatspolitischen und sozialökonomischen Ordnung, die nicht abgeschlossenen Prozesse der Nationsbildung, kulturhistorische und regionale Unterschiede, eine schwache Entfaltung der bürgerlichen Institutionen, die Rechtsunsicherheit sowie die geistige Leere, Demoralisierung und andere Folgeerscheinungen der totalitären und noch älteren Vergangenheit. Das akute Problem der Identifizierung wird nicht so sehr mit einer »Ausnahmesituation« oder »Rückschrittlichkeit« der Ukraine erklärt, sondern mit den einschneidenden Veränderungen, die sich in der Gesellschaft vollzogen haben und eine adäquate Antwort der Kirchen fordern, die jahrzehntelang beiseite geschoben am Rand des gesellschaftlichen Lebens dahin vegetierten oder mit Gewalt aus ihm herausgerissen worden waren. Die religiöse Freiheit verursachte die interkonfessionellen Konflikte nicht, sondern deckte jene Probleme auf, die sich im gesellschaftlichen Organismus seit Jahrhunderten angesammelt hatten, 
Turij, Historische Wurzeln interkonfessioneller Konflikte

insbesondere in der Periode der totalitären Unterdrückung des Gewissens der Gläubigen.

Im orthodoxen Milieu sind diese Schwierigkeiten der eigenen Identität am stärksten spürbar. Vor allem, weil sie hier durch die Spaltung in einige sich befehdende Jurisdiktionen eine institutionalisierte Erscheinung sind:

1. Die Entstehung der Ukrainischen Autokephalen Orthodoxen Kirche war vor allem eine Folge der inneren Krise der Russischen Orthodoxen Kirche. Es ging um die direkte Beteiligung der ROK an der Assimilierungspolitik des Russischen Reiches und der Sowjetunion (die national-kulturelle Russifizierung der Ukrainer und die Russifizierung der ukrainischen orthodoxen Tradition). Die enge Zusammenarbeit mit dem atheistischen sowjetischen Regime hat einen Teil der orthodoxen Hierarchie, Geistlichkeit und Gläubigen (vor allem in der Westukraine) bewogen, sich von diesem »Erbe« zu distanzieren und ihre kirchliche Identität mit dem bewahrten (oder wiedererweckten) ukrainischen Nationalbewusstsein in Einklang zu bringen. Weil die Herausbildung der ukrainischen Autokephalie auf der Welle der großen Begeisterung für die nationale Bewegung mitschwamm, hatte ihre Ideologie zunächst einen populistischen Charakter (»Orthodoxie des ukrainischen Kosakentums«) und eine deutliche »anti«-Richtung (anti-katholisch, anti-polnisch, anti-sowjetisch, anti-russisch). Die Anführer und Aktivisten der Ukrainischen Autokephalen Orthodoxen Kirche waren geneigt, auch von ihrer »Wiedergeburt « zu sprechen, wobei sie sich auf die Ereignisse der 1920er und 1940er Jahre beriefen. Allerdings gab es vor dem Zweiten Weltkrieg in Galizien nur vereinzelte orthodoxe Gemeinden. Nachdem diese Kirche bereits einige »Vereinigungen « und innere Spaltungen hinter sich gebracht hat, lässt sich in der gegenwärtigen Tätigkeit der UAOK eine gewisse Desorganisation und Desorientierung in der Kirchenleitung und im Klerus erkennen, die sich einerseits in der verzweifelten (oft chaotischen) Suche nach einem kompromissbereiten modus vivendi mit der ukrainischen 
Turij, Historische Wurzeln interkonfessioneller Konflikte

Regierung und der Weltorthodoxie (unter anderem dem Moskauer Patriarchat) zeigt, andererseits in den Bemühungen einzelner Hierarchen und aktiver Laien um eine tiefere Betrachtung und Festigung der national-historischen und ekklesial-kanonischen Grundlagen der Autokephalie.

2. Der wachsende Führungsanspruch des ukrainischen Exarchats in der Person des Metropoliten Filaret (nach seinem misslungenen Versuch, den Patriarchenstuhl in Moskau zu besteigen, und nach der Unabhängigkeitserklärung der Ukraine) und seiner Anhänger in Richtung einer »kanonischen" Autonomie und Autokephalie sowie die Vertiefung der Trennung von der ROK und die Ausrufung des Kiever Patriarchats waren ebenfalls Folgen der Krise der postimperialen (postsowjetischen) Orthodoxie, die jedoch nach dem Prinzip »entliehener Losungen« stattfand. Die Philippiken an die Adresse der »Unierten « und der »Spalter « sind allmählich gegen national-patriotische Phrasen und Aufrufe zur Vereinigung aller Christen und Kirchen der byzantinisch-ukrainischen Tradition ausgetauscht worden, die sich um das selbstausgerufene Patriarchat scharen mögen. Eine deutliche Dominante der Schaffung und weiteren Entfaltung der Ukrainischen Orthodoxen Kirche des Kiever Patriarchats war und bleibt die Idee, dass diese "einzige nationale" Kirche dem neuen ukrainischen Staat dienen solle, sowie eine enge Zusammenarbeit mit der Staatsmacht praktiziere (auch noch, als die Staatsmacht damit aufhörte, diese Kirche zu favorisieren).

3. Die Bewahrung des untergeordneten Status der Ukrainischen Orthodoxen Kirche unter der Jurisdiktion des Moskauer Patriarchats, die Unklarheit ihres autonomen Status, die scharfe Verurteilung der »Separatisten « und »Spalter» (roskolniki), die sie weiterhin mit der unbedingten Einhaltung der kanonischen Ordnung, der Bewahrung der »Reinheit des Glaubens und der Einheit der Kirche« sowie der Berufung auf die multinationale Zusammensetzung der Geistlichkeit und der Gläubigen begründet, werden in der Praxis oft als Angst 
Turij, Historische Wurzeln interkonfessioneller Konflikte

vor jedweder Veränderung aufgefasst. Hinter dem eigenartigen »Konservatismus« der Hierarchie der UOK (MP) und des gesamten Moskauer Patriarchats und der aus sowjetischer Zeit ererbten Rhetorik werden ernsthafte Schwierigkeiten (oder auch Ablehnung) sichtbar, die neuen Bedingungen des national-staatlichen und religiösen Lebens in der Ukraine als endgültige Realität wahrzunehmen. Für eine Kirche, die sich im Lauf von Jahrhunderten als geistige Stütze eines anderen Volkes verstanden hatte, ein integraler Bestandteil der Machtstrukturen eines anderen Staates gewesen war und den Gedanken nicht zuließ, dass innerhalb der Grenzen dieses Staates (d.h. ihres »kanonischen« Territoriums) andere Kirchen einen mit ihr gleichen Status besitzen könnten, ist es wahrhaftig schwierig, sich zu einem solchen Umdenken durchzuringen. Zumindest so lange, bis die Hierarchie der Ukrainischen Orthodoxen Kirche nicht die Frage beantwortet (vor allem sich selbst und ihren Gläubigen), was das erste Wort in ihrer Bezeichnung bedeutet. In letzter Zeit scheint es allerdings so, dass sich die Menschen in ihren Reihen dieses Problems bewusst sind und es zu lösen versuchen.

4. Die Besonderheit der Römisch-Katholischen Kirche in der Ukraine beruht darauf, dass einst die Zugehörigkeit zum lateinischen Ritus mit der polnischen Volkszugehörigkeit (in Transkarpatien mit der ungarischen) gleichgesetzt wurde. In der sowjetischen Zeit hat die Zahl der römisch-katholischen Gläubigen aufgrund der Deportation der polnischen Bevölkerung und der Repressionen gegenüber dem Klerus sowie einer Assimilation wesentlich abgenommen.

Nach der Unabhängigkeitserklärung der Ukraine sind die Gläubigen der Römisch-Katholischen Kirche ukrainische Staatsbürger aus zumeist gemischten Familien, sie sprechen entweder ukrainisch oder russisch. Gleichzeitig ist ein bedeutender Teil der Geistlichkeit polnischer Herkunft oder Staatsbürger Polens. In Zusammenhang damit stehen vor der Hierarchie der Römisch-Katholischen Kirche in der Ukraine zwei Alternativen für ihr sozio-religiöses Verhalten: a) die Polonisierung (oder in seltenen Fällen eine Repolonisierung), 
Turij, Historische Wurzeln interkonfessioneller Konflikte

b) die »Ukrainisierung « (d. h. eine Inkulturierung). Während der erste Weg, die Polonisierung durch Latinisierung, aus der Geschichte bekannt ist (bekannt sind auch seine tragischen Folgen), der im Blick auf die guten Nachbarbeziehungen zwischen der Ukraine und Polen ihre »mechanische Wiederherstellung « heute verhindert, so besteht der zweite auf der Grundlage eines intuitiven Suchens, wobei jegliche theoretische Sinngebung oder gar eine deutliche Artikulierung fehlen. Eine weitere Schwierigkeit für die Selbstfindung der ukrainischen römisch-katholischen Gläubigen besteht darin, dass sie in der Vergangenheit einer herrschenden Staatskirche angehört hatten, sich aber heute in die Rolle einer religiöser Minderheit fügen müssen.

5. Es könnte scheinen, dass die Gläubigen der Ukrainischen Griechisch-Katholischen Kirche das größte Problem mit ihrer Identität haben müssten, weil diese Kirche noch vor 20 Jahren in der Sowjetunion nicht offiziell »existierte«; für viele ist sie selbst heute noch ein »Irrtum der Geschichte«, ein »misslungener Versuch« oder das Haupthindernis auf dem Weg zu einem »Triumph des Ökumenismus« oder zu einem »Sieg der orthodoxen Zivilisation«. Das heißt, ihr ekklesialer Charakter ist problematisch sowohl in ihrer äußeren Akzeptanz als auch in der inneren eigenen Identität. Die Unionskonzeption als Zwischenstufe des Übergangs zum »würdevolleren und erhabeneren« lateinischen Ritus oder als Modell für eine päpstliche Jurisdiktion »des unvereinigten Ostens« haben die Prüfung der Zeit nicht bestanden und werden sowohl von Katholiken wie Orthodoxen, ja selbst von den »Unierten« (zumindest auf offizieller Ebene) abgelehnt. Aber die Unierten Kirchen selbst bestanden im Verlauf von mehr als vier Jahrhunderten eine solche Prüfung (und zwar nicht nur in der Geschichte, sondern auch durch ständige Verfolgung, Verbote und »Zwangsvereinigungen«) und bewahrten die wesentlichen Züge ihrer Identität, das Ethos des östlichen Christentums, die jurisdiktionelle Einheit mit dem Apostolischen Stuhl und die eucharistische Einheit mit den Römischen Katholiken. 
Turij, Historische Wurzeln interkonfessioneller Konflikte

Seit Mitte des 19. Jahrhunderts war die griechisch-katholische Geistlichkeit Galiziens eng mit der ukrainischen nationalen Bewegung und dem Streben nach ukrainischer Staatlichkeit verbunden. Dies führte zu komplizierten Beziehungen mit den römisch-katholischen Gläubigen und war ein Grund für Repressionen seitens der sowjetischen Machtorgane. Das Ringen der griechisch-katholischen Gläubigen um die Legalisierung ihrer Kirche war in den ausgehenden 1980er Jahren Teil des Widerstandes gegen das totalitäre Regime. Sie nahmen an den Demokratisierungsprozessen und der nationalen Wiedergeburt aktiv teil. Daher haben die Geistlichkeit und die Gläubigen keine Schwierigkeit, sich mit dem Nationalstaat zu identifizieren. Die Ukrainische Griechisch-Katholische Kirche als eine der größten verfolgten Kirchen in der Welt mit einer umfangreichen Widerstandsstruktur, die sich gegen das kommunistische Regime aufgelehnt hatte, erfreut sich einer hohen moralischen Autorität, zumal sie das Untergrunddasein überstand und somit ihren Teil zum Zusammenbruch des Regimes beitragen konnte. Sie hat die Erneuerung der geistigen Gefühle gefördert und viele Menschen angeregt, sich aktiv am kirchlichen Leben zu beteiligen, die sich durch die atheistische Propaganda und die Repressionen der Gewissensfreiheit von der Religion entfernt hatten.

Unter den heutigen Umständen jedoch untergräbt die Überbetonung der national-politischen Angelegenheiten seitens der Geistlichkeit und der schwach ausgebildeten Aktivisten unter den Laien (»Kämpfer-Komplex«), gepaart mit ungenügenden theologischen Kenntnissen und einer kaum ausgeprägten ökumenischen Einstellung den schwer errungenen Vertrauenskredit. Dies hält die Kirche von ihrer geistigen Mission fern, nährt xenophobe Stimmungen gegenüber anderen Christen und führt mitunter zu scharfen Vorwürfen an die eigene Kirchenleitung wegen ihres »unzureichenden Patriotismus«. Außerdem äußert sich dies nicht nur in Konflikten mit den Orthodoxen und Unstimmigkeiten mit den römisch-katholischen Gläubigen, sondern auch in den komplizierten Beziehungen der griechisch-katholischen Vertreter aus Galizien mit den Diözesen der transkarpatischen Union von Užhorod (geschlossen 1646), die 
Turij, Historische Wurzeln interkonfessioneller Konflikte

historisch nicht zur Metropolie Galiziens gehört hatten und auch heute nicht der Jurisdiktion der Ukrainischen Griechisch-Katholischen Kirche unterliegen.

\section{Konflikte}

Wenn von interkonfessionellen Konflikten die Rede ist, wird mit ihnen im Westen - dank entsprechender Medien und der »Dramatisierung « der eigenen »Nöte« durch interessierte Seiten - nicht selten das religiöse Leben in der Ukraine assoziiert. Dann aber redet man oft nur von einem Konflikt, nämlich dem orthodox-katholischen, obwohl er in der Praxis in seiner »reinen Form« gar nicht vorkommt, sondern seine spezifischen Erscheinungsformen hat, die davon abhängen, um welche Beziehungen konkreter Kirchen es geht. Ein charakteristischer Zug dieser gegenseitigen Beschuldigungen ist eine gewisse Akzentverlagerung.

Das Moskauer Patriarchat beispielsweise betrachtet die Legalisierung der Ukrainischen Griechisch-Katholischen Kirche als eine Äußerung der uralten »Aggression des Vatikans« und eine Folge des »Proselytismus« auf ihrem »kanonischen Territorium«. Dabei zieht es nicht in Betracht, dass die Pfarrgemeinden des östlichen Ritus in Galizien und in Transkarpatien niemals zur Moskauer Jurisdiktion gehört hatten und sie nur infolge der brutalen und nichtkanonischen Liquidierung der Union durch das stalinistische Regime in die Russische Orthodoxe Kirche geraten sind. Auch wenn heute die Geheimarchive der sowjetischen Geheimdienste und der Staatsorgane zum Teil geöffnet und zahlreiche Quellendokumente und analytische Untersuchungen publiziert sind, ist es charakteristisch, dass die Leitung der ROK in der Person ihres heutigen Patriarchen Kirill die Beschlüsse der so genannten »Lemberger Synode« von 1946 weiterhin für die »Wiedervereinigung der Uniaten mit der Orthodoxen Kirche« und für die »Rückkehr [...] der Schafe, die sich längere Zeit «weit ent- 
Turij, Historische Wurzeln interkonfessioneller Konflikte

fernt〉 aufhielten, « hält. ${ }^{5}$ Im »Schreiben der Heiligen Synode der Ukrainischen Orthodoxen Kirche an die Gläubigen und das ukrainische Volk anlässlich des 60-jährigen Gedenktages der Rückkehr der Griechisch-Katholischen in den Schoß der Orthodoxen Kirche« vom 9. März 2006 wird behauptet, dass die sowjetische Regierung nur »vom alten und aufrichtigen Wunsch der Mehrheit der Uniaten, sich mit der Orthodoxie zu vereinigen, Gebrauch machte ${ }^{6}{ }^{6}$ Die griechisch-katholische Synode hingegen bezeichnet in ihrem Schreiben vom 7. März zum selben Anlass »die Versammlung des Jahres 1946 in L'viv [...] als Pseudosynode, da sie unter Bedingungen eines furchtbaren Terrors veranstaltet wurde und in unzulässiger Weise die Normen des Kirchenrechts ebenso verletzte wie die der Religionsfreiheit. «Die Hierarchen der UGKK sind davon überzeugt, dass auch ihre »orthodoxen Brüder und Schwestern in ihrem Innersten höchstwahrscheinlich an der Unrechtmäßigkeit dieser Versammlung nicht zweifeln. Sie haben nicht so sehr Angst vor der Anerkennung der Tatsache, dass der Staat den Terror anwendete und die Instrumentalisierung ihrer eigenen Kirche unternahm, sondern eher vor den Folgen dieser Anerkennung für sich selbst «. ${ }^{7}$

Der neu erstandenen Ukrainischen Griechisch-Katholischen Kirche haben sich in den ausgehenden 1980er Jahren jene angeschlossen, die früher ihre Mitglieder waren, sowie deren Kinder und Kindeskinder, wobei diese ihre Wahl freiwillig getroffen haben. Mit Kategorien wie die von »kanonischen Territorien « in einer Zeit zu operieren, in der Menschenrechte und Gewissensfreiheit hoch geachtet werden, scheint zumindest anachronistisch zu sein. Gleichzeitig ruft das Anwachsen der Struktur der Römisch-Katholischen Kirche in der Ukraine keine so scharfe Reaktion seitens der Ukrainischen Orthodoxen Kirche hervor. Dieser Umstand beunruhigt, so paradox es klingen mag, die

5 http://www.interfax-religion.ru/?act=documents\&div=472.

6 http://archiv.orthodox.org.ua/page-2149.html.

7 http://risu.org.ua/ua/index/resourses/church_doc/ugcc_doc/34090/. 
Turij, Historische Wurzeln interkonfessioneller Konflikte

griechisch-katholischen Gläubigen. ${ }^{8}$ Ähnlich verhält es sich mit den Klagen des Moskauer Patriarchats über die »Stürmung«, gar die »Profanierung« der »orthodoxen « Kirchen in der Westukraine. ${ }^{9}$ Dabei zeigt die Statistik, dass sich die meisten Konflikte, die sich auf Kirchen beziehen, zwischen den griechisch-katholischen und autokephalen Christen und nicht zwischen den Angehörigen der Moskauer Jurisdiktion oder den verschiedenen orthodoxen Gemeinden abspielen. ${ }^{10}$ Die Schärfe dieses Problems nimmt übrigens ab, da neue Kirchenbauten errichtet werden und es zu Vereinbarungen zwischen den verschiedenen Gemeinden darüber kommt, in welcher Reihenfolge die Kirchen genutzt werden können. Gerade die Ukrainische Orthodoxe Kirche ist am wenigsten zu einer gemeinsamen Nutzung von Gotteshäusern bereit, wobei sie sich stets auf »kanonische« Gründe beruft.

Im Allgemeinen wird das Kriterium der »Kanonizität« vom Moskauer Patriarchat ziemlich »dialektisch« verwendet. Denn wenn es um die religiöse Situation in Galizien geht und besonders dann, wenn sie zum Gegenstand der Besprechungen auf internationalen ökumenischen Versammlungen wird, werden die »nichtkanonischen « Gemeinden für »dem Bekenntnis nach orthodox» und deren Klerus und Gläubigen für die »der Orthodoxie treu Gebliebenen« gehalten. ${ }^{11}$ Wenn es sich aber um innerorthodoxe Auseinandersetzungen und den Status einzelner Jurisdiktionen in der Ukraine handelt, wird behauptet, dass unter anderem die UOK-KP »eine gesellschaftliche Neuschöpfung religiöser Färbung sei, in dem alle vollzogenen «gottesdienstlichen Handlungen` ihre sa-

8 Siehe: Концепція екуменічної позиції Української греко-католицької церкви, Paragraph 20.

9 http://www.mospat.ru/index.php?page=29080; http://ru.wikipedia.org/wiki/ Православие_и_католицизм.

10 Васьковський: »Гарячі точки«: стан справ і шляхи врегулювання, 30-32.

11 Zitiert aus dem oben erwähnten Schreiben des Metropoliten Kyrill an Kardinal Ljubomyr (Huzar) vom 10. Juli 2006 unter: http://www.interfax-religion. $\mathrm{ru} /$ ?act=documents $\& \operatorname{div}=472$.

DigiOst 3 | 127 
Turij, Historische Wurzeln interkonfessioneller Konflikte

krale Bedeutung verloren hätten und ohne Gnade seien und ungültig und nicht heilsrelevant geworden wären«. Die religiöse Gemeinschaft selbst »entbehrt der rechtmäßigen hierarchischen Struktur und der apostolischen Sukzession«, sie habe sich "außer des heilbringenden Stalls der Weltorthodoxie" gestellt und sei heute eine Organisation, die von Laien in priesterlichen Gewändern geleitet werde $« .^{12}$ Ausgehend von einer solchen Ekklesiologie ist der Brauch der Wiederholung der Priester- und der Bischofsweihen oder sogar der Wiedertaufe jener Gläubigen, die »von der Spaltung zurückkehren «, eine »logische « Folge. ${ }^{13}$

Ihrerseits sind manche griechisch-katholische Gläubige bei den Konflikten mit den Orthodoxen, die zu »nichtkanonischen « Jurisdiktionen gehören, geneigt, in den Rangeleien das Werk der allmächtigen »Agenten« oder den überall gegenwärtigen »Arm Moskaus« zu vermuten. Somit erlaubt selbst eine oberflächliche Analyse des Verlaufs und des Wesens der Schwierigkeiten, die im religiösen Leben der Ukraine auftreten, festzustellen, dass zur Zeit viel eher die Streitigkeiten innerhalb einzelner Konfessionen die Gefahr von Konflikten in sich bergen als solche, die zwischen ihnen ausbrechen könnten:

12 »Das Schreiben der Heiligen Synode der Ukrainischen Orthodoxen Kirche an den [damaligen] Präsidenten der Ukraine, Viktor Juščenko, den [früheren] Parlamentsvorsitzenden der Ukraine, Oleksandr Moroz, und den [damaligen] Parlamentsabgeordneten, den Premierminister der Ukraine, Viktor Janukovič, die Gläubigen der Ukrainischen Orthodoxen Kirche und an die, die sich außer dem heilsbringenden Stall der Orthodoxen Kirche in der Ukraine befinden, an alle Bürger der Ukraine, denen das Schicksal der Ukrainischen Orthodoxie - des unentbehrlichen Bestandteiles unserer Identität und des historischen Hauptfaktors des Staatswerdens der Ukraine -, nicht gleichgültig ist «, vom 22. November 2006: http://www.pravoslavye.org.ua/index.php?__type=article\&action=fullinfo \&id $=13865$.

13 http://www.uaorthodox.info/ua/catalog/Publikatsiyi/Fakti_i_komentari/SHCHe_ raz_pro_hreshchennya.html; http://orthodoxy.org.ua/node/22666. 
Turij, Historische Wurzeln interkonfessioneller Konflikte

1. Im orthodoxen Milieu geht es bei dem Konflikt zwischen der (»kanonischen «) UOK (MP) und den Kirchen, deren kanonischer Status ungeklärt ist, faktisch um die Gegnerschaft zwischen der »ukrainischen «, mit der Betonung auf der nationalen oder staatlichen Dimension, und der "nicht-ukrainischen « Identität. Die letzte muss nicht unbedingt eine "anti-ukrainische« sein. (Soziologen haben in der heutigen Ukraine Orthodoxe mit »sowjetischem nationalpolitischem Selbstbewusstsein und sogar den einzigartigen Typ der »orthodoxen Atheisten « festgestellt.) Auf der ekklesialen Ebene hat dieser Konflikt noch den Charakter des ewigen Konfliktes zwischen Vätern und Kindern, wobei es im gegebenen Fall des Streitobjekts darum geht, herauszufinden, ob die Moskauer Kirche gegenüber Kiev als Mutterkirche betrachtet werden kann oder gerade umgekehrt, und welcher »Verwandtschaftsgrad « sie mit der Kirche Konstantinopels verbindet.

Besonders markant zeigte sich dieses Problem während der Feierlichkeiten anlässlich der 1020-Jahrfeier der Taufe der Rus' und des Besuchs der Patriarchen Bartholomäus und Aleksij II. in Kiev im Juli 2008. Im Vorfeld der Feierlichkeiten platzierte die Presseabteilung des Patriarchen von Konstantinopel auf der offiziellen Webseite des ukrainischen Präsidenten einen umfassenden »Überblick der kirchlichen Beziehungen zwischen der kyriarchalen Kirche (Mutterkirche) und seiner Tochter, der Kiever Kirche", in dem besonders hervorgehoben wurde, dass Letztere "während der ganzen über Tausend Jahre alten Geschichte der Ukrainischen Kirche von Kiev dem Patriarchenstuhl den gebührenden Gehorsam leistete «. ${ }^{14}$ In seinen Ansprachen in Kiev betonte der Konstantinopolitaner Hierarch, dass er mit Freude die Einladung von Staatspräsident Viktor Juščenko entgegennahm, »als Mutterkirche an den Feierlichkeiten anlässlich der 1020 Jahre der Taufe der ukrainischen Nation teilzunehmen [...], die den Weg zur Evangelisierung aller slavischen Fürstentümer Osteuropas geöffnet hatte«. Der Ökumenische Patriarch unterstrich, dass er nicht nur das

14 http://orthodox.org.ua/node/2599.

DigiOst 3 | 129 
Turij, Historische Wurzeln interkonfessioneller Konflikte

Recht habe, sondern sogar dazu verpflichtet sei, sich um das religiöse Leben in der Ukraine zu kümmern, denn die »Konstantinopolitanische Mutterkirche leidet zusammen mit der liebsten Tochter - der Ukrainischen Kirche - wegen der gefährlichen Spaltungen ihres kirchlichen Leibes und nimmt sich alles so zu Herzen, als ob es ihr eigener Leib wäre «. ${ }^{15}$

Es ist offensichtlich, dass sich die Interpretation des historischen Schicksals und des gegenwärtigen Charakters des kirchlichen Lebens in der Ukraine durch den Moskauer Würdenträger (also Aleksij II.) wesentlich davon unterschied. Seinen Worten folgend "wurde das Rus' ische Land dank der Mühen und Heldentaten des apostelgleichen Fürsten Volodymyr mit Wasser und Geist erleuchtet «, wodurch "aus vielen Stämmen im Kiever Taufbad das eine gnadentragende, starke christliche Volk geboren wurde«, das es vermochte, "sich auszubreiten und seine eigene christliche Zivilisation aufzubauen «. Auch wenn sich heute in Folge der historischen Umstände »das kirchliche Zentrum der Heiligen Rus'» in Moskau befinde, »habe Kiev als erster Metropolitansitz (prototronius) - die Mutter der russischen Städte - seine Bedeutung nicht verloren, [...] vielmehr bleibt es auch heute eines der wichtigsten Zentren, ja die südliche Hauptstadt der russischen Orthodoxie«. So schuf die Rus'ische Kirche nach Meinung des verstorbenen Patriarchen »alle Bedingungen, damit sich die Ukrainische Orthodoxe Kirche unter der Leitung des Metropoliten Volodymyr in voller Freiheit und Verantwortung seelsorglich um das ukrainische Volk kümmert «. Diese ihre Mission sei »mit der Bewahrung der Einheit der Russischen Orthodoxie vereinbar «. ${ }^{16}$ Die Hauptthesen der historiosophischen Konzeption des Moskauer Patriarchats wiederholte fast wörtlich auch sein neuer Ersthierarch Kirill (Gundjaev) bei seinen fast regelmäßigen Reisen in die Ukraine, als er deklarierte, dass »Russland und die Ukraine das Bollwerk der orthodoxen, ostslavischen Zivilisation bilden« und »Kiev unser Konstantinopel mit ihrer

15 http://www.ec-patr.org/docdisplay.php?lang=en\&id=968\&tla=ua.

16 http://orthodoxy.org.ua/uk/dopovidi_ta_promovi/2008/07/27/17721.html.

DigiOst 3 | 130 
Turij, Historische Wurzeln interkonfessioneller Konflikte

Heiligen Sophia und das geistliche Zentrum der russischen Orthodoxie ist. Nur so verstehen wir Kiev als die südliche Hauptstadt der russischen Orthodoxie «. ${ }^{17}$

Ein wichtiges Merkmal des innerorthodoxen Konfliktes ist sein exklusiver Charakter. Die Beteiligten können sich mit der Existenz von parallelen Strukturen nicht abfinden, wobei die eine Seite diese als »Auslandsagentur» bezeichnet, die andere von der "gnadenlosen Spaltung" spricht und dabei als letztes Ziel jeweils die endgültige Liquidierung der anderen Seite als einer eigenständigen religiösen Gemeinschaft gesehen wird. So versteht die UOK (MP) nur sich als »direkte und unmittelbare Erbin der Taufe Volodymyrs und auch die Nachfolgerin der alten Kiever Metropolie ${ }^{18}$ und beansprucht deshalb, als die einzige Ortskirche in der Ukraine zu gelten und monopolistisch die ukrainische Orthodoxie zu repräsentieren. Es ist offensichtlich, dass die UOK-KP eine diametral entgegengesetzte Position vertritt, die in der Form einer historisch-kanonischen Deklaration der Bischofssynode vom 19. April 2007 unter dem vielsagenden Titel »Kiever Patriarchat-Ukrainische Orthodoxe Ortskirche« verabschiedet wurde. ${ }^{19}$ Nur die UGKK versucht nicht eine exklusive, sondern eine inklusive Sicht der ukrainischen ekklesialen Tradition zu vertreten, indem sie nicht nur sich als »rechtmäßige Erbin der historischen Kiever Metropolie« versteht, sondern auch alle drei orthodoxen Jurisdiktionen. ${ }^{20}$ Noch deutlicher formuliert diese Position bezüglich der Versöhnung und Vereinigung der Christen in der Ukraine der ehemalige Großerzbischof Ljubomyr in seinem Brief vom 26. April 2008 an Seine Seligkeit, den Metropoliten Volodymyr Sabodan, das Oberhaupt der UOK (MP): »Die eine Ukrainische Ortskirche wird als Gemeinschaft der

17 http://www.patriarchia.ru/db/text/604287.html.

18 Vgl. die Antwort der Heiligen Synode der UOK (MP) auf das Schreiben des Oberhauptes der UGKK, Ljubomyr Kardinal Huzar, vom 26. April 2008: http:// orthodox.org.ua/uk/svyashhenniy_sinod/2008/07/16/3235.html.

$19 \mathrm{http://www.cerkva.info/uk/icd/193-declaracia-1.html.}$

20 Концепція екуменічної позиції Української греко-католицької церкви, Раragraph 6 und 32.

DigiOst 3 | 131 
Turij, Historische Wurzeln interkonfessioneller Konflikte

Kirchen der Kiever Tradition auferstehen, die sich selbst und einander als Erbinnen der Taufe des heiligen Volodymyr anerkennen.« Das Oberhaupt der UGKK bietet konkrete Schritte auf dem Weg der Verwirklichung zu einer solchen Vereinigung an und behauptet, dass "keine der Kirchen der Kiever Tradition die ganze Kiever Kirche oder ihre einzige Grundlage darstellt «. ${ }^{21}$

Ein weiteres, potentiell gefährliches Merkmal der Gegnerschaft innerhalb der ukrainischen Orthodoxie besteht darin, dass sie sich tendenziell in einen allgemeinstaatlichen Konflikt verwandeln kann im Unterschied zu den Streitereien mit den griechisch-katholischen Repräsentanten, die sich zumeist auf Vermögensfragen beschränken und in den westlichen Regionen lokalisiert sind. Die Konfliktanfälligkeit der innerorthodoxen Streitigkeiten in der Ukraine wird noch verstärkt durch die direkte Verwicklung verschiedener politischer Kräfte und Machtstrukturen sowohl ukrainischer als auch ausländischer Herkunft.

Zudem kann dieser Konflikt bei einer zielgerichteten Eskalation Formen einer bürgerkriegsähnlichen Gegnerschaft (zwischen Ukrainern und der sogenannten »russischsprachigen Bevölkerung «) und internationalen Anspannung annehmen, etwa mit Russland, für welches der »Schutz der Landsleute im nahen Ausland « eine der grundlegenden Prioritäten der außenpolitischen Doktrin und ein Instrument der Erneuerung seiner Einflüsse im postsowjetischen Raum ist. Das Anwachsen des innerorthodoxen Konfliktes in der Ukraine birgt die Gefahr einer Herbeiführung von Trennungsprozessen in der Weltorthodoxie in sich. Sie könnten durch eine Anerkennung der ukrainischen Autokephalie seitens Konstantinopels hervorgerufen werden oder im Falle einer Beziehungsaufnahme der autokephalen Landeskirchen, die über den Dominanzanspruch Moskaus verärgert sind, mit den "nichtkanonischen « Jurisdiktionen in der Ukraine; dies gilt auch im Falle, wenn sich eine gewisse "nichtkanonische Internationale « mit Kiev konsolidiert, was sich in den Kontakten des Patriarchen Filaret mit der Hierarchie der Orthodoxen Kirchen in Mazedonien und

21 http://www.ugcc.org.ua/fileadmin/user_upload/pdf/visnyk_7.pdf. 
Turij, Historische Wurzeln interkonfessioneller Konflikte

Montenegro, wie auch in der Unterstützung der alternativen Gruppierungen in Bulgarien, Griechenland, Russland und unter der ukrainischen Diaspora anbahnt. ${ }^{22}$

2. Der innere Konflikt im katholischen Milieu weist keine scharfen und dramatischen Merkmale auf, er hat vielmehr den Charakter einer »strategischen Konkurrenz« zweier Landeskirchen mit verschiedenem Ritus. Doch diese Gegnerschaft hat bereits eine »Tradition« von etlichen Jahrhunderten; sie beinhaltet die ganze Last der ukrainisch-polnischen historischen Abrechnungen und gegenseitigen Vorwürfe, von »Nationalismus« geleitet zu sein. Dabei ist zu betonen, dass die staatlichen Beziehungen zwischen der Ukraine und Polen und die Kontakte zwischen den Intellektuellen beider Völker in der Vergangenheit noch nie so lebendig und freundschaftlich gewesen sind wie jetzt. Im Gegensatz dazu haben sich die kirchlichen Kontakte abgekühlt, ja, es ist sogar zu direkten Konflikten gekommen, wie beispielsweise um die griechisch-katholische Kathedrale in Przemyśl (Peremyšl). Ein weiterer schmerzhafter Punkt in den griechisch- und römisch-katholischen Beziehungen sind Rückfälle in die einstige praestantia ritus latini (zumindest werden sie von griechisch-katholischen Gläubigen so aufgefasst), wie beispielsweise das Hinauszögern einer Anerkennung des Patriarchalstatus durch den Vatikan, die Behinderung des Aufbaus der Diözesanstrukturen der Ukrainischen Griechisch-Katholischen Kirche in den östlichen Gebieten der Ukraine, die Einschränkung der seelsorgerlichen Arbeit verheirateter Priester in der Diaspora und anderes. Eine Quelle der Verdächtigungen und des Misstrauens ist die bessere materielle und finanzielle Ausstattung des lateinischen Klerus sowie die Einschränkung unmittelbarer Kontakte und einer konkreten Zusammenarbeit.

22 Єленський: Розлам, Протистояння в українському православ’ї як конфлікт ідентичностей, 2-10; Кудлай: Міжправославний конфлікт в Україні: позиції сторін, 2-8. 
Turij, Historische Wurzeln interkonfessioneller Konflikte

Eine bestimmte Anspannung geht auch von einer gewissen Veränderung der historischen Rollen der beiden Kirchen im Zusammenhang mit der Änderung der katholischen Ekklesiologie durch das Zweite Vatikanische Konzil, den demographischen Prozessen in der Ukraine und ihrer staatlichen Unabhängigkeit aus. Die römisch-katholischen Gläubigen sind jetzt nicht nur eine religiöse Minderheit, sondern eine Minderheit unter den ukrainischen Katholiken. Sie müssen sich entweder an diese Rolle gewöhnen oder ihre Kraft einsetzen, um erneut eine »Mehrheit« zu werden. Diese letzte Perspektive ist ein zusätzlicher Grund für die griechisch-katholischen Gemeinden, Ängste zu entwickeln. Die griechisch-katholischen Gläubigen stehen selbst vor einer schwierigen Herausforderung: Sie müssen der Versuchung widerstehen, ihren Status einer "mitgliederreicheren und traditionellen« Kirche nicht für eine »historische Abrechnung « zu missbrauchen, sondern diesen Status für die Überwindung historischer Spannungen und die Zusammenarbeit zu nutzen. Sehr wichtige neue Impulse für die weitere Entwicklung der beiden katholischen Kirchen sowie für die Harmonisierung der innerkirchlichen Beziehungen hat der Besuch von Papst Johannes Paul II. in der Ukraine im Juni 2001 beigetragen, wie auch die neuesten Initiativen bezüglich des Beitrages der Katholiken auf beiden Seiten der Grenze zur Versöhnung und Vereinigung zwischen dem polnischen und dem ukrainischen Volk, insbesondere im Hinblick auf die tragischen Seiten der gemeinsamen Geschichte. ${ }^{23}$

Somit verläuft die globale Linie der religiösen Konflikte in der Ukraine nicht so sehr auf einer konfessionellen oder gar jurisdiktionellen Ebene, sondern viel eher auf der Gegnerschaft derjenigen, welche die historischen, ekklesialen, kulturellen, nationalen und anderen Eigenheiten des ukrainischen Christentums

23 Beispielsweise der Akt der gegenseitigen Vergebung während der Eucharistischen Kongresse in Warschau und L'viv im Juni 2005: http://old.ugcc.org.ua/ukr/ documents/appeal2005/paixe/; siehe auch: http://headugcc.info/vizyty-2/zakord/ hlava-uhkts-rozpochav-svij-istorychnyj-vizyt-do-polschi.html. 
Turij, Historische Wurzeln interkonfessioneller Konflikte

betonen, und den Kräften, die mit »universalistischen « Kategorien operieren und sich auf ukrainisch-ferne ekklesiale Autoritäten sowie nicht-ukrainische nationalpolitische Faktoren hin orientieren. Mit anderen Worten: Auch wenn die einzelnen Kirchen in den gegenseitigen Debatten die »kanonischen « (d. h. theologisch-ekklesiologischen) Argumente anzuwenden pflegen, bleiben in der Tat die faktische Anerkennung (oder Nichtanerkennung) des ukrainischen Staates und seiner demokratischen Auffassung durch diese Kirchen sowie die Akzeptanz (oder Nichtakzeptanz) der eigenen Rolle in diesem Staat, in der ukrainischen Gesellschaft und in der christlichen Ökumene Hauptursachen der Konflikte sowohl zwischen den einzelnen religiösen Gemeinschaften als auch innerhalb dieser Gemeinschaften.

\section{Literatur}

Єленський, Віктор: Розлам, Протистояння в українському православ’ї як конфлікт ідентичностей. In: Людина і світ 6 (2000), 2-10.

Єленський, Віктор: Релігія і »перебудова«. In: Людина і світ 11/12 (2000), 11-21.

Кудлай, Оксана: Міжправославний конфлікт в Україні: позиції сторін. In: Людина і світ 5/6 (1998), 2-8.

Паращевін, Максим: Релігія та релігійність в Україні. За ред. С. Макеєва. Київ 2009 [auch unter: http://polityka.in.ua/userfiles/religiya_i_ religiynist_v_Ukraini_2008.pdf (09.02.2015)].

Шангіна, Людмила: Релігійність українського суспільства. In: Національна безпека і оборона 8 (92) (2007), 21-23.

ЦЕНТР РАЗУМКОВА: Релігія і влада в Україні: проблеми взаємовідносин. Інформаційні матеріали до Круглого столу на тему: »Державно-конфесійні відносини в Україні станом на 2013 рік: рух до партнерства держави і Церкви чи до кризи взаємин?« 22 квітня 2013р. Київ 2013. 
Turij, Historische Wurzeln interkonfessioneller Konflikte

Himka, John-Paul: Religious Communities in Ukraine. In: Jordan, Peter / Kappeler, Andreas / Lukan, Walter / Vogl, Josef (Hgg.): Ukraine: Geographie - Ethnische Struktur - Geschichte - Sprache und Literatur - Kultur - Politik - Bildung - Wirtschaft - Recht / Österreichisches Ost- und Südosteuropa-Institut. Wien/Frankfurt am Main/Berlin/Bruxelles/New York/Oxford 2001, 241-258.

Kotschan, Natalja: Die griechisch-katholische Kirche in der Ukraine heute: Ideologische Hindernisse für den Dialog mit der Orthodoxie. In: Ost-West. Europäische Perspektiven 1(2) (2000), 135-144.

Durkot, Juri: Zwischen Zwist und Dialog. Ukrainische Kirchen und Konfessionen nach dem Papstbesuch. In: Konrad-Adenauer-Stiftung/Auslandsinformationen 8 (2001), 4-18.

Gudziak, Borys: Ukrainian Religious Life During the First Five Years of Independence. In: Kis, T. / Makaryk, I. / Weretelnyk (Hgg.): Towards a New Ukraine I: Ukraine and the New World Order, 1991-1996. Proceedings of a conference held at the University of Ottawa, March 21-22, 1997. Ottawa $1997,49-72$.

Turij, Oleh: Das religiöse Leben und die zwischenkonfessionellen Verhältnisse in der unabhängigen Ukraine. In: Mykhaleyko, Andriy / Petrynko, Oleksandr / Thiermeyer, Andreas-A. (Hgg.): Einheit: Auftrag und Erbe. Anthologie von Texten der ukrainischen Griechisch-Katholischen Kirche zu Fragen der Kircheneinheit mit Kommentar. L'viv 2012, 23-86.

\section{Internetseiten}

www.risu.org.ua/ukr/resourses/statistics/ (27.01.2014)

http://www.interfax-religion.ru/?act=documents\&div=472 (10.12.2014)

http://www.interfax-religion.ru/?act=documents\&div=472 (10.12.2014)

http://archiv.orthodox.org.ua/page-2149.html (10.12.2014)

DigiOst 3 | 136 
Turij, Historische Wurzeln interkonfessioneller Konflikte

http://risu.org.ua/ua/index/resourses/church_doc/ugcc_doc/34090/(09.02.2015) http://www.mospat.ru/index.php?page=29080) (10.12.2014)

http://ru.wikipedia.org/wiki/Православие_и_католицизм (10.12.2014)

http://www.interfax-religion.ru/?act=documents\&div=472 (09.10.2014)

http://www.pravoslavye.org.ua/index.php?r_type=article\&action $=$ fullinfo $\&$ $\mathrm{id}=13865(08.10 .2014)$

http://www.uaorthodox.info/ua/catalog/Publikatsiyi/Fakti_i_komentari/ SHCHe_raz_pro_hreshchennya.html (08.12.2014)

http://orthodoxy.org.ua/node/22666 (08.12.2014)

http://orthodox.org.ua/node/2599 (09.02.2015)

http://www.ec-patr.org/docdisplay.php?lang=en\&id=968\&tla=ua (10.12.2014)

http://orthodoxy.org.ua/uk/dopovidi_ta_promovi/2008/07/27/17721. html (10.12.2014)

http://www.patriarchia.ru/db/text/604287.html (10.12.2014)

http://orthodox.org.ua/uk/svyashhenniy_sinod/2008/07/16/3235. html (09.12.2014)

http://www.cerkva.info/uk/icd/193-declaracia-1.html (09.12.2014)

http://www.ugcc.org.ua/fileadmin/user_upload/pdf/visnyk_7.pdf (09.12.2014) http://old.ugcc.org.ua/ukr/documents/appeal2005/paixe/ (27.01.2015)

http://headugcc.info/vizyty-2/zakord/hlava-uhkts-rozpochav-svij-istorychnyjvizyt-do-polschi.html (09.02.2015) 
Turij, Historische Wurzeln interkonfessioneller Konflikte

\section{Abstract}

\section{Oleh Turij}

Historical Roots of Interfaith Conflicts in Contemporary Ukraine: Identity Problems of the Christian Churches

While in the Western hemisphere, religious conflicts in Ukraine are often enough explained by the "global« and "geopolitical « situation of the country, this article argues that the search for a singular identity within the most prominent Ukrainian churches is responsible for religious quarrelling. Most of all, the traditional churches - the Greek Catholic Church, the Roman Catholic Church, and the Orthodox churches - face three challenges to their modern identity: from the state, from society, and from their own ecclesiology. More than conflicts within the churches, intra-church conflicts characterize the present religious situation in Ukraine. 


\section{Olga Popova}

\section{Religiosity and Economic Reforms in Transition Countries}

\section{Introduction}

Countries of the former Soviet Union and Central and Eastern Europe, hereafter transition countries, undertook a number of economic reforms over the past two decades. ${ }^{1}$ In most transition countries, these reforms included primarily privatization of state sector enterprises, price and trade liberalizations, and economic stabilization. Yet, the economic performance and the progress of transition differ from country to country. In Table 1, selected economic and political indicators, such as gross domestic product (GDP) per capita, private sector share in GDP, and indices of government effectiveness and democracy, are presented. As demonstrated in this table, most countries started their transition with 5 to 10 percent share of private sector enterprises in their economy, but experienced the growth in the GDP per capita and private sector, although at different rates. Most transition countries also became more democratic, although the government effectiveness is still low in these states. Nevertheless, even though transition countries achieved substantial progress in economic development, their performance is still below the level of developed countries.

1 According to the classification suggested by the European Bank of Reconstruction and Development (EBRD), transition countries are Albania, Armenia, Azerbaijan, Belarus, Bosnia and Herzegovina, Bulgaria, Croatia, the Czech Republic, Estonia, FYR Macedonia, Georgia, Hungary, Kazakhstan, Kosovo, the Kyrgyz Republic, Latvia, Lithuania, Moldova, Montenegro, Mongolia, Poland, Romania, Russian Federation, the Slovak Republic, Slovenia, Serbia, Tajikistan, Turkmenistan, Ukraine, and Uzbekistan. 
Popova, Religiosity and Economic Reforms in Transition Countries

For instance, in 2010, according to the World Bank Development Indicators, GDP per capita measured in constant 2005 international dollars in the U.S. was 43952.4, while in Germany it was 33511.7. This is substantially higher than in any transition country.

Along with objective economic indicators such as GDP per capita, recent economic literature also emphasizes the role of life satisfaction for the measurement of economic performance, as advised by Stiglitz, Sen and Fitoussi (2009) in their famous report. Inspired by this report, a number of national governments, including those of Australia, Canada, France, Germany, Italy, UK, USA, and others, began to track the quality of life along with conventional GDP measure of economic progress. Also, international organizations started several initiatives on measuring the economic performance of nations, for instance, the European Commission's »Beyond GDP« initiative and OECD’s »Better Life« index.

Life satisfaction represents the individual judgment regarding one's own quality of life. Life satisfaction scores are available from surveys and are based on individual responses to the question $»$ All things considered, I am satisfied with my life now (1) Strongly disagree; (2) Disagree; (3) Neither disagree nor agree; (4) Agree; (5) Strongly agree« (the 5-point Likert scale) or modifications of this question on a 4-, 7-, 10-point Likert scale. ${ }^{2}$

Individuals from most transition economies report lower scores of life satisfaction as compared to individuals from developed economies due to economic changes undertaken in their countries (see Easterlin, 2009; Guriev and Zhuravskaya, 2009; Popova, 2010, among others).

2 A Likert scale, or rating scale, is a scale commonly employed in survey questionnaires. In Likert type questions a respondent is asked to evaluate the suggested statement. The Likert scale typically includes 4-, 5-, 7-, or 10 ordered response alternatives.

\begin{tabular}{l|l} 
DigiOst 3 & 140
\end{tabular} 
Popova, Religiosity and Economic Reforms in Transition Countries

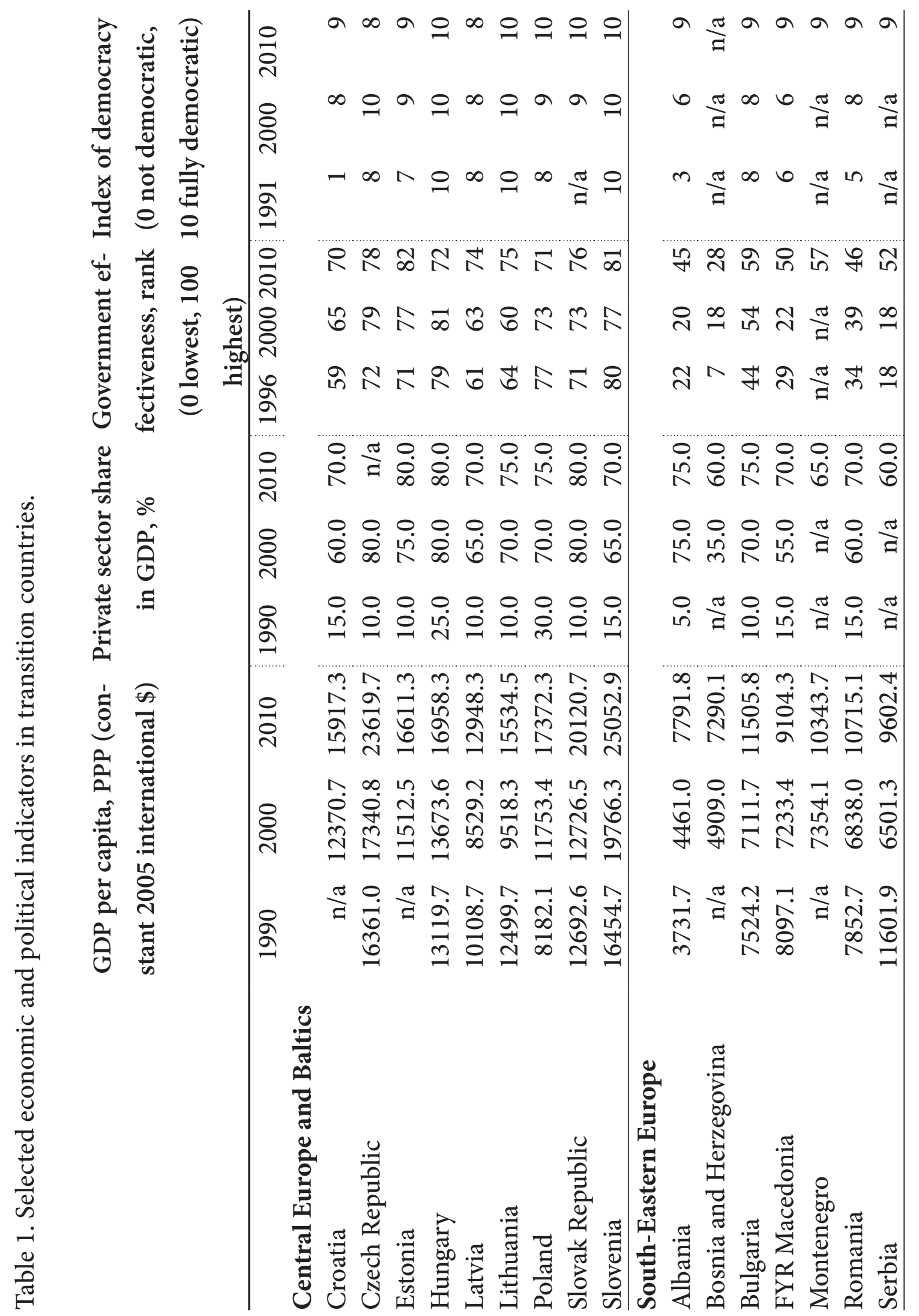

DigiOst 3 | 141 
Popova, Religiosity and Economic Reforms in Transition Countries

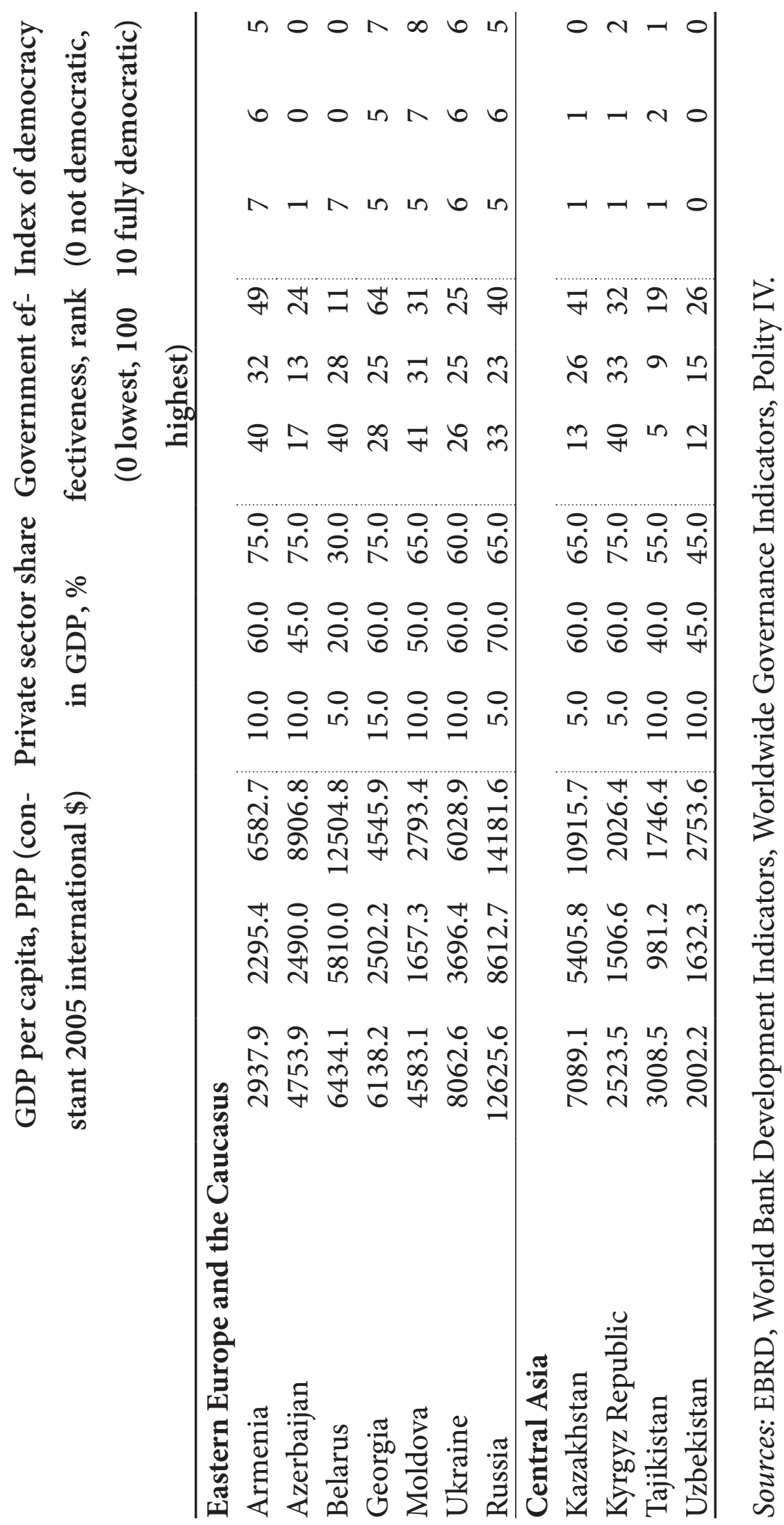

DigiOst 3 | 142 
Popova, Religiosity and Economic Reforms in Transition Countries

Economic literature suggests that religiosity increases life satisfaction and helps to overcome the consequences of stressful idiosyncratic and countrywide events (Clark and Lelkes, 2006 and 2009; Dehejia, DeLeire and Luttmer, 2007; Popova, 2010 and 2014). For instance, layoff decreases life satisfaction of all individuals, but for religious individuals the effect is less pronounced. Based on findings by Popova (2010), this study underscores the role of religiosity in the individual adaptation to economic reforms in transition countries. The paper suggests that religious individuals report higher scores of life satisfaction during economic reforms than non-religious individuals.

The rest of this paper is organized as follows. In the next section, methodology and data are described. Then, the findings are presented and discussed. The final section concludes.

\section{Methodology and Data}

The analysis of the effects of economic reforms on life satisfaction is conducted using the econometric modeling. The dependent variable of interest is the individual life satisfaction, which is measured on a 5-point Likert scale, as described above. Explanatory variables include various socioeconomic characteristics such as religiosity, age, gender, education, employment and marital statuses, income, etc., as well as variables indicating the progress of economic reforms. The specification also includes the interaction effects between religiosity and economic reforms. This helps to examine the difference in the effects of reforms for religious and non-religious individuals. ${ }^{3}$

Two main data sources are used. Individual data are taken from the Life in Transition Survey (LiTS) 2006. This survey is conducted by the EBRD in 29 transition countries and contains randomly sampled individual data. The

3 For the details of methodology, see Popova (2010). 
Popova, Religiosity and Economic Reforms in Transition Countries

sample for each country contains about 1000 respondents. The second data source is the EBRD transition indicators, which measure the progress of various economic reforms such as large and small-scale privatization, price and trade liberalizations, and others. As a complementary data source, the World Christian database is also used. It comprises data on the share of people of different religious denominations over time.

As defined by Need and Evans (2001), religiosity of an individual implies that he/she identifies himself/herself with a particular religious denomination, has religious beliefs, prays, and attends a religious organization. Although LiTS data contain the question regarding the self-identification with a particular religious denomination, there are no questions on the frequency of praying or attending a religious organization. Thus, religiosity in the present paper implies being an adherent of a particular religious denomination.

In Figure 1, sample descriptive statistics on different religious denominations are presented. As can be seen in this figure, a large share of individuals in the sample recognize themselves as adherents of a particular religious denomination.

Fig. 1. Sample descriptive statistics on religious denominations in transition countries.

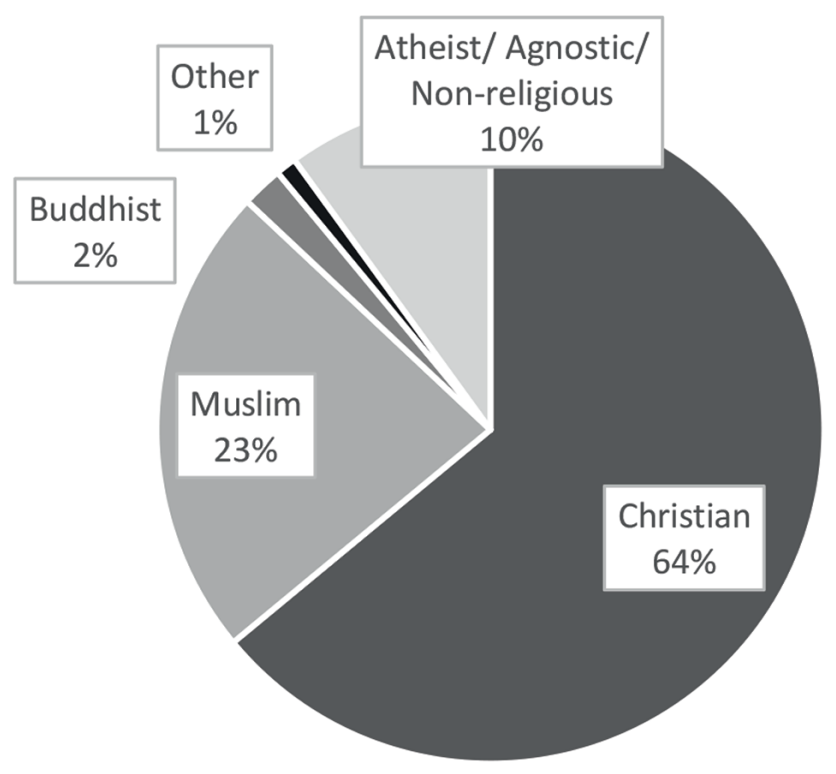

Source: LiTS 2006

DigiOst 3 | 144 
Popova, Religiosity and Economic Reforms in Transition Countries

Table 2. Percentage of individuals satisfied with life in transition countries

$\%$ of satisfied with life, LiTS 2006

\section{Central Europe and Baltics}

Croatia

54.5

Czech Republic

Estonia

66.7

Hungary

25.9

Latvia

55.5

Lithuania

52.3

Poland

51.9

Slovak Republic

58.0

Slovenia

70.4

\section{South-Eastern Europe}

Albania

46.2

Bosnia and Herzegovina

27.1

Bulgaria

28.4

FYR Macedonia

26.7

Montenegro

28.5

Romania

32.0

Serbia

26.0

\section{Eastern Europe and the Caucasus}

Armenia

Azerbaijan

Belarus

Georgia

Moldova

Ukraine

Russia

\section{Central Asia}

Kazakhstan

Kyrgyz Republic

Tajikistan 
Popova, Religiosity and Economic Reforms in Transition Countries

Data on religious denominations from LiTS are consistent with data from the World Christian database, which estimated in 2005 that $11.5 \%$ of individuals in Europe are non-religious.

The descriptive statistics on life satisfaction in transition countries are presented in Table 2. In this table, the percentage of individuals who answered 4 (»Agree») and 5 (»Strongly agree») to the question on life satisfaction is presented. As can be seen from Table 2, this share differs substantially between transition countries. As suggested by Stiglitz et al. (2009), among others, these differences may also reflect the different economic performance of these countries. For instance, Slovenia, which has the highest GDP per capita among transition countries, also has one of the highest shares of individuals who are satisfied with their life.

\section{Findings and Discussion}

The analysis of the impact of economic reforms on religious and non-religious individuals is undertaken for three different dependent variables, namely life satisfaction, satisfaction with the economic situation in one's own country, and satisfaction with the political situation in one's own country. The results are summarized in Tables 3 to 5 . $^{4}$ The effects of several economic reforms are studied. These reforms are distinguished according to the EBRD classification and include privatization of large and small enterprises, restructuring, price and trade liberalizations, reforms in competition policy, banking, security markets, and infrastructure.

In Tables 3 to 5, the direct and indirect effects of reforms are presented. The direct effect is the impact of a particular indicator of economic reform on the individual life satisfaction, satisfaction with the economic situation, or

4 Detailed results are presented by Popova (2010).

DigiOst 3 | 146 
satisfaction with the political situation. This effect represents the impact on an average individual. The indirect effect implies the impact of a particular reform on an average religious individual. For instance, in Table 3, the direct effect of a large-scale privatization reform is negative on the average individual, while the indirect effect of this reform on religious individuals is positive. This means that although large-scale privatization is related to life satisfaction negatively, this effect for religious individuals is partially mitigated by their religiosity. A similar effect is observed for competition policy reform and infrastructure reform. In the economic literature, this phenomenon is defined as "the insurance effect of religiosity« (see Clark and Lelkes, 2006 and 2009; Dehejia et al., 2007; Popova, 2010 and 2014).

The insurance effect of religiosity may be related to different perceptions of economic reforms by religious individuals. On the one hand, since religious individuals have norms and values that are different from that of non-religious individuals, they are likely to be affected by economic reforms differently. On the other hand, due to a generally greater propensity to believe, religious people may have a greater confidence in the success of economic reforms than non-religious individuals.

As seen from Table 3, price and trade liberalizations, banking and security market reforms do not affect life satisfaction. Enterprise restructuring, banking and security markets reforms also do not have effects on satisfaction with the economic and political situation (see Tables 4 and 5).

Additionally, as seen from Tables 3 to 5, religiosity has a positive effect on all three specifications (life satisfaction, satisfaction with economic situation, and satisfaction with political situation). That is, religious individuals are on average more satisfied with their life and with the economic and political situation of their country than non-religious individuals. 
Table 3. Direct and indirect effects of economic reforms on life satisfaction.

Direct effects Indirect effects

\begin{tabular}{ll:lll}
\hline Religiosity & + & & \\
\hline Large scale privatization & - & Religiosity ${ }^{\star}$ Large scale privatization & + \\
\hline Small scale privatization & + & Religiosity ${ }^{\star}$ Small scale privatization & - \\
\hline Enterprise restructuring & + & Religiosity ${ }^{\star}$ Enterprise restructuring & - \\
\hline Price liberalization & no & Religiosity ${ }^{\star}$ Price liberalization & No \\
\hline Trade liberalization & no & Religiosity & Trade liberalization & No \\
\hline Competition policy reform & - & Religiosity ${ }^{\star}$ Competition policy reform & + \\
\hline Banking reform & no & Religiosity ${ }^{\star}$ Banking reform & No \\
\hline Securities markets reform & no & Religiosity ${ }^{\star}$ Securities markets reform & No \\
\hline Overall infrastructure reform & - & Religiosity ${ }^{\star}$ Overall infrastructure reform & + \\
\hline
\end{tabular}

Source: own calculations, Popova (2010). Notes: +/-/no correspond to a positive/ negative/no statistically significant effect found in the econometric model.

Table 4. Direct and indirect effects of economic reforms on satisfaction with economic situation.

Direct effects Indirect effects

\begin{tabular}{ll:lll}
\hline Religiosity & + & & & \\
\hline Large scale privatization & - & Religiosity ${ }^{\star}$ Large scale privatization & No \\
\hline Small scale privatization & - & Religiosity ${ }^{\star}$ Small scale privatization & + \\
\hline Enterprise restructuring & no & Religiosity ${ }^{*}$ Enterprise restructuring & No \\
\hline Price liberalization & + & Religiosity & Price liberalization & No \\
\hline Trade liberalization & no & Religiosity ${ }^{\star}$ Trade liberalization & - \\
\hline Competition policy reform & + & Religiosity ${ }^{\star}$ Competition policy reform & - \\
\hline Banking reform & no & Religiosity ${ }^{\star}$ Banking reform & No \\
\hline Securities markets reform & no & Religiosity ${ }^{\star}$ Securities markets reform & No \\
\hline Overall infrastructure reform & + & Religiosity ${ }^{\star}$ Overall infrastructure reform & - \\
\hline
\end{tabular}

Source: own calculations, Popova (2010). Notes: +/-/no correspond to a positive/ negative/no statistically significant effect found in the econometric model. 
Popova, Religiosity and Economic Reforms in Transition Countries

Table 5. Direct and indirect effects of economic reforms on satisfaction with political situation.

Direct effects

Indirect effects

\begin{tabular}{ll:lll}
\hline Religiosity & + & & \\
\hline Large scale privatization & - & Religiosity ${ }^{\star}$ Large scale privatization & No \\
\hline Small scale privatization & no & Religiosity ${ }^{\star}$ Small scale privatization & + \\
\hline Enterprise restructuring & no & Religiosity ${ }^{\star}$ Enterprise restructuring & No \\
\hline Price liberalization & + & Religiosity ${ }^{\star}$ Price liberalization & - \\
\hline Trade liberalization & - & Religiosity & $\star$ \\
\hline Trade liberalization & No \\
\hline Competition policy reform & no & Religiosity ${ }^{\star}$ Competition policy reform & - \\
\hline Banking reform & no & Religiosity ${ }^{\star}$ Banking reform & No \\
\hline Securities markets reform & no & Religiosity ${ }^{\star}$ Securities markets reform & No \\
\hline Overall infrastructure reform & no & Religiosity ${ }^{\star}$ Overall infrastructure reform & No \\
\hline
\end{tabular}

Source: own calculations, Popova (2010). Notes: +/-/no correspond to a positive/ negative/no statistically significant effect found in the econometric model.

Interestingly, the different perception of economic reforms by religious individuals is observed not only in cases of negative direct effects, but also in cases of positive direct effects of reforms. That is, if the direct effect of a reform is positive, the satisfaction of religious people increases less than that of non-religious people. For instance, such effects are observed in cases of small-scale privatization and life satisfaction. It means that religiosity reduces the effect of reforms irrespectively of the direction of this effect.

\section{Conclusion}

Although transition economies had similar reforms, their economic performance, average levels of life satisfaction, and the speed of reforms' implementation differ from country to country. Based on the results of Popova (2010), 
Popova, Religiosity and Economic Reforms in Transition Countries

this paper suggests that religiosity helps to mitigate the potential negative effects of economic reforms. It implies that the speed of implementation and the sequencing of economic reforms may differ in religious and non-religious communities.

\section{References}

Clark, Andrew / Lelkes, Orsolya: Let Us Pray: Religious Interactions in Life Satisfaction. In: Paris School of Economics Working Paper 01 (2009).

Clark, Andrew / Lelkes, Orsolya: Deliver Us from Evil: Religion as Insurance. In: Papers on Economics of Religion from Department of Economic Theory and Economic History of the University of Granada 06/03 (2006).

Dehejia, Rajeev / DeLeire, Thomas / Luttmer, Erzo: Insuring Consumption and Happiness through Religious Organizations. In: Journal of Public Economics 91 (2007), 259-279.

Easterlin, Richard: Lost in Transition: Life satisfaction on the Road to Capitalism. In: Journal of Economic Behavior and Organization 71 (2009), 130145.

Guriev, Sergej / Zhuravskaya, Ekaterina: (Un)happiness in Transition. In: Journal of Economic Perspectives 23(2) (2009), 143-168.

Need, Ariana / Evans Geoffrey: Analyzing Patterns of Religious Participation in Post-Communist Eastern Europe. In: British Journal of Sociology 52(2) (2001), 229-248.

Popova, Olga: Can Religion Insure against Aggregate Shocks to Happiness? The Case of Transition Countries. In: CERGE-EI Working Paper 425 (2010). Popova, Olga: Can Religion Insure against Aggregate Shocks to Happiness? The Case of Transition Countries. Journal of Comparative Economics 42(3) (2014), 804-818. DOI: 10.1016/j.jce.2014.05.003 
Popova, Religiosity and Economic Reforms in Transition Countries

Stiglitz, Joseph / Sen, Amartya / Fitoussi, Jean-Paul: Report by the Commission on the Measurement of Economic Performance and Social Progress 2009, see: http://www.stiglitz-sen-fitoussi.fr/documents/rapport_anglais. $\operatorname{pdf}(02.02 .2015)$.

\section{Abstract}

\section{Olga Popova}

Religiosity and Economic Reforms in Transition Countries

Individuals from countries with transition economies report lower scores of life satisfaction when compared to individuals from developed countries. Based on the findings of Popova (2010), this paper suggests that although economic reforms undertaken by transition countries may negatively affect individual satisfaction, this impact is different for religious and non-religious individuals. Thus, the study underscores the role of religiosity on one's adaptation to economic reforms in transition countries. 
Katrin Boeckh - 978-3-86688-505-9 


\section{Maxim Gatskov / Ksenija Gatskova}

\section{Zum Anstieg der Religiosität in der postsowjetischen Ukraine: Empirische Befunde und theoretische Erklärungsansätze}

\section{Fragestellung}

Nachdem die Ideologie des Marxismus-Leninismus in der Sowjetunion in den 1980er Jahren ihrem Bankrott entgegensteuerte und immer mehr Sowjetbürger sich von den kommunistischen Idolen abwandten, erlebte die herkömmliche Religiosität im Land des »dialektischen Materialismus« einen stürmischen Aufschwung. Die Umfragen von 1989-1991 zeigten, dass neben Usbeken und Litauern die Ukrainer zu den drei sowjetischen Nationalitäten zählten, unter denen die Zahl der Gläubigen am Vorabend der Auflösung der UdSSR am höchsten war. ${ }^{1} 1991$ soll sogar die Hälfte aller Kirchen der Sowjetunion in der Ukraine gewesen sein. ${ }^{2}$ In den beiden postsowjetischen Dekaden setzte sich der Trend der Zunahme der Religiosität in allen ehemaligen Sowjetrepubliken weiter fort; in der Ukraine bezeichneten sich bei der Umfrage des European Social Survey im Jahr 2008 über 80\% der Bevölkerung als religiös (vgl. Abb. 1). Wie lässt sich dieser Trend erklären? Mit welchen sozialen Prozessen geht der Anstieg der Religiosität einher und auf welche Faktoren lässt er sich zurückzuführen? Welche Ansätze eignen sich am besten dazu, die entsprechenden Veränderungen in den Einstellungen und Werten theoretisch zu erfassen?

1 Lewada: Die Sowjetmenschen, 253.

2 Wilson: The Ukrainians, 240; vgl. auch im Abschnitt über die Bewahrung der Religiosität in der Ukraine. 
Gatskov / Gatskova, Zum Anstieg der Religiosität in der postsowjetischen Ukraine

Bevor man diese und ähnliche Fragen beantworten kann, muss zunächst hinterfragt werden, ob wir es in der Tat mit einer gestiegenen Religiosität in der ukrainischen Bevölkerung zu tun haben. Einer solchen Prüfung ist der erste Teil (Abschnitt 2) unserer Untersuchung gewidmet. Selbstverständlich soll es dabei nicht bloß darum gehen, eine Ja-oder-Nein-Antwort zu geben: Wenn man berücksichtigt, dass Religiosität unterschiedliche Erscheinungsformen aufweist, lässt sich die Beobachtung ihres allgemeinen Anstiegs in die Frage übersetzen, welche Art Religiosität in der Ukraine zugenommen hat. Von der Antwort auf diese Frage hängt unter anderem ab, ob man eine Desäkularisierungstendenz diagnostizieren kann, von einer neuartigen Entwicklung oder der Wiedererweckung einer unterdrückten Tradition sprechen soll bzw. ob diese Entwicklung als nachhaltig oder eher als konjunkturell zu betrachten ist. Ferner kann man erst nach einer genaueren Betrachtung der Empirie dazu übergehen, mit Hilfe von theoretischen Konzepten eine Erklärung für die festgestellten Tatsachen zu suchen.

Theoretischen Erklärungsansätzen ist der zweite Teil (Abschnitt 3) unserer Arbeit gewidmet. Diese können in diesem Rahmen allerdings nur kurz vorgestellt werden - eine weiterführende theoretische bzw. zeitdiagnostische Diskussion soll an einer anderen Stelle unter Heranziehung von zusätzlichem empirischem Material erfolgen. Der Schwerpunkt unserer Betrachtung liegt auf einer ausführlicheren diachronen Datenanalyse, während die bisherigen soziologischen Arbeiten zur Religiosität in der Ukraine entweder auf den Entwicklungsstand $\mathrm{zu}$ einem bestimmten Zeitpunkt eingehen oder breite internationale Vergleiche anstellen, ohne dabei die Daten aus verschiedenen Quellen konsequent zueinander in Beziehung zu setzen. Dies erscheint uns sehr wichtig, weil nur bei einer detaillierten Analyse der Religiosität, der in den einzelnen soziologischen Umfragen gewöhnlich ein geringerer Stellenwert beigemessen wird, Verzerrungen vermieden werden können.

Unsere empirische Untersuchung beruht auf mehreren repräsentativen Bevölkerungsumfragen. Für die Darstellung der Tendenzen in der subjektiven 
Gatskov / Gatskova, Zum Anstieg der Religiosität in der postsowjetischen Ukraine

Religiosität der Bevölkerung in der Ukraine greifen wir in erster Linie auf die World Values Surveys (WVS) 1996 und 2006 sowie auf die European Values Surveys (EVS) 1999 und 2008 zurück. Da in diesen Umfragen in Bezug auf Religion gleiche Frageformulierungen verwendet wurden, lassen sich die aggregierten Orientierungen der ukrainischen Bevölkerung im Zeitraum von 13 Jahren vergleichen. Das Monitoring »Ukrainische Gesellschaft « ${ }^{3}$ des Instituts für Soziologie der Ukrainischen Akademie der Wissenschaften wurde zur Abbildung der Vertrauensschwankungen zur Kirche und dem Klerus herangezogen. Eine detailliertere Aufschlüsselung der Struktur der Religiosität ermöglichten die ISSP-Daten (International Social Survey Programme) aus dem Jahr 2008, in dem Religion das Schwerpunktthema der Umfrage bildete. Zusätzlich wurden die Statistiken des ukrainischen Staatskomitees für Statistik und der Bericht des Razumkov-Zentrums »Religion und Staatsmacht: Probleme der wechselseitigen Beziehungen (2013) « herangezogen. ${ }^{4}$

\section{Empirische Analyse}

Auf den ersten Blick sprechen die empirischen Befunde für eine rapide und gleichmäßige Zunahme des religiösen Glaubens in der postsowjetischen Uk-

3 Die repräsentative $(\mathrm{N}=1800)$ Monitoring-Umfrage des Instituts für Soziologie der Nationalen Akademie der Wissenschaften der Ukraine (IS NANU) wird seit 1992 jährlich (bislang mit Ausnahme von 1993, 2007 und 2009) durchgeführt. Der Großteil des Fragebogens blieb in diesem Zeitraum unverändert.

4 Von den Daten des European Social Survey, die in der Ukraine in den Jahren 2004, 2006, 2008 und 2010 erhoben wurden, mussten wir absehen, da die subjektive Einschätzung der eigenen Religiosität mit Hilfe einer zehnstufigen Skala von »überhaupt nicht religiös" (1) bis »sehr religiös« (10) leider nicht eindeutig interpretiert werden kann. Vergleiche mit den Ergebnissen anderer Umfragen zeugen davon, dass die ukrainischen Befragten die Stufen 5 bis 3, die für »eher « bis »nicht religiös« stehen, offensichtlich als »etwas« bis »wenig religiös« auffassten.

DigiOst 3 | 155 
Gatskov / Gatskova, Zum Anstieg der Religiosität in der postsowjetischen Ukraine

raine. So stieg die Zahl der Menschen, die sich als religiös bezeichneten, laut den Umfrageergebnissen der World sowie European Values Surveys von 58\% im Jahr 1996 auf 81,3\% im Jahr 2008 an (Abb. 1). Das ergibt eine Zunahme von rund 23\%. Darüber hinaus fällt auf, dass sich bereits im Jahr 1996, d. h. lediglich vier Jahre nach der Auflösung der Sowjetunion, über die Hälfte der ukrainischen Bevölkerung zu einer Religion bekannte.

Diese Zahlen müssen allerdings etwas relativiert werden, da die angebotenen Antwortoptionen im WVS/EVS-Fragebogen den Befragten im Grunde eine relativ strikte Entscheidung zwischen den Kategorien "ein religiöser Mensch", »ein nicht religiöser Mensch« und »ein überzeugter Atheist« abverlangten. Die Antwortoption »Weiß nicht « sollte von den Interviewern nicht vorgelesen, sondern nur dann vermerkt werden, wenn die Befragten dies von sich aus sagten. Im Ergebnis war es in den Jahren 1996 und 1999 ein Zehntel der Ukrainer, die sich nicht eindeutig festlegen konnten (Abb. 1). In der Razumkov-Umfrage aus dem Jahr 2000, bei der die Befragten sich als »Jemand, der zwischen Glaube und Unglaube schwankt « bezeichnen konnten, wählten hingegen ganze 22,5\% diese Option (vgl. die zweite Spalte in Tabelle 1). Zusammen mit der Option "Schwer zu sagen « zeigte sich somit ein ganzes Viertel der Bevölkerung unentschieden. ${ }^{5}$

5 Die Antwort »Mir ist das gleichgültig « ist inhaltlich leider schwer zu deuten. Im ukrainischen Original genauso wie in der deutschen Übersetzung bleibt unklar, worauf sich das Demonstrativpronomen »das" bezieht: wenn auf die Religion, dann ist das einfach ein anderer Ausdruck für »Ich bin kein religiöser Mensch«. Wenn aber mit »Mir ist das gleichgültig« die Frage selbst gemeint sein soll, dann müsste man die Antwort wohl als »Ich habe darüber nicht nachgedacht « interpretieren, was eher der Antwortoption »Schwer zu sagen« entspricht.

DigiOst 3 | 156 
Gatskov / Gatskova, Zum Anstieg der Religiosität in der postsowjetischen Ukraine

Abb. 1 Gestiegene Religiosität in der Ukraine von 1996-2008, Angaben in Prozent

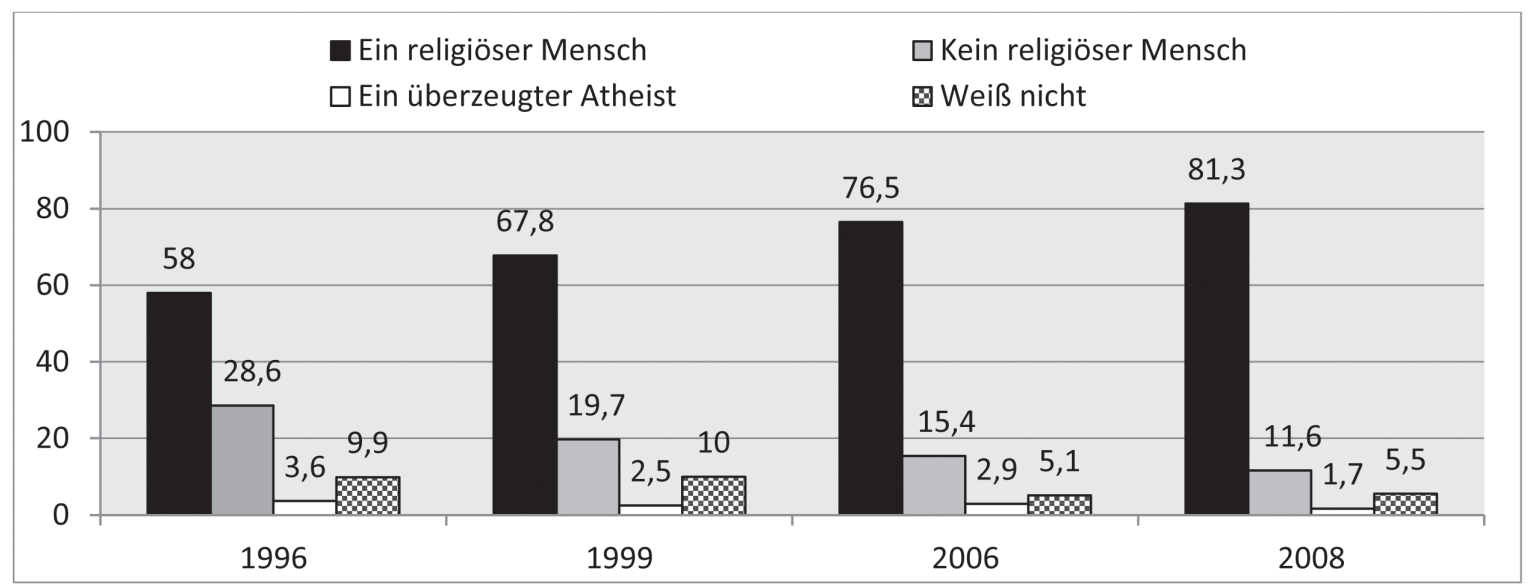

Quellen: WVS 1996, 2006; EVS 1999, 2008; Frage: »Einmal abgesehen davon, ob Sie in die Kirche gehen oder nicht - würden Sie sagen, Sie sind... 1. ein religiöser Mensch, 2. kein religiöser Mensch, 3. ein überzeugter Atheist«. Eigene Darstellung.

Im Jahr 2010 war der Prozentsatz der Unentschiedenen in der Razumkov-Umfrage mit 14,8\% bereits deutlich geringer (»Jemand, der zwischen Glauben und Nicht-Glauben schwankt" plus "Schwer zu sagen«). Obwohl ein direkter Vergleich mit den Ergebnissen des EVS 2008 nicht möglich ist (da, wie gesagt, die Option »Weiß nicht « vom Interviewer nicht angeboten wurde und die Zahl von $81,3 \%$ Religiösen deshalb etwas höher ausgefallen sein mag), ging der Anteil der Gläubigen im Jahr 2010 im Vergleich zu 2008 offenbar etwas zurück.

Für das Jahr 2013 registrierte das Razumkov-Zentrum einen erneuten Rückgang der Gläubigen auf 67\% und einen Zuwachs von Unentschiedenen (» Jemand, der zwischen Glauben und Nicht-Glauben schwankt « plus »Schwer zu sagen «) auf 20,4\%. ${ }^{6}$ Somit scheint die Ukraine etwas zeitversetzt einer ähn-

6 Razumkov-Zentrum: Relihija i vlada v Ukrajini, 24-25. Die Omnibus-Umfrage des Kiewer Zentrums SOCIS, in der drei Optionen zur Auswahl standen (»Ich glaube an Gott», »Ich glaube nicht an Gott«, »Schwer zu sagen«), ergab 75,1\% Gläubige im Jahr 2013. 
Gatskov / Gatskova, Zum Anstieg der Religiosität in der postsowjetischen Ukraine

lichen Entwicklung zu folgen, wie sie in den postkommunistischen Ländern Mittel- und Südosteuropas in der zweiten Hälfte der 1990er stattgefunden hat: der Stabilisierung und Normalisierung der Religiosität. ${ }^{7}$ Statt von einer rapiden und gleichmäßigen Zunahme wäre es deshalb wohl angemessener, von einem Aufschwung der Religiosität in der Ukraine am Ende der 1990er und in der ersten Hälfte der 2000er Jahre zu sprechen. Insbesondere wenn man die Entwicklungen vor der ukrainischen Unabhängigkeit berücksichtigt, wird deutlich, dass diesem Aufschwung eine Flaute vorausging.

Tab. 1 Vergleich der Angaben zur eigenen Religiosität bei verschiedenen Frageformulierungen, in Prozent

\begin{tabular}{|c|c|c|c|}
\hline EVS 1999 & Razumkov-Umfrage 2000 & EVS 2008 & Razumkov-Umfrage 2010 \\
\hline $\begin{array}{l}\text { Religiös } \\
67,8\end{array}$ & $\begin{array}{l}\text { Gläubig } \\
57,8\end{array}$ & $\begin{array}{c}\text { Religiös } \\
81,3\end{array}$ & $\begin{array}{c}\text { Gläubig } \\
71,4\end{array}$ \\
\hline- & $\begin{array}{l}\text { Jemand, der zwischen Glau- } \\
\text { be und Unglaube schwankt } \\
\qquad 22,5\end{array}$ & - & $\begin{array}{l}\text { Jemand, der zwischen Glau- } \\
\text { be und Unglaube schwankt } \\
\qquad 11,5\end{array}$ \\
\hline $\begin{array}{c}\text { Nicht religiös } \\
19,7\end{array}$ & $\begin{array}{c}\text { Nicht gläubig } \\
11,9\end{array}$ & $\begin{array}{c}\text { Nicht religiös } \\
11,6\end{array}$ & $\begin{array}{c}\text { Nicht gläubig } \\
7,9\end{array}$ \\
\hline $\begin{array}{l}\text { Ein überzeug- } \\
\text { ter Atheist } \\
2,5\end{array}$ & $\begin{array}{l}\text { Ein überzeugter Atheist } \\
\qquad 3,2\end{array}$ & $\begin{array}{c}\text { Ein überzeug- } \\
\text { ter Atheist } \\
1,7\end{array}$ & $\begin{array}{c}\text { Ein überzeugter Atheist } \\
\qquad 1,4\end{array}$ \\
\hline- & $\begin{array}{l}\text { Mir ist das gleichgültig } \\
2,6\end{array}$ & - & $\begin{array}{l}\text { Mir ist das gleichgültig } \\
\qquad 4,4\end{array}$ \\
\hline $\begin{array}{l}\text { Weiß nicht } \\
\quad 10,0\end{array}$ & $\begin{array}{c}\text { Schwer zu sagen } \\
2,0\end{array}$ & $\begin{array}{l}\text { Weiß nicht } \\
5,5\end{array}$ & $\begin{array}{c}\text { Schwer zu sagen } \\
3,3\end{array}$ \\
\hline
\end{tabular}

Quellen: EVS 1999, 2008; Razumkov-Zentrum: Relihija i vlada v Ukrajini, Frage: "Einmal abgesehen davon, ob Sie in die Kirche gehen oder nicht - würden Sie sagen, Sie sind ... 1. gläubig, 2. jemand, der zwischen Glauben und Nicht-Glauben schwankt, 3. nicht gläubig, 4. ein überzeugter Atheist, 5. Mir ist das gleichgültig, 6. Schwer zu sagen.« Eigene Darstellung.

7 Vgl. Pollack: Das Verhältnis von Religion und Politik in den postkommunistischen Staaten; Müller et al.: Wandel religiös-kirchlicher Orientierungsmuster. 
Gatskov / Gatskova, Zum Anstieg der Religiosität in der postsowjetischen Ukraine

\section{Die Bewahrung der Religiosität in der Ukraine nach dem Zweiten Weltkrieg}

Trotz des deklarierten Aufbaus einer auf "progressive Wissenschaft " und »dialektischen Materialismus« basierenden Gesellschaftsordnung durfte die Russische Orthodoxe Kirche (ROK) in der Sowjetunion - nicht zuletzt als staatliches Instrument der Kontrolle über die Gläubigen ${ }^{8}$ - eingeschränkt existieren. Die Ukraine und Ukrainer spielten dabei eine gemessen an ihrem Territorium und Bevölkerungsanteil herausragende Rolle in der ROK, vor allem dadurch, dass aus ihnen, oft sogar aus den Westukrainern, vorzugsweise der ROK-Klerus rekrutiert wurde. ${ }^{9} \mathrm{Zu}$ den zwei Hauptfaktoren, die eine deutlich höhere religiöse Aktivität in der Ukraine im Vergleich zu Russland (bzw. zur RSFSR) bedingten, kann man die Wiedereröffnung mehrerer ukrainischen Kirchen während des Zweiten Weltkrieges und die Bestrebungen der staatlich erzwungenen Eingemeindung der Ukrainischen Griechischen Katholischen Kirche (UGKK) in die Russische Orthodoxie zählen. ${ }^{10}$ Der UGKK blieb bis zur Besetzung der Westukraine durch die Rote Armee nicht nur das Schicksal der ROK weitgehend erspart, sondern sie wuchs während der "polnischen Zeit" weiter in ihre Bedeutung als ukrainische Nationalkirche hinein. ${ }^{11}$ Die Ende der 1940er Jahre verbotene, aber im sowjetischen Untergrund weiter existierende UGKK stellte für viele (West-)Ukrainer »einen geistigen Freiraum, in dem Glaube, aber auch politischer Nonkonformismus und Dissens [...] artikuliert

8 Boeckh: Orthodoxie und demokratische Transformation in der Ukraine, 108. Darüber hinaus konnte das internationale Engagement der ROK für die sowjetische auswärtige Politik nutzbar gemacht werden, vgl. Lane: Christian Religion in the Soviet Union, 33, 35.

9 Mitrokhin: Orthodoxy in Ukrainian Political Life 2004-2009, 231.

10 Sysyn: The Ukrainian Orthodox Question in the USSR, 78.

11 Boeckh / Völkl: Ukraine. Von der Roten zur Orangenen Revolution, 100.

DigiOst 3 | 159 
Gatskov / Gatskova, Zum Anstieg der Religiosität in der postsowjetischen Ukraine

werden konnte $\aleph^{12}$, dar. Als »Konkurrenzangebot « hielten bis zu einem Viertel aller vorhandenen orthodoxen Kirchen der Sowjetunion ihre Pforten in der westlichen Ukraine mit einer Bevölkerung von 7 bis 8 Millionen (rund 3\% der Gesamtbevölkerung der UdSSR) geöffnet. ${ }^{13}$ Selbst laut den offiziellen Zahlen waren Anfang der 1970er Jahre rund 40\% der in der Ukrainischen SSR lebenden Bürger religiös (gegenüber ca. 25\% in der RSFSR). ${ }^{14}$

Die Religionsforscher weisen dabei darauf hin, dass die offiziellen Statistiken die realen Werte nach unten verzerrten, ${ }^{15}$ wovon unter anderem mehrere Inkonsistenzen zeugen. Während sich beispielsweise Ende der 1960er/Anfang der 1970er Jahre nur 3\% der jungen Menschen in der Sowjetunion zur Religion bekannt haben sollen, zeugen viele Untersuchungen davon, dass sich die Zahl der Taufen in dieser Zeit auf dem Niveau von 40 bis $50 \%$ stabilisiert hat. ${ }^{16}$ Natürlich kann man von der Anzahl der Taufen nicht direkt auf die spätere Religiosität der Getauften schließen. Dennoch lässt sich konstatieren, dass die Religiosität in der einen oder der anderen Form (also zumindest als nominelles Bekenntnis) bei den Eltern verbreitet war und an die junge Generation zumindest rituell weitergegeben wurde. Im ersten Jahr der Perestrojka wurden internen Parteiberichten zufolge immerhin $26 \%$ der Neugeborenen in der Ukraine getauft und über $40 \%$ (in den westlichen Gebieten bis zu 70\%) aller Bestattungen kirchlich durchgeführt, wobei diese Zahlen nicht die Tätigkeit der Untergrund-Kirchen und rituelle Dienste, die privat geleistet wurden, enthalten. ${ }^{17}$

Insgesamt kann man festhalten, dass die Verbreitung der Religiosität gemessen an der Anzahl registrierter Kirchen, Häufigkeit der Kirchenbesuche

12 Boeckh: Orthodoxie und demokratische Transformation in der Ukraine, 108.

13 Sysyn: The Ukrainian Orthodox Question in the USSR, 78; unter Berufung auf Bociurkiw: The Orthodox Church and the Soviet Regime in the Ukraine 1953-1971.

14 Lane: Christian Religion in the Soviet Union, 223.

15 Yelensky: Religiosity in Ukraine according to Sociological Surveys, 214.

16 Lane: Christian Religion in the Soviet Union, 224, respektive 44.

17 Yelensky: Religiosity in Ukraine according to Sociological Surveys, 214.

DigiOst 3 | 160 
Gatskov / Gatskova, Zum Anstieg der Religiosität in der postsowjetischen Ukraine

und Ausbildungszahlen von Priestern - in der Ukrainischen SSR bis zum Zusammenbruch der Sowjetunion ungebrochen am höchsten blieb. ${ }^{18}$ Dies bedeutet, dass man, wenn die gesamtsowjetischen Umfragen aus den Jahren 1989 und 1990 jeweils $47 \%$ und 56\% Religiöse ergaben, ${ }^{19}$ in der Ukraine von etwa 50\% für das Jahr 1989 und 60\% für das Jahr 1990 ausgehen kann. ${ }^{20}$ Ein solch sprunghafter Anstieg der Anzahl sich als religiös bezeichnender Sowjetbürger (9\% innerhalb eines Jahres!) ist selbstverständlich kein Ausdruck einer wirklichen Zunahme an Religiosität. Dahinter steckt in erster Linie das veränderte Antwortverhalten der Befragten - nach mehreren Jahren der Glasnost'-Politik und der Rückkehr der Kirche in den normalen Alltag hatten die Menschen weniger Bedenken, ihre Religiosität offen zuzugeben. Sicherlich kam darin auch politischer Dissens zum Ausdruck.

Juri Lewada und sein Forscherteam machten neben dem »deutlichen Rückgang der Angst vor der Obrigkeit « ferner den »Umstand, dass in der katastrophenhaften Situation, die im Moment hierzulande herrscht, die unmittelbare Angst vor dem Tod wächst«, für diesen Anstieg verantwortlich. ${ }^{21}$ Sie sagten einen weiteren Anstieg der Anzahl der Religiösen voraus - dadurch, dass die »nach Glauben Strebenden « zum Glauben finden würden -, und gingen von einer Vertiefung des Glaubens aus.

18 Mitrokhin: Orthodoxy in Ukrainian Political Life 2004-2009, 231.

19 Lewada: Die Sowjetmenschen, 234. Die Frage lautete: »Halten Sie sich für einen gläubigen Menschen, und wenn ja, zu welcher Religion zählen Sie sich?«.

20 Unter den ethnischen Ukrainern sollen es sogar $72 \%$ gewesen sein (Lewada: Die Sowjetmenschen, 253), wobei die Möglichkeit einer eindeutigen ethnischen Zuordnung in diesem Fall fragwürdig ist.

21 Lewada: Die Sowjetmenschen, 235. 
Gatskov / Gatskova, Zum Anstieg der Religiosität in der postsowjetischen Ukraine

Der Anstieg der Religiosität in der Ukraine nach der Unabhängigkeit

Geht man, wie oben ausgeführt, von ca. 60\% religiösen Ukrainern im Jahr 1990 aus, so überrascht die Prozentzahl von 58\% im Jahr 1996 eher dadurch, dass sie in der ersten Hälfte der 1990er Jahre nicht zugenommen hat. Der Anteil der Gläubigen von 57,8\%, den die Razumkov-Umfrage noch im Jahr 2000 (vgl. Tab. 1) erfasste, legt die Vermutung nahe, dass auf die explosive Zunahme an Menschen, die sich zu Zeiten der Wende zur Religion bzw. zum Glauben bekannten, zunächst eine Flaute von etwa fünf bis sieben Jahren folgte. Mit Angstgefühlen - verschwundener Angst vor der Obrigkeit und zunehmender Angst vor dem Tod -, auf die Lewada hinwies, lässt sich somit nur der erste (der spätsowjetische) Aufschwung der Religiosität erklären. Gleichzeitig weisen die Ergebnisse des EVS 1999, die mit der unterschlagenen Antwortoption "Schwer zu sagen " deutlich höher als die der Razumkov-Umfrage 2000 ausfielen, darauf hin, dass sich unter den vielen Schwankenden (24,5\% in der Razumkov-Umfrage 2000) ein Großteil der »nach Glauben Strebenden«, wie sie Lewada nannte, befand. Nicht zufällig ergab der EVS 2008 sogar über 80\% der Religiösen.

Auch die Zahlen des Vertrauens zur Kirche und zum Klerus sprechen dafür, dass die Entwicklung der Religiosität Mitte der 1990er Jahre stagnierte. Die Daten des Monitorings »Ukrainische Gesellschaft « zeigen, dass der Anteil derer, die der Kirche und dem Klerus eher oder voll vertrauten, von 1994 bis 1998 stabil bei etwa 35\% verblieb. Erst ab 2000 begann dieser Anteil zu steigen und erreichte in den Jahren 2008-2010 mehr als 55\%, bevor er im Jahr 2012 wieder leicht zurückging (vgl. Abb. 2 sowie Tab. 4 im Anhang). 
Gatskov / Gatskova, Zum Anstieg der Religiosität in der postsowjetischen Ukraine

Abb. 2 Vertrauen zur Kirche und zum Klerus, Veränderung des Mittelwerts 1994-2012 in der Gesamtbevölkerung

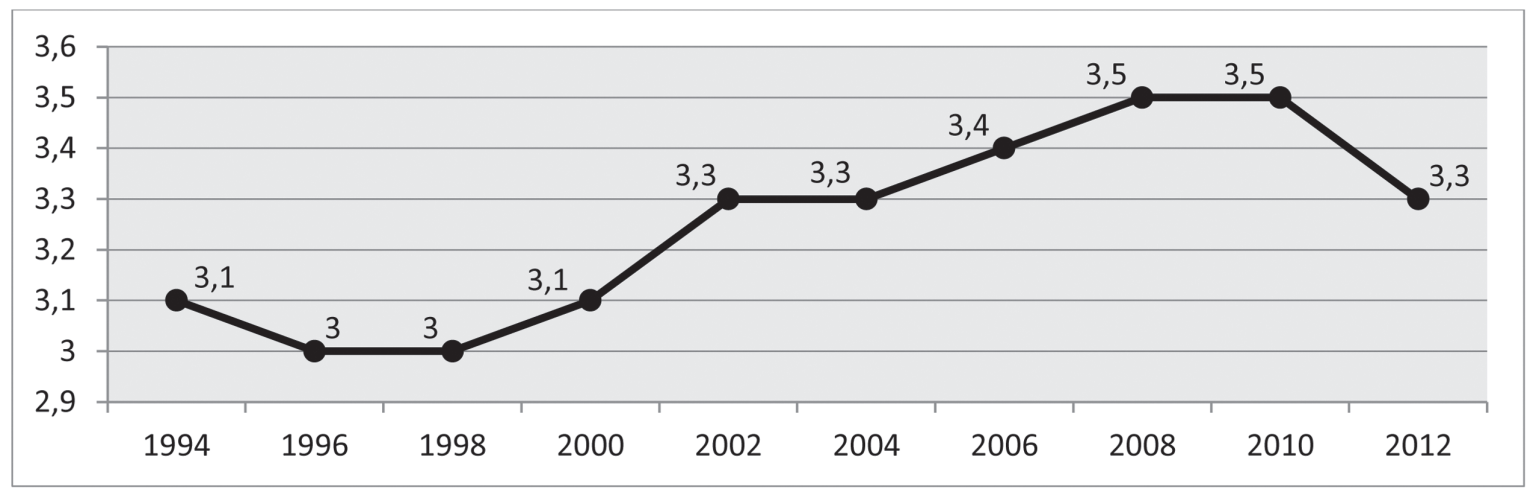

Quellen: Monitoring IS NANU; Frage: »Vertrauen Sie der Kirche und dem Klerus? 1. Nein, gar nicht, 2. Eher nicht, 3. Schwer zu sagen, ob ich vertraue oder nicht, 4. Eher ja, 5. Ja, voll.« Eigene Berechnungen.

Der Vergleich mit den anderen Datensätzen zeigt dabei, dass das Vertrauen höher ausfällt, wenn in der Frage nicht die Kirche und der Klerus gemeinsam genannt werden, sondern die Kirche allein. Das kann so gedeutet werden, dass die Menschen auf eine »abstrakte " Kirche viel mehr Hoffnungen und Erwartung projizieren, als die "reale« Kirche ihrer Meinung nach leistet - Vertrauen ist schließlich eine Kategorie, die sich auf menschliches Handeln bezieht. In den WVS/EVS-Umfragen gaben um bis zu 30\% mehr Ukrainer an, der Kirche zu vertrauen: 1996 waren es 67\%, 2008 insgesamt 78,1\%. Das Razumkov-Zentrum berichtet folgende Ergebnisse: 2000: 63,1\%; 2010: 72,5\%; 2013: 63,8\% der Ukrainer vertrauten der Kirche eher oder voll. ${ }^{22}$ Gleichwohl widerspiegeln diese Ergebnisse eine ähnliche Entwicklung, wie sie von der Kurve in Abb. 2 dargestellt ist.

Der Eindruck, dass sich der Anstieg der Religiosität in der Ukraine in zwei Schüben vollzog, zwischen denen es eine Flaute gab, verfestigt sich ferner,

22 Razumkov-Zentrum: Relihija i vlada v Ukrajini, 42. 
Gatskov / Gatskova, Zum Anstieg der Religiosität in der postsowjetischen Ukraine

wenn man eine weitere Frage heranzieht. Nach der Bedeutung von Gott in ihrem Leben mit Hilfe einer zehnstufigen Skala befragt, wählten im Jahr 1996 insgesamt 45,6\% der Menschen die Stufen 7 bis 10 (vgl. Abb. 7 im Anhang). Drei Jahre später war dieser Prozentsatz nur leicht gestiegen - auf 48,9\%, während er in den Jahren 2006 und 2008 bereits bei rund 66\% lag, was einen schnelleren Anstieg in der ersten Hälfte der 2000er Jahren, als in der zweiten Hälfte der 1990er bedeutet. Diese Zahlen drücken zwar eher eine (von Lewada vorhergesagte) Vertiefung bzw. Intensivierung des Glaubens aus, unterstützen aber indirekt auch die These einer schubartigen Entwicklung der Religiosität insbesondere, wenn man nicht die Gesamtbevölkerung betrachtet, sondern die Gruppe derer, die sich als religiös bezeichnen (Abb. 3).

Abb. 3 »Bedeutung von Gott in Ihrem Leben«, Anteil in Prozent der Religiösen

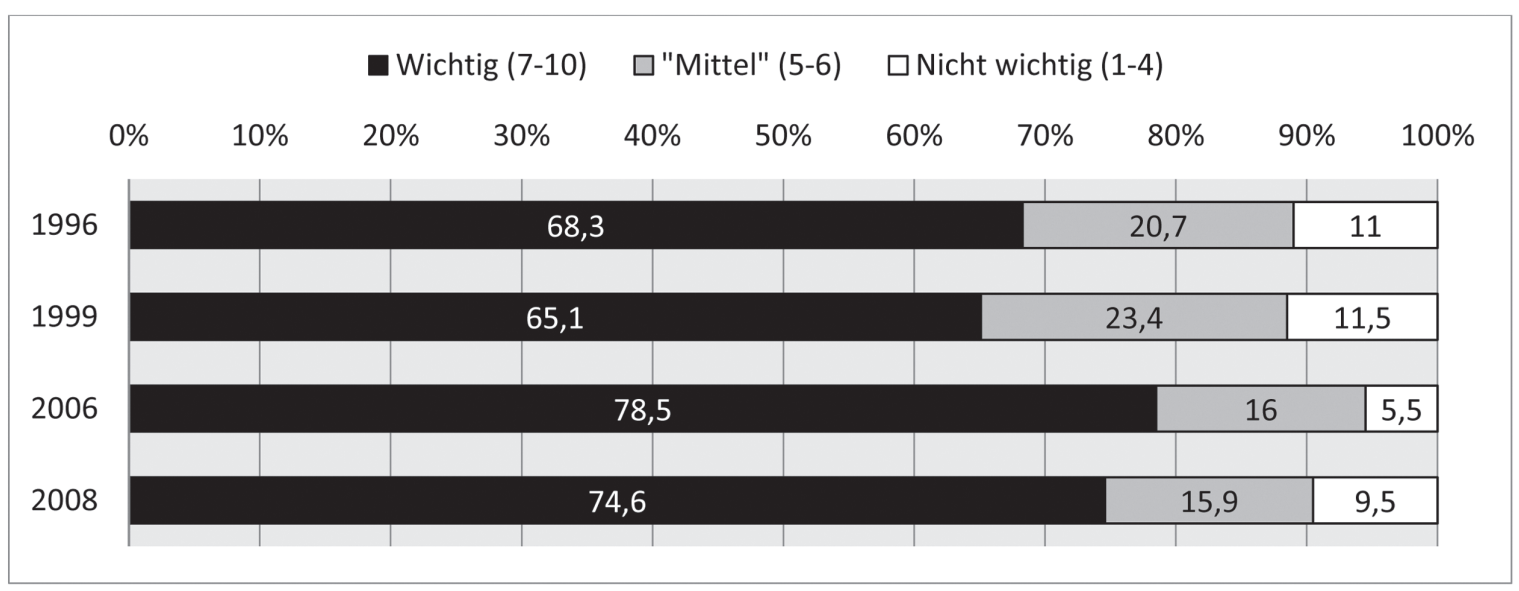

Quellen: WVS 1996, 2006; EVS 1999, 2008; Frage: »Wie wichtig ist Gott in Ihrem Leben? 1. Überhaupt nicht wichtig ... 10. Sehr wichtig«. Eigene Berechnungen. 
Gatskov / Gatskova, Zum Anstieg der Religiosität in der postsowjetischen Ukraine

Tab. 2 Kirchliche Institutionen und Klerus - Veränderung im Vergleich zur letzten Periode in Prozent

\begin{tabular}{lccc} 
Einrichtungen/Organisationen & 2006 & 2009 & 2012 \\
\hline Administrative Einrichtungen & 24,1 & 13,7 & 10,3 \\
\hline Gemeinden & 25,1 & 6,8 & 5,9 \\
\hline Klöster & 39,4 & 11,9 & 9,0 \\
\hline Missionsstellen & 44,4 & 10,0 & 5,9 \\
\hline Bruderschaften & 43,4 & $-2,6$ & 8,1 \\
\hline Bildungseinrichtungen & 38,9 & 12,0 & 2,6 \\
\hline GESAMT & 25,5 & 7,0 & 6,0 \\
\hline Geistliche & 25,7 & 5,1 & 3,3 \\
\hline
\end{tabular}

Quellen: Ukrajina u cyfrach 2012, 18. Eigene Berechnungen (für die absoluten Zahlen siehe Tab. 5 im Anhang).

Als Zwischenfazit lassen sich an dieser Stelle zwei Thesen zur Entwicklung der Religiosität in der Ukraine formulieren: Erstens: Der Anstieg der Religiosität erfolgte in den letzten 25 Jahren schubartig. Auf den ersten Aufschwung der Religiosität, der mit 1987-1992 datiert werden kann (wir wollen ihn deshalb spätsowjetisch nennen), folgte eine Flaute von etwa fünf bis sieben Jahren. Zwar formierten bzw. entwickelten sich die ukrainischen Kirchen in dieser Zeit institutionell weiter, ${ }^{23}$ der Anteil der sich zur Religion bekennenden Ukrainer »stagnierte« jedoch auf dem Niveau von etwa 60\%. Am Ende der 1990er und insbesondere in der ersten Hälfte der 2000er Jahre gab es einen weiteren Aufschwung, der sich in der Verbreitung der Religiosität, im Anstieg der Anzahl kirchlicher Einrichtungen sowie in der Zunahme an Vertrauen zur

23 Vgl. Wilson: The Ukrainians, Chapter XIV; Boeckh: Orthodoxie und demokratische Transformation in der Ukraine. 
Gatskov / Gatskova, Zum Anstieg der Religiosität in der postsowjetischen Ukraine

Kirche (und dem Klerus) äußerte. Dieser postsowjetische Aufschwung dauerte ungefähr zehn Jahre, allerspätestens endete er im Jahr 2010. ${ }^{24}$ Zweitens: Der Anstieg der sich als religiös bzw. gläubig bezeichnenden Ukrainer belief sich auf schätzungsweise 15 bis $20 \%$. Obwohl die zahlenmäßige Zunahme der religiösen Menschen von einer Intensivierung des Glaubens begleitet war, liegt die Vermutung nahe, dass ein beträchtlicher Teil dieses postsowjetischen Aufschwungs, den die quantitativen Umfragen erfassen, auf einem nominellen Bekenntnis beruhte. ${ }^{25}$

Diese Annahme wollen wir prüfen, in dem wir die Struktur der Religiosität anhand einer Clusteranalyse ${ }^{26}$ der ISSP-Daten aus dem Jahr 2008 untersuchen. Glücklicherweise bildete in diesem Jahr, in dem der postsowjetische Aufschwung der Religiosität in der Ukraine seinen Höhepunkt erreichte, das Thema Religion den Schwerpunkt der Umfrage.

24 Unser Befund ist somit völlig konträr zu der Behauptung von Paul M. Zulehner, Miklós Tomka und Inna Naletova, die - interessanterweise ebenfalls unter Verweis auf die EVS/WVS-Daten - den Schluss ziehen, in der Ukraine hätte es in den 1990er Jahren einen "vorübergehenden Anstieg der orthodoxen Religiosität « gegeben, auf den eine Abnahme der Zugehörigkeit zur orthodoxen Kirche von 56 auf 41\% bzw. ein allgemeiner Rückgang der Religiosität gefolgt sei; Zulehner et al.: Religionen und Kirchen in Ost(Mittel)Europa, 145.

25 Den Ausdruck »nominell« übernehmen wir von Yelensky: Religiosity in Ukraine according to Sociological Surveys, 217-218.

26 Die Clusteranalyse ist eine statistische Methode, Objekte (Personen) nach ihrer Ähnlichkeit so zu gruppieren, dass die Gruppen einerseits möglichst homogen hinsichtlich bestimmter Merkmale sind und sich gleichzeitig möglichst stark voneinander unterscheiden. Unsere Cluster (Gruppen) wurden anhand des K-Means-Verfahrens gebildet.

DigiOst 3 | 166 
Gatskov / Gatskova, Zum Anstieg der Religiosität in der postsowjetischen Ukraine Typen der Religiosität in der Ukraine

Die Bildung von Gruppen (Cluster) erfolgte unter Heranziehung von vier Merkmalen: Glaube an Gott, subjektive Religiosität, Häufigkeit der Teilnahme an Gottesdiensten und Häufigkeit des Betens. Die Einteilung der Befragten in vier Gruppen stellte eine statistisch stabile Lösung dar, die vor den anderen möglichen Lösungen aufgrund der inhaltlichen Plausibilität bevorzugt wurde. Die vier Clusterzentren, die in Tab. 3 aufgeführt sind, bilden idealtypische Profile von vier Bevölkerungsgruppen.

Zur Gruppe A gehörten im Jahr 2008 13\% der ukrainischen Bevölkerung. Diese Menschen können als religiöse Kirchengänger bezeichnet werden, da sie nicht nur oft beten, sondern im Vergleich zu den anderen drei Gruppen deutlich öfter an Gottesdiensten teilnehmen: im Durchschnitt fast wöchentlich.

Gemäßigt Religiöse (Gruppe B) bilden mit 31,9\% die größte von allen vier Gruppen. Sie geben ihre Religiosität tendenziell auf der untersten von den ersten drei Stufen an (Stufe 4 bedeutet »teils ... teils« und Stufe 5 bereits "gemäßigt nicht religiös ${ }^{27}$ ), nehmen nur gelegentlich an den Gottesdiensten teil, beten jedoch relativ oft, und das ist auch das Merkmal, das sie hauptsächlich von der Gruppe $\mathrm{C}$ unterscheidet.

Gruppe C sind die sogenannten passiv Gläubigen (26,8\%), die sich dadurch auszeichnen, dass sie zwar an Gott glauben, sich selbst aber als wenig religiös bezeichnen. Sie beten etwa einmal im Monat und nehmen nur gelegentlich an

27 Die etwas unglücklich formulierte Abstufung ist wohl der Grund, warum sich die Cluster A, B und C so wenig im Merkmal »subjektive Religiosität« unterscheiden (siehe Tab. 3). Die Stufe 1, »außerordentlich religiös«, wirkte offenbar zu extrem, so dass sie nur von wenigen Menschen gewählt wurde. Die Stufe 3 hingegen, "gemäßigt religiös«, klang als subjektive Einschätzung eben angenehm gemäßigt, so dass die Befragten sie im Zweifelsfall der Stufe 2, »sehr religiös", anscheinend präferiert haben. Hieße die Stufe 3 »eher religiös«, so hätten womöglich mehr Menschen die Stufe 2 gewählt. 
Gatskov / Gatskova, Zum Anstieg der Religiosität in der postsowjetischen Ukraine

den Gottesdiensten teil. Passiv Gläubige scheinen mit der religiösen Lehre und der entsprechenden Kirche nur insofern in Verbindung zu stehen, als sie sich als einer bestimmten Religion bzw. Konfession zugehörig ausweisen würden und die sozial etablierten religiösen Feste wie etwa (bei Christen) Weihnachten und Ostern wahrnehmen, ihre Kinder taufen etc., darüber hinaus jedoch säkularisiert sind..$^{28}$ Der ukrainische Religionsforscher Viktor Yelensky weist in diesem Kontext auf den Umstand hin, dass Befragte nicht selten angeben, der Russischen Orthodoxen Kirche anzugehören, obwohl es in ihren Wohnorten diese Kirche nicht gibt. An die Stelle des kirchlichen Zugehörigkeitsgefühls tritt somit die nationale Selbstidentifikation. ${ }^{29}$ Auch den Unterschied zwischen den Ukrainischen Orthodoxen Kirchen des Moskauer und des Kiewer Patriarchats können, wie der ukrainische Publizist Mykola Rjabtschuk bemerkt, viele »nur auf dem Papier feststellen (beispielsweise bei Umfragen), nicht aber in der Praxis «. ${ }^{30}$ Dass das Moskauer Patriarchat das Kiewer nicht anerkennt und es als schismatisch bezeichnet, scheint den Großteil der passiv Gläubigen (Gruppe C), aber wohl auch der gemäßigt Religiösen (Gruppe B) nicht sonderlich zu irritieren. Rjabtschuk - im Einklang mit anderen ukrainischen Intellektuellen - bringt es mit der allgemeinen (man könnte sagen: ideologischen) Orientierungslosigkeit in Verbindung. ${ }^{31}$

28 In einem Gespräch mit dem Vorsteher der Armenischen Kirche in L'viv im Oktober 2013 beklagte dieser, dass die Mitglieder der Kirchengemeinschaft nicht selten hauptsächlich am Ritual interessiert seien und religiöse Gespräche mit der Bemerkung unterbrechen würden, er solle es bitte nicht so kompliziert machen. Es gibt Anzeichen dafür, dass das Ritual auch schon vor 1917 im kirchlichen Leben wichtiger als die Lehre gewesen war; vgl. Lane: Christian Religion in the Soviet Union, 31. Die Gruppe der passiv Gläubigen korrespondiert mit dem Typus der »Kulturreligiösen« bei Zulehner et al.: Religionen und Kirchen in Ost(Mittel) Europa, $74 \mathrm{ff}$.

29 Yelensky: Religiosity in Ukraine according to Sociological Surveys, 217-218, 222.

30 Rjabtschuk: Die reale und die imaginierte Ukraine, 32-33.

31 Rjabtschuk: Die reale und die imaginierte Ukraine, 32-33. 
Gatskov / Gatskova, Zum Anstieg der Religiosität in der postsowjetischen Ukraine

Tab. 3 Typen der Religiosität: Clusterzentren und Anzahl der eingruppierten Personen

\begin{tabular}{lllll} 
& $\begin{array}{l}\text { Cluster A } \\
\text { Religiöse } \\
\text { Kirchengänger }\end{array}$ & $\begin{array}{l}\text { Cluster B } \\
\text { Gemäßigt } \\
\text { Religiöse }\end{array}$ & $\begin{array}{l}\text { Cluster C } \\
\text { Passiv } \\
\text { Gläubige }\end{array}$ & $\begin{array}{l}\text { Cluster D } \\
\text { Areligiöse }\end{array}$ \\
\hline $\begin{array}{l}\text { Gläubig } \\
\text { Ja (2.97) }\end{array}$ & Ja (2.84) & Ja (2.63) & Ja \& nein (1.95) \\
\hline $\begin{array}{l}\text { Subjektive Reli- } \\
\text { giosität }\end{array}$ & Eher religiös & $\begin{array}{l}\text { Eher religiös } \\
(2.7)\end{array}$ & $\begin{array}{l}\text { Eher religiös } \\
(3.4)\end{array}$ & $\begin{array}{l}\text { Eher nicht religiös } \\
(4.8)\end{array}$ \\
\hline $\begin{array}{l}\text { Teilnahme an } \\
\text { Gottesdiensten }\end{array}$ & Fast wöchentlich & $\begin{array}{l}\text { Mehrmals } \\
\text { im Jahr }\end{array}$ & $\begin{array}{l}\text { Mehrmals im } \\
\text { Jahr }\end{array}$ & $\begin{array}{l}\text { Seltener als einmal } \\
\text { im Jahr }\end{array}$ \\
$\begin{array}{l}\text { Häufigkeit des } \\
\text { Betens }\end{array}$ & Einmal pro Tag & $\begin{array}{l}\text { Mehrmals } \\
\text { pro Woche }\end{array}$ & $\begin{array}{l}\text { Etwa einmal } \\
\text { im Monat }\end{array}$ & Nie \\
$\begin{array}{l}\text { Anzahl der Be- } \\
\text { fragten }\end{array}$ & 238 & 586 & 492 & 519 \\
\hline
\end{tabular}

Quelle: ISSP 2008, Ukraine, eigene Berechnungen. Glaube an Gott: 1 - »nicht-gläubig«, 2 - »schwankend « und 3 - "gläubig«. Subjektive Religiosität: 7-Items-Likert-Skala von 1 - »außerordentlich religiös« bis 7 - »außerordentlich nicht religiös« (vgl. hierzu Anmerkung 27 oben). Häufigkeit der Teilnahme an Gottesdiensten: 9 Antwortmöglichkeiten von »Nie« bis »Mehrmals pro Woche«. Häufigkeit des Betens: 11 Optionen von "Nie« bis "Mehrmals pro Tag»). 21 Fragebögen, die inkonsistente Antworten beinhalteten, wurden aus der Analyse ausgeschlossen.

Am Vorabend der Auflösung der Sowjetunion deckten die Umfragen auf, dass der größte Personenkreis (47\% der sich zum Glauben Bekennenden) »sich für gläubig hält, ohne daraus unbedingt irgendwelche Schlüsse zu ziehen, die für sie allgemeingültigen Charakter besitzen oder den eigenen Standpunkt festigen $«{ }^{32}$ Viele solcher nominell Gläubigen sind offenbar in der Gruppe D enthalten. Interessant ist, dass die statistische Analyse 28,3\% der Befragten unabhängig davon, ob sie an Gott zu glauben und nicht zu glauben (oder zu schwanken) angeben, zu einem Cluster zuordnet - und zwar weil sie eher

32 Lewada: Die Sowjetmenschen, 236.

DigiOst 3 | 169 
Gatskov / Gatskova, Zum Anstieg der Religiosität in der postsowjetischen Ukraine

nicht religiös sind, nie beten und so gut wie nie in die Kirche gehen. Das ist die Gruppe der Areligiösen. ${ }^{33}$

Abb. 4 stellt die Prozentanteile der vier Religiositätstypen in den vier Regionen der Ukraine dar. Es fällt auf, dass sich die Westukraine hierbei stark von den anderen drei Regionen unterscheidet. Die größte Gruppe in dieser Region sind mit 41,3\% die religiösen Kirchengänger, während der Anteil der Areligiösen äußerst gering ist - 3,4\%. Im Gegensatz dazu macht der Anteil der Areligiösen im Zentrum, Süden und Osten der Ukraine rund ein Drittel der Bevölkerung aus, zusammen mit der Gruppe der passiv Gläubigen fast zwei Drittel. Die religiösen Kirchengänger sind hingegen eine kleine Minderheit (von 7,3\% im Zentrum bis 3,6\% im Osten).

Abb. 4 Typen der Religiosität in den Regionen der Ukraine, Anteil in Prozent

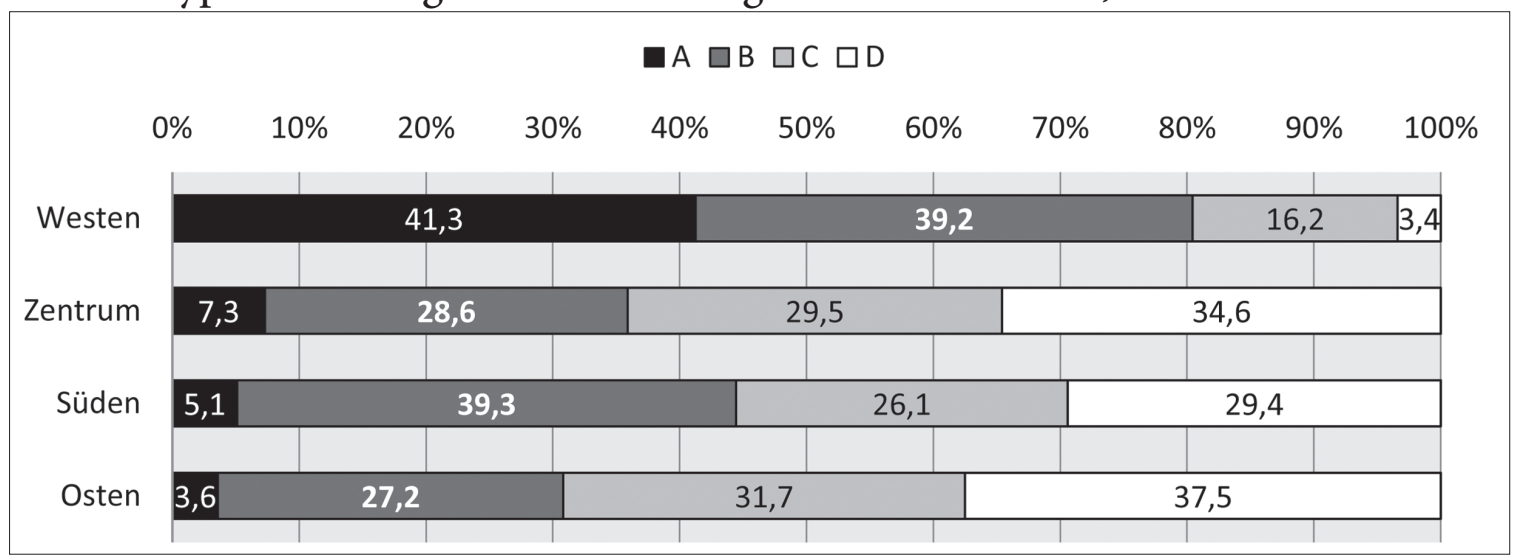

Quelle: ISSP 2008, Ukraine, eigene Berechnungen. Die regionale Einteilung der ukrainischen oblasti (darunter die Stadt Kiev und die Autonome Republik Krim) folgt der Gruppierung des Razumkov-Zentrums. ${ }^{34}$

33 Die Gläubigen unter diesen Areligiösen können mit Detlef Pollack als »Areligiöse in der Kirche« bezeichnet werden. Diese sind Personen, denen der Bezug zur Sinnfrage fehlt und die »orthodoxierte, ritualisierte routinisierte Vollzugsformen" von Religiosität aufweisen; vgl. Pollack: Säkularisierung, 51.

34 Westen: Volyns'ka, Zakarpats'ka, Ivano-Frankivs'ka, L'vivs'ka, Rivnens'ka, Ternopils'ka, Černivec'ka; Zentrum: Kyjiv, Kyjivs'ka, Vinnyc'ka, Žytomyrs'ka, Kirovohrads'ka, Poltavs'ka, Sums'ka, Chmelnic'ka, Čerkas'ka, Černihivs'ka; Süden: 
Gatskov / Gatskova, Zum Anstieg der Religiosität in der postsowjetischen Ukraine

Schlüsselt man nun auch den Anstieg der Religiosität in der Ukraine zwischen 1996 bis 2008 (vgl. Abb. 1) regional auf, so wird deutlich, dass er größtenteils auf die Zunahme des Bekenntnisses zur Religion in den zentralen, südlichen und östlichen Gebieten der Ukraine zurückgeht (Abb. 5). Die westlichen Gebiete, in denen die UGKK dominiert, waren bereits in den 1990er Jahren sehr religiös (was angesichts der im Punkt 2.1. beschriebenen Geschichte nicht überrascht); der Anstieg erfolgte von 88,8\% auf den sehr hohen Wert von 97,7\%. Umso stärker fiel der zahlenmäßige postsowjetische Aufschwung der Religiosität in den anderen Regionen aus. Gerade aber der ukrainische Osten, wo die beiden Gruppen der Areligiösen (Cluster D) und passiv Gläubigen (Cluster C) einen besonders großen Anteil haben, legte am meisten zu: von 43,1\% Religiösen im Jahr 1996 auf 75,1\% im Jahr 2008, was einen Anstieg von 32\% ergibt. Somit ist ein - indirekter - empirischer Beweis erbracht, dass der recht hohe Anteil der Religiösen am Höhepunkt des postsowjetischen Aufschwungs (zwischen 2007 und 2010) nicht unerheblich auf das nominelle Bekenntnis zurückgeht. Abb. 5 Steigende Anzahl religiöser Personen in den ukrainischen Regionen, Angaben in Prozent

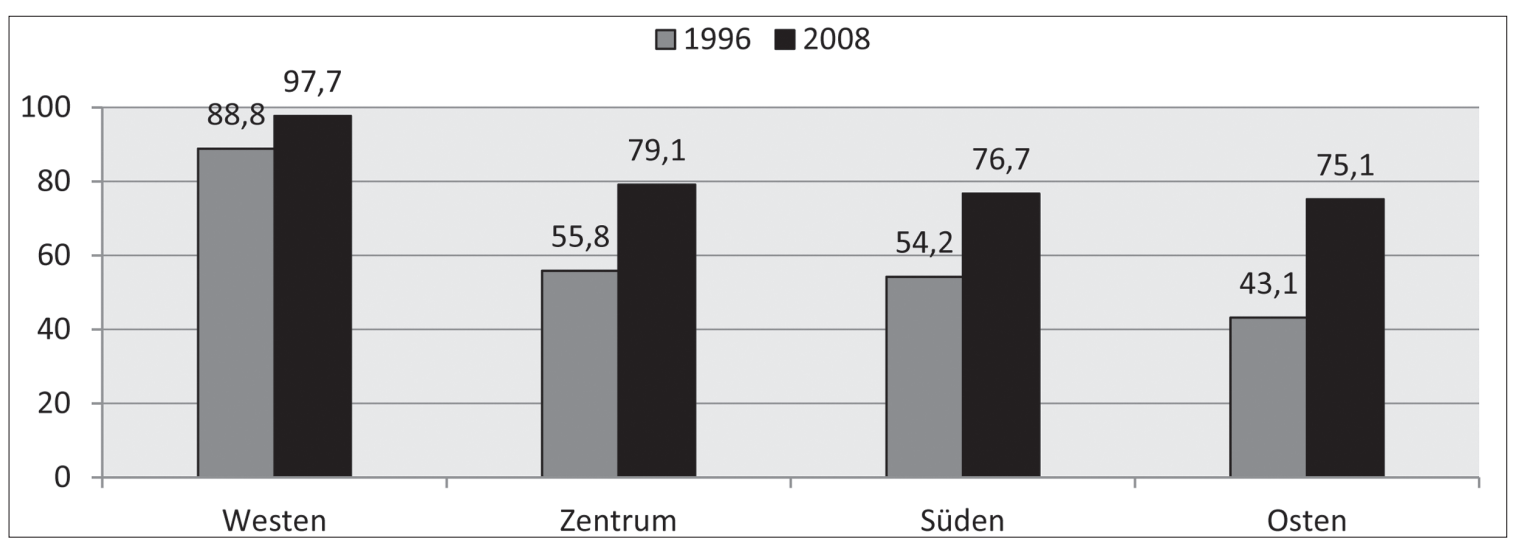

Quellen: WVS 1996; EVS 2008; Frage: »Einmal abgesehen davon, ob Sie in die Kirche gehen oder nicht - würden Sie sagen, Sie sind ... 1. ein religiöser Mensch, 2. kein religiöser Mensch, 3. ein überzeugter Atheist«. Eigene Darstellung.

Krym, Mykolajivs'ka, Odes'ka, Chersons'ka; Osten: Dnipropetrovs'ka, Donec'ka, Zaporiz'ka, Luhans'ka, Charkivs'ka oblast'. 
Gatskov / Gatskova, Zum Anstieg der Religiosität in der postsowjetischen Ukraine

\section{Theoretische Erklärungsansätze}

Drei theoretische Ansätze scheinen besonders geeignet, um die im Abschnitt 2 beschriebenen Entwicklungen zu erklären. In erster Linie muss man den postsowjetischen Aufschwung der Religiosität in den Kontext der institutionellen Transformationsdynamik stellen. Eine weitere Ursache der sprunghaften Zunahme von religiösen Menschen könnte darin gefunden werden, dass man die sowjetisch-kommunistische Ideologie als quasireligiösen Ersatz versteht, der nach seiner Zersetzung ein Vakuum hinterließ, das schnell (und hier besteht eine weitere metaphorische Parallele) von der Religion aufgefüllt werden konnte. Da der Anstieg der Religiosität nicht zuletzt auf die Verbreitung eines eher nominellen Bekenntnisses zur Religion bzw. zum Glauben zurückgeht, meinen wir drittens, dass in diesem Fall konjunkturelle Mechanismen am Werk sein können, die auf Nachahmung der sozialen Handlungen und anderen diskursiven Vorgängen beruhen. ${ }^{35}$

\section{Der institutionelle Erklärungsansatz}

Eine der ersten Phasen und Herausforderungen der postkommunistischen Transformation bestand im Aufbau einer neuen Ordnung politischer Institutionen. In der Ukraine erfolgte dieser Aufbau langsamer als beispielsweise in Russland - die erste Verfassung der unabhängigen Ukraine wurde erst 1996 verabschiedet. Da die Kirchen in der Umbruchsphase zu den Faktoren gehörten, die auf das Ende des kommunistischen Regimes hinwirkten, nicht zuletzt weil »viele ukrainische Dissidenten zu kommunistischer Zeit kirchlich

35 Die Faktoren der religiösen Sozialisation (vor allem für die Westukraine relevant), der religiösen Pluralität sowie soziodemografische Faktoren bleiben hier aus Platzgründen ausgeklammert.

DigiOst 3 | 172 
Gatskov / Gatskova, Zum Anstieg der Religiosität in der postsowjetischen Ukraine

gebunden oder selbst Geistliche « waren, ${ }^{36}$ war entsprechend das Vertrauen in die Kirche relativ hoch. Außerdem konnte die Religion während der tiefen Krise von nahezu allen Gesellschaftsbereichen als eine neue bzw. altbewährte soziokulturelle Stütze dienen. Nicht nur die Intelligenzija, sondern auch Teile der Führungsschicht erwarteten, dass Religion bzw. die Kirchen helfen würden, soziale Werte zu erneuern. ${ }^{37}$

Abb. 6 Institutionelles Vertrauen 1992-2012, Anteil in Prozent der Gesamtbevölkerung

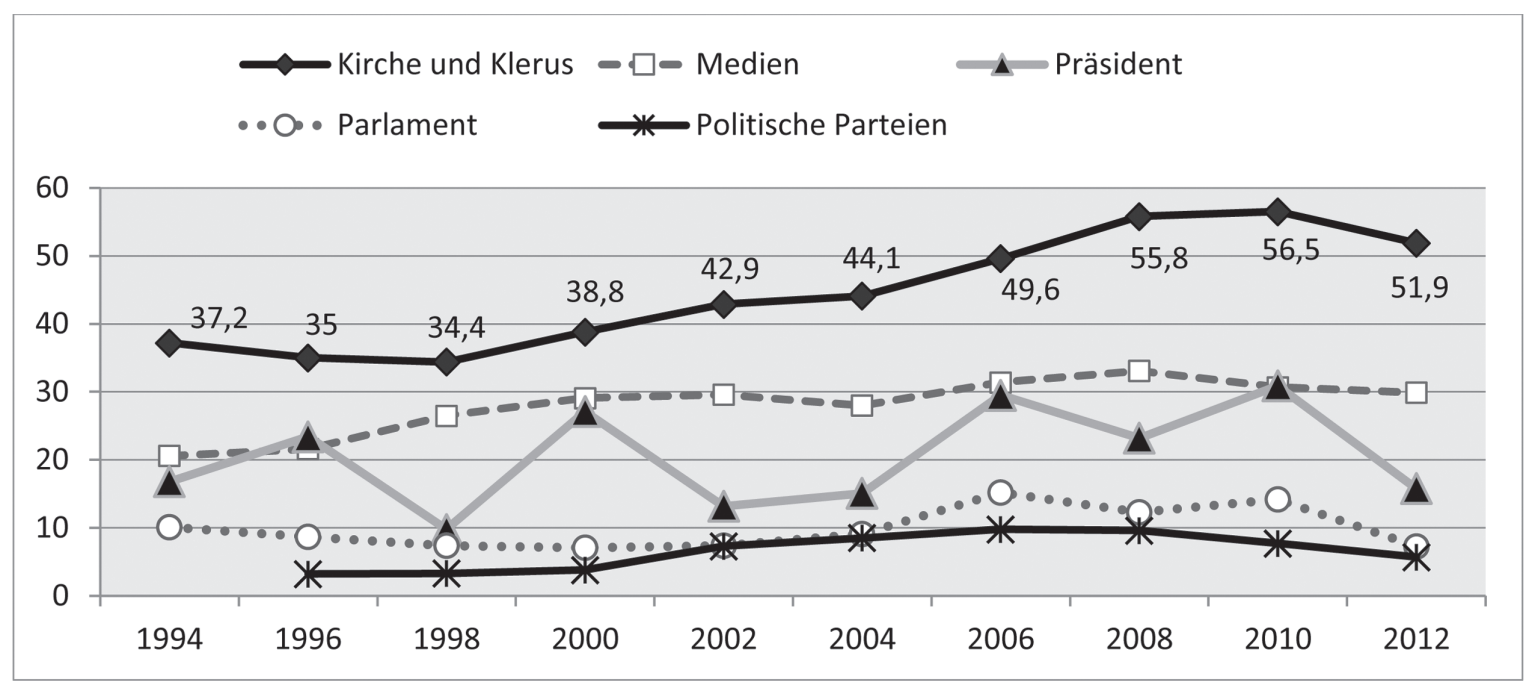

Quellen: Monitoring IS NANU; Frage: »Vertrauen Sie... [Institution]? 1. Nein, gar nicht, 2. Eher nicht, 3. Schwer zu sagen, ob ich vertraue oder nicht, 4 . Eher ja, 5. Ja, voll«; die Kurven geben den Anteil jener wider, welche die Optionen 4 und 5 wählten. Eigene Berechnungen.

Der Verlauf der Kurven auf der Abb. 6 zeigt, dass das Vertrauen zur Kirche stets höher bis viel höher als zu den anderen Institutionen ausfiel, und in den 2000er Jahren als einziges deutlich anstieg. Die Daten ergeben außerdem, dass

36 Boeckh: Orthodoxie und demokratische Transformation in der Ukraine, 118.

37 Yelensky: Religiosity in Ukraine according to Sociological Surveys, 218. 
Gatskov / Gatskova, Zum Anstieg der Religiosität in der postsowjetischen Ukraine

auch wenig oder nicht religiöse Menschen der Kirche meistens mehr Vertrauen schenkten als politischen Institutionen.

Man muss hierbei berücksichtigen, dass die Kirchen sich in den 1990er Jahren erst re-institutionalisieren mussten, bevor sie sich als korporative Akteure ${ }^{38}$ aktiv in das soziale Leben einbringen konnten. Die oben beschriebene intensive Entwicklung kirchlicher Einrichtungen (Tab. 2) war nicht nur ein Ergebnis des spätsowjetischen religiösen Aufschwungs sowie allgemeiner Liberalisierung und Demokratisierung der unabhängigen Ukraine, sondern ihrerseits ein Antriebsfaktor bzw. die Voraussetzung des nachfolgenden postsowjetischen Aufschwungs der Religiosität. Ein vergleichsweise einfacher Mechanismus, der hier greift, ist die erhöhte Häufigkeit des Kontakts der Bevölkerung mit Vertretern des Klerus sowie mit sakralen Objekten (Ikonen, Kruzifixen, heiligen Wasserquellen etc.) und religiösen Bauten - mittlerweile sind Kirchen und Kapellen sowohl in den ukrainischen Städten als auch in den ländlichen Gebieten weit verbreitet bzw. unübersehbar. Die neue religiöse Normalität wurde somit zur Plattform für die weitere Verbreitung von Religiosität.

In der Ukraine, wo das konfessionelle und denominationale Spektrum sehr plural ist, nahmen und nehmen die Kirchen ferner aktiv am politischen Prozess teil, ${ }^{39}$ was zusätzliche Präsenz im öffentlichen Raum mit sich bringt. Die aktive humanitäre Beteiligung der Kirchen am revolutionären »EuroMajdan« 2013/2014 lässt vermuten, dass das Vertrauen zu den Kirchen kurzfristig noch mehr steigen und die mit der Kirche verbundenen Aspekte der Religiosität gestärkt werden. Gleichwohl fiel den Beobachtern auf, dass den Gottesdiensten und Kundgebungen auf dem »Euro-Majdan« vereinfachenden

38 Im Sinne von James S. Coleman: Macht und Gesellschaftsstruktur.

39 Siehe u. a. Mitrokhin: Orthodoxy in Ukrainian Political Life 2004-2009; Boeckh: Orthodoxie und demokratische Transformation in der Ukraine. 
Gatskov / Gatskova, Zum Anstieg der Religiosität in der postsowjetischen Ukraine

Elementen, die im Einklang mit einer »tradierten Volksreligiosität « stünden, große Bedeutung zukam. ${ }^{40}$

\section{Der »ideologische« Erklärungsansatz}

Versteht man allgemein die Religion als ein Sinnsystem mit einer transzendenten Dimension, so lässt sich das sowjetkommunistische Projekt als ein quasireligiöses Sinnsystem deuten. Wenn man im nächsten Schritt, Max Weber folgend, die religiösen Einstellungen und Handlungen der Menschen als zentral für die (Religions-)Soziologie betrachtet, ${ }^{41}$ dann wird klar, warum es gerechtfertigt und sinnvoll ist, religiöse Elemente in der bolschewistischen Ideologie und Praxis zu suchen: Es »[...] erweist sich, dass der Kommunismus der religiösen Erfahrung nicht trotz, sondern gerade aufgrund der Radikalität seiner atheistischen Ansprüche zutiefst verwandt ist. Atheismus, der Wissenschaftlichkeit für sich reklamiert, nähert sich einer religiösen Ekstatik an, die ohne Jenseits auskommt, aber eine nicht weniger tragfähige Grundlage in der Transzendenz des Immanenten erlangt hat. ${ }^{42}$

Ob man den Sowjetkommunismus dabei als eine »politische«, »säkulare«, "nicht-theistische « oder eine "Zivilreligion« etikettieren soll, ist eine essentialistische Diskussion und als solche für die Soziologie nebensächlich ${ }^{43}$ mit den

40 Zimmermann und Melnikow: Gott ist mit uns!«, 272.

41 Vgl. Pickel: Religionssoziologie, 18.

42 Ryklin: Kommunismus als Religion, 48.

43 Karl Popper mahnt dazu, nicht um Wörter zu streiten, sondern nach Erklärungen zu suchen: »Begriffe oder Worte als solche können weder wahr noch falsch sein. Sie dienen nur der beschreibenden und begründenden menschlichen Sprache. Es sollte nicht unser Ziel sein, Bedeutungen zu analysieren, sondern nach interessanten und bedeutsamen Wahrheiten zu suchen; das heißt, nach wahren Theorien." (Popper: Auf der Suche, 200; Hervorhebung im Orig.) Armin Pfahl-Traughber weist zwar zurecht darauf hin, dass, wenn man das sozialwissenschaftliche Religionskonzept 
Gatskov / Gatskova, Zum Anstieg der Religiosität in der postsowjetischen Ukraine

Worten von Thomas Luckmann:»Unsere Untersuchung sollte zur Entdeckung der gemeinsamen Elemente oder, wie wir sagen können, der den historischen Artikulationen der Religion zugrundeliegenden religiösen Funktionen und der strukturellen Determinanten der wesentlichsten gesellschaftlichen Formen der Religion führen. $\aleph^{44}$ Obwohl man gegenwärtig nicht von einem breiten sozialwissenschaftlichen Konsens bezüglich der Quasireligiosität der sowjetkommunistischen Ideologie sprechen kann, begegnet man dieser Position in der sozialwissenschaftlichen Literatur durchaus häufig; eine Reihe von Arbeiten beschäftigt sich ausführlich mit diesem Thema. ${ }^{45}$

Auf Parallelen zwischen der Entstehung des Marxismus und des Christentums wies unter anderem Talcott Parsons hin. ${ }^{46}$ Marx' sozialhistorische Teleologie wurde von den westlichen Intellektuellen und Wissenschaftlern bald als eine Heilserwartung enttarnt; Michail Ryklin weist diesbezüglich treffend darauf hin, dass »die Kommunisten einen blinden Glauben haben mussten, um wenigstens irgendwelche Anzeichen wahrnehmen zu können, dass sie sich ihm [dem Ziel der Revolution] näherten oder sich wenigstens auf dem richtigen Weg

allein auf die funktionelle Dimension abstellt, in diesem Fall die inhaltliche (essenzielle) Besonderheit der Religion im herkömmlichen Sinne verloren geht und der Religionsbegriff somit verwischt wird (Pfahl-Traughber: "Politische Religion« und »Zivilreligion«, 236; zur Unterscheidung zwischen essenzieller (substanzieller) und funktioneller Dimension siehe Pickel: Religionssoziologie, 16 ff.). Aus soziologischer bzw. sozial-psychologischer Perspektive ist die funktionelle Dimension für unsere Fragestellung jedoch die entscheidende, wenn nicht sogar die einzig relevante.

44 Luckmann: Die unsichtbare Religion, 118; zur Kritik seines Ansatzes siehe Pickel: Religionssoziologie, $188 \mathrm{ff}$. und Pollack: Säkularisierung, $6 \mathrm{ff}$.

45 Für einen Überblick vgl. Maier: Totalitarismus und Politische Religionen.

46 Parsons: Religion in Postindustrial America, 208-209. Nicht zufällig zitiert auch ein anderer moderner Klassiker der Soziologie den Religionssoziologen David Martin: „Wenn Katholiken aufhören, konservativ zu sein, werden sie leicht Marxisten« (Berger: Auf den Spuren der Engel, 30). 
Gatskov / Gatskova, Zum Anstieg der Religiosität in der postsowjetischen Ukraine

befanden «. ${ }^{47}$ Ähnlich äußert sich der Klassiker der Totalitarismus-Forschung Carl Friedrich: »Die totalitären Ideologien [...] setzen den Glauben an die Stelle der Vernunft und magische Beschwörung tritt an die Stelle des gesunden Menschenverstandes. $\aleph^{48}$

Die Selbstsakralisierung des totalitären Herrschaftsapparats schloss neben der Ersetzung der christlichen Dreifaltigkeit durch Marx, Engels und Lenin eine ganze Hierarchie von Sakralinstanzen ein, die ihn durch neu erfundene Rituale legitimierten. ${ }^{49}$ "Sie bedienen sich dabei selektiv der sakralen Traditionen der christlichen Religionen, deren Mythen, Kulte, Riten und Kosmologien sie in ihr eigenes Repertoire der innerweltlichen Erlösungskulte zu integrieren versuchen. $\aleph^{50}$ Eine ganze Riege von Parteifunktionären war in der Sowjetunion »[...] amtsmäßig damit befasst [...], die korrekte Auslegung des Dogmenstandes zu überwachen, die Reglementierung der Lehrautorität auf den Gebieten der Unterweisung und Mission voranzutreiben und die Sakraltexte so zu reformulieren, dass sie auch der Volksreligiosität zugänglich wurden « ${ }^{51}$ Die »immanente Transzendenz« trat für die breite Masse der Sowjetmenschen neben der Verheißung eines baldigen kommunistischen Paradieses auf Erden auch durch die Hölle der Stalinschen Arbeitslager in Erscheinung.

Ohne hier die Parallelen zwischen der sowjetisch-kommunistischen Ideologie und den herkömmlichen Religionen weiter zu verfolgen, kann man

47 Ryklin: Kommunismus als Religion, 47-48.

48 Friedrich: Totalitäre Diktatur, 22. Analog: »An die Stelle einer Orientierung in der Welt tritt der Zwang, mit dem man sich selbst zwingt, von dem reißenden Strom übermenschlicher, natürlicher oder geschichtlicher Kräfte mitgerissen zu werden.« (Arendt: Elemente und Ursprünge, 966).

49 Fulcher / Scott: Sociology, 408-409; ausführliche Beispiele bringt Ryklin: Kommunismus als Religion; zu den Ritualen im Kommunismus vgl. auch Zulehner et al.: Religionen und Kirchen in Ost(Mittel)Europa, 34.

50 Riegel: Der Marxismus-Leninismus als "politische Religion «, 17.

51 Riegel: Der Marxismus-Leninismus als "politische Religion«, 38; Hervorhebung nicht im Original. 
Gatskov / Gatskova, Zum Anstieg der Religiosität in der postsowjetischen Ukraine

konstatieren, dass der homo sovieticus durch und durch ein »homo religiosus« war. Der spätsowjetische Aufschwung der Religiosität kann somit als eine weltanschauliche Kompensation der ideologischen Krise verstanden werden, von der die sowjetische Gesellschaft in den Jahren der Perestrojka immer mehr erfasst wurde. Genauso logisch erscheint in diesem Zusammenhang die Flaute in der Entwicklung der Religiosität in der ersten Hälfte der 1990er Jahre, als die allgemeine Aufbruchsstimmung und liberal-demokratische Begeisterung die sich weiter vertiefende (vor allem ökonomische) Krise noch zu überdecken vermochten. Der postsowjetische religiöse Aufschwung traf dann mit der endgültigen »Transformationsernüchterung « zusammen: Ende der 1990er Jahre gab es keine säkularen ideologischen Konstrukte mehr, die den postsowjetischen Menschen helfen konnten, den Verlust ontologischer Sicherheit (Anthony Giddens) zu bewältigen. Die herkömmliche Religiosität wurde in ihrer Funktion der Kontingenzbewältigung ${ }^{52}$ alternativlos.

\section{Der sozialpsychologische Erklärungsansatz}

Während für die Untersuchung von Mechanismen der weltanschaulichen Kompensation hauptsächlich individualpsychologische Theorien herangezogen werden sollen, setzt die soziologische Theoriebildung bei der Erkenntnis an, dass die handelnden Menschen ihre Wahrnehmungen und Einstellungen mit jenen ihrer Mitmenschen dauernd abgleichen. ${ }^{53}$ Es ist gut belegt, dass von der sozialen Umgebung ein Konformitätsdruck ausgeht, der insbesondere bei allem, was mit der Gruppenidentität zu tun hat, stark suggestiv wirkt. Durch

52 Vgl. Pickel: Religionssoziologie, 21-22; Pollack: Säkularisierung, 42 ff. sowie Kap. zu theoretischen Erklärungsansätzen.

53 Klassisch hierzu die Soziologen Erving Goffmann, Herbert Blumer, Peter Berger und Thomas Luckmann. 
Gatskov / Gatskova, Zum Anstieg der Religiosität in der postsowjetischen Ukraine

seine Identifikation mit einem kollektiven »Wir« empfindet der Mensch nicht nur soziale Sicherheit, sondern kann ungeahnte Stärke und andere intensive Gefühle erleben, was nicht zuletzt Erfahrungen bei religiösen Massenveranstaltungen bestätigen. ${ }^{54}$ Insbesondere Einstimmigkeit in der Gruppe übt einen starken Konformitätsdruck aus, worin Psychologen »gute Gründe « für totalitäre Regime sehen, Abweichler jeglicher Art zu unterdrücken. ${ }^{55}$

Da der religiöse (bzw. vor allem denominationale) Pluralismus in der Ukraine, wie oben ausgeführt, von der breiten Bevölkerung nur eingeschränkt wahrgenommen wird, dürfte auch seine antikonformistische Wirkung ziemlich bescheiden ausfallen. ${ }^{56}$ Das posttotalitäre Erbe des homo sovieticus hingegen könnte über verschiedene Mechanismen, darunter der Sozialisation, die Neigung zur Konformität allgemein verstärken.

Zum großen Teil kann der Mechanismus der Verbreitung von äußerlicher bzw. nomineller Religiosität mit Hilfe von Schwellenwertmodellen der Diffusion von Kollektivverhalten erfasst werden. ${ }^{57}$ Diese Modelle beschreiben, wie Menschen ihre Entscheidungen anhand der Informationen aus den sozialen Netzwerken treffen. Demnach steht die Übernahme einer Eigenschaft - einer Einstellung, Wertorientierung oder eines Handlungsmusters - im direkten Zusammenhang mit der Anzahl der Träger dieser Eigenschaft, mit denen das handelnde Subjekt in Berührung kommt. In unserem Fall bedeutet das, dass die Wahrscheinlichkeit, dass jemand z. B. seine Kinder taufen, eine Ikone in seinem

54 Hemminger: Grundwissen Religionspsychologie, 197.

55 Gleitman et al.: Psychology, 510. Wie im Kap. zu theoretischen Erklärungsansätzen angedeutet, fordern p politische Religionen [...] eine exklusive Identifikation mit ihren Erlösungsvisionen« (Riegel: Der Marxismus-Leninismus als "politische Religion «, 16).

56 Dennoch stimmen wir der Annahme José Casanovas, dass sich der religiöse Pluralismus in der Ukraine positiv auf die Entwicklung der Demokratie und Zivilgesellschaft auswirke, im Prinzip zu (Casanova: Between Nation and Civil Society).

57 Vgl. Granovetter/Soong: Threshold Models; Hedström: Contagious Collectivities. 
Gatskov / Gatskova, Zum Anstieg der Religiosität in der postsowjetischen Ukraine

Auto anbringen oder gefärbte Ostereier in der Kirche weihen wird, umso größer ist, je mehr Freunde und Bekannte dies tun. Manchen Menschen genügen dabei ein paar Vorbilder, um ihr Verhalten zu ändern, während bei den anderen die Nachahmungsschwelle viel höher ist. Wenn aber in der Gesellschaft eine kritische Masse an Menschen entsteht, die sich in einer bestimmten Weise verhalten, avancieren entsprechende Handlungsmuster zu allgemeingültigen sozialen Normen: Die Subjekte bilden wechselseitige Erwartungen heraus, über die nicht mehr reflektiert werden muss (und gegebenenfalls auch nicht mehr darf). ${ }^{58}$

Während die Sowjetbürger ihre Religiosität eher zu verschweigen geneigt bzw. gezwungen waren, war es nach dem spätsowjetischen religiösen Aufschwung bereits üblich, zu religiösen Festen bestimmte ritualisierte Grußformeln auszusprechen sowie gemeinsam manche religiösen Rituale zu begehen: Wasser am Dreikönigstag aus einer Quelle zu holen, Weiden am »Weidensonntag“ (Palmsonntag) nach Hause zu bringen oder eine Ostermesse zu besuchen. Der postsowjetische Aufschwung lässt sich somit unter anderem durch das Erreichen einer kritischen Masse an ihr religiöses Bekenntnis sichtbar machenden Menschen erklären. Eine geläufige Formel umformulierend kann man hier von believing by doing sprechen.

Jedoch zieht die Teilnahme an Ritualen und Ähnlichem nicht immer eine Vertiefung der individuellen Religiosität oder etwa ein Überdenken des alltäglichen Handelns aus der Sicht der Werte der jeweiligen religiösen Lehre nach sich. Hieraus kann man wiederum eine (Teil-)Erklärung ableiten, warum nach einem Aufschwung wieder eine (konjunkturelle) Flaute kommen kann: Rücken einige nominell Gläubige vom believing by doing wieder ab, so wirkt der Diffusionsmechanismus in die umgekehrte Richtung.

58 Klassisch hierzu Peter Berger und Thomas Luckmann.

DigiOst 3 | 180 
Gatskov / Gatskova, Zum Anstieg der Religiosität in der postsowjetischen Ukraine

\section{Zusammenfassung und abschließende Bemerkungen}

Die Ausgangsfrage dieser Untersuchung, ob es nach dem Zusammenbruch der Sowjetunion wirklich zu einem starken Aufschwung von Religiosität und Kirchlichkeit in der Ukraine kam, kann eindeutig positiv beantwortet werden. Unsere empirische Analyse zeigt, dass sich dieser Aufschwung in zwei Schüben vollzog: Der spätsowjetische Aufschwung lässt sich auf die Jahre 1987-1992 und der postsowjetische Aufschwung auf die Jahre 1999-2009 datieren. Auf dem Höhepunkt des Letzteren, im Jahr 2008, erreichte der Anteil der sich zur Religion bekennenden Ukrainer rund 80\%. Diese Zahl erscheint auf den ersten Blick sehr hoch. Sie relativiert sich aber zum einen dadurch, dass sie infolge einer entsprechenden Frageformulierung einen Teil der Schwankenden absorbiert; zum anderen geht sie, wie wir gezeigt haben, zu einem großen Teil auf den Zuwachs von nomineller Bekenntnis zur Religion in der Bevölkerung des ukrainischen Zentrums, Ostens und Südens zurück. Der Westen der Ukraine stellt einen Sonderfall dar: Dort sind - und waren schon in den 1990er Jahren - fast alle Menschen sehr bis gemäßigt religiös.

Die viel bemühten soziologischen Konzepte der Sozialisation (verstanden als allgemeine soziohistorische Prägung, etwa durch »den Sozialismus«), Individualisierung und Modernisierung lassen sich somit als Erklärungsfaktoren der Desäkularisierung der postsowjetischen ukrainischen Gesellschaft nur begrenzt heranziehen. Vor allem die Modernisierungsthese scheint eher für oberflächliche Makrovergleiche zu taugen, die in der gegenwärtigen Religionssoziologie ziemlich beliebt sind, ${ }^{59}$ sowie eine erneute Bestätigung der recht allgemeinen Korrelation zwischen dem wirtschaftlichen Entwicklungsniveau bzw. Transformationsfortschritt und religiösen Orientierungen. Ansonsten »folgen die religiösen Entwicklungen in den einzelnen osteuropäischen Län-

59 Vgl. z. B. Norris / Inglehart: Sacred and Secular, Kap. 5; Pollack: Das Verhältnis von Religion und Politik in den postkommunistischen Staaten. 
Gatskov / Gatskova, Zum Anstieg der Religiosität in der postsowjetischen Ukraine

dern äußerst unterschiedlichen Mustern ${ }^{60}$ - was Sozialwissenschaftler, welche die entsprechenden Länder nicht allein aus statistischen Datensätzen kennen und die nicht bloß nach statistischen Mustern, sondern nach mechanistischen Erklärungen suchen, nicht überraschen dürfte.${ }^{61}$ Nur wenn man sich die konkreten Mechanismen anschaut, wird z. B. klar, warum das, was für mehrere Länder Europas gilt, nämlich dass dort die Erosion des Glaubens bei den mehr konkreten, anschaulichen und bildhaften Formen einsetze und sich nach und nach auf die abstrakten und schwerer fassbaren Glaubensformen ausweite, ${ }^{62}$ in der Ukraine genau umgekehrt funktioniert: Die Zunahme der Religiosität und des Glaubens scheint bei äußerlichen Formen anzusetzen, sich durch Nachahmung auszuweiten und zu sozialer Norm zu verfestigen, um sich anschließend zu vertiefen. Dies lässt sich mit dem institutionellen Vertrauen in die Kirchen, mit dem postsowjetischen »Ideologievakuum» und Mechanismen kultureller Diffusion von Wertorientierungen erklären.

Die weitere Entwicklung der Religiosität in der Ukraine wird sich wahrscheinlich vor allem in ihrer Vertiefung äußern, wobei der hohe quantitative Anteil der Religiösen (je nach Frageformulierung zwischen 70 und 80\%) in der ukrainischen Bevölkerung höchstwahrscheinlich erhalten bleibt. Je nachdem, wie sich die orthodoxen Kirchen in den nächsten Jahren in der Gesellschaft positionieren - und nach dem jüngsten Konflikt mit Russland nicht zuletzt zur Moskauer Orthodoxie -, kann es zu Verschiebungen von Sympathien der

60 Müller et al.: Wandel religiös-kirchlicher Orientierungsmuster, 120.

61 Beim näheren Hinsehen wird schnell klar, dass Vergleiche zwischen beispielsweise Kroatien, der DDR, Rumänien und Russland empirisch nicht sinnvoll sind und inhaltlich recht schwache Ergebnisse erbringen - die gemeinsame sowjetsozialistische Vergangenheit ist nicht ausreichend, um in Bezug auf alle möglichen Fragestellungen die Länder des östlichen Europas über einen Kamm zu scheren; vgl. hierzu Gatskov: Über die Revolution, 21ff. Zum Unterschied zwischen den mechanistischen und statistischen Erklärungen siehe Hedström: Anatomie des Sozialen, $36 \mathrm{ff}$.

62 Müller et al.: Wandel religiös-kirchlicher Orientierungsmuster, 103. 
Gatskov / Gatskova, Zum Anstieg der Religiosität in der postsowjetischen Ukraine

Gläubigen zwischen ihnen kommen, aber auch zur erhöhten Zuwendung zu anderen christlichen Denominationen.

\section{Anhang}

Abb. 7 »Bedeutung von Gott in Ihrem Leben«, Anteil in Prozent der Gesamtbevölkerung

\begin{tabular}{|c|c|c|c|c|c|c|c|c|c|c|}
\hline \multirow[b]{2}{*}{$0 \%$} & \multirow[b]{2}{*}{$10 \%$} & \multicolumn{2}{|c|}{ Wichtig (7-10 } & \multicolumn{2}{|c|}{ 口"Mittel" (5-6 } & \multicolumn{3}{|c|}{$\square$ Nicht wichtig (1-4) } & \multirow[b]{2}{*}{$90 \%$} & \multirow[b]{2}{*}{$100 \%$} \\
\hline & & $20 \%$ & $30 \%$ & $40 \%$ & $50 \%$ & $60 \%$ & $70 \%$ & & & \\
\hline 1996 & \multicolumn{3}{|c|}{45,6} & & \multicolumn{2}{|c|}{21,9} & \multicolumn{3}{|c|}{32,4} & \\
\hline 1999 & \multicolumn{3}{|c|}{48,9} & & \multicolumn{2}{|r|}{21,6} & \multicolumn{3}{|c|}{29,5} & \\
\hline 2006 & \multicolumn{4}{|c|}{66,6} & & & \multicolumn{2}{|c|}{16,8} & \multicolumn{2}{|l|}{16,6} \\
\hline 2008 & \multicolumn{4}{|c|}{66,5} & & & \multicolumn{2}{|c|}{16,7} & 16,7 & \\
\hline
\end{tabular}

Quellen: WVS 1996, 2006; EVS 1999, 2008; Frage: "Wie wichtig ist Gott in Ihrem Leben? 1. Überhaupt nicht wichtig ... 10. Sehr wichtig«. Eigene Darstellung.

Tab. 4 Vertrauen zur Kirche und zum Klerus, Angaben in Prozent

\begin{tabular}{lrrrrrrrrrr} 
& 1994 & 1996 & 1998 & 2000 & 2002 & 2004 & 2006 & 2008 & 2010 & 2012 \\
\hline Misstrauen & 28.5 & 31.7 & 32.5 & 30 & 23.9 & 23.1 & 19.8 & 17.8 & 16.7 & 21.8 \\
\hline Schwer zu sagen & 34.3 & 33.3 & 33.1 & 31.2 & 33.2 & 32.8 & 30.7 & 26.4 & 26.8 & 26.2 \\
\hline Vertrauen & 37.2 & 35 & 34.4 & 38.8 & 42.9 & 44.1 & 49.6 & 55.8 & 56.5 & 51.9 \\
\hline
\end{tabular}

Quellen: Monitoring IS NANU; Frage: »Vertrauen Sie der Kirche und dem Klerus? 1 . Nein, gar nicht, 2. Eher nicht, 3. Schwer zu sagen, ob ja oder nein, 4 . Eher ja, 5. Ja, voll.« 
Gatskov / Gatskova, Zum Anstieg der Religiosität in der postsowjetischen Ukraine

Tab. 5 Anzahl der kirchlichen Institutionen

\begin{tabular}{lrrrrrrr} 
Einrichtungen/Organisationen & 2001 & 2006 & 2009 & 2010 & 2011 & 2012 & 2013 \\
\hline Administrative Einrichtungen & 241 & 299 & 340 & 350 & 362 & 375 & 382 \\
\hline Gemeinden & 23400 & 29262 & 31257 & 31940 & 32521 & 33099 & 33581 \\
\hline Klöster & 277 & 386 & 432 & 439 & 459 & 471 & 500 \\
\hline Missionsstellen & 214 & 309 & 340 & 347 & 357 & 360 & 370 \\
\hline Bruderschaften & 53 & 76 & 74 & 76 & 78 & 80 & 81 \\
\hline Bildungseinrichtungen & 126 & 175 & 196 & 199 & 200 & 201 & 202 \\
\hline GESAMT & 24311 & 30507 & 32639 & 33351 & 33977 & 34586 & 35116 \\
\hline Geistliche & 22626 & 28431 & 29892 & 30516 & 30199 & 30880 & 31313 \\
\hline
\end{tabular}

Quellen: Ukrajina u cyfrach, 2012: 18.

\section{Literatur}

Arendt, Hannah: Elemente und Ursprünge totaler Herrschaft. 11. Aufl. München 2006.

Berger, Peter L.: Auf den Spuren der Engel. Frankfurt a. M. 1970.

Boeckh, Katrin: Orthodoxie und demokratische Transformation in der Ukraine. In: Leininger, Julia (Hg.): Religiöse Akteure in Demokratisierungsprozessen. Wiesbaden 2013, 105-147.

Boeckh, Katrin / Ekkehard Völkl: Ukraine. Von der Roten zur Orangenen Revolution. Regensburg 2007.

Casanova, José: Between Nation and Civil Society: Ethnolinguistic and Religious Pluralism in Independent Ukraine. In: Hefner, Robert W. (Hg.): Democratic Civility. The History and Cross-Cultural Possibility of a Modern Political Ideal. New Brunswick 1998, 203-228.

Coleman, James: Macht und Gesellschaftsstruktur. Tübingen 1979.

Friedrich, Carl J. (unter Mitarbeit von Zbigniew K. Brzezinski): Totalitäre Diktatur. Stuttgart 1957. 
Gatskov / Gatskova, Zum Anstieg der Religiosität in der postsowjetischen Ukraine

Fulcher, James / John Scott: Sociology. 3rd ed. New York 2007.

Gatskov, Maxim: Über die Revolution, die es nicht gab. In: Gatskov, Maxim / Wagensohn, Tanja (Hgg.): Revolution!? Farbe, Erinnerung, Theorie nach 1989. Berlin 2009, 15-29.

Gleitman, Henry / Fridlund, Alan J. / Reisberg, Daniel: Psychology. 5th ed. New York 1999.

Granovetter, Mark / Soong, Roland: Threshold Models of Diffusion and Collective Behavior. In: Journal of Mathematical Sociology 9 (1983), 165-179. Hedström, Peter: Contagious Collectivities: On the Spatial Diffusion of Swedish Trade Unions, 1890-1940, In: American Journal of Sociology 99/5 (1994), 1157-1179.

Hedström, Peter: Anatomie des Sozialen - Prinzipien der analytischen Soziologie. Wiesbaden 2008.

Hemminger, Hansjörg: Grundwissen Religionspsychologie. Freiburg 2003. ISSP - International Social Survey Programme 2008: Religion III. GESIS Data Archive, Cologne. ZA4950 Data file Version 2.2.0, doi:10.4232/1.11334.

Lane, Christel: Christian Religion in the Soviet Union. London 1978.

Lewada, Juri: Die Sowjetmenschen 1989-1991. Soziogramm eines Zerfalls. München 1993.

Luckmann, Thomas: Die unsichtbare Religion. Frankfurt a. M. 1991.

Maier, Hans (Hg.): Totalitarismus und Politische Religionen. 3 Bände. Paderborn 1996, 1997, 2003.

Mitrokhin, Nikolay: Orthodoxy in Ukrainian Political Life 2004-2009. In: Religion, State \& Society 3/2010 (Vol. 38), 229-251.

Müller, Olaf / Pickel, Gert / Pollack, Detlef: Wandel religiös-kirchlicher Orientierungen und Verhaltensweisen in Osteuropa. In: Brocker, Manfred / Behr, Hartmut / Hildebrandt, Mathias (Hgg.): Religion - Staat - Politik. Zur Rolle der Religion in der nationalen und internationalen Politik. Wiesbaden 2003, 99-124. 
Gatskov / Gatskova, Zum Anstieg der Religiosität in der postsowjetischen Ukraine

Norris, Pippa / Inglehart, Ronald: Sacred and Secular. Religion and Politics Worldwide. Cambridge 2004.

Parsons, Talcott: Religion in Postindustrial America: The Problem of Secularization. In: Social Research 2/1974 (Vol. 41), 193-225.

Pfahl-Traughber, Armin: »Politische Religion« und »Zivilreligion«. Politische Theorie. In: Liedhegener, Antonius / Tunger-Zanetti, Andreas / Wirz, Stephan (Hgg.): Religion - Wirtschaft - Politik. Zürich 2011, 223-240.

Pickel, Gert: Religionssoziologie. Wiesbaden 2011.

Pollack, Detlef: Das Verhältnis von Religion und Politik in den postkommunistischen Staaten und seine Auswirkungen auf die Vitalität von Religion. In: Minkenberg, Michael / Willems, Ulrich (Hgg.): Politik und Religion (Politische Vierteljahresschrift, Sonderheft 33). Wiesbaden 2003, 435-455. Pollack, Detlef: Säkularisierung - ein moderner Mythos? Tübingen 2003.

Popper, Karl R.: Auf der Suche nach einer besseren Welt - Vorträge und Aufsätze aus dreißig Jahren. München 1984.

Razumkov-Zentrum: Relihija i vlada v Ukrajini: problemy vzajemovidnosyn. Informacijni materialy do kruglogo stolu [»Religion und Staatsmacht in der Ukraine: Probleme der wechselseitigen Beziehungen. Informationen zum Runden Tisch«]. Kyjiv 2013. Online-Dokument: http://www.razumkov.org. ua/upload/Przh_Religion_2013.pdf(01.02.2015).

Riegel, Klaus-Georg: Der Marxismus-Leninismus als »politische Religion«. In: Lübbe, Hermann / Besier, Gerhard (Hgg.): Politische Religion und Religionspolitik. Zwischen Totalitarismus und Bürgerfreiheit. Göttingen 2005, 15-48.

Rjabtschuk, Mykola: Die reale und die imaginierte Ukraine. Frankfurt a. M. 2015.

Ryklin, Michail: Kommunismus als Religion. Frankfurt a. M. 2008.

Sysyn, Frank E.: The Ukrainian Orthodox Question in the USSR. In: Plokhy, Serhii / Sysyn. Frank E. (Hgg.): Religion and Nation in Modern Ukraine. Edmonton, Toronto 1983, 74-97. 
Gatskov / Gatskova, Zum Anstieg der Religiosität in der postsowjetischen Ukraine

Wilson, Andrew: The Ukrainians. Unexpected Nation. New Haven, London 2000.

Yelensky, Viktor: Religiosity in Ukraine according to Sociological Surveys. In: Religion, State \& Society 3/2010 (Vol. 38), 213-227.

Zulehner, Paul M. / Tomka, Miklós / Naletova, Inna: Religionen in Ost(Mittel) Europa. Entwicklungen seit der Wende. Ostfildern 2008.

\section{Abstract}

\section{Maxim Gatskov / Ksenija Gatskova \\ The Growth of Religiosity in Post-Soviet Ukraine: Empirical Findings and Theoretical Approaches}

The article examines the growth of religiosity in Ukraine during the last twenty-five years. In the first part, we carefully assess the developments of religiosity by combining various data sources that separately yield quite different results. In order to better understand the state of religious affairs in the late Soviet years, we undertake a brief historical review of the Ukraine's post-1945 period. From this starting point, we can clearly see that there were two waves of religious upswing: between 1987 and 1992 as well as between 1999 and 2009. In the second part, we look more closely at types of religiosity in four regions of Ukraine, revealing that the population of the Western region was and remains much more religious than the rest of the country. The analysis of religiosity growth in different regions provides evidence that part of this growth has been nominal. Finally, we review three possible theoretical approaches that can explain the observed developments: an institutional approach, an »ideological» approach, and a socio-psychological approach. 
Katrin Boeckh - 978-3-86688-505-9 


\section{Miriam Frey}

\section{Werte und Normen in der heutigen Ukraine im regionalen Kontext}

\section{Einleitung}

Regionale Disparität, die viel differenzierter zu betrachten ist als der weithin konstatierte »Ost-West-Gegensatz« oder gar die "Spaltung « des Landes in einen »Osten « und einen »Westen«, ist ein wesentliches Charakteristikum der gesellschaftlichen Wirklichkeit der heutigen Ukraine. So finden sich in der Literatur vielfach Hinweise auf die Bedeutung des regionalen Kontexts bei der Untersuchung von Ethnizität und Sprache ${ }^{1}$, Armutsquoten ${ }^{2}$ und Migrationsverhalten ${ }^{3}$. Doch es sind nicht nur demographische und ökonomische Unterschiede, die das Bild der heutigen Ukraine prägen. Vielmehr wurde in der Literatur auch bereits auf regionale Divergenz hinsichtlich der Einstellungen der in der Ukraine lebenden Menschen hingewiesen, was Lewicka als »regionale Mentalität« bezeichnet. ${ }^{4}$

Nun sind regionale Besonderheiten innerhalb eines Landes kein ausschließlich ukrainisches Phänomen, jedoch scheinen diese in der Ukraine besonders ausgeprägt. ${ }^{5}$ Dies verdeutlicht beispielsweise ein Blick auf die Ergebnisse der

1 Ursulenko: Russian Language in Ukraine.

2 World Bank: Ukraine: Poverty Assessment.

3 UCSR/SSCU: Ukrainian External Labour Migration.

4 Lewicka: Regional Differentiation of Identity.

5 Dies ist vor allem im Hinblick auf einen Vergleich mit den Nachbarländern induziert. So zeigt Lewicka (Lewicka: Regional Differentiation of Identity) in einer umfragebasierten Gegenüberstellung polnischer und ukrainischer Regionen hinsichtlich der Frage nach lokaler und nationaler Identität, dass die Unterschiede 
Frey, Werte und Normen in der heutigen Ukraine im regionalen Kontext

Parlamentswahlen im Jahr 2007. Während in der West- und Zentralukraine der »Block Tymošenko« den jeweils größten Stimmenanteil erzielte, dominierte in den südlichen und östlichen Landesteilen die »Partei der Regionen «. ${ }^{6}$ Ein ähnliches regionales Clustering ist auch in Bezug auf Religion zu beobachten. Dem in der Ostukraine vorherrschenden orthodoxen Glauben steht die in der Westukraine weit verbreitete griechisch-katholische Glaubensrichtung ${ }^{7}$ sowie eine generell sehr große Anzahl verschiedener Religions- und Kirchengemeinschaften gegenüber.

Dieser Beitrag möchte der Diskussion um regionale Mentalitäts- und sonstige Unterschiede in der Ukraine einen weiteren relevanten Aspekt hinzufügen, indem er der Frage nachgeht, inwiefern in der heutigen Ukraine regionale Unterschiede bezüglich der Bedeutung von Werten und Normen bestehen. Dies erfolgt anhand von Umfrageergebnissen, welche unter Einbeziehung verschiedener regionaler Gliederungskonzepte sowohl deskriptiv als auch statistisch analysiert werden.

\section{Daten}

Die dieser Arbeit zugrunde liegenden Daten entstammen einer Haushaltsbefragung, welche 2007 in der Ukraine durchgeführt wurde. ${ }^{8}$ Dieser Survey bietet Informationen zu mehr als 10.000 ukrainischen Haushalten und mehr als 20.000 Haushaltsmitgliedern. Von den insgesamt mehr als 1.000 auf Haushaltsebene enthaltenen Variablen werden im Folgenden lediglich die Antworten der Haushalte auf folgende Fragen analysiert:

bezüglich psychologischer Charakteristika innerhalb Polens weniger stark ausgeprägt sind als über die ukrainischen Regionen hinweg.

6 Pleines: Ein Sieg für die Demokratie.

7 Lewicka: Regional Differentiation of Identity.

8 SSCU: Ukrainian Household Budget Survey. 
Frey, Werte und Normen in der heutigen Ukraine im regionalen Kontext

Frage: Welche Bedeutung haben die Werte Gesundheit, Familie, Wohlergehen, Arbeit/Karriere, Bildung, Freunde/Kommunikation, Vertrauen in die Zukunft und soziale Gerechtigkeit für den Haushalt?

Antwortmöglichkeiten: höchste Priorität, zweithöchste Priorität, dritthöchste Priorität

Frage: Wer ist für das Wohlergehen des Haushalts verantwortlich? Antwortmöglichkeiten: ausschließlich Staat, hauptsächlich Staat, Staat und Haushalt, hauptsächlich Haushalt, ausschließlich Haushalt, weiß nicht

Bei der Untersuchung regionaler Differenzen stellt sich insbesondere die Frage nach der Gruppierung der ukrainischen Gebiete (oblasti). Ein Blick in die Literatur ergibt diesbezüglich kein einheitliches Bild. Während einige Autoren eine bloße West-Ost-Einteilung vornehmen, fassen andere Autoren benachbarte oblasti beispielsweise zu vier, ${ }^{9}$ fünf ${ }^{10}$ oder acht ${ }^{11}$ Regionen zusammen.

Demzufolge kommen auch in diesem Beitrag zwei regionale Gliederungskonzepte zur Anwendung. Einerseits werden die ukrainischen oblasti entsprechend ihrer geographischen Lage in die folgenden fünf Regionen eingeteilt: ${ }^{12}$

West:Černivci, Ivano-Frankivs'k, L'viv, Rivne, Ternopil', Volyn'ska oblast', Zakarpats'ka oblast'

Zentral: Čerkasy, Chmel'nyc'kyj, Kirovohrad, Poltava, Vinnycja

Nord: Černihiv, Kiev, Kiev Stadt, Sumy, Žytomyr

Ost: Charkiv, Dnipropetrovs'k, Donec'k, Luhans'k, Zaporižžja

Süd: Autonome Republik Krim, Cherson, Mykolajiv, Odessa, Sevastopol'

9 Tomka: Comparing Countries by their Religiosity.

10 UCSR/SSCU: Ukrainian External Labour Migration.

11 Barrington, Faranda: Reexamining Region, Ethnicity, and Language.

12 Die Einteilung entspricht jener des Kiev International Institute of Sociology. 
Frey, Werte und Normen in der heutigen Ukraine im regionalen Kontext

Zum anderen werden die Daten zusätzlich in Hinblick auf einen möglichen West-»Zentral-Nord-Ost-Süd«-Unterschied hin untersucht. Der westliche Teil der Ukraine entspricht dabei den oblasti aus der Region West, während alle weiter östlich gelegenen oblasti als »Zentral-Nord-Ost-Süd«-Teil bezeichnet werden.

\section{Deskriptive Analyse}

Der erste Teil dieser Analyse widmet sich der Verteilung der Antworten der ukrainischen Haushalte auf die Frage nach der Bedeutung der oben genannten Werte und Normen in den verschiedenen Regionen und Landesteilen. Diese finden sich in den Tabellen 1 bis 9. Der jeweils mittlere Teil der Tabelle gibt dabei Aufschluss über die Verteilung in den fünf Regionen, während im rechten Teil eine Gegenüberstellung des westlichen Landesteils und aller weiter östlich gelegenen Regionen (hier zusammengefasst als »Zentral-Nord-Ost-Süd «-Teil) erfolgt. Im Allgemeinen ist festzuhalten, dass über die Regionen und Landesteile hinweg Einigkeit bezüglich der Priorisierung der untersuchten Werte und Normen besteht. So weist in allen Regionen und Landesteilen der überwiegende Teil der befragten Haushalte dem Wert Gesundheit die höchste und dem Wert Familie die zweithöchste Priorität zu, wohingegen allen weiteren Werten nur die dritthöchste Priorität zugeschrieben wird. Bei genauerer Betrachtung der Verteilungen der einzelnen Werte in den verschiedenen Regionen und Landesteilen zeigen sich dennoch interessante Unterschiede.

DigiOst 3 | 192 
Frey, Werte und Normen in der heutigen Ukraine im regionalen Kontext

Tabelle 1: Bedeutung von Gesundheit (Anteile in Prozent)

\begin{tabular}{l|ccccc|cc} 
& \multicolumn{3}{c}{ Vergleich der fünf Regionen } & & \multicolumn{2}{c}{$\begin{array}{c}\text { West-»Zentral-Nord- } \\
\text { Ost-Süd«-Vergleich }\end{array}$} \\
\hline & West & Zentral & Nord & Ost & Süd & Westteil $\begin{array}{l}\text { "Zentral-Nord- } \\
\text { Ost-Süd«-Teil }\end{array}$ \\
\hline $\begin{array}{l}\text { höchste } \\
\text { Priorität }\end{array}$ & 87,41 & 83,96 & 82,98 & 82,97 & 80,80 & 87,41 & 82,79 \\
$\begin{array}{l}\text { Zweithöchste } \\
\text { Priorität }\end{array}$ & 11,18 & 14,76 & 15,12 & 14,28 & 16,71 & 11,18 & 15,02 \\
\hline $\begin{array}{l}\text { dritthöchste } \\
\text { Priorität }\end{array}$ & 1,41 & 1,29 & 1,90 & 2,75 & 2,49 & 1,41 & 2,19 \\
\hline
\end{tabular}

Quelle: eigene Darstellung basierend auf SSCU: Ukrainian Household Budget Survey

Was die Bedeutung von Gesundheit betrifft, zeigt sich, dass der prozentuale Anteil der befragten Haushalte, welche Gesundheit als den Wert mit der höchsten Priorität betrachten, von der Westukraine über die Zentral- und Nordukraine bis in den östlichen und südlichen Teil der Ukraine stetig abnimmt. Der West«Zentral-Nord-Ost-Süd «-Vergleich bestätigt, dass im Westteil der Ukraine ein größerer prozentualer Anteil der Befragten Gesundheit als den Wert mit der höchsten Bedeutung ansieht als im Rest der Ukraine. 
Frey, Werte und Normen in der heutigen Ukraine im regionalen Kontext

Tabelle 2: Bedeutung von Familie (Anteile in Prozent)

\begin{tabular}{l|ccccc|cc} 
& \multicolumn{4}{c}{ Vergleich der fünf Regionen } & \multicolumn{2}{c}{$\begin{array}{c}\text { West-»Zentral-Nord- } \\
\text { Ost-Süd«-Vergleich }\end{array}$} \\
\hline & West & Zentral & Nord & Ost & Süd & Westteil $\begin{array}{c}\text { "Zentral-Nord- } \\
\text { Ost-Süd«-Teil }\end{array}$ \\
\hline $\begin{array}{l}\text { höchste } \\
\text { Priorität }\end{array}$ & 14,52 & 18,11 & 18,26 & 19,37 & 21,70 & 14,52 & 19,26 \\
$\begin{array}{l}\text { Zweithöchs- } \\
\text { te Priorität }\end{array}$ & 79,48 & 74,43 & 76,36 & 72,83 & 71,04 & 79,48 & 73,66 \\
$\begin{array}{l}\text { dritthöchste } \\
\text { Priorität }\end{array}$ & 6,01 & 7,46 & 5,38 & 7,80 & 7,26 & 6,01 & 7,08 \\
\hline
\end{tabular}

Quelle: eigene Darstellung basierend auf SSCU: Ukrainian Household Budget Survey

Während der Anteil der befragten Haushalte, welche der Familie lediglich die dritthöchste Priorität einräumen, mit Werten zwischen 5,38 und 7,80\% in den fünf Regionen ähnlich groß ist, hat die Familie in der Südukraine für einen größeren Anteil der Befragten (21,70 \%) als in der Westukraine (14,52 \%) höchste Priorität. Wiederum zeigt sich folgendes Muster: Die prozentualen Anteile innerhalb der Kategorie »höchste Priorität« nehmen zu, je weiter östlich bzw. südlich man kommt. Dementsprechend ist die Familie für 19,26 \% der Befragten im »Zentral-Nord-Ost-Süd «-Teil der Ukraine von höchster Bedeutung, im Westteil liegt der entsprechende Wert hingegen nur bei 14,52\%. 
Frey, Werte und Normen in der heutigen Ukraine im regionalen Kontext

Tabelle 3: Bedeutung von Wohlergehen (Anteile in Prozent)

\begin{tabular}{l|ccccc|cc} 
& \multicolumn{4}{c}{ Vergleich der fünf Regionen } & \multicolumn{2}{c}{$\begin{array}{c}\text { West-»Zentral-Nord- } \\
\text { Ost-Süd«-Vergleich }\end{array}$} \\
\hline & West & Zentral & Nord & Ost & Süd & Westteil $\begin{array}{c}\text { "Zentral-Nord- } \\
\text { Ost-Süd«-Teil }\end{array}$ \\
\hline $\begin{array}{l}\text { höchste } \\
\text { Priorität }\end{array}$ & 2,14 & 2,94 & 2,45 & 6,75 & 4,84 & 2,14 & 4,73 \\
$\begin{array}{l}\text { Zweithöchste } \\
\text { Priorität }\end{array}$ & 23,10 & 23,49 & 25,45 & 33,40 & 27,33 & 23,1 & 28,59 \\
$\begin{array}{l}\text { dritthöchste } \\
\text { Priorität }\end{array}$ & 74,76 & 73,58 & 72,10 & 59,85 & 67,84 & 74,76 & 66,68 \\
\hline
\end{tabular}

Quelle: eigene Darstellung basierend auf SSCU: Ukrainian Household Budget Survey

Die Bedeutung von Wohlergehen wird in allen fünf Regionen eher gering eingeschätzt. Allerdings fällt auf, dass in der Ostukraine der prozentuale Anteil der Haushalte, für welche das Wohlergehen höchst prioritär ist, fast dreimal so groß ist wie in der Westukraine. Werden die Regionen Zentral, Nord, Ost und Süd als ein Teil der Ukraine betrachtet, verringert sich dieser Anteil im Vergleich zur Ostukraine um 2,02\% auf 4,73\%. 
Frey, Werte und Normen in der heutigen Ukraine im regionalen Kontext

Tabelle 4: Bedeutung von Arbeit/Karriere (Anteile in Prozent)

Vergleich der fünf Regionen

West-»Zentral-Nord-

Ost-Süd«-Vergleich

\begin{tabular}{l|ccccc|cc}
\hline & West & Zentral & Nord & Ost & Süd & Westteil & $\begin{array}{c}\text { "Zentral-Nord- } \\
\text { Ost-Süd«-Teil }\end{array}$ \\
\hline $\begin{array}{l}\text { höchste } \\
\text { Priorität }\end{array}$ & 2,70 & 2,49 & 6,19 & 7,80 & 12,82 & 2,70 & 7,36 \\
\hline $\begin{array}{l}\text { zweithöchste } \\
\text { Priorität }\end{array}$ & 27,03 & 23,88 & 16,67 & 28,76 & 30,77 & 27,03 & 25,56 \\
$\begin{array}{l}\text { dritthöchste } \\
\text { Priorität }\end{array}$ & 70,27 & 73,63 & 77,14 & 63,44 & 56,41 & 70,27 & 67,08 \\
\hline
\end{tabular}

Quelle: eigene Darstellung basierend auf SSCU: Ukrainian Household Budget Survey

Auch wenn in allen fünf Regionen Arbeit und Karriere für mehr als 50 Prozent der befragten Haushalte nur die dritthöchste Priorität besitzen, ist doch ein deutlicher Unterschied bei der Kategorie »höchste Priorität« zu beobachten, insbesondere zwischen der West- und der Südukraine (2,70 gegenüber 12,82 Prozent). Ein klarer Unterschied in dieser Kategorie bleibt auch bestehen, wenn der West- und der »Zentral-Nord-Ost-Süd«-Teil der Ukraine miteinander verglichen werden (2,70 gegenüber 7,36 Prozent). 
Frey, Werte und Normen in der heutigen Ukraine im regionalen Kontext

Tabelle 5: Bedeutung von Bildung (Anteile in Prozent)

Vergleich der fünf Regionen

West-»Zentral-Nord-

Ost-Süd«-Vergleich

\begin{tabular}{l|ccccc|cc}
\hline & West & Zentral & Nord & Ost & Süd & Westteil $\begin{array}{c}\text { "Zentral-Nord- } \\
\text { Ost-Süd «-Teil }\end{array}$ \\
\hline $\begin{array}{l}\text { höchste } \\
\text { Priorität }\end{array}$ & 3,20 & 8,45 & 4,48 & 8,62 & 9,52 & 3,2 & 7,89 \\
\hline $\begin{array}{l}\text { Zweithöchste } \\
\text { Priorität }\end{array}$ & 23,20 & 23,94 & 23,88 & 40,52 & 31,75 & 23,2 & 31,55 \\
\hline $\begin{array}{l}\text { dritthöchste } \\
\text { Priorität }\end{array}$ & 73,60 & 67,61 & 71,64 & 50,86 & 58,73 & 73,6 & 60,57 \\
\hline
\end{tabular}

Quelle: eigene Darstellung basierend auf SSCU: Ukrainian Household Budget Survey

Ein ähnliches Bild ergibt sich ebenso bezüglich der Bedeutung von Bildung. Höchsten Stellenwert besitzt diese in der Westukraine nur für 3,20 Prozent der Befragten, wohingegen in der Südukraine 9,52 Prozent der befragten Haushalte Bildung als vorrangig ansehen. Insgesamt kommt Bildung im »Zentral-NordOst-Süd«-Teil der Ukraine mehr Bedeutung zu als im Westteil. Jedoch muss hier darauf hingewiesen werden, dass von den mehr als 10.000 befragten Haushalten lediglich 442 eine Antwort auf diese Frage gegeben haben. 
Frey, Werte und Normen in der heutigen Ukraine im regionalen Kontext

Tabelle 6: Bedeutung von Freunden/Kommunikation (Anteile in Prozent)

\begin{tabular}{l|ccccc|c|cc} 
& \multicolumn{4}{c}{ Vergleich der fünf Regionen } & \multicolumn{2}{c}{$\begin{array}{c}\text { West-»Zentral-Nord- } \\
\text { Ost-Süd«-Vergleich }\end{array}$} \\
\hline & West & Zentral & Nord & Ost & Süd & Westteil $\begin{array}{c}\text { "Zentral-Nord- } \\
\text { Ost-Süd«-Teil }\end{array}$ \\
\hline $\begin{array}{l}\text { höchste } \\
\text { Priorität }\end{array}$ & 0,00 & 0,00 & 1,04 & 2,21 & 6,02 & 0,00 & 2,36 \\
$\begin{array}{l}\text { Zweithöchste } \\
\text { Priorität }\end{array}$ & 23,00 & 14,93 & 15,63 & 20,59 & 19,28 & 23,00 & 18,06 \\
$\begin{array}{l}\text { dritthöchste } \\
\text { Priorität }\end{array}$ & 77,00 & 85,07 & 83,33 & 77,21 & 74,70 & 77,00 & 79,58 \\
\hline
\end{tabular}

Quelle: eigene Darstellung basierend auf SSCU: Ukrainian Household Budget Survey

Bei der Betrachtung von Tabelle 6 fällt auf, dass sich unter den befragten Haushalten in der West- und Zentralukraine kein Haushalt dafür ausgesprochen hat, dass Freunde und Kommunikation von höchster Relevanz seien. Dies ist wiederum vor allem im Vergleich zur Südukraine interessant, wo Freunde und Kommunikation für immerhin 6,02 Prozent der Befragten höchste Priorität besitzen. Im West-«Zentral-Nord-Ost-Süd «-Vergleich fällt der Unterschied in der Kategorie "höchste Priorität« dagegen deutlich geringer aus. Allerdings ist wie bei der Frage zur Bedeutung von Bildung die mit 482 relativ geringe Anzahl von Beobachtungseinheiten zu beachten. 
Frey, Werte und Normen in der heutigen Ukraine im regionalen Kontext

Tabelle 7: Bedeutung von Vertrauen in die Zukunft (Anteile in Prozent)

Vergleich der fünf Regionen

West-»Zentral-Nord-

Ost-Süd«-Vergleich

\begin{tabular}{l|ccccc|cc}
\hline & West & Zentral & Nord & Ost & Süd & Westteil & $\begin{array}{c}\text { "Zentral-Nord- } \\
\text { Ost-Süd«-Teil }\end{array}$ \\
\hline $\begin{array}{l}\text { höchste } \\
\text { Priorität }\end{array}$ & 2,22 & 2,19 & 4,78 & 3,78 & 3,07 & 2,22 & 3,54 \\
\hline $\begin{array}{l}\text { zweithöchste } \\
\text { Priorität }\end{array}$ & 18,41 & 15,36 & 13,90 & 14,12 & 17,96 & 18,41 & 15,09 \\
$\begin{array}{l}\text { dritthöchste } \\
\text { Priorität }\end{array}$ & 79,37 & 82,45 & 81,32 & 82,10 & 78,98 & 79,37 & 81,36 \\
\hline
\end{tabular}

Quelle: eigene Darstellung basierend auf SSCU: Ukrainian Household Budget Survey

Vertrauen in die Zukunft spielt sowohl im West- und »Zentral-Nord-Ost-Süd «Teil der Ukraine als auch in allen fünf Regionen eine ähnlich untergeordnete Rolle. Die Region mit dem größten prozentualen Anteil an befragten Haushalten, welche Vertrauen in die Zukunft für höchst wichtig halten, ist in diesem Fall die Nordukraine. 
Frey, Werte und Normen in der heutigen Ukraine im regionalen Kontext

Tabelle 8: Bedeutung von sozialer Gerechtigkeit (Anteile in Prozent)

Vergleich der fünf Regionen

West-»Zentral-Nord-

Ost-Süd«-Vergleich

\begin{tabular}{l|ccccc|cc}
\hline & West & Zentral & Nord & Ost & Süd & Westteil & $\begin{array}{c}\text { "Zentral-Nord- } \\
\text { Ost-Süd«-Teil }\end{array}$ \\
\hline $\begin{array}{l}\text { höchste } \\
\text { Priorität }\end{array}$ & 0,47 & 1,42 & 6,67 & 3,58 & 2,11 & 0,47 & 3,58 \\
\hline $\begin{array}{l}\text { zweithöchste } \\
\text { Priorität }\end{array}$ & 5,61 & 15,60 & 10,91 & 14,66 & 10,56 & 5,61 & 13,25 \\
$\begin{array}{l}\text { dritthöchste } \\
\text { Priorität }\end{array}$ & 93,93 & 82,98 & 82,42 & 81,76 & 87,32 & 93,93 & 83,18 \\
\hline
\end{tabular}

Quelle: eigene Darstellung basierend auf SSCU: Ukrainian Household Budget Survey

Dies trifft ebenfalls auf die Frage nach der Bedeutung von sozialer Gerechtigkeit zu, welche in der Nordukraine von 6,67 Prozent der befragten Haushalte als höchst bedeutend angesehen wird, in der Westukraine jedoch nur von 0,47 Prozent der Befragten. Ebenso zeigt der West-»Zentral-Nord-Ost-Süd«-Vergleich, dass die Bedeutung von sozialer Gerechtigkeit im Westteil deutlich geringer eingestuft wird als im übrigen Teil der Ukraine. 
Frey, Werte und Normen in der heutigen Ukraine im regionalen Kontext

Tabelle 9: Träger der Verantwortung (Anteile in Prozent)

Vergleich der fünf Regionen

West-»Zentral-Nord-

Ost-Süd«-Vergleich

\begin{tabular}{l|ccccc|cc}
\hline & West & Zentral & Nord & Ost & Süd & Westteil $\begin{array}{c}\text { "Zentral-Nord- } \\
\text { Ost-Süd«-Teil }\end{array}$ \\
\hline $\begin{array}{l}\text { ausschließlich } \\
\text { Staat }\end{array}$ & 10,31 & 10,97 & 13,33 & 18,38 & 17,77 & 10,31 & 15,56 \\
\hline $\begin{array}{l}\text { hauptsächlich } \\
\text { Staat }\end{array}$ & 24,01 & 21,71 & 21,86 & 21,54 & 20,91 & 24,01 & 21,53 \\
\hline $\begin{array}{l}\text { Staat und } \\
\text { Haushalt }\end{array}$ & 59,48 & 60,61 & 54,16 & 51,68 & 52,47 & 59,48 & 54,31 \\
$\begin{array}{l}\text { hauptsächlich } \\
\text { Haushalt }\end{array}$ & 4,73 & 5,62 & 8,09 & 7,24 & 6,54 & 4,73 & 6,94 \\
\hline $\begin{array}{l}\text { ausschließlich } \\
\text { Haushalt }\end{array}$ & 1,38 & 1,09 & 2,40 & 1,16 & 2,31 & 1,38 & 1,62 \\
\hline \begin{tabular}{l} 
weiß nicht \\
\hline
\end{tabular} & 0,09 & 0,00 & 0,17 & 0,00 & 0,00 & 0,09 & 0,04 \\
\hline
\end{tabular}

Quelle: eigene Darstellung basierend auf SSCU: Ukrainian Household Budget Survey

Tabelle 9 enthält die Ergebnisse auf die Frage, wer nach Meinung der befragten Haushalte für das Wohlergehen derselben zuständig sei. In allen fünf Regionen sehen mehr als die Hälfte der befragten Haushalte sowohl den Staat als auch den Haushalt in der Verantwortung. Interessant ist allerdings, dass der prozentuale Anteil der Befragten, welche ausschließlich den Staat als für ihr Wohlergehen verantwortlich betrachten, in der Ost- und Südukraine nahezu doppelt so groß ist wie in der West- und Zentralukraine. Dies spiegelt sich auch im West-»Zentral-Nord-Ost-Süd«-Vergleich wider. Der Prozentsatz der Befragten, für welche das Wohlergehen ausschließlich in der Verantwortung der Haushalte liegt, ist über alle Regionen und Landesteile hinweg hingegen vergleichbar gering. 
Frey, Werte und Normen in der heutigen Ukraine im regionalen Kontext

\section{Statistische Tests}

Die bisherige Analyse war lediglich beschreibenden Charakters und ihr Informationsgehalt somit begrenzt. Insbesondere bleibt zu klären, ob sich die Antworten der befragten Haushalte bezüglich der Bedeutung der einzelnen Werte und Normen in den verschiedenen Regionen und Landesteilen statistisch signifikant voneinander unterscheiden. Dieser Frage wird mit Hilfe eines statistischen Tests nachgegangen. Der so genannte Kruskal-Wallis-Test ${ }^{13}$ wird durchgeführt, um mehrere unabhängige Gruppen, in diesem Fall die fünf Regionen und die beiden Landesteile, zu vergleichen. Die im Rahmen dieses Tests zu überprüfende Hypothese besagt, dass verschiedene Stichproben ${ }^{14}$ derselben Grundgesamtheit entstammen und somit denselben Median ${ }^{15}$ besitzen. Um die fünf Regionen jeweils paarweise vergleichen und so die sich signifikant von einander unterscheidenden Regionen identifizieren zu können, wird darüber hinaus eine modifizierte Version des Kruskal-Wallis-Tests ${ }^{16}$ angewandt. ${ }^{17}$

Tabelle 10 enthält die Ergebnisse hinsichtlich der Frage, ob zwischen dem West- und dem »Zentral-Nord-Ost-Süd«-Teil der Ukraine ein signifikanter Unterschied bezüglich der Bedeutung der untersuchten Werte und Normen

13 Kruskal und Wallis: Use of Ranks.

14 Im Falle der Analyse der fünf Regionen entspricht eine Stichprobe allen innerhalb einer dieser Regionen befragten Haushalten. Analoges gilt für die Untersuchung des West-»Zentral-Nord-Ost-Süd «-Vergleichs.

15 Zur Bestimmung des Medians werden alle Beobachtungen der Größe nach aufsteigend geordnet und anschließend nach dem Wert gesucht, welcher die geordneten Beobachtungen genau in zwei Hälften teilt.

16 Caci: KWALLIS2.

17 Dies ist notwendig, da in der einfachen Version des Kruskal-Wallis-Tests lediglich überprüft wird, ob sich mindestens zwei der Gruppen statistisch signifikant voneinander unterscheiden, jedoch nicht bestimmt werden kann, um welche Gruppen es sich dabei handelt. 
Frey, Werte und Normen in der heutigen Ukraine im regionalen Kontext

besteht. Auf dem 1-Prozent-Signifikanzniveau ${ }^{18}$ ist dies bei den Werten Gesundheit, Familie, Wohlergehen, Bildung und soziale Gerechtigkeit zu bejahen. Ein Unterschied in den Antworten auf die Frage, wer für das Wohlergehen des Haushalts verantwortlich sei, lässt sich immerhin noch auf dem 5-Prozent-Signifikanzniveau feststellen.

Tabelle 10: West-«Zentral-Nord-Ost-Süd «-Vergleich (verschiedene Signifikanzniveaus ${ }^{19}$ )

\begin{tabular}{|c|c|c|}
\hline & Unterschied & kein Unterschied \\
\hline Gesundheit & $\sqrt{ }^{* * *}$ & \\
\hline Familie & $\sqrt{ }^{* * *}$ & \\
\hline Wohlergehen & $\sqrt{ }^{* * *}$ & \\
\hline Arbeit/Karriere & & $\checkmark$ \\
\hline Bildung & $\checkmark^{* * *}$ & \\
\hline Freunde/Kommunikation & & $\checkmark$ \\
\hline Vertrauen in die Zukunft & & $\checkmark$ \\
\hline Soziale Gerechtigkeit & $\sqrt{ }^{* * *}$ & \\
\hline Verantwortung & $\sqrt{ }^{* *}$ & \\
\hline
\end{tabular}

Quelle: eigene Darstellung basierend auf SSCU: Ukrainian Household Budget Survey

Fasst man die Ergebnisse der auf der Ebene der fünf Regionen durchgeführten Tests zusammen, ergeben sich die in Tabelle 11 aufgeführten Resultate. Auffällig

18 Das Signifikanzniveau gibt die Fehlerwahrscheinlichkeit an.

$19^{* * *}: 1$ Prozent Signifikanzniveau, ${ }^{* *} 5$ Prozent Signifikanzniveau. 
Frey, Werte und Normen in der heutigen Ukraine im regionalen Kontext

ist, dass zwischen der West- und der Zentral- bzw. der Nordukraine, ebenso wie zwischen der Nord- und der Zentralukraine, bei keinem der untersuchten Werte und Normen ein signifikanter Unterschied hinsichtlich deren Bedeutung besteht. Gleichwohl finden sich zwischen der West- und der Ostukraine einerseits und der West- und der Südukraine andererseits signifikante Unterschiede bei gleich vier bzw. drei der insgesamt neun untersuchten Werte und Normen. Auch im Falle der Zentral- und Nordukraine bestehen signifikante Unterschiede im Vergleich zur östlichen und südlichen Region, jedoch in einem geringeren Umfang. Die Ost- und Südukraine unterscheiden sich hingegen nur in einem einzigen Punkt, nämlich hinsichtlich der Bedeutung von Wohlergehen.

Über den bloßen Vergleich der Anzahl der sich unterscheidenden Werte und Normen hinaus lohnt auch ein Blick auf deren Merkmale. So zeigt sich einerseits, dass Unterschiede in Bezug auf die Bedeutung von materiellen Werten wie Wohlergehen, Arbeit und Karriere über mehrere Regionen hinweg existieren. Indes finden sich divergierende Antworten die Bedeutung von immateriellen Werten wie Gesundheit und Bildung betreffend ausschließlich zwischen der West- und der Ost- bzw. Südukraine.

Diese Ergebnisse stehen im Einklang mit dem Fazit einer Untersuchung der ukrainischen Regionen, in welcher insbesondere die Gegensätze zwischen der Westukraine einerseits und der Ost- und Südukraine andererseits betont werden. ${ }^{20}$ Ferner wird der Zentralukraine ${ }^{21}$ dort eine $»$ wichtige Ausgleichsfunktion zwischen den Landesteilen ${ }^{22}$ zugeschrieben, wie sie sich auch anhand der hier durchgeführten Analyse ableiten lässt.

20 Klüsener: Die Regionen der Ukraine.

21 Dieser Region entsprechen die in dieser Arbeit als Nord- und Zentralukraine bezeichneten Regionen.

22 Klüsener: Die Regionen der Ukraine. 
Frey, Werte und Normen in der heutigen Ukraine im regionalen Kontext

Tabelle 11: Vergleich der fünf Regionen (1 Prozent Signifikanzniveau ${ }^{23}$ )

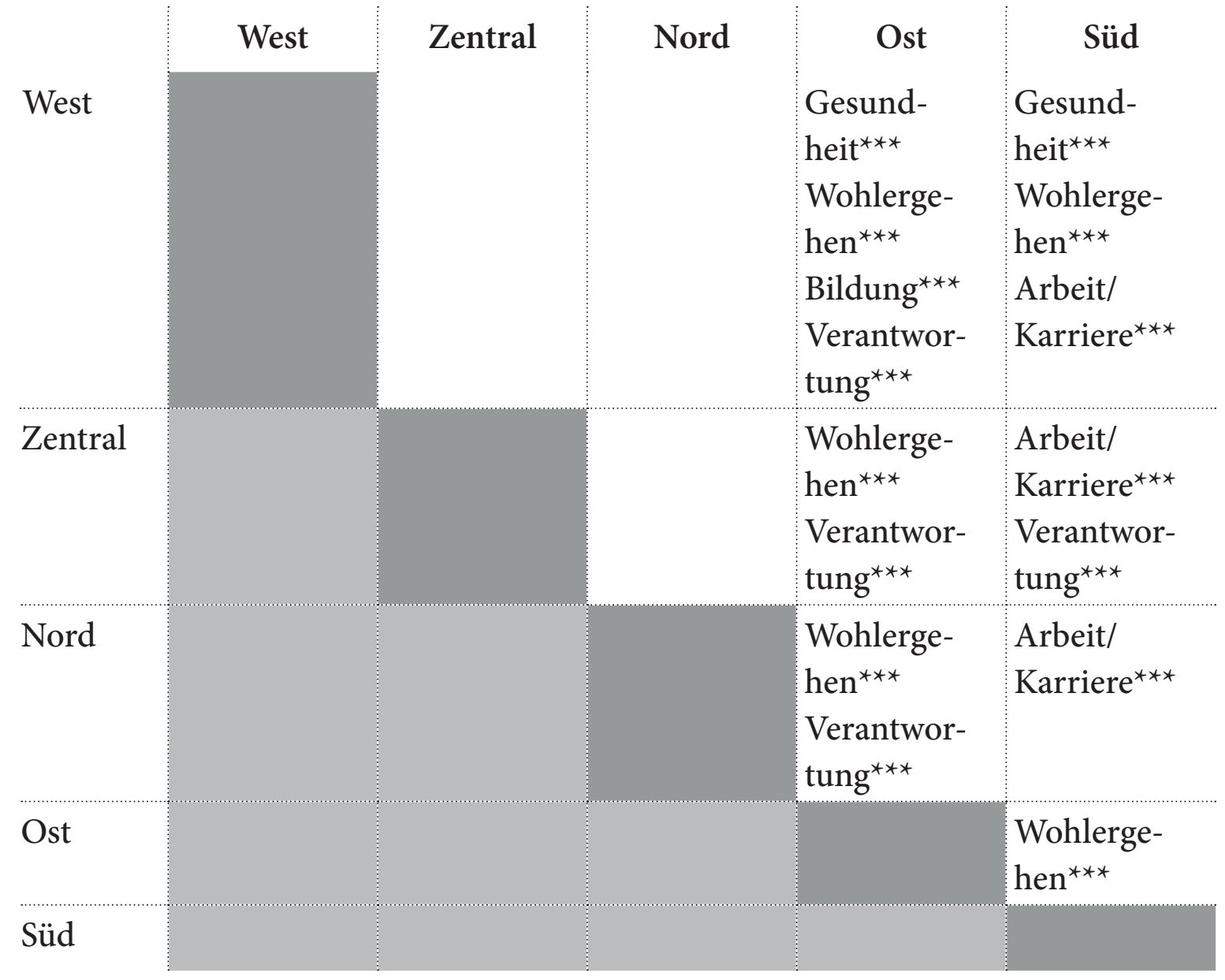

Quelle: eigene Darstellung basierend auf SSCU: Ukrainian Household Budget Survey

\section{Diskussion}

Nachdem mittels statistischer Tests regionale Unterschiede in der heutigen Ukraine hinsichtlich der Bedeutung verschiedener Werte und Normen nachgewiesen wurden, stellt sich nun die Frage nach deren Ursprüngen. Über die reine Deskription hinausgehende Arbeiten liefern verschiedene mögliche Er-

$23^{* * *}: 1$ Prozent Signifikanzniveau. 
Frey, Werte und Normen in der heutigen Ukraine im regionalen Kontext

klärungsansätze. So wurden in der Literatur bereits geographische, historische, aber auch sozioökonomische Faktoren identifiziert.

Lewicka sieht im historischen Einfluss Polens beziehungsweise Österreich-Ungarns im westlichen Teil der Ukraine und in der Bedeutung des Russischen Reichs für den Ostteil der Ukraine den am häufigsten angeführten Grund für regionale Unterschiede. ${ }^{24}$ Bestätigung erfährt diese Auffassung durch zwei Arbeiten, welche sich mit der Persistenz der historischen Aufteilung der ukrainischen Bevölkerung zwischen zwei Imperien befassen. ${ }^{25}$

Eine weitere, und mit dem erst genannten Punkt zusammenhängende Erklärung könnte in den eingangs bereits erwähnten regional variierenden religiösen Überzeugungen liegen. Ein Indiz dahingehend findet sich beispielsweise bei Barrington und Faranda. ${ }^{26}$ Diese gehen der Frage nach den Bestimmungsfaktoren unterschiedlicher Einstellungen gegenüber Russland nach. Zwar heben sie besonders die Bedeutung der regionalen Variablen hervor, jedoch kommen sie auch zu dem Schluss, dass, verglichen mit den griechisch-katholischen Gläubigen, unter den orthodoxen Gläubigen sowie unter den Atheisten eine positivere Einschätzung Russlands vorherrscht.

Demgegenüber zeigt Alwin, ${ }^{27}$ dass es weniger die Differenzen über die verschiedenen Konfessionen hinweg, als vielmehr Unterschiede bezüglich der Religiosität sind, welche zu verschiedenen Werteorientierungen in der elterlichen Kindererziehung führen. Bestätigt wird dies durch eine Studie über den Zusammenhang zwischen Religiosität und der Bedeutung von Werten, die insofern eine wichtige Ergänzung zur bisherigen Diskussion liefert, als sie für eine kontextbezogene Betrachtung plädiert. ${ }^{28}$ So können weitere Faktoren wie die sozioökonomische Entwicklung eines Landes die Werte-Religiosi-

24 Lewicka: Regional Differentiation of Identity.

25 Becker et al.: The Empire is Dead und Peisakhin: In History's Shadow.

26 Barrington, Faranda: Reexamining Region, Ethnicity, and Language.

27 Alwin: Religion and Parental Child-Rearing Orientations.

28 Saroglou et al.: Values and Religiosity. 
Frey, Werte und Normen in der heutigen Ukraine im regionalen Kontext

tät-Beziehung beeinflussen. ${ }^{29}$ In diesem Zusammenhang schlägt eine andere Untersuchung vor, soziale Variablen wie den Anteil religiöser Menschen an der Gesamtbevölkerung zu berücksichtigen. ${ }^{30}$

Auf dieses Argument aufbauend, werden im Folgenden die einzelnen oblasti erneut zu Gruppen zusammengefasst. Die Gruppierung erfolgt dieses Mal jedoch nicht anhand der geographischen Lage, sondern basierend auf den Grad der Religiosität der Bevölkerung. Dieser wird approximiert über den Anteil der Menschen an der Gesamtbevölkerung, ${ }^{31}$ welche mindestens einmal pro Woche einen Gottesdienst besuchen. ${ }^{32}$ Auf Grundlage der Klassifikation von Krindatch ${ }^{33}$ werden die ukrainischen Gebiete in die vier, in Tabelle 12 enthaltenen Gruppen eingeteilt.

29 Saroglou et al.: Values and Religiosity.

30 Roccas: Religion and Value Systems.

31 SSP Research Group: International Social Survey Programme 2008.

32 Diese Angabe beinhaltet immerhin die Tatsache der öffentlichen Konfession einer privaten Glaubenszugehörigkeit sowie die Bereitschaft, dieser eine Regelmäßigkeit und einen gewissen zeitlichen Aufwand zuzuschreiben; sie gibt aber keinen Hinweis auf die innere Überzeugung und auf die tatsächliche Umsetzung religiöser Vorgaben im Alltag.

33 Krindatch: Religion in Postsoviet Ukraine. 
Frey, Werte und Normen in der heutigen Ukraine im regionalen Kontext

Tabelle 12: Anteil der Befragten (in Prozent), welche mindestens einmal pro Woche einen Gottesdienst besuchen

\begin{tabular}{l|l|l|l} 
Gruppe 1: $<5$ & Gruppe 2: 5-10 & Gruppe 3: 10-20 & Gruppe 4: 20-40 \\
\hline Čerkasy & Autonome Repu- & Černivci & Ivano-Frankivs'k \\
Černihiv & blik Krim & Rivne & L'viv \\
Charkiv & Chmel'nyc'kyj & Volyn'ska oblast' & Ternopil' \\
Cherson & Dnipropetrovs'k & & Zakarpats'ka oblast' \\
Donec'k & Kiev Stadt & & \\
Kirovohrad & Mykolajiv & & \\
Kiev Gebiet & Odessa & & \\
Luhans'k & Poltava & & \\
Sumy & Vinnycja & & \\
Zaporižžja & Žytomyr & &
\end{tabular}

Quelle: eigene Darstellung basierend auf SSP Research Group: International Social Survey Programme 2008

Untersucht man die resultierenden Gruppen daraufhin in Bezug auf ihre geographische Lage, so fällt auf, dass sich in den Gruppen 3 und 4 ausschließlich diejenigen oblasti finden, welche in der Westukraine liegen. Die Einteilung der ukrainischen Gebiete anhand des Grads der Religiosität ihrer Bevölkerung liefert somit ein regionales Gliederungsmuster, welches eher mit der Aufteilung der Ukraine in einen West- und einen »Zentral-Nord-Ost-Süd«-Teil, als mit dem Konzept der fünf geographischen Regionen übereinstimmt.

Kombiniert mit der oben durchgeführten Analyse hinsichtlich signifikanter Unterschiede in der Bedeutung der untersuchten Werte und Normen kann man die Ergebnisse wie folgt zusammenfassen: Zum einen unterscheiden sich der West- und der »Zentral-Nord-Ost-Süd«-Teil der Ukraine in sechs von neun untersuchten Werten und Normen signifikant voneinander. Zum anderen ist der Grad der Religiosität im Westteil der Ukraine höher als im »Zentral-Nord-Ost-Süd«-Teil. 
Frey, Werte und Normen in der heutigen Ukraine im regionalen Kontext

Auch wenn man in diesen Ergebnissen einen Hinweis auf den in der Literatur bereits erwähnten Zusammenhang zwischen der Religiosität der Bevölkerung und der individuellen Bedeutung von Werten und Normen sehen könnte, muss dennoch beachtet werden, dass dieses Vorgehen nicht nur keinerlei Aussage über die Kausalität des untersuchten Zusammenhangs erlaubt, ${ }^{34}$ sondern zudem weitere Faktoren unberücksichtigt lässt, welche die Werte-Religiosität-Beziehung beeinflussen könnten.

\section{Fazit}

Die eingangs gestellte Frage, inwiefern in der Ukraine regionale Unterschiede hinsichtlich der Bedeutung von Werten und Normen existieren, muss vor dem Hintergrund der in dieser Arbeit durchgeführten deskriptiven und statistischen Analyse klar mit "Ja« beantwortet werden. Darüber hinaus wurde gezeigt, dass zwischen dem West- und dem »Zentral-Nord-Ost-Süd «-Teil der Ukraine nicht nur signifikante Unterschiede bezüglich der Bedeutung verschiedener Werte und Normen bestehen, sondern dass sich diese beiden Landesteile auch hinsichtlich des Grades der Religiosität ihrer Bevölkerung unterscheiden. Ob zwischen diesen beiden Faktoren jedoch ein kausaler Zusammenhang besteht und falls ja, in welche Richtung, konnte im Rahmen dieser Analyse nicht geklärt werden. Dennoch haben die hier vorgelegten Ergebnisse gezeigt, dass weiterhin

34 Möchte man den kausalen Zusammenhang zwischen Religiosität und der Bedeutung von Werten und Normen untersuchen, müsste auch der Effekt von kulturellen Normen auf die Religiosität einer Bevölkerung in Betracht gezogen werden. Dieser umgekehrte Einfluss wird beispielsweise von Roccas und Schwartz (Roccas und Schwartz: Church-State Relations) sowie Campbell und Curtis (Campbell und Curtis: Religious Involvement Across Societies) betont. Da eine Analyse der kausalen Zusammenhänge im Rahmen dieser Arbeit nicht geleistet werden kann, wird auch das Problem der umgekehrten Kausalität hier nicht näher betrachtet. 
Frey, Werte und Normen in der heutigen Ukraine im regionalen Kontext

Forschungsbedarf auf diesem Gebiet besteht. Die bisherigen Resultate sind daher auch als Motivation für weitere empirische Untersuchungen hinsichtlich der Bestimmungsfaktoren regionaler Unterschiede bei der Bedeutung von Werten und Normen in der Ukraine zu verstehen.

\section{Literatur}

Alwin, Duane F.: Religion and Parental Child-Rearing Orientations: Evidence of a Catholic-Protestant Convergence. In: American Journal of Sociology 92 (1986), 412-440.

Barrington, Lowell / Faranda, Regina: Reexamining Region, Ethnicity, and Language in Ukraine. In: Post-Soviet Affairs 25 (2009), 232-256.

Becker, Sascha O. / Boeckh, Katrin / Hainz, Christa / Woessmann, Ludger: The Empire is dead, long live the Empire! Long-run Persistence of Trust and Corruption in the Bureaucracy. Discussion Paper Series, Forschungsinstitut zur Zukunft der Arbeit 2011, unter http://hdl.handle.net/10419/51599 (08.11.2013). [Erscheint in Economic Journal].

Caci, Herve M.: KWALLIS2: Stata Module to perform Kruskal-Wallis Test for Equality of Populations, Statistical Software Components, S379201, Boston College Department of Economics, 1999, unter http://fmwww.bc.edu/ repec/bocode/k/kwallis2.ado (26.11.2013).

Campbell, Robert A. / Curtis, James E.: Religious Involvement Across Societies: Analyses for Alternative Measures in National Surveys. In: Journal for the Scientific Study of Religion 33 (1994), 215-229.

Klüsener, Sebastian: Die Regionen der Ukraine: Abgrenzung und Charakterisierung. In: Ukraine-Analysen 23 (2007), 2-6, unter http://www.laenderanalysen.de/ukraine/pdf/UkraineAnalysen23.pdf (08.11.2013).

Krindatch, Alexei D.: Religion in Postsoviet Ukraine as a Factor in Regional, Ethno-Cultural and Political Diversity. In: Religion, State \& Society 31 (2003), 37-73. 
Frey, Werte und Normen in der heutigen Ukraine im regionalen Kontext

Kruskal, W. H. / Wallis, W. A.: Use of Ranks in One-Criterion Variance Analysis. In: Journal of the American Statistical Association 47 (1952), 583-621. Lewicka, Maria: Regional Differentiation of Identity: a Comparison of Poland and Ukraine. In: Regional and Local Studies (2007), 21-51.

Peisakhin, Leonid: In History's Shadow: Persistence of Identities and Contemporary Political Behavior. Working Paper, Juan March Institute Center for Advanced Study in the Social Sciences (CEACS) 2012, unter http:// www.march.es/Recursos_Web/Ceacs/Paginas_personales/Publicaciones/ lpeisakhin632.pdf (08.11.2013).

Pleines, Heiko: Ein Sieg für die Demokratie - hoffentlich mal wieder. In: Ukraine-Analysen 28 (2007), 5-6, unter http://www.laender-analysen.de/ ukraine/pdf/UkraineAnalysen28.pdf (08.11.2013).

Roccas, Sonia: Religion and Value Systems. In: Journal of Social Issues 61 (2005), 747-759.

Roccas, Sonia / Schwartz, Shalom H.: Church-State Relations and the Association of Religiosity With Values: A Study of Catholics in Six Countries. In: Cross-Cultural Research 31 (1997), 356-375.

Saroglou, Vassilis / Delpierre, Vanessa / Dernelle, Rebecca: Values and Religiosity: a Meta-Analysis of Studies using Schwartz's Model. In: Personality and Individual Differences 37 (2004), 721-734.

SSP Research Group: International Social Survey Programme 2008: Religion III (ISSP 2008), GESIS Data Archive, Cologne, 2012. ZA4950 Data file Version 2.2.0, doi:10.4232/1.11334.

State Statistics Committee of Ukraine (SSCU): Ukrainian Household Budget Survey. Kiev 2007.

Tomka, Miklós: Comparing Countries by their Religiosity in Eastern Europe. In: Marinović Jerolimov, Dinka / Zrinščak, Siniša / Borowik, Irena (Hgg.): Religion and Patterns of Social Transformation. Zagreb 2004, 49-60.

Ukrainian Center for Social Reforms (UCSR), State Statistics Committee of Ukraine (SSCU) (Hgg.): Ukrainian External Labour Migration. Kiev, 2009. 
Frey, Werte und Normen in der heutigen Ukraine im regionalen Kontext

Ursulenko, Kseniia: Russian Language in Ukraine: Does it Concern only Russians? Kurzanalysen und Informationen 50, Osteuropa-Institut Regensburg 2011, unter http://www.dokumente.ios-regensburg.de/publikationen/info/ info-50.pdf (08.11.2013).

World Bank: Ukraine: Poverty Assessment. Poverty and Inequality in a Growing Economy. Report No. 34631-UA, December 2005.

\section{Abstract}

\section{Miriam Frey}

Values and Norms in Contemporary Ukraine in a Regional Context

Differences across Ukrainian regions are well established in the literature. They range from ethnicity and language to poverty rates and political orientations. This paper extends this list by asking whether Ukrainian regions also differ with respect to values and norms such as health, family, and career. Using data from a household survey and applying two different regional concepts, this paper first offers a descriptive analysis. This is followed by reference to statistical tests in order to compare Ukrainian regions. The article demonstrates there are indeed statistically significant differences, especially between West Ukraine and East and South Ukraine. Looking for possible reasons for this regional diversity, the author discusses the potential link between the religiousness of the population and the importance of values and norms. Even though Ukraine's Western and Eastern parts differ substantially with regard to both factors, no causal relationship can be established within this framework, which clearly leaves space for further research. 


\section{Viktor Jelensky}

\section{Religionspluralismus, Religionsfreiheit und Entsäkularisierung: der Fall Ukraine}

Ende der 1980er Jahre herrschte in der Ukraine ein Durcheinander an religionspolitischen Gegensätzen, und die Experten gingen davon aus, dass gewalttätige, auf religiösen Konflikten basierende Auseinandersetzungen unvermeidlich sein würden. Die Griechisch-Katholische Kirche in der Ukraine, die den Untergrund verlassen hatte, verlangte nach Gerechtigkeit, die Orthodoxen wollten dagegen anfangs die Tatsache nicht akzeptieren, dass sich die unierte Kirche als derart widerstandsfähig erwiesen hat. Der Konflikt zwischen den Orthodoxen und der Griechisch-Katholischen Kirche wühlte hunderte von Dörfern und Städten in der Westukraine auf. Der Streit zwischen den Orthodoxen, die sich nach einer »eigenen «, vom Moskauer Patriarchat unabhängigen autokephalen Kirche sehnten, und jenen, die keinen Bruch mit Moskau wollten, war noch schärfer und drohte, den Frieden unter den Bürgern zu sprengen. Bis zum Krieg kam es allerdings nicht, bis zum Ende der 1990er Jahre etablierte sich im Land ein labiles Gleichgewicht in den Beziehungen zwischen den Hauptakteuren der religiösen Szene. Dieses Gleichgewicht beruhte auf einer Kräfteparität - keine der Kirchen, die ihre Geschichte auf die Christianisierung der Kiever Rus' zurückführen (das sind die drei ukrainischen orthodoxen Kirchen - des Moskauer und Kiever Patriarchats sowie die Autokephale Kirche - und die Ukrainische Griechisch-Katholische Kirche), kommt auf mehr als ein Viertel der Gläubigen unter den Erwachsenen. Traditionell stark sind in der Ukraine darüber hinaus die Protestanten und Religionsgemeinschaften der indigenen Völker (vor allem der Krim-Tataren) sowie der nationalen Minderheiten (Juden, Polen, Ungarn, Rumänen). Die rivalisierenden Kirchen haben eine vergleichbare Unterstützung sowohl in der Gesellschaft als auch bei der politischen Elite. Sie haben außerdem gelernt, das Fehlen von Ressourcen durch etwas anderes 
Jelensky, Religionspluralismus, Religionsfreiheit und Entsäkularisierung

auszugleichen - die knappen Finanzen durch die positive öffentliche Meinung, die Misshelligkeiten mit den zentralen Behörden durch die Verständigung mit Machthabern vor Ort. Dies hat auch zu einem stabileren Gleichgewicht beigetragen. Die einseitigen Deklarationen über die Notwendigkeit, das Gleichgewicht zu stören, waren als rhetorische Floskeln zu betrachten. Dazu hatten die Parteien nicht genügend Potential, und für den Staat bedeutete der Status quo gesellschaftlichen Frieden.

Aus der konfessionellen Vielfalt wuchs nach und nach der konfessionelle Pluralismus heran, das heißt, die Akzeptanz der ganzen Variationsbreite durch Hauptakteure der ukrainischen religiösen Szene, die Möglichkeit für diese Akteure, eigene Besonderheiten, das »Anderssein«, zu erklären, sowie die Freiheit der Religionswahl.

Pluralismus und starker Wettbewerb kennzeichnen die ukrainische religiöse Landschaft, sie sind der Schlüssel zum Verständnis für die hier stattfindenden Prozesse. Sie haben dazu beigetragen, dass die Ukraine ordentliche Standards im Bereich der Glaubensfreiheit erreicht hat. Keine Kirche konnte alleine dominieren und religiöse Minderheiten diskriminieren. 2009 schnitt die Ukraine beim Index der staatlichen Einschränkung der Religionsfreiheit besser ab als alle anderen postsowjetischen Staaten mit Ausnahme von baltischen Ländern und sogar als einige EU-Mitgliedstaaten (Belgien, Bulgarien, Deutschland, Frankreich, Griechenland, Rumänien und die Slowakei). ${ }^{1}$ Im Index der staatlichen Eingriffe in die Belange der religiösen Gemeinschaften stand die Ukraine nach den baltischen Staaten ebenfalls am besten da. Dieser Index, der nach Kriterien wie staatliche Bevorzugung einer Religion, Regulierung des religiösen Lebens und Einstellung der Gesellschaft zur Religion ermittelt wird, lag für die Ukraine bei 19,99 Punkten. Hier schnitt das Land nicht nur besser als Russland, sondern auch als Ungarn, Polen, Bulgarien, Kroatien und Rumänien ab. ${ }^{2}$

1 Global Restrictions on Religion, 50-51.

2 Fox: A World Survey of Religion and the State, 14. 
Jelensky, Religionspluralismus, Religionsfreiheit und Entsäkularisierung

Freilich kann die Religionsfreiheit nicht isoliert von anderen Rechten und Freiheiten betrachtet werden, sie ist kaum erreichbar bei heutiger Behördenwillkür und aktuellem Zustand der Justiz in der Ukraine. Darüber hinaus ist eine religiöse Organisation derzeit besser geschützt als die religiöse Persönlichkeit. Der Gläubige steht nicht selten vor einem unerträglichen Dilemma - entweder akzeptiert er eine Bluttransfusion, die Arbeit am Samstag oder die individuelle Identifikationsnummer und begeht auf diese Weise eine Todsünde, oder er stirbt (lebt als Behinderter weiter, verliert Arbeit oder Rente). Die am wenigsten belastende Alternative, die zum Grundprinzip der internationalen Standards im Bereich der Religionsfreiheit wurde und die der Staat verpflichtet ist, einer Person anzubieten, wenn die Einschränkung ihrer Freiheit unvermeidbar ist, findet in der Ukraine nur begrenzt Anwendung (hauptsächlich beim Recht, den Zivildienst zu leisten). Trotzdem waren noch Ende 2010 etwa 77 Prozent der befragten Ukrainer der Meinung, dass es in ihrem Land »eine absolute Gewissensfreiheit und die Gleichheit der Religionen vor dem Gesetz « ${ }^{3}$ gäbe.

Die Situation hat sich nach den Präsidentschaftswahlen im Jahr 2010 dramatisch geändert. Der neugewählte Präsident Viktor Janukovyč hat bereits am ersten Tag den Wunsch signalisiert, das etablierte System der Beziehungen zwischen Staat und Kirche in der Ukraine zu revidieren - vor der Amtseinführung nahm er an einem Gottesdienst teil, der vom Patriarchen von Moskau und der ganzen Rus' Kirill zelebriert wurde. Janukovyčs Sicht auf die religiöse Situation in der Ukraine und ihre mögliche Entwicklung entstand unter dem Einfluss seines Beichtvaters, Schiarchimandrit Zosima (Sokur). Folgende Zeilen aus seinem geistlichen Vermächtnis gehören bei Gegnern der ukrainischen unabhängigen Kirche zu den beliebtesten Textpassagen: „Für den Fall einer Abkehr der Ukraine von Moskau, ob mit kanonischer oder nicht kanonischer Autokephalie, werden die Bindungen zum Kiever Metropoliten automatisch

3 Церковно-релігійна ситуація та державно-церковні відносини в Україні: підсумки десятиліття, тенденції і проблеми, 71.

DigiOst 3 | 215 
Jelensky, Religionspluralismus, Religionsfreiheit und Entsäkularisierung

getrennt. «Es ist weiter offensichtlich, dass Janukovyč auch die von den Würdenträgern und Sprechern des Moskauer Patriarchats wiederholt aufgestellte These verinnerlicht hat, das Kiever Patriarchat werde nur von politischen Säulen getragen und falle, sobald diese entfernt würden. Im Laufe des Jahres 2010 und in der ersten Hälfte des Jahres 2011 traf sich Präsident Janukovyč mehrmals mit Patriarch Kirill und ignorierte demonstrativ die Bitten des All-Ukrainischen Rats für Kirchen und Religiöse Organisationen um ein Treffen. Zu Weihnachten 2010/2011 gratulierte er ebenfalls demonstrativ nur den Orthodoxen und »vergaß « fast dreieinhalb Millionen Gläubige der Ukrainischen Griechischen Katholischen Kirche, die Weihnachten ebenfalls nach dem Julianischen Kalender feiern. Priester und Gemeinden des Kiever Patriarchats wurden unter Druck gesetzt, sich dem Moskauer Patriarchat anzuschließen. Es handelte sich dabei keinesfalls um »Auswüchse vor Ort«, da der Präsident die gesamte Macht im Lande hatte und ohne einen Impuls von oben diese Vorgänge nicht zu einer Tendenz geworden wären.

Der Präsident (wie auch der Ministerpräsident) wurde Mitglied im »Wirtschafts- und-Ethik-Rat « des Patriarchen Kirill, was außer ihm noch kein anderes Staatsoberhaupt auf dem »kanonischem Gebiet« der Russischen Orthodoxen Kirche gemacht hat. In seinem Amt - also im Namen des ukrainischen Staates, wie es in der Verfassung betont wird - leitete Janukovyč einige inhaltsschwere Schritte ein, die ernsthafte Veränderungen in den Beziehungen zwischen Staat und Kirche beweisen sollten.

Die Gesellschaft hat ziemlich schnell den Charakter und die Richtung dieser Veränderungen durchschaut. 2010 waren 29,4 Prozent der Befragten der Meinung, dass »die Macht alle religiösen Gemeinschaften in der Ukraine gleich behandelt«. 2013 teilten nur noch 22,8 Prozent diese Auffassung. Gleichzeitig wuchs die Anzahl der Bürger, die der Ansicht waren, dass es »Kirchen gibt, die von der Macht besser behandelt werden als die anderen«, von 24,3 auf 35,2 Prozent beträchtlich an. Und die Zahl jener, die glauben, dass es in der Ukraine »eine absolute Glaubensfreiheit und Gleichheit der Religionen vor dem Gesetz« 
Jelensky, Religionspluralismus, Religionsfreiheit und Entsäkularisierung

herrschen, ging auf zehn Prozent zurück. ${ }^{4}$ Auch beim Index der staatlichen Einschränkung der Religionsfreiheit rutschte das Land schlagartig ab. ${ }^{5}$

Doch es ist nicht gelungen, das konfessionelle Feld "neu zu formatieren." Die zum Konfessionswechsel aufgeforderten orthodoxen Gemeinden leisteten erbitterten Widerstand, und die Ukrainische Orthodoxe Kirche unter Jurisdiktion des Moskauer Patriarchats zeigte sich nicht bereit, die Verantwortung für Verfolgungen mit dem Staat zu teilen. Obwohl der Rückgang der Religionsfreiheit in der Ukraine, dem "am meisten pluralistischen Religionsmarkt in Osteuropa «, ${ }^{6}$ und im Ausland registriert wurde, beugte sich Janukovyč nicht. Die in seiner jährlichen Botschaft an das ukrainische Parlament formulierten Grundsätze über die Beziehungen zwischen Staat und Kirche standen im krassen Widerspruch zu allem, was der Präsident in diesem Bereich bislang praktiziert hatte. ${ }^{7}$ Das war das Eingeständnis der Fehlerhaftigkeit der »neuen Religionspolitik« und deren Fiasko.

Das Scheitern der Kirchenpolitik von Viktor Janukovyč in den Jahren 2010-2011 hätte eigentlich auf ein viel größeres Interesse bei den Beobachtern stoßen sollen, als dies tatsächlich der Fall war. In derselben Zeit ist es

4 Die Umfragen wurden vom Razumkov-Zentrum vom 18. bis 22. November 2010 und vom 28. Februar bis 6. März 2013 durchgeführt. In allen Regionen des Landes wurden 2001 bzw. 2010 Erwachsene über 18 Jahren befragt. Die Angaben hier und im Weiteren sind in der Zeitschrift Національна безпека і оборона 1/138 (2013), die vom Razumkov-Zentrum herausgegeben wird, zu finden unter: http:// www.razumkov.org.ua/ukr/files/category_journal/Zhrnl_Religy_2013_smll.pdf (24.09.2014).

5 Vgl. die Studie von Pew Research Center's Forum on Religion \& Public Life: Tide of Restrictions on Religion, 62.

6 Der Ausdruck stammt vom bekannten amerikanischen Religionssoziologen José Casanova. Vgl. Casanova: Incipient Religious Denominationalism in Ukraine and Its Effect on Ukrainian-Russian Relations, 9.

7 Модернізація України - наш стратегічний вибір. Щорічне Послання Президента України до Верховної Ради України, 42-43. 
Jelensky, Religionspluralismus, Religionsfreiheit und Entsäkularisierung

dem Präsidenten gelungen, die Verfassung und das Wahlrecht zu ändern, die Oppositionsführer ins Gefängnis zu schicken, dem ukrainischen Parlamentarismus einen empfindlichen Schlag zu versetzen sowie die Kontrolle über das Verfassungsgericht und die Judikative insgesamt zu erlangen. Die anvisierten Ziele im religiösen Bereich konnten jedoch nicht realisiert werden. Dieser Typ der Religionskultur, der einen so massiven Widerstand gegen den staatlichen Druck leisten konnte, ist viel stärker in der Ukraine verwurzelt als die junge und anfällige demokratische politische Kultur.

Die Stärke des Widerstands ist von der massiven Unterstützung einer religiösen Gemeinschaft abhängig, und mit diesem Widerstand musste das Regime rechnen. Eine solche Unterstützung ist durch eine Reihe von geschichtlichen Faktoren bedingt, am wichtigsten ist dabei jedoch die Rolle, die eine konkrete Konfession und - nicht weniger wichtig - eine konkrete Gemeinschaft im Prozess der Nationsbildung und/oder in dramatischen Momenten für die Nation gespielt hat. Solche Momente sind von sich aus ein Bestandteil der Nationsbildung, weil die Nation nicht ein erstarrtes Wesen, sondern nach Ernest Renan ein täglicher Plebiszit ist. Diese Rolle kann beträchtlich oder sogar entscheidend dort sein, wo a) die Grenzen der Ethnie, die gerade dabei ist, sich in eine Nation zu transformieren, mit den Religionsgrenzen übereinstimmen; b) die Religion das wichtigste oder sehr ausgeprägte Merkmal ist, das eine werdende Nation von anderen Nationen, mit denen sich eine solche Nation am ehesten vergleicht und von denen sie sich distanzieren will, unterscheidet; c) die nationsbildende Ethnie andere wichtige Merkmale der kollektiven Identität - etwa die Sprache oder das gemeinsame Territorium - eingebüßt hat; d) die Kirche die am stärksten institutionalisierte Kraft der Nationsbildung ist. ${ }^{8}$

8 Diese Problematik wird vom Verfasser ausführlich in folgendem Aufsatz erörtert: Yelensky: Globalization, Nationalism and Orthodoxy: the Case of Ukrainian Nation Building. 
Jelensky, Religionspluralismus, Religionsfreiheit und Entsäkularisierung

Im Falle der Ukraine kann man sich wohl darauf einigen, dass die Ukrainische Griechische Katholische Kirche Ende des 19. Jahrhunderts und im ersten Drittel des 20. Jahrhunderts eine besondere Rolle bei der Herausbildung der Identität der galizischen Ruthenen und in ihrer Selbstidentifizierung als Ukrainer gespielt hat.

Mit der Orthodoxie ist die Sache schwieriger. Die These, dass sie eine negative Rolle in der ukrainischen Nationsbildung gespielt hat, weil sie die sogenannte gesamtrussische Identität gefestigt hat, bedarf einer eingehenden Überprüfung. Erstens vermochte es die Russische Orthodoxe Kirche nicht, die aus der Sicht der russischen Kirchenführung schädliche Eigentümlichkeit der ukrainischen Eparchien aufzuheben. Zweitens war die Orthodoxie ein extrem wichtiges Identifikationsmerkmal für Bauern, vor allem in der rechtsufrigen Ukraine, in ihrem Konflikt mit der polnischen Szlachta und der jüdischen Bevölkerung. Für ukrainische Bauern waren eben die Polen und die Juden »die anderen ", einen Russen bekam ein durchschnittlicher Bauer möglicherweise sein Leben lang nicht zu Gesicht. Sogar Ende des 19. Jahrhunderts machten die Russen (oder die Großrussen nach der damals üblichen Terminologie) 5,9 Prozent der Bevölkerung im Gouvernement Kiev, 3,5 Prozent in Wolhynien und 3,3 Prozent in Podolien aus. ${ }^{9}$ Die Orthodoxie wurde von Bauern als klarer Demarkationsfaktor wahrgenommen, die soziale Distanz bekam einen religiösen Hintergrund, was eine größere Verbundenheit mit eigener Kirche und eigenem Glauben zur Folge hatte. Die Zeitzeugnisse aus der Mitte des 19. Jahrhunderts lassen eine größere religiöse Leidenschaft in der Bevölkerung der drei rechtsufrigen Gouvernements Kiev, Wolhynien und Podolien im Vergleich mit der Sloboden-Ukraine ${ }^{10}$ und besonders mit den Gouvernements Ekaterinoslav, Cherson und Taurien

9 Vgl. dazu: Первая всеобщая перепись населения Российской империи. Т. 8, viii.

10 Das Gouvernement Sloboda-Ukraine wurde 1835 in Gouvernement Charkiv umbenannt. 
Jelensky, Religionspluralismus, Religionsfreiheit und Entsäkularisierung

feststellen. Die Beobachter sprechen von der Frömmigkeit der »Kleinrussen in der Region Südwesten« (d.h. in der rechtsufrigen Ukraine) und betonen die religiöse Kälte der Einwohner »Neurusslands«. Mitte des 19. Jahrhunderts entfiel auf eine orthodoxe Kirche folgende Anzahl der »rechtsgläubigen Seelen beider Geschlechter «: im Gouvernement Podolien 689, im Gouvernement Wolhynien 839, im Gouvernement Kiev 1.201, im Gouvernement Černigov 1.208, im Gouvernement Charkov 1.611, im Gouvernement Poltava 1628, im Gouvernement Cherson 2.075, im Gouvernement Ekaterinoslav 2.377 und im Gouvernement Taurien 2.840. ${ }^{11}$

Dabei hoben die Beobachter hervor, dass die Kirchen im Süden der Ukraine von den Behörden gebaut wurden, die »sich höchste Mühe geben, um die abgekühlten religiösen Gefühle bei Menschen wieder zum Leben zu erwecken «, ${ }^{12}$ in der rechtsufrigen Ukraine wurden die Kirchen dagegen meistens von den Gemeindemitgliedern selbst errichtet. ${ }^{13}$ Sie finanzierten auch zum großen Teil

11 Vgl. dazu: Военно-статистическое описание Российской империи, издаваемое по Высочайшему повелению при 1-м Отделении Департамента Генерального Штаба. Том Х. Часть 3. Волынская губерния; Том XI. Часть 1. Херсонская губерния; Том. XII. Часть 1. Харьковская губерния; Том XII. Часть 2. Черниговская губерния; Том XII. Часть 3. Полтавская губерния; Том X. Часть 1. Киевская губерния; Том Х. Часть 2. Подольская губерния; Том XI. Часть 4. Екатиронославская губерния; Том ХІ. Часть 2. Таврическая губерния.

12 Материалы для географии и статистики России, собранные офицерами Генерального штаба. Том XI. Часть 2, 592.

13 Im Amtsbezirk Žytomyr sind die Angaben darüber, von wem die 44 Kirchen gebaut wurden, nicht erhalten geblieben; neun Kirchen wurden von Gemeindemitgliedern unter Einbeziehung staatlicher Fördermittel, sechs von Gemeindemitgliedern und Grundbesitzern, 18 von Grundbesitzern, zehn durch den Staat, zwei durch die Kirche selbst, eine von einem Kaufmann und 51 - die Mehrheit - von Gemeindemitgliedern gebaut. Vgl. dazu: Девятисотлетие православия на Волыни. 992-1892 г. Часть 2. Статистические сведения о приходах Волынской епархии, 1-20. Im Amtsbezirk Kiev hat der Adel 13 Kirchen, die hier im letzten Viertel des 19. Jahrhunderts bestanden, bauen lassen (darunter hat Mychajlo Berdjaev, der

DigiOst 3 | 220 
Jelensky, Religionspluralismus, Religionsfreiheit und Entsäkularisierung

die Pfarreischulen. ${ }^{14}$ Für diese Zeit kann man schon von der Herausbildung verschiedener Typen der Religionskulturen nicht nur in denjenigen Teilen des Landes sprechen, die zu verschiedenen Staaten gehörten, sondern auch in den Gebieten, die innerhalb eines Staates lagen. Diese unterschiedlichen Typen der Religionskultur wiesen starke Unterschiede beim Widerstand gegen die sowjetische Zwangssäkularisierung und bei der Überlebensfähigkeit unter der auf Vernichtung der Religion ausgerichteten Staatspolitik auf.

Daher haben die Prozesse, die im Laufe des letzten Vierteljahrhunderts in der Ukraine stattfinden und die in der Publizistik als »religiöse Wiedergeburt « und in der Religionssoziologie immer öfter als »Entsäkularisierung « bezeichnet werden, eine unterschiedliche Prägung in den Regionen des Landes. Der in den USA tätige Soziologe Vyacheslav Karpov schlägt vor, die Entsäkularisierung als Prozess der Gegensäkularisierung zu betrachten. Dabei gewinnt die Religion ihren sozialen Stellenwert zurück; je nachdem, wer die Entsäkularisierung einleitet und nach vorne treibt, kann sie »von unten « und »von oben « angetrieben werden. Um eine Entsäkularisierung »von unten« handelt es sich dann, wenn sie durch Gemeinschaften und von Gläubigen aus eigener Initiative betrieben

Großvater des berühmten Philosophen, die Kirche in Obuchiv gestiftet), die Kiever Bischöfe, Klostervorsteher und die Klöster haben neun Kirchen bauen lassen, der Staat finanzierte sieben Kirchen, jeweils eine Kirche haben ein Stadtbürger, ein Kaufmann und eine - offenbar wohlhabende - Bauernfamilie bauen lassen, 61 Kirchen wurden von den einfachen Gemeindemitglieder gebaut. Noch fünf Kirchen wurden von Gemeindemitgliedern mit staatlicher Unterstützung gebaut, und eine zusammen mit dem Gutsbesitzer. Im Amtsbezirk Vasylkiv des Gouvernements Kiev wurden fast alle orthodoxen Kirchen von Gemeindemitgliedern gebaut oder wieder aufgebaut. Vgl. dazu: Памятная книжка Киевской епархии, 3-27.

14 Beispielsweise wurden die Pfarreischulen in der Eparchie Kiev im Schuljahr 1895-1896 zu mehr als drei Vierteln durch Landgemeinden finanziert. Vgl. dazu: Отчет о состоянии школ церковно-приходских и народной грамоты Киевской епархии за 1895-1896 учебный год, 53-55. 
Jelensky, Religionspluralismus, Religionsfreiheit und Entsäkularisierung

wird. Die Entsäkularisierung »von oben« wird von Eliten sowie von politischer Führung und Kirchenleitung initiiert und vorangetrieben. ${ }^{15}$

Wie ging die Entsäkularisierung in der Ukraine vonstatten? 1988, im Jahr des 1000-jährigen Jubiläums der Taufe der Rus', das als Anhaltspunkt betrachtet werden kann, befanden sich 56 Prozent der ukrainischen Kirchengemeinden in sieben westukrainischen Gebieten, während im Donbass weniger als fünf Prozent, in den Gebieten Dnipropetrovs'k und Zaporižžja zusammen nur zwei Prozent beheimatet waren. Als es möglich wurde, ungehindert neue Gemeinden zu gründen, entstanden sie vorrangig nicht in den Regionen mit schwacher Präsenz der Kirche, sondern eben im Westen des Landes, wo die einfachen Menschen die wichtigste treibende Kraft hinter der Entsäkularisierung waren. Diese Menschen kümmerten sich um die Registrierung von Statuten neuer Gemeinden, restaurierten die ihnen zurückgegebenen, heruntergekommenen Kirchen und bauten neue Kirchen - all dies meistens auf eigene Kosten.

Mitte der 1990er Jahre waren 40 Prozent aller Kirchengemeinden in der Ukraine immer noch in Galizien und in Transkarpatien angesiedelt. Wann begann sich die Situation zu ändern? Dies geschah in dem Moment, als die Eliten im Süden und im Osten, die zunächst den für sie ziemlich uninteressanten geistigen und kulturellen Bereich im Tausch gegen die Handlungsfreiheit bei der Umverteilung des Volkseigentums an die "Nationalisten « abgetreten hatten, die Legitimierung von ihrem Vermögen und ihrem Einfluss auf die Tagesordnung setzten. Sie fingen an, die Orthodoxie als wichtige ideologische Ressource und die Kirche als Faktor für politische Mobilisierung und Herausbildung der regionalen Identität zu betrachten. Im Donbass beschleunigte sich der Kirchenbau - von 1992 bis 1997 wurden hier 21 Kirchen gebaut, 1998 kamen 13 neue hinzu, und 1999 waren es bereits 43. Die Kirchen wurden aber nicht von Berg- oder Hüttenarbeitern, sondern von Geschäftsleuten und der Obrigkeit errichtet, die wiederum die Unternehmer damit beauftragte. Der

15 Karpov: Desecularization: A Conceptual Framework, 232-270.

DigiOst 3 | 222 
Jelensky, Religionspluralismus, Religionsfreiheit und Entsäkularisierung

milliardenschwere Industrielle Viktor Nusenkis gründete in seinem Konzern Energo vor allem in der Region Donec'k 50 orthodoxe, baute hier 35 Kirchen und öffnete 15 Gebetsräume. Wie die Pressestelle des Ministerpräsidenten Viktor Janukovyč mitteilte, wurden zwischen 1996 und 2002 unter seiner Schirmherrschaft 63 Kirchen gebaut und 35 restauriert. ${ }^{16}$ Gleichzeitig stieß der Versuch der Stadtväter in Dymytriv, Gebiet Donec'k, die Bergarbeiter für den Bau der Kirche zu begeistern und sie dazu zu bewegen, ihren Tagelohn dafür zu spenden, auf heftigen Protest. ${ }^{17}$

Dies ist eine typische Entsäkularisierung "von oben«. Sie unterscheidet sich von der Entsäkularisierung "von unten « durch eine prinzipiell niedrigere Beteiligung einfacher Menschen am Leben der Kirche. Eine reguläre finanzielle Unterstützung der Kirche leisten 28,5 Prozent der Befragten im Westen des Landes und nur 3,7 Prozent im Osten; niemals haben eine Spende für die Kirche 6,9 Prozent der Befragten im Westen und 36,5 Prozent im Osten gemacht. Unter den Orthodoxen, die einer konkreten Konfession angehören, unterstützen 13,2 bis 13,8 Prozent ihre Kirche auf regulärer Basis, bei den Gläubigen der Griechisch-Katholischen Kirche liegt dieser Anteil bei 28,1 Prozent. ${ }^{18}$ Die Entsäkularisierung »von oben « weist durch gebaute Kirchen oder unzählige Weihen von Gebäuden und bei öffentlichen Zeremonien sichtbare institutionelle Resultate auf, sie wird aber nicht von ernsthaften Veränderungen im religiösen Verhalten begleitet. Die Anzahl der Gemeinden in den Gebieten Zaporižžja und Dnipropetrovs'k hat sich in den letzten 25 Jahren verzwanzigfacht, im Gebiet Cherson ist sie um das Fünfzehnfache gewachsen; die Kirchen besuchen dort einmal in der Woche oder öfter nur 4,9 bzw. 3,8 oder 2,1 Prozent der Befragen. In den westlichen Gebieten ist die Situation dagegen anders: in

16 Віктор Янукович відвідав Свято-Успенську Святогірську лавру.

17 В Донецкой области людей заставляют жертвовать на храм МП - депутат.

18 Razumkov: 2013. 
Jelensky, Religionspluralismus, Religionsfreiheit und Entsäkularisierung

Wolhynien sind es 19,5 Prozent, in Chmel'nyc'kyj 20 Prozent, in Ternopil' 36 Prozent, in Ivano-Frankivs'k 40 Prozent und in L'viv 49,4 Prozent. ${ }^{19}$

Eine viel stärkere Integration in die Belange der Kirche und eigener Kirchengemeinden führt zu einem wesentlich höheren Stellenwert der sozialen Rolle der Kirche und hat ein stärkeres Vertrauen zur Folge. Im Westen des Landes sind 74,8 Prozent der Befragen der Meinung, dass die Kirche eine positive Rolle in der ukrainischen Gesellschaft spielt, während es im Osten nur 38,8 Prozent sind; diese Ansicht teilen bei den Gläubigen des Moskauer Patriarchats 64,5 Prozent, des Kiever Patriarchats 66,8 Prozent und der Ukrainischen Griechischen Katholischen Kirche 82,3 Prozent. Davon, dass die Kirche keine sichtbare Rolle spielt, waren 16 Prozent der Befragten im Westen und 41,3 Prozent im Osten überzeugt; bei den Anhängern des Moskauer Patriarchats waren es 29,6 Prozent, beim Kiever Patriarchat 25,2 Prozent und bei der Griechisch-Katholischen Kirche 11,5 Prozent. ${ }^{20}$ Bei einer Entsäkularisierung "von unten" sind die Menschen vielmehr der Meinung, dass die Kirche die Interessen von Armen und Benachteiligten vertritt, und nicht von Reichen und Machthabern.

Die Entsäkularisierung "von oben « hat schließlich keine Auswirkungen auf die gesellschaftliche Moral. Dagegen weisen die Regionen, in denen die Bevölkerung ein konsequent religiöses Verhalten pflegt, die niedrigsten Raten bei Verbrechen, Selbstmorden, Abtreibungen, HIV-Infektionen usw. auf. ${ }^{21}$

19 Die Umfrage wurde im Rahmen des internationalen Forschungsprojekts »Region, Nation and Beyond. A Transcultural and Interdisciplinary Reconceptualization of Ukraine« durchgeführt. Im April 2013 wurden 6.000 Erwachsene, also Personen über 18 Jahre, in allen Regionen der Ukraine befragt.

20 Razumkov: 2013.

21 Vgl. dazu: ВІЛ-інфекція в Україні, 21; Домбровська (Нg.): Як нам зменшити кількість самогубств в Україні, 12-13; Статистичний збірник »Регіони України 2009«, 340. Andererseits kann eine ähnliche Abhängigkeit zwischen Religiosität und bürgerlichen Werten nicht festgestellt werden - obwohl die Beamten im Süden und im Osten des Landes öfter Bestechungsgeld einfordern, bietet man dieses im 
Jelensky, Religionspluralismus, Religionsfreiheit und Entsäkularisierung

Bei seiner Analyse der Entsäkularisierung "von oben", die nach seiner Auffassung in Russland stattfindet, prognostiziert Vjačeslav Karpov, dass sie letztlich zu einem spürbaren Rückgang der Frömmigkeit unter den Russen und zu den Austritten von jungen und gebildeten Menschen aus der Russischen Orthodoxen Kirche führen wird. ${ }^{22}$

Diese zwei sehr unterschiedlichen Modelle der Entsäkularisierung "von oben« und »von unten« mit einer deutlichen regionalen Prägung könnten die massiven regionalen Differenzen weiter verstärken, die konfessionellen Trennlinien festigen und im Endeffekt den Prozess der nationalen Konsolidierung untergraben. Gleichzeitig verhindern einige Faktoren die Eskalation nach einem solchen Szenario. Erstens stellen die Westukraine und der Donbass zwei Pole, zwei Extreme und zwei Idealmuster der Entsäkularisierung dar. Zwischen diesen Polen liegt die Zentralukraine, wo sich die beiden Modelle kreuzen und parallel wirken. Aber selbst im Donbass handelt es sich - wenn man die Situation dort unter die Lupe nimmt - nicht um ein reines Modell der Entsäkularisierung »von oben«. Sogar hier sehen wir eine Entsäkularisierung "von unten«, deren Akteure beispielsweise die Gläubigen der Evangelischen Kirche sind. Sie haben insgesamt 43 Prozent der Religionsgemeinden im Gebiet Donec'k gegründet, den Orthodoxen aller Konfessionen einschließlich Auslandskirche und Altgläubigen gehören dagegen 48 Prozent der Gemeinden. Zweitens verfolgen alle Hauptakteure der Religionsszene gesamtukrainische und nicht regionale Interessen, was ihre Führung mehrfach betont hat. ${ }^{23}$

Westen öfter freiwillig an. Vgl. dazu: Стан корупції в Україні. Порівняльний аналіз загальнонаціональних досліджень: 2007-2009, 2011, 34-38.

22 Karpov: The social dynamics of Russias desecularization: A comparative and theoretical perspective, 275-276.

23 Das trifft besonders auf die Ukrainische Griechisch-Katholische Kirche zu, die 80 Prozent der Gemeinden in Galizien und weitere elf Prozent in Transkarpatien stellt, ihren gesamtukrainischen Status aber sehr deutlich artikuliert und sich dafür einsetzt. Vgl. dazu unter anderem: Блаженніший Любомир Гузар: »Ми 
Jelensky, Religionspluralismus, Religionsfreiheit und Entsäkularisierung

Drittens bedeuten konfessioneller Pluralismus und Wettbewerb zwischen den Akteuren keinen unüberbrückbaren Gegensatz. Die Umfrageergebnisse zeigen ein anderes Bild. Eine Minderheit unter den Gläubigen verschiedener orthodoxen und der Griechisch-Katholischen Kirche vertritt die Meinung, dass nur ihre Religion die wahre ist: 19,2 Prozent der Gläubigen der Ukrainischen Orthodoxen Kirche des Moskauer Patriarchats (UOK [MP]), 13,2 Prozent beim Kiever Patriarchat (UOK-KP) und 12,3 Prozent bei der Ukrainischen Griechisch-Katholischen Kirche (UGKK). Gleichzeitig glauben 36,8 Prozent der Anhänger der UOK (MP) (36,2 Prozent bei der UOK-KP, 39,5 Prozent bei der UGKK), dass »jede Religion, die Gemeinwohl, Liebe und Barmherzigkeit predigt sowie die Existenz anderer Menschen nicht gefährdet, ein Existenzrecht hat." Besonders interessant fällt der Vergleich in den Regionen aus, in denen das Verhältnis zwischen den Orthodoxen nicht spannungsfrei ist. In Wolhynien war die Haltung gegenüber der UOK (MP) bei 81,5 Prozent der im Rahmen des Projekts Region, Nation and Beyond Befragten "gut ", gegenüber der UOK-KP bei 94,6 Prozent; für Transkarpatien liegen die ermittelten Umfragewerte bei 81,1 bzw. 93,8 Prozent, im Gebiet Rivne bei 77 Prozent für die UOK (MP) und 80 Prozent für die UOK-KP. Als »schlecht« sehen die UOK (MP) nur 5,4 Prozent der Ukrainer, die UOK-KP gar 1,8 Prozent. ${ }^{24}$ Viertens konnten die Kirchen trotz eines starken Wettbewerbs gemeinsame Forderungen an den Staat und eine gemeinsame Tagesordnung mit aktuellen Problemen der Gesellschaft formulieren. Die drei orthodoxen Kirchen, die Griechisch- und die Römisch-Katholische Kirche, die Armenische Kirche, die mitgliederstarken protestantischen Bewegungen sowie die jüdischen und muslimischen Verbände, die sich im Allukrainischen Kirchenrat zusammengeschlossen haben,

не $є$ провінційна Церква десь на краю України, куди нас хотіли відіпхати«; Любомир [Гузар, глава УГКЦ]. Один Божий Народ у краї на Київських горах. 24 Diese Zahlen gehen zurück auf eine 2013 durchgeführte Untersuchung innerhalb des internationalen Projekts »Region, Nation and Beyond. A Transcultural and Interdisciplinary Reconceptualization of Ukraine« (SNF Grant CR11I1L_135348).

DigiOst 3 | 226 
Jelensky, Religionspluralismus, Religionsfreiheit und Entsäkularisierung

treten mit wichtigen Initiativen auf, die über die Beziehungen zwischen Staat und Kirche hinausgehen. Zwischen 2011 und 2013 haben die Kirchenführer ein Programm zur Verbesserung der gesellschaftlichen Moral vorgeschlagen, sich um das Recht bemüht, ein Gnadengesuch einzureichen, den Präsidenten um die Begnadigung Julija Tymošenkos gebeten, die Rücknahme des durch die präsidententreue Parlamentsmehrheit verabschiedeten Sprachengesetzes von Kivalov-Koleničenko gefordert, ${ }^{25}$ das nach der Auffassung der Kirchen zur Spaltung des Landes beigetragen habe, und zweimal in Brüssel Überzeugungsarbeit bei EU-Beamten geleistet, um die Europäische Union zur Unterzeichnung des Assoziierungsabkommens mit der Ukraine im November 2013 zu bewegen. Als Antwort auf die Appelle der Kirchenführung der UOK (MP), UOK-KP und UGKK wurde die Initiative »Erster Dezember« gegründet, die sich zum Ziel gesetzt hat, »die kritische Masse der Bürger zu erreichen, die in Freiheit und in Wahrheit leben, ihr Handeln verantworten und sich für Moral in der Politik und Gemeinwohl einsetzen würden«.

Auch wenn der Staat von offenem Druck auf Kirchen und ihre Gläubigen abgesehen hat, will er seine Kontrolle über die Religionsgemeinschaften nicht lockern. Er ignorierte systematisch die Bitten des Allukrainischen Kirchenrats, manipulierte die religiösen Organisationen, machte sich immer wieder Probleme zunutze, die bei manchen Kirchen etwa mit Eigentum oder der Registrierung der Statuten auftreten, um sie zu erpressen, und versuchte, die Kirchen für eigene politische Interessen zu instrumentalisieren. 2012 hat die Parlamentsmehrheit entgegen ihrer früheren Zusicherungen die Änderungen

25 Dieses Gesetz von 2012 sollte dem Russischen bzw. der Sprache jeder anderen Minderheit den Status einer »Regionalsprache« geben, wo der Anteil der nationalen Minderheiten zehn Prozent der Gesamtbevölkerung eines definierten administrativen Bezirks übertraf. Gegner dieses Gesetzes fürchteten, dass die Annahme des Russischen als Minderheitensprache das Ukrainische unterminieren und zu einer Trennung zwischen der östlichen und westlichen Ukraine führen könnte.

DigiOst 3 | 227 
Jelensky, Religionspluralismus, Religionsfreiheit und Entsäkularisierung

zum Gesetz über die Gewissensfreiheit und religiöse Organisationen beschlossen, die bei den Kirchen auf einen aktiven Widerstand gestoßen sind. Die Oppositionspartei Bat'kivščyna sah darin den Rückfall in die sowjetischen Muster der Kirchenbeobachtung sowie den Wunsch, eine umfassende Kontrolle über den Glauben und das menschliche Gewissen zu etablieren. »Die Unterdrückung der Glaubensfreiheit«, hieß es in der Erklärung der Partei, »ist ein weiterer Schritt zu dem von der Partei der Regionen aufgebauten Polizeistaat und zur Etablierung eines autoritären Regimes, das selbst zur politischen Religion werden will und deswegen panische Angst vor einem Wettbewerb mit Kirchen und Religionsgemeinschaften hat, die sich für Würde und Freiheit der Menschen einsetzen. $\aleph^{26}$

Der staatliche Druck führt aber gleichzeitig dazu, dass die Kirchen im Kampf um ihre Interessen, die vielleicht nicht immer, aber doch sehr oft mit den gesellschaftlichen Interessen identisch sind, konsolidiert auftreten. Für die Schlüsselrolle der Kirchen und Religionsgemeinschaften in der heutigen Etappe der Nationsbildung in der Ukraine wird folglich nicht die Konsolidierung der Nation auf der Basis von gemeinsamen Glauben, Bräuchen und Symbolen entscheidend sein, sondern die Fähigkeit, in der Vorhut von tiefen gesellschaftlichen und moralischen Veränderungen zu stehen. In diesem Fall kann die Religion eine extrem wichtige Rolle für die Zukunft der Ukraine spielen.

\section{Literatur}

Віктор Янукович відвідав Свято-Успенську Святогірську лавру, 29.07.2014, unter http://www.kmu.gov.ua/control/publish/article?art_id=7627635 (16.02.2014).

26 Влада почала наступ на релігійну свободу.

DigiOst 3 | 228 
Jelensky, Religionspluralismus, Religionsfreiheit und Entsäkularisierung

Віктор Янукович відвідав Свято-Успенську Святогірську лавру. In: Прес-служба Кабінету Міністрів України, 29.07.2004, unter www.kmu. gov.ua/control/publish/article?art_id=7627635 (16.02.2014).

ВІЛ-інфекція в Україні. Інформаційний бюлетень 29 (2008).

Влада почала наступ на релігійну свободу, Ззаява Об'єднаної опозиції »Батьківщина«, 19.11.2012, unter http://gazeta.ua/articles/politics/_ vlada-pochala-nastup-na-religijnu-svobodu-zayava-batkivschini/467876 (23.09.2014).

Военно-статистическое описание Российской империи, издаваемое по Высочайшему повелению при 1-м Отделении Департамента Генерального Штаба. Том Х. Часть 3. Волынская губерния. - СПб: типография Департамента Генерального Штаба, 1850; Том XI. Часть 1. Херсонская губерния- СПб, 1849; Том. ХІІ. Часть 1. Харьковская губерния. - СПб, 1850; Том XII. Часть 2. Черниговская губерния. - СПб, 1851. Том XII. Часть 3. Полтавская губерния. - СПб, 1848. Том Х. Часть 1 Киевская губерния. - СПб, 1849. Том Х. Часть 2. Подольская губерния. - СПб, 1850. Том ХІ. Часть 4. Екатиронославская губерния. - СПб, 1850. Том XI. Часть 2. Таврическая губерния. - СПб, 1849.

В Донецкой области людей заставляют жертвовать на храм МП - депутат, 16.06.2011, unter http://podrobnosti.ua/society/2011/06/16/775814. html (16.02.2014).

Гузар, Любомир [Блаженніший]: »Ми не є провінційна Церква десь на краю України, куди нас хотіли відіпхати.« In: Високий замок, 21.04.2014. Гузар, Любомир: Один Божий Народ у краї на Київських горах. In: Патріярхат 4/383 (2004).

Девятисотлетие православия на Волыни. 992-1892 г. Часть 2. Статистические сведения о приходах Волынской епархии. Житомир 1892.

Домбровська, В., Як нам зменшити кількість самогубств в Україні. Проект міждисциплінарної програми суїцидальної превенції (громадська ініціатива). Одеса 2007.

DigiOst 3 | 229 
Jelensky, Religionspluralismus, Religionsfreiheit und Entsäkularisierung

Материалы для географии и статистики России, собранные офицерами Генерального штаба. Составил Генерального штаба полковник А. Шмидт. Том XI. Часть 2. Санкт-Петербург 1863.

Модернізація України - наш стратегічний вибір. Щорічне Послання Президента України до Верховної Ради України. Київ 2011.

Отчет о состоянии школ церковно-приходских и народной грамоты Киевской епархии за 1895-1896 учебный год. Киев 1897, 53-55.

Памятная книжка Киевской епархии. Историко-статистические сведения об учреждениях духовного ведомства Киевской епархии, статистические списки церквей епархии и общие статистические сведения по всем сторонам епархиальной церковно-религиозной жизни. Киев 1882.

Первая всеобщая перепись населения Российской империи. Т. 8. Санкт-Петербург 1897.

Стан корупції в Україні. Порівняльний аналіз загальнонаціональних досліджень: 2007-2009, 2011. Звіт за результатами соціологічних досліджень. Київ 2011.

Статистичний збірник »Регіони України 2009«. Київ 2009.

Церковно-релігійна ситуація та державно-церковні відносини в Україні: підсумки десятиліття, тенденції і проблеми, in: Національна безпека і оборона (2011) № 1-2 (119-120), 2-77.

Casanova, José: Incipient Religious Denominationalism in Ukraine and Its Effect on Ukrainian-Russian Relations. In: Harriman Review 40/9 (1996), $38-42$.

Fox, Jonathan: A World Survey of Religion and the State. New York 2008.

Karpov, Vyacheslav: Desecularization: A Conceptual Framework. In: Journal of Church and State 52/2 (2010), 232-270.

Karpov, Vyacheslav: The Social Dynamics of Russia's Desecularization: A Comparative and Theoretical Perspective. In: Religion, State and Society 41/3 (2013), 254-283.

DigiOst 3 | 230 
Jelensky, Religionspluralismus, Religionsfreiheit und Entsäkularisierung

Pew Research Center: Global Restrictions on Religion. Washington, DC 2009. Yelensky, Viktor: Globalization, Nationalism and Orthodoxy: the Case of Ukrainian Nation Building. In: Eastern Orthodoxy in a Global Age: Tradition Faces the Twenty First Century. Walnut Creek 2005, 144-178. http://www.razumkov.org.ua/ukr/files/category_journal/Zhrnl_Religy_2013_ smll.pdf (24.09.2014).

\section{Abstract}

\section{Viktor Jelensky}

Religious Plurality, Religious Freedom, and De-Secularization: The Case of Ukraine

In the 1990s and 2000s, religious pluralism and strong competition between churches led to a comparatively high level of religious freedom in Ukraine. Despite the fact that Victor Yanukovych's regime sought to brutally destroy the foundations of this freedom, the principal actors of the Ukrainian religious scene managed to define a common platform for defending their social, political, civic, cultural, and moral positions. The failure of Yanukovych's "religious policy «, directed mostly against the Kyiv Patriarchate and the Ukrainian Greek Catholic Church, is connected with the different roles played by local churches in the formation of the modern Ukrainian nation. The same factors lay behind the different types of desecularization that have unfolded in Ukraine since mid-1980s. At the present stage of the Ukrainian nation-building process, the key factor that will define the role of churches and religious organizations is not their attempts to consolidate the nation based on common customs, beliefs, and symbols. Rather, it is their ability to stay at the forefront of radical social and moral transformations. 
Katrin Boeckh - 978-3-86688-505-9 
Kirchen in autoritären Regimen 
Katrin Boeckh - 978-3-86688-505-9 


\section{Oleksandr Lysenko}

\section{Die Kunst des Möglichen: Die orthodoxe Kirche in der Ukraine im Zweiten Weltkrieg}

In der Geschichte der ukrainischen Orthodoxie gibt es nicht viele Episoden, die man mit den 20er und 30er Jahren des 20. Jahrhunderts vergleichen kann, die durchaus an die Verfolgungen der Christen im Alten Rom und ihre irrationale Grausamkeit erinnern. Unerklärliche Wendungen der Geschichte modellieren eine Situation nicht selten als ein »Déjà-vu«, aber mit anderen inhaltlichen Konnotationen und gesellschaftlich-politischen Kontexten. Der gegebene Zeitraum war für die orthodoxe Kirche durch die Notwendigkeit gekennzeichnet, eine Wahl zu treffen. Eigentlich fokussiert sich auch der Glaubensimperativ von Christen auf die Wahl zwischen Gut und Böse. Wenn aber die Rede von den Beziehungen zwischen Staat und Kirche in den 20er und 30er Jahren des 20. Jahrhunderts ist, sind kategorische Wertungen fehl am Platze oder kaum produktiv.

Der Aufruf von Metropolit Sergij I. (Stragorodskij), des damaligen Patriarchatsverwesers (1925-1943; dann bis 1944 Patriarch von Moskau und Ganz Russland), am 22. Juni 1941 zur Zusammenarbeit mit der bolschewistischen Macht wurde von vielen orthodoxen Priestern, insbesondere in der Emigration, beinahe als Verrat an der Kirche interpretiert. Doch wer die Geschichte des Stalinismus aufmerksam studiert hat und die Politik der sowjetischen Führung sowie die Besonderheiten des Staatsmechanismus kennt, muss zugeben, dass das Oberhaupt der Russischen Orthodoxen Kirche keine andere Wahl hatte. Die niederschmetternde Welle des militanten Atheismus mutierte bald von einer rein ideologischen Kampagne zu einer Strafaktion, in der nur die Suche nach einem Kompromiss und die absolute Loyalität den »Träumern in Kreml’" 
Lysenko, Die Kunst des Möglichen: Die orthodoxe Kirche in der Ukraine

gegenüber eine Chance boten, die kirchlichen Strukturen von einer totalen Zerschlagung zu retten.

Freilich kann man aus der heutigen Situation heraus in der Möglichkeitsform darüber sinnieren, welchen Weg die Geschichte genommen hätte, wenn das Oberhaupt der Russischen Orthodoxen Kirche sich gegenüber der »Diktatur des Proletariats « nicht kompromissbereit gezeigt hätte. Es ist aber bekannt, dass selbst nach dem Aufruf von Metropolit Sergij der politische Kurs einer massiven Einschränkung der orthodoxen Kirche keiner Korrektur unterzogen wurde. Mehr noch, die totale Vernichtung der Kirche und die Ausmerzung des religiösen Bewusstseins wurden offen als strategisches Ziel verkündet. Als eindeutiger Beweis dafür gilt der Beschluss des Politbüros des ZK der KP(b)U über die Auflösung orthodoxer Gemeinden (wie auch der Gemeinden anderer Konfessionen) 1929, der bis zum Angriff NS-Deutschlands auf die Sowjetunion in Kraft war. Darüber hinaus waren die Geistlichen unter den Opfern des Großen Terrors in den 1930er Jahren, was die orthodoxe Kirche der Führungsspitze, der Hierarchen und des Großteils des Klerus beraubte.

Bis zum Anfang des Zweiten Weltkriegs blieben in der Sowjetukraine lediglich rund 100 legale orthodoxe Priester, aber auch ihnen war es verboten, Gottesdienste zu zelebrieren. ${ }^{1}$ In den Gebieten Vinnycja, Donec'k, Kirovohrad, Mykolajiv, Sumy und Chmel'nyc'kyj wurden sämtliche orthodoxe Kirchen geschlossen, in den Regionen Luhansk, Poltava und Charkiv blieb jeweils nur eine Pfarrei. ${ }^{2}$ Von 1918 bis Anfang der 1940er Jahre kamen in der Sowjetunion fast 42.000 Geistliche um. ${ }^{3}$

In der Zweiten Rzeczpospolita wurde in den ukrainischen ethnischen Gebieten in der zweiten Hälfte der 1920er bis zur Mitte der 1930er Jahre die

1 Беркхоф: Чи було релігійне відродження в Україні під час нацистської окупації?, 17.

2 Одинцов: Хождение по мукам. 1930-1938, 56.

3 Поспеловский: Русская православная церковь в XX веке, 168. 
Lysenko, Die Kunst des Möglichen: Die orthodoxe Kirche in der Ukraine

Assimilierungspolitik umgesetzt. Dabei wurden in den Regionen differenzierte Ansätze verfolgt. So versuchte der wolhynische Woiwode Henryk Józewski, da die orthodoxe Kirche in Wolhynien besonders stark war, die ukrainische Bevölkerung für den polnischen Staat durch die Isolation von der "separatistischen Bewegung in Ostgalizien durch Festigung der sogenannten Konfessionsgrenze von Sokal ${ }^{4}$ zu "gewinnen«. Der Woiwode verfolgte den Kurs der »Toleranz der ukrainischen Bewegung in der orthodoxen Kirche und eine entschiedene Bekämpfung der Aktionen von Neu-Unierten «. ${ }^{5}$ Parallel zur Ukrainisierung der Orthodoxie (Einführung der ukrainischen Sprache in der Kirchenverwaltung, in den Gottesdiensten und im Religionsunterricht in den Schulen) versuchte die Administration der Woiwodschaft, polnische Einflüsse zu verstärken, insbesondere bei der Katechese in Schulen mit polnischer Unterrichtssprache, wenn die ukrainische Bevölkerung vor Ort keinen Widerstand leistete. ${ }^{6}$

In der Woiwodschaft Lublin waren die Assimilierungstendenzen noch deutlicher, was unter anderem in der Kampagne zur »Säuberung der Pfarreien von Priestern und anderen Personen, die als politisierende Ukrainer galten «, zum Ausdruck kam.

Ende der 1930er Jahre kam es zu Re-Polonisierungsaktionen in brutalsten Formen, die man als Konfessionsterror und sogar Völkermord qualifizieren könnte (auch wenn der Verfasser sehr vorsichtig gegenüber solchen Behauptungen ist). Durch Re-Polonisierungs- und Pazifizierungsaktionen haben die polnischen Behörden allein im Juni und Juli 1938 in Podlachien und im Chełm-Land 112 Kirchen abgerissen, darunter 98, die noch vor der Union von

4 Chojnowski: Koncepcje narodowościowej polityki rządów polskich w latach 1921-1939, 98.

5 Ebenda.

6 Из печати. Нужды и задачи церковной жизни, 125-126.

7 Стоколос: Конфесійно-етнічні трансформації в Україні, 213. 
Lysenko, Die Kunst des Möglichen: Die orthodoxe Kirche in der Ukraine

Brest gebaut worden waren. ${ }^{8}$ Erzbischof Oleksij (Hromads'kyj), der Sekretär des Wolhynischen Konsistoriums Ivan Vlasovs'kyj und andere orthodoxe Würdenträger wie auch der Großteil des Kirchenvolkes bewerteten nicht nur den offiziellen Kurs Warschaus gegenüber der ukrainischen Orthodoxie negativ, sondern auch die Perspektiven für die Verständigung zwischen der orthodoxen Kirche und radikalen polnischen Politikern auf dem widersprüchlichen konfessionellen Feld. ${ }^{9}$

Der Hitler-Stalin-Pakt vom August 1939 veränderte die Situation schlagartig. Zum Generalgouvernement kamen das westliche San-Land, das Lemken-Land, Podlachien und das Chełmer Land; Wolhynien und Ostgalizien wurden dagegen mit der Sowjetukraine »wiedervereinigt«, wie es in der sowjetischen Propaganda hieß. Ein wesentlicher Teil der 500.000 Ukrainer in der deutschen Besatzungszone gehörten nun zur Eparchie Warschau-Chełm mit Metropolit Dionysios (Valedyns'kyj) als Oberhaupt der orthodoxen Kirche im ehemaligen Polen an der Spitze. Die Eparchien Wolhynien, Polessien, Wilna und Hrodno kamen in die sowjetische Zone. Es stellte sich sofort die Frage der Verwaltung dieser Eparchien. Die Synode, zu der die Erzbischöfe Oleksandr (von Polessien und Pinsk) und Oleksij (von Wolhynien und Kremenec') gehörten, bestätigte Ende 1939 den Status quo, das heißt die Unterordnung unter Metropolit Dionysios.

In Moskau musste man der Tatsache Rechnung tragen, dass mit den neugewonnenen Gebieten mehr als 3.000 orthodoxe Pfarreien, 64 Klöster (davon 19 in der Westukraine), einige Priesterseminare und 7,5 Millionen Gläubige hinzukamen. ${ }^{10}$ Auch wenn Stalin die Grundsätze der antikirchlichen Politik nicht aufgegeben hatte, musste das Regime in den neu erworbenen Regionen

8 Пастернак: До 45-ліття руйнування українських православних церков на Холмщині та Підляшші, 388.

9 Власовський: Митрополит Олексій Громадський: 1943-1963, 7.

10 Шкаровский: Русская Православная Церковь при Сталине и Хрущёве: государственно-церковные отношения в СССР в 1939-1964 годах, 102.

\begin{tabular}{l|l} 
DigiOst 3 & 238
\end{tabular} 
Lysenko, Die Kunst des Möglichen: Die orthodoxe Kirche in der Ukraine

etwas zurückhaltender agieren. Allerdings waren Erpressung, wirtschaftliche Sanktionen, fiskalische Maßnahmen sowie Aktionen der Geheimdienste als erprobte Methoden zur Bändigung der Andersdenkenden auch hier alltägliche Praktiken. Zusammen mit Verhaftungen, Deportationen und Ermordung von Geistlichen und religiösen Aktivisten nahm dies die Züge von Terror an.

Die Lösung der konfessionellen Frage wurde vom Kreml' als selbstverständlich betrachtet. Dort konnte man sich nicht vorstellen, dass sich zahlreiche Pfarreien und die Kirchenführer einem Zentrum im Ausland unterordnen würden. Im Sommer 1940 wurden die gesamte Kirchenspitze der westlichen Regionen von Weißrussland und der Ukraine nach Moskau bestellt, wo sie gezwungen wurde, alle Formalitäten zu erledigen und sich unter die Obhut der Russischen Orthodoxen Kirche zu begeben. Die Erzbischöfe Oleksij (Hromads'kyj) und Pantelejmon (Rožnovs'kyj), die Bischöfe Antonius (Marčenko) und Simon (Ivanivs'kyj) haben die "gebetskanonische Vereinigung mit der Moskauer Mutterkirche" akzeptiert. Allerdings haben sich der Erzbischof von Polessien und Pinsk Oleksandr (Inozemcev) und der Bischof von Luc'k Polykarp (Sikors'kyj) für einen anderen Weg entschieden. Sie setzten sich über den Befehl hinweg und reisten nicht nach Moskau. Oleksandr (Inozemcev) wurde sofort suspendiert, Polykarp (Sikors'kyj) wurde dagegen einfach ignoriert. Sein Amt wurde an Nikolaus Jaruševič als Erzbischof von Wolhynien und Luc'k übertragen, gleichzeitig wurde der letztere zum Exarchen der Ukraine ernannt. Im März 1941 wurde er zum Metropoliten befördert.

Dieser Schritt der sowjetischen Führung war Teil einer ausgeklügelten Kombination, die zunächst die Russische Orthodoxe Kirche in der Region stärken sollte. Danach sollte sich die Russische Orthodoxe Kirche die Griechisch-Katholische Kirche einverleiben und die Römisch-Katholische Kirche in Galizien schwächen. Anschließend sollte die orthodoxe Kirche liquidiert werden.

Waren die Kirchenführung, der Klerus und die Gläubigen auf diese Transformationen nach innen und nach außen vorbereitet? Eine davon war die neue 
Lysenko, Die Kunst des Möglichen: Die orthodoxe Kirche in der Ukraine

Jurisdiktion der westukrainischen Eparchien. Ganz offensichtlich war dies eine schicksalhafte Herausforderung, und die Entscheidungen standen meist im Widerspruch zum eigenen Gewissen, Pflichtgefühl und Würde sowie zu persönlichen weltanschaulichen und politischen Vorstellungen.

Doch das Schicksal hielt für die orthodoxe Kirche noch eine weitere Prüfung parat. Der Angriff Deutschlands und seiner Verbündeten auf die Sowjetunion, die schnelle Besetzung von riesengroßen Gebieten, darunter der gesamten Ukraine, haben die gesellschaftspolitische Konfiguration schlagartig verändert. Der Klerus stand wieder vor der Wahl, deren Preis das menschliche Leben werden konnte.

Die Bildung von neuen territorialen Verwaltungseinheiten in den von der Wehrmacht besetzten ukrainischen Gebieten ließ wiederholt die Frage über die Verwaltung der orthodoxen Kirche aufkommen. In Berlin gab es keine klaren Vorstellungen, wie man das Leben der religiösen Gemeinden organisieren solle. Man war sich jedoch des Potentials der orthodoxen Kirche bewusst, daher kamen zunächst ziemlich moderate Weisungen aus der Zentrale. Einer der SD-Leiter, Reinhard Heydrich, legte nahe, »keine Maßnahmen gegen den Wunsch der orthodoxen Kirche zur Ausbreitung ihres Einflusses auf die Massen zu ergreifen. Im Gegenteil, man soll dies fördern und bei dieser Gelegenheit auf Trennung der Kirche vom Staat dringen, jedoch die Bildung einer einheitlichen Kirche verhindern. $\ll^{11}$

In diesem und in anderen Dokumenten kann man das Kalkül erkennen, die orthodoxe Kirche als die einzige nicht-staatliche Struktur, die bei der lokalen Bevölkerung Autorität hatte, zum fügsamen und effizienten Instrument für die Mobilisierung der Menschen zu machen, damit diese die Verordnungen der Besatzungsadministration befolgten. Tatsächlich überschätzten die Besatzungsbehörden die Möglichkeiten der orthodoxen Kirche. Sie war atomisiert

11 Zitiert nach: Осадчук: Секретна справа рейху. ОУН-УПА в донесеннях німецької розвідки, 141.

DigiOst 3 | 240 
Lysenko, Die Kunst des Möglichen: Die orthodoxe Kirche in der Ukraine

und demoralisiert, vermochte nicht, ihre Struktur sofort wiederaufzubauen und folglich die auferlegten Funktionen zu erfüllen.

Die wichtigsten Richtlinien der Politik der deutschen Verwaltung wurden in zahlreichen Weisungen, Richtlinien und Verfügungen konkretisiert. So schickte Alfred Rosenberg, der Reichsminister für die besetzten Ostgebiete, am 18. November 1941 eine Verfügung an den Reichskommissar der Ukraine Erich Koch, in der Kirchen und Sekten untersagt wurde, sich mit Politik zu befassen und öffentliche Erklärungen abzugeben. Die Bischöfe sollten nicht die Interessen des ukrainischen Volkes repräsentieren, sondern de facto durch das Reichsministerium für die besetzten Ostgebiete ernannte Beamte sein. ${ }^{12}$

Am 13. Mai 1942 erschien die Verordnung des Reichsministers, die betonte, dass die Kirchenverwaltung der Struktur von militärischen Verwaltungseinheiten entsprechen sollte: Das Gebiet einer Eparchie sollte einen Generalbezirk umfassen. Zugelassen waren zwei Eparchien in einem Bezirk - jeweils für die Autonome und für die Autokephale Orthodoxe Kirche. Das Auftreten von zwei orthodoxen Kirchen verkörperte die Tendenz zur Ukrainisierung der Kirche und zu deren Unabhängigkeit von der Russischen Orthodoxen Kirche. Diese Tendenz war nicht nur beim Klerus, sondern auch in der Gesellschaft sichtbar. Im Sommer 1941 gründeten die Bischöfe, die sich vorher unter die Obhut des Moskauer Patriarchats begeben hatten, die Autonome Orthodoxe Kirche mit Oleksandr (Hromads'kyj) als Oberhaupt. Gleichzeitig verkündeten die Bischöfe, die sich für Autokephalie in der ukrainischen Orthodoxie einsetzten, auf der Synode in Pinsk im Februar 1942 die Gründung der Ukrainischen Autokephalen Orthodoxen Kirche (UAOK) sowie ihre organische Verbindung mit der 1921 gegründeten UAOK. Um die Fragen der inneren Struktur und der Unterordnung der UAOK zu lösen, sanktionierte Reichskommissar Rosenberg die Ernennung von Bischof Polykarp (Sikors'kyj) zum »zeitweiligen Verwalter der Autokephalen Orthodoxen Kirche auf den befreiten Gebieten der Ukrai-

12 Косик: Україна і Німеччина у Другій світовій війні, 187.

DigiOst 3 | 241 
Lysenko, Die Kunst des Möglichen: Die orthodoxe Kirche in der Ukraine

ne«, da Metropolit Dionysos die Kirche im Reichskommissariat Ukraine aus Warschau nicht leiten konnte und die Bewegungsmöglichkeiten zwischen verschiedenen Besatzungszonen beschränkt waren.

Als Teil einer komplizierten Intrige, deren Ziel eine totale Kontrolle über das religiöse Leben war, erhob die deutsche Führung Erzbischof Serafim (Ljade) zum Metropolit und ernannte ihn zum Oberhaupt aller Orthodoxen im Dritten Reich sowie in den besetzten Gebieten. Aus den bereits erwähnten Gründen konnte Serafim (Ljade) seine neue Funktion nicht ausüben, deswegen erwies sich diese Idee als Fiktion.

Berlin schuf also die rechtliche Grundlage für die orthodoxen Institutionen und hoffte, dass die existierenden orthodoxen Gemeinschaften sich in deren Rahmen bewegen werden. Allerdings waren nicht alle Würdenträger - trotz ihrer erklärten Loyalität zur Besatzungsmacht - willige Vollzieher deutscher Verordnungen. Die Bewegung für die Wiedergeburt der UAOK mit Status eines Patriarchats, deren schillerndste Persönlichkeit Erzbischof Hilarion von Chełm und Podlachien war, nahm solche Züge an, dass ihre klare politische Komponente nach Überzeugung deutscher Behörden eine Gefahr für die Interessen des Dritten Reiches darstellte. In einem von Hilarion verfassten »Memorandum über die künftige Struktur der Ukrainischen Orthodoxe Kirche« vom 31. August 1941 betonte er, die UAOK solle zum Rückgrat der Wiedergeburt werden. ${ }^{13}$ Indes formulierte Erzbischof Oleksandr (Hromads'kyj) mit seinen Anhängern sein eigenes Konzept, demgemäß sich die ukrainische orthodoxe Kirche auf Autonomiebasis unter der Judisdiktion des Moskauer Patriarchats entwickeln sollte.

Ein weiterer Flügel der autokephalen Bewegung entstand mit dem Allukrainischen Orthodoxen Kirchenrat. Einer der Leiter dieser Institution, Pantelejmon Rudyk (M. Rybačuk), definierte ihre Position wie folgt: »Die

13 Міненко: Православна Церква в Україні під час Другої світової війни 1939-1945, 229.

DigiOst 3 | 242 
Lysenko, Die Kunst des Möglichen: Die orthodoxe Kirche in der Ukraine

ukrainische Kirche soll nicht nur ein religiöses, sondern auch ein politisches Zentrum sein, dessen Aufgabe darin besteht, den Kampf für die unabhängige Ukraine zu führen und die Ukraine im nationalen Geiste zu erziehen. « ${ }^{14}$ Dank dem Rat breitete sich die Bewegung für die Ukrainisierung der orthodoxen Kirche in der Bevölkerung aus.

Die unterschiedlichen Visionen für die Perspektiven der Orthodoxie unter neuen Bedingungen verschärften die Widersprüche zwischen der autonomen und autokephalen Kirchenführung, die im Frühjahr 1942 schon beinahe persönlich ausgetragen wurden. In die Angelegenheit schaltete sich sogar der Metropolit der Griechisch-Katholischen Kirche, Andrej Šeptyc'kyj (1901-1944), ein, der die orthodoxen Bischöfe zur Verständigung aufrief.

Die Autokephale Kirche hatte nur wenige Bischöfe, deswegen hielt man die Weihe für die einzig mögliche Lösung des Problems. Auf der Synode in Pinsk vom 8. bis 10. Februar 1942 wurden drei neue Bischöfe geweiht: Nikanor (Abramovyč), Ihor (Huba) und Jurij (Korenistov). Zunächst sprachen die Autonomisten wie nach der Rückkehr der Sowjetmacht dann auch die Russische Orthodoxe Kirche bei diesen neuen Bischöfen von »Selbstweihe«.

Die deutschen Behörden spürten die klare Politisierung der autokephalen Bewegung und lösten am 11. Februar 1942 den Allukrainischen Orthodoxen Kirchenrat auf, bald wurde Rybačuk verhaftet.

Ab Juni 1942 änderten sich die Beziehungen zwischen den Oberhäuptern der Autonomen und der Autokephalen Kirche, bedingt durch den beiderseitigen Wunsch, den Streit zu beenden und sich aufeinander zuzubewegen. Nach Beratungen unterzeichneten Metropolit Oleksij, Erzbischof Nikanor und Bischof Mstyslav am 8. Oktober 1942 in Počajiv trotz des Verbots der Besatzungsbehörden den »Vereinigungsakt « zweier Kirchen. Die Bischöfe der Autonomen Kirche hatten jedoch Metropolit Oleksij unter Druck gesetzt,

14 Центральний державний архів вищих органів влади і управління України: F. 3676, op. 4, spr. 474, ark. 329.

DigiOst 3 | 243 
Lysenko, Die Kunst des Möglichen: Die orthodoxe Kirche in der Ukraine

wonach er seine Unterschrift widerrief. Noch ein Grund dafür war die Forderung deutscher Behörden, den Akt zu desavouieren. Der von Erich Koch, dem Reichskommissar der Ukraine, bestimmte Stellvertreter Paul Dargel zitierte zunächst Oleksij, dann Mstyslav zu sich und bewertete den Beschluss von Počajiv äußerst negativ. Mstyslav wurde verboten, seine Eparchie zu verlassen, später wurde er verhaftet und in Gefängnissen von Kiev, Žytomyr, Černihiv und Pryluky gehalten, bis er schriftlich erklärte, sich von politischen Angelegenheiten fernzuhalten. ${ }^{15}$

Das Zusammenspiel von objektiven und subjektiven Faktoren machte es unmöglich, die orthodoxen Kirchen in der Ukraine zu vereinigen. Wenn anfangs Berlin die Ukrainische Autokephale Kirche für ihre antibolschewistische Position unterstützte, betrachtete man später ihre klare unabhängige Linie als reale Gefahr für Hitlers Pläne. Um die Balance herzustellen, fingen die Besatzungsbehörden an, die Autonome Orthodoxe Kirche stärker zu tolerieren, die Autokephalen spürten dagegen einen immer größeren Druck.

Neben den komplizierten Beziehungen zu den Besatzern mussten die Würdenträger der Autonomen und Autokephalen Kirche auch andere, manchmal sogar gegensätzliche Faktoren berücksichtigen. Es handelt sich um sowjetische Partisanen und Untergrundkämpfer sowie um die ukrainische Unabhängigkeitsbewegung. Der Unwille der Priester, mit der einen oder der anderen Seite zusammenzuarbeiten, kostete nicht wenigen das Leben. Deswegen traf jeder seine eigene Wahl.

Die Rückkehr der Sowjetmacht stellte den orthodoxen Klerus wieder vor die Wahl. Diejenigen, die nicht in die Hände des Geheimdienstes gerieten, mussten sich registrieren lassen, von der Lebendigen bzw. Autokephalen Kirche lossagen, Buße tun und sich unter die Obhut des Moskauer Patriarchats begeben. Einige wählten die Emigration, die anderen gaben die Seelsorge auf.

15 Ebenda, spr. 476, ark. 970.

DigiOst 3 | 244 
Lysenko, Die Kunst des Möglichen: Die orthodoxe Kirche in der Ukraine

Zusammenfassend lässt sich feststellen, dass sich die Konfliktzone zwischen den "großen« Konfessionen und den herrschenden Regimes auf dem Territorium der Ukraine in der Kriegszeit auf sämtliche Bereiche ihrer Wirkung erstreckte.

1. Es ging vor allem um mentale und ideologische Unterschiede in den weltanschaulichen Grundsätzen des Christentums auf der einen Seite und verschiedene Formen des Autoritarismus und Totalitarismus auf der anderen. Die Rassenideologie des Nationalsozialismus und die Klassenideologie des Bolschewismus standen im Konflikt zur christlichen Glaubenslehre in den für das Leben der Gesellschaft grundlegenden Fragen. Indem sie einzelnen ethnischen, sozialen und politischen Gruppen das Existenzrecht absprachen, stellten die totalitären Regimes die Gleichheit aller Menschen vor Gott in Frage. Im Falle der Juden handelte es sich um die Vernichtung einer riesigen ethno-konfessionellen Gemeinschaft durch die Nationalsozialisten.

2. Die totalitären Regimes machten illegale Formen sozialer Aktivitäten so gut wie unmöglich. So verzweigte Strukturen wie große konfessionelle Gemeinschaften mit einem spezifischen Ritus konnten in der Situation einer totalen Kontrolle einer aufmerksamen Beobachtung der Geheimdienste nicht entkommen. Unter diesen Bedingungen haben die großen Kirchen aus zwei Alternativen - entweder in der Versenkung zu verschwinden oder mit der Macht zusammenzuleben - letztere gewählt. Diese Wahl ist nicht unter moralischem, sondern unter dem kanonischen Gesichtspunkt zu werten, demgemäß sich die Kirche jeder Macht unterordnen solle.

Eine andere Sache ist, dass diese Beziehungen und deren Inhalte von den Machthabern definiert wurden. Durch Zwang und Erpressung nötigten sie den Klerus zu Handlungen, die man schwer beurteilen kann, wenn man sich nicht im Klaren darüber ist, dass die totalitären Regimes die Religionsgemeinschaften in Mobilisierungsinstrumente, eine gewisse Ergänzung zum Staatsmechanismus, verwandeln wollten.

DigiOst 3 | 245 
Lysenko, Die Kunst des Möglichen: Die orthodoxe Kirche in der Ukraine

3. Der Krieg kristallisierte aufs Äußerste das Problem der Wahl zwischen Leben und Tod nicht nur auf der individuellen, sondern auch auf der kollektiven Ebene heraus. Dabei war die Zugehörigkeit zu einer der sozialen, weltanschaulichen oder politischen Gruppe eine reale Gefahr für das Leben. Unter diesen Bedingungen bleibt weiter festzustellen, inwieweit die Kirche ihre Mission erfüllt hat, die Verfolgten und Rechtlosen zu schützen und sie von den Schicksalsschlägen zu bewahren, die Folgen des Krieges und die todbringenden Maßnahmen der Macht zu mildern, und inwieweit sie daran von letzterer gehindert wurde.

Im Zusammenhang damit steht das Problem der Beziehungen zwischen den religiösen Organisationen und der Macht. Es muss noch erforscht werden, inwieweit die Zusammenarbeit der orthodoxen Kirche mit der Besatzungsmacht zu einer Kooperation wurde, die den Bestand einer Straftat aufwies und dementsprechend einer Strafverfolgung ausgesetzt werden sollte. Es ist sehr wichtig, die Grenzen der moralischen Verantwortung von Geistlichen zu definieren, die in einem existentiellen Prokrustesbett von allerlei Einschränkungen und Verboten agierten. Der Krieg zwang nicht nur die orthodoxe Kirche, sondern auch jeden Priester und jeden Gläubigen dazu, eine Wahl zu treffen.

Der Glaube gewährte in der Zeit massenhaften Leidens und der Banalisierung des Todes geistigen Rückhalt, er heilte die Wunden schmerzhafter Verluste und Enttäuschungen, sorgte für Elan, Standhaftigkeit und Mut im Kampf. Gleichzeitig gab es Zweifel und Angst, Verrat und Eigennutz, Gefühlskälte und Gleichgültigkeit, geistige Blindheit und Taubheit. Die Menschheit zeigte wieder einmal - wie nie zuvor - mit abscheulichem Freimut die fehlende Immunität gegen Gewalt, Gemeinheit und die Versuchung, das eigene Leben auf Kosten anderer Menschenleben zu retten. Doch ist die Kirche schuld daran? 
Lysenko, Die Kunst des Möglichen: Die orthodoxe Kirche in der Ukraine

\section{Literatur}

Chojnowski, Andrzej: Koncepcje narodowościowej polityki rządów polskich w latach 1921-1939. Warszawa, Wrocław, Kraków, Gdańsk 1979.

Беркхоф, Карел: Чи було релігійне відродження в Україні під час нацистської окупації? In: Український історичний журнал 3 (2005), 16-36.

Власовський, Іван: Митрополит Олексій Громадський: 1943-1963. In: Українське Православне Слово 8 (1963), 5-7.

Из печати. Нужды и задачи церковной жизни. In: Воскресное чтение 8 (1933), 125-126.

Косик, Володимир: Україна і Німеччина у Другій світовій війні. Париж, Нью-Йорк, Львів 1993.

Міненко, Тимофій: Православна Церква в Україні під час Другої світової війни 1939-1945: Т. 1 (Волинський період). Вінніпег, Львів 2000.

Одинцов, Михаил: Хождение по мукам. 1930-1938. In: Наука и религия 7 (1990), 56-57.

Осадчук, Петро: Секретна справа рейху. ОУН-УПА в донесеннях німецької розвідки. In: Biче 4 (1992), 136-151.

Пастернак, Євген: До 45-ліття руйнування українських православних церков на Холмщині та Підляшші. In: В обороні віри: Збірник статей, присвячений 1000-літтю хрещення України в 988 р.: Ч. 5. Торонто $1984,69-74$.

Поспеловский, Дмитрий: Русская православная церковь в XX веке. Москва 1995.

Стоколос, Надія: Конфесійно-етнічні трансформації в Україні (XIX - перша половина XX ст.). Рівне 2003.

Шкаровский, Михаил: Русская Православная Церковь при Сталине и Хрущёве: государственно-церковные отношения в СССР в 1939-1964 годах. Москва 1992. 
Lysenko, Die Kunst des Möglichen: Die orthodoxe Kirche in der Ukraine

Поспеловский, Дмитрий: Русская православная церковь в XX веке. Москва 1995.

Стоколос, Надія: Конфесійно-етнічні трансформації в Україні (XIX - перша половина XX ст.). Рівне 2003.

Шкаровский, Михаил: Русская Православная Церковь при Сталине и Хрущёве: государственно-церковные отношения в СССР в 1939-1964 годах. Москва 1992.

\section{Abstract}

\section{Oleksandr Lysenko}

The Art of the Possible: The Orthodox Church in Ukraine during the Second World War

Until 1939, the state apparatus massively repressed the Orthodox Church in Soviet Ukraine. During the Second World War, German forces occupied Ukraine, turning into the Reichskommissariat Ukraine. Here, Orthodox churches were instrumentalized to mobilize the population. In both the Soviet and occupied situations, large numbers of Orthodox representatives collectively chose to obey the regimes, in order to secure the institutional existence of the Church and to conduct religious and social services. More research is needed on Church activities to help endangered persons and to conduct social and humanitarian support under the constraint of totalitarian regimes. 


\section{Natalja Šlichta}

\section{"Verschieden « und »Identisch «: Orthodoxe und griechisch-katholische Gläubige in der Ukrainischen Sowjetrepublik nach dem Zweiten Weltkrieg}

Von 8. bis 10. März 1946 fand in Lemberg eine »Synode« der Ukrainischen Griechisch-Katholischen Kirche (UGKK) statt. Wie auch andere ähnliche kirchliche Synoden (z.B. die Dritte All-Ukrainische Orthodoxe Synode der Ukrainischen Autokephalen Kirche am 28. und 29. Januar 1930), die unter dem unmittelbaren Druck und mittels bewaffneter Kräfte des stalinistischen Staates durchgeführt wurden, führte diese zur »Selbstliquidation«. »Im Namen der gesamten Geistlichkeit und der Gläubigen « dieser Kirche in Galizien tat sie den Wunsch kund, »die Beschlüsse der Synode von Brest-Litovsk von 1596 aufzuheben, die Union zu liquidieren, sich vom Vatikan zu lösen und $\mathrm{zu}$ unserem väterlichen heiligen orthodoxen Glauben und der Orthodoxen Kirche der Rus' zurückzukehren. « ${ }^{1}$ Als Ergebnis der Lemberger Pseudo-Synode und einer drei Jahre später durchgeführten Liquidationsaktion in der Karpaten-Ukraine ${ }^{2}$ beendete die UGKK ihre institutionelle Existenz innerhalb der Grenzen der UdSSR. Ihre Geistlichkeit und ihre Gläubigen wählten entweder eine Untergrund-Existenz, wandten sich der römisch-katholischen Kirche zu oder aber traten, in der überwiegenden Mehrheit, zur Orthodoxie über, wie es von ihnen verlangt wurde.

1 Сергійчук: Нескорена Церква, 109.

2 Die Liquidierung der Kirche in der Karpaten-Ukraine wurde administrativ vollzogen, ohne ein »Selbst-Liquidations-Konzil«. Sie wurde als vollendete Tatsache am 29. Juni 1949 während der Feier des Festes Christi Himmelfahrt im St.-Nikolaus-Frauenkloster in der Stadt Mukačevo verkündet. 
Šlichta, »Verschieden« und »Identisch»

Der Prozess der »Wiedervereinigung « mit der Russischen Orthodoxen Kirche (ROK) und der weiteren Überführung in die »Orthodoxie« (opravoslavlenn$\mathrm{ja} / »$ Orthodoxierung «) - oder aber, in der Sprache kirchlicher Dokumente, der »orthodoxen Einkirchung « (pravoslavne vocerkovlennja) - wurde jedoch keine freudvolle und unproblematische "Rückkehr in den Schoß der Mutter Kirche«. Vielmehr wurden die griechisch-katholischen Gläubigen nur formal orthodox und bewahrten ihre religiös-nationale Eigenart, indem sie - der Möglichkeit einer besonderen institutionellen Existenz enthoben - eine »Kirche in der Kirche« schufen. ${ }^{3}$ Die »Kirche in der Kirche«, obzwar eine »wiedervereinigte» Glaubensgemeinschaft, bewahrte ihre Eigenart und schuf damit (gemeinsam mit der Untergrundkirche) die Bedingungen für die institutionelle Wiedergeburt der UGKK Ende der 1980er Jahre. Die Hauptursache für diese Entwicklung war nicht einmal der Umstand, dass die UGKK und die ROK, die gleich nach der Angliederung der westukrainischen Gebiete 1939 ein unmittelbares Zusammenzuwirken begonnen hatten, ein unterschiedliches ekklesiologisches Erbe und einen bestimmten Bestand von Besonderheiten in Theologie, Ritus und Brauchtum hatten. Die wesentliche Rolle spielte eher, dass sie sich gegenseitig als »verschieden « betrachteten; die politischen Umstände, unter denen sie sich begegneten, verstärkten nur das gegenseitige Gefühl des »Andersseins«.

Wie die staatliche, so sah auch die kirchliche Führung in Moskau die »Uniaten« als »Andersartige« wegen a) des Einfluss des Vatikans und der »lateinischen Praktiken« und b) wegen ihres ukrainischen Nationalismus an. Gleichzeitig betrachteten die Galizier die »Orthodoxen« als »Andersartige«a) ob der Gleichsetzung der ROK mit dem Regime und b) ob der Gleichsetzung der ROK mit dem russischen Nationalismus. In beiden Fällen war die »Andersartigkeit « eine »feindliche«: Im ersten Fall wurde sie zum wesentlichen Grund für die beharrlichen Assimilierungsversuche des kommunistischen Regimes

3 Die Urheberschaft für den Ausdruck »Kirche in der Kirche« liegt bei Vasyl' Markus; siehe Markus: 153.

DigiOst 3 | 250 
und der kirchlichen Führung, im zweiten Fall wurde sie genau umgekehrt zum Grund für das beharrliche Bemühen, sich dieser Assimilation nicht zu unterwerfen und seine Eigenart zu bewahren. Dennoch fanden sich beide, orthodoxe und griechisch-katholische Gläubige, in der Ukrainischen Sowjetrepublik der Nachkriegszeit durch den Willen des Staates in einer Situation wieder, in der sie nicht voneinander isoliert bleiben und sich durchaus gegenseitig beeinflussen konnten.

Für die weitere Untersuchung dieses Umstandes seien einige methodologische Anmerkungen vorausgeschickt: Erstens waren die beiden Hauptakteure, die in diesem Beitrag neben dem kommunistischen Staat, dem stalinistischen Regime, behandelt werden, wie bereits deutlich geworden ist, keine Phänomene mit einem gleichen institutionellen Charakter. Während der Terminus »orthodox", wie er in die Überschrift aufgenommen wurde, vor allem als Bezeichnung für die Führung des Moskauer Patriarchats benutzt wird, die sich in ihrer Sicht der Dinge gegenüber den »ehemaligen Uniaten« und der ROK als Institution mit dem kommunistischen Regime einig war, wird der Begriff "griechische Katholiken « für die Gläubigen und den Klerus der liquidierten UGKK benutzt, denen alle Möglichkeiten einer institutionellen Existenz gewaltsam entzogen worden waren. Zweitens betrachtet der Schlussteil des vorliegenden Beitrages, in dem der gegenseitige Einfluss der orthodoxen und griechisch-katholischen Geistlichen behandelt wird, ausschließlich die »wiedervereinigte« Glaubensgemeinschaft, nicht aber die »Katakombenkirche«. Und schließlich erlauben die genutzten Quellen die Rekonstruktion der Situation im historischen Gebiet Galiziens (die heutigen oblasti Lemberg, Ternopil' und Ivano-Frankivs'k), sie berühren aber nicht die Besonderheiten der konfessionellen Situation in der Karpaten-Ukraine, die erst nach dem Zweiten Weltkrieg zur Sowjetunion kam. Die griechisch-katholische Eparchie von Mukačevo verfügte über ein besonderes ekklesiologisches Erbe und wies deshalb auch eine wesentlich andere Geschichte der gegenseitigen Beziehungen mit der Orthodoxie in der zweiten 
Šlichta, »Verschieden« und »Identisch»

Hälfte des 20. Jahrhunderts auf. Somit werden hier die Termini "westukrainisch« und »Westukrainer« synonym für »galizisch« und »Galizier» gebraucht.

\section{"Sie« sind »anders«. Die Sicht der Moskauer Führungen}

Das Schicksal der UGKK im sowjetischen Staat war vom Moment des endgültigen Anschlusses der westukrainischen Gebiete an die Ukrainische Sowjetrepublik nach dem Zweiten Weltkrieg besiegelt: Eine Kirche, an deren oberster Hierarchie der Papst in Rom stand, die als Verkörperung des ukrainischen Nationalismus angesehen wurde, die auf den überwiegenden Teil der Bevölkerung des Landes Einfluss nahm und sich gleichzeitig auf deren Unterstützung verlassen konnte sowie die sich schließlich im Laufe der Geschichte angewöhnt hatte, sich im imperialen Staat ${ }^{4}$ "andersartig " zu fühlen, eine solche Kirche konnte im stalinistischen Staat freilich nichts anderes als die unabwendbare und schnelle Liquidation erwarten. Die feindselige Haltung zur UGKK erfuhr auch dadurch eine Verstärkung, dass nach der »großen Abkehr« Stalins weg vom Kommunismus (und hin zum russischen Nationalismus) in der Mitte der 1930er Jahre (nach der Definition von Nikolaj Timashev ${ }^{5}$ ) und nach der An-

4 In Bezug auf Letzteres erklärte der Bischof der Untergrund-UGKK Mychajlo Sabryha: „Vergleichen wir unsere griechisch-katholische Kirche mit der orthodoxen, so sehen wir, dass gegenüber der orthodoxen Kirche jede politische Führung die Kraft und die Macht hat zu führen. [...] Während die orthodoxe Kirche das Charakteristikum aufweist, sich allen unterzuordnen, so hat die katholische Kirche ihren obersten Hierarchen, den Papst. [...] Die Welt verfolgt diejenigen, über die sie keine Macht hat. Sie hasst diejenigen, denen sie nichts diktieren kann.« Interview mit Bischof Mychajlo Sabryha vom 30.03.1994, Stadt Ternopil', in: Archiv Instytutu Istoriji Cerkvy (L'viv) (nachfolgend: AIIC), P-1-1-321, ark. 49.

5 Timasheff: Religion in Soviet Russia, 147-148.

DigiOst 3 | 252 
Šlichta, »Verschieden« und »Identisch»

näherung des Regimes und der ROK im Laufe des Zweiten Weltkrieges ${ }^{6}$ (nach dem Diktum Bohdan Bocjurkivs) an die Stelle der ideologischen Unvereinbarkeit des stalinistischen Regimes und der nationalen russischen Kirche »ihre gemeinsame Identifikation mit dem traditionellen russischen Interesse « trat. ${ }^{7}$ Und dieses »Interesse« schrieb traditionell eine negative Haltung gegenüber dem »Uniatentum « (uniatstvo) vor.

Nach der offiziellen »Wiedervereinigung « begann der lange Prozess der »Orthodoxierung " der »ehemaligen Uniaten«, der eine Assimilierung und Unifizierung, eine »Umerziehung der Galizier zu Bürgern der Sowjetischen Ukraine, dieses nicht abtrennbaren Teils der Sowjetunion « zum Ziel hatte. ${ }^{8}$ Die Erfolge dieses Prozesses bewertete der Exarch der Ukraine, Metropolit Filaret (Denysenko), in einer Ansprache auf der Regionalsynode der ROK 1971 ziemlich zweideutig: »In 25 Jahren wurde durch Erzpriester und Priester viel getan für die Beseitigung der Folgen der Union und die Stärkung des orthodoxen Bewusstseins. [...] Dennoch darf nicht vergessen werden, dass in 350 Jahren die Union sowohl im kirchlichen Bewusstsein, als auch in den Riten entsprechende Spuren hinterlassen hat. [...] Den Erzpriestern und Priestern obliegt es, die einfühlsamen Versuche zur Beseitigung der Folgen der Union fortzusetzen und dabei die fürsorgliche Einstellung gegenüber jenen lokalen

6 Genauer über die Umstände und den Charakter der staatlich-kirchlichen Verständigung in den Jahren des Zweiten Weltkrieges zum Beispiel Шкаровский: Русская православная церковь при Сталине и Хрущёве (Государственно-церковные отношения в СССР в 1939-1964 годах), 95-216; Лисенко, Церковне життя в Україні, 1943-1946; ders.: До питання про становище Церкви в Україні у період Другої світової війни, 73-81.

7 Bociurkiw: Religion and Nationalism in the Contemporary Ukraine, 82.

8 Єкельчик: Імперія пам'яті: Російсько-українські стосунки в радянській історичній уяві, 99.

DigiOst 3 | 253 
Šlichta, »Verschieden« und »Identisch»

kirchlichen Gebräuchen und Riten, die nicht im Widerspruch zu den orthodoxen Glaubensgrundsätzen stehen, beizubehalten. ${ }^{9}$

In seiner Ansprache sagte Metropolit Filaret nichts Neues, sondern wiederholte im Wesentlichen das, worauf staatliche und kirchliche Funktionäre im Laufe der Jahrzehnte immer wieder hingewiesen hatten: Die »Umerziehung « der »ehemaligen Uniaten « zu Orthodoxen sei ein Ideal mit wenig Chancen zur Realisierung in der Praxis.

Inhaltlich können wir den Prozess der »Orthodoxierung « (der in einigen Punkten »unakzeptable Abkehrungen von der Orthodoxie« und deshalb eine "Andersartigkeit» der griechisch-katholischen Gläubigen markierte) mittels einer Analyse der Quellenüberlieferung des Rates für die Angelegenheiten der ROK $^{10}$ sowie innerkirchlicher Dokumentationen rekonstruieren. Die Leitung des Rates für die Angelegenheiten der ROK schlug vor, zwischen »innerkirchlichen " und jenen Aspekten der "Orthodoxierung « zu unterscheiden, die einen »deutlichen politischen Charakter « hätten. Als wesentliche "politisch wichtige« Änderungen legte man die folgenden Punkte fest: die Einführung der Gedenkbitte für den Moskauer Patriarchen anstatt für den Papst sowie auch

9 Central'nyj Deržavnyj Archiv Vyščych Orhaniv Ukrajiny (nachfolgend: CDAVO), f. 4648, op. 5, spr. 278, ark. 129. Die Ansprache ist publiziert in: Выступление Экзарха Украины, Митрополита Киевского и Галицкого Филарета на Поместном Соборе. In: Журнал Московской патриархии (nachfolgend: ŽMP) 8 (1971), 7-14.

10 Der Rat für die Angelegenheiten der ROK beim Rat der Volkskommissare bzw. Ministerrat der UdSSR war das zentrale Staatsorgan für die Kontrolle der ROK und wurde unter den Bedingungen der staatlich-kirchlichen Verständigung im Jahre 1943 gegründet. Im Jahre 1965 wurde er in Folge seiner Zusammenlegung mit dem Rat für die Angelegenheiten der Religiösen Kulte zum Rat für Religiöse Angelegenheiten umorganisiert. Zur Qualität der Vollmachten des Rates gegenüber der Kirche und über die Prinzipien und Realitäten ihres Zusammenwirkens siehe: Шліхта: Поосередницька« роль Ради у справах Російської православної церкви, 39-45.

DigiOst 3 | 254 
der Gedenkbitte für den orthodoxen Episkopat; das Gebet für die Sowjetmacht entsprechend der Formel, die durch das Moskauer Patriarchat angenommen war; die Vernichtung der unierten Ikonen sowie auch anderer »offen nationalistischer « kirchlicher Kultgegenstände. ${ }^{11}$ Diese Änderungen sollten die "Andersartigkeit» der Westukrainer ausmerzen und sie in Orthodoxe und damit in richtige sowjetische Subjekte umwandeln. Gerade sie zogen die prioritäre Aufmerksamkeit bei den zahlreichen Überprüfungen der »wiedervereinigten« Eparchien auf sich. Im Bericht des Bevollmächtigten des Rates für die Angelegenheiten der ROK für die Sowjetukraine, Hryhorij Korčevyj, heißt es für das Jahr 1952: »Viele der wiedervereinigten Priester sprechen die Gedenkbitten für die orthodoxen Hierarchen so aus, dass die Gläubigen sie nicht deutlich vernehmen oder nicht begreifen, wessen gedacht wird. (12 $^{12}$ Und im Jahre 1953 berichtet er noch immer: „Ein Teil der wiedervereinigten Priester gedenkt auch heute noch nicht der orthodoxen Geistlichkeit oder spricht die Gedenkbitten so aus, dass die Gläubigen sie nicht hören oder nicht verstehen, wessen gedacht wird. «13

Die Leitung der sowjetukrainischen Filiale des Rates für die Angelegenheiten der ROK und, noch stärker, ihre Bevollmächtigten vor Ort verstanden jedoch, dass es die Änderungen waren, die man in Moskau als »ihrem Charakter nach dogmatisch oder kanonisch « betrachtete und somit keine schwerwiegende politische Belastung mit sich trugen, die in der Realität am schwersten $\mathrm{zu}$ erreichen waren. Sie mussten jedoch notwendigerweise erreicht werden, wenn die Assimilation das Ziel war, zeigten doch gerade die Ausstattung der Kirchen und die äußere Erscheinung der Geistlichkeit, die rituellen Praktiken, die lokalen religiösen Traditionen, die Gebete und weiteres die »Andersar-

11 Gosudarstvennyj Archiv Rossijskoj Federacii (nachfolgend: GARF), f. 6991, op. 1c, d. 1054, 1. 210.

12 Central'nyj Deržavnyj Archiv Hromads'kych Ob’jednan' Ukrajiny (nachfolgend: CDAHO), f. 1, op. 20, spr. 1572, ark. 43.

13 GARF, f. 6991, op. 1c, d. 1054, 1. 210. 
Šlichta, »Verschieden« und »Identisch»

tigkeit « der westukrainischen Christen selbst nach ihrer Aufnahme in den Schoß der orthodoxen Kirche, indem sie - nach der Feststellung von Coleen McDannel - spezifische »religiöse Werte, Normen, Verhaltensformen und Einstellungen « formten und stärkten. ${ }^{14}$ Eine interessante Beobachtung machte der Bevollmächtigte D. Kysljakov im Jahre 1959: „Ich habe keinen einzigen Priester der ehemaligen Uniaten im Raso [langes Überkleid der orthodoxen Priester] mit langen Haaren oder mit Bart, mit einem Brustkreuz oder anderen Attributen eines 〈Popen` gesehen. In der Mehrheit [...] bewahren sie das äußere Erscheinungsbild eines griechisch-katholischen 〈Pfarrers « ${ }^{15}$

Die visuelle »Andersartigkeit» der »wiedervereinigten « Glaubensgemeinschaft wurde umso deutlicher, wenn es um den westukrainischen Episkopat ging. Einer der formalen Anhänger der »Wiedervereinigung « und Wortführer der unter Druck und durch Einwirken der Sicherheitsorgane geschaffenen »Initiativgruppe für die Wiedervereinigung der Griechisch-Katholischen Kirche mit der Russisch-Orthodoxen Kirche«, der Bischof von Drohobyč und Sambir Mychajil (bürgerlich: Mel'nyk), wurde im Jahr seines geheimnisvollen Todes (1955) als "verdeckter Uniat und (ukrainischer) Nationalist « bezeichnet, ${ }^{16}$ und das nicht zuletzt wegen seines Äußeren, das so gar nicht dem Muster der Hierarchie der orthodoxen Kirche entsprach. Seinen Nachfolger auf dem Bischofsstuhl und Teilnehmer der Lemberger »Synode«, Bischof Hryhorij (Zakaljaka), trafen zahlreiche Anschuldigungen, weil er aussah wie eine »Westler« (zapadnyk): «Schaut ihn an: Er ist rasiert und sein Haar ist kurz geschnitten. «17

14 McDannell: Material Christianity. Religion and Popular Culture in America, 2.

15 GARF, f. 6991, op. 1s, d. 538, 1. 13.

16 Interview mit dem Priester Mychail Dacyšynym am 11.02.1993, Stryj, Gebiet Lemberg, in: AIIC, P-1-1-97, 21.

17 CDAVO, f. 4648, op. 1, spr. 429, ark. 99 (aus den kritischen Bemerkungen der altorthodoxen Opposition an der Adresse von Bischof Hryhorij). Siehe auch: CDAVO, f. 4648, spr. 364, ark. 47.

DigiOst 3 | 256 
Šlichta, »Verschieden« und »Identisch»

Der kanonische Inhalt der »Orthodoxierung « wurde in den Verordnungen des Heiligen Synods vom 8. Juli 1947 und 12. Dezember 1949 konkret. Die kirchliche Führung bezeichnete die Abkehr von orthodoxen Praktiken unter "lateinischen Einflüssen" als »inakzeptabel« und forderte ihre Beseitigung zugunsten der Bekehrung der Westukrainer zum »heiligen orthodoxen Glauben der Väter«. In der ersten der genannten Verordnungen wurde prioritäres Gewicht auf die Einführung der richtigen Formel der Gedenkbitte für den Patriarchen von Moskau und der ganzen Rus' und für die orthodoxe Hierarchie sowie auf das Verbot einer Gedenkbitte für den Papst und die Einführung des orthodoxen Glaubensbekenntnisses gelegt. ${ }^{18}$ Als nicht weniger wichtig wurden die Einführung orthodoxer liturgischer Praktiken, die Durchführung der Liturgie mit fünf Prosphoren [für die Kommunion gebackene Brote] und anderes wie die Popularisierung der orthodoxen Tradition des massenhaften Gebrauchs von Kerzen gelegt. Die Kirchenführung forderte die Einführung bestimmter Änderungen in der Ausstattung der Kirchen (etwa die Beseitigung von katholischen Ikonen und von Porträts des Metropoliten Andrej Šeptyc'kyj und den Austausch von Altardecken »uniatischer Herkunft « gegen orthodoxe) sowie die Verstärkung der missionarischen Tätigkeit. ${ }^{19}$ Die Synodalverordnung vom 12. Dezember 1949 schrieb detailliert spezifische Maßnahmen vor, die auf die Assimilation von »früheren Uniaten « gerichtet war: Von der Verstärkung der missionarischen Tätigkeit bis zur Sicherstellung der Versorgung der "wiedervereinigten « Eparchien mit orthodoxen Mess- und Gebetbüchern. ${ }^{20}$

Es wurde schon oben die Bewertung des Metropoliten Filaret dieser gegen Ende der 1940er Jahre verordneten Maßnahmen der »Orthodoxierung « erwähnt. Eine nicht weniger bezeichnende Bewertung finden wir in der Dokumentation einer »Speziellen Patriarchalen Kommission«, die 1960 die »wiedervereinigten»

18 GARF, f. 6991, op. 2, d. 59a, 1. 57.

19 GARF, f. 6991, op. 2, d. 59a, 1. 57-58.

20 GARF, f. 6991, op. 2, d. 73a, 1. 66-68.

\begin{tabular}{l|l} 
DigiOst 3 & 257
\end{tabular} 
Šlichta, »Verschieden« und »Identisch»

Eparchien untersuchte: »Die früheren Uniaten sagen oft: 〈Ihr habt euch uns angeschlossen und nicht wir euch». Leider kann man das häufig beobachten. Im Kreise der früheren uniatischen Geistlichkeit verloren auch die orthodoxen Priester ihr Gesicht. $\ll^{21}$ Indem sie äußerliche Charakteristika akzentuierte, zeigte die Kommission nicht nur, dass die »früheren Uniaten « "Andersartige " geblieben waren, sondern auch, dass sie ebenfalls in entsprechender Weise Einfluss auf die orthodoxen Geistlichen nahmen, die zum Zwecke der "Umerziehung" der örtlichen Bevölkerung nach Galizien geschickt worden waren.

\section{Galizier über die Russische Orthodoxe Kirche}

Während für die Staatsführung und das Moskauer Patriarchat die »Andersartigkeit» der »Uniaten« die Dringlichkeit ihrer Assimilierung unterstrich, wurde für die Galizier selbst die »Andersartigkeit» der ROK ein gewichtiges, wenn nicht das gewichtigste Hindernis auf dem Weg zur Änderung ihrer konfessionellen Zugehörigkeit. Im vorliegenden Fall geht es nicht nur um jene, die eine »Katakombenexistenz« wählten oder sich der Römisch-Katholischen Kirche zuwandten, sondern auch um jene, die sich formal zur Orthodoxie bekehrten. Das im Folgenden zu zeigende Bild der ROK ist, wie jede Rekonstruktion, eine Verallgemeinerung, welche die Existenz anderer Perspektivn auf die Orthodoxie, wie es sie zum Beispiel unter den sogenannten »Ostlern« (vostočniki), den Anhängern des »östlichen Ritus« gab, nicht ausschließt. Andererseits schwächten die politischen Umstände, unter denen die Orthodoxie auf galizisches Gebiet vorgedrungen war, diese Sympathien wesentlich. Schließlich galt, was der Führer des »Wiedervereinigungsprozesses«, Havryil Kostel’nyk, bereits in einem Referat vom 10. Februar 1941 formulierte: »Die 〈Ostler〉 und die 〈Westler〉 erachten jetzt ihre Sache als nicht aktuell. [...] Das ist ein völlig

21 GARF, f. 6991, op. 1c, d. 1441, 1. 193.

DigiOst 3 | 258 
Šlichta, »Verschieden« und »Identisch»

falscher Gedanke, sind doch die «Ostler` im Geiste verkappte Orthodoxe. Der Kampf wurde bei uns nur für den Erhalt unserer Kirche geführt und nicht gegen den katholischen Glauben in seinem idealen Verständnis. $\aleph^{22}$

Kostel'nyk schrieb weiter: »Das galizische Territorium hat seine besondere Geschichte, und diese Geschichte schuf Menschen mit einer besonderen Mentalität. [...] Die Galizier haben eine sehr große Erfahrung im religiösen und im nationalen Kampf, denn seit Jahrhunderten haben sie sich in diesem Kampf geübt. «³

Diese Selbstwahrnehmung der ukrainischen griechisch-katholischen Gläubigen kann man als »ekklesialer Nationalismus« kategorisieren, wie er von Pedro Ramet vorgeschlagen wird. Der »ekklesiale Nationalismus« geht davon aus, dass eine Nation nicht ohne eine nationale Kirche existieren kann und deshalb »die Nation einen transzendentalen Charakter erhält und ein Wechsel der Religion gleichbedeutend mit einer Assimilation wird. $\aleph^{24}$ Unter Berücksichtigung ihres ekklesialen Nationalismus (»Niemals war unsere Kirche besonders abgetrennt von einem Nationalstaat ${ }^{25}$ ) und ebenso des gewaltsamen Charakters - zudem vollzogen im Interesse eines fremden, kommunistischen, russischen Staates - der Bekehrungsaktion, konnten die Westukrainer die ROK nicht anders annehmen als eine russische Kirche und als einen bereitwilligen Agenten der Moskauer Russifizierungspolitik.

Die ROK antizipierte man üblicherweise als »Moskauer Kirche«, und »Russländisches« wurde deutlich mit »Fremdem« assoziiert. »Die Moskauer

22 Referat vom 10. Februar 1941: „Чи ожливе перетворення уніатської церкви в Західній Україні в автокефальну православну церкву?«, zitiert nach: Ліквідація УГКЦ (1939-1946), 128.

23 Ebenda. Kursive durch die Autorin.

24 Ramet: Autocephaly and National Identity in Church-State Relations in Eastern Christianity, 8.

25 Interview mit P. Petro Dutčak 20.05.1994, Dorf Lysec', Tysmenic'kyj rajon, Gebiet Ivano-Frankivs'k, in: AIIC, P-1-1-385, ark. 25. 
orthodoxe Kirche ist für das ukrainische Volk absolut schädlich und [...] sie brachte dem ukrainischen Volk gewaltige Verluste. ${ }^{26}$ Die Bekehrung zur Orthodoxie wurde als Schritt zur unwiderruflichen und vollständigen Russifizierung betrachtet. Die ROK wurde vollständig mit dem Moskauer Regime gleichgesetzt, dessen Politik gegenüber den unterworfenen Völkern traditionell zum Versuch der Russifizierung und völligen Assimilierung führte. "Stalin hat die Orthodoxie eingeführt (wie Peter I.), [...] um mit seinem russischen orthodoxen Glauben unsere Ukraine zuzudecken. $\ll^{27}$

Die ROK nahm man aber nicht einfach nur als Agenten der Moskauer Russifizierungspolitik an. Die Assoziierungen mit dem Regime waren um vieles stärker. Die ROK war eine »bolschewistische« bzw. »staatliche«bzw. »staatseigene« Kirche, die vollständig von einem atheistischen (genauso wie früher von einem autoritären) Regime abhängig war und durch dieses kontrolliert wurde. Gläubige aus der Westukraine formulierten in einem Brief an den »Orthodoxen Anzeiger (Pravoslavnyj vistnyk) im Jahre 1971 ihre Bedenken folgendermaßen: »Der heutige Zustand der russischen Orthodoxie und der ROK ist so traurig und beklagenswert. Die ROK [...] führt eine erbarmungswürdige Existenz unter der Autorität und der Bevormundung des gottlosen Kommunismus und Materialismus, sie wurde von ihrem Volk getrennt, ja weggejagt. « $^{28}$ Die orthodoxe »bolschewistische Kirche« »stand ganz offensichtlich im Dienste des Staatsapparats $«{ }^{29}$

26 Interview mit P. Josyf Kladočny (Mönch Jeremija), 27.05.1993, Stadt Lemberg, in: AIIC, P-1-1-304, ark. 29.

27 Interview mit Bischof Sofron Dmyterko, 06.11.1997, Stadt Lemberg, in: AIIC, P-1-1-419, ark. 22.

28 CDAVO, f. 4648, op. 5, spr. 278, ark. 183.

29 Interview mit Bischof Sofron Dmyterko, 26.11.1993, Stadt Ivano-Frankivs'k, in: AIIC, P-1-1-419, ark. 5. Interview mit P. Ivan Kubaj, 10.04.1993, Dorf Zymna Voda, Pustomytivs'kyj rajon, Gebiet Lemberg, in: AIIC, P-1-1-192, ark. 39. 
Šlichta, »Verschieden« und »Identisch»

Die fehlende Akzeptanz der ROK führte auch zu einem Antagonismus zwischen »Modernität « und »Traditionalismus«, zwischen »wahrem Glauben» und »Ritualglauben « (obrjadovirstvo, der »oberflächlichen Frömmigkeit» der Orthodoxen). Die ROK wurde als Kirche "wenig kultureller Menschen", überwiegend der Bauern, betrachtet, deren Geistlichkeit nur über eine unzureichende und oberflächliche theologische Bildung verfügte und deshalb eine Gruppe von »wenig gebildeten kleinen Popen [popyky]« blieb. ${ }^{30}$ Ein Orthodoxer würde nicht einmal das wahre Wesen der Religion kennen, davon waren griechisch-katholische Gläubige überzeugt: »Er kann sich bekreuzigen, mehr kann er nicht. «1

In einem Referat vom 3. August 1945 beschrieb Havryjil Kostel'nyk ausführlich das stereotype Bild des »fremden«, des »russischen « Popen, indem er es mit allen - für die Bevölkerung des Landes - inakzeptablen äußeren Charakteristika versah:

"Auch bangen unsere Geistlichen, dass die Russische Orthodoxe Kirche uns nicht ihr äußeres Bild eines Geistlichen überwirft: langes Haar, obligatorischer Bart, weitgeschneiderter Raso, Brustkreuz, ständige Tragepflicht des Raso. [...] Das äußere Bild eines orthodoxen russischen Geistlichen passt nicht zum heutigen Aussehen anderer Menschen, deshalb schaut man bei uns auf solche Geistlichen wie auf etwas Wundersames. [...] Wenn aber der schlechtere Typ eines solchen Geistlichen auftaucht (schmutzig, zerzaust), dann fürchten sich unsere Leute einfach nur, weil sie ein solches Aussehen eines Geistlichen für einen Abfall vom geistlichen Stand halten. Ich bin auch selbst entschieden dagegen, dass unsere Geistlichen das äußerliche

30 GARF, f. 6991, op. 2, d- 256, 1. 3. Interview mit P. Izydor Butkovs'kyj, 28.01.1994, Stadt Lemberg, in: AIIC, P-1-1-294, ark. 58; Interview mit Anna Svirs'ka (Schwester Darija OSBM), 23.04.1993 und 24.05.1993, Gebiet Lemberg, in: AIIC, P-1-1-55, ark. 56.

31 Interview mit P. Mychajlo Dacyšyn, ark. 9. 
Šlichta, »Verschieden« und »Identisch»

Bild eines orthodoxen russischen Priesters übernehmen. Lieber sollten die orthodoxen Geistlichen langsam unser äußerliches Bild übernehmen, denn ihr Aussehen ist rückständig [...] und macht aus dem Geistlichen einen plumpen und schwerfälligen Menschen, macht auf alle liberal eingestellten Menschen den ungünstigen Eindruck der Rückständigkeit.«"32

Eine wichtigere für die weitere Betrachtung der wechselseitigen Beeinflussungen von orthodoxen und griechisch-katholischen Geistlichen ist die scheinbar beiläufige Bemerkung Kostel'nyks: »Lieber sollten die orthodoxen Geistlichen langsam unser äußerliches Bild übernehmen.«

Ebenso wenig konnten die Westukrainer die Kirchenfunktionäre akzeptieren, die »aus dem Osten " geschickt worden waren. Das betraf nicht einmal nur die eigentlichen Russen. ${ }^{33}$ Typisch war die Reaktion der Initiativgruppe auf die Kandidatur des Bischofs Makarij (Oksijuk), den man für die neugeschaffene Eparchie Lemberg und Ternopil' ausersehen hatte. Zunächst wollte man für die größte der »wiedervereinigten « Eparchien den Bischof von Donec'k und Vorošylovhrad Nykon (Petin) ernennen. Von seiner Kandidatur nahm man schließlich "mit Blick auf seine Unkenntnis der ukrainischen Sprache« (so die Formulierung im Sitzungsprotokollheft des Heiligen Synods Nr. 8 vom 18. April 1945) Abstand. ${ }^{34}$ Die Kandidatur Oksijuks empfahl dem Patriarchat der Rat für die Angelegenheiten der ROK vor allem deshalb, weil dieser aus Podlachien stammte, deshalb ukrainisch sprach und die »spezifische Situation

32 Ліквідація УГКЦ (1939-1946). Т. 2, 137-138.

33 Es gab mit Erzbischof Fotij (Tapiro) von Lemberg und Ternopil', einem früheren Bischof und Anhänger der »Lebendigen Kirche« (obnovlenčestvo), ohnehin nur einen einzigen ethnischen Russen, der eine »wiedervereinigte "Eparchie leitete (Januar bis 20. August 1952).

34 GARF, f. 6991, op. 2, spr. 34a, 1. 9.

DigiOst 3 | 262 
Šlichta, »Verschieden« und »Identisch»

in der Westukraine « viel besser verstand als die Bewohner der Ostukraine oder Russlands. ${ }^{35}$ Dennoch trat die Initiativgruppe gegen diese Kandidatur auf:

»Den örtlichen Bischof der griechisch-katholischen Gläubigen kann der jetzige Bischof Makarij nicht ersetzen, denn obwohl er seiner Abstammung nach ein Ukrainer ist, ist er doch in den Augen sowohl des Volkes als auch der Geistlichkeit einer Fremder durch seine Kleidung und sein Äußeres, auch durch seine Zelebrierung des Gottesdienstes und sogar durch seine christliche Mentalität. [...] Bischof Makarij repräsentiert durch seine Person nicht die ukrainische orthodoxe Kirche.«

Die inakzeptable »Andersartigkeit« der Orthodoxie sah Kostel'nyk als Führer der Initiativgruppe im Bereich der alltäglichen Praxis, in den religiösen Gebräuchen und den rituellen Traditionen. Durch alle seine Äußerungen und alle offiziellen Dokumente der Initiativgruppe zieht sich die These, dass eine schnelle und vollständige Änderung der rituellen Gebräuche, der örtlichen Praktiken und Traditionen unmöglich sei. In seinem Brief an Patriarch Aleksij (Simanskij) vom 3. Oktober 1945 betonte Kostel'nyk: »Die Änderungen im Ritus werden langsam von Statten gehen, innerhalb von Jahrzehnten, denn unsere galizische Kirche muss noch Dutzende von Jahren ihre deutliche Außergewöhnlichkeit, sozusagen ihre Autonomie in der orthodoxen gesamtrussischen Kirche bewahren. [...] Die Orthodoxie [...] wird zunächst nur eine äußere Lackierung sein. ${ }^{36}$

Das war jene »Andersartigkeit«, welche die durchschnittlichen Gläubigen in der Westukraine einfach »nicht wahrnahmen «. Sie nahmen sie nicht wahr, weil sich nach der »Wiedervereinigung « in ihrem alltäglichen kirchlichen Leben nur wenig veränderte. Der Bevollmächtigte Kysljakov resümierte einen

35 Чумаченко: Государство, Православная Церковь, Верующие. 1941-1961 г.г., 56. 36 Ліквідація УГКЦ (1939-1946). Т. 2, 286-287. Kursive durch die Verfasserin. 
Šlichta, »Verschieden« und »Identisch»

bedauernswerten Fortgang der »Orthodoxierung " gegen Ende der 1950er Jahre: »Den Gläubigen selbst ist es vollkommen angenehm, dass sich nach der Wiedervereinigung weder der Geistliche selbst noch die Ordnung der kirchlichen Dienste fast nicht geändert hat. ${ }^{37}$ Gerade in der alltäglichen Praxis bot sich für die Galizier eine Möglichkeit, nach der »Wiedervereinigung « ihre Besonderheit zu verbergen. Und dieser stille Widerstand gegen die Politik des Regimes erwies sich als recht erfolgreich, wie uns die oben angeführten Bewertungen des trostlosen Fortgangs der "Orthodoxierung « verraten, wie auch schließlich die bloße Tatsache der Existenz einer »Kirche in der Kirche«.

\section{Gegenseitige Einflüsse}

Neben der Bekräftigung dessen, dass orthodoxe und griechisch-katholische Gläubige selbst nach der formalen Bekehrung der letzteren zur Orthodoxie »verschieden« blieben, wäre es ein Fehler, ihre gegenseitigen Einflüsse zu ignorieren, die vorwiegend im Bereich der alltäglichen Glaubenspraxis stattfanden. Auch wenn es paradox klingt: Der Einfluss der "Wiedervereinigten« auf die religiöse Praxis der Orthodoxen war nicht weniger wahrnehmbar als der Einfluss des Prozesses der "Orthodoxierung" gerade auf deren religiöses Leben. Mehr noch, das assimilatorische Eigenpotenzial der "Kirche in der Kirche» erwies sich als derart bedeutend, dass es zur Ukrainisierung der Orthodoxen Kirche in der Ukraine und zum Aufkommen eben einer ukrainischen Orthodoxie beitrug, die nach dem Zerfall der UdSSR seine institutionelle Form in den Strukturen der Ukrainischen Autokephalen Orthodoxen Kirche und der Ukrainischen Orthodoxen Kirche (Kiever Patriarchat) fand. ${ }^{38}$

37 GARF, f. 6991, op. 1c, d. 538, 1. 33.

38 Genauer zum Einfluss der "wiedervereinigten " Gemeinschaft auf das religiöse Leben im Ukrainischen Exarchat der ROK siehe: Шліхта: Західноукраїнський 
Šlichta, »Verschieden« und »Identisch»

Vlad Naumescu weist nachdrücklich darauf hin, dass die Konzentration auf die Praxis - ein wesentlicher Zug einer liturgiezentrierten Kirche - die Bekehrung der griechisch-katholischen Gläubigen zur Orthodoxie aus dem einen einfachen Grund erleichterte, dass der Unterschied im Ritus zwischen beiden Kirchen so bedeutend nicht gewesen sei. ${ }^{39}$ Auf der anderen Seite machte genau diese Konzentration auf die Praxis deren volle bzw. tatsächliche Inkorporation in die ROK unmöglich. Wir können auch nicht die Umstände sozial-politischen Charakters ignorieren: Trotz der Inakzeptanz der ROK als »etwas anderes« und des daraus folgenden Versuchs, meistmöglich ihre Eigenständigkeit zu bewahren, konnten die Westukrainer kaum völlig erfolgreich den Bekehrungsmaßnahmen widerstehen, die im Interesse des Staates und durch die Hand des Staates durchgeführt wurden, eines Staates, der üblicherweise als totalitär charakterisiert wird. Änderungen gab es sogar auf der Ebene der Riten und der alltäglichen Glaubenspraxis, also dort, wo sich vor allem die Eigenart der "wiedervereinigten « Glaubensgemeinschaft verbarg.

Eine Analyse des Feierns von Ostern und Weihnachten belegt die Bewahrung der »eigenen «, "galizischen « rituellen Praktiken durch die »Kirche in der Kirche« deutlich. Die Berichte der Gebiets-Bevollmächtigten von Mitte der 1940er bis in die 1960er Jahre bestätigen, dass man in den "früheren uniatischen Kirchen « Ostern und Weihnachten fortgesetzt entsprechend den »uniatischen Kanones « feierte. Die »Wiedervereinigten « wollten nicht die orthodoxen, die ganze Nacht hindurch dauernden Gottesdienste (vsenoščni) am Vorabend von Ostern bzw. Weihnachten besuchen. Sie übernahmen nicht die orthodoxe Tradition des »Sauberen Donnerstags « und kehrten nicht mit brennenden Kerzen aus der Kirche nach Hause zurück. Sie bewahrten die griechisch-katholische

вплив на Український екзархат: несподівані наслідки »возз’єднання«, 430-447.

39 Naumescu: Modes of Religiosity in Eastern Christianity: Religious Processes and Social Change in Ukraine, 15.

DigiOst 3 | 265 
Šlichta, »Verschieden« und »Identisch»

Tradition der Verehrung des Grabtuches Christi. Sie stellten es am Karfreitag in der Kirche seitlich auf und die Laien mussten zum Küssen desselben niederknien, nicht wie in der orthodoxen Kirche, wo das Grabtuch in der Mitte ausgestellt wird. Den Kreuzweg an Feiertagen beging man in der traditionellen Richtung (gegen den Sonnenlauf), und nicht entsprechend den orthodoxen Kanones (mit dem Sonnenlauf). Die Gläubigen blieben dabei, das Osterbrot (paska) und die Osterspeisen bereits am Nachmittag des Ostersamstag zu weihen und nicht entsprechend der orthodoxen Traditionen. Die religiösen Feiern wurden von populären Volkstraditionen begleitet: Weihnachts- und Neujahrssingen (koljakdy und ščedrivky) und genauso Weihnachtskrippen (vertepy), Gedenkbitten für die Verstorbenen am Ostermontag und nicht am Sonntag nach Ostern, Maisingen (majivky) und Frühlingsspiele (hajivky) usw.

Eine kleine Änderung der Formulierungen, die, wie wir in den Berichten der Bevollmächtigten im Gebiet Lemberg, Vyšnevs'kyj und Vynnyčenko, sehen, zeigt meiner Ansicht nach, dass mit der Zeit der Rat für die Angelegenheiten der ROK und später der Rat für Religiöse Angelegenheiten gezwungen war, das Scheitern seiner beständigen Bemühungen, »die uniatischen Riten zu verändern «, einzugestehen. In den Berichten von Mitte der 1940er bis Anfang der 1950er Jahre betonte Vyšnevs'kyj, dass sich »die Wiedervereinigten « weiterhin an die »uniatischen «, nicht aber an die orthodoxen Traditionen des Weihens des Osterbrotes, der Gedenkbitten für die Toten usw. hielten. ${ }^{40}$ Die Berichte Vyšnevs'kyjs vom Ende der 1950er Jahre und Vynnyčenkos aus den 1960er Jahren zeichnen ein und dasselbe Bild in einem etwas anderen Licht. Anstatt dass sie die Unterschiede zwischen den orthodoxen und »uniatischen « rituellen Praktiken unterstrichen, kommentierten die Bevollmächtigten einfach, dass die Riten entsprechend der »rückständigen örtlichen Traditionen« vollzogen würden. ${ }^{41}$

40 CDAVO, f. 4648, op. 1, spr. 193, ark. 51; ebenda, spr. 298, ark. 16.

41 Ebenda, op. 5, spr. 7, ark. 110; ebenda, spr. 42, ark. 98.

DigiOst 3 | 266 
Šlichta, »Verschieden« und »Identisch»

Das Feiern von Ostern und Weihnachten unterlag trotzdem einem gewissen orthodoxen Einfluss. Vom Beginn der 1950er Jahre an beobachteten die Beauftragten das Auftreten eines neuen Phänomens. Während sie die traditionellen Arten des Feierns und die rituellen Praktiken beibehielten, begannen viele Pfarreien, gleichzeitig einige orthodoxe Praktiken zu übernehmen. Am häufigsten finden wir in den Berichten der Bevollmächtigten eine Information über den Besuch von vsenoščni am Vorabend von Ostern und Weihnachten und über die Ausweitung der Tradition, die paska am Morgen des Ostersonntags, nach der heiligen Liturgie, zu weihen. Die Bevollmächtigten beeilten sich nicht, diese Veränderungen als Erfolg einer - wenigstens teilweisen - „Orthodoxierung « zu interpretieren. Der spezifische, synthetische "uniatisch-orthodoxe Ritus" (Vlad Naumescu gebraucht die Termini »besondere religiöse Tradition« und »spezifische Prozesse synkretischer Formierung ${ }^{42}$ ) zeugt aber eher von einer praktischen Anpassungsfähigkeit der »Kirche in der Kirche«.

Die regulären Arbeitszeiten schränkten die Möglichkeiten für die Laien zum Besuch des Feiertagsgottesdienstes zu Weihnachten ein, wodurch sie gezwungen waren, die vsenoščna am Heiligen Abend zu besuchen. In seinem Bericht über die Weihnachtsfeierlichkeiten im Jahre 1958 in Lemberg hielt Vyšnevs'kyj (zum ersten Mal seit 1946) fest: »In allen Kirchen Lembergs wurden die Gottesdienste auf orthodoxe Art zelebriert, man hielt also eine vsenoščna am Vorabend von Weihnachten ab, in überfüllten Kirchen. In den vergangenen Jahren wurden $v$ senoščni überhaupt nicht zelebriert oder nur von einer kleinen Zahl von Gläubigen besucht. « ${ }^{43}$ Er resümierte mit der nicht allzu optimistischen Bemerkung darüber, dass diese Änderungen kaum für einen erfolgreichen Fortgang der »Orthodoxierung« sprächen: »Es ist offensichtlich, dass diese Situation nicht unwesentlich dadurch bedingt war, dass viele Gläubige zur Zeit der Gottesdienste an Weihnachten an ihren Arbeitsplätzen beschäftigt waren

42 Naumescu: Modes of Religiosity, 31.

43 CDAVO, f. 4648, op. 1, spr. 176, ark. 95. 
und sich deshalb bemühten, die Kirche am Weihnachtsvorabend, nach dem Arbeitstag, zu besuchen. $\aleph^{44}$ Eben solche pragmatischen Kalkulationen - vor allem der Wunsch, seine eigene Teilnahme im Kirchenleben zu verdecken leiteten die Gläubigen, wenn sie die vsenoščnu am Ostersamstag besuchten oder die paska am Morgen des Ostersonntags weihen ließen. Der Bevollmächtigte Šerstjuk erklärte in seinem Bericht für das Jahr 1959: »Eine bedeutende Zahl der Gläubigen brachten die paska am frühen Morgen [am Ostersonntag] zum Weihen, damit niemand sie sah. ${ }^{45}$

Die Praxis der gleichzeitigen Vollziehung der Riten entsprechend den orthodoxen und den griechisch-katholischen Kanones trug nicht, auch wenn das unerwartet klingt, zur Umformung der westukrainischen Christen in orthodoxe bei, sondern zeugt davon, dass die "Kirche in der Kirche« ihre Eigenart bewahrte. Zwei Glaubensgemeinschaften, die »Kirche in der Kirche« sowie die orthodoxe, die sich aus örtlichen "Altorthodoxen « und zugereisten »Ostlern" zusammensetzte, existierten weiterhin gesondert, praktisch voneinander unabhängig. Dieser Zug des religiösen Lebens offenbarte sich vor allem in den Städten. In bestimmten Fällen teilten sich beide Glaubensgemeinschaften eine Kirche. Häufiger existierten Kirchen, die entweder nur von »Wiedervereinigten« oder nur von Orthodoxen aufgesucht wurden. Die Grenzen der Existenz zweier Kirchen wurden entsprechend bemerkbar in den Festperioden. Die Bevollmächtigten berichteten, dass die pasky durch die "Wiedervereinigten « am Ostersamstag geweiht wurden, am Morgen des Ostersonntags jedoch durch die Altorthodoxen und die »Ostler«. Die Gedenkgottesdienste auf den Friedhöfen wurden durch die »wiedervereinigte« Gemeinschaft der Gläubigen am Ostermontag gefeiert, durch die Altorthodoxen und die »Ostler« hingegen am Sonntag nach Ostern. ${ }^{46}$ Die Eigenartigkeiten zweier religiöser Gemeinschaften

44 CDAVO, f. 4648, op. 1, spr. 176, ark. 95.

45 CDAVO, f. 4648, op. 1, spr. 193, ark. 25.

46 CDAVO, f. 4648, op. 5, spr. 88, ark. 88. Ebenso: CDAVO, f. 4648, op. 5, spr. 189, ark. 43. 
Šlichta, »Verschieden« und »Identisch»

wurden besonders sichtbar in dörflichen Örtlichkeiten und kleineren Städtchen. Ein - zumeist »wiedervereinigter « - Priester zelebrierte in ein und derselben Kirche getrennte Gottesdienste für jede der Gemeinschaften. Diese Praxis rief eine große Beunruhigung bei den Bevollmächtigten hervor, konnten doch "Gläubige, welche die uniatischen [wiedervereinigten] Kirchen besuchten, denken, dass ihre Kirche etwas Besonderes sei und zu einem gewissen Teil die frühere, griechisch-katholische geblieben sei.« ${ }^{47}$

Wenn wir die umgekehrten Einflüsse der »wiedervereinigten « Glaubensgemeinschaft auf das religiöse Leben im ukrainischen Exarchat der ROK analysieren, dann geht es auch hier vor allem um den Bereich der religiösen Praxis. Nach der formalen »Wiedervereinigung « erhielten sich in der Westukraine über Jahrzehnte hinweg zwei besondere Praktiken des Ritus entsprechend den beiden religiösen Gemeinschaften: die "wiedervereinigte« Glaubensgemeinschaft und die kleine orthodoxe Glaubensgemeinschaft, die sich, wie gesagt, aus den örtlichen Altorthodoxen und den hinzugereisten "Ostlern « zusammensetzte. Die beiden Glaubensgemeinschaften blieben zweifellos nicht völlig isoliert voneinander, übernahm doch die »wiedervereinigte« Glaubensgemeinschaft allmählich einige originär orthodoxe rituelle Praktiken, wenn dieses half, das religiöse Leben unter den Bedingungen der Verfolgung seitens des kommunistischen Staates zu gewährleisten. Aber in den Berichten der Gebiets-Bevollmächtigten, die dokumentierten, wie der Unterschied »zwischen Altorthodoxen und früheren Uniaten allmählich verschwindet «, ist nur selten von der Annahme orthodoxer Riten durch die »Wiedervereinigten« die Rede. ${ }^{48}$

Ein deutliches Zeugnis für diesen Prozess war die Annahme der griechisch-katholischen Tradition, die pasky und die Osterspeisen bereits am Ostersamstag zu weihen, durch die orthodoxe »Glaubensgemeinschaft «. Schon zu Beginn der 1950er Jahre führten die Gebiets-Bevollmächtigten (besonders

47 CDAHO, f. 1, op. 24, spr. 5028, ark. 27-28.

48 GARF, f. 6991, op. 1c, d. 230, 1. 29; CDAHO, f. 1, op. 23, spr. 5069, ark. 387.

\begin{tabular}{l|l} 
DigiOst 3 & 269
\end{tabular} 
im Gebiet Lemberg, wo die Mehrheit der Altorthodoxen und viele Migranten aus der Ost- und Zentralukraine sowie aus Russland lebten) in ihren Berichten aus: »Die altorthodoxen Kirchen passten sich in diesem Jahr auch fast völlig den örtlichen Begebenheiten an. Sie begannen mit der Weihe [der Osterspeisen] auch am Abend [des Ostersamstages]. $\aleph^{49}$ Wie auch im Falle der Annahme orthodoxer Riten durch die »wiedervereinigte« Gemeinschaft der Gläubigen erklärt sich dieses Phänomen teilweise durch die praktische Anpassungsbereitschaft der Gläubigen. Vyšnevs'kyj hatte wichtige Gründe für seine Feststellung: »Die altorthodoxen Gläubigen beginnen, sich in ihrem Ritus ein Beispiel an der örtlichen Bevölkerung zu nehmen, ist es doch bequemer, [die paska] tagsüber [am Ostersamstag] weihen zu lassen, als die ganze Nacht nicht zu schlafen. $\aleph^{50}$ Was immer auch die Motive dafür gewesen sein mögen, eine solche allmähliche Anpassung der orthodoxen Gemeinschaft an die Besonderheiten des westukrainischen religiösen Lebens belegt das Assimilationspotenzial der "wiedervereinigten« Glaubensgemeinschaft.

Die »wiedervereinigte« Glaubensgemeinschaft übte einen bedeutenden Einfluss auf die orthodoxe Geistlichkeit aus der Ost- und Zentralukraine sowie aus Russland aus. Die kirchliche Führung setzte ihre Priester in den "wiedervereinigten « Pfarreien ein, damit diese die »Orthodoxierung « der Westukrainer wirkungsvoll umsetzten. In Wirklichkeit jedoch war ein solcher orthodoxer Priester gezwungen, den Erwartungen seiner neuen Pfarrangehörigen zu entsprechen, um eine effiziente Leitung der Pfarrei zu erreichen. Nach Analyse der Berichte der Gebiets-Funktionäre zog der für die Ukrainische Sowjetrepublik Bevollmächtigte des Rates für die Angelegenheit der ROK, Hryhorij Pinčuk, im Jahr 1959, anderthalb Jahrzehnte nach der Lemberger

49 Bericht des Bevollmächtigten Vyšnevs'kyj über die Osterfeierlichkeiten im Jahr 1957 in: CDAVO, f. 4648, op. 1, spr. 160, ark. 119. Siehe auch: CDAVO, f. 4648, op. 1 , spr. 219, ark. 114.

50 Bericht über die Osterfeierlichkeiten im Jahr 1959 in: CDAVO, f. 4648, op. 1, spr. 193, ark. 119. 
Šlichta, »Verschieden« und »Identisch»

Scheinsynode, die Schlussfolgerung: »[Die orthodoxen Geistlichen] passten sich unter dem Anschein von deren [der westukrainischen Gläubigen] 〈Orthodoxierung〉 in Wirklichkeit an diese an. $\aleph^{51}$ Die Priester vollzogen die "uniatischen Riten" und änderten sogar das äußere Erscheinungsbild des »orthodoxen Popen « zu einem »westukrainischen Pfarrer« (paroch), um für die Galizier annehmbar zu werden. ${ }^{52}$

Eine deutliche Erscheinung des assimilatorischen Einflusses der »wiedervereinigten « Glaubensgemeinschaft war ihr Einfluss auf die orthodoxen Erzpriester, die zur Leitung der westukrainischen Eparchien geschickt worden waren. Nach ihrer Ernennung für »wiedervereinigte« Eparchien hat die Mehrheit von ihnen ziemlich schnell verstanden, dass eine Festigung der Stellung der orthodoxen Kirche in Galizien nur unter der Bedingung der Anpassung der Orthodoxie an die örtlichen Traditionen des religiösen Lebens möglich war.

Trotz anfänglicher Nichtakzeptanz von Erzbischof Makarij (Oksijuk) erkannte nicht nur die »wiedervereinigte " Glaubensgemeinschaft, sondern auch die Untergrund-UGKK einvernehmlich an, dass er »ein guter Ukrainer« und "ein echter Priester « gewesen sei und dass er die Maßnahmen der "Orthodoxierung « sehr vorsichtig durchführte. ${ }^{53}$ Den Grund hierfür muss man in seiner Bereitschaft sehen, sich an die Erwartungen der Westukrainer und an die örtlichen religiösen Traditionen und Gebräuche anzupassen. Erzbischof Makarij sprach ukrainisch und hielt auch seine Predigten ukrainisch. ${ }^{54}$ In seinen Predigten und zahlreichen erzbischöflichen Botschaften versuchte er, die Orthodoxie von der negativen Assoziation mit Russischem zu säubern und

51 GARF, f. 6991, op. 1c, d. 1788, 1. 16.

52 GARF, f. 6991, op. 1c, d. 1442, 1. 194; d. 1788, 1. 16.

53 Interview mit P. Mychajlo Dacynyšyn, ark. 26. Interview mit P. Mykola Markevyč am 17.03.1993, Mykolaïv, in: AIIC, P-1-1-337, ark. 13.

54 Ковальський В. (прот.): Из Львовской епархии, in: ŽMP, 12/1947, 46. 
Šlichta, »Verschieden« und »Identisch»

sie als den nationalen Glauben des ukrainischen Volkes darzustellen, ${ }^{55}$ geweiht mit dem Blut der »Kosaken, die im Kampf für den orthodoxen Glauben gefallen waren $\ll \cdot{ }^{56}$ Der Erzbischof sprach sich für eine Beibehaltung der örtlichen Gottesdienstpraxis (gelesene Liturgie) und populärer religiöser Gebräuche (koljadky, Fronleichnamsfest u. a.) aus. Die kirchliche Führung, die ihn offiziell für seine »Bemühungen in der Sache der Wiedervereinigung der Griechisch-Katholischen mit der Orthodoxen Kirche (das war die Formulierung, die seine Erhebung zum Erzbischof 1946 begleitete) lobte, ${ }^{57}$ kritisierte ihn gleichzeitig scharf für seine »Nachgiebigkeit gegenüber den Unierten «. ${ }^{58}$

Etwas anderes ist das anschauliche Beispiel eines der Nachfolger von Erzbischof Makarij auf dem Bischofsstuhl von Lemberg und Ternopil', des Erzbischofs Palladij (Kamins'kyj). Erzbischof Palladij wird entgegen seiner unstrittigen, stets deklarierten Loyalität in den offiziellen Dokumenten als »doppelgesichtiger Bischof", als unaufrichtig in den gegenseitigen Beziehungen mit dem Rat für die Angelegenheiten der ROK und sogar als der »reaktionärste Bischof» charakterisiert. ${ }^{59}$ Die Haltung von Erzbischof Palladij gegenüber den »Wiedervereinigten « war der wesentliche Grund für entsprechende Anschuldigungen der Illoyalität. Erzbischof Palladij »bewahrte bewusst« in der Eparchie Lemberg und Ternopil' Züge des »kriegerischen Katholizismus und des ukrainischen Nationalismus", die »charakteristisch für die uniatische Kirche waren«. Die Bevollmächtigten unterstrichen, dass die Sankt-Georgs-Kathedrale während seiner Zeit auf dem erzbischöflichen Sitz einer Hauptkirche der UGKK glich

55 Siehe beispielsweise: Макарій, архієпископ, Слово перед молебнем на спомин роковин Львівського церковного Собору; ders.: Великоднє привітання; ders.: Різдвяне послання; ders.: Обращение.

56 Ліквідація УГКЦ (1939-1946). Т. 1, 810.

57 ŽMP (1946) 5, 13.

58 Журнал заседания Священного Синода Nr. 35, 28.12.1946, in: GARF, f. 6991, op. 2, spr. 34a, ark. 105-106.

59 GARF, f. 6991, op. 1c., d. 1788, ark. 15. 
und dass er die Liturgie eher entsprechend den unierten als den orthodoxen Anforderungen nach feierte. ${ }^{60}$ Noch mehr, er versuchte die Kirchenführung davon zu überzeugen, dass die Achtung gegenüber den örtlichen Traditionen des religiösen Lebens eine unabdingbare Voraussetzung für Aufbau der Orthodoxie in den westukrainischen Gebieten sei. So rief er in seinem Brief an Patriarch Aleksij vom 18. März 1958 dazu auf, die örtlichen Ehetraditionen zu tolerieren. ${ }^{61}$

\section{Schlussfolgerungen}

Nach der gewaltsamen Liquidierung der UGKK und ihrer »Wiedervereinigung« mit der ROK wurden die »ehemaligen« griechisch-katholischen keine »orthodoxen« Gläubigen. Nicht nur die Mitglieder der »Katakomben «-Kirche, sondern auch die "wiedervereinigten " Gemeinden wurden durch die Staatsmacht und die Orthodoxen als »Uniaten « betrachtet, die auf jede Art und Weise versuchten, ihr »Anderssein « zu bewahren. Im kirchlichen Alltag und in den täglichen Praktiken brach die durch den kommunistischen Staat vorgeschriebene »Orthodoxierung " völlig ein. Gleichzeitig lassen sich genau auf dieser Ebene am allerdeutlichsten die gegenseitigen Einflüsse nachverfolgen. In beiden Fällen wurde die Bereitschaft, »sich zu ändern «, direkt durch die Notwendigkeit zur Anpassung bestimmt. Im Fall der westukrainischen Christen war es eine Anpassung an die "sozialistische Realität«; im Fall der Orthodoxen an die Bedingungen des religiösen Lebens in den »wiedervereinigten « Eparchien.

60 Siehe beispielsweise CDAHO, f. 1, op. 24, spr. 4927, ark. 311; Сергійчук (упор.): Нескорена Церква, 334-335; Пащенко: Православ'я в новітній історії України, 290.

61 CDAVO, f. 4648, op. 1, spr. 176, ark. 186. 
Šlichta, »Verschieden« und »Identisch»

Wie auch der Charakter der Ansichten der orthodoxen und der griechisch-katholischen Gläubigen übereinander, so waren auch die Besonderheiten ihrer gegenseitigen Beeinflussung durch den Staat bestimmt: Entweder unmittelbar (im ersten Fall) oder mittelbar, über die Bildung eines entsprechenden gesellschaftlich-politischen und soziokulturellen Raumes für Wechselwirkungen (sowohl im ersten als auch im zweiten Fall). Eine der am wenigsten erhofften und (offensichtlich) durch niemanden vorausgesehene Folge dieser Wechselwirkung war das Entstehen einer spezifisch ukrainischen Variante der Orthodoxie und das auf einem Gebiet, das sich bei weitem nicht auf die »wiedervereinigten« Eparchien beschränkte.

\section{Literatur}

Макарій, архієпископ: Великоднє привітання, in: Православний вісник (1948) 5, 134.

Макарій, архієпископ: Обращение, in: Журнал Московской патриархии (1949) 10, 8-9.

Макарій, архієпископ: Різдвяне послання, in: Православний вісник (1949) $1,6$.

Макарій, архієпископ: Слово перед молебнем на спомин роковин Львівського церковного Собору, in: Православний вісник (1948) 3, $67-68$.

Єкельчик, Сергій: Імперія пам'яті: Російсько-українські стосунки в радянській історичній уяві. Київ 2008.

Ліквідація УГКЦ (1939-1946). Документи радянських органів державної безпеки. Т. 1-2. Київ 2006.

Лисенко, Олександр Є.: До питання про становище Церкви в Україні у період Другої світової війни, in: Український історичний журнал 3 (1995), 73-81. 
Šlichta, »Verschieden« und »Identisch»

Лисенко, Олександр Є.: Церковне життя в Україні, 1943-1946. Київ 1998. Пащенко, Володимир О.: Православ’я в новітній історії України. Ч. 1. Полтава 1997.

Сергійчук, Володимир (упор.): Нескорена Церква: Подвижництво грекокатоликів України в боротьбі за віру і державу. Київ 2001.

Чумаченко, Татьяна А.: Государство, Православная Церковь, Верующие. 1941-1961 г.г. (Серия »Первая монография«), in: „AНРО-ХХ«. Москва 1999.

Шкаровский, Михаил В.: Русская православная церковь при Сталине и Хрущёве (Государственно-церковные отношения в СССР в 1939 1964 годах). Москва 2000.

Шліхта, Наталя: Західноукраїнський вплив на Український екзархат: несподівані наслідки »возз'єднання«, in: Турій, Олег: Насилля влади проти свободи сумління = Ковчег. Науковий збірник із церковної історії, Т. 6. Львів 2012, 430-446.

Шліхта, Наталя: „Посередницька« роль Ради у справах Російської православної церкви (на матеріалах Української РСР, 1943-1965рр.). In: Наукові записки НаУКМА, Історичні науки 78 (2008), 39-45.

Bociurkiw, Bohdan R.: Religion and Nationalism in the Contemporary Ukraine. In: Simmonds, G. W. (Hg.): Nationalism in the USSR and Eastern Europe in the Era of Brezhnev and Kosygin. Detroit 1977, 81-95.

Markus, Vasyl: Religion and Nationalism in Ukraine: The Uniates in the Ukraine. In: Ramet, Pedro (Hg.): Religion and Nationalism in Soviet and East European Politics. Durham, London 1989, 138-170.

McDannell, Colleen: Material Christianity. Religion and Popular Culture in America. New Haven, London 1995.

Naumescu, Vlad: Modes of Religiosity in Eastern Christianity: Religious Processes and Social Change in Ukraine. Berlin 2008.

Ramet, Pedro: Autocephaly and National Identity in Church-State Relations in Eastern Christianity: An Introduction. In: Ramet, Pedro (Hg.). East- 
Šlichta, »Verschieden« und »Identisch»

ern Christianity and Politics in the Twentieth Century. Durham, London 1988, 3-19.

Timasheff, Nikolai S.: Religion in Soviet Russia. London 1944.

\section{Abstract}

\section{Natalja Šlichta}

"Different« or »the Same«: Orthodox Believers and Greek-Catholics in Soviet Ukraine After the Second World War

The article examines the confessional situation in Soviet Ukraine after the formal liquidation of the Ukrainian Greek Catholic Church in 1946. Describing the complex interrelations between Orthodox and Greek Catholics, which were largely dictated and mediated by the Soviet authorities, the author focuses on how they viewed each other and how they mutually influenced each other after the forceful »reunification «. The major argument is that the "former Uniates" and the Orthodox did not become »the same«, although their mutual influence at the level of everyday religious practice (unexpectedly for all the sides involved) led to the emergence of Ukrainian Orthodoxy. 


\section{Katrin Boeckh}

\section{Kirchen und staatliche Institutionen in der Ukraine. Die Transformationen des Staatskomitees für Religiöse Angelegenheiten (1917-2013)}

Im öffentlichen Raum sind administrative und andere Institutionen vielfach dafür zuständig, dass Interaktionen zwischen der politischen Ebene - also der Regierung, der Verwaltung, der Gesetzgebung und der Rechtsprechung - und den Bürgern in der Praxis stattfinden können. Sie sollen für die Durchsetzung politischer Vorschriften sorgen und für ihren Kompetenzbereich Rechtssicherheit gewährleisten. Diese staatlich installierten Einrichtungen sind dabei an Regeln gebunden, die festlegen, wer an einer politischen Entscheidung beteiligt ist. ${ }^{1}$ Institutionen werden auch als Bedingung für eine aktive und partizipative Demokratie gesehen. ${ }^{2}$ Oftmals werden staatliche Institutionen daher für sie als systemstabilisierend eingeschätzt. Gleichwohl sind sie aber auch für Staaten ohne demokratische Ordnung grundlegend.

Die Existenz staatlicher Institutionen bedeutet nicht, dass diese für immer ihre ursprüngliche Gestalt behalten. ${ }^{3}$ Institutionen verändern sich, genauso wie sich ihr politisches Umfeld verändert. Der Wechsel und die Ablösung eines politischen Systems, wie dies nach dem Fall des Kommunismus im östlichen Europa geschah, sind daher auch durch institutionelle Veränderungen geprägt. Dadurch, dass die kommunistische Staatsdoktrin fiel, wurden nicht alle Be-

1 Steinmo: What is Historical Institutionalism?, 123-124.

2 So führte Putnam: Making Democracy Work den unterschiedlichen Entwicklungsstand in Nord- und Süditalien auf einen langen historischen Prozess zurück, der Netzwerke zivilen Engagements, bestimmte Wertehaltungen und gegenseitiges soziales Vertrauen hervorgebracht habe.

3 Vgl. die Studie des Nobelpreisträgers North: Institutions, Institutional Change and Economic Performance. 
Boeckh, Kirchen und staatliche Institutionen in der Ukraine

hörden und Institutionen aufgelöst oder ihre Aufgaben umdefiniert, aber für viele änderte sich die Zielsetzung. Überraschend ist es, wenn Institutionen, die zu sowjetischer Zeit als ein Instrument zur Drangsalierung der Bevölkerung eingesetzt wurden, nach dem Ende des Kommunismus die Unterstützung jener finden, die sie einstmals gegängelt hatten. Dies ist der Fall beim Rat für Religiöse Angelegenheiten in der Ukraine. Seine Geschichte und sein Wirken stehen im Mittelpunkt der vorliegenden Analyse, weil er noch zwei Jahrzehnte nach Ende der Sowjetherrschaft bestand - wenn auch in gewandelter Form -, nachdem die Religionsgemeinschaften in der Ukraine gegen seine bevorstehende Auflösung laut Protest erhoben haben. Es soll im Folgenden die erstaunliche Metamorphose dieser Institution dargestellt werden. Dabei wird beschrieben, mit welchen Methoden und Mechanismen sie während der sowjetischen Zeit gegen Kirchen und Religionsgemeinschaften agierte. Im Weiteren wird nachgezeichnet, welche strukturellen Veränderungen sie in der postsowjetischen Zeit erfuhr und wie sie trotz der staatlichen Bestrebung, sie aufzulösen, beibehalten wurde, weil sie die Unterstützung ihrer ehemaligen Opfer - der verschiedenen Glaubensgemeinschaften - erlangt hat. Die zeitliche Achse, an der sich die diachrone Janusköpfigkeit dieser Institution spiegelt, ist die politische Wende nach 1991.

Die Quellengrundlage für die Darstellung bieten vor allem Berichte, die von dieser Institution selbst verfasst wurden. Genauere Einblicke in ihre Tätigkeit, in ihre Kompetenzen und in ihre Zusammenarbeit mit anderen sowjetischen Repressionsorganen zu sowjetischer Zeit sind erst seit der Öffnung der Archive zu Beginn der 1990er Jahre möglich; ${ }^{4}$ vorher konnten nur Vermutungen angestellt werden. Aus den archivalischen Quellen sind gleichzeitig Erkenntnisse darüber zu ziehen, dass antireligiös agierende Kommissionen und Räte in unterschiedlicher Form in der Sowjetunion und in ihren Republiken schon von allem Anfang an eingesetzt wurden und dass Kirchen und Religionsgemeinschaften

4 Anderson: The Archives of the Council for Religious Affairs; Катуніна, Катунін: Політіка партиї та радянського уряду.

DigiOst 3 | 278 
Boeckh, Kirchen und staatliche Institutionen in der Ukraine

per se bis zum Ende der Sowjetunion als antisowjetische Brennherde von der kommunistischen Herrschaft bekämpft wurden. Für die neuere und neueste Entwicklung finden sich zahlreiche Verordnungen, viele online publiziert, in denen der Handlungsradius der Institution in der Gegenwart transparent wird.

\section{Sowjetische antireligiöse Kommissionen in der Zwischenkriegszeit}

Religionen, Konfessionen und Glaubensgemeinschaften generell wurden von der sowjetischen Herrschaft als Träger des Ancien Régime, als unabhängige und auch national agierende Kräfte und damit als störend für die öffentliche Ordnung verstanden. Wegen der großen Menge der Anhänger war es aber nie möglich, sie vollständig aus dem öffentlichen Leben zu verbannen; daher ging die sowjetische Regierung in Etappen gegen sie vor. Bereits unmittelbar nach der bolschewistischen Machtübernahme in Petrograd im Oktober bzw. November (n.St.) 1917 begann sie mit Maßnahmen der Verdrängung von Hierarchien aus dem öffentlichen Raum. Dabei wurden aber die antikirchlichen Schritte nicht durch das Staatsoberhaupt vollzogen, auch die Partei oder einzelne hohe politische Repräsentanten traten dabei nicht öffentlich in Erscheinung. Vielmehr wurden sie Kommissionen übertragen, die in enger Verbindung mit den Organen des Innenministeriums agierten, ${ }^{5}$ während das Volkskommissariat für Justiz und eine Abteilung für Kulte die generelle Kontrolle über die Religionsgemeinschaften hatte. So bestanden nach der Oktoberrevolution die »Kommission für antireligiöse Propaganda beim Agitprop des ZK«, angesiedelt am Volkskommissariat für Bildung, die 1922 ins Leben gerufene »Zentrale Kommission für die Beschlagnahmung der Kirchenschätze«, die »Kommission für kirchliche Bewegungen« und die »Kommission für Sektenfragen«. Während

5 Luchterhandt: The Council for Religious Affairs, 56.

DigiOst 3 | 279 
Boeckh, Kirchen und staatliche Institutionen in der Ukraine

diese Einrichtungen teils ad hoc entstanden waren und nach Erfüllung ihrer Aufgaben wieder aufgelöst wurden, gründete man 1922 eine ständige und zentrale Einrichtung für den Kirchenkampf, die sogenannte »Antireligiöse Kommission« beim Zentralkomitee der Russländischen Kommunistischen Partei (Bol'ševiki) [russ. Rossijskaja Kommunističeskaja Partija (bol’ševikov)]; der ursprüngliche Name lautete: »Kommission zur Durchführung der Trennung der Kirche vom Staat«. Das Sekretariat für die Angelegenheiten der Kulte, das die Abteilung für Kulte am Volkskommissariat für Justiz ersetzte, wurde ebenfalls zu einer permanenten Einrichtung. ${ }^{6}$

1929 wurde die »Antireligiöse Kommission « aufgelöst, ihre Aufgaben gingen auf andere Behörden über. Dieses Jahr brachte eine neue Etappe in der Religionsverfolgung. Denn mit dem Dekret »Über die religiösen Vereinigungen« des Allrussischen Zentralexekutivkomitees und des Rates der Volkskommissare (SNK) der RSFSR von 1929 setzte die Sowjetmacht ihren Griff auf die Gemeinden an, deren Existenzberechtigung voll von der staatlichen Zustimmung abhängig gemacht wurde. ${ }^{7}$ Die Registrierungspflicht für Kirchen und Gemeinden - jedoch nicht für Klöster - wurde in einem Dekret verankert, das ihnen den Status einer rechtlichen Person verweigerte. Erst die mit einigen Auflagen verbundene Registrierung bei der zuständigen staatlichen Verwaltung machte es einer Gemeinde möglich, ihre Tätigkeiten aufzunehmen. Gemeinden, die sich nicht zur Registrierung meldeten, wurden für aufgelöst erklärt. Mit diesem Dekret verloren die Geistlichen auch ihren Status als volle Staatsbürger, denn ihnen wurden - bis zur Verfassung von 1936 - das aktive und passive Wahlrecht verwehrt. Dies bedeutete gleichzeitig den Verlust wichtiger Lebensgrundlagen, denn sie konnten damit weder Lebensmittel noch Wohnraum mehr erhalten.

6 Walters: A Survey of Soviet Religious Policy, 5.

7 Vgl. die Textausgabe in Орлеанский: Закон о религиозных объединениях РСФСР и действующчее законы, 6-25, sowie ausschnittsweise bei: Hauptmann, Stricker: Die Orthodoxe Kirche in Russland, 735-738. 
Boeckh, Kirchen und staatliche Institutionen in der Ukraine

Die Exekutive dieses Dekrets und seit dessen Revisionen im Jahr 1932 auch die Registrierung der Gemeinden blieb den lokalen Religionsbehörden als den für die Gemeinden und Geistlichen zuständigen Organe überlassen, die über deren legale Existenz entschieden. ${ }^{8}$ Als direktes Repressionsorgan griff man seit 1931 auf eine Kommission für Kulte (kul'tkommissija) am Volkskommissariat für Innere Angelegenheiten zurück. ${ }^{9}$

Der Vorteil dieser Kommissionen bestand für das Regime darin, dass die Kirchenverfolgung nicht unmittelbar der Regierung oder der Partei zugeschrieben werden konnte, sondern in der Außenperspektive in die Verantwortung eben einer Kommission fiel. Das war wichtig für den äußeren Schein, denn die Religionsrepression war eine unpopuläre Angelegenheit, die einen großen Teil der Bevölkerung direkt betroffen hat. Noch in der Volkszählung des Jahres 1937 bekannten sich die Hälfte der Stadtbewohner und sogar 70 Prozent der Landbevölkerung in der Sowjetunion zu einer Glaubensgemeinschaft. ${ }^{10}$ Diese hohe Zahl ist sehr erstaunlich, denn zu Beginn der 30er Jahre waren bereits die Hierarchien der meisten Glaubensgemeinschaften gewaltsam zerstört worden, und auch die staatliche antireligiöse Propaganda hatte bereits systematisch und breit gegen Kirchen Front gemacht.

\section{Religionspolitisches »Tauwetter« im Zweiten Weltkrieg}

Der Zweite Weltkrieg brachte eine Verschnaufpause in der Verfolgung von Kirchen und Glaubensgemeinschaften, unter Ausnahme jener Gebiete, die von der Roten Armee ab 1939 besetzt waren, wo Geistliche zur Unterdrückung mög-

8 Anderson: The Council for Religious Affairs and the Shaping of Soviet Religious Policy, 690.

9 Ebenda.

10 Heller: Die Russische Orthodoxe Kirche, 21. 
Boeckh, Kirchen und staatliche Institutionen in der Ukraine

licher politischer Opposition verfolgt wurden. Weil das Stalinsche Regime an der Heimatfront zu sehr auf die Unterstützung der Massen bei der Verteidigung angewiesen war, ließ es einige kulturelle Lockerungen zu. Dazu gehörte auch, dass Stalin die Russische Orthodoxe Kirche als patriotisches Mobilisierungsinstrument einsetzte und unter anderem die Wahl eines Patriarchen erlaubte. Weil Stalin außerdem besonderen Wert auf das außenpolitische Ansehen der Sowjetunion bei den westlichen Alliierten legte, durfte die Russische Orthodoxe Kirche wieder öffentlich auftreten. Sie war allerdings durch die staatlichen Übergriffe der 1920er und 1930er Jahre aufs Äußerste geschwächt, hatte ihre besten Köpfe verloren und wurde im Weiteren voll durch staatliche Organe gelenkt. So musste sie auch zulassen, dass Bischofsernennungen nur mit der Erlaubnis des Innenministeriums - NKVD, später KGB - erfolgen konnten und hier nur vom System akzeptierte Personen zum Zug kamen. Die internen Abstimmungsvorgänge darüber wurden geheim gehalten.

Auch die weitere Überwachung und Kontrolle aller kirchlichen und religiösen Organisationen im Land blieb still und in der Öffentlichkeit unauffällig, was vor allem spezielle politische Einrichtungen gewährleisteten, die nun erstmalig mit einem hierarchischen Aufbau bis hinunter zu den unteren administrativen Einheiten in der gesamten UdSSR wirkten. Zur Lenkung der Glaubensgemeinschaften in der UdSSR wurden nämlich zwei Räte auf oberster staatlicher Ebene eingesetzt - dies waren während des Zweiten Weltkrieges die einzigen neu geschaffenen Institutionen, die keine direkte Verbindung mit militärischen Angelegenheiten hatten. ${ }^{11}$ Exklusiv für die größte Kirche, die Russische Orthodoxe Kirche, wurde 1943 der »Rat für die Angelegenheiten der Russischen Orthodoxen Kirche beim Ministerrat der UdSSR « (Sovet po delam russkoj pravoslavnoj cerkvi pri Sovete Ministrov SSSR) in Moskau eingerichtet. Er fungierte als Bindeglied zwischen den Einrichtungen der orthodoxen Kirche

11 Чаварівський, Утворення та діяльність державних органів у справах релігій радянського періоду. (1943-1965rr.), 142.

DigiOst 3 | 282 
Boeckh, Kirchen und staatliche Institutionen in der Ukraine

und den Parteiorganen und hatte die Aufgabe, die »Verbindung zwischen der sowjetischen Regierung und dem Patriarchen von Moskau und Ganz Russland in Fragen, für welche die Erlaubnis der sowjetischen Regierung erforderlich war «, herzustellen. ${ }^{12}$ Sein erster Vorsitzender wurde Georgij Grigor'evic Karpov (Lebensdaten 1897-1967). ${ }^{13}$

Am 19. Mai 1944 setzte der Ministerrat in Moskau für die anderen Glaubensrichtungen einschließlich der Sekten eine ähnliche Organisation mit gleicher Hierarchie, einen Rat für Religiöse Kulte (Sovet po delam religioznych kul'tov pri Sovete Ministrov SSSR), ein. Seine Aufgabe bestand darin, »zwischen der Regierung der UdSSR und den Führern der religiösen Vereinigungen der armenisch-gregorianischen, der altgläubigen, der katholischen, der griechisch-katholischen, der lutheranischen Kirche, der muslimischen, jüdischen, buddhistischen Religion sowie auch den Sekten Kontakt herzustellen in Fragen, für die diese Konfessionen die Erlaubnis der sowjetischen Regierung benötigten $«{ }^{14}$ Vorsitzender dieses Rates wurde Ivan Vasil’evič Poljanskij (1944-1956). Die Verzahnung von Kirchenkontrolle und geheimdienstlicher Überwachung wurde dadurch gewährleistet, dass beide Bevollmächtigte NKVD-Mitarbeiter waren. Poljanskij war in dieser Eigenschaft bereits in den 1920er Jahren mit

12 GARF fond 6991, opis 2, delo 1, 1. 2: Совет Народных комиссаров СССР. Постановление № 993 от 14 октября 1943. Об организации совета русской православной церкви. [Gez.] Сталин, председатель Совета Народных Комиссаров Союза ССР. Управляющий Делами совета народных комиссаров СССР Я. Чадаев.

13 Eine biographische Notiz zu Karpov bei Шкаровский: Русская православная церковь при Сталине и Хрущеве, 204, Anm. 3.

14 CDAHOU fond 1, opys 23, spr. 887, ark. 2: Совет Народных Комиссаров СССР. Постановление № 572 от 19 мая 1944 г. об организации Совета по делам религиозных культов. [Gez.] Председатель Совета Народных Комиссаров Союза ССР I, Сталин, Управляющий Делами совета народных комиссаров СССР Я. Чадаев. Москва, Кремль. Чумаченко: Государство, православная церковь, верующие, 26-45, zum Gesamtaufbau des Rates.

DigiOst 3 | 283 
Boeckh, Kirchen und staatliche Institutionen in der Ukraine

religiösen Organisationen befasst; Karpov leitete bis 1955 eine Abteilung eines NKVD-Direktorats. ${ }^{15}$ Nach Anweisung Molotovs sollte die doppelte Tätigkeit Karpovs aber nicht bekannt gegeben werden. ${ }^{16}$

Während die früheren sowjetischen Religions-Kommissionen Kapazitäten vermisst hatten, um in anderen Republiken wie der Ukraine und in Weißrussland effektiver durchgreifen zu können und hier beispielsweise Kirchenschätze an sich zu ziehen, ${ }^{17}$ waren die neuen Räte nun nicht mehr nur auf der obersten staatlichen Ebene zu finden. Vielmehr verfügten sie in den einzelnen sowjetischen Republiken und Gebieten über Bevollmächtige und Unterstrukturen. In der Ukraine, in Armenien und in der Russischen Föderativen Sowjetrepublik waren die Räte dem Republiksministerrat angeschlossen. Karpov gab an, sein Rat besitze über hundert Vertreter in der Sowjetunion; ${ }^{18}$ in der Ukraine waren neben dem Vertreter des Rates für Religiöse Kulte, P. Chodčenko (Lebensdaten: 1880-1967), und seinem Stellvertreter in Kiev zehn weitere Angestellte tätig. Die Ernennung von Beauftragten für Religiöse Kulte auf Gebiets-Ebene erfolgte auf Beschluss des Rates der Volkskommissare der UdSSR vom 18. Dezember 1943 und nach einem Brief des Rates für die Russische Orthodoxe Kirche an den Ministerrat vom 30. November 1944. So wurde beispielsweise 1945 am Exekutivkomitee des Gebiets Lemberg zwar ein Apparat für den Bevollmächtigen des Rates für Religiöse Kulte und für den Bevollmächtigten des Rates für die Russische Orthodoxe Kirche eingerichtet. ${ }^{19}$ Vorläufig blieben aber ihre

15 Chumachenko: Church and State in Soviet Russia, 16; Одинцов: Государство и Церковь в России, 44.

16 Ebenda, 48.

17 Dies wurde beispielsweise im Jahr 1932 für die »Antireligiöse Kommission« beim Zentralkomitee der Russländischen Kommunistischen Partei bemängelt; vgl. Русская Православная Церковь и коммунистическое государство. 1917-1941, 292-293.

18 Inkeles: Social Change in Soviet Russia, 224.

19 So in den Vorbemerkungen in DALO fond R-1332, opys 1 mit der Korrespondenz des Bevollmächtigten des Rates für Religion am Ministerrat der UdSSR für das 
Boeckh, Kirchen und staatliche Institutionen in der Ukraine

Stellen vakant; ihre Aufgaben nahm der Sekretär des Exekutivkomitees wahr. Auf Beschluss des Exekutivkomitees vom 13. Februar 1945 hin wurde A. A. Vyšnevskij zum Bevollmächtigten des Rates der Russischen Orthodoxen Kirche und durch einen weiteren Beschluss vom 4. September 1945 P. L. Kučerjavyj zum Bevollmächtigten des Rates für Religiöse Kulte ernannt.

Bei den Räten handelte es sich nur nach außen hin um "vermittelnde» Organe: Karpov erwartete vom Russischen Orthodoxen Patriarchat, dass sich dieses in allen Belangen direkt an seine Institution richte, wie er in einem offiziellen Brief 1957 schrieb. Jede andere Praktik sei »unnormal « und »gesetzeswidrig $\lll .{ }^{20}$ Nach außen hin mag tatsächlich der Eindruck entstanden sein, dass nach dem Zweiten Weltkrieg eine Kooperation zwischen dem Regime und den Glaubensgemeinschaften bestand. Dieser Eindruck sollte auch erweckt werden angesichts der Tatsache, dass sich die sowjetische Regierung vor den westlichen Alliierten im Zweiten Weltkrieg möglichst positiv darstellen wollte und als neue europäische Großmacht nun stärker auf ihr internationales Ansehen achtete. Aber generell bestanden die Aufgaben beider Räte in der genauen Beobachtung der Gläubigen und Gemeinden, in der Vorbereitung und Durchführung von repressiven Maßnahmen gegen sie sowie in der Zusammenarbeit mit anderen sowjetischen Behörden wie NKGB und NKVD, die dann Strafmaßnahmen einleiteten und exekutierten - oft genug mit konstruierten Anklagen. Die Räte waren in der Nachkriegs-Sowjetunion jene Behörde, die dem Regime die verdeckte Kirchenverfolgung erst ermöglichte, denn offizielle Verbote - wie der Ausübung des »Kultes « oder des Kirchenbesuches - wurden nie ausgesprochen. Es waren aber die Räte, die den Gläubigen klar machten, dass sie sich im Falle eines offenen religiösen Engagements gegen den Staat stellten und ihnen dann jegliches berufliche Vorankommen verwehrt wurde, und die zusammen mit

Gebiet Lemberg.

20 Шліхта: Церква тих, что вижив. Радянська Україна, середина 1940-х - пос̌аток 1970-x pp., 86-87.

DigiOst 3 | 285 
Boeckh, Kirchen und staatliche Institutionen in der Ukraine

anderen sowjetischen Organen antireligiöse Propaganda betrieben. In Galizien haben die beiden Räte unter anderem bei der sogenannten »Liquidierung der Unierten Kirche« 1946 und in der Karpaten-Ukraine 1949 eine wichtige und verhängnisvolle Rolle gespielt. ${ }^{21}$ Sie haben Informationen über unierte Geistliche weitergegeben, und sie waren zuständig für die Registrierung von kirchlichen Gemeinden und von »Kultdienern«, also den Geistlichen; somit trugen sie einen wesentlichen Anteil an der Verfolgung der Unierten Kirche, die in der Sowjetunion zu den am heftigsten bekämpften Glaubensgemeinschaften gehörte.

Die Registrierung von religiösen Gemeinden wurde in einem Beschluss des Ministerrats der UdSSR vom 28. November 1943 erneut festgelegt. ${ }^{22}$ Dieser überantwortete die Öffnung von Kirchen zunächst den lokalen Exekutivkomitees, deren Entscheidung vom Rat in Moskau sowie vom sowjetischen Ministerrat bestätigt werden musste. Für die Registrierung waren wiederum die Bevollmächtigten vor Ort die Dreh- und Angelpunkte. Sie stellten Listen über die Anzahl der Geistlichen, Kirchen, Kapellen, Gebetsräume und Kirchengemeinden zusammen, ermittelten die kirchlichen Besitztümer und Liegenschaften und verfassten Analysen über die allgemeine Religiosität sowie über die Beziehungen zwischen Kirchen und Gläubigen. Sie unternahmen Informationsreisen in die Gebiete, befragten Geistliche und Gläubige und prüften schriftliches Material, Vorträge und ähnliches. Dies alles leiteten sie weiter an die übergeordneten Räte auf Republiksebene, die dann Zusammenfassungen nach Moskau gaben.

Weil die lokalen Bevollmächtigten die Anträge der Gemeinden und der »Kultdiener« auf Registrierung prüften, hing von ihrer Bewertung vielfach die Existenz der Gemeinden ab. In der Praxis griffen sie auf eine Vielzahl von Möglichkeiten zurück, die Registrierungen abzulehnen. Als gesetzliche Handhabe

21 Vgl. die Dokumentation der Aktivitäten der Räte bei der Verfolgung der griechisch-katholischen Kirchen bei: Сергійчук: Нескорена Церква.

22 Перелугин: Русская Православная Церковь на Орловщине, 130; Chumachenko, Church and State in Soviet Russia, 57. 
Boeckh, Kirchen und staatliche Institutionen in der Ukraine

gegen die Eröffnung oder Rückgabe von neuen Kirchen konnten verschiedene Hinderungsgründe vorgebracht werden, darunter die Unmöglichkeit, ein früher kirchliches Gebäude von neuen kulturellen oder militärischen Aufgaben zu entbinden, bautechnische Unzulänglichkeiten eines kirchlichen Gebäudes oder unkorrekte Unterschriften der für eine Gemeinde nötigen Mindestzahl von 20 Gläubigen. Oft genug legten die Räte diese Vorschriften gegen die kirchlichen Antragsteller aus.

In der Verhinderung der Kirchenöffnungen gingen sie bei allen Religionsgemeinschaften gleich konsequent vor. Alle im vierten Quartal des Jahres 1947 eingegangenen Anträge auf die Öffnung von Gebetshäusern im Gebiet Lemberg beispielsweise - die römisch-katholische Kirche hatte drei, die jüdische Gemeinde eine, die Unierte Kirche vier und die Baptisten zwei gestellt - wurden abgelehnt. ${ }^{23}$ Zudem wurde die Zahl der Gemeinden (oftmals durch die Schließung ihrer Gotteshäuser) stetig reduziert, so dass zu Beginn der 1950er Jahre nur mehr ein Bruchteil des früheren Bestandes vorhanden war; die Gemeinden der griechischen-katholischen Gläubigen und der Christen Evangelischen Glaubens waren im Gebiet Lemberg völlig aufgelöst worden. Für die Bevollmächtigten vor Ort bedeutete die erfolgreiche Verdrängung der Gläubigen ein positives Resultat ihrer Arbeit. Dass ihnen dies gelang, sahen sie darin begründet, dass es mit ihrem Zutun zu einer Verstärkung der sowjetischen Organe kam, zum Aufbau von Parteiorganisationen und zur systematischen Agitationsarbeit unter der Bevölkerung. Dafür führten sie Vorträge und Lesungen über antireligiöse Themen durch, organisierten sogar Sportveranstaltungen und andere Freizeitaktivitäten wie Exkursionen von Kolchosarbeitern in Museen, Theater und ähnliches, und betrieben antikirchliche Propaganda in den Schulen. ${ }^{24}$

23 Vgl. die Statistik über die Anträge auf die Öffnung von Gebetsgebäuden im Gebiet Lemberg für das vierte Quartal 1947 unter: DALO fond R 1332, opys 1, spr. 8, ark. 124 verte.

24 Arbeitsbericht des Bevollmächtigten für die Russische Orthodoxe Kirche in Lemberg in: DALO fond R 1332, opys 1, spr. 19, ark. 34-41, hier ark. 36-37. 
Boeckh, Kirchen und staatliche Institutionen in der Ukraine

\section{Erneute Kirchenverfolgung unter Chruščev}

Nicht nur Lenin und Stalin, sondern auch und insbesondere Chruščev, der unter dem Schlagwort des »Tauwetters" gewisse kulturelle Liberalisierungen zuließ, war ein erneut streng antireligiöser Kurs zuzuschreiben. Äußerlich sichtbar wurde er durch den Wechsel in der Leitung des Rates für die Russische Orthodoxe Kirche im Jahr 1960, als der zögerliche Karpov durch den aktiveren Vladimir A. Kuroedov (Lebensdaten: 1906-1994, Vorsitzender des Rates bis 1965) ersetzt wurde. Die kirchenrepressive Wende in den Jahren zwischen 1958 und 1964, die die sowjetische Gesellschaft auf die kommunistische Zukunft hin ausrichten sollte, zog eine massenweise Schließung von Kirchen und Klöstern und eine erneute Verfolgung von Geistlichen und Gläubigen nach sich. Dabei behielt Chruščev jedoch die Stoßrichtung bei, nach außen hin und mit Blick auf die internationale Lage dafür zu sorgen, dass das Sowjetregime nicht in den Verdacht kommen könnte, die Religionsfreiheit in seinem Land einzuschränken. Um dies zu verhindern, trat beispielsweise die Russische Orthodoxe Kirche 1961 dem Weltrat der Kirchen bei; somit wurde sie erfolgreich als außenpolitisches Instrument genutzt - während im selben Jahr das Kloster eines ihrer größten Heiligtümer, des Kiever Höhlenklosters, geschlossen wurde. Kirchenrepräsentanten, die nicht der neuen antireligiösen Linie folgten, wurden ausgewechselt wie der für die außenpolitischen Angelegenheiten des Moskauer Patriarchats zuständige Metropolit Nikolaj, der nach der Kritik des neuen Vorsitzenden des Komitees für die Russische Orthodoxe Kirche, Kuroedov, seinen Posten räumte und kurz darauf unter nicht geklärten Umständen zu Tode kam. ${ }^{25} \mathrm{Im}$ Land und in den Regionen ging es darum - nachdem die Hierarchie fest im staatlichen Griff war -, die einfachen Gläubigen und die Religionsausübung unter staatlicher Kontrolle zu halten; dafür waren die zur Verfügung stehenden und verdeckt agierenden Staatsorgane wiederum ein nützliches Werkzeug.

25 Anderson: The Archives of the Council for Religious Affairs, 400.

DigiOst 3 | 288 
Boeckh, Kirchen und staatliche Institutionen in der Ukraine

In der Ukrainischen Sowjetrepublik wurden Moskaus Vorgaben willig umgesetzt und in die Form von Beschlüssen des ZK der KP der Ukraine gegossen wie in jenen vom 9. Oktober 1962 »Über Zustand und Verbesserungsmaßnahmen der wissenschaftlich-atheistischen Erziehung der Bevölkerung in der Ukrainischen SSR «. Dessen Wortlaut und Zielsetzung hat die sowjetische Öffentlichkeit nicht erreicht, allerdings war der antikirchliche Kurs für sie durch die Aktivitäten der Räte erkennbar, die als Schnittstellen zwischen der Regierung bzw. den staatlichen Behörden und Bevölkerung agierten. Sie sorgten dafür, dass phasenweise exzessiv antikirchliche Propaganda betrieben wurde. Sie starteten beispielsweise im Sommer 1963 eine Kampagne, die den sowjetischen Arbeitern die gesetzliche Lage der religiösen Kulte nahe bringen sollte. ${ }^{26}$ Dazu wurden Kommissionen an den Exekutivausschüssen der Rayons, Städte und Gebiete sowie auf Dorfebene gebildet, in die zahlreiche Mitglieder berufen wurden. Pro Gebiet waren dies mehrere hundert Personen, im Gebiet Černivci sogar über 3.300. In allen Gebieten wurden Seminare zur Thematik »Die Verwurzelung der neuen sowjetischen Gebräuche« unter Teilnahme der Bevollmächtigten durchgeführt. In Rivne wurde speziell für weibliche Atheisten (»ženščiny ateisti «) ein solches Seminar abgehalten. Die Ukraine wirkte bei dieser Kampagne so vorbildhaft, dass auch aus anderen Republiken Delegationen eintrafen und sich über den Fortgang in ukrainischen Städten wie Kiev, Poltava, Lemberg, Drohobyč, Uman und anderen informierten. ${ }^{27}$

Die Vertreter der Räte verknüpften ihren antireligiösen Einsatz mit »wissenschaftlich «-atheistischer Propaganda. Dazu wurden etwa Filme in den Kinotheatern gezeigt über Priester, die Kirchengüter unterschlagen hätten und denen dafür ein Gerichtsprozess gemacht wurde. ${ }^{28}$ Daneben wurden in Betrie-

26 Bericht des Bevollmächtigten für die Russische Orthodoxe Kirche für das Jahr 1963 in: CDAHOU fond 1, opys 24, spr. 5908, ark. 4-43, hier ark. 7.

27 Ebenda ark. 19.

28 Bericht des Bevollmächtigten für die Russische Orthodoxe Kirche für das Jahr 1959 in: CDAHOU fond 1, opys 24, spr. 5116, ark. 11-50, hier ark. 26. 
Boeckh, Kirchen und staatliche Institutionen in der Ukraine

ben und Unternehmen atheistische Unterweisungen durchgeführt, und nicht zuletzt wurden für Gläubige heilige Orte regelrecht »liquidiert«, um dadurch Anziehungspunkte für Pilger und Wallfahrer zu zerstören. Neben Klöstern in der Ukraine waren das auch Quellen und Brunnen. Insgesamt wurden im Jahr 1959 in der Ukraine 29 solcher Orte beseitigt. ${ }^{29}$

Die Prozedur der Registrierung von Gemeinden und Geistlichen wurde weiterhin von den Bevollmächtigten als Druckmittel zur Zurückdrängung religiösen Engagements benutzt. Dabei hatten sie sich an die Anweisung zu halten, die Gemeinden und die Rechte der Leiter zu schwächen, zu ihrer verstärkten Kontrolle beizutragen, die Einkünfte der Kirchen zu verringern und den innerkirchlichen Kampf zu stärken. ${ }^{30}$ Priester aller Glaubensrichtungen waren ein zentrales Ziel staatlicher Überwachung und Verfolgung. Die Bevollmächtigten verfügten über Zuträger und Spitzel aus der nahen Umgebung der Geistlichen, denn sie wussten über wörtliche Aussagen dieser Bescheid und wo und wann sie welche als antisowjetisch ausgelegten Formulierungen gebrauchten.

In der Westukraine wurden Geistliche der in den Untergrund getriebenen griechisch-katholischen Kirche besonders verfolgt. Im Jahr 1963 wussten die Behörden von mehreren hundert unierten Geistlichen, die in L'viv, Ivano-Frankivs'k, Zakarpatt'ja und in Ternopil' »illegal « religiös tätig waren. Schätzungsweise handelte es sich dabei um 400 Priester und über 600 Mönche. ${ }^{31}$ Allerdings war auch die Russische Orthodoxe Kirche weiter im Visier der Bevollmächtigten, besonders deren leitende Repräsentanten. 1963 waren dies zehn Bischöfe, drei Metropoliten und ein Erzbischof, die den 14 Bistümern der Russischen Orthodoxen Kirche in der Ukraine vorstanden. Bischöfe, die nicht im Sinn der Bevollmächtigten agierten, wurden von diesen an den Rat

29 Ebenda, ark. 30.

30 Ebenda, ark. 43.

31 Bericht für 1963 wie oben zitiert in: CDAHOU fond 1, opys 24, spr. 5908, hier ark. 30. 
Boeckh, Kirchen und staatliche Institutionen in der Ukraine

der Russischen Orthodoxen Kirche am sowjetischen Ministerrat gemeldet und in Gebiete außerhalb der Republik versetzt. Dies geschah 1963 mit dem Erzbischof der Karpaten-Ukraine, Nikolaj (N. V. Kutepov), der auf Drängen des ukrainischen Bevollmächtigten aus der Ukraine entfernt wurde. Drei weitere Bischöfe standen in der Gefahr, ebenfalls zwangsversetzt zu werden, da sie sich den Empfehlungen des Bevollmächtigten der Russischen Orthodoxen Kirche verweigerten, sich darum zu bemühen, das religiöse Engagement der Geistlichkeit zu stärken und - wie es heißt - den »religiösen Fanatismus unter den Gläubigen « zu entzünden. ${ }^{32}$ Besonders negativ fiel der Bischof von Černihiv, Feodosij (I. I. Procjuk), auf, der die Schließung des Nonnenklosters in Černihiv nicht auf sich beruhen lassen wollte, eine Suche nach Schuldigen in dieser Angelegenheit begann und Anstrengungen unternahm, ein anderes Kloster wieder zurückzuerhalten, das seinem Bistum entzogen worden war. Er habe systematisch Gläubige zu Klagen »inspiriert «, die auf einer Rückgabe beharrten, da die übrigen Kirchengebäude überfüllt seien. Weiter habe er eine große Zahl an Geistlichen in seinen Messen angezogen und die »Empfehlungen« des Bevollmächtigten ignoriert, da er die Mission verfolgt habe, die Anzahl der Kirchen im Gebiet wieder herzustellen. ${ }^{33}$ Auch der Exarch der Ukraine seit 1944, Metropolit Ioann (Sokolov), stand in keinem guten Licht beim Bevollmächtigten des Rates für die Russische Orthodoxe Kirche, denn man beschuldigte ihn, er würde seine Autorität im Sinne des Bevollmächtigten und der staatlichen Ideologie weder unter den Bischöfen noch unter der Geistlichkeit allgemein nutzen. 1963 traf er sich nur ein einziges Mal mit dem Bevollmächtigten, weitere Zusammenkünfte lehnte er mit Verweis auf seine schlechte Gesundheit ab $^{34}-1959$ war er 83 Jahre alt. Der Kontakt wurde aber durch den Exarchatsverwalter und Vorsteher der

32 Ebenda, ark. 15.

33 Ebenda, ark. 16.

34 Bericht für 1963 wie oben zitiert in: CDAHOU fond 1, opys 24, spr. 5908, hier ark. 16. 
Boeckh, Kirchen und staatliche Institutionen in der Ukraine

Kathedrale in Kiev, Skoropostižnyj, aufrecht erhalten, der es sich jedoch den Behörden gegenüber anmerken ließ, dass er deren Maßnahmen, die Geistlichen in die gesetzlichen Schranken zu verweisen, aus tiefster Seele ablehne.

Nach der Absetzung Chruščevs wurden die beiden Räte auf Unions- und Republikebene $1965 \mathrm{zu}$ einem gemeinsamen »Rat für Religiöse Angelegenheiten « (bis 1984 unter der Leitung von Kuroedov) zusammengelegt, dessen Intention in der »Kontrolle der Kaderpolitik der Kirche« (was auch die Überprüfung von Bischofsernennungen bedeutete), in der "propagandistische[n] Anleitung, Zensur der Publikationen, Kontrolle der Auswahl und Ausbildung der Nachwuchskräfte ebenso wie des kirchlichen Bauwesens $\aleph^{35}$ bestand und damit die staatliche Unterwanderung der kirchlichen Einrichtungen garantierte. Ein wenig später wurden die Räte auf den Gebietsebenen ebenfalls zusammengeführt. Im Gebiet Lemberg wurden der Rat für die Angelegenheiten der Russischen Orthodoxen Kirche und der Rat für die Angelegenheiten der Religiösen Kulte im Jahr 1966 in den Apparat des Bevollmächtigten des Rates "po delam religii pri Sovete Ministrov USSR po L'vovskoj oblasti« (für die Angelegenheiten der Religion am Ministerrat der USSR für das Gebiet Lemberg) überführt.

Dieser Schritt bedeutete aber keine Reduzierung des staatlichen Einflusses auf bestehende Kirchenorganisationen, sondern auch weiterhin blieb die staatliche Unterwanderung der kirchlichen Einrichtungen garantiert. Erst 1976 wurden durch die Annahme des "Vorschlags über die religiösen Vereinigungen in der Ukrainischen SSR « die Rechte religiöser Organisationen wieder etwas gestärkt, allerdings wurden selbst einfache Gläubige bis zum Ende der Sowjetunion überwacht und verfolgt. ${ }^{36}$ Allein 1980 wurden in der Ukraine 219 Personen aus religiösen Motiven verurteilt, 55 von ihnen waren Zeugen Jehovas. ${ }^{37}$

35 von Borcke: KGB, 116.

36 Vgl. etwa die KGB-Berichte bis 1989 in: Corley, Religion in the Soviet Union, 382-384.

37 Бондарчук: Релігійність населення України у 40-48-х роках XХст., 103. 
Boeckh, Kirchen und staatliche Institutionen in der Ukraine

Auch auf internationale Veränderungen reagierte man: Neben dem Stellvertreter des KGB-Chefs und dem stellvertretenden Außenminister wurde Kuroedov 1979 als Vorsitzender des Rates für Religiöse Angelegenheiten in eine vom ZK eingesetzte Kommission berufen, die Gegenmaßnahmen zur Politik des Vatikan in den sozialistischen Staaten einleiten sollte, um den Einfluss des populären Papstes Johannes Paul II. in Osteuropa zurückzudrängen..$^{38}$ In der Ukraine war der Rat in den 1980er Jahren im Zusammenschluss mit anderen staatlichen Propagandastellen weiter aktiv darin, die Wiedererrichtung der Unierten Kirche zu bekämpfen. ${ }^{39}$

\section{Perestrojka und postsowjetische Transformation in der Ukraine}

Die Versuche des neuen ZK-Sekretärs Michail Gorbačev, das sowjetische System durch politische Reformen zu erneuern, scheiterten in der Sowjetukraine lange am Unwillen der Kiever Republikführung. Als sich aber am Ende der 1980er Jahre die Politik der Perestrojka durchsetzte, war es der Rat für Religiöse Angelegenheiten, der ein erstes äußeres Zeichen dafür setzte. Denn nachdem sich im Oktober 1989 eine Lemberger Gemeinde als zur bis dato verbotenen Unierten Kirche zugehörig erklärt hatte, bot der Rat im folgenden Monat an, unierte Gemeinden zu registrieren. ${ }^{40}$ Als dann Papst Johannes Paul II. einige Tage später Gorbačev in Rom empfangen hatte, wurde die staatliche Blockade der Unierten Kirche in der Ukraine vollends aufgehoben. Ab diesem Zeitpunkt konnte das kirchliche Leben in der Sowjetunion wieder öffentlich ausgeübt

38 Corley: Soviet Reaction to Pope John Paul II, 44.

39 Anderson: The Council for Religious Affairs and the Shaping of Soviet Religious Policy, 695.

40 Yelensky: Das Recht der Religionsgemeinschaften in der Ukraine, 523. 
Boeckh, Kirchen und staatliche Institutionen in der Ukraine

werden, 1990 erlaubte die KPdSU Gläubigen die Mitgliedschaft, und die staatliche Kontrolle wurde zurückgefahren. Dies wurde offenkundig in einem 1990 verabschiedeten neuen sowjetischen Gesetz »über die Glaubensfreiheit und die religiösen Organisationen «. Es hielt zwar an der Existenz des Rates für Religiöse Angelegenheiten fest, entzog ihm aber die oberste Aufsicht über die religiösen Gemeinschaften und transformierte ihn zu einer repräsentativen, konsultativen und kommunikativen Institution auf Unionsebene. ${ }^{41}$ Damit hatte der Rat in der Sowjetunion die führende Stellung als Organisationsinstrument über die Kontrolle der Kirchengemeinschaften eingebüßt, obwohl der Staat selbst weiter das staatliche Gewaltmonopol über Kirchen und Religionen und alle weiteren Kräfte im Land für sich beanspruchte.

Auch in der noch sowjetischen Ukraine änderte sich 1991, nachdem der »Rat der Minister der Ukrainischen Sowjetrepublik« in »Kabinett der Minister der Ukrainischen Sowjetrepublik« umbenannt worden war, zunächst nur kosmetisch die Bezeichnung für den weiter bestehenden Rat in »Rat für Religiöse Angelegenheiten am Kabinett der Minister der Ukrainischen Sowjetrepublik«. Sein Leiter blieb weiterhin M. Kolesnyk. Allerdings wurde nun erstmals ein Einblick in die Struktur möglich, von der bekannt wurde, dass sie sich aus einem Sektor für rechtliche und Expertenarbeit und einem Sektor für internationale Beziehungen zusammensetzte und dass sie über eine Kanzlei und technische Mitarbeiter verfügte. ${ }^{42}$ Informationen dieser Art waren der sowjetischen Bevölkerung bisher nicht zugänglich gemacht worden; das Handeln der für die kirchlichen (und auch alle anderen) Fragen zuständigen Behörden sollte möglichst klandestin ablaufen.

Dies endete erst allmählich, nachdem die Ukraine aus der Sowjetunion austrat und sich 1991 als unabhängiger Staat proklamierte. Noch vor der Verab-

41 Luchterhandt: The Council for Religious Affairs, 75-76; Anderson: Religion, State and Politics in the Soviet Union and Successor States, 193.

42 Владиченко: До історії дер’авного органу у справах релігій в Україні. 
Boeckh, Kirchen und staatliche Institutionen in der Ukraine

schiedung der neuen ukrainischen Verfassung im Juni 1996 stellte das "Gesetz über die Gewissensfreiheit und die religiösen Organisationen« vom 23. April 1991 das Verhältnis zwischen Staat und den Kirchen in der Ukraine auf eine neue Grundlage. Es folgte zwar in vielen Regelungen dem sowjetischen Gesetz vom Herbst 1990, gestand jedoch den Kirchen wesentlich größere Spielräume und Freiheiten als zu sowjetischer Zeit zu. ${ }^{43}$ Allerdings ließ es offen, ob es Kirchen als nationale Körperschaften anerkannte oder nur als Gemeinden und als religiöse Institutionen. Im Unterschied zum sowjetischen Gesetz sah das ukrainische vor, dass der Rat für Religiöse Angelegenheiten weiter größere Kompetenzen behielt, weil ihm und den lokalen Räten die Aufsicht über die Durchsetzung des Gesetzes eingeräumt wurde. ${ }^{44}$ Der Hintergrund war die Erkenntnis, dass Kirchen und Religionen in der Ukraine ein bedeutsamer Faktor in der Öffentlichkeit wurden, denn die Anzahl von religiösen Gemeinden in der Ukraine stieg schlagartig, weil viele Religionsgemeinschaften nun den Zustand der Illegalität ablegen und sich öffentlich betätigen durften. Das Religionsgesetz schuf die Voraussetzungen dafür, dass sich vor allem die in den Untergrund getriebene Ukrainische Griechisch-Katholische Kirche und die Ukrainische Autokephale Orthodoxe Kirche, aber auch protestantische und muslimische Gemeinden nun registrieren ließen. Schätzungen des Rates für Religiöse Angelegenheiten zufolge wuchs die Zahl der 1990 registrierten 6.000 Religionsgemeinden auf rund 15.000 im Jahr 1994 an. ${ }^{45}$ Auch die realistische Erwartung, dass der neue konfessionelle Pluralismus zu Konflikten unter den Gemeinden führen könne, motivierte die Beibehaltung des Rates für Religiöse Angelegenheiten.

43 Kovalenko: Church and State in Ukraine.

44 D’Anieri, Kravchuk, Kuzio: Politics and Society in Ukraine, 73; Biddulph: Religious Liberty and the Ukrainian State, 328-335.

45 Biddulph: Religious Liberty and the Ukrainian State, 336. 
Boeckh, Kirchen und staatliche Institutionen in der Ukraine

Weiter blieb er auch ein politisches Werkzeug: die postsowjetische ukrainische Regierung unter Präsident Kravčuk (1990-1994) wollte durch ihn Einfluss auf die Religionsgemeinschaften im Land ausüben, um durch sie auch die nationale Einheit der Ukraine zu fördern. ${ }^{46}$ Die Instrumentalisierung der ukrainischen Religionsgemeinschaften zielte vor allem auf die orthodoxe Kirche als größte Glaubensgemeinschaft ab, deren Unabhängigkeit vom Moskauer Patriarchat die staatliche Unabhängigkeit stützen sollte.

Die staatliche Vereinnahmung funktionierte aber nur bedingt: Viele der religiösen Gemeinschaften der post-sowjetischen Ukraine gehörten »traditionellen « Kirchen und Religionen an, waren also historisch in der Ukraine angesiedelt. Darüber hinaus kamen aber auch immer mehr ausländische Missionare in die Ukraine und begannen, neue Gemeinschaften zu gründen. Dieser »Einfluss von außen « - und dabei ging es in erster Linie um »westliche« Konfessionen, die in der Ukraine Fuß zu fassen begannen, weniger um aus Russland kommende Gemeinden - wurde als Bedrohung für die Herstellung der staatlichen Einheit wahrgenommen. In der Folge wurde nun im Jahr 1993 der Aktionsradius für ausländische Missionare durch Gesetzeszusätze eingeschränkt. Damit wurden gleichzeitig die Kompetenzen des Rates für Religiöse Angelegenheiten aufgewertet, weil dieser nun für eine verstärkte Kontrolle der Registrierungen von Gemeinden zu sorgen hatte. ${ }^{47}$ So richtete sich das Amt für Visaregistrierung (OVIR) bei der Vergabe von Einreisevisa an ausländische Religionsvertreter nach dem Beschluss des Rates für Religiöse Angelegenheiten, womit der Rat de facto die entscheidende Instanz bei der Visavergabe wurde. Auf lokaler Ebene schrieben Vertreter des Rates auch vor, welche Konfessionsgemeinschaften welche Ausländer mit welchen Zielen einladen durften. ${ }^{48}$ Dadurch, dass nun aber religiöse Freiheiten sowohl für Bürger als auch für Ausländer in der Uk-

46 Boeckh, Staat und Kirchen während der Transformation in der Ukraine, 77-78.

47 Biddulph: Religious Liberty and the Ukrainian State, 335-343.

48 Biddulph: Religious Liberty and the Ukrainian State, 343-344. 
Boeckh, Kirchen und staatliche Institutionen in der Ukraine

raine eingeschränkt wurden und der Rat für Religiöse Angelegenheiten dies überwachte, wurde er auch weiter als sowjetisches Relikt wahrgenommen. Dies wurde noch dadurch unterstützt, dass sein Leiter, A. Zinčenko versuchte, wieder eine restriktivere Religionspolitik zu implementieren. ${ }^{49}$

Wohl auch aus diesem Grund bestand einer der ersten Akte des neuen Präsidenten Kučma (1994-2005) kurz nach seiner Amtseinführung darin, den Rat für Religiöse Angelegenheiten aufzulösen. Allerdings richtete er bereits 1995 ein neues Staatskomitee für Religiöse Angelegenheiten (Deržavnyj komitet v spravach relihiji) ein, das dem Justizministerium unterstand ${ }^{50}$ und die Strukturen der sowjetischen Vorgängerorganisation übernahm: Es gab eine Zentrale in Kiev und Filialen in allen ukrainischen Gebieten. Für die Regierung Kučma hatte es nur eine beratende Funktion. Seine Aufgaben bestanden darin, die Kultusfreiheit zu überwachen, religiöse Organisationen zu registrieren, den Dialog zwischen Staat und Kirchen zu sichern und dazu regelmäßige Treffen mit Vertretern der religiösen Gemeinschaften abzuhalten. Genau diese Agenda und die Kontrollfunktionen waren es auch, die Kirchenvertreter kritisierten. Sie waren deshalb zunächst misstrauisch, weil sie den Verdacht hatten, das neue Staatskomitee würde genauso wie der sowjetische Rat für Religiöse Angelegenheiten als Instrument der Kirchenunterdrückung agieren.

Allerdings setzte nun sichtbar ein Umschwung der Diskussionskultur ein. Denn gleichzeitig verstanden die Religionsgemeinschaften, dass auch sie miteinander ins Gespräch kommen mussten, auch wenn (und weil) es eine Menge von Konfliktstoff aller Art vor allem zwischen den größeren Kirchen gab. Daher fanden sie sich 1996 in einer von Kučma initiierten und noch immer bestehenden Plattform zusammen, im All-Ukrainischen Rat für Kirchen und

49 Biddulph: Religious Liberty and the Ukrainian State, 344.

50 Németh: Religionsrecht in der Ukraine, 129. 
Boeckh, Kirchen und staatliche Institutionen in der Ukraine

religiöse Organisationen. ${ }^{51}$ In diesem Rat sind fast alle Repräsentanten der wichtigsten Religions- und Kirchenvereinigungen vertreten. Der All-Ukrainische Rat intensivierte tatsächlich den interkonfessionellen Dialog, was zu einer wirklichen Ökumene von unten führte und gleichzeitig den Dialog zwischen Kirchen und Staat, vertreten durch das Staatskomitee, verstärkte. Dieses erlangte schließlich die Akzeptanz der Glaubensgemeinschaften, denn es wurde eine Plattform für das Gespräch zwischen Kirchen und Politik. Dabei diente es auch insbesondere der Aufwertung der nicht-orthodoxen, also der kleineren Religionsgemeinschaften in der Ukraine, die damit ein besonderes Interesse hatten, sich über den All-Ukrainischen Rat für Kirchen und religiöse Organisationen zu artikulieren. Dass es einen Dialog zwischen den Kirchengemeinschaften einerseits und den staatlichen Organen andererseits gab, sieht man beispielsweise daran, dass 1997 ein staatlich vorgeschlagenes Memorandum über die gewaltlose Lösung religiöser Auseinandersetzungen von den Vertretern der größeren Denominationen unterzeichnet worden ist. ${ }^{52}$

\section{Säkularisation in orange}

Unter dem »orangenen« Präsidenten Viktor Juščenko, der Anfang 2005 in das Amt gekommen war, veränderte sich das Verhältnis zwischen Staat und Kirchen: Juščenko betonte immer wieder, dass er für religiöse Toleranz gegenüber allen Kirchengemeinschaften in der Ukraine stehe, gleichzeitig solle der Staat aber säkularer und den Kirchen gegenüber neutraler sein, also nicht mehr in sie hineinregieren und sie nicht mehr instrumentalisieren. Dies mag der Grund für ihn gewesen sein, Anfang 2005 das Staatskomitee als postsowjetisches Re-

51 Zum All-Ukrainischen Rat für Kirchen und Religiöse Organisationen vgl. Krawchuk, Constructing Interreligious Consensus in the post-Soviet Space.

52 Boeckh, Staat und Kirchen während der Transformation in der Ukraine, 74. 
Boeckh, Kirchen und staatliche Institutionen in der Ukraine

likt aufzulösen. Spätestens zu diesem Zeitpunkt wurde jedoch klar, dass sich diese Institution als akzeptierter Dialogpartner der Religionsgemeinschaften erwiesen hatte und diese auf seine Existenz zählten. Denn sie erhoben gegen die Auflösung einen so lauten Protest, dass Juščenko seine Entscheidung revidierte. Allerdings stufte die zwischen Februar und September 2005 amtierende Regierung Tymošenko das Komitee auf eine für Religionsangelegenheiten zuständige Abteilung des Justizministeriums herab, die im Mai 2005 eingerichtet wurde. Die Regierung von Viktor Janukovyč, im Amt von August 2006 bis November 2007, nutzte das Religionskomitee dafür, Juščenko auf dem Gebiet der Religionspolitik Paroli zu bieten: zum einen dadurch, dass das Komitee wieder zu einem eigenständigen Staatskomitee für Nations- und Religionsangelegenheiten (Deržavnjy komitet u spravach nacional'nostej ta relihiji) aufgewertet wurde, zum anderen durch die Besetzung von dessen Leitungsposition durch einen ehemals kommunistischen Abgeordneten, Heorhij Popov. Die zweite Regierung Tymošenko (Dezember 2007 bis März 2010) postierte hier im Gegenzug mit Oleksandr Sahan wiederum einen vormaligen Berater des Präsidenten. ${ }^{53}$

Trotz der vom All-Ukrainischen Rat für Kirchen und religiöse Organisationen erhobenen Proteste verfügte Präsident Viktor Janukovyč am 15. Dezember 2010 die Auflösung des Staatskomitees für Nations- und Religionsangelegenheiten, was neben anderen zentralen Organen einer administrativen Verschlankung geschuldet war. ${ }^{54}$ Viele Religionsgemeinschaften und zivilgesellschaftliche Organisationen kritisierten die Auflösung des Staatskomitees, da sie dem ukrainischen Gesetz »Über die Freiheit des Gewissens und religiöser Organisationen " widerspreche. Dieses sehe ein eigenständiges staatliches Organ für religiöse Angelegenheiten vor, das zuständig sei für die Registrierung religiöser Organisationen; nach der Auflösung des Staatskomitees wurde sie jedoch einem

53 Németh: Religionsrecht in der Ukraine, 129-130.

54 Про ліквідацію Держкомнацрелігій [1.1.2011]; Президент ліквідував Держкомнацрелігій [10 грудня 2010]. 
Boeckh, Kirchen und staatliche Institutionen in der Ukraine

staatlichen Registrierungsservice übertragen. ${ }^{55}$ Der All-Ukrainische Rat für Kirchen und religiöse Organisationen wandte sich an den Präsidenten und an den Premierminister mit der Bitte, ein einheitliches staatliches Organ für die religiösen Angelegenheiten aufrecht zu erhalten und im Ministerium für Kultur eine Abteilung für religiöse Angelegenheiten herzustellen. Die Oberhäupter der Konfessionen hoben hervor, dass die Hauptaufgabe eines solchen Organs die Harmonisierung des Dialogs zwischen Staat und Konfessionen und der zwischenkonfessionellen Beziehungen sein müsse, aber auch die Hilfestellung bei gesellschafts-relevanten Aufgaben der religiösen Organisationen in der Ukraine. Vor allem die kleineren Religionsgemeinschaften fühlten sich zurückgesetzt, weil der Kontakt zwischen ihnen und Regierungsvertretern abgerissen sei. Der Vorgang steigerte auch ihre Angst, dass in der Ukraine ein Modell der Kirche-Staat-Beziehungen etabliert werde wie in Russland, wo die Orthodoxie quasi als Staatskirche fungiert.

Im Januar 2012 beschloss das Kabinett, die Zuständigkeiten des aufgelösten Staatskomitees für Nationalitäten und Religionen dem Kulturministerium zu übertragen. Hier wurde insofern ein eigenständiges staatliches Organ mit der Registrierung religiöser Organisationen betraut, als innerhalb des Kulturministeriums ein Department für Religionen und Nationalitäten eingerichtet wurde. ${ }^{56}$ Bezüglich dieser beiden Ausrichtungen lag der Schwerpunkt des Departments allerdings auf Religionen, denn diesen waren von fünf Abteilungen drei mit der größeren Personalausstattung zuzuordnen, nämlich die Abteilung für »Experten-analytische Arbeit und Verbindungen mit den religiösen Organisationen «, die Abteilung für die »Registrierung und die statistische Erfassung der religiösen

55 Максим Васін, Президент В. Янукович ліквідував Держкомнацрелігій. Що далі: зміна Закону про свободу совісті? [10 грудня 2010].

56 У структурі Мінкультури створено департамент у справах релігій та національностей [17 жовтня 2011]; Кабмін передав Міністерству Культури повноваження Держкомітету у справах релігії [24 січня 2012].

DigiOst 3 | 300 
Boeckh, Kirchen und staatliche Institutionen in der Ukraine

Organisationen« sowie die Abteilung für die »Unterstützung der internationalen, sozialen und humanitären Tätigkeit religiöser Organisationen «. ${ }^{57}$

In seine Tätigkeit bezog das Department die kirchlichen Organisationen mit ein. So richtete es im März 2011 eine Arbeitsgruppe zur Vorbereitung der Änderung des Gesetzes über Gewissensfreiheit ein, an der auch die Oberhäupter der Konfessionen im All-Ukrainischen Rat für Kirchen und religiöse Organisationen beteiligt waren. ${ }^{58}$ Allerdings zeigten sich die Kirchenvertreter bereits in diesem Stadium von der Neufassung nicht überzeugt. Sie lehnten überhastete Reformen am Gesetz ab, und dies umso mehr, als das Parlament am 16. Oktober 2012 das Gesetz annahm und Janukovyč es in der Folge unterzeichnete. Kritisiert wurde, dass es religiösen Organisationen erschwere, den Status einer juristischen Person zu erreichen, dass ihnen das Versammlungsrecht nur mehr eingeschränkt zugesprochen werde, und dass für ausländische Religionsvertreter die Prozedur zur Erlangung eines Visums verschärft werde. ${ }^{59}$

Trotz des Departments im Kulturministerium gab es nun für die Religionsgemeinschaften in der Ukraine keine spezielle religiöse Kommission mehr, und damit fehlte ihnen auch der direkte staatliche Ansprechpartner: Die Tendenz ging dahin, dass die Staatsspitze die Probleme der Kirchen ignorierte. Zwar traf sich Janukovyč im Jahr 2012 zweimal mit dem All-Ukrainischen Rat für Kirchen und religiöse Organisationen, die hier von den Kirchen gestellten Fragen beachtete die Regierung aber nicht weiter. Angesichts der großen Zahl gerade auch an sozialen Problemen, die sich in der Ukraine noch zwei Dekaden nach Ende der sowjetischen Herrschaft stellen, plädierte der All-Ukrainische Rat für Kirchen und religiöse Organisationen für die Einrichtung einer permanenten

$57 \mathrm{Vgl}$. die homepage http://mincult.kmu.gov.ua/mincult/uk/publish/ article/265586?search_param=\%CC.\%C1\%F3.

58 У Мінкультури хочуть змінити Закон України »Про свободу совісті та релігійні організації« [2 лютого 2012].

59 Religionsgemeinschaften kritisieren Änderungen im Religionsgesetz. In: Religion \& Gesellschaft in Ost und West (2013) Nr. 1, 7. 
Boeckh, Kirchen und staatliche Institutionen in der Ukraine

Konferenz und eines Konsultativorgans, das sich aus Mitgliedern der präsidialen Administration, des Rates selbst sowie aus einzelnen Glaubensgemeinschaften rekrutieren soll. Unter Janukovyč blieb dieser Vorstoß aber vergeblich. ${ }^{60}$

\section{Fazit}

Kirchen und Religionen sind ein Thema im öffentlichen Leben der Ukraine und zwar nicht erst seit 1991, sondern sie waren es auch schon lange vorher, sichtbar an der Bestandskontinuität der für sie im Lauf des 20. Jahrhunderts jeweilig zuständigen staatlichen Institutionen. Diese machten durch die Veränderungen der politischen Großwetterlage Neujustierungen oder sogar einen politischen Seitenwechsel durch, wie nach dem Ende der sowjetischen Herrschaft am Staatskomitee für Religiöse Angelegenheiten zu beobachten ist. Bezogen auf die Aufgaben und die Ausrichtungen dieser Institution lassen sich folgende Zusammenhänge herausheben:

Während ein großer Teil der Geistlichen bald nach dem Oktoberumsturz 1917 physisch liquidiert oder in Lager und Gefängnissen gesteckt wurde, begann der konzertierte Angriff auf die unteren Ebenen und die Gemeinden etwas später: 1929 durch die Einführung der Registrierung der einzelnen Gemeinden bei sowjetischen Organen. Während der Zwischenkriegszeit wurde daher eine größere Zahl an staatlichen Institutionen damit beschäftigt, direkten Zwang und indirekten Druck auf Religionen, Konfessionen und Glaubensgemeinschaften generell auszuüben. Diese wurden dann während des Zweiten Weltkrieges auf zwei Räte reduziert, die direkt am Obersten Sowjet in Moskau angesiedelt wurden und deren Aufgabe es war, verdeckt und in Zusammenarbeit mit anderen Repressionsorganen Religionsgemeinschaften zu kontrollieren. Dabei

60 Ukraine: Kirchenoberhäupter wollen Beziehungen zwischen Kirchen und Staat vertiefen. 
Boeckh, Kirchen und staatliche Institutionen in der Ukraine

wurde differenziert zwischen der größten Kirchengemeinschaft, der Russischen Orthodoxen Kirche, und vielen weiteren Konfessionen, die in der Sowjetunion und insbesondere in der Sowjetukraine bestanden, weil ersterer, nach den Verfolgungen der Zwischenkriegszeit, eine besondere Duldung eingeräumt wurde. Die institutionelle Trennung der für die Kirchen zuständigen Behörden führte nicht nur zur Spezialisierung der Aufgabengebiete letzterer, sondern sie segregierte auch die betroffenen Kirchen voneinander, auf deren Hierarchien anhaltende Repressionen ausgeübt wurden. Damit erfüllten die Religionsbehörden weitgehend ihre Aufgabe, nämlich unter der Vorgabe, Fragen zwischen Staat und Kirchen nach außen hin neutral zu behandeln, zugleich aber eine Schwächung der öffentlich sichtbaren Kirchenstrukturen, die Zurückdrängung religiöser Bekundungen und die Bereitstellung von Informationen über kirchliche und religiöse Vorgänge für weitere sowjetische Organe herbeizuführen. Die verdeckte Zusammenarbeit mit anderen Institutionen, die dafür sorgte, dass über diese administrativen Maßnahmen hinausgehende Eingriffe gegen Kirchen erfolgten - wie beispielsweise das Innenministerium, das Verhaftungen und Verurteilungen von Geistlichen und Gemeindeangehörigen durchführen ließ -, war ein weiteres Charakteristikum für die Arbeitsmethode der sowjetischen Religionsbehörden. Insgesamt wurde durch Spezialisierung und Arbeitsteilung ein recht effektives System zur Kontrolle und Verdrängung der Religion in der Sowjetunion aufrechterhalten, sofern es den öffentlichen Bereich betraf, und es wirkte damit auch insgesamt systemstabilisierend.

Dies führte aber nicht dazu, dass Religion an sich verschwand. Daher blieben in der Ukraine auch in der postsowjetischen Transformationszeit entsprechende Behörden bestehen. Es änderte sich aber die politische Zielsetzung, die mit ihnen verbunden wurde. Nunmehr ging es darum, Kirchen und Religionsgemeinschaften in das Politische einzubeziehen, um sie nach Möglichkeit für die neuen großen Problematiken zu gewinnen, insbesondere für die nationale Einheit. Die 1991 einsetzende Instrumentalisierung der Kirchen für politische Zwecke, sichtbar an der mehrfachen Reorganisierung der Religionsbehörde, 
Boeckh, Kirchen und staatliche Institutionen in der Ukraine

wurde aber zunehmend zurückgefahren. Der Grund dafür war, dass sich die Religionsgemeinschaften in der Ukraine unabhängig von ihren interkonfessionellen Konflikten miteinander verständigten. Der All-Ukrainische Rat für Kirchen und religiöse Organisationen wurde zu einer ökumenischen Phalanx, die sich dem staatlichen Akteur gegenüber stellt und vor allem dann auftritt, wenn Verstöße oder Verschlechterungen im Bereich der Gewissensfreiheit bemerkbar werden. Dieses Gremium erkannte wiederum die Notwendigkeit, dass ein staatliches Organ für Kirchenangelegenheiten als Ansprechpartner für Religionsgemeinschaften und die von ihnen begleiteten sozialen, politischen und sonstigen Probleme Bestand haben müsse. Dass der All-Ukrainische Rat für Kirchen und religiöse Organisationen Forderungen trotz einiger Rückschläge durchsetzte, belegt, dass er sich gerade wegen seiner Vielstimmigkeit Gehör verschaffen kann.

\section{Abkürzungen}

CDAHOU Центральний Державний Архів Громадських Об'єднань України (Kiev)

DALO Державний Архів Львівської Області (Lemberg)

GARF Государственный Архив Российской Федерации (Moskau)

\section{Literatur}

Бондарчук, П.М.: Релігійність населення України у 40-80-х роках ХХст.: оціокультурні впливи, особливості, тенденції змін. Київ 2009.

Одинцов М.И.: Государство и Церковь в России. ХХ век. Москва 1994. Орлеанский, Н: Закон о религиозных объединениях РСФСР и действующие законы, инструкции, циркуляры с отдельными комментариями по 
Boeckh, Kirchen und staatliche Institutionen in der Ukraine

вопросам, связанным с отделением церкви от государства и школы от церкви в Союзе ССР. Москва 1930, repr. Westmeat u.a. 1971.

Перелыгин, А. И.: Русская православная церковь на Орловщине в годы Великой отечественой войны. In: Отечественная история. (1995) Н. 4, S. 126-136.

Русская Православная Церковь и коммунистическое Государство. 1917-

1941. Документы и фотоматериалы. Сост. О.Ю. Васильева. Москва 1996.

Сергійчук, Володимир: Нескорена Церква. Подвижництво греко-католиків України в боротьбі за віру і державу. Київ 2001.

Шкаровский, М. В.: Русская Православная церковь при Сталине и Хрущеве. (Государственно-Церковные отношения в СССР в 1939 - 1964 годах). Москва 1999.

Шліхта, Наталя: Церква тих, что вижив. Радянська Україна, середина 1940-х - початок 1970-х рр. Харків 2011.

Anderson, John: Religion, State and Politics in the Soviet Union and Successor States. Cambridge 1994.

Anderson, John: The Archives of the Council for Religious Affairs. In: Religion, State \& Society 20/3-4 (1992), 399-404.

Anderson, John: The Council for Religious Affairs and the Shaping of Soviet Religious Policy. In: Soviet Studies 43 (1992) No. 4, 689-710.

Biddulph, Howard L.: Religious Liberty and the Ukrainian State: Nationalism Versus Equal Protection. In: Brigham Young University Law Review 321 (1995) Issue 2, 321-346.

Boeckh, Katrin: Staat und Kirchen während der Transformation in der Ukraine. In: Bremer, Thomas (Hg.): Religion und Nation. Die Situation der Kirchen in der Ukraine. Wiesbaden 2003, S. 67-89.

von Borcke, Astrid: KGB. Die Macht im Untergrund. Neuhausen, Stuttgart 1987. 
Boeckh, Kirchen und staatliche Institutionen in der Ukraine

Chumachenko, Tatiana A.: Church and State in Soviet Russia. Russian Orthodoxy from World War II to the Khrushchev Years. Armonk, New York; London 2002.

Corley, Felix: Religion in the Soviet Union. An Archival Reader. New York 1996.

Corley, Felix: Soviet Reaction to the Election of Pope John Paul II. In: Religion, State \& Society 22/1 (1994), 37-64.

D’Anieri, Paul / Kravchuk, Robert / Kuzio, Taras: Politics and Society in Ukraine. Boulder/Colorado, Oxford/England 1999.

Gassenschmidt, Christoph / Tuchtenhagen, Ralph (Hgg.): Politik und Religion in der Sowjetunion 1917-1941. Wiesbaden 2001.

Hauptmann, Peter / Stricker, Gerd (Hgg.): Die Orthodoxe Kirche in Russland. Dokumente ihrer Geschichte (860-1980). Göttingen 1988.

Heller, Wolfgang: Die Russische Orthodoxe Kirche 1917-1941. In: Gassenschmidt, Christoph / Tuchtenhagen, Ralph (Hgg.): Politik und Religion in der Sowjetunion 1917-1941. Wiesbaden 2001, 13-46.

Inkeles, Alex: Social change in Soviet Russia. Cambridge, Mass. 1968.

Kovalenko, Lesia: Church and State in Ukraine. In: Ferrari, Silvio / Durham,

W. Cole / Sewell, Elizabeth A. (Hgg.): Law and Religion in Post-Communist Europe. Leuven 2003, 355-382.

Krawchuk, Andrii: Constructing Interreligious Consensus in the post-Soviet Space: the Ukrainian Council of Churches and Religious Organizations. In: Krawchuk, Andrii / Bremer, Thomas (Hgg.): Eastern Orthodox Encounters of Identity and Otherness. Values, Self-Reflection, Dialogue. New York 2014, 273-300.

Luchterhandt, Otto: The Council for Religious Affairs. In: Ramet, Sabrina Petra (Hg.): Religious Policy in the Soviet Union. Cambridge 1993, 55-83.

Németh, Thomas Mark: Religionsrecht in der Ukraine. In: Kanon XX. Jahrbuch der Gesellschaft für das Recht der Ostkirchen. Die Kirchen in Europa. Egling 2008, 119-136. 
Boeckh, Kirchen und staatliche Institutionen in der Ukraine

North, Douglass C.: Institutions, Institutional Change and Economic Performance. Cambridge u. a. 1990.

Putnam, R. D.: Making Democracy Work: Civic Traditions in Modern Italy. Princeton 1995.

Steinmo, Sven: What is Historical Institutionalism? In: Della Porta, Donatella / Keating, Michael (Hgg.): Approaches and Methodologies in the Social Sciences. A Pluralistic Perspective. Cambridge 2008, S. 118-138.

Walters, Philip: A Survey of Soviet Religious Policy. In: Ramet, Sabrina Petra (Hg.): Religious Policy in the Soviet Union. Cambridge 1993, 3-30.

Yelensky, Victor: Das Recht der Religionsgemeinschaften in der Ukraine. In: Lienemann, Wolfgang / Reuter, Hans-Richard (Hgg.): Das Recht der Religionsgemeinschaften in Mittel-, Ost- und Südosteuropa. Baden-Baden 2005, 519-545.

\section{Internetseiten}

Кабмін передав Міністерству Культури повноваження Держкомітету у справах релігії [24 січня 2012], unter http://risu.org.ua/ua/index/all_news/ state/authorities_religious_affairs/46457 (23.12.2013).

Катуніна, О. В., Катунін, Ю. А.: Політіка партиї та радянського уряду у відношенні релігійних культів Круму у 40-60-ті роки XX століття: Джерелознавчий огляд. In: Культура народов Причерноморья Nr. 114, S. 122-124, unter http://library.svpurst.crimea.ua/dudchenko/111-120/ fulltext/knp114/knp114_122-124.pdf (23.12.2013).

Лариса Владиченко: До історії державного органу у справах релігій в Україні. Частина II: 1920-1991 роки Частина 2. In: Релігія в україні [14. 9. 2011], unter http://www.religion.in.ua/main/analitica/11954-do-istoriyiderzhavnogo-organu-u-spravax-religij-v-ukrayini-chastina-ii-1920-1991roki.html (21.12. 2013). 
Boeckh, Kirchen und staatliche Institutionen in der Ukraine

Максим Васін, Президент В. Янукович ліквідував Держкомнацрелігій. Що далі: зміна Закону про свободу совісті? [10 грудня 2010], unter http:// risu.org.ua/ua/index/expert_thought/comments/39545 (23.12.2013).

Президент ліквідував Держкомнацрелігій [10 грудня 2010], unter http:// risu.org.ua/ua/index/all_news/state/authorities_religious_affairs/39542 (23.12.2013).

Про ліквідацію Держкомнацрелігій, unter http://risu.org.ua/ua/index/ resourses/goverments_doc/departments/40477/ (23.12.2013).

У структурі Мінкультури створено департамент у справах релігій та національностей [17 жовтня 2011], unter http://risu.org.ua/ua/index/ all_news/state/authorities_religious_affairs/44908 (23.12.2013).

У Мінкультури хочуть змінити Закон України »Про свободу совісті та релігійні організації [2 лютого 2012], unter http://risu.org.ua/ua/index/ all_news/state/authorities_religious_affairs/46614 (23.12.2013)

Ukraine: Kirchenoberhäupter wollen Beziehungen zwischen Kirchen und Staat vertiefen, unter: http://www.kirchen.ch/g2w/index.php?option=com_co ntent\&view $=$ article\&id $=840 \% 3$ Aukraine-kirchenoberhaeupter-wollenbeziehungen-zwischen-kirchen-und-staat-vertiefen\&catid=1\%3Anews\&I temid $=28$ (23.12.2013).

Чаварівський, У.: Утворення та діяльність державних органів у справах релігій радянського періоду (1943-1956pp.). In: Збірник наукових праць (2010) вип. 22, 135-144, unter http://archive.nbuv.gov.ua/portal/ Soc_Gum\%20/Edu/2010_22/fail/Khavarivskyi.pdf (21.12.13).

http://mincult.kmu.gov.ua/mincult/uk/publish/article/265586?search_param= \%CC. \%C1\%F3 (23.12.2013).

DigiOst 3 | 308 
Boeckh, Kirchen und staatliche Institutionen in der Ukraine

\section{Abstract}

Katrin Boeckh

Churches and State Institutions in Ukraine: The Transformation of the State Committee for Religious Affairs (1917-2013)

That some Soviet institutions survived post-Soviet transformations is not surprising. That such institutions survived because their former victims supported them certainly is. This is the case of the Soviet State Committee for Religious Affairs in Ukraine. The committee's story and its astounding metamorphosis is the topic of this article. It still existed in different forms in post-Soviet Ukraine, because religious communities protested loudly when it was to be abolished. This study contrasts the committee's actions during the communist era with developments after 1991. While under communism, the committee worked closely with repressive institutions, after the end of Soviet rule, the committee - no longer an instrument of church suppression - became a communication channel between Ukrainian religious communities and politicians. 
Katrin Boeckh - 978-3-86688-505-9 


\section{Die religiöse Dimension im historischen Gedächtnis}


Katrin Boeckh - 978-3-86688-505-9 


\section{Thomas Wünsch}

\section{Die Heiligsprechung des Lemberger Franzis- kaners Johannes von Dukla (ca. 1414-1484) durch Papst Johannes Paul II. im Jahr 1997: Eine kirchenpolitische Maßnahme zur Europäisierung der Ukraine?}

\section{Mittelalterliche Grundlage: die Vita des Johannes von Dukla}

Johannes (poln. Jan z Dukli, ukr. Ян з Дуклі; ca. 1414-1484) wurde in Dukla geboren, einem Ort an der Südgrenze des Bistums Krakau in Kleinpolen. ${ }^{1}$ Weder die Namen der Eltern noch das genaue Geburtsdatum sind aus den Quellen zu belegen, und auch über seine Ausbildung herrscht weitgehend Unklarheit. Angenommen wird, dass Johannes von Dukla im nahe gelegenen Krosno die Pfarrschule besuchte - während die Angabe, er habe an der Krakauer Universität studiert, erst in der zweiten Hälfte des 17. Jahrhunderts erscheint und damit dem Kontext der frühen Versuche einer Heiligsprechung zuzurechnen ist. Der geistliche Werdegang führte Johannes von Dukla zunächst in ein Franziskanerkloster, wofür dasjenige in Krosno in Frage käme; das Eintrittsjahr dürfte zwischen 1434 und 1440 gelegen haben. Die für die Franziskaner jener Zeit übliche Ausbildung setzte Johannes von Dukla in einem anderen Kloster derselben Kustodie fort, in Lemberg. Das Datum der Priesterweihe ist unbekannt; im Orden wirkte Johannes von Dukla als Beichtvater, Prediger und mehrfach gewählter Guardian (Klostervorsteher).

1 Zu den biografischen Angaben vgl. Wyczawski / Murawiec: Święty Jan z Dukli, $35-53$. 
Wünsch, Die Heiligsprechung des Lemberger Franziskaners Johannes von Dukla

Seine Karriere gipfelte in dem Vorstand der Kustodie, die aus sieben Klöstern mit Hauptsitz im Heiligkreuz-Kloster in Lemberg bestand; als Zeitspanne für diese Tätigkeit kommen die Jahre 1443 bis 1461 in Frage. Die Hauptaufgabe der Franziskaner in der "russischen Kustodie« war missionarischer Natur: Es galt, die orthodoxen Ruthenen zum Katholizismus zu bekehren. 1461 wurde Johannes von Dukla zum Prediger in der Kirche zum Hl. Geist in Lemberg ernannt, deren überwiegende Klientel aus dem deutschsprachigen Patriziat der Stadt kam; von daher ist die Annahme plausibel, dass Johannes von Dukla die deutsche Sprache beherrscht haben muss. Aus dieser Phase ist außerdem ein soziales Engagement bekannt: Johannes von Dukla gehörte einer Kommission an, die sich darum bemühte, die Lasten der Einwohner des Klosterdorfes Czyżki bei Lemberg zu erleichtern.

Für das Jahr 1463 ist ein Wechsel des Johannes von Dukla zu den Minderbrüder-Observanten zu verzeichnen. Diese Richtung firmiert in Polen nach dem Namen des Bernardino von Siena als »Bern(h)ardiner « und war dort erst seit kurzem präsent, d.h. seit dem Auftreten des italienischen Observanten Johannes Kapistran (1386-1456) in Krakau im Jahr 1453. Die Initiative für die Ausbreitung der Bernardiner ging von dem mächtigen Krakauer Bischof Zbigniew Oleśnicki (1389-1455) aus, wobei das Missionsanliegen in Richtung Orthodoxe auch die königliche Politik jener Zeit prägte. In den nächsten Jahren wurden zehn Bernardinerklöster in Polen eingerichtet; der Konvent in Lemberg stammt aus dem Jahr 1460. Johannes von Dukla hat bei den Observanten 21 Jahre verbracht, darunter einige Zeit in Posen, bevor er in das Kloster zum Hl. Andreas in Lemberg eintrat. Die Entscheidung für die Observanten kann durchaus, wie in der Literatur angenommen, einem Impuls in Richtung strengerer Askese und erhöhter Spiritualität gehorcht haben; als Wechsler der Ordensrichtung war Johannes von Dukla jedenfalls kein Einzelfall. Bis zu seinem Tod im Jahr 1484 als Prediger und Beichtvater tätig, bekleidete Johannes von Dukla jedoch keine Ämter mehr, so dass er in den offiziösen Schriftstücken (Urkunden, Ordenskonstitutionen etc.) nicht auftaucht. Wohl 
Wünsch, Die Heiligsprechung des Lemberger Franziskaners Johannes von Dukla

gegen Ende seines Lebens scheint Johannes von Dukla erblindet zu sein, was das Bild eines einfachen Bettelbruders, fern von Ordensfunktionen und Gelehrsamkeit, verstärkt. Seine Grabstätte fand Johannes von Dukla in der Klosterkirche in Lemberg. Eine angeblich bestehende Sammlung von Predigten und selbstverfassten Gebeten des Johannes von Dukla ist nie zum Vorschein gekommen und dürfte - wie sein angebliches Studium - nachträglichen Versuchen einer Intellektualisierung des Verehrten entspringen. Dies, sowie die Tatsache, dass die erste biographische Skizze erst Jahrzehnte nach seinem Tod verfasst wurde - von dem Ordensbruder Johannes von Komorowo (ca. 1465-1536) im Jahr 1521 -, lassen Johannes von Dukla als historisch fassbare Gestalt eher blass erscheinen. Die gleichwohl unübersehbare Präsenz ergibt sich aus der Verehrungsgeschichte; vor allem die überquellende Schriftproduktion im Zuge von zwei langwierigen Prozessen zuerst der Seligsprechung und dann der Heiligsprechung hat wesentlich dazu beigetragen. Alle näheren Angaben zu Vita und Geistigkeit Johannes von Dukla entspringen diesen späteren Überlieferungsschichten und sind zeitgenössisch nicht belegbar.

\section{Frühneuzeitliche Verehrung: der Seligsprechungsprozess}

Dem Mangel an historischen Realien korrespondiert eine ausgesprochene Fülle in der Verehrungsgeschichte, was in der historischen Forschung immer wieder dazu geführt hat, das Nachleben des Johannes von Dukla ausschließlich als Geschichte seines Kultes zu entwerfen. ${ }^{2}$ Schon vom Jahr 1486 an sind Bemühungen der Bernardiner belegt - bis hin zu einem förmlichen Antrag bei Papst Innozenz VIII. -, den Leichnam des Johannes von Dukla erhöhen und damit den Kult approbieren zu lassen. Doch zog sich der Abschluss der Prozedur

2 Zu den Kanonisationsverfahren vgl. Wyczawski / Murawiec: Święty Jan z Dukli, 75-133. 
Wünsch, Die Heiligsprechung des Lemberger Franziskaners Johannes von Dukla

bis 1521 hin, als der Provinzial Johannes von Komorowo eine Visitation in Lemberg durchführte.

1615 begann der Seligsprechungsprozess, angestoßen vom Lemberger Erzbischof Jan Andrzej Próchnicki (1614-1633) und unterstützt nicht nur vom Orden, sondern auch von König Zygmunt III. Wasa (1587-1632) und einer Anzahl von Senatoren und dem ganzen Sejm. ${ }^{3}$ Insgesamt vollzog sich der Prozess in vier Stufen, wobei die teilweise umfangreiche Einvernahme von Zeugen in Befragungskampagnen das Hauptcharakteristikum ist. Die erste Kampagne lief von 1615 bis 1619, die zweite (flankiert von zahlreichen "Litterae postulatorie« seitens des Königs, des Erzbischofs von Lemberg, hoher weltlicher Amtsträger, des Sejm sowie der Stadt Lemberg an die Kurie) von 1625 bis 1630, die dritte von 1643 bis 1649 und die vierte von 1727-1729. Seinen Abschluss fand das Verfahren dann 1731 in Lemberg bzw. 1733 in Rom unter Papst Clemens XII. (1730-1740). Derselbe Papst erhob Johannes von Dukla im Jahr 1739 - auf Antrag des Wettinerkönigs August III. (1733-1763), einer Reihe von Bischöfen und Kathedralkapiteln sowie des Lemberger Magistrats ${ }^{4}$ - zum Patron von Polen und Litauen; im Jahr darauf erfolgte die Umbettung der Gebeine des Johannes von Dukla in ein silbernes Sarkophag-Reliquiar sowie die Exposition auf dem Altar in der Lemberger Bernardinerkirche. Papst Benedikt XIV. gewährte 1742 zu Ehren von Johannes von Dukla einen Generalablass für die Oberservantenklöster in Polen.

Der Prozess der Heiligsprechung wurde schon wenige Jahre nach der Seligsprechung von den Bernardinern in Angriff genommen. 1754 richtete der polnische König August III. eine entsprechende Bitte an den Heiligen Stuhl, die 1764 von König Stanisław August erneuert und von den im Sejm versammelten Ständen bekräftigt wurde. Die Teilungen Polens nach 1772 und der Josephinismus in Galizien verhinderten ein Weiterkommen des Vorhabens.

3 Archivum Provinciae OFM (Bernardinorum) Cracoviae, Manuskript Nr. XXII-e-2.

4 Vgl. Wyczawski / Murawiec: Święty Jan z Dukli, 111. 
Wünsch, Die Heiligsprechung des Lemberger Franziskaners Johannes von Dukla

Auch die vermehrten Anstrengungen in Richtung Heiligsprechung, die zu den runden Jubiläen unternommen wurden (1884 zum 400. Todestag und 1933 zum 200. Jahrestag der Seligsprechung), brachten nicht den gewünschten Erfolg. Dieser blieb der Nachkriegszeit vorbehalten: 1947 legte die Ordensprovinz der Bernardiner ein entsprechendes Gesuch vor, das im Jahr darauf vom polnischen Episkopat mit einer Bitte an den Hl. Stuhl flankiert wurde und den apostolischen Prozess »super miraculo« in Gang setzte. 1997 wurde der Heiligsprechungsprozess unter Papst Johannes Paul II. zum Abschluss gebracht.

\section{Gegenwärtiges Erscheinungsbild: Johannes von Dukla seit den 1990er Jahren}

Johannes Paul II. kam selbst aus Kleinpolen, und das Städtchen Dukla dürfte ihm nicht unbekannt gewesen sein. Mit der Heiligsprechung ${ }^{5}$ wurde die alte Klammer, die zwischen dem heutigen Ostpolen und der heutigen Westukraine als Teilen der alten Rzeczpospolita bestand, wieder sichtbar. Zugleich tauchen, neben den überstaatlichen, auch die zeitübergreifenden Verbindungslinien auf: Die in Mittelalter und Früher Neuzeit entstandenen Bilder von Johannes von Dukla werden bis in die Gegenwart hinein wiederbelebt - was angesichts der gewandelten Umstände zwangsläufig neue Bilder produziert.

Die im Zusammenhang mit der Heiligsprechung entstandenen Quellen spiegeln dies wider. Zeitlich lassen sich drei Blöcke unterscheiden: im Vorfeld der Heiligsprechung, im Augenblick der Handlung selbst und im Nachgang; in Jahreszahlen ausgedrückt: von 1994 bis 2012. Systematisch erscheint Johannes von Dukla nicht nur als Gegenstand der offiziellen Verlautbarungen des Vatikans (so im »Decretum super virtutibus« vom 2. Juli 1994 und in den »Litterae decretales« vom 10. Juni 1997) sowie der (vornehmlich) kirchlichen

5 Zum letzten Abschnitt vgl. Wyczawski / Murawiec: Święty Jan z Dukli, 133-137. 
Wünsch, Die Heiligsprechung des Lemberger Franziskaners Johannes von Dukla

Presseberichterstattung in Polen und (ansatzweise) der Ukraine zur Heiligsprechung und den nachfolgenden Aktionen. Der frisch erhobene Heilige bildet auch ein Thema der zeitgenössischen Homiletik (Kazania o św. Janie z Dukli, 1999) und der wissenschaftlichen Behandlung (Biographie durch Wyczawski und Murawiec 1997). Damit ist - verglichen mit den Möglichkeiten der Vormoderne - eine neue mediale Qualität erreicht. Im Folgenden soll der gegenwärtige Erinnerungsort Johannes von Dukla aus den wichtigsten gedruckten und im Internet platzierten Quellenzeugnissen ermittelt werden. Dabei wird es vor allem darauf ankommen, die Qualität des Johannes von Dukla als eines spezifisch polnisch-ukrainischen Erinnerungsortes näher zu bestimmen.

Ganz auf der Linie einer von Westen (das heißt Rom) her gerichteten Sichtweise auf die lateinisch-griechisch-unierte Konfessionslandschaft in der Ostgrenze der ehemaligen Rzeczpospolita liegt das "Decretum super virtutibus« vom 2. Juli 1994. ${ }^{6}$ Das Schriftstück darf als Feststellung der erwiesenen Heiligmäßigkeit des Johannes von Dukla gelten und wurde in Rom von $\mathrm{Ku}$ rienkardinal Angelo Felici (1919-2007) ausgestellt. Johannes wird darin als "Sohn des polnischen Landes« bezeichnet (filius terrae Polonicae), dessen Kult 1733 von Papst Clemens XII. bestätigt wurde; damit war die Stufe der Seligsprechung erreicht. In dem dann weiter geschlagenen Bogen wird der Radius des Kults abgeschritten: Johannes werde nicht nur in seiner "geistlichen Familie" (religiosa familia), d.h. seinem Orden, verehrt, sondern auch in der Diözese (Halicz-)Lemberg sowie in ganz Polen und dem benachbarten Litauen - und das von den Katholiken wie von den orthodoxen Brüdern. Was mit diesen fratres orthodoxi gemeint ist, wird nicht gesagt; offenbar handelt es sich um einen Rückbezug auf die ersten Belege der Wundertätigkeit des Verehrten, die sich laut dem Zeugnis des Johannes von Komorowo auch außerhalb der römisch-katholischen Kommunität in Lemberg abspielten. Der Beginn der Verehrung des Johannes von Dukla als Patron Polens und Litauens wird im

6 Wyczawski / Murawiec: Święty Jan z Dukli, 158-164.

DigiOst 3 | 318 
Wünsch, Die Heiligsprechung des Lemberger Franziskaners Johannes von Dukla

"Decretum « mit 1742 angegeben - also dem Jahr des Generalablasses (statt 1739, dem offiziellen Datum der Patronatserhebung). Dass Johannes in der Custodia Russiae (seu Ruteniae) aufgetreten sei, und sich dort durch Predigtleistung und Seelsorge ausgezeichnet habe, gehorcht dem inzwischen etablierten biographischen Duktus. Die territoriale Reichweite seiner Aktivität wird im "Decretum « in den heutigen Kategorien angegeben: Außer Polen und Litauen, die schon genannt wurden, sind dies die Staaten Ukraine, Moldova und Belarus. Mittelpunkt seiner Wirksamkeit zu Lebzeiten war es laut dem »Decretum «, die (von der Römischen Kirche) getrennten Ruthenen und Armenier, die in Polen und der Russia (= der heutigen Westukraine) lebten, an die katholische Kirche »herangeführt" (adducere) zu haben. Das sei der Grund, warum sich Johannes von Dukla den Ehrentitel eines "glühenden Glaubensverbreiters" (ferventis propagatoris fidei) verdient habe. Das kurz rekapitulierte Kanonisationsverfahren wirkt wie die logische Fortsetzung dieser Lebensleistung; nach einem (unkommentierten) Bruch zwischen 1733 und 1948 wird dann eine gewisse Zielstrebigkeit des Verfahrens insinuiert, das schließlich von Johannes Paul II. zu Ende gebracht worden sei.

Es ist die klassische West-Ost-Richtung, die hier aufscheint: Johannes von Dukla wird als Wundertäter, Prediger, Landespatron und Missionar gepriesen, als der er seit dem Seligsprechungsverfahren im 17./18. Jahrhundert bevorzugt dargestellt wird. Seine Aufgabe war die Predigt, und zwar in Gestalt einer missionierenden Predigt - und diese Aufgabe hat Johannes - das ist der Sinn seiner Verehrung - überdurchschnittlich erfolgreich gelöst. Die Lebensleistung besteht darin, in einem gemischtkonfessionellen Umfeld die Konfessionsgemeinschaft der Katholiken vergrößert zu haben, indem er Angehörige anderer Konfessionen auf die römische Seite gezogen hat; adducere hat, wenn man den aktiven Teil betonen will, durchaus etwas mit »Seelenfang« zu tun. Johannes wirkt in dieser Lesart des Heiligen Stuhls wie ein in Ostpolen stationierter Franz Xaver; zwar sind es nicht Indien und Japan, die hier missioniert werden, aber von einem Bewusstsein, dass die in Ruthenien vorhandenen anderen (stärksten) 
Wünsch, Die Heiligsprechung des Lemberger Franziskaners Johannes von Dukla

Konfessionen, allen voran die Orthodoxie, ebenfalls christlich waren, fehlt jede Spur. Fast hat man den Eindruck, dass Rom auch im Jahr 1994 noch ganz dem Geist der Gegenreformation ergeben ist: Die andere Seite (also alles, was nicht römisch-katholisch ist) hat keine gleichberechtigte Stellung, und man fragt sich, ob sie überhaupt eine Existenzberechtigung hat. Eine Trans-Konfessionalität kann sich daraus nicht ergeben, und so wird die Frage dringlich, wie das Gegenüber, also die ukrainische Bevölkerung und der ukrainische Klerus, diesen Heiligsprechungsakt aufgefasst haben.

Eine Möglichkeit ist, die Predigten zu untersuchen, die von ukrainischen Geistlichen ebenfalls im Vorfeld und dann bis zur Heiligsprechung selbst gehalten wurden - auch wenn es sich dabei um Angehörige der katholischen Kirche handelt, und von daher keine Opposition zur kurialen Meinungsvorgabe zu erwarten ist. In der etwa 300 Seiten starken Sammlung von Homilien zu Johannes von Dukla aus den Jahren 1994 bis $1997^{7}$ finden sich immerhin vier Predigten von Angehörigen der ukrainischen Hierarchie. Bischof Jan Purwiński (geb. 1934), lettischer Herkunft, in Riga ausgebildet, 1977 zum Administrator der Pfarrei der hl. Sofia in Žytomyr ernannt und 1991 zum Bischof dieser Diözese erhoben, hat noch im November 1994 eine Predigt zu Ehren des Johannes von Dukla verfasst. ${ }^{8}$ Er thematisiert vor allem die geistliche Laufbahn des Johannes, seinen Klostereintritt und seinen Ordenswechsel, und stellt diese Akte in einen Zusammenhang mit der eigenen Gegenwart. Insofern Bischof Purwiński aber die Gegenwart geprägt sieht von einem vorherrschenden "praktischen Atheismus«, in dem die Menschen zwar ihre Katholizität bekennen, dann aber faktisch ein »heidnisches« Leben führen (żją po pogańsku), bekommt die historische Gestalt des Johannes von Dukla eine neue Funktion: Er ist nicht mehr der klassische Missionar für ein wie immer geartetes Außen, sondern er ist der geborene Verfechter der inneren

7 Kazania o św. Janie z Dukli.

8 Predigt vom 26.11.1994, in: Kazania o św. Janie z Dukli, 56-63.

DigiOst 3 | 320 
Wünsch, Die Heiligsprechung des Lemberger Franziskaners Johannes von Dukla

Mission. Sein Arbeitsfeld sind nicht die Orthodoxen und Armenier, sondern die Lateiner, die Katholiken selbst. Aus einem Franz Xaver wird, wenn man so will, ein Franz von Assisi.

Um die Seelenlage der Gegenwartsgesellschaft geht es auch einem zweiten Exponenten des katholischen ukrainischen Klerus, Weihbischof Stanisław Szyrokoradiuk, ebenfalls aus der Diözese Žytomyr. Szyrokoradiuk ist Ukrainer (geb. 1956) und seit 1994 Weihbischof von Žytomyr, 2012 zum Administrator der Diözese Luck ernannt. Seine Kontextualisierung der Lebensleistung des Johannes von Dukla vollzieht sich in Form einer Anekdote, ${ }^{9}$ in der er von einer Frau berichtet, die in der Zeit des Stalinismus nach Sibirien verschleppt wurde, nach ihrer Rückkehr in die Ukraine aber nicht in ihrer Heimat landete, sondern an anderer Stelle. Dort organisierte sie einen katholischen Gebetskreis und baute so, in den Zeiten des Kommunismus, eine Art Kryptokatholizismus auf. Die Botschaft ist wieder nach innen gerichtet, auf die Katholiken (der Ukraine) hin - und Johannes von Dukla bleibt in einem sehr allgemeinen Sinn die Verkörperung einer außergewöhnlichen Glaubensleistung.

Diesen Akzent führte der Metropolit von Lemberg weiter, Erzbischof Marian Jaworski (geb. 1926 in Lemberg). ${ }^{10}$ In seiner ersten Predigt, von $1995,{ }^{11}$ gestaltete er Johannes von Dukla als klassischen Heiligen, also als Vermittlungsglied zwischen Mensch und Gott. Nur der Hinweis auf die seit kommunistischer Zeit leer stehende Säule am Platz der Bernardinerkirche in Lemberg verrät, dass es hier um einen Heiligen aus Lemberg geht. Die zweite Predigt des Metropoliten von

9 Predigt vom 22.04.1995, in: Kazania o św. Janie z Dukli, 96-102.

10 Jaworski wurde ausgebildet an der Kalwaria Zebrzydowska und der Jagiellonenuniversität sowie der Katholischen Theologischen Akademie in Warschau, war 1984 Apostolischer Administrator des polnischen Teils der Erzdiözese Lemberg mit Sitz in Lubaczów, 1991-2008 Erzbischof von Lemberg, und ist seit 2001 Kardinalpresbyter.

11 Predigt vom 17.06.1995, in: Kazania o św. Janie z Dukli, 113-118.

DigiOst 3 | 321 
Wünsch, Die Heiligsprechung des Lemberger Franziskaners Johannes von Dukla

$1997^{12}$ setzt dagegen ganz auf den historischen Johannes von Dukla: Hier wird seine Leistung als Fürbitter und Retter herausgehoben, zu Lebzeiten und weit darüber hinaus. Die kriegerischen Bedrohungen Lembergs durch Kosaken, Tataren und Osmanen seien mit seiner Hilfe abgewendet worden, und die mediale Präsenz des Verehrten in Form von Bildnissen und bis hin zu Senatsprotokollen finde so ihre Berechtigung. Ein Bezug auf die eigene Gegenwart unterbleibt; aber man wird nicht fehlgehen, wenn man auch hier wieder eine eher auf die eigene Gruppe gerichtete Exegese der Lebensleistung und der Kultpräsenz des Johannes von Dukla am Werk sieht. Zwar kommt zur Sprache, dass Johannes (und das Gedenken an ihn) in der Auseinandersetzung mit Andersgläubigen verwendet wurde - aber das waren allesamt keine Glaubensgruppen, die in der Ruthenia beheimatet waren. Der kämpferische, missionarische Aspekt, der in der frühneuzeitlichen Johannes von Dukla-Verehrung spätestens seit der Mitte des 17. Jahrhunderts aufkommt und dann immer wieder neu variiert wird, fehlt in den Ausführungen des ukrainischen, in Polen sozialisierten Oberhirten.

An diesem Punkt sollte der Heilige Vater selbst zu Wort kommen. Papst Johannes Paul II. hat während der feierlichen Heiligsprechungszeremonie in Krosno am 10. Juni 1997 eine fulminante Predigt gehalten, ${ }^{13}$ die von 600.000 Menschen, darunter auch Pilgern aus der Ukraine, gehört wurde. Von der Seite der Geistlichkeit waren nicht nur der Lemberger katholische Erzbischof Jaworski und der griechisch-katholische Bischof Marcjan Trofimiak anwesend, sondern auch der orthodoxe Erzbischof Aleksander von Sanok. ${ }^{14}$ Johannes Paul zeichnete den (durchaus fraglichen) Bildungsweg des Johannes von Dukla nach, betonte seine Rolle als Patron der Stadt Lemberg und des ganzen Lemberger Landes - schlug dann jedoch den Bogen zurück zur Gesamtkirche und präsentierte Johannes von Dukla als geistigen Sohn (duchowy syn) des hl.

12 Predigt vom 22.02.1997, in: Kazania o św. Janie z Dukli, 207-211.

13 Als Audiodokument: http://www.polskieradio.pl/77/937/Artykul/328541/.

14 http://www.papiez.gorzow.pl/1997/zdjecia/krosno/krosno.htm.

DigiOst 3 | 322 
Wünsch, Die Heiligsprechung des Lemberger Franziskaners Johannes von Dukla

Franz von Assisi. Die Bedeutung für das anbrechende dritte Jahrtausend sah der Papst darin, dass Johannes von Dukla zusammen mit dem hl. Adalbert, dem hl. Stanislaus und der hl. Königin Jadwiga den polnischen Heiligenhimmel bereichern solle. Damit wurde Johannes von Dukla gewissermaßen domestiziert und auf eine Bedeutung für den rein polnischen Kontext zurückgestutzt.

Nun war es ein polnischer Papst, der mit einem polnischen Heiligen umgehen musste, und auch die Situation in Krosno war sicherlich nicht dazu angetan, besonders konfessions- oder nationsübergreifend werden zu können. Dass das aber von päpstlicher Seite durchaus auch gewollt war, zeigen die "Litterae decretales" vom 10. Juni 1997, die als offizielle Heiligsprechungsurkunde in den Acta Apostolicae Sedis vom 3. Juni 1998 publiziert wurden. ${ }^{15}$ Hier ist der Anknüpfungspunkt die Mission, ergänzt durch die Seelsorge. Der Wirkungsradius wird mit Polen, der Ukraine, Moldova und Belarus angegeben; die geistige Heimstatt mit den Namen des Bernardino von Siena und seinem Propagator in Polen, Johannes von Capestrano, angedeutet. Die Nennung von Belarus dürfte sich daraus ergeben, dass das Land in historischer Zeit ein Teil des Großfürstentums Litauen gewesen ist; ${ }^{16}$ Moldova könnte deshalb in die Liste gekommen sein, weil die Erzdiözese Lemberg im Mittelalter auch Teile des Fürstentums Moldau umfasste. ${ }^{17}$

Interessant wird es bei der Funktionsbestimmung des neuen Heiligen, denn hier starten die »Litterae decretales« einen ökumenischen Impetus in Richtung der Ruthenen und Armenier. Es geht um den historischen Johannes von Dukla, und der habe sich nicht nur dadurch hervorgetan, dass er für Gott und gegen das Übel gesprochen habe. Sein Eifer sei auf die Einheit bzw. Wieder-Vereinigung der christlichen Kirche gerichtet gewesen, und aus einem

15 Acta Apostolicae Sedis XC 3 Iunii 1998, 377-379.

16 Kultzeugnisse dagegen gibt es erst aus rezenter Zeit; vgl. die Karte bei Wyczawski / Murawiec: Święty Jan z Dukli, Anhang.

17 Vgl. Positio 1993, 301.

DigiOst 3 | 323 
Wünsch, Die Heiligsprechung des Lemberger Franziskaners Johannes von Dukla

brennenden ökumenischen Geist heraus (ferventissime oecumenico sensu imbutus) habe er den Dialog mit den Bruderkirchen der Ruthenen und Armenier gesucht (adlaboravit ad dialogum cum Fratribus Ecclesiarum Rutenae et Armenae instituendum). Zweck des Ganzen sei es gewesen, die Barrikaden der Trennung und der Vorurteile, die zwischen den christlichen Gemeinden bestehen, aufzuheben (obices divisionum et inter Christi discipulos praeiudiciorum tollerentur). Wie in den frühneuzeitlichen Quellen auch, wird nicht klar, ob es sich dabei um die von den Kirchen-Unionen von Florenz 1439 und Brest 1596 erfassten griechisch-katholischen Mitglieder der römischen Kirche handelt oder um nicht Unierte. Doch scheint das nicht entscheidend: Wie in der Frühen Neuzeit erstreckte sich der Missionierungsimpuls von römischer Seite her sowohl auf die Orthodoxen (und Armenier) wie auf die Unierten.

Seit Beginn der lateinischen Missionsoffensive, deren Blaupause in dem Traktat "Elucidarius errorum ritus ruthenici« des Johannes Sacranus von Auschwitz aus dem Jahr 1500 vorliegt, ${ }^{18}$ war die Union keine gleichberechtigte Alternative gegenüber Rom. Die Inferiorität der Unierten war vielmehr Programm, und sie spiegelt den nie aufgegebenen Anspruch der Römischen Kirche, die Union lediglich als Zwischenschritt auf dem Weg zur eigentlichen Kirche zu sehen, und das war die römisch-päpstliche. Immerhin werden die Modifikationen, die Papst Pius XII. in der Enzyklika »Mystici Corporis« von 1943 angebracht hatte, und die eine Zusammenfügung der gesamten christlichen Kirche - allerdings ohne Aufgabe der ekklesiologischen Positionen des Katholizismus - ins Visier nahmen, weitergeschrieben: Es erfolgt keine Verunglimpfung der Gegenseite, keine Verdammnis der Orthodoxie, kein Vorwurf der Häresie oder des Schismas. Die Gesprächsbereitschaft des Westens wird betont, und mit dem Begriff des Dialogs verbindet sich implizit die Annahme, dass die Gegenseite ebenbürtig ist, also eine Gemeinschaft mit eigenem Lebensrecht bildet und Anspruch auf Respekt und Akzeptanz hat. Der von Pius XII.

18 Vgl. Wünsch: Das römische Modell einer Kirchenunion.

DigiOst 3 | 324 
Wünsch, Die Heiligsprechung des Lemberger Franziskaners Johannes von Dukla

in »Mystici Corporis« entfaltete Ökumenismus wird von Johannes Paul II. fortgesetzt; der die ganze Frühe Neuzeit hinweg spürbare Uniformitarismus, der mit rhetorischer und faktischer Gewalt die konfessionelle Eindeutigkeit (im Sinne Roms) in der Ostgrenze Polens herstellen wollte, bleibt Geschichte.

Die Frage ist, ob dies auch von Osten her, also in der heutigen Ukraine, so wahrgenommen wird. Um das zu beantworten, muss der Blick auf andere Verehrungskontexte, außerhalb der Heiligsprechung, fallen; und das möglichst grenzüberschreitend. Ein erster Modus, in dem sich ganz traditionell Verehrung dokumentiert, ist die Pilgerfahrt. Sie wird gepflegt, vielleicht sogar neu belebt, nach der Heiligsprechung vom 10. Juni 1997. Schon im August dieses Jahres ist eine Pilgerfahrt nach L'viv dokumentiert, die sich als Ausfluss der jüngst vollzogenen Kanonisation versteht. Das polnisch-ukrainische Internetportal "Cracovia Leopolis« berichtet darüber, dass die "Gesellschaft der Freunde Lembergs und der südöstlichen Grenzlande (Towarzystwo Miłosników Lwowa i Kresów Południowo-Wschodnich) eine solche Fahrt veranstaltet hat. ${ }^{19}$ Begleitet von polnischen Geistlichen aus dem Bernardinerorden, anderen Orden und Weltgeistlichen, wurde in Lemberg eine Messe gefeiert, in deren Predigt die Rolle des Johannes von Dukla als Heiliger Lembergs, aber auch als erster Heiliger der gesamten Region zur Sprache kam. Eine Beteiligung der Ortsansässigen ist aus dem Internetbericht nicht zu ersehen.

Die jedoch erscheint umso markanter im Zuge einer neuerlichen Pilgerfahrt aus dem Jahr 2011. Eine Gruppe aus der Region von Dukla, 52 Personen stark, eröffnete in Lemberg den Ablass zu Ehren von Johannes von Dukla (odpust $k u$ czci św. Jana $z$ Dukli). ${ }^{20}$ Die Messe wurde durchgeführt von der ukrainischen katholischen Kirchenspitze: Erzbischof Mieczysław Mokrzycki und, als Prediger, Bischof Szyrokoradiuk. Als Konzelebranten agierten aber auch der Vorsitzende der geistlichen Orden in der Ukraine (Dobrosław Kopesteryński

19 http://www.cracovia-leopolis.pl/index.php?pokaz=art\&id=1347.

20 http://www.7dni.info/news/religia/wydarzenia/11071101.html.

DigiOst 3 | 325 
Wünsch, Die Heiligsprechung des Lemberger Franziskaners Johannes von Dukla

[sic!]), dazu (katholische) Ordensbrüder und Weltgeistliche aus der Ukraine. Selbst wenn von einer orthodoxen Beteiligung nichts zu hören ist, wird doch eine gewisse Breitenwirkung angedeutet: Herzliche Gespräche habe es mit den Pilgern und Gläubigen aus der Ukraine gegeben, so der Internetbericht.

Mehr als ein vages Zeichen für eine gewisse Breitenwirkung hält auch der einzige rein ukrainische Reflex auf die Heiligsprechung von Johannes von Dukla nicht bereit. Das Mitteilungsblatt der Diözese von Charkiv-Zaporižžja (des lateinischen Ritus) erwähnt im Zuge der Berichterstattung zur 630-Jahrfeier der Erzdiözese (Halicz-)Lemberg in aller Kürze die Heiligsprechung des Johannes von Dukla im Jahr 1997. Genannt wird seine Funktion als Patron der Stadt Lemberg, ${ }^{21}$ was seine Leistung als Retter der Stadt in den Zeiten des Kosakenaufstands unter Bogdan Chmel'nyc'kyj und der nachfolgenden Belagerungen betont. Eine wie auch immer geartete Bedeutung für die Gegenwart bleibt unerwähnt, und lediglich das dem Internetartikel beigegebene Bild von einer Massenversammlung erweckt den Eindruck, dass das angesprochene Faktum auch für die Jetztzeit noch von Bedeutung sein könnte.

Sehr viel deutlicher, was eine gegenwärtige Verwendungsmöglichkeit des Heiligen angeht, wird das polnische katholische Monatsblatt "Nasza Archa", das - offenbar ohne konkreten Anlass - in seiner Nummer 8 vom Jahr 2006 einen Artikel mit der Überschrift »Patron vieler Völker« (»Patron wielu narodów«) bringt. ${ }^{22}$ Hier wird auf die länderübergreifende Funktion der Johannes von Dukla-Verehrung hingewiesen, eingeleitet von der aus der Vita des Johannes von Komorowo übernommenen Nachricht, dass die ersten beiden Wunder des Johannes von Dukla zwei Lembergern passierten: dem Guardian des Klosters von Johannes sowie der Stadtbürgerin Hedwig/Jadwiga Orłowa, die nach zehnjähriger Blindheit aufgrund eines Gebets am Grab des Johannes

$21 \mathrm{http} / / / \mathrm{rkc} . k h . u a /$ index.php? $\mathrm{L}=\mathrm{u} \& \mathrm{M}=\mathrm{H} \& \mathrm{P}=\mathrm{N} \& \mathrm{~S}=05 \& \mathrm{R}=25 \& \mathrm{~N}=051023 \mathrm{a} \# 05102$ $3 \mathrm{a}$.

22 http://www.nasza-arka.pl/2006/rozdzial.php? numer=8\&rozdzial=4. 
Wünsch, Die Heiligsprechung des Lemberger Franziskaners Johannes von Dukla

von Dukla ihr Augenlicht wieder erlangte. Diese Belege für die Effektivität der Fürbitten an Johannes von Dukla werden im weiteren ausgedehnt auf die kriegerischen Bedrohungen der polnischen Adelsrepublik in der Frühen Neuzeit, vor allem in Gestalt der Kosaken, Osmanen und Russen. Johannes von Dukla wurde dadurch zum Fluchtpunkt nicht allein für die Polen, sondern auch für die Litauer, Ruthenen und Armenier. Diese historischen Reminiszenzen, erweitert um Erwähnungen von Stiftungen im 19. Jahrhundert, machen den Großteil des im Internet zugänglichen Textes aus; die Übertragung auf die Gegenwart ist mager: Sie äußert sich lediglich in der Form, dass als »heutige Verehrer« des Heiligen einige Erzbischöfe (Marian Jaworski, Lemberg; Józef Michalik und Ignacy Tokarczuk, Przemyśl; Edward Nowak, Kurienerzbischof aus der Diözese Przemyśl in Rom) und andere Bischöfe genannt werden.

Dem steht die vielleicht konkreteste Form einer neuzeitlichen Heiligenverehrung gegenüber: Das Onkologische Zentrum des Lubliner Bezirks erwählte im Jahr 2007 Johannes von Dukla zu seinem Schutzpatron und formalisierte diese Beziehung 2010 durch eine offizielle Namensänderung, die vom Wojewodschaftssejm sanktioniert wurde. Der neue Name lautet seitdem: Centrum Onkologii Ziemi Lubelskiej imienia Św. Jana z Dukli«. ${ }^{23}$ Die auf der Homepage mitgeteilte Entstehungsgeschichte mutet mittelalterlich an: Als die Direktorin des Zentrums im Mai 2007 eine Wanderung unternahm und dabei mit dem Kloster in Dukla bekannt wurde, fasste sie den Entschluss, Johannes von Dukla zum Patron ihrer Einrichtung erheben zu lassen. Auffällig ist, dass neben den unerlässlichen Informationen über den Kanonisationsprozess des Johannes von Dukla als Ausweis seiner Lebensleistung lediglich die Rettungsaktion im Jahr 1648, während der Belagerung Lembergs durch die Kosaken und andere Truppen, genannt wird. Vielleicht fühlt sich das Zentrum heute in einer ähnlichen Lage, und die kryptische Andeutung, dass die Hilfe des Heiligen bei der Lösung der Probleme für die Lubliner Onkologie benötigt werde,

23 http://cozl.eu/index.php/nasze-centrum/nasz-patron.

DigiOst 3 | 327 
Wünsch, Die Heiligsprechung des Lemberger Franziskaners Johannes von Dukla

spricht eher dafür, dass man Johannes von Dukla als Intervenienten für den Fortbestand einer Institution braucht, nicht als Seelsorger, Missionar etc. Die Einrichtung eines Sanktuariums im Jahr 2009 bietet aber auch den Patienten selbst einen Anhaltspunkt für die eingegangene Beziehung zwischen Medizin und Wundertäter.

Das vorerst letzte Zeichen einer weiterhin lebendigen Verehrung des Johannes von Dukla hat mit einem Reliquientransfer zu tun. Ort des Geschehens ist Lemberg, und es geht um die Verlagerung von Reliquien des Heiligen in die dortige Kathedrale, die 2012 stattfand. Der Bericht der katholischen Website »Kościół.Wiara " (»Kirche.Glaube«) birgt darüber hinaus einige Informationen über die nationsübergreifende Dimension des Geschehens. ${ }^{24}$ Zum einen wird gleich im ersten Satz erwähnt, dass die Predigt während der Hl. Messe in polnischer und ukrainischer Sprache gehalten worden sei (vom Provinzial des Ordens der Minderbrüder in der Ukraine, Dobrosław Kopysteryński [sic!]). Zum zweiten wurden die Gesänge, an denen der Chor aus der Pfarrei Dukla und der Chor aus Žytomyr beteiligt waren, auf Ukrainisch geboten. Zum dritten schließlich wird die zahlreiche Anwesenheit von griechisch-katholischen Gläubigen aus der Ukraine bei dieser Zeremonie in Lemberg erwähnt - und zugleich bedauert, dass niemand aus der Stadtregierung gekommen sei, um dem Patron Lembergs die Ehre zu erweisen.

\section{Fazit}

Johannes von Dukla ist präsent in der »Ostgrenze« der alten polnischen Adelsrepublik, also im heutigen Ostpolen und in der heutigen Westukraine. Seine beiden lebenszeitlichen Standbeine Kleinpolen und Lemberg spiegeln sich zwar nicht direkt proportional in der Anzahl der Kultorte wider; dafür

24 http://kosciol.wiara.pl/doc/1195577.Relikwie-sw-Jana-z-Dukli-w-katedrze. 
Wünsch, Die Heiligsprechung des Lemberger Franziskaners Johannes von Dukla

ist die Dichte in Polen, vor allem im Südosten, einfach zu überwältigend. ${ }^{25}$ Aber man kann nicht übersehen, dass es von westlicher Seite (und das heißt: polnischer, lateinischer, römischer Seite) ein Bedürfnis gibt, die nations- und konfessionsübergreifende Dimension, die sich mit dem Leben und dem Kult des Johannes von Dukla verbindet, mit neuen Formen weiter zu pflegen. Die Heiligsprechung hat hier ein markantes Signal gesetzt, und die vielen kleineren Aktivitäten im Anschluss daran gehen in eine ähnliche Richtung. Johannes von Dukla war Missionar, d. h. sein Wirkungsfeld war schon durch seine Lebensaufgabe unipolar ausgerichtet. Er war kein Mittler zwischen den Religionen, kein Ökumenist und kein Ireniker. Seine Aufgabe war es, mit Hilfe der bernardinischen Spiritualität die Bevölkerung in Ruthenien an die römisch-katholische Kirche heranzuführen. In der Verehrung nimmt sich diese biographische Konstante allerdings weniger eindimensional aus: Viele Zeichen deuten darauf hin, dass Johannes von Dukla auch für die orthodoxe und armenische Bevölkerung in Ruthenien attraktiv war. Die von den Zeugenaussagen des 17. und 18. Jahrhunderts überlieferten Pilgerströme lassen darauf schließen, dass man Johannes von Dukla nicht nur als Missionsprediger und Vertreter eines aggressiven Katholizismus wahrgenommen hat. Auch als solcher wurde er verwendet - aber sein Markenzeichen war eine mehrfache Funktionalität.

Selbst wenn also die mit ihm verbundene Transkonfessionalität eine aus dem Westen stammende Ambition ist, und insofern eine asymmetrische Integrationsidee zu Grunde liegt, taugt der Heilige doch in einem anderen Sinn als Integrationsfigur. Man wird sie eher auf der Ebene der Stadt- und Regionalgeschichte ansetzen dürfen - also nicht im religiösen Feld, sondern im kulturellen. Johannes von Dukla war und ist Teil der lokalen Kultur Lembergs, und damit der heutigen Ukraine. Die Heiligsprechung (samt Vorlauf und Nachwirkungen) bezieht damit die Ukraine in einen genuin (ost)mitteleuropäischen Zusam-

25 Vgl. die Aufstellung bei Wyczawski / Murawiec: Święty Jan z Dukli, 175-185, für die Jahre 1460 bis 1985. 
Wünsch, Die Heiligsprechung des Lemberger Franziskaners Johannes von Dukla

menhang ein. Mag auch die Heiligsprechung selbst kein aktives Moment einer kirchlichen »Ukrainepolitik « gewesen sein, so sind die Folgen doch erkennbar politisch: Auf der Ebene der "Zivilgesellschaft « wird eine Nivellierung des Abstands zwischen Polen und der Ukraine betrieben, der sich aus getrennten historischen Kontexten und, seit 2004, aus der neuen Ostgrenze der EU ergibt. Die Heiligsprechung bedeutet einen Brückenschlag von Polen in die Ukraine, der auf der Basis von kulturellen Isomorphen stattfindet. Nicht nur wird Polen mit seiner eigenen Geschichte konfrontiert, die sich bekanntlich über Jahrhunderte auch in einem ruthenisch-galizisch-ukrainischen Raum abspielte. Mit der Heiligsprechung wird - über den Wirkungsradius des Johannes von Dukla - die Ukraine als gleichwertiger Teil Europas (als einer kulturellen Gemeinschaft) anerkannt. Der für Johannes von Dukla positiv verlaufene processus super virtutibus, der seine Heiligmäßigkeit erwiesen hat, kann (in zugespitzter Analogie) für die Ukraine als Feststellung ihrer EU-Tauglichkeit wenigstens in kultureller Hinsicht gesehen werden. Die Erinnerung an Ruthenien als einer Region der vielen Konfessionen (und deren über lange Zeiten hinweg harmonisches Zusammenleben) ist ein auch politisch relevantes Projekt. Um die lokale und regionale Identität zu stärken, die als Trägerin politischer Kraft neben dem Staat längst erkannt ist, bedarf es geeigneter Bezugspersonen. Johannes von Dukla - als Teil des kulturellen Gedächtnisses - könnte eine solche sein. Sie demonstriert die politische Dimension von Religion und zeigt das Potential, das sich aus der Mehrkonfessionalität ergibt.

\section{Literatur}

Acta Apostolicae Sedis XC 3 Iunii 1998.

Archivum Provinciae OFM (Bernardinorum) Cracoviae, Manuskript Nr. XXII-e-2. 
Wünsch, Die Heiligsprechung des Lemberger Franziskaners Johannes von Dukla

Binder, Jeremiasz (Hg.): Kazania o św. Janie z Dukli. Wydane w drogą rocznicę kanonozacji św. Jana. Kalwaria Zebrzydowska 1999.

Leopolien[sis] et Praemislien[sis] Canonizationis Beati Joannis de Dukla sacerdotis professi Ordinis Fratrum Minorum (vulgo Bernardinorum, 14141484): De vita et virtutis. Cracoviae 1993 [= Positio 1993].

Wünsch, Thomas: Das römische Modell einer Kirchenunion mit der Orthodoxie und sein Architekt, Johannes Sacranus von Auschwitz/Oświęcim (1443-1527). In: Roczniki Historyczne 74 (2008), 83-112.

Wyczawski, Hieronim / Murawiec, Wiesław: Święty Jan z Dukli (ok. 14141484). Kraków 1997.

\section{Internetseiten}

http://www.polskieradio.pl/77/937/Artykul/328541/ (13.08.2013). http://www.papiez.gorzow.pl/1997/zdjecia/krosno/krosno.htm (13.08.2013). http://www.cracovia-leopolis.pl/index.php?pokaz=art\&id=1347 (13.08.2013). http://www.7dni.info/news/religia/wydarzenia/11071101.html (13.08.2013).

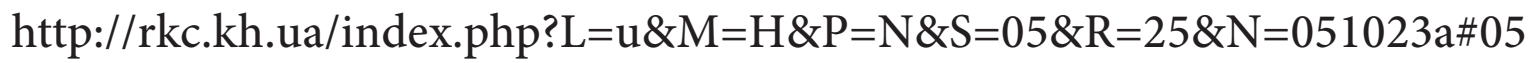
1023a (13.08.2013).

http://www.nasza-arka.pl/2006/rozdzial.php?numer=8\&rozdzial=4 (13.08.2013). http://cozl.eu/index.php/nasze-centrum/nasz-patron (13.08.2013). http://kosciol.wiara.pl/doc/1195577.Relikwie-sw-Jana-z-Dukli-w-katedrze (13.08.2013). 
Wünsch, Die Heiligsprechung des Lemberger Franziskaners Johannes von Dukla

\section{Abstract}

\section{Thomas Wünsch}

The 1997 Beatification of the Franciscan John of Dukla from Lviv (ca. 1414-1484) by Pope John Paul II: A Political Measure of the Church for the Europeanization of Ukraine?

John of Dukla (pol. Jan z Dukli, ukr. Ян з Дуклі, ca. 1414-1484) is an important site of religious remembrance for the identity of contemporary Eastern Poland and Western Ukraine (former Red Ruthenia). The cult of John - based on his activity as a Franciscan and later as a Bernardian friar in Little Poland and Lviv - became very popular especially under the multi-confessional and multi-national circumstances of the former Republic of Nobles. The cohabitation of Catholics, Orthodox, and Armenians produced a special milieu, in which John acted as a preacher during his lifetime. After his death, he was also widely venerated as a miracle worker, a saver of Lviv during the Cossack uprising, a patron of Poland-Lithuania, a missionary, and even a mediator between various denominations. The most recent step in this over 500-year history of veneration was the canonisation of John of Dukla by Pope John Paul II in 1997. This final act showed - and this is the core of the thesis presented here - the Roman Catholic Church's long lasting interest in winning over the Orthodox and Armenians (at least via church union). Referring to the political circumstances, this act may also be interpreted as an assertion of Ukraine's affiliation with a common European cultural identity. The old ties connecting Poland and Ukraine, which the act of canonisation makes visible, are likely to transform the cultural heritage of a functioning multi-confessionalism into mutual trust valuable for future regional and international Eastern European politics. 
Yuriy Voloshyn

\section{Die Erinnerung an die Schlacht von Poltava in der Zeitschrift "Poltavskie Eparchial'nye Vedomosti« in den Jahren 1907 bis 1909}

\section{Konkurrierende Erinnerungen an die Schlacht}

Die Schlacht von Poltava am 27. Juni (das ist der 8. Juli nach dem gregorianischen Kalender) 1709 gilt als Schlüsselepisode im Großen Nordischen Krieg (1700-1721). In dieser Schlacht besiegte die Armee des russischen Zaren Peter I. die Armee des schwedischen Königs Karl XII. Man geht allgemein davon aus, dass Schweden nach dieser Schlacht seine Großmachtstellung eingebüßt und sich Russland den Weg zur Dominanz in Osteuropa gebahnt hat.

In der Vergangenheit wurde die Erinnerung an dieses Ereignis zum Bestandteil eines Geschichtsmythos - zunächst für das Russische Reich, später für die Sowjetunion und letztlich für Russland. Trotz kleiner Unterschiede in der Interpretation wurde die Schlacht immer als Wendepunkt in der russischen und europäischen Geschichte interpretiert. In allen beteiligten Staaten war und bleibt sie ein integraler Bestandteil der kanonischen Geschichtsschreibung - ob für die akademische Geschichte oder im Schulunterricht. In der zweiten Hälfte des 19. Jahrhunderts und am Anfang des 20. Jahrhunderts nahm die Schlacht von Poltava einen zentralen Platz für die Herausbildung des russischen Metanarrativs ein. Die Rolle der Schlacht von Poltava hatte seinerzeit der Dozent der Kadettenschule von Poltava Ivan Pavlovskij sehr präzise formuliert: „Es gibt in der Geschichte des russischen Volkes keinen anderen Sieg der russischen Waffen, der so wichtige Folgen für Russland hätte. Auf den Feldern von Poltava 
Voloshyn, Die Schlacht von Poltava in »Poltavskie Eparchial'nye Vedomosti«

wurde Russland gegründet. « ${ }^{1}$ Es sei betont, dass damals nach offizieller Lesart unter dem Begriff »russisch" drei slavische Völker zusammengefasst wurden - Großrussen, Kleinrussen und Weißrussen. ${ }^{2}$ Keinem dieser Völker wurde das Recht auf Selbständigkeit anerkannt. Sie galten also alle als Erben des Sieges von Poltava. Zu den aktiven Verfechtern dieser Idee zählte damals auch die Russische Orthodoxe Kirche, die über sämtliche Mittel für deren erfolgreiche Weiterverbreitung verfügte.

Doch bereits in der zweiten Hälfte des 20. Jahrhunderts, also in der Zeit, als sich die klassische ukrainische Geschichtsschreibung zu etablieren und die ukrainische nationale Bewegung aktiv zu entwickeln begann, bildete sich eine andere, ukrainische nationale Version der Erinnerung an die Schlacht von Poltava heraus, die mit der oben erwähnten Version in Konflikt geriet. Sie stellte zwar die Tragweite der Schlacht nicht in Frage, betrachtete sie jedoch aus einer anderen politischen Perspektive. Den Schwerpunkt dieser Vision brachte Anfang der 1990er Jahre der ukrainische Historiker Bohdan Jakymovyč auf den Punkt: »Die Katastrophe von Poltava war der schwerste Schlag für das ukrainische Volk, sie brach ihm das Rückgrat, machte die Ideen der Unabhängigkeit zunichte. Am schlimmsten war, dass in den Dienst für den Staat von Peter I. der gesamte ukrainische Klerus übertrat, der sowieso schon zum Teil sittenlos geworden war ... «. ${ }^{3}$

Als eine der zentralen Gestalten in beiden Versionen tritt Hetman Ivan Mazepa auf, der sich im Herbst 1708 mit einem Teil des Kosakenheeres vom russischen Zaren abgewendet und einen Pakt mit dem schwedischen König geschlossen hat. Im russischen Narrativ wird er als Verräter, im ukrainischen dagegen als Nationalheld dargestellt, der den letzten Versuch zur Rettung des Kosakenstaates unternommen hat.

1 Павловский: Музей Полтавской битвы, 1077.

2 Плохій: Великий переділ: Незвичайна історія Михайла Грушевського, 105.

3 Якимович: Альфред Єнсен та його »Мазепа«, 157. 
Voloshyn, Die Schlacht von Poltava in »Poltavskie Eparchial'nye Vedomosti«

Dieser Konflikt der zwei Erinnerungen hindert die Stadt Poltava allerdings nicht, aus dem Mythos über die Schlacht nicht unerhebliche politische und finanzielle Dividenden herauszuschlagen. Lange Zeit gehörte die Stadt zum Russischen Reich, wo der Jahrestag an die Schlacht von Poltava auf der Liste der offiziellen staatlichen Feste stand. Auch wenn dieses Fest bisweilen in Vergessenheit geriet, worauf Alexander Kamenskij hinweist, ${ }^{4}$ wurden die wichtigen Jahrestage doch immer auf hohem Niveau gefeiert. Die Stadt profitierte in der Regel von solchen Feierlichkeiten. Die ukrainische Forscherin Valentyna Šandra vermutet, dass eben aus diesem Grund Poltava anstelle von Černihiv 1802 zur Hauptstadt des Generalgouvernements Kleinrussland erhoben wurde. ${ }^{5}$ Gerade in diesem Jahr wurde mit den Vorbereitungen zum 100-jährigen Jubiläum der Schlacht begonnen. Dies führte zum planmäßigen Ausbau der Stadt und deren Entwicklung zur modernen Hauptstadt des Gouvernements. Zum 200-jährigen Jubiläum im Jahr 2009 wurden Poltava und seine Infrastruktur noch einmal ausgebaut. Aber 2009 konnten sich die Stadt und die Regierung in Kiev nicht darauf einigen, welches von beiden erwähnten Erinnerungsmodellen bei den Feierlichkeiten anlässlich des 300-jährigen Jubiläums dominieren solle. Die Stadtväter von Poltava, ehemalige Komsomol-Funktionäre, die in der Sowjetzeit in der imperialen Lesart dieser Episode erzogen waren, haben de facto sämtliche Bestrebungen der Zentralregierung sabotiert, den Jahrestag nach der nationalen Version zu feiern. Trotzdem hat die Stadt eine Subvention aus dem Staatshaushalt für die Gestaltung öffentlicher Räume erhalten und davon Gebrauch gemacht.

In Poltava gibt es ziemlich viele Erinnerungsorte ${ }^{6}$ an die Schlacht. Der zentrale Ort ist logischer Weise das Schlachtfeld. Hier stehen das Museum, die

4 Kamenskii: The Battle of Poltava in Russian Historical Memory, 198-199.

5 Шандра: Генерал-губернаторства в Україні: XIX - початок XX століття, 82.

6 Unter dem Begriff»Erinnerungsort « verstehen wir nach Pierre Nora bestimmte Konkreta und Abstrakta wie Museen, Denkmäler, Friedhöfe, Archive und Kirchen 
Voloshyn, Die Schlacht von Poltava in »Poltavskie Eparchial'nye Vedomosti«

Sampson-Kirche, das Denkmal auf dem Massengrab der russischen Soldaten, Redouten der russischen Armee, das Denkmal für Schweden von Russen und das Denkmal für Schweden von Schweden. ${ }^{7}$ In der Stadt selbst sind es die Siegessäule, die Erlöserkirche, das Denkmal am Rastplatz von Peter I. und das Denkmal für den Kommandanten der Festung von Poltava, Oberst Kelin. ${ }^{8}$ Sie wurden alle in der Reichszeit gebaut, und ihre Bestimmung war es, den imperialen Mythos und das imperiale Gedenken an die Schlacht zu wahren. Die Versuche, ukrainische Erinnerungsorte in den Jahren 2008-2009 zu errichten, sind gescheitert. Trotz eines Präsidialdekrets wurde in Poltava kein Denkmal für Hetman Mazepa aufgestellt. ${ }^{9}$ Der Hauptgrund dafür war möglicherweise nicht nur der Unwille der Stadtväter, sondern auch die Verwurzelung des alten imperialen Mythos bei einem großen Teil der älteren Bürger von Poltava.

\section{Die Zeitschrift der Eparchialverwaltung von Poltava}

In diesem Aufsatz wird ein Versuch unternommen, die Rolle der Zeitschrift »Poltavskie Eparchial'nye Vedomosti« (PEV), die von 1863 bis 1919 herausgegeben wurde, bei der Herausbildung und Weitergabe der imperialen Variante der Erinnerung an die Schlacht unter dem Klerus und den Gläubigen der Eparchie Poltava der Russischen Orthodoxen Kirche zu erforschen.

Diese Zeitschrift soll deswegen zur Analyse herangezogen werden, weil sie die am meisten verbreitete amtliche Veröffentlichung im Bistum Poltava war,

mit einem übergroßen symbolischen Gehalt für das kollektive Gedächtnis. Vgl. dazu: Нора: Между памятью и историей. Проблематика мест памяти, 26.

7 Vgl. Павленко: Музей I. Ф. Павловського на полі Полтавської битви, 114-119; Павленко: Памятник російським воїнам на полі Полтавської битви, 163-180.

8 Устименко: Історія пам'ятника захисникам Полтавської фортеці і коменданту Келіну в фотодокументах, 133-138.

9 Shebelist: Memory and Memorials: Poltava without Mazepa and Petliura. 
Voloshyn, Die Schlacht von Poltava in »Poltavskie Eparchial'nye Vedomosti«

daher lassen sich in ihr die Formen und Erinnerungen der staatlich-kirchlichen Erinnerungspolitik und ihrer Rezeption durch die lokale Bevölkerung veranschaulichen. Der Schwerpunkt wird auf die Publikationen aus den Jahren 1907 bis 1909 gelegt, die im Vorfeld und im Jubiläumsjahr der Schlacht von Poltava veröffentlicht wurden.

1907 gab es nur eine solche Publikation über die Schlacht. In der Ausgabe Nr. 14 vom Mai 1907 in der Meldung über die Sitzung des Kirchenkomitees für Geschichte und Archäologie von Poltava ${ }^{10}$ wurde mitgeteilt, dass deren Hauptthema die Einrichtung eines Museums auf dem Schlachtfeld von Poltava war. Mit der Einrichtung wurde der bekannte lokale Historiker und Dozent der Kadettenschule Ivan Pavlovskij beauftragt. ${ }^{11}$

1908 gab es bereits drei Publikationen. Als erster wandte sich der Priester Vasyl' Romanov dem Thema der Schlacht in der Februar-Ausgabe der Zeitschrift zu. ${ }^{12}$ Der nächste Beitrag, unterzeichnet mit dem Kryptonym »Vol. Jep. Ved. «, erschien in der Juni-Ausgabe anlässlich des 200. Jahrestages der Hinrichtung von Vasyl' Kočubej und Ivan Iskra, die Hetman Ivan Mazepa 1708 bei Peter I. denunziert hatten. Sie hatten dem Hetman geheime Kontakte zum schwedischen König Karl XII. und zum polnischen König Stanisław Leszczyński unterstellt. Der Zar schenkte ihnen jedoch keinen Glauben und lieferte die Denunzianten an den Hetman aus. Bald darauf wurden sie im Juni 1708 hingerichtet. ${ }^{13}$ Nachdem sich Mazepa auf die Seite von Karl XII. geschlagen hatte, wurden Iskra und Kočubej als Märtyrer behandelt, die unschuldig von einem Verräter ermordet worden seien. ${ }^{14}$

10 Diese wissenschaftliche kirchliche Institution bestand in Poltava von 1906 bis 1920. Vgl.: Енциклопедія історії України, 374-375.

11 PEV 10.05.1907, 684-686.

12 PEV 10.02.1908, 211-212.

13 Таирова-Яковлева: Мазепа, 206-212.

14 PEV 10.06.1908, 744. 
Voloshyn, Die Schlacht von Poltava in »Poltavskie Eparchial'nye Vedomosti«

Als dritter Beitrag erschien ein Artikel des bereits erwähnten Ivan Pavlovskij in der Ausgabe Nr. 27 vom 20. September 1908. Der Verfasser berichtete detailliert über die Ausstellung und rief zur Spendensammlung für den Ausbau des Museums und zur Suche nach Ausstellungstücken auf. ${ }^{15} \mathrm{Zu}$ diesem Zeitpunkt besaß das Museum keine Originalgegenstände mit einem direkten Bezug zur Schlacht in seiner Sammlung.

Die meisten Beiträge erschienen freilich 1909. In diesem Jahr wurden in PEV acht Publikationen zum Thema der Schlacht veröffentlicht. Sie konzentrieren sich auf die Monate Juni und Juli. Die Ausgabe Nr. 16 vom 1. Juli 1909 beinhaltete einen Beitrag zur Geschichte der Erlöserkirche in Poltava, in der Peter I. nach der Schlacht betete. ${ }^{16}$ In den Ausgaben Nr. $17^{17}$ und $18^{18}$ vom 10. bzw. 20. Juni gab es einen recht großen Artikel »Zum 200. Jahrestag der Schlacht von Poltava«, in dem über die Bedeutung der Schlacht für die Geschichte Russlands berichtet und die Ereignisse des Großen Nordischen Kriegs im Allgemeinen und in der Ukraine im Besonderen nacherzählt wurden.

Die meisten Beiträge - insgesamt sechs - entfielen auf Ausgabe Nr. 20 vom 10. Juli 2009: die Festrede des Bischofs von Poltava, Ioann (Smirnov), beim Empfang des Zaren Nikolaus II., ${ }^{19}$ die Rede des Rektors des Priesterseminars von Poltava, Archimandrit Varlaam, ${ }^{20}$ eine Reportage über die Jubiläumstage in Poltava, ${ }^{21}$ der Beitrag des Priesters Čalenko $Z Z u$ den Feierlichkeiten in Poltava $«,{ }^{22}$ das extra zum Jubiläum von dem Priester Bjelkin verfasste Gedicht »Peter der

15 PEV 20.09.1908, 1078-1082.

16 PEV 01.06.1909, 675-693.

17 PEV 10.06.1909, 743-763.

18 PEV 20.06.1909, 788-804.

19 PEV 10.07.1909, 879-880.

20 PEV 10.07.1909, 881-884.

21 PEV 10.07.1909, 884-890.

22 PEV 10.07.1909, 891-893.

DigiOst 3 | 338 
Voloshyn, Die Schlacht von Poltava in »Poltavskie Eparchial'nye Vedomosti«

Große $\ll^{23}$ und die Erzählung von Petro Bogoslovcev »Aus den Erinnerungen des Urgroßvaters «. ${ }^{24}$

Eine eingehende Analyse der Texte lässt einige spezifische Themen heraustreten, die sich in drei Blöcke aufteilen lassen. Zum ersten gehören Beiträge, die sich mit den Erinnerungsorten befassen; der zweite beinhaltet Artikel, die über Kommemorationspraktiken oder Gedenkzeremonien berichten, und den dritten Block bilden Beiträge, deren Autoren die Schlacht und die Erinnerung daran als Argument für die Lösung der gegenwärtigen Probleme instrumentalisieren.

"Erinnerungsorte« werden in vier Beiträgen thematisiert. Zwei davon - in den Ausgaben vom 10. Mai 1907 und vom 20. September 1908 - sind der Einrichtung des Museums auf dem Schlachtfeld von Poltava gewidmet, um das sich die Kirchengesellschaft für Geschichte und Archäologie von Poltava kümmerte. Als Begründung galt der Bedarf für die Einrichtung einer Gedenkstätte zum 200-jährigen Jubiläum der Schlacht, die, wie bereits erwähnt, nicht nur Russland begründet, sondern auch dazu beigetragen habe, dass Poltava »durch dieses geschichtliche Ereignis unter den Hauptstädten der Gouvernements aufgelistet wird $«{ }^{25}$

Der dritte Beitrag aus diesem Block ist »Die Geschichte der Erlöserkirche in Poltava«, veröffentlicht am 1. Juni 1909. Sein Verfasser war der damalige Pfarrer der Kirche, Gaponovyč. Diese Kirche ist mit der Schlacht von Poltava dadurch verbunden, dass Peter I. dort betete, als er nach der Schlacht am 28. Juni 1709 in die Stadt gekommen war. Der Autor behauptet, dass diese Kirche seitdem "zum historischen Heiligtum des gesamten russischen Volkes, zum historischen Heiligtum, dem Kleinod von Poltava wurde « ${ }^{26}$ Noch eine Publikation, die $\mathrm{zu}$ dem von Pierre Nora formulierten Begriff »Erinnerungsort « passt, ist die

23 PEV 10.07.1909, 893-899.

24 PEV 10.07.1909, 900-905.

25 PEV 10.06.1909, 788.

26 PEV 01.07.1909, 775.

DigiOst 3 | 339 
Voloshyn, Die Schlacht von Poltava in »Poltavskie Eparchial'nye Vedomosti«

Erzählung von Petro Bogoslovcev »Aus den Erinnerungen des Urgroßvaters«. Darin wurde in apokalyptischen Tönen das Auftreten der schwedischen Armee in der Region Poltava während der Überwinterung von 1708 bis 1709 geschildert. »Man sagt, es gruselte jedem in der Ukraine vor dem Einmarsch der Schweden, und in der Region Poltava war es noch gruseliger. Was auch alles im Volk geplaudert wurde! Manchmal hörst du solche Geschichten und kannst nachts nicht mehr einschlafen. ${ }^{27}$

Den Feierlichkeiten zur Erinnerung an die Schlacht von Poltava sind zwei Beiträge in der Ausgabe Nr. 20 aus dem Jahr 1909 gewidmet. Das ist die Festrede des Bischofs von Poltava Ioann, die er in der Bischofskirche am 26. Juni 1909 beim Empfang des Zaren Nikolaus II. gehalten hat, und die Reportage »Jubiläumstage in Poltava «, die über alle zeremoniellen feierlichen Veranstaltungen unter Beteiligung des Monarchen und seines Trosses berichtete. Die Feierlichkeiten wurden an allen Orten begangen, die einen symbolischen Bezug zur Schlacht von Poltava hatten. Auf dem Schlachtfeld waren es die Sampson-Kirche und das Massengrab der russischen Soldaten. In der Stadt waren es die Erlöserkirche, der Rastplatz von Peter I., das Denkmal für den Kommandanten der Festung von Poltava Oberst Kelin und die Siegessäule.

Die Hälfte aller Publikationen hatte allerdings keinen direkten Bezug zur Schlacht. Es war eher ein Versuch, die Erinnerung daran zur Lösung der aktuellen gesellschaftlichen Probleme des Reiches zu instrumentalisieren. Kurz davor hatte Russland im Russisch-Japanischen Krieg (1904-1905) eine Niederlage erlitten und die Revolution von 1905-1907 erlebt. Auch die nationalen und sozialen Bewegungen wurden immer stärker, die Ideen von einer demokratischen Staatsordnung gewannen immer mehr an Boden. Die Herrschaftsdynastie verspürte ein reales Bedürfnis, die Nation zu konsolidieren, und ein Mittel dafür war der Versuch, mit Hilfe der Erinnerung an den ruhmreichen Sieg des Zaren Peter I. den Patriotismus zu kultivieren. Dessen Bild und die Erinnerung an seinen Sieg

27 PEV 10.07.1909, 900.

DigiOst 3 | 340 
Voloshyn, Die Schlacht von Poltava in »Poltavskie Eparchial'nye Vedomosti«

sollten zur gesellschaftlichen Eintracht und zum inneren Zusammenhalt der Gemeinschaft beitragen, die damals »russische Nation « genannt wurde.

Allerdings bezog sich der erste dieser Beiträge vom 10. Februar 1908 nicht auf die gesamtstaatlichen Probleme, sondern auf die Probleme der Eparchie. Der bereits erwähnte Vater Vasyl' Romanov appellierte in seinem Artikel unter dem Titel »Die großen Defizite« an das Jubiläum der Schlacht; das Ziel des Beitrags war, Erinnerungen an die Geschichte von Pfarrkirchen in der Eparchie von Poltava zu sammeln. Das Bedürfnis, historische Informationen über Kirchen niederzuschreiben, begründete der Autor mit der Notwendigkeit, Gewinne und Verluste der Kirchen von Poltava seit der Schlacht zusammenzufassen. In diesem Fall diente der Bezug zur Schlacht für den Verfasser als Argument, das zur Lösung eines lokalen Problems der Eparchie beitragen sollte - der Inventur der alten Kirchen. Diesen Bezugspunkt wählte Vater Romanov deswegen, weil "durch ihre Treue zum Zaren, durch die Vermittlung dieser Treue dem Volk" die Kirche »an einem großen Ereignis beteiligt war «. ${ }^{28}$

Der bereits erwähnte Beitrag über Vasyl' Kočubej und Ivan Iskra war nicht so sehr als Gedenken an den Jahrestag ihrer Hinrichtung gedacht, als gegen die nationalen Bewegungen gerichtet, die nach Auffassung des Autors "die geschichtliche Konstellation und die Einheit des russischen Staates unterminieren wollten «. ${ }^{29}$ Nachdem im Laufe der Revolution von 1905 einige demokratische Freiheiten eingeräumt worden waren, verstärkten sich die nationalen Bewegungen unter den Völkern des Reiches. Die größten Sorgen bereitete dem Klerus der Eparchie die ukrainische Bewegung: »die utopischen Träumer von der selbständigen kleinrussischen Republik «. ${ }^{30}$ Dem Autor zufolge sollte sie die Erinnerung an die Heldentat von »zwei heiligen Märtyrern«, die mit ihrem Blut »dem Thron und dem Gesalbten« die Treue bezeugt hatten, auf

28 PEV 10.02.1908, 211-212.

29 PEV 10.06.1908, 744.

30 Ebenda.

DigiOst 3 | 341 
Voloshyn, Die Schlacht von Poltava in »Poltavskie Eparchial'nye Vedomosti«

den richtigen Weg bringen. Solche Bilder bei den Nachkommen wieder zu beleben, sei »aufschlussreich und nützlich«, insbesondere in der Zeit, als sich "grundloser Kosmopolitismus und zerstörerischer Separatismus « verbreiteten. ${ }^{31}$ Zum Symbol dafür und zur Bedrohung für die russische Reichsverwaltung am Anfang des 20. Jahrhunderts in der Ukraine wurde wie bekannt Hetman Ivan Mazepa hochstilisiert. ${ }^{32}$ In diesem kurzen Text wird er sieben Mal als Verräter abgestempelt und mit Judas verglichen. Zur Bestätigung der patriotischen These, dass die Zukunft der Ukraine in Treue und Ergebenheit dem russischen Zaren und Thron liege, beruft sich der Verfasser auf die »Heldentat « von Kočubej und Iskra. Ihnen werden die Eigenschaften der Propheten zugeschrieben, die »besser als wir verstanden haben«, dass die Erlösung nicht in der republikanischen Ordnung mit einem Präsidenten an der Spitze, nicht in den trügerischen Privilegien der Rzeczpospolita und nicht in der osmanischen Abhängigkeit bestehe. ${ }^{33}$ Das auf diese Weise konstruierte Gedenken an dieses Ereignis hatte also zum Ziel, ein Problem der Gegenwart zu lösen: die Bekämpfung der ukrainischen nationalen Wiedergeburt.

Mit Patriotismus und Heimatliebe setzte sich auch der große Redaktionsbeitrag "Zum 200. Jahrestag des Sieges von Poltava « auseinander. Er beginnt mit einem langen Einstieg, in dem hervorgehoben wird, wie wichtig es für die "dankbaren Nachkommen" sei, die Namen und Taten von Vorfahren in Erinnerung zu behalten. Der Verfasser betonte, dass die Erinnerung des Volkes an die ruhmreichen Siege der großen Ahnen die Quelle ist, aus der in schwierigen Zeiten, die ja Russland gerade erlebe, »Mut, Standfestigkeit, Drang nach Heldentaten, Opferbereitschaft, lebendiger Glaube an die geistige Kraft des Volkes und seine bessere Zukunft « ${ }^{34}$ geschöpft würden. Danach folgte die Erzählung

31 PEV 10.06.1908, 745.

32 Сокирко: Український Рубікон. Полтавська битва 27 червня 1709 р. (Частина II), 67.

33 PEV 10.06.1908, 745.

34 PEV 10.06.1909, 745.

DigiOst 3 | 342 
Voloshyn, Die Schlacht von Poltava in »Poltavskie Eparchial'nye Vedomosti«

über den Großen Nordischen Krieg: über dessen Gründe, die Kämpfe auf dem Gebiet der Ukraine, die Verteidigung Poltavas, die Schlacht von Poltava und die Siegesfeier. Ein Abschnitt wurde Hetman Mazepa gewidmet, der als Judas dargestellt wurde, danach wurde die Zarentreue der Ukrainer hervorgehoben. Auf diese Weise versuchte der Autor, Mazepa nicht als Verräter von Peter I., sondern als Verräter der Interessen der Ukrainer darzustellen. Anders als von Mazepa gehofft, hätten sich die letzteren nicht an seinem Beispiel »angesteckt«, sondern "sich alle wie ein Mann zur Verteidigung des Vaterlandes erhoben «. ${ }^{35}$ Mazepa wurde als Mann dargestellt, der sich auf die Seite von Karl XII. geschlagen hatte, um eigene Ambitionen zu verfolgen, und der die Hoffnungen der Ukrainer nicht verstehen konnte. Das Ziel dieser Publikation war also nicht nur die Erinnerung an ein historisches Ereignis, sondern vor allem die Festigung des Patriotismus, der zur damaligen Zeit unter dem Einfluss der ukrainischen Nationalbewegung deutliche Risse bekommen hat. Es sei darauf hingewiesen, dass damals diese Bewegung im Russischen Reich mit dem Namen von Hetman Mazepa im Zusammenhang gebracht und »mazepynstvo« genannt wurde.

»Das Wort am Siegestag von Poltava«, das Archimandrit Varlaam in der Bischofskirche von Poltava am 27. Juni 1909 gesprochen hat, war nicht nur auf die Festigung des patriotischen Geistes, sondern auch auf die Verteidigung des orthodoxen Glaubens vor Angriffen der Katholiken gerichtet. Diese hätten Anfang 1709 angeblich bereits die gesamten westlichen Gebiete von Sankt Petersburg bis Kiev und Poltava erobert. Als Folge kamen der Staat, der Glaube und die Frömmigkeit zu Schaden. Der Katholizismus, der nach Worten des Archimandriten »unsere wahren slavischen Brüder - Polen und Tschechen mit Gewalt unterworfen hatte, wollte nun auch nach uns greifen $«{ }^{36}$ Doch durch die Schlacht von Poltava konnte »der Vormarsch des Katholizismus» gestoppt werden.

35 PEV 10.06.1909, 754.

36 PEV 10.07.1909, 881.

DigiOst 3 | 343 
Voloshyn, Die Schlacht von Poltava in »Poltavskie Eparchial'nye Vedomosti«

$\mathrm{Zu}$ den Hauptthesen des Texts von Vater Čalenko »Zu den Feierlichkeiten in Poltava" gehörten die Deklaration der Zarentreue und die Suche nach den Ursachen für die gesellschaftliche Krise, die im Russischen Reich nach der Revolution von 1905-1907 herrschte. Der Geistliche sah diese Ursachen darin, dass die Zeitgenossen das Vermächtnis der Sieger von Poltava vergessen hatten. Deswegen wurden sie vom »Todesschlaf der Moral« und von »zersetzendem Kosmopolitismus« heimgesucht. Das habe dazu geführt, dass sich die »unwürdigen Nachkommen den Ketzereien der Grenzgebiete « hingaben und sich nach einer republikanischen Staatsordnung und demokratischen Freiheiten sehnten. Der Priester war überzeugt, dass die Feierlichkeiten zum 200. Jahrestag der Schlacht von Poltava das russisch-nationale Selbstbewusstsein wecken und die Zarenmacht festigen würden. »Unter dem hehren Blicke von Peter I., vor dem Grab der auf dem Schlachtfeld von Poltava gefallenen Soldaten, unserer Ahnen, wollen wir unsere Schmach tilgen, uns als richtige Söhne des Vaterlandes zeigen, die parteilichen Auseinandersetzungen vergessen; Russen! Wollen wir uns alle wie ein Mann unter die Zarenfahne des Ur-Urgroßenkels von Peter stellen, unseres Zaren Nikolaus II. ...", appellierte der Geistliche. ${ }^{37}$

Im ähnlichen Stil ist auch das Gedicht »Peter der Große« eines anderen Priesters gehalten. Die Idee von Priester Belkin besteht darin, dass Peter vom Himmel das Geschehen im heutigen Russland sehen könne, daran schwer leide und darüber nachdenke. Die Ursache für das Unheil sehe der Zar in der Müßigkeit des Volkes und darin, dass seine ruhmreichen Taten in Vergessenheit geraten seien. In diesem Gedicht ist Peter auch schwer besorgt über die Niederlage im Russisch-Japanischen Krieg von 1904-1905. Er wirft Admiral Nikolaj Nebogatov vor, dass dieser Russland Schmach angetan habe, als er vier russische Schiffe am zweiten Tag der Schlacht von Tsušima am 15. Mai 1908 kapitulieren ließ.

37 PEV 10.07.1909, 893.

DigiOst 3 | 344 
Voloshyn, Die Schlacht von Poltava in »Poltavskie Eparchial'nye Vedomosti«

Insgesamt hat die Zeitschrift »Poltavskie Eparchial'nye Vedomosti« demnach eine wichtige Rolle bei der Berichterstattung über die Vorbereitung und Durchführung der feierlichen Veranstaltungen zum 200-jährigen Jubiläum der Schlacht von Poltava im Juli 1909 gespielt. Die Publikationen zeugen davon, dass die orthodoxe Kirche Anfang des 20. Jahrhunderts als Institution zur Vertretung der Gemeinschaft der Gläubigen das historische Gedächtnis aktiv mitgeprägt hat. Die Beiträge in der Zeitschrift belegen auch, dass das Bild der Schlacht von Poltava in der imperialen Variante des nationalen Gedächtnisses zur Lösung der aktuellen Probleme durch die russische Monarchie genutzt wurde: zur Konsolidierung der Gesellschaft und Bekämpfung der Nationalbewegungen, vor allem der ukrainischen.

\section{Literatur}

Kamenskii, Alexander: The Battle of Poltava in Russian Historical Memory. In: Harvard Ukrainian Studies Vol. 31, No. 1/4 (2012): Poltava 1709: The Battle and the Myth. Ed. by Serhii Plokhy, 195-204.

Енциклопедія історії України. Т. 8. Київ 2008.

Нора, Пьер: Между памятью и историей. Проблематика мест памяти. In: Франция-пам'ять. Санкт-Петербург 1999, 17-50.

Павленко, Валерій: Музей І. Ф. Павловського на полі Полтавської битви (історична довідка). In: Полтавська битва 1709 року погляд крізь призму трьох століть 1709-2009. Полтава 2009, 114-119.

Павленко, Валерій: Памятник російським воїнам на полі Полтавської битви. In: Полтавська битва 1709 року погляд крізь призму трьох століть 1709-2009. Полтава 2009, 163-180.

Павловский, Иван: Музей Полтавской битвы. In: Полтавские епархиальные ведомости (ПЕВ). Часть неофициальная. 20.09.1908, 1077. 
Voloshyn, Die Schlacht von Poltava in »Poltavskie Eparchial'nye Vedomosti«

Плохій, Сергій: Великий переділ: Незвичайна історія Михайла Грушевського. Київ 2011.

Полтавские епархиальные ведомости. Полтава 1907-1909 [diverse Ausgaben]

Сокирко, Олексій: Український Рубікон. Полтавська битва 27 червня 1709 р. (Частина II). Київ 2008.

Устименко, О.: Історія пам'ятника захисникам Полтавської фортеці і коменданту Келіну в фотодокументах. In: Полтавська битва 1709 року погляд крізь призму трьох століть 1709-2009. Полтава 2009, 133-138.

Таирова-Яковлева, Татьяна: Мазепа. Москва 2007.

Шандра, Валентина: Генерал-губернаторства в Україні: XIX - початок XX століття. Київ 2005.

Якимович, Богдан: Альфред Єнсен та його »Мазепа«. In: Вітчизна 11 (1991), 157.

Shebelist, Sergii: Memory and Memorials: Poltava without Mazepa and Petliura, unter: http://historians.in.ua/index.php/istoriya-i-pamyat-vazhkipitannya/472-sergii-shebelist-memory-and-memorials-poltava-withoutmazepa-and-petliura (21.01.2014)

\section{Abstract}

Yuriy Voloshyn

Memory of the Battle of Poltava in the Publications of the Poltava Diocesan News Almanac (1907-1909)

The article analyses the role of the Poltava Diocesan News Almanac (1863-1919) in the construction of Russian imperial historical memory of the Battle of Poltava in 1709. The author will scrutinise different types of texts published in honour of the $200^{\text {th }}$ commemoration of the battle in the Poltava Diocesan News. 


\section{Carola Söller}

\section{Gedenken - Mahnen - Aufarbeiten? Kirchen und kommunistische Vergangenheit in der Ukraine und in Polen}

Ab Anfang der Neunzigerjahre wurden in vielen Ländern Mittel- und Osteuropas Debatten bezüglich einer Auseinandersetzung mit der jüngsten nationalen Vergangenheit geführt. Es kamen dabei rechtliche, politische, wissenschaftliche und ethisch-moralische Perspektiven zum Tragen. Stets wurde in der politischen und öffentlichen Diskussion um einen bestimmten Aspekt früher oder später mit besonderer Intensität gerungen: nämlich um die Frage nach Verantwortlichkeiten bzw. nach der Identifizierung von Tätern, Opfern und Helden im kommunistischen System. Besonders großes, oftmals auch mediales Interesse weckte die Vergangenheit bekannter Persönlichkeiten des öffentlichen Lebens, das heißt von Politikern, Künstlern und nicht zuletzt auch von Vertretern der Geistlichkeit im jeweiligen Land. Die Frage danach, wie sich die Kirchen als Institutionen, aber auch einzelne höher- und niederrangige Vertreter der Gemeinschaften im vergangenen System positioniert hatten, wurde dabei häufig erst gestellt, nachdem die Debatten um die jüngste Vergangenheit bereits eine gewisse Dynamik entfaltet hatten.

Der vorliegende Beitrag widmet sich der Frage, wie sich die Auseinandersetzung mit der kommunistischen Vergangenheit in Bezug auf die Kirchen in der Ukraine und in Polen seit Anfang der Neunzigerjahre gestaltete. Ausgehend von einem kurzen Überblick zur Situation der Kirchen in der Ukraine und in Polen vor dem Systemwechsel sollen die Beschäftigung der Kirchen mit dieser Thematik und die damit einhergehenden Debatten näher beleuchtet werden. Der vergleichende Blick auf Ukraine und Polen erlaubt es dabei, die Frage nach Intensität, Themenwahl und Argumentationslinien in der öffentlichen 
Söller, Gedenken - Mahnen - Aufarbeiten? Kirchen und kommunistische Vergangenheit

Diskussion sowie nach Rollen und Strategien der Glaubensgemeinschaften in beiden Ländern in einen breiteren Kontext zu stellen.

Polen wird in Bezug auf seine Auseinandersetzung mit der eigenen Vergangenheit in anderen Länder Ostmittel-, Südost- und Osteuropas immer wieder als Referenzmodell und Vorbild herangezogen. So wurden in der Slowakei und in Tschechien in Anlehnung an das polnische Institut für Nationales Gedenken (Instytut Pamięci Narodowej, IPN) ähnliche Einrichtungen zur Aufarbeitung der nationalen Vergangenheit im 20. Jahrhundert geschaffen. Auch in der Ukraine entstand im Jahr 2006 ein Institut für Nationales Gedenken (Ukraïns'kyj instytut nacional'noï pam-jati, UINP), das sich in der Namenswahl deutlich an das polnische Pendant anlehnt, wenn auch die Kompetenzen des Instituts und der Zeitraum, mit welchem sich das ukrainischen UINP beschäftigt, stark von der Ausrichtung des polnischen IPN abweichen.

Nicht nur in institutioneller Hinsicht, auch in Bezug auf Debatten um die Aufarbeitung wirkte Polen in der Vergangenheit als Vorbild auf andere Länder Mittel- und Osteuropas ein. So wurde beispielsweise in Tschechien und Rumänien gerade die Diskussion um Verstrickungen polnischer Geistlicher in das staatssozialistische System zum Anstoß genommen, um eine kritische Auseinandersetzung mit diesem Aspekt der kirchlichen Vergangenheit auch im eigenen Land einzufordern. Ob Polen und die Ukraine als Nachbarländer, die in Bezug auf ihre gemeinsame jüngste Vergangenheit in immer wieder auch schwierigem Austausch stehen, in Bezug auf die Aufarbeitung der Rolle der Kirchen im Kommunismus Einfluss aufeinander ausübten, wird somit im Beitrag ebenfalls thematisiert. 
Söller, Gedenken - Mahnen - Aufarbeiten? Kirchen und kommunistische Vergangenheit

\section{Die Situation der Kirchen vor 1989 in der Ukraine und in Polen - Verbot, Verfolgung, Duldung}

Zweifellos standen Kirchen und Glaubensgemeinschaften sowohl in Polen als auch in der Ukraine in der Zeit der kommunistischen Machtausübung unter besonderem Druck. ${ }^{1}$ In der gesamten Sowjetunion waren alle Religionen, Konfessionen und ihre Gläubigen von einer »Kombination aus diskriminierender Gesetzgebung, administrativer Willkür, Polizeiterror und antireligiöser Agitation $\aleph^{2}$ betroffen. In der Ukraine wurden die Kirchen nicht nur als religiöser, sondern auch als nationaler Faktor wahrgenommen und umso rigoroser verfolgt. ${ }^{3}$ Die Repression gegen die Kirchen durch den kommunistischen Staat setzte dabei auf Teilen des heutigen ukrainischen Staatsgebiets mit der SchlieBung von Kirchen, der Beschlagnahmung von Eigentum, der Deportation von Geistlichen und Gläubigen sowie der Auflösung der Ukrainischen Autokephalen Orthodoxen Kirche bereits in den Zwanziger- und Dreißigerjahren ein. ${ }^{4}$ Der zunehmende Druck führte zu Loyalitätserklärungen einiger Kirchenvertreter gegenüber dem Sowjetregime. ${ }^{5}$ Die Griechisch-Katholische Kirche wurde in der zweiten Hälfte der Vierzigerjahre verboten und mit der Russischen Orthodoxen Kirche zwangsvereinigt. Sie konnte lediglich im Exil und als Untergrundkirche fortbestehen. Auch alle anderen Kirchen und Glaubensgemeinschaften, wie die römisch-katholische Kirche, protestantische Kirchen sowie jüdische und

1 Zur Geschichte der Kirchen in der Ukraine im 20. Jahrhundert vgl. Heyer: Kirchengeschichte der Ukraine; Anderson: Religion, State and Politics. Zur Religionspolitik zwischen 1941 und 1953 in der Ukraine vgl. Boeckh:»Liberalisierung" und Repression. Zu verschiedenen Phasen der staatlichen Kirchenpolitik in der Sowjetunion und in Polen vgl. Ramet: Nihil Obstat, 10-49.

2 Vulpius: Kirchenverfolgung und Holodomor, 76.

3 Boeckh: Staat und Kirchen, 87.

4 Boeckh: »Liberalisierung « und Repression, 122-123.

5 Vulpius: Kirchenverfolgung und Holodomor, 76-77. 
Söller, Gedenken - Mahnen - Aufarbeiten? Kirchen und kommunistische Vergangenheit

muslimische Gemeinden, wurden unterdrückt und deutlich zurückgedrängt. ${ }^{6}$ Die Russische Orthodoxe Kirche wurde hingegen letztlich geduldet und konnte ab der Nachkriegszeit als »staatliches Instrument der Kontrolle über die Gläubigen eine eingeschränkte Existenz « weiterführen. ${ }^{7}$ Eine freie Tätigkeit der Kirchen war folglich nicht mehr möglich. Die staatliche Strategie der Spaltung der Kirchen, der umfassenden Verfolgung sowie im Anschluss der - auch personellen - Kontrolle der Kirchen hatte somit vielfach Erfolg gezeigt.

Auch in Polen versuchte der Staat nach 1945, zunehmend Kontrolle über die Kirchen und religiösen Gemeinschaften auszuüben. Vor allem die katholische Kirche Polens und ihre Geistlichen wurden nach 1945 über weite Zeiträume staatlicherseits als die größten Widersacher des Systems betrachtet. Indem der Staat die Gruppe der so genannten »Patrioten-Priester « förderte, die in ihrem Umfeld zeitweise circa zehn Prozent der katholischen Geistlichen versammelte, wurde versucht, die Kirche zu schwächen und zu spalten. ${ }^{8}$ Im Jahr 1953 versuchte zudem der Staatsrat, also das ab 1952 kollektive "Staatsoberhaupt «, das legislative und exekutive Aufgaben vereinte, die katholische Kirche und ihre Personalpolitik unter seine Kontrolle zu bringen, indem er ein Dekret zur staatlichen Besetzung kirchlicher Posten erließ und Loyalitätseide zur Volksrepublik von den Priestern einforderte. ${ }^{9}$ Nachdem sich die katholischen Bischöfe zunächst weigerten, das Dekret zu akzeptieren, folgten Schauprozesse gegen Priester und im September 1953 die Internierung von Primas Erzbischof Stefan Wyszyński (1901-1981). In Konsequenz legten die restlichen sich noch in Freiheit befindenden Mitglieder des Episkopats Loyalitätserklärungen gegenüber der Volksrepublik ab. ${ }^{10}$ Wyszyński und weitere Bischöfe wurden erst im

6 Boeckh: Staat und Kirchen, 88. Ausführlicher vgl. Boeckh:»Liberalisierung« und Repression, 155ff.

7 Boeckh: Staat und Kirchen, 73.

8 Dudek: Ślady PeeReLu, 242-243.

9 Dudek: Ślady PeeReLu, 74-79.

10 Dudek: Ślady PeeReLu, 244.

DigiOst 3 | 350 
Söller, Gedenken - Mahnen - Aufarbeiten? Kirchen und kommunistische Vergangenheit

Jahr 1956 aus der Haft entlassen. In den Folgejahren sicherte sich das Regime die Mitsprache bei der Besetzung kirchlicher Posten. Staatlichen Stellen wurde per Dekret ein dreimonatiges Einspruchsrecht bei der Ernennung von Pfarrern und anderen Geistlichen bis hin zu Bischöfen zugesprochen, von welchem diese umfassend Gebrauch machten. ${ }^{11}$ Trotz der abgerungenen Loyalitätserklärungen und der Einflussnahme des Staates auf die Besetzung kirchlicher Ämter war die katholische Kirche in Polen jedoch immer auch ein Gegenspieler des Staates, der von offizieller Seite geduldet werden musste. Ziel der staatlichen Politik auch in Polen war zwar eine Spaltung und somit Schwächung der Kirchen, dies war letztlich jedoch nur teilweise erfolgreich.

Zur Gewährleistung einer Kontrolle der Kirchen gehörte zur festen Strategie des Staates und seiner Sicherheitsdienste in der Ukraine und in Polen auch der Versuch, Geistliche für eine Kooperation mit den Staatssicherheitsdiensten zu verpflichten. In der Ukraine versuchte die Kommission für antireligiöse Propaganda des Politbüros bereits in den Zwanzigerjahren durch Informanten und Agenten Einfluss auf die damals noch existenten Kirchen auszuüben. ${ }^{12}$ In der später geduldeten Russischen Orthodoxen Kirche konnte keine Ernennung zum Bischof ohne Bestätigung durch das Zentralkomitee der Kommunistischen Partei und den KGB erfolgen. ${ }^{13}$ Die Geistlichen waren, wollten sie Positionen in wichtigen Diözesen und höhere Kirchenämter bekleiden, auf die Zustimmung des Rates für Religiöse Angelegenheiten im KGB angewiesen. ${ }^{14}$ In Polen versuchte das Regime ebenfalls, mittels gezielten Aktionen eine "Politik der Desintegration « auch in Personalfragen gegenüber den Kirchen auszuüben. ${ }^{15}$

11 Dudek: Ślady PeeReLu, 48-49.

12 Bilokin: The Kiev Patriarchate, 183ff.

13 Bilokin: The Kiev Patriarchate, 188-189.

14 Bilokin: The Kiev Patriarchate, 189. Zur Kontrolle und Überwachung der Russischen Orthodoxen Kirche durch Kommunistische Partei und KGB bis 1991 vgl. auch Dunlop: The Russian Orthodox Church, 28-29.

15 Dudek: Ślady PeeReLu, 48.

DigiOst 3 | 351 
Söller, Gedenken - Mahnen - Aufarbeiten? Kirchen und kommunistische Vergangenheit

Teil der staatlichen Vorgehensweise war dabei immer auch - mit den unterschiedlichsten Mitteln und Methoden - die Anwerbung von Informanten für die Staatssicherheitsdienste unter den Geistlichen. ${ }^{16}$

Letztlich stellten die Kirchen in Polen und in der Ukraine trotz staatlichem Druck und Kontrolle jedoch ebenso gewisse - auch geistige - Freiräume dar, die sich in der Bindung vieler Dissidenten an die Kirche äußerten, sowie darin, dass sich in beiden Ländern Geistliche für oppositionelle Belange stark machten. ${ }^{17}$

Die Unterschiede im Ausmaß der Repression gegen kirchliche Akteure und Glaubensgemeinschaften in ihren verschiedenen Phasen hatten in der Ukraine und in Polen unterschiedliche Handlungsspielräume für die Kirchen und religiösen Gemeinschaften zur Folge. In Bezug auf die Positionierung der Kirchen zwischen staatlicher Repression, Widerstand, Anpassung und Kooperation auf institutioneller wie individueller Ebene wies die Situation in beiden Staaten dennoch ähnlich vielfältige Ausformungen auf. Gerade diese vielschichtige Vergangenheit der Kirchen und Religionsgemeinschaften harrte somit nach dem Systemwechsel in beiden Ländern einer öffentlichen Thematisierung, wenn nicht sogar Aufarbeitung.

\section{Die polnischen Kirchen nach 1989 - Restitution, Lustration, Kommissionen}

In Polen wurden die Religionsgemeinschaften und zuvorderst die römisch-katholische Kirche nach 1989 deutlich als Gegner und Opfer des vergangenen Systems begriffen, was sich beispielsweise in der bereits 1989 erlassenen gesetzlichen Regelung über das Verhältnis zwischen polnischem Staat und katholischer Kirche niederschlug. Es wurde darin die Möglichkeit der Resti-

16 Dudek: Instytut, 304-305.

17 Boeckh: Staat und Kirchen, 83; Ramet: Nihil Obstat, $101 \mathrm{ff}$.

DigiOst 3 | 352 
Söller, Gedenken - Mahnen - Aufarbeiten? Kirchen und kommunistische Vergangenheit

tution enteigneter, ehemals kirchlicher Immobilien festgehalten, die über eine so genannte Eigentumskommission durchgeführt wurde. ${ }^{18}$ Auch für andere Religionsgemeinschaften wie die Ukrainische Autokephale Orthodoxe Kirche und die Evangelisch-Augsburgische Kirche wurden nach diesem Prinzip Kommissionen gegründet. Kritische Stimmen bemängelten jedoch, dass die katholische Kirche bei der Rückübertragung von Eigentum privilegiert behandelt werde. ${ }^{19}$ Tatsächlich wurden im Jahr 2010, als über eine Einstellung der Kommissionstätigkeit debattiert wurde, verstärkt Vorwürfe laut, die katholische Kirche sei teilweise unrechtmäßig bevorzugt worden. Letztlich wurde gegen beteiligte Personen gar Anklage wegen Korruption und Bestechung erhoben. ${ }^{20}$ Zentrale Persönlichkeit war dabei auch ein Bevollmächtigter kirchlicher Institutionen in der Kommission, bei dem es sich pikanterweise um einen ehemaligen Funktionär der volksrepublikanischen Staatssicherheit handelte. ${ }^{21}$ Vertreter der kirchlichen Seite wiesen eine grundsätzliche Kritik an der Arbeit der Kommission hingegen zurück und betonten, auch andere Konfessionen hätten von deren Tätigkeit profitiert. ${ }^{22}$

In Bezug auf die Frage nach Verantwortlichkeit für individuelles Verhalten in der Volksrepublik Polen hatte sich die katholische Kirche in Polen bereits Anfang der Neunzigerjahre zu Wort gemeldet. In Zusammenhang mit der Debatte um eine Lustration ${ }^{23}$ in Polen forderten die katholischen Bischöfe, dass die

18 Nieruchomości kościołów i innych związków wyznaniowych.

19 Bingen: Aufarbeitung der kommunistischen Vergangenheit, 71-72.

20 Pietraszewski: Komisja majątkowa - skrywany raport rządu: Kościołowi ile się da.

21 Rogojsz: Komisja majątkowa. Nadal bezkarna; Dudek: Instytut, 305.

22 Biskupi: zarzuty wobec komisji niesprawiedliwe; Koniec Komisji Majątkowej.

23 Als Lustration (poln. lustracja) bezeichnet man in Polen die Überprüfung von Anwärtern und Inhabern einer Reihe von öffentlichen und politischen Funktionen auf eine Kooperation mit den Staatssicherheitsdiensten der Volksrepublik Polen. Seit dem Jahr 1997 existiert in Polen ein später mehrfach überarbeitetes so genanntes »Lustrationsgesetz« (poln. ustawa lustracyjna), das die Sperrung für

DigiOst 3 | 353 
Söller, Gedenken - Mahnen - Aufarbeiten? Kirchen und kommunistische Vergangenheit

Vergangenheit von Personen in öffentlichen Ämtern offengelegt werden solle und sich diese zu einer eventuellen Schuld bekennen sollten, um Vergebung zu ermöglichen. ${ }^{24}$ Die Frage, ob und wieweit Verbindungen zwischen kommunistischem Staat, Staatssicherheit und Kirchen vor 1989 bestanden hatten, wurde zu diesem Zeitpunkt in der öffentlichen Debatte in Polen hingegen kaum thematisiert. Auch als ab Ende der Neunzigerjahre wissenschaftliche Arbeiten vorlagen, die das Vorgehen des Staates gegen Kirchen und Religionsgemeinschaften in der Volksrepublik Polen behandelten und in diesem Zusammenhang ebenfalls auf die Kollaboration von Geistlichen mit dem System hinwiesen, ${ }^{25}$ zogen die polnischen Kirchen zunächst keine Rückschlüsse im Sinne einer aktiven Aufarbeitung dieses Aspekts ihrer Vergangenheit.

Umfassender wandten sich die Kirchen der Thematik erst im Jahr 2005 zu. Seit dem Beginn der Lustration von Inhabern und Anwärtern öffentlicher Ämter durch den so genannten Fürsprecher für Öffentliches Interesse (Rzecznik Interesu Publicznego) sowie der Öffnung der Dokumentenbestände der ehemaligen Staatssicherheitsdienste durch das Institut für Nationales Gedenken waren zu diesem Zeitpunkt bereits einige Jahre vergangen. Anlass waren Informationen, die durch das IPN über einen Informanten der Staatssicherheit im direkten Umfeld von Papst Johannes Paul II. verbreitet wurden. ${ }^{26}$ Das Institut gab schließlich mit dem Dominikanerpater Konrad Hejmo $\left({ }^{\star} 1936\right)$ einen polnischen Mönch als Informationsquelle der Staatssicherheit an, der in Rom das offizielle Gästehaus für polnische Pilger geleitet hatte. Mit der Veröffentli-

eine Reihe öffentlicher Ämter vorsieht, falls der Anwärter bzw. Amtsinhaber über seine Kontakte zu den Staatssicherheitsdiensten nachweislich falsche Angaben gemacht hat.

24 Biskupi do Narodu [Die Bischöfe an das Volk].

25 Zum Beispiel Grajewski: Kompleks Judasza; Dudek / Gryz: Komuniści i Kościoł w Polsce (1945-1989).

26 Winnicka: Plamy na sutannach. Zum »Fall Pater Hejmo« und den anschließenden Debatten im und um das IPN vgl. auch Dudek: Instytut, 219-227. 
Söller, Gedenken - Mahnen - Aufarbeiten? Kirchen und kommunistische Vergangenheit

chung eines Buches über den Werdegang Karol Wojtyłas in den Berichten der polnischen Staatssicherheit erhielt die Diskussion um weitere Informanten im päpstlichen Umfeld im Folgejahr erneut Nahrung. ${ }^{27}$ Einen Höhepunkt in der öffentlichen Aufmerksamkeit in Polen erreichte die Thematik jedoch im Januar 2007, als der frisch gewählte Metropolit von Warschau, Erzbischof Stanisław Wielgus ( $\left.{ }^{*} 1939\right)$, zwei Tage nach seiner Amtsübernahme aufgrund seiner belasteten Vergangenheit von diesem Posten zurücktreten musste. ${ }^{28}$

Die Fälle von Verstrickungen polnischer Geistlicher mit der früheren Staatssicherheit führten zu einer zunehmenden Auseinandersetzung der Kirchen in Polen mit der volksrepublikanischen Vergangenheit. So richtete die katholische Kirche kirchliche Kommissionen in den Diözesen zur Aufarbeitung der Thematik ein. ${ }^{29}$ Am deutlichsten tat sich der katholische Priester Tadeusz Isakowicz-Zaleski ( $\left.{ }^{*} 1956\right)$ aus Krakau hervor, der sich öffentlich für eine transparent durchgeführte Lustration kirchlicher Würdenträger einsetzte, damit jedoch auch innerhalb der katholischen Kirche Kritik hervorrief. ${ }^{30}$ Dennoch veröffentlichte Isakowicz-Zaleski im Jahr 2007 unter dem Titel »Die Priester gegenüber der Stasi am Beispiel der Erzdiözese Krakau« ein einschlägiges Buch. ${ }^{31}$ Im Jahr 2010 wurde er durch das IPN mit dem Preis »Kustos des nationalen Gedächtnisses « für einen besonders aktiven Beitrag für die Erinnerung der polnischen Geschichte im Zeitraum 1939 bis 1989 ausgezeichnet. ${ }^{32}$

Die Bischofskonferenz der katholischen Kirche in Polen setzte sich nach dem »Fall Hejmo« gleich mehrfach mit der Thematik auseinander. Sie betonte in ihren Stellungnahmen einerseits, dass eine Verurteilung von Personen allein

27 Sadecki: Bezpieka nie dała rady Wojtyle; Wiśniewska: Wojtyła na muszcie bezpieki.

28 Veser: Die große Angst des Stanisław Wielgus; Czakowska: Czy arcybiskup współpracował z SB.

29 Królak: Erinnerung, Versöhnung, Zeugnis, 137.

30 Dudek: Instytut, 306.

31 Isakowicz-Zaleski: Księża wobec bezpieki na przykładzie archidiecezji krakowskiej.

32 Nagroda Kustosz Pamięci Narodowej. 
Söller, Gedenken - Mahnen - Aufarbeiten? Kirchen und kommunistische Vergangenheit

aufgrund von Informationen aus den Dokumentenbeständen der ehemaligen Staatssicherheitsdienste falsch sei und nicht vergessen werden dürfe, dass diese Materialien von Gegnern der Kirche erstellt worden seien. ${ }^{33}$ Die Funktionäre der Geheimdienste würden, so die Bischöfe, straffrei bleiben, während ihre Opfer öffentlich angeklagt würden. In einer Denkschrift, die sich explizit der Zusammenarbeit von Priestern mit den Organen der Staatssicherheit zwischen 1944 und 1989 widmete, betonte das polnische Episkopat jedoch auch, dass sich die Kirche nicht vor der Wahrheit fürchte, bezeichnete die »Zusammenarbeit mit den Feinden der Kirche" als Sünde und rief alle betroffenen Geistlichen zu Buße, Eingeständnis und Entschuldigung bei den Leidtragenden auf. ${ }^{34}$ Die aktuellen Erfahrungen sollten zu einer Erneuerung der Kirche und größerer Transparenz führen..$^{35}$ Die Bischofskonferenz unterstrich aber ebenso, dass die Kirche Licht auf die Helden der jüngsten Vergangenheit werfen solle, die verfolgt wurden und ihre Standhaftigkeit teilweise gar mit dem Leben bezahlt hätten. ${ }^{36}$ Die Idee einer polnischen »Kommission für Wahrheit und Versöhnung « (Komisja Prawdy i Pojednanie), die noch im Jahr 2005 von einigen führenden Geistlichen der katholischen Kirche in Polen vorangetrieben worden war und die kommunistische Vergangenheit unter veränderten Gesichtspunkten, nämlich außerhalb der Frage einer Lustration, aufarbeiten sollte, griff das Episkopat hingegen nicht mehr auf. ${ }^{37}$

33 Polnische Bischofskonferenz: Komunikat z 336. Zebrania Plenarnego Konferencji Episkopatu Polski.

$34 »[\ldots]$ współpraca z wrogami Kościoła [...]«, Memoriał Episkopatu Polski w sprawie współpracy niektórych duchownych z organami bezpieczeństwa w Polsce w latach 1944-1989.

35 Polnische Bischofskonferenz: Słowo Biskupów Polskich do wszystkich wiernych Kościoła w Polsce.

36 Memoriał Episkopatu Polski w sprawie współpracy niektórych duchownych z organami bezpieczeństwa w Polsce w latach 1944-1989.

37 Żakowski: UBerracja. Rozmowa z abp. Józefem Życińskim o Komisji Prawdy i Pojednania. 
Söller, Gedenken - Mahnen - Aufarbeiten? Kirchen und kommunistische Vergangenheit

Ab Herbst 2006 setzten sich schließlich eine eigens einberufene kirchliche historische Kommission sowie im Anschluss eine kirchliche Arbeitsgruppe zur ethisch-rechtlichen Bewertung mit den Dokumentenbestände des IPN bezüglich der damaligen polnischen katholischen Bischöfe auseinander und erklärten, einige von ihnen seien als geheime Mitarbeiter der Staatssicherheit registriert gewesen. ${ }^{38}$ Namen wurden jedoch nicht genannt, ein Bericht zu den Ergebnissen der Kommissionen wurde nicht veröffentlicht. Im Jahr 2008 schloss die Kommission ihre Tätigkeit ab und sandte ihre Schlussfolgerungen an den Heiligen Stuhl. Dieser habe festgestellt, so heißt es in einer Erklärung des Episkopates aus dem Jahr 2009, dass die polnischen Bischöfe »obwohl sie nicht dazu verpflichtet waren, sich mutig mit der kommunistischen Vergangenheit auseinandergesetzt « hätten. ${ }^{39}$ Der Vatikan habe ebenfalls betont, dass es keine Grundlage dafür gebe, den Mitgliedern des polnischen Episkopats eine »verschuldete und freiwillige Kooperation mit den Staatssicherheitsdiensten der Volksrepublik Polen « vorzuwerfen. ${ }^{40}$ Die Bischofskonferenz fällte daraufhin den Entschluss, die Angelegenheit als abgeschlossen zu betrachten und keine Stellungnahmen mehr zu Dokumenten der ehemaligen Staatssicherheitsdienste abzugeben. Diese Entscheidung rief umgehend auch kritische Stimmen hervor. ${ }^{41}$ Das Thema lasse sich nicht schließen, so der Priester Isakowicz-Zaleski, die Kirche gebe die Aufarbeitung somit lediglich an weltliche Forscher ab. ${ }^{42}$

38 Zum folgenden Absatz: Czakowska: Watykan: teczki SB to nie powód, by odwoływać hierarchów.

$39 »[$... ] mimo iż nie byli do tego zobowiązani, zmierzyli się odważnie z przeszłością okresu komunistycznego.« Episkopat Polski: Lustracja biskupów sprawą zamkniętą. Uwagi ks. Tadeusza Isakowicza-Zaleskiego.

$40 »[\ldots]$ zawinioną i dobrowolną współpracę ze służbami bezpieczeństwa PRL-u.« Episkopat Polski: Lustracja biskupów sprawą zamkniętą. Uwagi ks. Tadeusza Isakowicza-Zaleskiego.

41 Wiścicki: Biskupi nie zmierzyli się z przeszłością.

42 Episkopat Polski: Lustracja biskupów sprawą zamkniętą. Uwagi ks. Tadeusza Isakowicza-Zaleskiego. 
Söller, Gedenken - Mahnen - Aufarbeiten? Kirchen und kommunistische Vergangenheit

Auch für andere Kirchen in Polen war die Thematik mit dem Beschluss des katholischen Episkopats noch nicht beendet. So berief die Evangelisch-Augsburgische Kirche in Polen nach entsprechenden Medienberichten eine historische Kommission ein, welche feststellte, dass das geistliche Oberhaupt der Kirche als geheimer und bewusster Informant der Staatssicherheit tätig gewesen war. In Folge kürzte die Synode der Kirche dessen Amtszeit und beraumte die Wahl eines neuen Vorsitzenden an. ${ }^{43}$ In der Autokephalen Orthodoxen Kirche Polens führten umfassende Vorwürfe von Historikern aus dem IPN sowie von Journalisten an das Oberhaupt der Kirche, Bischof Sawa $\left({ }^{\star} 1938\right)$, er habe seit Mitte der Sechzigerjahre intensiv mit den Staatssicherheitsdiensten kooperiert, jedoch nicht zu dessen Abberufung oder Rücktritt. ${ }^{44}$ Der Bischof selbst wies in einem Zeitungsinterview die Vorwürfe zurück und schloss im Jahr 2009 die Einberufung einer Historischen Kommission mit dem Argument aus, dass man nicht in »Sünden Anderer herumwühlen« werde und »jeder sich selbst vor Gott verantworten« müsse. ${ }^{45}$

\section{Die ukrainischen Kirchen nach 1991 zwischen Kirchenkampf und Kooperation}

In der sich auflösenden Sowjetunion wurde der Frage nach einer Kollaboration von Geistlichen mit dem KGB im Vergleich zu Polen deutlich früher öffentliche Aufmerksamkeit zuteil als in Polen. Bereits im Jahr 1992 wurde über die Verbindungen hoher geistlicher Würdenträger der orthodoxen Kirche zum KGB berichtet, als kurzzeitig Akten des KGB unter anderem für eine Parlaments-

43 Bp Jagucki przyznał się do współpracy z SB, synod luteran skrócił jego kadencję.

44 Gmyz: Przeszłość arcybiskupa Sawy.

$45 »[\ldots]$ w cudzych grzechach grzebać nie będziemy, każdy odpowiada za siebie przed Bogiem. «Wiśniewska / Turnau: Gra z bezpieką o życie Cerkwi - rozmowa z abp Sawą.

DigiOst 3 | 358 
Söller, Gedenken - Mahnen - Aufarbeiten? Kirchen und kommunistische Vergangenheit

kommission geöffnet wurden. ${ }^{46}$ Mitglied der Kommission und Teilnehmer der Aktensichtung war dabei auch der Priester Gleb Jakunin $\left({ }^{\star} 1934\right)$. In der Folgezeit wurden verschiedene hochrangige Vertreter der orthodoxen Kirche beschuldigt, mit dem KGB kooperiert zu haben, und ihre Decknamen wurden veröffentlicht. Betroffen war unter anderem der damalige Kiever Metropolit der Russischen Orthodoxen Kirche, Filaret (Denysenko) $\left({ }^{*} 1929\right)$, der bald darauf aktiv das Projekt einer unabhängigen Ukrainischen Orthodoxen Kirche vorantrieb. ${ }^{47}$ Auch gegen Volodymyr Jarema (1915-2000), der 1993 zum Patriarchen der Ukrainischen Autokephalen Orthodoxen Kirche ernannt wurde, wurden Vorwürfe erhoben.$^{48}$ Die Frage einer Offenlegung persönlicher Verstrickungen hoher geistlicher Würdenträger fiel in dieser Zeit mit dem Kampf um die kirchliche Vorherrschaft in der Ukraine zusammen und wurde nach Meinung von Wissenschaftlern und Kommentatoren hierbei auch gezielt instrumentalisiert. ${ }^{49}$ Mit dem Abflauen der schärfsten zwischenkirchlichen Auseinandersetzungen in den folgenden Jahren wurde dem Thema einer Kollaboration von Geistlichen im sowjetischen System zunehmend weniger öffentliche Aufmerksamkeit zuteil. Das Patriarchat der Russischen Orthodoxen Kirche in Moskau hatte im Jahr 1992 zwar einen eigenen Untersuchungsausschuss zur Frage der Kooperation von Geistlichen mit dem KGB eingesetzt, dieser veröffentlichte jedoch keine Ergebnisse und wurde durch den eigenen Vorsitzenden als Farce bezeichnet. ${ }^{50}$ Im Gegenteil intervenierte die Kirche gezielt für einen Verschluss der KGBAkten. ${ }^{51}$ In der Ukraine löste in den Jahren 2006 bis 2009 auch die Debatte

46 Dunlop: The Russian Orthodox Church, 30f.; Armes: Chekists in Cassocks, 72ff.

47 Anderson: Religion, State and Politics, 189; Armes: Chekists in Cassocks, 76-77.

48 Bilokin: The Kiev Patriarchate, 197.

49 Ramet: Nihil Obstat, 255; Bilokin: The Kiev Patriarchate, 197; Losjev: Vladyka-deržavnyk: Pozycija Filareta vrjatuvala Kyïvs 'kyj patriarchat vid rozkolu $j$ rozčynennja $\mathrm{v} »$ Russkom mirje«.

50 Behrens: Die Russische Orthodoxe Kirche, 135ff.

51 Behrens: Die Russische Orthodoxe Kirche, 133ff.

DigiOst 3 | 359 
Söller, Gedenken - Mahnen - Aufarbeiten? Kirchen und kommunistische Vergangenheit

im Nachbarland Polen zur Kooperation von Geistlichen mit den ehemaligen Staatssicherheitsdiensten keine erneute umfassende Diskussion zum Thema aus. Wenn ukrainische Zeitungen die Entwicklungen in Polen erwähnten, geschah dies meist ohne Rückbezüge auf die möglichen Verstrickungen der Geistlichkeit im eigenen Land. ${ }^{52}$ Von Seiten der Ukrainischen Orthodoxen Kirche Kiever Patriarchats wird in öffentlichen Stellungnahmen aktuell vor allem darauf verwiesen, dass eine Zusammenarbeit mit dem KGB für die Geistlichen unvermeidlich gewesen sei. ${ }^{53}$

Der Allukrainische Rat der Kirchen und Religiösen Organisationen (Vseukrajins'ka Rada Cerkov i relihijnych orhanizacij, VRCiRO), der aus religiösen Führern der orthodoxen, griechisch-katholischen, römisch-katholischen, protestantischen, jüdischen und muslimischen Gemeinschaften besteht, positionierte sich in den vergangenen Jahren jedoch durchaus mit gemeinsamen Stellungnahmen zur nationalen Vergangenheit. So bekundeten die Religionsführer im Jahr 2010 ihre Sorge über » Versuche, die Verbrechen des Stalinismus $\mathrm{zu}$ vertuschen oder $\mathrm{zu}$ rechtfertigen " und erinnerten an die Verfolgung der Christen, die Verbannung in Konzentrationslager und die Erschießung von hunderttausenden Gläubigen sowie die Zerstörung von Kirchen und allem religiösen Erbe des ukrainischen Volkes, welche in der Zeit des autoritären bolschewistischen Regimes stattgefunden habe. ${ }^{54}$ Im Oktober 2012 folgte eine Erklärung des Rates, in welcher er unter dem Titel »Kenntnis der Vergangenheit - Weg in die Zukunft« noch einmal betonte, dass eine besondere Aufmerk-

52 Vgl. z. B. zum Fall Wielgus: Pop-skandal; Gudzyk: Ryms'kyj papa usuvaje archijepyskopa-agenta.

53 Trehub: Patriarch Filaret: „Za Kyïvs'kym patriarchatom stojat' mil'jony ljudej, jaki vže nikoly ne zachočut’ pidporjadkovuvatysja Moskvi«; Losjev: Vladyka-deržavnyk: Pozycija Filareta vrjatuvala Kyïvs'kyj patriarchat vid rozkolu j rozčynennja $\mathrm{v} »$ Russkom mirje«.

$54 »[\ldots]$ popytkach utait' ili opravdat' prestuplenija stalinizma.« Vseukrainskij Sovet Cerkvej i religioznych organizacij provel zasedanie. 
Söller, Gedenken - Mahnen - Aufarbeiten? Kirchen und kommunistische Vergangenheit

samkeit der tieferen Erforschung der tragischen Seiten der Geschichte des 20. Jahrhunderts und der Aufdeckung der Wahrheit über die Verbrechen der totalitären Regime in der Ukraine gelten solle. ${ }^{55}$ Insbesondere den Opfern des Holodomor, der stalinistischen politischen Repression, des Holocaust und der Zwangsdeportationen sollte gedacht werden. Aber auch Helden, die ihr eigenes Leben riskierten, um andere vor dem Tod zu bewahren, sollten erinnert werden. Die Ideologie und die Ausführer der Verbrechen von Nationalsozialismus und Stalinismus verurteilte der VRCiRO, wie er betonte, in gleichem Maße. Der Rat erinnerte somit zwar an die zweifelsohne dramatischen Ereignisse und die Repressionen unter Stalinismus und Nationalsozialismus, klammerte nachstalinistische und spätere Jahrzehnte jedoch aus. Die Begriffe »Sozialismus« oder »Kommunismus« fielen in Zusammenhang mit einem Gedenken der jüngsten ukrainischen Vergangenheit folglich nicht. Eher abstrakt blieben in den Äußerungen des Rates auch die Verantwortlichen für die genannten Verbrechen, die eine konkrete Benennung von Tätergruppen umgingen. Letztlich wurde auch auf mögliche Verstrickungen kirchlicher Institutionen oder einzelner Geistlicher in das vergangene System nicht eingegangen.

Die Restitution kirchlichen Eigentums stellte für die religiösen Gemeinschaften in der Ukraine hingegen ein gleichbleibend zentrales Thema dar. Diesbezügliche rechtliche Regelungen waren bereits im Jahr 1992 erlassen worden und sahen, im Gegensatz zu anderen Organisationen, für religiöse Gemeinschaften die Rückgabe von Immobilien vor, wenn es sich dabei um unmittelbar zum Gottesdienst eingesetzte Gebäude handelte. ${ }^{56} \mathrm{Im}$ Jahr 2010 erklärte das Staatskomitee für Nationalitäten und Religionen (Deržavnyj komitet u spravach nacional'nostej ta relihij), dass der Großteil der betroffenen

55 Deklaracija VRCiRO "Znannja mynuloho - šljach do majbutn’ho«.

56 Boeckh: Staat und Kirchen, 75f. Andere Gebäude, wie Schul- oder Gemeindehäuser, sind ausgenommen.

DigiOst 3 | 361 
Söller, Gedenken - Mahnen - Aufarbeiten? Kirchen und kommunistische Vergangenheit

Objekte bereits an die Religionsgemeinschaften zurückgegeben worden sei. ${ }^{57}$ Noch im Jahr 2012 forderten jedoch alle großen religiösen Organisationen die Regierung auf, ein transparentes rechtliches Verfahren einzuführen, um Restitutionsforderungen abzuwickeln. Der Großteil der Gemeinschaften betonte Probleme und Verzögerungen bei der Rückgabe von Objekten..$^{58}$ Der Anspruch verschiedener religiöser Gruppierungen auf die Restitution ein und derselben Objekte stellt dabei eine der Problematiken des Verfahrens dar. ${ }^{59}$ Die Streitigkeiten weisen aktuell zwar nicht mehr die Schärfe wie Anfang der Neunzigerjahre auf, sie sind teilweise jedoch nach wie vor nicht abschließend geklärt. ${ }^{60}$ Dennoch spricht der Großteil der religiösen Gemeinschaften gegenwärtig in der Frage der Restitution mit einer Stimme, beispielsweise wenn es sich um die Einführung eines Moratoriums bezüglich der Privatisierung von konfisziertem kirchlichem Eigentum dreht. Ab 2011 wandte sich der VRCiRO mit entsprechenden Forderungen an das ukrainische Parlament und an den damaligen Präsident Viktor Janukovyč. ${ }^{61}$

\section{Fazit: Die Kirchen nach dem Systemwechsel - Themen, Rollen, Strategien}

Die Kirchen in Polen und der Ukraine nahmen nach dem Systemwechsel mehrere Rollen in Bezug auf eine Auseinandersetzung mit dem vergangenen System ein.

57 Ukraine 2012 International Religious Freedom Report, 5.

58 Ukraine 2012 International Religious Freedom Report, 5; Boeckh: Staat und Kirchen, 75-76.

59 Ukraine 2012 International Religious Freedom Report, 5.

60 Bezüglich der Situation in den Neunzigerjahren vgl. Ramet: Nihil Obstat, 257ff. Zur aktuellen Lage vgl. Berežnaja: Der Kiewer Kirchenstreit.

61 Verchovnaja Rada otklonila zakonoproekt $\mathrm{o}$ moratorii na privatizaciju byvšich cerkovnych sooruženij. 
Söller, Gedenken - Mahnen - Aufarbeiten? Kirchen und kommunistische Vergangenheit

Sie traten als Opfer von Repression und Enteignung im Bereich der Restitution zum einen aktiv als fordernde Partei auf. Grundsätzlich wurde in beiden Ländern in den Jahren nach dem Systemwechsel in der Frage der Restitution kirchlichen Organisationen eine privilegierte Stellung zuteil, die sich in frühen rechtlichen Schritten von Seiten des Staates und somit einer Bevorzugung im Vergleich zu anderen Organisationen zeigt. In der Restitutionspraxis konnten die großen Kirchen in beiden Ländern tendenziell eine bessere Position einnehmen als kleinere Gemeinschaften. In Polen nahm die katholische Kirche offenbar gar Intransparenz und Bevorteilung in Kauf, was nach über zwei Jahrzehnten der Restitutionspraxis in einem Skandal endete. In der Ukraine werden einstimmige Forderungen von Vertretern unterschiedlicher Glaubensgemeinschaften nach einem schnelleren und transparenten Verfahren von Streitigkeiten um konkrete Immobilien auf lokaler Ebene begleitet. Entsprechende Konflikte erreichen momentan jedoch nicht mehr die Heftigkeit der Neunzigerjahre.

Die Kirchen in Polen und der Ukraine treten in Bezug auf eine Auseinandersetzung mit der jüngsten nationalen Vergangenheit überdies als Mahner in Erscheinung. In der Ukraine sprechen die Kirchen und religiösen Gemeinschaften in dieser Hinsicht mit einer gemeinsamen Stimme und weisen in Bezug auf Stalinismus, Holodomor und Holocaust auch auf die zahlreichen Opfer der Kirchen und ihrer Gläubigen hin. Heroisches Verhalten einzelner Personen wird in diesem Zusammenhang ebenfalls erwähnt, es überwiegt jedoch deutlich der Aufruf zum Gedenken an die begangenen Verbrechen und ihre Opfer. Hinweise auf eine Verstrickung von Kirchen und Geistlichen in das System und eine nähere Thematisierung auch der nachstalinistischen Periode fehlen hingegen völlig. Falls eine Kooperation von Geistlichen durch einzelne Kirche angesprochen wird, scheint eine Relativierung dieser Zusammenarbeit vorzuherrschen. Obwohl in der Ukraine und der zerfallenden Sowjetunion Debatten um die persönlichen Verstrickungen orthodoxer Geistlicher bereits Anfang der Neunzigerjahre aufflammten, wurde das Thema danach schnell ad acta gelegt. Personelle Konsequenzen gab es nicht.

DigiOst 3 | 363 
Söller, Gedenken - Mahnen - Aufarbeiten? Kirchen und kommunistische Vergangenheit

Auch die Kirchen in Polen traten in Bezug auf die Aufarbeitung der polnischen volksrepublikanischen Vergangenheit als Mahner auf. Insbesondere die katholische Kirche Polens äußerte sich bereits früh mit einem Aufruf zur aktiven Auseinandersetzung mit Verantwortung und Schuld. Mit der Thematik der Kollaboration in den eigenen Reihen mussten sich die Kirchen in Polen im Vergleich zur Ukraine zwar später, dann jedoch umso extensiver befassen. Als größte polnische kirchliche Institution, die auch in der Volksrepublik Polen eine exponierte Stellung eingenommen hatte, stand hier bald die katholische Kirche im Fokus der öffentlichen und medialen Aufmerksamkeit. Sie agierte dabei nicht in erster Linie aus eigenem Antrieb heraus, sondern vor allem in Reaktion auf skandalträchtige Enthüllungen durch Journalisten und das polnische Institut für Nationales Gedenken. Wie in der zerfallenden Sowjetunion verschrieben sich lediglich einzelne Geistliche einer aktiven Aufarbeitung der kirchlichen Vergangenheit. Die Debatte zur Verstrickung von Kirchenvertretern in das System sprang im Anschluss auch auf weitere polnische Glaubensgemeinschaften über, die sich in unterschiedlichem Maße mit der Thematik auseinandersetzten. Die Strategie der katholischen Kirche umfasste in Reaktion auf die Enthüllungen sowohl die Betonung der Opfer- als auch der Heldenrolle der Kirche im kommunistischen System sowie die klare Verurteilung des Regimes und der Kollaboration durch einzelne Geistliche. Sie äußerte sich umfassend zur Thematik, richtete, wie die Evangelisch-Augsburgische Kirche in Polen, Kommissionen ein und zog schließlich auch einzelne personelle Konsequenzen. Angesichts der angekündigten Erneuerung der Kirche musste die recht kurze Arbeit der zentralen katholischen Kirchenkommission, das anschließende Unterverschlusshalten ihrer Berichte und das Ausbleiben weiterer personeller Veränderungen jedoch manche Erwartungen enttäuschen.

Die Debatten in Polen und der Ukraine um die Position der Kirchen in Stalinismus und Kommunismus zeigen sich folglich als Teil der allgemeinen Diskussion um eine Aufarbeitung der Vergangenheit im jeweiligen Land. Vor dem Hintergrund von Lustration und Aktenöffnung wurden die Kirchen Polens 
Söller, Gedenken - Mahnen - Aufarbeiten? Kirchen und kommunistische Vergangenheit

deutlich vehementer dazu gedrängt, sich offen in Bezug auf institutionelle und individuelle Verstrickungen in der Vergangenheit zu positionieren. Obwohl die Thematik in der Ukraine früher aufflammte, wurde der Frage angesichts einer allgemeinen Zurückhaltung in Bezug auf die Vergangenheit von Persönlichkeiten des öffentlichen Lebens im Anschluss kaum noch umfassende Aufmerksamkeit zuteil. Auch die polnische Debatte, die durchaus in der Ukraine wahrgenommen wurde, konnte offenbar keine erneute umfassendere inner-ukrainische Diskussion zum Thema auslösen. In Polen ist es nur eine Frage der Zeit, bis angesichts der steten weiteren Forschung in den Dokumentenbeständen der ehemaligen Staatssicherheitsdienste Enthüllungen zu einzelnen Geistlichen erneut über Wissenschaft oder Publizistik an die Öffentlichkeit gelangen. In der Ukraine wurden in den vergangenen Jahren über aktuelle Nachrichtendienste zwar Aktenbestände der ehemaligen Staatssicherheitsdienste freigegeben, eine umfassende Erforschung ist angesichts weiterhin bestehender Beschränkungen in nächster Zeit jedoch schwieriger. Ein aktiv durch die Kirchen betriebener personeller Wechsel scheint dennoch in beiden Ländern größtenteils ausgeschlossen. Die Strategie der meisten beteiligten Kirchen und Religionsgemeinschaften in der Ukraine und in Polen in Bezug auf Verstrickungen von Geistlichen in das vergangene System scheint momentan ein abwartendes Schweigen zu sein.

\section{Literatur}

Anderson, John: Religion, State and Politics in the Soviet Union and Successor States. Cambridge 1994.

Armes, Keith: Chekists in Cassocks. The Orthodox Church and the KGB. In: Demokratisatsiya 4/1993, 72-83.

Behrens, Kathrin: Die Russische Orthodoxe Kirche: Segen für die »neuen Zaren«? Religion und Politik im postsowjetischen Rußland (1991-2000). Paderborn 2002. 
Söller, Gedenken - Mahnen - Aufarbeiten? Kirchen und kommunistische Vergangenheit

Berežnaja, Lilija: Der Kiewer Kirchenstreit. »Erinnerungsorte« der Konfessionen. In: Osteuropa 6/2009, 171-188.

Bilokin, Serhiy: The Kiev Patriarchate and the State. In: Bourdeaux, Michael (Hg.): The Politics of Religion in Russia and the New States of Eurasia. Armonk 1995, 182-201.

Bingen, Dieter: Die Aufarbeitung der kommunistischen Vergangenheit in Polen. In: Unverhau, Dagmar (Hg.): Lustration, Aktenöffnung, demokratischer Umbruch in Polen, Tschechien, der Slowakei und Ungarn. Münster 2005, 57-99.

Biskupi do Narodu [Die Bischöfe an das Volk]. In: Gazeta Wyborcza. Nr. 145, 22.06.1992, 3 .

Biskupi: zarzuty wobec komisji niesprawiedliwe [Bischöfe: Die Vorwürfe gegen die Kommission sind ungerecht]. In: Rzeczpospolita, 30.09.2012, unter: http://www.rp.pl/artykul/542757-Biskupi--zarzuty-wobec-komisjiniesprawiedliwe.html (14.11.2013).

Boeckh, Katrin: Staat und Kirchen während der Transformation in der Ukraine. In: Bremer, Thomas (Hg.): Religion und Nation. Die Situation der Kirchen in der Ukraine. Wiesbaden 2003, 67-89.

Boeckh, Katrin: "Liberalisierung « und Repression. Zur Praxis der Religionspolitik in der Ukraine während NS-Besatzung und stalinistischer Herrschaft 1941-1953. In: Gevers, Lieve / Bank, Jan (Hgg.): Religion under Siege. Protestant, Orthodox and Muslim Communities in Occupied Europe (1939-1950). Leuven, Paris, Dudley 2007, 119-174.

Bp Jagucki przyznał się do współpracy z SB, synod luteran skrócił jego kadencję [Bischof Jagucki bekannte sich zur Zusammenarbeit mit der Stasi, die lutherische Synode kürzte seine Amtszeit]. In: Gazeta.pl, 19.04.2009, unter http://wiadomosci.gazeta.pl/wiadomosci/1,114873,6514063,Bp_Jagucki_ przyznal_sie_do_wspolpracy_z_SB__synod.html (10.11.2013).

Czakowska, Ewa K.: Czy arcybiskup współpracował z SB [Arbeitete der Erzbischof mit der Stasi zusammen]. In: Rzeczpospolita, Nr. 296, 20.12.2006, 1. 
Söller, Gedenken - Mahnen - Aufarbeiten? Kirchen und kommunistische Vergangenheit

Czakowska, Ewa K.: Watykan: teczki SB to nie powód, by odwoływać hierarchów [Vatikan: Stasi-Dossiers sind kein Grund, die Kirchenoberen abzuberufen]. In: Rzeczpospolita, 14.01.2009, unter http://www.rp.pl/artykul/247960Watykan-teczki-SB-to-nie-powod-by-odwolywac-hierarchow-.html (14.11.2013).

Deklaracija VRCiRO »Znannja mynuloho - šljach do majbutn’oho« [Erklärung des VRCiRO »Kenntnis der Vergangenheit - Weg in die Zukunft«]. In: Vseukrajins'ka Rada Cerkov i religijnych organizacij [Allukrainischer Rat der Kirchen und Religiösen Organisationen], 03.10.2012, unter http:// vrciro.org.ua/index.php?option=com_content\&task=view\&id=182\&Item $\mathrm{id}=1$ (10.11.2013).

Dudek, Antoni: Ślady PeeReLu. Ludzie, wydarzenia, mechanizmy [Spuren der Volksrepublik. Menschen, Ereignisse, Mechanismen]. Krakau 2005.

Dudek, Antoni: Instytut. Osobista historia IPN [Das Institut. Eine persönliche Geschichte des IPN]. Warschau 2011.

Dudek, Antoni / Gryz, Ryszard: Komuniści i Kościoł w Polsce (1945-1989) [Die Kommunisten und die Kirche in Polen (1945-1989)]. Krakau 2003.

Dunlop, John B.: The Russian Orthodox Church as an "Empire-Saving " Institution. In: Bourdeaux, Michael (Hg.): The Politics of Religion in Russia and the new States of Eurasia. Armonk 1995, 15-40.

Episkopat Polski: Lustracja biskupów sprawą zamkniętą. Uwagi ks. Tadeusza Isakowicza-Zaleskiego [Polnisches Episkopat: Lustration der Bischöfe ist abgeschlossen. Bemerkungen von Priester Tadeusz Isakowicz-Zaleski]. In: Bibuła. Pismo niezależne, 12.03.2009, unter http://www.bibula. $\mathrm{com} / ? \mathrm{p}=7641(10.11 .2013)$.

Gmyz, Cezary: Przeszłość arcybiskupa Sawy [Die Vergangenheit von Erzbischof Sawa]. In: Rzeczpospolita, 13.01.2009, unter http://www.rp.pl/ artykul/247370.html (10.11.2013).

Grajewski, Andrzej: Kompleks Judasza. Kościół zraniony. Chrześcijanie w Europie Środkowo-Wschodniej między oporem a kolaboracją [Der Judas-Kom- 
Söller, Gedenken - Mahnen - Aufarbeiten? Kirchen und kommunistische Vergangenheit

plex. Die verletzte Kirche. Christen in Ostmitteleuropa zwischen Widerstand und Kollaboration]. Posen 1999.

Gudzyk, Klara: Ryms'kyj papa usuvaje archijepyskopa-agenta [Der Papst in Rom entfernt Erzbischof-Agenten]. In: Den', 10.01.2007, unter http://www. day.kiev.ua/uk/article/cuspilstvo/cerkvi-svitu-63 (10.11.2013).

Heyer, Friedrich: Kirchengeschichte der Ukraine im 20. Jahrhundert. Göttingen 2003.

Isakowicz-Zaleski, Tadeusz: Księża wobec bezpieki na przykładzie archidiecezji krakowskiej. Krakau 2007.

Koniec Komisji Majątkowej [Ende der Eigentumskommission]. In: Rzeczpospolita, 30.11.2010, unter http://www.rp.pl/artykul/571685-Koniec-KomisjiMajatkowej.html (14.11.2013).

Królak, Tomasz: Erinnerung, Versöhnung, Zeugnis. Kirchliche Lustration im freien Polen. In: Osteuropa 6/2009, 129-144.

Losjev, Ihor: Vladyka-deržavnyk: Pozycija Filareta vrjatuvala Kyïvs'kyj patriarchat vid rozkolu j rozčynennja v »Russkom mirje« [Patriarch und Staatsmann. Die Position Filarets rettete das Kiever Patriarchat vor einem Schisma und der Auflösung in der »Russischen Welt»]. In: Tyžden', 09.07.2012, unter http://tyzhden.ua/Society/53978 (18.11.2013).

Memoriał Episkopatu Polski w sprawie współpracy niektórych duchownych z organami bezpieczeństwa w Polsce w latach 1944-1989 [Denkschrift des Polnischen Episkopats zur Zusammenarbeit einiger Geistlicher mit Sicherheitsorganen in Polen zwischen 1944 und 1989]. In: opoka.org.pl, 25.8.2006, unter http://www.opoka.org.pl/biblioteka/W/WE/kep/memorial_25082006. html (10.11.2013).

Nagroda Kustosz Pamięci Narodowej [Preis Kustos des Nationalen Gedächtnisses]. In: Instytut Pamięci Narodowej [Institut für Nationales Gedenken], 2013, unter http://ipn.gov.pl/o-ipn/nagroda-kustosz-pamieci-narodowej (13.10.2013). 
Söller, Gedenken - Mahnen - Aufarbeiten? Kirchen und kommunistische Vergangenheit

Nieruchomości kościołów i innych związków wyznaniowych [Immobilien von Kirchen und anderen Glaubensgemeinschaften]. In: Restytucja mienia w Polsce. Portal informacyjny [Eigentumsrestitution in Polen. Informationsportal], 2012, unter http://propertyrestitution.pl/Restytucja,mienia,po,rok u,1989, regulacje,prawne,11.html\#nieruchomosci_kosciolow (10.11.2013).

Pietraszewski, Marcin: Komisja majątkowa - skrywany raport rządu: Kościołowi ile się da [Die Eigentumskommission - der verheimlichte Regierungsbericht: Der Kirche soviel wie geht]. In: Gazeta Wyborcza, 17.02.2012, unter http://wyborcza.pl/1,76842,11164181,Komisja_majatkowa__skrywany_ raport_rzadu_Kosciolowi.html (10.11.2013).

Polnische Bischofskonferenz: Komunikat z 336. Zebrania Plenarnego Konferencji Episkopatu Polski [Kommunikat der 336. Plenarversammlung der Konferenz des Polnischen Episkopats]. In: Konferencja Episkopatu Polski [Konferenz des Polnischen Episkopats], 25.06.2006, unter http://episkopat. pl/dokumenty/komunikaty_zp_kep/4779.1,Komunikat_z_336_Zebrania_ Plenarnego_Konferencji_Episkopatu_Polski.html (10.11.2013).

Polnische Bischofskonferenz: Słowo Biskupów Polskich do wszystkich wiernych Kościoła w Polsce [Worte der Bischofskonferenz an alle Gläubigen der Kirche in Polen]. In: Konferencja Episkopatu Polski [Konferenz des Polnischen Episkopats], 12.01.2007, unter http://episkopat.pl/dokumenty/listy_ pasterskie/4494.1,Slowo_Biskupow_Polskich_do_wszystkich_wiernych_ Kosciola_w_Polsce.html (10.11.2013).

Pop-skandal [Pfaffen-Skandal]. In: Korrespondent, 11.1.2007, 8.

Ramet, Sabrina P.: Nihil Obstat. Religion, Politics, and Social Change in East-Central Europe and Russia. Durham, London 1998.

Rogojsz, Łukasz: Komisja Majątkowa. Nadal bezkarna [Eigentumskommission weiterhin straffrei]. In: Newsweek, 26.08.2012, unter http://polska. newsweek.pl/komisja-majatkowa--nadal-bezkarna,102848,1,1.html (10.11.2013). 
Söller, Gedenken - Mahnen - Aufarbeiten? Kirchen und kommunistische Vergangenheit

Sadecki, Jerzy: Bezpieka nie dała rady Wojtyle [Die Stasi kam mit Wojtyła nicht zu Rande]. In: Rzeczpospolita, 17.03.2006, 5.

Trehub, Hanna: Patriarch Filaret: »Za Kyïvs'kym patriarchatom stojat' mil'jony ljudej, jaki vže nikoly ne zachočut’ pidporjadkovuvatysja Moskvi« [Patriarch Filaret: »Hinter dem Kiever Patriarchat stehen Millionen Menschen, die sich alle nie Moskau unterordnen wollen «]. In: Tyžden’, 10.07.2012, unter http://tyzhden.ua/Society/53980 (10.11.2013).

Ukraine 2012 International Religious Freedom Report. In: U.S. Department of State, unter http://www.state.gov/documents/organization/208590.pdf (10.11.2013).

Verchovnaja Rada otklonila zakonoproekt o moratorii na privatizaciju byvšich cerkovnych sooruženij [Das Parlament lehnte Gesetzesprojekt über ein Moratorium zur Privatisierung ehemaliger kirchlicher Gebäude ab]. In: Vseukrajins'ka Rada Cerkov i religijnych organizacij [Allukrainischer Rat der Kirchen und Religiösen Organisationen], 30.06.2011, unter http://vrciro. org.ua/index.php?option $=$ com_content $\&$ task=view\&lang $=$ ru\&id $=156$ (10.11.2013).

Veser, Reinhard: Die große Angst des Stanisław Wielgus. In: Frankfurter Allgemeine Zeitung, 05.01.2007, Nr. 4, 3.

Vseukrainskij Sovet Cerkvej i religioznych organizacij provel zasedanie [Der Allukrainische Rat der Kirchen und Religiösen Organisationen traf sich zur Sitzung]. In: Vseukrajins'ka Rada Cerkov i religijnych organizacij [Allukrainischer Rat der Kirchen und Religiösen Organisationen], 29.04.2010, unter http://vrciro.org.ua/index.php?option=com_content\&task=view\&la ng=ru\&id=132 (10.11.2013).

Vulpius, Ricarda: »Inseln der Autonomie beseitigen«. Kirchenverfolgung und Holodomor. In: Osteuropa 12/2004, 72-89.

Winnicka, Ewa: Plamy na sutannach [Flecken auf den Sutanen]. In: Polityka, Nr. 18, 07.05.2005, 20. 
Söller, Gedenken - Mahnen - Aufarbeiten? Kirchen und kommunistische Vergangenheit

Wiścicki, Tomasz: Biskupi nie zmierzyli się z przeszłością [Die Bischöfe setzten sich nicht mit der Vergangenheit auseinander]. In: Rzeczpospolita, 22.03.2009, unter http://www.rp.pl/artykul/280203-Biskupi-nie-zmierzylisie-z-przeszloscia.html? p=3 (14.11.2013).

Wiśniewska, Katarzyna / Turnau, Jan: Gra z bezpieką o życie Cerkwi - rozmowa $\mathrm{z}$ abp Sawą [Spiel mit der Stasi um das Leben der Kirche - Gespräch mit Erzbischof Sawa]. In: Gazeta Wyborcza, 03.01.2009, unter http://wyborcza. pl/1,88473,6116478,Gra_z_bezpieka_o_zycie_Cerkwi__rozmowa_z_abp_ Sawa.html (10.11.2013).

Wiśniewska, Katarzyna: Wojtyła na muszcie bezpieki [Wojtyła im Visier der Stasi]. In: Gazeta Wyborcza, 11./12.03.2006, 25.

Żakowski, Jacek: UBerracja. Rozmowa z abp. Józefem Życińskim o Komisji Prawdy i Pojednania [Stasimanie. Ein Gespräch mit Erzbischof Józef Życiński über die Kommission für Wahrheit und Versöhnung]. In: Polityka, Nr. 24, 18.06.2005, 24-27.

\section{Abstract}

\section{Carola Söller}

Remembrance, Admonishing, Coping with the Past? Churches and the Communist Past in Ukraine and Poland

Since the beginning of the 1990s, debates around how to cope with the communist past have taken place in many Central and Eastern European countries. A crucial issue in these disputes has always been the question of responsibility and of identifying perpetrators, victims, and heroes. This essay highlights the main arguments in the public debate on the churches' past in Ukraine and in Poland. By comparing the two countries, the article stresses the strategies religious communities in both countries used. As victims of the former systems, 
Söller, Gedenken - Mahnen - Aufarbeiten? Kirchen und kommunistische Vergangenheit

churches actively demanded restitution. As admonishers, they called for coping with the past. Nevertheless, the entanglement of the church as an institution and of single clerics in the communist system was not actively dealt with. Although harsh public debates in Poland led to the creation of ecclesiastic historical commissions investigating the past of single priests, later on most churches did not execute further punishments and even declared the issue closed. The debate is very unlikely to end, however. In Ukraine, public discussion of the past of often high-level clerics started earlier than in Poland; it was connected to churches' struggle for predominance in the early 1990s. With the weakening of the conflict, however, the topic was not again raised comprehensively. The current dominant strategy of most churches in both countries concerning individual guilt in their own ranks seems to be one of silence. 
Religiöse Minderheiten und religiöse Kultur 
Katrin Boeckh - 978-3-86688-505-9 


\section{Viktoria Lyubashchenko}

\section{Die Rolle der protestantischen Kirchen im religiösen und politischen Leben der Ukraine}

Bei einer kontinuierlichen Beobachtung des Protestantismus in der Ukraine konnte man noch vor zehn Jahren ziemlich optimistisch seine quantitative und qualitative Dynamik einschätzen, in der Gegenwart ist aber eine vorsichtigere Kommentierung anzuraten. Einige Bemerkungen zu Quantität und Qualität seien vorangestellt: Der Status einer Religion in einem Land wird erstens durch die Anzahl der Gläubigen definiert. Experten weisen beispielsweise heute nicht ohne Grund auf den Zuwachs der muslimischen Bevölkerung in Russland hin und sehen darin für das Moskauer Patriarchat beunruhigende Veränderungen. Zweitens wird die Rolle einer Religion - und das ist viel wichtiger - dadurch definiert, wie sie die nationalen und geschichtlich-kulturellen Traditionen ihrer Mitglieder repräsentiert, sowie durch ihr geistiges Potential und den tatsächlichen Einfluss auf die gesellschaftlichen und politischen Prozesse. Der Protestantismus hat in der Ukraine im Gegensatz zur Orthodoxie und zum Katholizismus beider Riten immer bescheidene Anhängerzahlen aufgewiesen und ein durch Qualität, nicht durch Quantität geprägtes Erscheinungsbild in der Gesellschaft angestrebt. Dies bezieht sich vor allem auf verschiedene Anpassungsformen des Protestantismus an den kulturellen, gesellschaftlichen und politischen Kontext des Landes. Hier stellt sich aber sofort die Frage: Kann sich eine Religion in einem Land wirklich nur durch ihr inneres Potential (Doktrin, Missionare, Philanthropie) ohne Unterstützung der Machtstrukturen oder herrschender Eliten durchsetzen und eine Perspektive ohne ständige Selbsterneuerung dieses Potentials erreichen?

Der Protestantismus in der Ukraine, dessen Geschichte eigentlich mit der europäischen Reformation beginnt, konnte sich nicht selten einer Unterstützung »von oben« erfreuen und zeigte bemerkenswerte Anpassungsfähigkeiten. 
Lyubashchenko, Die Rolle der protestantischen Kirchen

Im 16. und 17. Jahrhundert wurden die protestantischen Strömungen, vor allem Kalvinismus und Sozinianismus, von den Eliten entdeckt, die in diesem neuen Glauben die Möglichkeit sahen, ihre eigenen Interessen durchzusetzen: Polnische Magnaten und Adel wollten in ihrer Konfrontation mit dem König ihre Freiheiten sichern, und für ukrainische weltliche Eliten ging es um die Wahrung ihrer wirtschaftlichen und politischen Rechte in der Rzeczpospolita. Laut dem ukrainischen Historiker Orest Levyc'kyj drangen die Protestanten bis zur Mitte des 17. Jahrhunderts vom polnisch-ukrainischen Grenzland tief in das Kiever Land ein, wo es unter der lokalen Szlachta "so viele Anhänger der Sekte gab, dass sie manchmal die Provinzsejme füllten und hier die dominierende Partei waren ${ }^{1}{ }^{1}$ Nicht nur der Glaube, sondern vielmehr der elitäre Charakter des damaligen Protestantismus und das Vermögen seiner Oberschicht gefährdeten diese Konfession in der Zeit der Chmel'nyc'kyj-Aufstände und der polnischen Reaktion. Deswegen konnten weder ihr Streben, sich in die kulturellen und Bildungsprozesse zu integrieren, noch ihr Liebäugeln mit den gesellschaftlichen Eliten und den Kosaken die Protestanten vor den durch diskriminierende Glaubensgesetze gerechtfertigten Verfolgungen und Enteignungen schützen.

Im 18. und 19. Jahrhundert ermöglichten die Dekrete von Katharina II., die deutschen Kolonisten bedeutsame Privilegien gewährten, den Protestanten in der Ukraine eine neue, vor allem wirtschaftliche Nische zu finden, indem sie auf Zuspruch bei ukrainischen Wirten und Kleinunternehmern stießen. Die Reformen des russischen Premierministers Stolypin (1906-1911) öffneten neue Chancen für das Entstehen einer ukrainischen »Mittelschicht«, deren religiösen Typen der deutsche Soziologe Max Weber eindrucksvoll schilderte.

Das sowjetische System löschte das wirtschaftliche und politische Potential des Protestantismus aus und entzog ihm sowohl die politische wie auch die gesellschaftliche und moralische Unterstützung. Das führte zu einer allmählichen

1 Левицкий: Социнианство в Польше и Юго-Западной Руси в XVI-XVII вв. Кн. 6, 406. 
Lyubashchenko, Die Rolle der protestantischen Kirchen

Neuordnung der Konfession. Das kirchliche Segment, etwa die Lutherische Kirche und der Calvinismus, wurden fast vollständig zurückgedrängt und durch radikale Strömungen wie Baptismus, Pfingstbewegung und Adventismus ersetzt. Diese Strömungen konnten im Untergrund besser überleben; sie betrachten das Märtyrertum als Zeugnis für die Wahrhaftigkeit und Heiligkeit der Evangelischen Kirche. Die Verfolgungen verliehen dieser Konfession deswegen neue Impulse.

In den 1990er Jahren führten diese Impulse nach den politischen Veränderungen in der Ukraine zu einem Durchbruch. Das schnelle Wachstum der Anzahl der Protestanten, teilweise auch dadurch bedingt, dass die Gemeinden den Untergrund verlassen hatten und aktiv von ausländischen Missionen unterstützt wurden, die schnellstmöglich die internationale Isolierung ihrer Mitgläubigen aufbrechen wollten, verleitete einige Beobachter dazu, dem ukrainischen Bürger das Gespenst einer möglichen "Protestantisierung" an die Wand zu malen. ${ }^{2}$ Ähnliche Prognosen findet man auch heute in einigen Kommentaren zu den Jahresberichten des Staatskomitees für Nationalitäten

2 Laut Oleksander Sahan sind »30 Prozent der religiösen Organisationen protestantische Gemeinden, so findet der Protestantismus eine immer größere Verbreitung in der Ukraine« (В Украине протестанты постепенно вытесняют православных: http://ua.proua.com/news/2009/02/12/081821). Ihm pflichtet Anatolij Kolodnyj bei; nach seiner Schätzung stellen die drei orthodoxen Kirchen 50,2 Prozent der Gemeinden, und nur 36 bis 48 Prozent der Befragten halten sich für orthodoxe Christen. Laut Kolodnyj ist die Ukraine also »kein orthodoxes Land, wie das einige darstellen wollen, sondern ein Land mit der dominierenden orthodoxen Konfession« (Релігійна мережа в Україні на січень 2009 року: http://ukreligieznavstvo. wordpress.com/2009/03/15/релігійна-мережа-україни-на-січень-2009-p/). Die These einer »Protestantisierung « wird seit langem vertreten, siehe u.a. Феномен української культури, 56; Релігія і влада в Україні: розвиток правових засад взаємовідносин, 9-10; Політика і культура, № 16, 22-27; Колодний: Християнство за умов глобалізації, 302-311; Титаренко: П’ятидесятниця та витоки нового християнського руху. Частина друга. П’ятдесятництво в Україні: www.religion.in.ua/main/analitica/595-pyatdesyatnictvo-v-ukrayini.html.

DigiOst 3 | 377 
Lyubashchenko, Die Rolle der protestantischen Kirchen

und Religionen der Ukraine. In der Regel werden in diesen Kommentaren aber jeweils nur zwei Jahre miteinander verglichen.

Allerdings sprechen die Zahlen zur Situation der letzten 15 Jahre eine andere Sprache. Der größte unter den protestantischen Kirchen, der Gesamtukrainische Verband der Evangeliumschristen-Baptisten, war von 1997 bis 2002 um 572 Gemeinden gewachsen, ${ }^{3}$ in den nächsten fünf Jahren um 190 und in den letzten vier Jahren lediglich um 30. Die Zuwächse beim Gesamtukrainischen Kirchenverband der evangelischen Christen der Pfingstbewegung betrugen im selben Zeitraum 266, 86 bzw. 56 Gemeinden. Auch das Wachstum bei der Ukrainischen Union der Adventisten des Siebten Tages verlangsamte sich: 298, 81 und 21 Gemeinden im selben Zeitraum. Die Anzahl der Gemeinden der Christuskirche hatte sich zwischen 1998 und 2008 fast verdoppelt, in den letzten fünf Jahren kamen jedoch nur fünf neue Gemeinden dazu. Die Neuapostolische Kirche ließ seit 2004 keine einzige neue Gemeinde eintragen.

Ein zögerliches Wachstum kann im Protestantismus der kirchlichen Tradition festgestellt werden. Bis vor kurzem ist die Reformatorische Kirche in Transkarpatien jedes Jahr um eine bis zwei Gemeinden gewachsen, seit 2009 gibt es hier kein Wachstum mehr. Von 1997 bis 2008 gab es keine neuen Gemeinden in der Deutschen Evangelisch-Lutherischen Kirche, seit 2010 wurden hier zwei neue Pfarreien registriert. Die Ukrainische Lutherische Kirche ließ von 2004 bis 2008 ebenfalls nur zwei Gemeinden registrieren, in den letzten drei Jahren kam keine weitere dazu. Die Presbyterianer konnten von 2007 bis 2010 einige neue Gemeinden gründen, ein Jahr später ging aber die Zahl der Gemeinden auf den alten Stand wieder zurück.

3 Die Zahlen in diesem Beitrag wurden den Berichten über die Kirchen und religiöse Organisationen in der Ukraine des Staatskomitees für Religionen (1997-2002) und des Staatskomitees für Nationalitäten und Religionen (2008-2012) entnommen. Berücksichtigt wurden nur offiziell registrierte religiöse Organisationen. 
Lyubashchenko, Die Rolle der protestantischen Kirchen

Nur die charismatischen Bewegungen konnten sich aktiv entwickeln, wenn auch nicht mehr so stark wie früher. Die Evangeliumskirche wuchs von 1997 bis 2002 um über 70 Prozent, von 2004 bis 2008 um 32 Prozent, und in den letzten drei Jahren nur um 20 Prozent.

Es ist ganz offensichtlich, dass der Protestantismus in der Ukraine die Dynamik der 1990er Jahre eingebüßt hat. Zwar nimmt die Zahl der Gemeinden weiterhin zu, wenn aber von 1985 bis 1995 der Zuwachs der protestantischen Gemeinden 7,1 Prozent betrug, so lag er im Zeitraum von 1997 bis 2008 bei nur 3 Prozent. 2009 machte der Anteil der Protestanten an der Gesamtzahl der religiösen Gemeinschaften 27,6 Prozent aus, 2011 lag er bei 27,3, und 2012 bei 27,1 Prozent. ${ }^{4}$ Auf dem Missionarskongress des Gesamtukrainischen Verbandes der Evangeliumschristen-Baptisten, der im Sommer 2013 in Chmel'nyc'kyj stattfand, wurde betont, dass im Jahr 2012 in 1.145 Gemeinden, also in knapp 40 Prozent von deren Gesamtzahl, keine Taufe gespendet wurde. ${ }^{5}$

Dabei weisen die Statistiken für die Orthodoxen und Katholiken allmählich steigende Zahlen auf. In den Jahren 2008-2009 betrug der Zuwachs der protestantischen Gemeinden nur noch 1,8 Prozent, für die drei orthodoxen Kirchen lag das Wachstum dagegen bei 4,6 Prozent, und für die Römisch-Katholische Kirche bei 15,8 Prozent. 2009 bis 2011 gründeten die orthodoxen Kirchen, die Römisch-Katholische und die Griechisch-Katholische Kirche in der Ukraine zusammen 1.407 Pfarreien, alle Protestanten dagegen nur 410. Wenn die Orthodoxen 2009 noch 53,2 Prozent der Religionsgemeinden stellten, lag ihr Anteil im Jahr 2012 bereits bei 54 Prozent. Die Katholiken beider

4 Eine ausführlichere Analyse des protestantischen Umfeldes in der Ukraine in den letzten fünfzehn Jahren findet man in: Любащенко: Протестантизм в Україні i »підводні камені« статистики, 28-31; Протестантизм в Україні: творення стереотипів триває, 90-104; Сучасний протестантизм в Україні у звітах Держкомнацрелігій: соціологічний коментар, 301-315.

5 www.religion.in.ua/news/vazhlivo/22490-skorochuyetsya-chiselnist-baptistivukrayini.html. 
Lyubashchenko, Die Rolle der protestantischen Kirchen

Riten nahmen in den letzten drei Jahren zwei Prozent zu. So beträgt heute der Anteil der katholischen und der orthodoxen Gemeinden an allen registrierten Gemeinden in der Ukraine 68,6 Prozent.

Wie aus den Zahlen ersichtlich wird, zeigt dieser soziologische Schnitt beunruhigende Tendenzen für den Protestantismus. Allerdings muss man betonen, dass die Anzahl der Gemeinden einen sehr oberflächlichen Eindruck über den tatsächlichen Zustand einer Religion vermittelt. Es ist wohl kaum ein Zufall, dass vor zwanzig, vor zehn Jahren oder auch heute die Gesamtzahl der Protestanten in der Ukraine trotz wachsenden Gemeindezahlen ungefähr gleich bleibt. Einige Meinungsforscher beziffern sie auf 1 Prozent, die anderen auf 1,5, die großzügigsten auf 2 Prozent aller Gläubigen. ${ }^{6}$ Damit unterscheidet sich die

6 Laut einer 2008 im Rahmen des International Social Survey Programme durchgeführten Umfrage hielten sich 39 Prozent der Gläubigen für Anhänger der Ukrainischen Orthodoxen Kirche des Moskauer und Kiever Patriarchats und der Ukrainischen Autokephalen Orthodoxen Kirche, 44 Prozent bezeichneten sich einfach als orthodox, acht Prozent als griechisch-katholisch, jeweils ein Prozent als Protestanten und Anhänger anderer Religionen (Українці навертаються до Бога). In dem durch das U.S. Department of State 2008 zusammengestellten Bericht »Internationale Religionsfreiheit« ist von 5 Prozent religiösen Minderheiten in der Ukraine die Rede; als solche werden außer den Protestanten auch Juden, Buddhisten, Mormonen und Krishna-Anhänger bezeichnet (Bureau of Democracy, Human Rights, and Labor: Ukraine. International Religious Freedom Report 2008). Die hier angegeben Zahlen korrelieren mit der Religionsstatistik in den Großstädten. Die Umfrage der Stiftung "Hromadska dumka Ukrajina» aus dem Jahr 2008 ermittelte in Kiev 1,5 Prozent Protestanten (Кияни віддають перевагу Українській Церкві). Ähnlich niedrig - bis zu zwei Prozent - ist auch ihr Anteil in Lemberg (Історія Львова. T. 3, 429). Die Umfragen von 2011 bis 2012 zeigen keine großen Veränderungen. Siehe dazu etwa die letzten Umfragen der Abteilung Meinungsforschung vom Ukrainischen Zentrum für wirtschaftliche und politische Forschung (Razumkov-Zentrum): Центр Разумкова: Соціологічне опитування: Віруючим якої церкви, конфесії Ви себе вважаєте?.

DigiOst 3 | 380 
Lyubashchenko, Die Rolle der protestantischen Kirchen

Ukraine kaum von den meisten Nachfolgestaaten der ehemaligen Sowjetunion. ${ }^{7}$ Man kann sich kaum vorstellen, wie diese wenigen Prozente das religiöse Gesamtbild in der Ukraine ändern und ihre »Protestantisierung« bewirken können. Mehr als zwanzig Jahre Religionsfreiheit, von der die Protestanten so lange geträumt haben, weil sie in der rechtlichen Drangsalierung und Herabwürdigung beinahe das Haupthindernis für ihre Etablierung gesehen haben, haben letztlich keinen besonderen Aufschwung für die Protestanten gebracht. Als religiöse Minderheit kann diese Konfession wohl kaum einen großen Einfluss auf die religiösen Prozesse in der Ukraine ausüben, auch wenn sie moralische und materielle Unterstützung von den Auslandskirchen bekommt, die starke Positionen in den Ländern der Europäischen Union, Nordamerikas und in Südkorea haben. Diese Unterstützung für die ukrainischen Glaubensbrüder ist heute spürbar zurückgegangen, und die ausländischen Missionen haben ihren Enthusiasmus etwas eingebüßt.

Immerhin machen sich die Protestanten selbst immer mehr Gedanken über das innere Potential ihrer Kirchen, das ihnen eine besser wahrnehmbare Nische im religiösen Leben der Ukraine finden helfen soll. In dieser konfessionellen Gemeinschaft gibt es heute immer mehr Pessimisten, die in ihren Ausgaben und Auftritten bei kirchlichen und missionarischen Fachtagungen über die Krise sprechen, die zahlreiche protestantische Kirchen erfasst hat. Grund zur Besorgnis sind »religiöse Abkühlung«, der »Verlust des Geistes für Selbstlosigkeit und Einheit«, »Brain Drain«, also die Abwanderung der

7 In Russland, Belarus und Moldova gibt es nicht mehr als 1 Prozent Protestanten, in Litauen und zentralasiatischen Staaten bis zu 0,5 Prozent (Лункин: Протестанты и политические конфликты в Евразии: спасение души и управляемая демократия, 175-222). Nur in zwei baltischen Ländern mit langer lutherischer Tradition gibt es mehr Protestanten: in Lettland sind es fast 20 Prozent, in Estland sind es 12 Prozent. Allerdings hat sich ihre Anzahl in den letzten zehn Jahren auch hier verringert (Трифонов: Religare: Эстония теряет христианскую идентичность; Мазур: Религиозная ситуация в Латвии). 
Lyubashchenko, Die Rolle der protestantischen Kirchen

Pastoren und Gemeindemitglieder ins Ausland, aber auch die »Dominanz der westlichen Theologen und religiösen Praktiken, die die Entwicklung eigener Traditionen verhindern $« .{ }^{8}$ Nach Meinung der Delegierten des Internationalen Missionarsforum der Assoziation »Geistige Wiedergeburt « (Irpin', 2008) ist es an der Zeit, nicht von einzelnen Problemen, sondern von einer Systemkrise zu reden: »Die Auslandshilfe und die Arbeit von tausenden westlichen Missionaren haben nicht die erwarteten Resultate gebracht, und die nationalen Kirchen haben die Ressourcen nicht effizient nutzen können und somit die einmalige Möglichkeit für die Etablierung eigenständiger Gottesdienste eingebüßt. « ${ }^{9}$

Etwas zurückhaltender wird die Situation von den Pastoren eingeschätzt, die auf der Suche nach frischem Wind für ihre Kirchen mit mehr Mut jene Veränderungen einleiten, die in den evangelischen Strömungen, insbesondere in den regionalen konservativen Gemeinden, immer abgelehnt wurden. Einerseits geht es um die aktive Erneuerung der Kader, die Eingliederung von jungen Brüdern und Schwestern ${ }^{10}$ in die Leitungsgremien, die Verbesserung der weltlichen und

8 Über diese und andere Zeugnisse für kritische Veränderungen im Protestantismus in der unabhängigen Ukraine vgl. Lyubashchenko: Protestantism in Ukraine: Achievements and Losses, 263-287.

9 В Украине прошел международный »антикризисный м миссионерский форум.

10 Es handelt sich um die Ordination von Frauen, bislang allerdings nur bei charismatischen Bewegungen, wo Pastorinnen schon ziemlich oft anzutreffen sind. Bei den Adventisten, Pfingstlern und Baptisten wird das jedoch kritisch beurteilt, gleichzeitig aber festgestellt: »Die widersprüchlichste Sache ist die der Ordination der Schwestern, [...] im Westen dienen die Frauen schon längst als Pastorinnen, [...] das sorgt für viele Diskussionen. Wir sollen darüber nachdenken, wie wir die Schwestern in den Dienst besser integrieren können « (Тенденции мирового баптизма). Für die ukrainische lutherische Kirche dagegen ist selbst die Fragestellung über den Dienst der Frauen ein Zeugnis für Liberalismus und Verfall der Grundsätze des Christentums (Жінка-священик: веління часу чи перекручення Біблії?, 7-8). 
Lyubashchenko, Die Rolle der protestantischen Kirchen

geistigen Bildung sowie die Gründung von neuen Bildungseinrichtungen, ${ }^{11}$ was der latenten Auswanderung der Jugend über das Studium in ausländischen Predigerseminaren und der Suche nach Selbstverwirklichung in anderen Konfessionen entgegenwirken soll. Andererseits geht es um die Förderung von Initiativen, die von einer neuen intellektuellen Ressource angeboten werden, die sich im Protestantismus in der unabhängigen Ukraine entwickelt hat: Es handelt sich um eine Reihe von Projekten, die auf die Entwicklung der theologischen und kirchengeschichtlichen Schulen ausgerichtet sind und auch die die Rolle des Protestantismus in der Nationalgeschichte und -kultur einschließen. Dies bezieht sich auch auf die Ausbildung von Theologen, die den protestantischen Gedanken an die ostchristliche Tradition heranführen könnten, oder eigene theologische Studien zur orthodoxen Tradition, um ihre Kirchen als natürliches Element des religiösen und kulturellen Lebens der Ukraine zu positionieren. Zur Realisierung dieser Aufgabe sollen Programme der kontextuellen Theologie und des Dienstes für die Kirche beitragen, die in vielen baptistischen Seminaren und dem Seminar der Hl. Sofia der Ukrainischen Lutherischen Kirche als Priorität und in einigen Bildungseinrichtung der Pfingstler und Adventisten als wünschenswert beschlossen worden sind. Dabei sind alle Protestanten an der Weiterentwicklung von nationalen Verbänden interessiert, die sich unter anderem an der Pflege ihres Kulturerbes orientieren, das von den lokalen Gemeinden repräsentiert wird: die ungarische Kultur von den reformatorischen Gemeinden Transkarpatiens, die deutsche von deutschen Lutheranern und Mennoniten, die tschechischen von böhmischen Brüdern, die ukrainischen und russischen von ukrainisch- bzw. russischsprachigen Gemeinden. Gestützt auf eine große geschichtliche Erfahrung bei der Kontextualisierung seiner

11 Von 1997 bis 2007 haben die Protestanten die Anzahl ihrer Bildungseinrichtungen verzehnfacht; diese machen rund 40 Prozent des religiösen Bildungssegments in der Ukraine aus. Allerdings wächst die Zahl der Predigerseminare und Bibelinstitute in den letzten fünf Jahren vorrangig in den charismatischen Bewegungen.

DigiOst 3 | 383 
Lyubashchenko, Die Rolle der protestantischen Kirchen

Dogmen und religiösen Praktiken will der Protestantismus auch weiterhin diese multikulturelle Funktion ausüben, die er für einen Bestandteil des religiösen Pluralismus und einen Toleranzfaktor in einem polykonfessionellen Staat hält.

Obwohl es den protestantischen Gemeinden in der kurzen Zeit der Religionsfreiheit gelungen ist, zahlreiche Gotteshäuser zu errichten und Missionen, Seminare, Verlage, eine Reihe von nationalen Verbänden sowie von interkonfessionellen Gesellschaften zu gründen, sind die Protestanten heute selbst der Meinung, dass ihre Kirchen einen Neuanfang benötigen und eine Suche nach neuen Modellen der Selbstverwirklichung und einer erfolgreicheren Realisierung in der Gesellschaft einleiten müssen.

Letztere wird, wie alles im Protestantismus, durch den Blickpunkt der Bibel und der Gebote Gottes interpretiert, welche die Grenze der Zusammenarbeit eines Christen mit der »Welt« definieren. Das heißt, im Kreise der eventuellen gesellschaftlichen Interessen der protestantischen Kirche stehen Aspekte, bei denen sie nicht nur dem Menschen, sondern vor allem Gott dient. Das ist ein ziemlich breites Spektrum der weltlichen Aktivitäten - die Teilnahme an gesellschaftlichen Bewegungen auf dem Gebiet der Menschenrechte und Religionsfreiheit, ein gesunder Lebensstil, die Bekämpfung der Nikotin-, Alkohol- und Drogenabhängigkeit, Umwelt- und Denkmalschutz, Projekte in den Bereichen Kultur, Bildung, Sport, Erholung usw. Es sei auf die Zusammenarbeit der protestantischen Kirchen mit den Strafvollzugsbehörden hingewiesen, unter anderem bei der sozialen Rehabilitierung ehemaliger Häftlinge, mit dem Gesundheitsministerium bei der Pflege von Behinderten und von AIDSKranken, der Förderung von Waisenhäusern und Altersheimen; mit dem Bildungsministerium bei der Einführung des Unterrichts für christliche Ethik in den weltlichen Schulen und bei der Gründung von christlichen Schulen mit materieller Unterstützung der Kirchen. Die gesellschaftlichen Interessen der Protestanten widerspiegeln sich in den Lernprogrammen ihrer Seminare und Bibelinstitute. Die letzteren bilden nicht nur Missionare aus, sondern auch Fachkräfte in den Bereichen Pädagogik, Psychologie, Sozialarbeit, Journalis- 
Lyubashchenko, Die Rolle der protestantischen Kirchen

mus, Kulturologie, Management und Wirtschaft. Protestanten sind in lokalen Gremien, in der Journalistik, Wissenschaft, Bildung und als Geschäftsleute tätig.

Außerdem zeigen Protestanten ein besonderes Interesse am interkonfessionellen Dialog, den sie als gewichtigen Faktor für religiöse Toleranz betrachten. Die Mannigfaltigkeit des Protestantismus führt zu seiner sichtbaren Präsenz im Gesamtukrainischen Rat der Kirchen und religiösen Organisationen, der als interkonfessionelles Beratungsgremium fungiert - von 18 Mitgliederkirchen sind neun protestantisch. Der Großteil davon (fünf dieser neun) ist Mitglied in der interkonfessionellen Konferenz der Vertreter christlicher Kirchen der Ukraine, dessen Ziele die »Verbreitung der Grundsätze von Christentum und Religionsfreiheit, [...] Dialog zwischen den Christen, [...] Förderung der interkonfessionellen Verständigung und Eintracht in der Gesellschaft, Zusammenarbeit mit staatlichen Behörden und lokaler Selbstverwaltung « sind..$^{12}$ Die Protestanten waren maßgeblich an der Gründung der Ukrainischen Bibelgesellschaft, der ukrainischen Vertretung des Internationalen Verbands für Religionsfreiheit, der Vereinigung der christlichen Militärangehörigen der Ukraine sowie einer Reihe von Berufsverbänden, zumeist für junge Fachkräfte, beteiligt (wie z. B. am Verband von Journalisten, Verleger und Rundfunkanstalten für Christen "Novomedia«, an Verbänden christlicher Unternehmer, Juristen, Ärzte, Künstler und der Allianz christlicher Fachkräfte, die "gläubige Fachkräfte aus verschiedenen Berufen für Entwicklung ihrer professionellen, geistigen und Führungsqualitäten sowie für den gemeinsamen Dienst durch ihren Beruf an Gott und Menschen in den Kirchen und in der Gesellschaft « vereinigt). ${ }^{13}$

Vorsichtiger sind die Protestanten in ihrem Verhältnis zur Politik, obwohl sogar evangelische Strömungen, die mit der traditionellen Verurteilung der Politik als christenfremd aufs engste verbunden sind, ihre programmatischen

12 Konferenz der Vertreter christlicher Kirchen der Ukraine: http://religions.unian. net/ukr/detail/261.

13 Про Альянс.

DigiOst 3 | 385 
Lyubashchenko, Die Rolle der protestantischen Kirchen

Grundsätze längst revidiert haben. Im Credo der Evangeliumschristen-Baptisten der Ukraine steht: »Die Mitgliedschaft in den gewählten Gremien, Parteien und gesellschaftlichen Organisationen ist zulässig, abhängig vom Gewissen jedes einzelnen, wenn deren Tätigkeit nicht gegen die Grundsätze des Evangeliums verstößt. Diese Mitgliedschaft darf aber nicht im Namen der Kirche erfolgen und ist nicht wünschenswert für den Diener, der sich Christus vollständig widmet.« Und noch mehr: »Von unserem Glauben her sehen wir keine Hindernisse für das Bekleiden staatlicher Ämter «. ${ }^{14}$ Allerdings ist eine gewisse Vorsicht bei den jüngsten Versuchen einiger protestantischer Leiter und Gläubigen zu bemerken, in die Politik zu gehen und hohe staatliche Ämter zu bekleiden, ${ }^{15}$ was zu einer kontroversen Einschätzung geführt hat und in einigen Gemeinden negativ wahrgenommen worden ist.

Es handelt sich auch um die Ereignisse auf dem Majdan im Jahr 2004, als sich einzelne Pastoren und Vorsitzende der protestantischen Verbände trotz der offiziellen Erklärung der Konferenz der Vertreter christlicher Kirchen der Ukraine über »die Vereitelung der Versuche, die Kirche in politischen Prozessen zu instrumentalisieren und die Priester in die politische Werbung

14 Zitiert nach: История баптизма, 483; 433.

15 Es geht um die Wahl des Pastors einer charismatischen Gemeinde, Volodymyr Šuškevyč, zum Abgeordneten des ukrainischen Parlaments im Jahr 1998, um die Ernennung des baptistischen Pastors Oleksandr Turčynov zum ersten Vizepremier der ukrainischen Regierung (vom Dezember 2007 bis März 2010), davor zum Chef des Nachrichtendienstes der Ukraine (Februar bis September 2005) und zum ersten stellvertretenden Sekretär des Rats für nationale Sicherheit und Verteidigung der Ukraine (Mai bis November 2007). Der Baptist Juryj Rešetnikov war in den Jahren 2009-2010 Vorsitzender des Staatskomitees für Nationalitäten und Religionen. Einige Medien haben behauptet, dass der ehemalige Kiever Oberbürgermeister Leonid Černovec'kyj Mitglied einer charismatischen Bewegung und der ehemalige Präsident des Obersten Gerichtshofs der Ukraine Vasylyj Onopenko Mitglied bei den Pfingstlern sei (vgl. Кухарчук: Народный депутат Василий Онопенко: „Украина тогда встанет на ноги, когда станет перед Господом Богом на колени«, 6.4.2004.

DigiOst 3 | 386 
Lyubashchenko, Die Rolle der protestantischen Kirchen

einzubeziehen ${ }^{16}{ }^{\text {offen }}$ - sowohl durch ihre Teilnahme an den Protestaktionen als auch in den Medien - auf die Seite der demokratischen Kräfte geschlagen haben. Diese Unterstützung, die sich bereits in den vorangegangenen Wahljahren abgezeichnet hatte, wurde von einigen protestantischen Verbänden nicht gebilligt, wie etwa von der Freikirche der Adventisten des Siebten Tages. ${ }^{17}$ Die charismatischen Bewegungen haben dagegen nicht nur ihre Zusammenarbeit mit den Behörden ausgeweitet, etwa mit dem ehemaligen Oberbürgermeister von Kiev und seiner Verwaltung, sondern sogar eine neue Mission für die Kirche in der Gesellschaft formuliert: »Die Kirche kann und muss in die Politik gehen; [...] man muss für die Kirche ein neues Ziel formulieren, und das heißt, Einfluss auf die Situation im Land zu nehmen. «18

Die politischen Veränderungen in der Ukraine in den letzten drei Jahren haben neue Kirchensympathien der Machthaber sichtbar gemacht. Ihr Verhältnis zu den Protestanten hat sich erneut abgekühlt, Letztere haben Posten in Kiev und in den Regionen verloren. Das hat ihnen die möglichen Gefahren einer zu tiefen "Integration « in die Politik und Annäherung der Kirche an die Machthaber, und folglich die Unabänderlichkeit der biblischen Worte über Gott und Kaiser, ins Bewusstsein gebracht. Deswegen war die Präsenz der protestantischen Führer bei den letzten ukrainischen Parlamentswahlen im Vergleich zu vorherigen Wahlkämpfen wohl am geringsten. Das Hauptaugenmerk der Protestanten fokussiert sich heute auf die lokalen Wahlen; hier können insbesondere Gemeinden im Süden und im Osten des Landes erfolgreich

16 Die Erklärung der Konferenz der Vertreter christlicher Kirchen der Ukraine zu den Versuchen, die Kirche im Wahlkampf zu instrumentalisieren (vgl. »Віддавайте кесареве кесареві, а Боже Богові«. Мф. 22:21).

17 »Wir können keine Verpflichtungen im Bereich der politischen Tätigkeit auf uns nehmen, weil es unbedingt notwendig sein wird, christliche Grundsätze für den aktuellen politischen Moment zu opfern. Es ist unmöglich, sich mit der Politik zu beschäftigen und bis zum Ende Christ zu bleiben« (Вісник Миру Nr. 10, 5).

18 Дзюба: Украинская миссия - предвестник революции в России. 
Lyubashchenko, Die Rolle der protestantischen Kirchen

sein, wo die Protestanten, vor allem die charismatischen Bewegungen, eine gewisse Dynamik und missionarische Ressource beibehalten. In den westlichen Regionen haben Chancen auf Vertretung in den lokalen Machtgremien Pfingstler in Wolhynien, Vertreter der Ungarischen Reformatorischen Gemeinde in Transkarpatien, Adventisten in Transkarpatien und in der Bukowina, wo sie einen sichtbaren Anteil in einigen Orten aufweisen. In Galizien sind diese Chancen geringer, obwohl hier ein Pastor der Pfingstler aus einem Dorf in der Nähe von Lemberg achtmal den Gang in die Politik versucht hat, zweimal mit Erfolg. Ungeachtet des immer größeren und durchaus begründeten Interesses der Protestanten an der Politik bleibt ihre Beteiligung an politischen Tätigkeiten vorerst trotzdem nicht allzu auffallend; sie können im Moment weder mit den Orthodoxen noch mit den Griechisch-Katholischen mithalten.

Das Gesetz über die Gewissensfreiheit und religiöse Organisationen in der Ukraine ist vor kurzem zwanzig Jahre alt geworden. Dieses bescheidene Jubiläum wurde in den protestantischen Gemeinden gefeiert. Zwanzig Jahre bedeuten aber auch für die Kirche eine gewisse Zäsur. Auf dem Prüfstand steht ihre Bereitschaft, unter neuen gesellschaftlichen Voraussetzungen zu arbeiten, die für den geistigen Fortschritt des Landes nicht besonders förderlich waren. Das verlangt der Kirche in gewisser Weise »erhöhte Forderungen « ab. Einige protestantische Führer schlagen heute eine Diskussion nicht nur darüber vor, was Kirchenverbände und lokale Gemeinden nicht zu lösen vermochten, sondern »was wir als evangelische Protestanten sind, [...] was die Identität des Protestantismus ist, [...] ob wir verstehen, dass es an der Zeit ist, ein neues Bild des Christen zu kreieren, der eine neue Kirche aufbauen wird «. ${ }^{19}$ Trotz der

19 Черенков: Евангельская вера в постатеистических сообществах; Черенков: Наше время - это критическая точка разрыва всех традиций. Ähnliche Fragestellung finden wir auch bei den baptistischen Autoren Podberezskij, Nevolin und Sorokin in der protestantischen Zeitung »Mirt (http://gazeta.mirt.ru/?2-8-1/2). Vgl. auch: Рабер: Радость или горе: размышляя о переменах, произошедших в среде украинских евангельских христиан за годы независимости страны. 
Lyubashchenko, Die Rolle der protestantischen Kirchen

Emotionalität solcher Fragen ist die Fragestellung selbst positiv zu beurteilen. Nach einer Etappe der extensiven Entwicklung sind sich die Protestanten in der unabhängigen Ukraine (zumindest die gebildeten Kreise und die Jugend, die nicht durch Pastorenämter und Routinepflichten belastet ist) über die Herausforderungen im Klaren, vor denen die Konfession in ihrem Wunsch nach einer dynamischeren Integration in die ukrainische Gesellschaft steht. Die Beantwortung dieser Fragen könnte wohl dem Protestantismus neue Impulse verleihen.

Die aktuelle Situation zeigt also, dass dem Protestantismus auch in der Gegenwart Probleme vor Augen stehen. Weitere konzeptuelle Gedanken über die Entwicklung des Protestantismus in der Ukraine nicht nur durch nationale, sondern auch durch ausländische Experten ${ }^{20}$ werden eine vertiefte Prognose über seine etwaigen Perspektiven ermöglichen.

\section{Literatur}

Віддавайте кесареве кесареві, а Боже Богові. Мф. 22:21, unter http://risu. org.ua/ua/index/resourses/church_doc/ecumen_doc/34081/(15.01.2014). Вісник Миру. Київ 1997. Nr. 10, 5.

В Украине протестанты постепенно вытесняют православных, unter http://ua.proua.com/news/2009/02/12/081821 (wird umgeleitet zur Zeitschrift Komentari; 15.01.2014).

20 Interesse an der Geschichte des Protestantismus in der Ukraine besteht unter anderem in Deutschland (siehe dazu das Buch des ukrainischen Adventisten-Pastors Khiminets: Protestantismus in der Ukraine: Rolle und Stellung des Protestantismus im soziokulturellen Kontext der Geschichte der Ukraine). Der Zustand und die Entwicklungstendenzen des Protestantismus in der unabhängigen Ukraine warten dagegen auf ihre Erforschung.

DigiOst 3 | 389 
Lyubashchenko, Die Rolle der protestantischen Kirchen

В Украине прошел международный »антикризисный миссионерский форум, unter www.creationism.org/crimea/news14.html (13.01.2014). Дзюба, Александр: Украинская миссия - предвестник революции в России, unter www.archipelag.ru/ru_mir/religio/anphas/harbinger (14.01.2014). Жінка-священик: веління часу чи перекручення Біблії? In: Стяг. ТернопільКиїв 1996. №. 3, 7-8

Історія Львова. У 3-х томах. Т. 3. Львів 2007.

История баптизма. Одесса 1996.

Кияни віддають перевагу Українській Церкві, unter http://www.unian. ua/politics/116222-kiyani-viddayut-perevagu-ukrajinskiy-tserkvi.html (15.05.2008).

Колодний, Анатолій: Християнство за умов глобалізації. In: Людина i культура в умовах глобалізації. Київ 2003, 302-311.

Кухарчук, Руслан: Народный депутат Василий Онопенко: „Украина тогда встанет на ноги, когда станет перед Господом Богом на колени«. In: Камень Краеугольный. Київ, 06.04.2004, unter http://old.risu.org.ua/rus/ religion.and.society/other.articles/article;3225/ (16.01.2014).

Левицкий, Орест: Социнианство в Польше и Юго-Западной Руси в XVIXVII вв. In: Киевская старина 6 (1882), 406.

Лункин, Роман: Протестанты и политические конфликты в Евразии: спасение души и управляемая демократия. In: Религия и конфликт. Москва 2007, 175-222.

Любащенко, Вікторія: Протестантизм в Україні і »підводні камені« статистики. In: Людина і світ. Київ 2001. № 2-3, 28-30.

Мазур, Сергей: Религиозная ситуация в Латвии, unter http://shh.neolain. lv/seminar14/religija.htm (5.01.2014).

Політика і культура. Київ 2000. № 16, 22-27.

Про Альянс, unter www.acp.org.ua/pro-alyans/ (14.01.2014).

Протестантизм в Україні: творення стереотипів триває. In: Журнал »Ї«. Львів 2001. № 10, 90-104.

DigiOst 3 | 390 
Lyubashchenko, Die Rolle der protestantischen Kirchen

Рабер, Мэри: Радость или горе: размышляя о переменах, произошедших в среде украинских евангельских христиан за годы независимости страны. In: Вестник служений и церквей »Восток-Запад« (East-West Church and Ministry Report) 12/1 (2004), unter http://www.eastwestreport. org/articles/R12.1.1.html (14.01.2014).

Релігія і влада в Україні: розвиток правових засад взаємовідносин. Київ 1999.

Релігійна мережа в Україні на січень 2009 року, unter http://ukreligieznavstvo. wordpress.com/2009/03/15/релігійна-мережа-україни-на-січень2009-p/; (16.01.2014).

Сучасний протестантизм в Україні у звітах Держкомнацрелігій: соціологічний коментар. In: Державно-конфесійні відносини в Україні: сучасний стан та тенденції розвитку. Київ 2012, 301-315.

Тенденции мирового баптизма, unter http://baptist.org.ru/read/article/94334 (02.07.2008).

Титаренко, Віта: П'ятидесятниця та витоки нового християнського руху. Чистина друга. П’ятдесятництво в Українію. In: Релігія в Україні, 15.06.2009, unter www.religion.in.ua/main/analitica/595-pyatdesyatnictvov-ukrayini.html (04.01.2014).

Трифонов: Religare: Эстония теряет христианскую идентичность, unter http://baznica.info/article/religare-estoniya-teryaet-khristianskuyu-i (01.02.2015)

Українці навертаються до Бога, unter http://jerelo.info/Podiyi-v-Ukrayini/ Ukrayintsi-navertayutsya-do-Boga.htm (29.03.2009).

Феномен української культури. Київ 1996.

Центр Разумкова: Соціологічне опитування: Віруючим якої церкви, конфесії Ви себе вважаєте?, unter http://www.razumkov.org.ua/ukr/poll. php?poll_id=300 (15.10.2014). 
Lyubashchenko, Die Rolle der protestantischen Kirchen

Черенков, Михаил: Евангельская вера в постатеистических сообществах, unter http://www.baznica.info/index.php?name=Pages\&op=page\&pid=3745 (14.01.2014).

Черенков, Михаил: Наше время - это критическая точка разрыва всех традиций, unter http://www.baznica.info/index.php?name=Pages\&op=page\&pid= 5231 (14.01.2014).

http://gazeta.mirt.ru/?2-8-1/2 (14.01.2014).

http://www.religion.in.ua/news/vazhlivo/22490-skorochuyetsya-chiselnistbaptistiv-ukrayini.html (05.01.2014).

Bureau of Democracy, Human Rights, and Labor: Ukraine. International Religious Freedom Report 2008, unter www.state.gov/j/drl/rls/irf/2008/108477. htm (5.01.2014).

Khiminets, Pavlo: Protestantismus in der Ukraine: Rolle und Stellung des Protestantismus im soziokulturellen Kontext der Geschichte der Ukraine. Frankfurt a. M. 2006.

Konferenz der Vertreter christlicher Kirchen der Ukraine, unter http://religions. unian.net/ukr/detail/261 (14.01.2014).

Lyubashchenko, Victoria: Protestantism in Ukraine: Achievements and Losses. In: Religion, State \& Society. 38/3 (2010), 263-287.

\section{Abstract}

\section{Viktoria Lyubashchenko}

The Role of Protestant Churches in the Religious and Political Life of Ukraine

This article analyzes the current state of Ukrainian Protestantism. The author argues that the role of Protestant churches in the social, cultural, and political life of the country has been gradually strengthening. Nevertheless, the pa- 
Lyubashchenko, Die Rolle der protestantischen Kirchen

per offers a critical look at Ukrainian sociology and the conclusions of some Ukrainian analysts about a »Protestant boom « in Ukraine. The author analyzes the contradictory processes, which are affecting Ukrainian Protestantism today, and demonstrates a fall in the rate of its dynamic development. 
Katrin Boeckh - 978-3-86688-505-9 


\section{Stefan Rohdewald}

\section{Vom ukrainischen "Antemurale Christianitatis" zur politischen Nation? Geschichtsbilder der Ukraine und muslimische Krimtataren}

Die Europäische Union möchte kein »christlicher Verein« sein und versucht bewusst, sich durch ethnische und religiöse Vielfalt zu definieren. Zahlreiche Staaten Europas stehen wie die meisten modernen politischen Gemeinschaften vor der Herausforderung, von einer staatstragenden identitätspolitischen Funktion von früher oft nationalstaatlich verstandener Religion noch stärker als in den vergangenen Jahrzehnten ohnehin Abstand zu nehmen, wenn sie allen ihren Bürgern ein akzeptables und gleichwertiges staatsbürgerliches politisches Identitätsangebot machen möchten: Abgesehen von zahlreichen Konfessionslosen, christlichen Konfessionen sowie der jüdischen Religion und anderen religiösen Gruppierungen gilt es zu berücksichtigen, dass inzwischen der Islam als zweitgrößte Religionsgemeinschaft Europas anzusehen ist. ${ }^{1}$ Am Beispiel der Ukraine, die seit ihrer Unabhängigkeit 1991 vor komplexen identitätspolitischen Herausforderungen wie der Integration einer großen russischsprachigen Bevölkerungsgruppe steht, sei hier die Thematik des Entwurfs der Beschreibung einer ethnisch und religiös heterogenen Bevölkerung in einer politischen, ukrainischen Gemeinschaft auch durch Historiker exemplarisch am Fall der muslimischen Krimtataren besprochen.

Die Skizze beginnt mit einem in zwei Teile gegliederten Überblick über Rollen des Islams im ukrainischen Geschichtsbild bis in die Gegenwart. Zunächst wird die Entstehung ukrainischer »Bollwerk-Diskurse«bzw. der ostgalizischen Übernahme des Diskurses vom »Antemurale Christianitatis« aus der polni-

1 Hunter: Islam, Europe's Second Religion; Thiel, Prügel: Understanding Diversity, 3-7; Maréchal u.a.: Muslims in the Enlarged Europe.

DigiOst 3 | 395 
Rohdewald, Vom ukrainischen »Antemurale Christianitatis« zur politischen Nation?

schen Historiographie geschildert. Es folgt eine Darlegung von Betrachtungen ukrainischer Geschichte, die den Islam integrieren. Nach Hinweisen auf die gegenwärtige Lage des Islams und der Tataren auf der Krim und in der Ukraine allgemein wird sodann dem politischen und geschichts- bzw. erinnerungspolitischen Versuch nachgegangen, den Islam unter Partizipation der Krimtataren im Sinne der Verfassung der Ukraine als Teil einer ukrainischen politischen Nation zu verstehen: »im Namen des ukrainischen Volkes, der Bürger der Ukraine aller Nationalitäten ${ }^{2}{ }^{2}$

\section{Die Entstehung des ukrainischen Antemurale-Diskurses}

In der Frühen Neuzeit übertrug sich die ursprünglich abendländisch-lateinische Vorstellung vom »Bollwerk der Christenheit « auf Länder, die zur orthodoxen Christenheit gehören. Auch die ukrainischen Zaporoger Kosaken legitimierten sich seit dem 16. Jahrhundert gelegentlich als »Bastion des Christentums «. ${ }^{3}$ Im 19. Jahrhundert wurde diese Vorstellung zu einer die ukrainische Nation konstitutierenden Rahmenerzählungen. Der galizische, griechisch-katholische Lehrer Stepan Kačala (1815-1888) schrieb 1879 im ersten längeren ukrainophilen Geschichtswerk:

»Die Rus'-Ukraine schickte [...] die Elite ihrer Jugend in die weiten Steppen in den Krieg mit den Ungläubigen, um den Strom der asiatischen Wilden aufzuhalten. Die Kosaken verteidigten die Rus' und Polen und indirekt auch

2 Verfassung der Ukraine auf der Website des Präsidenten der Ukraine http://www. president.gov.ua/content/constitution.html.

3 Srodecki: Antemurale Christiantiatis, 818. 
Rohdewald, Vom ukrainischen »Antemurale Christianitatis« zur politischen Nation?

Europa vor den Mohammedanern, was ihr großes Verdienst in der Kulturgeschichte der Welt darstellt. $\ll^{4}$

Mit dieser Argumentationsstrategie wurden verschiedene diskursive Ziele verfolgt: Zum einen wurde die Rus' als souveräner Staat Ukrajina inszeniert, zum anderen wurde dieser Staat als Teil Europas dargestellt, dem, drittens, eine wichtige Rolle in der Verteidigung des Kontinents und, viertens, der gesamten »Kulturgeschichte der Welt« zukam. Mit dem Verweis auf die »asiatischen Wilden « wurde, fünftens, bekräftigt, dass dieser Staat auf einer höheren Kulturstufe als die Muslime stehen sollte. Schließlich sollte der so definierte Staat einen herausragenden, ehrenvollen Platz in der Menschheitsgeschichte einnehmen. In der von der imperialen russländischen Peripherie ausgehenden Argumentation wurde damit die Vision einer zentralen Position der Ukraine entworfen. Der diskursive Gegner war aber Polen: Kačala dekonstruierte mit seinem Text die polnische Vorstellung vom »Przedmurze cywilizacyi i chrześcijaństwa«, indem er Polen den Friedensschluss mit dem osmanischen Sultan Süleyman (1527) und die Aufgabe von Podolien sowie die Kooperation mit Krimtataren gegen christliche Kosaken, Russen und Schweden zum Vorwurf machte. ${ }^{5}$

Ruthenische Historiker Ostgaliziens stellten die polnische Eroberung von Halyč-Wolhynien oder Rotreußen als »Fremdherrschaft « dar und versuchten nachzuweisen, dass sie nicht, wie von polnischen Historikern behauptet, dazu diente, Raubzüge von Tataren zu unterbinden, sondern vielmehr zu ihrer Zunahme führte, insbesondere nach 1430, als sie das Khanat auf der Krim einrichteten. Die lokale Bevölkerung habe sich weiterhin gegen Plünderungen

4 Kačala: Polityka Polaków, 64, zit. gemäß Wöller: „Europa« als historisches Argument, 293.

5 Wöller: »Europa« als historisches Argument, 296. 
Rohdewald, Vom ukrainischen »Antemurale Christianitatis« zur politischen Nation?

verteidigt, der Erfolg ihrer Maßnahmen sei aber wegen der mangelhaften Strategie der polnischen Streitkräfte beschränkt geblieben. ${ }^{6}$

Kornylo Zaklyns'kyj (1857-1884) beschrieb 1882 die Kosaken als Kämpfer für »die europäische Zivilisation«: Das Bündnis Rudolphs II. mit ihnen sei wichtig für den »Kampf zwischen Asien und Europa, zwischen dem Islam und der Christenheit und zwischen der Barbarei und der europäischen Zivilisation" gewesen, da Polen am Frieden mit dem Osmanischen Reich festhalten habe wollen. ${ }^{7}$

V'jačeslav Budzynovs'kyj (1868-1935) hingegen setzte sich 1907 mit der von polnischen Historikern in der Absicht, die Ukrainer in einen asiatischen oder orientalischen Zusammenhang zu stellen, vertretenen These der ukrainischen Beeinflussung durch die Krimtataren auseinander, indem er die Vorzeichen der Bewertung des Vorgangs austauschte: Er vertrat in einer an ein breites Publikum gerichteten Broschüre die Ansicht, die Übernahme von Praktiken der »Asiaten« durch ukrainische Kosaken sei positiv zu bewerten. Indem man vom Gegner lernte, sei die eigene Verteidigung ermöglicht worden:

»Das Volk der Zaporoher [narod Zaporoža] erzog sich durch das gemeinsame Leben unter Tataren und mit Tataren im 13. und 14. Jahrhundert zu Kosaken. Erst in der zweiten Hälfte des 15. Jahrhunderts, als die Krimtataren begannen, in die Ukraine einzufallen, unterstützten die kosakischen Gebräuche der Zaporoher den Kampf gegen die Tataren. ${ }^{8}$

Budzynovs'kyj beschrieb die Jahrhunderte der ruthenischen Kooperation mit den »Asiaten« ausführlich:

6 Wöller: »Europa« als historisches Argument, 278.

7 Zaklyns'kyj: Znošenja cîsarja Rudolfa II., 1, zit. gemäß Wöller: »Europa« als historisches Argument, 298.

8 Budzynovs'kyj: Naši het'many, 11, vgl. Wöller: »Europa «als historisches Argument, 296. 
Rohdewald, Vom ukrainischen »Antemurale Christianitatis« zur politischen Nation?

"Das ganze Volk der Zaporoher wurde deswegen kosakisch, da im ganzen südlichen Steppenteil der fürstlichen Rus' seit dem 10. Jahrhundert die Horden der Asiaten herrschten. Diese lebten dort gemeinsam mit der rusischen Bevölkerung, getrennt von den Ländern des rusischen Staates [ruskoji derža$v y$ ]. Zunächst waren das die Horden der Pečenegen, dann der Torken und darauf die der Polovcer. Obwohl diese Horden das rusische Land, das unter den rusischen Fürsten verblieben war, verwüsteten, lebten die Zaporoher (sie nannten sich damals noch nicht so) im Einklang mit ihren Herren - denn sie mussten dies. Erst als aus Asien eine neue Horde kam, die tatarische, und auf die Polovcer einwirkte, vereinigten sich die Zaporoher mit den Tataren, nicht wissend, dass die rusischen Fürsten den Polovcern zu Hilfe kommen würden. Die Tataren schlugen und vernichteten die Horde der Polovcer am Fluss Kalka im Jahr 1223 mit der Hilfe der Zaporoher. So kam es, dass anstelle der Polovcer die Tataren sich auf den Zaporoher Steppen verbreiteten. Die Tataren lebten auf diesen Steppen gemeinsam mit ihren Verbündeten, den Zaporohern, in bester Eintracht. [...] Während sie zwei Jahrhunderte unter Tataren und unter tatarischer Obrigkeit lebten, übernahmen die Zaporoher einige tatarische Bezeichnungen. Alle Zaporoher waren leicht bewaffnete Mitglieder der Horde, weswegen sie sich auf Tatarisch «Kosaken` nannten. ${ }^{9}$

Er verschwieg auch nicht den späteren Einsatz von Gewalt gegen Tataren nach deren Vorbild: »So wie die Tataren ukrainische Dörfer überfielen, so überfielen sie tatarische Dörfer und Weidegebiete. Mit einem Wort - sie handelten wie Kosaken. Daher ihr Name: 〈Kosaken〉. « ${ }^{10}$

Budzynovs'kyj beschrieb damit deutlich ein langes und enges Zusammenleben mit den Tataren, blieb aber ganz im Diskurs der Zeit, als er die »Horden der Asiaten« erwähnte: Die Vorstellung der Verteidigung eines »Bollwerks

9 Budzynovs'kyj, Naši het'many, 11-12.

10 Budzynovs'kyj, Naši het'many, 12. 
Rohdewald, Vom ukrainischen »Antemurale Christianitatis « zur politischen Nation?

der Christenheit " gegen kulturell auf einer anderen Stufe sehende "Asiaten " blieb eines der wichtigsten Narrative einer der Einschreibung der ukrainischen Geschichte in einen europäischen Zusammenhang. ${ }^{11}$

Der Historiker V'jačeslav Lypyns'kyj (1882-1931) kann als ein Beispiel für die Betonung der Rolle der religiösen Komponente in der ukrainischen, staatsorientierten Historiographie gelten: In seiner Schrift »Religion und Kirche in der Geschichte der Ukraine« stellte er 1925 in Philadelphia fest, wegen der »völligen Abhängigkeit der geistlichen von der weltlichen Macht« sei es den Fürsten der Rus' nicht gelungen, gegen »den Tatarensturm [...] einen eigenen Kreuzzug zu organisieren; sie konnten sich nicht auf alle kulturellen, geistigen und moralischen Kräfte der ganzen Gesellschaft, der ganzen Nation [nacija] stützen«, weil das Christentum »den Massen durch den Staat nur mechanisch aufgesetzt " gewesen sei, "genauso, wie ihnen eine neue staatliche Organisation aufgesetzt wurde, die die neuen Eroberer - die Tataren - mit sich brachten ${ }^{12}$

Den Tataren gewann er auch in seiner Darstellung des weiteren Verlaufs der Geschichte nichts Gutes ab, vielmehr dienten sie ihm zur Asiatisierung der sozialistischen Sowjetunion: »Aber wie während der üblen Jahre der Tatarenherrschaft [za tatars'koho lycholittja], so ist es auch während der bolschewistischen Plage [za lycholittja bol'ševyc'koho] «. Die »moralische und nationale Wiedergeburt«, die »in der großen Ukraine« begann, scheiterte »wegen ihrer Abhängigkeit von der weltlichen Macht und wegen der Trennung von der Nation, von der Gesellschaft, von der orthodoxen Religion und Kirche «. ${ }^{13}$ Lypyns'kyj definierte damit eine staatliche, nationale und religiöse ukrainische Identität gleichfalls namentlich in der Abgrenzung gegenüber den Tataren.

Auch in der Sowjetunion blieben Adaptionen der Vorstellung vom "Antemurale« als Mythos mit der Funktion, politische Gemeinschaft zu stiften,

11 Wöller: »Europa« als historisches Argument, 322.

12 Lypyns'kyj: Relihija i cerkva, 31.

13 Lypyns'kyj: Relihija i cerkva, 37.

DigiOst 3 | 400 
Rohdewald, Vom ukrainischen »Antemurale Christianitatis« zur politischen Nation?

in Verwendung. Insbesondere die Unterscheidung von sesshaften Ostslaven und nomadischen Tataren wurde mit kultur- und zivilisationsgeschichtlicher Bedeutung aufgeladen. Aber auch nach 1991 blieb der Diskurs in wichtigen Werken in Kraft: In einer selbst in der 2. Auflage von 2001 vom ukrainischen Bildungsministerium empfohlenen "Skizze ukrainischer Kulturgeschichte" hielt Myroslav Popovyč (1. Auflage 1998) fest: »Für die Pforte wurde es immer schwerer, militärische Erfolge zu erreichen [...]. Und dabei spielte die energische Organisation des Widerstandes der Staaten Zentral- und Osteuropas keine geringe Rolle. « ${ }^{14}$ Popovyč nannte die Möglichkeit eines komplexeren, vermittelnden Kommunikationszusammenhangs, aber gleichzeitig erklärte er ihn für bedeutungslos:

»Es scheint, als ob diese kriegerische Steppenkomponente des tatarischen Volkes zur Vermittlung zwischen der ukrainischen und der tatarischen Kultur diente. Aber obwohl zeitweilige militärische Bündnisse, der Einfluss der Tataren auf die ukrainischen Länder bei inneren Konflikten, Traditionen der Kiever Rus' fortführten, brachten sie nur kurzfristige militärische Verbrüderungen und nicht wenige Fälle von Verrat und Plünderung mit sich. «15

Der Entwurf eines übergreifenden Kontextes wird damit auch noch im postsowjetischen Zusammenhang durch die in der Regel exklusive Vorstellung vom religiösen und zivilisatorischen Antemurale verstellt. Der Islam und insbesondere die Steppennomaden bleiben in zahlreichen Darstellungen ukrainischer Geschichte außerhalb einer Beschreibung einer meist ethnisch und religiös, wenn auch nicht konfessionell, homogen entworfenen nationalen »ukrainischer Kultur«.

14 Popovyč: Narys istoriji kul'tury Ukraïny, 132.

15 Popovyč: Narys istoriji kul'tury Ukraïny, 134.

DigiOst 3 | 401 
Rohdewald, Vom ukrainischen »Antemurale Christianitatis« zur politischen Nation?

\section{Der Islam und die Tataren als integrativer Bestandteil ukrainischer Geschichte}

Dabei hatte sich im 20. Jahrhundert längst auch eine über Budzynovs'kyj hinausgehende, integrativere Anschauung ukrainischer Geschichte entwickelt. Während Lypyns'kyj im Gegensatz zur auf einem ukrainischen Volk aufbauenden Volksgeschichte im Sinne von Hruševs'kyj und anderer den polonisierten Adel in eine ukrainische, territorialisierte Geschichtsdarstellung miteinbezog, entwickelte namentlich Omeljan Pritsak neue Perspektiven auch auf die nicht christlichen Tataren. In der in München und New York in den 1960er Jahren veröffentlichten Enzyklopädie der Ukrainekunde gab er im Abschnitt »Kultur« umfassende Informationen auch zu Turk- und anderen Steppenvölkern, die, trotz ihres später islamischen Glaubens und ihrer nicht slavischen Sprache hier mit zur Konzeption ukrainischer Geschichte zählten. Etwa verwies Pritsak auf den vorchristlichen Titel »kagan « der Kiever Herrscher. ${ }^{16}$ Allerdings folgte diesem Abschnitt ein Kapitel über "Charakterzüge des ukrainischen Volkes«, der explizit mit rassistischen Interpretamenten eine homogene Bevölkerung voraussetzte und wie der daran anschließende über »Ukrainische Philosophiegeschichte« keinerlei Hinweise auf andere Ethnien oder nicht christliche Religionen berücksichtigende Zugänge enthielt.

Pritsak arbeitete später deutlicher heraus, wie seit der Entstehung der Rus' gerade am Steppenrand sesshafte und nomadische Bevölkerungsgruppen sowie reisende Kriegerhändler in einem engen wechselseitigen Kontakt standen. "Nomaden des Meeres«, die Waräger, und »Nomaden der Steppe«, die Chazaren, fanden gemeinsame Handlungspraktiken, die im 9./10. Jahrhundert zur Einrichtung des »Wolga-Rus' Khanats« führten. Igor, aus der Dynastie der Wolga-Rus'-Khane, eroberte um $930 \mathrm{Kiev}$ und verlagerte den Schwerpunkt

16 Pritsak: Skladnyky ukrajins'koji kul'tury: Abschnitt (694-700) im Beitrag Čyževs'kyj / Pritsak: Kul'tura, hier 699-700. 
Rohdewald, Vom ukrainischen »Antemurale Christianitatis « zur politischen Nation?

der Symbiose an den Dnjepr (ukr. Dnipro). ${ }^{17}$ Pritsak arbeitete auch zu den Verflechtungen zwischen Moskau, dem Khanat von Kazan' und der Goldenen Horde $^{18}$, unter anderem zum ersten »türkisch-ukrainischen Bündnis (1648) «. ${ }^{19}$ Im Rahmen einer ukrainischen Nationalgeschichte spielten die Tataren allerdings auch für Pritsak kaum eine Rolle. ${ }^{20}$ Dennoch: Mit diesen, hier nur exemplarisch genannten Arbeiten erprobte Pritsak Ansätze, die Zugängen zu überregionalen Verflechtungen im Mittelalter und in der Frühneuzeit in den letzten Jahren entsprechen und die ältere Vorstellung homogener Kulturräume unterminieren. Victoria Bulgakova etwa vertritt in einem von Martin Borgolte herausgegebenen Band die These, dass sich in der Übernahme islamischer Kunstformen in christlichen Bauwerken in Sugdaia auf der Krim im 13. Jahrhundert eine »religiöse «Affinität zum Christentum« in der neuen seldschukischen Oberschicht widerspiegele. Deren »Tradition religiöser Toleranz« habe die architektonischen Stile der christlichen Bevölkerungsmehrheit dauerhaft beeinflusst und dadurch die muslimische Herrschaft über die Stadt gefestigt. Bulgakova spricht für die Überlagerung christlicher und islamischer Kommunikationskreise von einer weiträumigen und im Laufe von Jahrhunderten entstandenen »Kontaktzone « ${ }^{21}$ Dieses Konzept kann sich auch für die spätere Zeit als ergiebig erweisen. Die Eingliederung der heutigen zentralukrainischen Gebiete in das Großfürstentum Litauen führte zur Teilhabe einiger Tataren bzw. Karaimen als Hilfstruppen der Fürsten an der zumindest in diesem Bereich entstehenden zwischenethnischen Kommunikationsgemeinschaft. ${ }^{22}$ Das Großfürstentum und die östlichen Regionen der polnischen Krone wurden als

17 Pritsak: The Origin of Rus', 268-271.

18 Pritsak: Moscow, the Golden Horde.

19 Pritsak: Das erste türkisch-ukrainische Bündnis.

20 Pritsak: The Ukraine and the Dialectics of Nation-Building, 239.

21 Bulgakova: Islamisch-christlicher Kulturkontakt, 273.

22 Bednarczuk: Stosunki językowe.

DigiOst 3 | 403 
Rohdewald, Vom ukrainischen »Antemurale Christianitatis« zur politischen Nation?

"transkulturelle Kommunikationsregion « betrachtet. ${ }^{23}$ Auch das Osmanische Reich ${ }^{24}$ und das Krimkhanat ${ }^{25}$ werden mit Gewinn in einen überregionalen, ja kontinenteübergreifenden historischen Verflechtungszusammenhang eingeordnet. In dieser Hinsicht hat Dariusz Kołodziejczyk mit Studien über die Beziehungen der Khane und der osmanischen Sultane mit Polen-Litauen neue Maßstäbe gesetzt. ${ }^{26}$ Insgesamt wird ukrainische Geschichte zunehmend als ein für transnationale geschichtswissenschaftliche Ansätze sehr lohnendes Feld angesehen. ${ }^{27}$

\section{Die politische Situation der Krimtataren im postsowjetischen Zusammenhang der Ukraine}

Nach diesem Einstieg in Beschreibungen der Tataren in der älteren und neueren ukrainischen und internationalen Historiographie ist nun ein Blick auf die konkrete Lage vor Ort zu werfen: Vier Prozent der heutigen Bevölkerung der Ukraine sind Muslime, das ist gemessen an Frankreich (neun Prozent) oder Bulgarien (zwölf Prozent) im europäischen Vergleich wenig und entspricht ziemlich genau den Verhältnissen in Deutschland, wo die Zahlen auf zwei bis fünf Prozent Muslime geschätzt werden. ${ }^{28}$ Auf der Halbinsel Krim, die im Rahmen der Zugehörigkeit zur Ukraine eine eigene Verfassung hat, leben

23 Rohdewald, Frick, Wiederkehr: Litauen und Ruthenien.

24 Helmedach: Das osmanische Europa.

25 Kołodziejczyk: Das Krimkhanat als Gleichgewichtsfaktor; Klein: The Crimean Khanate between East and West.

26 Kołodziejczyk: Das Krimkhanat als Gleichgewichtsfaktor; Kołodziejczyk: Ottoman-Polish Diplomatic Relations; Kołodziejczyk: The Crimean Khanate and Poland-Lithuania.

27 Kasianov, Ther: A Laboratory of Transnational History.

28 Leveau, Hunter: Islam in France, 3 f.; Rohdewald: Multiple Europäizitäten, 100. 
Rohdewald, Vom ukrainischen »Antemurale Christianitatis« zur politischen Nation?

heute etwa 260.000 tatarische Muslime. Sie stellen dort etwa zwölf Prozent der Bevölkerung - so viel, wie der muslimische Anteil an der Bevölkerung Russlands beträgt. Die meisten von ihnen kamen nach 1991 aus Usbekistan, wohin sie oder ihre Familien während des Zweiten Weltkrieges deportiert worden waren. Zwischen 60.000 und 176.000 von ihnen behielten zunächst die usbekische Staatsangehörigkeit, um während der angebotenen Beantragung des ukrainischen Passes keine Phase einer Staatenlosigkeit erfahren zu müssen. ${ }^{29}$ Die Mehrheit der Bevölkerung der Halbinsel, gegen 60 Prozent, identifiziert sich als Russen, und etwa 25 Prozent als Ukrainer. Je nach Umfrage gaben bis zu 80 oder sogar 95 Prozent der Bevölkerung Russisch als Muttersprache an. Nur einen sehr kleinen Anteil der Bevölkerung stellen jüdische Krimčaken und Karaimen dar. Lokal repräsentieren die Tataren damit einen Schwerpunkt des Islams in der Ukraine. Während das Verhältnis zwischen Krim-Russen, russischsprachigen Muslimen einerseits und Krimtataren andererseits als gespannt beschrieben wird, haben sich lokale Allianzen zwischen den Tataren und Vertretern des ukrainischen Staates entwickelt. Entsprechend sind in der Ukraine unterschiedliche muslimische Organisationen entstanden: Die Geistliche Verwaltung der Muslime der Krim ${ }^{30}$ in Simferopol' ist durch Krimtataren dominiert, während sich in Kiev die Geistliche Verwaltung der Muslime der Ukraine, ${ }^{31}$ die Geistliche Verwaltung der Muslime der Ukraine »Umma «32 und die Religiöse Leitung der unabhängigen muslimischen Gemeinschaften der Ukraine "Kiever Muftijat « ${ }^{33}$ etabliert haben. Die zahlreichen Organisationen stehen für unterschiedliche, ja konkurrierende Standpunkte und die allgemeine Vielfältigkeit gesellschaftlicher Formen des Islams. ${ }^{34}$

29 Petrauskas: Issues of Citizenship, 36-37.

30 http://qirimmuftiyat.org.ua, auch: http://dcmk.org.

$31 \mathrm{http}: / / \mathrm{www}$.islamyat.org.

$32 \mathrm{http} / /$ umma.in.ua.

33 http://muftiyat.com.ua.

34 Weitere Organisationen: Yarosh, Brylov: Muslim Communities, 254.

DigiOst 3 | 405 
Rohdewald, Vom ukrainischen »Antemurale Christianitatis« zur politischen Nation?

Die Mehrheit der Krimtataren hat in mehreren Wahlen Kandidaturen des für eine Annäherung an die EU eintretenden Politikers Viktor Juščenkos unterstützt, während die restlichen Bewohner der Krim insgesamt überwiegend den stärker an Russland orientierten Viktor Janukovyč wählten. Entsprechend lässt sich Mustafa Džemilev, der langjährige Leiter der krimtatarischen Nationalbewegung und ihrer Versammlung (Qırımtatar Milliy Meclisi), auf der entsprechenden Internetseite mit ukrainischer Anstecknadel am Revers darstellen. Als mehrfach gewähltes Mitglied des ukrainischen Parlaments war er Mitglied der Fraktion »Unsere Ukraine«, d.h. des Blocks verschiedener ukrainischer politischer Parteien und Organisationen, die Juščenko unterstützten. ${ }^{35}$ Džemilev steht vor diesem Hintergrund für eine bewusste und praktizierte partizipatorische Integration der muslimischen Krimtataren in einen ukrainischen unabhängigen Staat.

Konnte der Islam seit 1991 Teil einer politisch definierten ukrainischen Nation werden? Beispielsweise die Facebook-Sammlung »Moscheen der Ukraine ${ }^{36}$ oder das hellblau-gelb und mit einer Darstellung der territorialen Form der Ukraine entworfene Logo der von arabischen Studenten gegründeten Allukrainischen Assoziation der gesellschaftlichen Organisationen »Al'raid «, eines Dachverbandes islamischer Verbände bzw. der Muslimbruderschaft der Ukraine, der seinerseits Mitglied mehrerer europäischer islamischer Organisationen ist, ${ }^{37}$ weisen auf Strategien der Selbstintegration in den ukrainischen und in den europäischen politischen Kontext hin. Im Folgenden sei ein Beispiel eines

35 http://qtmm.org; http://cidct.info/press/2008/20082112.html; http://qtmm. org/крымскотатарское-национальное-движение; http://qtmm.org/депу тат-верховной-рады-украины-мустафа-джемилев.

36 https://www.facebook.com/media/set/?set=a.192693170815335.46916.11517959 5233360\&type $=1$.

37 http://www.arraid.org/ua (24.1.2014); Yarosh, Brylov: Muslim Communities, 262-263.

DigiOst 3 | 406 
Rohdewald, Vom ukrainischen »Antemurale Christianitatis« zur politischen Nation?

ethnische und religiöse Grenzen überschreitenden politischen und historischen Identitätsentwurfs exemplarisch ausführlicher besprochen.

\section{Der Islam als Teil einer politischen ukrainischen Nation?}

Ajder Ibrahimov führte ein von 2000 bis 2008 aktives »Informations- und Dokumentationszentrum der Krimtataren «, das auf seiner Homepage mehrere Tagungsbände bereitstellt, deren Beiträge unterschiedliche Standpunkte vertreten. ${ }^{38}$ Oleksandr Majboroda, der die Abteilung Ethnopolitik des Instituts für politische und ethnonationale Forschung der Akademie der Wissenschaften in Kiev leitet, vertrat in einem dort zugänglichen Aufsatz mit dem Titel »Die Geschichte der ukrainisch-krimtatarischen Beziehungen als Bestandteil des ukrainischen Nationalbewusstseins" für einen 2004 in Kiev erschienenen Sammelband Thesen zu einer politischen ukrainischen Nation. Majboroda hob zunächst hervor, dass bei der Aufnahme der Ukraine in den Europarat lobend festgehalten worden war, dass »in der Ukraine Maßnahmen zur Bewahrung eines ethnischen Charakters des ukrainischen Staates « fehlen: »Das heißt, die demokratische Evolution ist identisch mit der Festigung eines Nationalstaats, in dem die Nation alle Staatsbürger umfasst, unabhängig von deren ethnischer Identität. $\ll{ }^{39}$ Mit Ernest Renan definierte Majboroda die polyethnische, politische Nation als »tägliches Plebiszit«:

"Die polyethnische Nation verkörpert besonders deutlich die bekannte Aussage, dass die Nation ein tägliches Plebiszit ist. Abgesehen vom Staat bestärkt

38 http://cidct.info/uk/publications/index.html.

39 Majboroda: Istorija ukrajins'ko-kryms'kotatars'kych vidnosyn. 
Rohdewald, Vom ukrainischen »Antemurale Christianitatis« zur politischen Nation?

die Bewusstmachung gemeinsamer Interessen - ökonomische, politische, das gemeinsame Projekt des zukünftigen Lebens - die polyethnische Nation. $\aleph^{40}$

Die Frage, die Majboroda aufwarf, war nun, inwieweit »alle ethnischen Segmente der polyethnischen Ukraine bereit sind anzuerkennen, dass in allen [diesen Segmenten] ein Charakterzug der nationalen Identität vorhanden ist und welchen Charakter und welchen Inhalt diese gemeinsamen Züge erlangen können «. Zu diesem Zweck verwies Majboroda auf die Diskussion um die "Ukrainische Idee« und ruft zu einer nationalen Erinnerungspolitik auf, die er in diesem kurzen Text zugleich ganz konkret programmatisch entwirft. Er definiert die "nationale Idee« pragmatisch als eine Dreiheit (Triade), die bestehen soll aus einem

»in der Vergangenheit erworbenen gemeinsamen historischen Mythos, der mit dem heutigen nationalen Interesse (dem ökonomischen, dem politischen, dem sozialen, dem geistigen und dem religiösen) abgeglichen ist und ausgerichtet ist auf das zukünftige nationale Ideal«

in diesen gesellschaftlichen Bereichen. ${ }^{41}$ Der Ukraine fehle noch ein solches »Projekt «, das »die ethnischen nicht-Ukrainer um die vorherrschende Titularnation inkorporieren würde «. ${ }^{42}$ Dazu müsse die Titularnation, die den für den nationalen Mythos zentralen Staatsbildungsvorgang getragen habe, ihr eigenes Bewusstsein verändern:

"Aber seine Verwirklichung steht vor einer Reihe von Problemen. Das wichtigste liegt darin, dass die bedeutendste und entscheidende Kraft im Vorgang

40 Majboroda: Istorija ukrajins'ko-kryms'kotatars'kych vidnosyn.

41 Majboroda: Istorija ukrajins'ko-kryms'kotatars'kych vidnosyn.

42 Majboroda: Istorija ukrajins'ko-kryms'kotatars'kych vidnosyn. 
Rohdewald, Vom ukrainischen »Antemurale Christianitatis« zur politischen Nation?

der Erlangung der Staatlichkeit in der Ukraine das ukrainische Titularethnos (titul'nyj etnos) darstellt. Entsprechend werden in dessen historischen Bewusstsein andere ethnische Gemeinschaften gemäß dem Charakter ihrer früheren Beziehungen zu ihm beurteilt, gemäß der Loyalität oder Illoyalität zu seinen Bemühungen, sich zu befreien und Staatlichkeit aufzubauen. Man kann nicht unberücksichtigt lassen, dass das Bewusstsein der nationalen Mehrheit vorläufig weiterhin ethnisch ist, was sich in ihrem historischen Gedächtnis zeigt, in ihren Einstellungen gegenüber anderen ethnischen Gemeinschaften und dabei auch gegenüber den Krimtataren. Der Übergang von diesem Bewusstsein zu einer überethnischen allgemeinnationalen Ebene wird nicht von alleine stattfinden, er benötigt Anstrengungen der intellektuellen Elite auf der Suche nach einer allgemeinakzeptablen Konzeption der Geschichte der ethnischen Ukrainer mit den anderen Völkern und nationalen Minderheiten der Ukraine. « ${ }^{43}$

$\mathrm{Zu}$ diesem Zweck forderte er ein »neues historisches Paradigma « ein..$^{44}$ Er reiht sich damit ein in eine ganze Serie geschichtspolitischer Initiativen, wie sie etwa auch während der Präsidentschaft Juščenkos in der weiterhin in einem Think Tank um den Präsidenten (Nationales Institut strategischer Forschung beim Präsidenten der Ukraine/Nacional'nyj instytut stratehičnych doslidžen' pry Prezydentovi Ukraïny) ${ }^{45}$ erscheinenden Zeitschrift »Strategische Prioritäten « vertreten worden waren. ${ }^{46}$ Konkret erhebt Majboroda die Forderung anzuerkennen, dass das Krimkhanat früher als das Kosakenhetmanat entstanden sei und "als Bestandteil des allgemeinnationalen Staatsbildungsprozesses

43 Majboroda: Istorija ukrajins'ko-kryms'kotatars'kych vidnosyn.

44 Majboroda: Istorija ukrajins'ko-kryms'kotatars'kych vidnosyn.

45 http://www.niss.gov.ua/catalogue/30/.

46 Hierzu: Rohdewald: Post-Soviet Remembrance of the Holocaust, 177. Besonders Zernij: Istoryčna pam'jat', 74.

DigiOst 3 | 409 
Rohdewald, Vom ukrainischen »Antemurale Christianitatis« zur politischen Nation?

betrachtet werden muss «. ${ }^{47}$ Insbesondere die in der ukrainischen Historiographie prominent vertretenen Verweise auf die krimtatarische Praxis des Menschenraubs sei differenzierter zu betrachten, und zwar als in der ganzen Region unter allen Gruppen verbreitete Praxis, ${ }^{48}$ wie er mit Beispielen von Raubzügen von Kosaken erläuterte:

"Die in der Ukraine zirkulierende wissenschaftlich-populäre Literatur ist voller Klagetöne bei der Beschreibung der menschlichen Tragödien, die durch Beutejäger verursacht wurden. Schuld an diesen Tragödien haben dabei Menschen anderen, nicht christlichen Glaubens, so dass der Menschenraub ausschließlich den Krimtataren zugeschrieben wird, während das slavische Milieu als Antipode beschrieben wird, die frei von dieser widernatürlichen Praxis war. Ein solcher Stereotyp, mit dem Völker, ihre moralischen und ethischen Traditionen in «schwarz-weiß〉 Malerei gegenübergestellt werden, stellen ein Hindernis dar nicht nur für die Gestaltung einer gemeinsamen Nation, sondern auch für das gewöhnliche gegenseitige Verständnis. « ${ }^{49}$

Majboroda nennt sodann Beispiele aus der Geschichte der Kosaken, die vom weit verbreiteten Menschenraub zeugen sollten:

"Zudem zogen die Kosaken gegen die Krim weniger, um gefangene Glaubensgenossen zu befreien, sondern vielmehr, um Beute zu machen. Sie unterschieden sich in diesem Sinn ihrer wesentlichen Vorstellungen kaum von ihrem Gegenüber. Auch die Kosaken verachteten es nicht, Unfreie zu nehmen.

47 Majboroda: Istorija ukrajins'ko-kryms'kotatars'kych vidnosyn.

48 Géza / Fodor: Ransom Slavery.

49 Majboroda: Istorija ukrajins'ko-kryms'kotatars'kych vidnosyn.

DigiOst 3 | 410 
Rohdewald, Vom ukrainischen »Antemurale Christianitatis« zur politischen Nation?

Davon gibt es zahlreiche Zeugnisse, die besonders in der "Geschichte der Zaporoger Kosaken« von D. Javornyc'kyj dargelegt wurden. $\aleph^{50}$

Majboroda fährt noch konkreter fort:

"So drangen 1589 Kosaken unter der Führung von Kulaha in Kozlov ein, plünderten die Stadt, und die Überlebenden nahmen sie in die Unfreiheit mit. Danach machten sie bei Akerman und Azov erneut 300 Einwohner zu Gefangenen. Der legendäre Nalyvajko verbrannte 1594 hunderte türkische und tatarische Siedlungen, nahm bis zu 4000 türkische und tatarische Gefangene, die er in die Ukraine ausführen wollte, woran er aber vom Hospodaren der Moldau Aoron gehindert wurde, der die Kosaken überfiel. 1603 kehrten kosakische Zagon aus Weißrussland zurück und nahmen vor Ort zahlreiche Gefangene, um diese später gegen Lösegeld freizugeben, drei bis vier Frauen und drei bis vier Kinder pro Kosak. 1638 nahmen Türken nahe der Insel Tender den Kosaken zehn Schiffe mit gefangenen Frauen und Kindern ab. 1660 nahmen Kosaken, nachdem sie die Stadt Arslan eingenommen hatten, einen Teil der Bewohner als Gefangene und verkauften sie später in ukrainischen Städten. ${ }^{51}$

Weiter heißt es, die krimtatarischen Beispiele seien ja aus dem Schulunterricht jedem bekannt. Letztlich habe der Menschenhandel von der Rus' bis zur Aufhebung der Leibeigenschaft im Russländischen Reich aber auch unabhängig von den Krimtataren floriert. ${ }^{52}$ Auf dem Territorium der Ukraine seien Ackerbauern und Nomaden immer in einem sehr engen Verhältnis zueinander gestanden. Die Ursprünge der Kosaken seien schließlich stärker als üblich in einen $\mathrm{Zu}$ -

50 Majboroda: Istorija ukrajins'ko-kryms'kotatars'kych vidnosyn.

51 Majboroda: Istorija ukrajins'ko-kryms'kotatars'kych vidnosyn.

52 Majboroda: Istorija ukrajins'ko-kryms'kotatars'kych vidnosyn. 
Rohdewald, Vom ukrainischen »Antemurale Christianitatis« zur politischen Nation?

sammenhang mit den zahlreichen Wanderungen von Turkstämmen zu stellen, wobei die der Krimtataren nur das letzte Glied der Kette gewesen seien. Es sei deshalb nicht nur von kultureller Nähe, sondern von einer »Blutsverwandtschaft" (krovnoji bliyz'kosti) zu sprechen. ${ }^{53}$

Ein weiterer wichtiger Teil des »neuen historischen Paradigmas« Majborodas für eine ukrainische Idee war zudem der Abbau der Vorstellung einer Feindschaft gegenüber dem Russländischen Staat. Dies sei nötig, weil das Projekt einer polyethnischen Nation »einen großen Teil ethnischer Russen« einzugliedern habe. Außerdem werde es dann schwerer, Feindbilder äußerer »böser Kräfte« zu konstruieren, und leichter, innergesellschaftliche Widersprüche zu benennen. ${ }^{54}$ Der Verfasser war sich der Schwierigkeiten des Projektes bewusst. Sein Erfolg hänge nicht zuletzt von der Entwicklung des krimtatarischen Selbstbewusstseins ab, vom Kurs der krimtatarischen Volksbewegung, die unter der Leitung des schon genannten Mustafa Džemilev seit dem Beginn der 1990er Jahre und weiterhin früher oder später auf die Etablierung einer krimtatarischen Staatlichkeit abziele. ${ }^{55}$ Jedenfalls würde die »Vereinigung aller ethnischen Segmente in eine ukrainische Nation mit einer überethnischen Identität ein langwieriger und schwieriger Vorgang, dessen Erfolg niemand garantieren kann.$^{56}$ Ein sehr wichtiger Schritt in der »Herausbildung einer Psychologie der toleranten wechselseitigen Einschätzung der Geschichte«, so Majboroda, sei die umfassende Behandlung der Geschichte der Krimtataren in den Schulen, "wie es der Artikel 19 der Haager Empfehlungen bezüglich der Rechte nationaler Minderheiten auf Bildung seitens der OSZE fordert «. Eine politische, polyethnische Nation der Ukraine sei in diesem Entwurf eines

53 Majboroda: Istorija ukrajins'ko-kryms'kotatars'kych vidnosyn.

54 Majboroda: Istorija ukrajins'ko-kryms'kotatars'kych vidnosyn.

55 Majboroda: Istorija ukrajins'ko-kryms'kotatars'kych vidnosyn.

56 Majboroda: Istorija ukrajins'ko-kryms'kotatars'kych vidnosyn. 
Rohdewald, Vom ukrainischen »Antemurale Christianitatis« zur politischen Nation?

»neuen historischen Paradigmas« für eine nationale Geschichtspolitik in einem europäischen Zusammenhang gestellt. ${ }^{57}$

Eine geschichtspolitische Umsetzung einer Konzeption nationaler Geschichte im hier vorgeführten Sinne hat sich aber als nicht realisierbar erwiesen: 2008 und 2009 wurde im Auftrag des Kiever Instituts des Nationalen Gedenkens ${ }^{58}$ zwar nach Diskussionen unter angesehenen Akademikern unter der Federführung der prominenten Leiterin der Mohyla-Akademie Natalija Jakovenko ein umfangreiches Programm für den Unterricht der Geschichte in den Schulen der Ukraine erstellt, das gerade die Vorstellung vom Antemurale sowie des vermeintlichen krimtatarischen Alleinstellungsmerkmals, über Jahrhunderte hinweg Menschenräuber gewesen zu sein, dekonstruieren sollte. ${ }^{59}$ Nach dem Wechsel der Leitung des Instituts unter dem im Februar 2010 eingesetzten ukrainischen Präsidenten Janukovyč und der Übernahme der Direktion durch Valerij Soldatenko im Juli 2010 wurde dieses Projekt aber nicht weiter verfolgt. ${ }^{60}$ Die staatlich unterstützte Konstruktion ukrainischer Nationalität trat in den folgenden Jahren in den Hintergrund. Allerdings fand noch im Dezember 2010 am Nationalen Institut strategischer Forschung beim Präsidenten der Ukraine ein Runder Tisch zum Thema der rechtlichen Regulierung der ethnopolitischen Integration in die ukrainische Gesellschaft statt. ${ }^{61}$

57 Majboroda: Istorija ukrajins'ko-kryms'kotatars'kych vidnosyn.

58 http://www.memory.gov.ua.

59 Jakovenko (Hg.): Škil'na istorija 48, 67, 119; auch: Jakovenko (Hg.): Propozyciji do koncepciji; Jakovenko (Hg.): Koncepcija ta prohramy; für den Zugang zu diesen Bänden danke ich Jurij Vološyn (Universität Poltava).

60 Auskunft von Jurij Vološyn (Universität Poltava) vom 13.01.2014.

$61 \mathrm{http} / / / w w w . n i s s . g o v \cdot u a /$ articles/327/. 
Rohdewald, Vom ukrainischen »Antemurale Christianitatis« zur politischen Nation?

\section{Schluss}

Das hier zuletzt ausgeführte Beispiel einer Forderung nach einer bewusst staatlich gelenkten Erinnerungspolitik mit der Zielrichtung der Festigung einer politischen Nation, welche die Vorstellung eines ukrainischen christlichen Antemurale überwindet, ist in einen europäischen Zusammenhang zu stellen. Nahezu alle Staaten Europas, auch Großbritannien, Frankreich und gerade Deutschland mit seiner noch nicht lange zurückliegenden Debatte über eine sogenannte »Leitkultur « oder den sehr kontrovers aufgenommenen präsidialen Stellungnahmen über die Zugehörigkeit des Islams zu Deutschland, stehen angesichts postkolonialer und postmoderner Migrationsgesellschaften vor vergleichbaren Problemen der pragmatischen Überwindung älterer, ethnisch oder auch religiös exklusiver Nationsentwürfe. Im bulgarischen Fall hat sich die »Bewegung für Rechte und Freiheiten" (bulg. DPS, Dviženie za prava $i$ svobodi, türk. HÖH, Hak ve Özgürlükler Hareketi), die Mitglied der Europäischen Liberaldemokratischen Reformpartei ist und hauptsächlich von der türkischen, muslimischen Minderheit getragen wird, nach $1989 \mathrm{zu}$ einem innenpolitischen Stabilitätsfaktor entwickelt. Sie wurde als Träger des Konzepts des »Bulgarischen ethnischen Modells«, das für eine nur politisch bulgarisch genannte, aber überethnisch und auch nicht nominal religiös entworfene politische Nation steht, mehrfach inoffiziell und dann auch offiziell Teil von Koalitionsregierungen geworden, ${ }^{62}$ zuletzt auch mit der nationalistischen Partei »Ataka«, was neue Probleme aufgeworfen hat.

Eine heutige Staatsgesellschaft sollte sich, entsprechend der Verfassung, auch in der Ukraine auf allen Ebenen als nicht religiös oder religiöse Gemeinschaften übergreifend und überethnisch definieren, soll das Konzept einer

62 Rohdewald: Die »Bewegung für Rechte und Freiheiten«. 
Rohdewald, Vom ukrainischen »Antemurale Christianitatis « zur politischen Nation?

ukrainischen politischen Nation sich weiter durchsetzen. ${ }^{63}$ Die Rede von einer »Blutsgemeinschaft« von Krimtataren und Ostslaven ist dazu nicht erforderlich, es genügt eine Einordnung der gegenwärtigen Gesellschaft und ihrer Geschichte in einen überregionalen Interaktions- und Kommunikationszusammenhang. Das Aufgreifen der Forderung und der Entwurf der Umordnung der Lehrpläne bezeugen die Bemühungen, eine politische Deutung der Nation zu vertreten - die Ablehnung der Lehrpläne hingegen sind Ausdruck der Widerstände, die einer nicht ethnisch-nationalen Geschichtsdeutung nicht nur in der Ukraine immer noch gegenüberstehen. Die Abkehr von dem neuen Geschichtsentwurf erfolgte offenbar seitens der Präsidentschaft Janukovyč aus einem Desinteresse an der Entwicklung einer gesamtukrainischen Identität gegenüber der Anlehnung an Russland. Immerhin vertrat die genannte Zeitschrift »Strategische Prioritäten « auch 2013 mit der Publikation eines Beitrags von Anastasija Nečytajlo das Konzept einer politischen Nation: „Das bedeutet, dass ein Bürger der Ukraine, der sich bewusst zur ukrainischen Nation zählt, gleichzeitig ein ethnischer Russe, Deutscher, Armenier, Krimtatar oder Vertreter einer anderen Gemeinschaft sein kann. «64

Die in der Geschichte Europas nach 1945 beispiellose Annexion der Krim durch die Russländische Föderation im Frühjahr 2014 machte deutlich, dass zahlreiche Krimtataren und ihre politische Führung die Zugehörigkeit der Autonomen Republik Krim und ihrer multiethnischen Bevölkerung zur Ukraine im Sinne einer überethnischen, politischen ukrainischen Nation gegenüber dem Wechsel des Gebiets in die Russische Föderation vorzogen. ${ }^{65} 95$ Prozent

63 Vgl. Rohdewald: »Freiheit (...) ungeschmälert durch Unterschiede der Sprache und der Religion."

64 Nečytajlo: Nacional'na identyčnist', 59.

65 Vgl. die Berichterstattung über Demonstrationen für den Verbleib der Krim in der Ukraine am 14.03.2014 auf der ukrainischen Nachrichtenseite zn.ua: http:// zn.ua/UKRAINE/bolee-40-tysyach-zhiteley-kryma-proveli-akciyu-za-celostnost- 
Rohdewald, Vom ukrainischen »Antemurale Christianitatis« zur politischen Nation?

der Krimtataren sollen die Abstimmung vom 16. März über den Status der Krim boykottiert haben. ${ }^{66}$ Der meclis, die krimtatarische Volksversammlung, sprach sich am 18. März gegen die Anerkennung des Übergangs der Krim in die Russische Föderation aus. ${ }^{67}$ Dennoch erneuerte sich die Deutung der Krim im russischen und postsowjetischen Diskurs als »Perle des Imperiums « ${ }^{68}$. Der imperiale Anspruch des russischen Präsidenten Vladimir Putin auf Einfluss über so genannte $»$ historische Territorien ${ }^{69}{ }^{69}$ und die Rede vom Schutz des »russischen Volks « jenseits der Grenzen der Russischen Föderation stehen im Widerspruch zu den hier besprochenen Bemühungen, eine in der Zivilgesellschaft begründete politische Nation der Ukraine zu festigen.

Mit der militärischen Intervention Russlands in der Ukraine einher ging eine markante Zuspitzung identitäts- und geschichtspolitischer Debatten in der gesamten Region, die auch in den zentral- und ostukrainischen Gebieten zu einer weiteren Konsolidierung der ukrainischen Staatlichkeit und politischen Loyalität der meisten ihrer Bürger in der Abgrenzung gegenüber Russland führte, wie die Präsidentschafts- und Parlamentswahlen 2014 zeigten. Die Handlungen der russischen Regierung vor Ort - etwa die Schließung des

ukrainy-i-protiv-referenduma-141117_html. Mustafa Džemilev weigerte sich im Gespräch mit Vladimir Putin, ein Votum für den Wechsel der Krim in die Russische Föderation zu geben. Stattdessen warnte er im NATO-Hauptquartier in Brüssel vor einem Zerfall Russlands, falls es zu einem offenen Krieg zwischen der Ukraine und Russlands kommen sollte. Nachrichtenagentur UNIAN vom 14.3.2014: http:// www.unian.net/politics/896577-voyna-s-ukrainoy-budet-nachalom-kontsa-rossiii-privedet-k-raspadu-rf-djemilev.html.

66 So die Nachrichtenseite Interplus (16.03.2014) mit Verweis auf Angaben der krimtatarischen Volksversammlung: http://podrobnosti.ua/power/2014/03/16/964961. html.

67 So die Seite der Zeitschrift Zerkalo Nedeli (18.03.2014) mit Verweis auf Angaben der krimtatarischen Volksversammlung: http://zn.ua/POLITICS/medzhlisotkazalsya-priznavat-vhozhdenie-kryma-v-sostav-rossii-141401_.html.

68 Jobst: Die Perle des Imperiums.

69 Ansprache Vladimir Putins am 18.03.2014: http://news.kremlin.ru/news/20603.

DigiOst 3 | 416 
Rohdewald, Vom ukrainischen »Antemurale Christianitatis« zur politischen Nation?

krimtatarischen Fernsehens im Frühjahr 2015 - sowie die Berichterstattung in den staatlich gelenkten Medien wirken sich negativ auf ein ethnische Grenzen übergreifendes russländisches Staatsbürgerschaftsverständnis aus und stehen für eine gerade im Krieg mit der Ukraine intensivierte russische Nationalisierung des russländischen Vielvölkerstaates.

\section{Literatur}

Bednarczuk, Leszek: Stosunki językowe na ziemiach Wielkiego Księstwa Litewskiego. Krakau 1999.

Budzynovs'kyj, V'jačeslav: Naši het'many. L'viv 1907.

Bulgakova, Victoria: Islamisch-christlicher Kulturkontakt im nördlichen Schwarzmeerraum. Sugdaia unter Herrschaft der Seldschuken. In: Borgolte, Michael u. a. (Hgg.): Mittelalter im Labor. Die Mediävistik testet Wege zu einer transkulturellen Europawissenschaft. Berlin 2008, 261-273. Čyževs'kyj, Dmytro / Pritsak, Omeljan: Kul'tura. In: Encyklopedija ukrajinoznavstva. Zahal'na častyna (Eu - I). München, New York 1949, Bd. 2, 694708.

Géza, Dávid / Fodor, Pál (Hgg.): Ransom Slavery along the Ottoman Borders (Early Fifteenth-Early Eighteenth Centuries). Leiden 2007.

Helmedach, Andreas u. a. (Hgg.): Das osmanische Europa. Methoden und Perspektiven der Frühneuzeitforschung zu Südosteuropa. Leipzig 2014.

Hunter, Shireen T. (Hg.): Islam, Europe's Second Religion. The New Social, Cultural, and Political Landscape. Westport CT 2002.

Jakovenko, Natalija (Hg.): Koncepcija ta prohramy vykladannja istoriji Ukrajiny v školi (proekt). Kyjiv 2009.

Jakovenko, Natalija (Hg.): Propozyciji do koncepciji istoryčnoji osvity v Ukrajini. Materialy II Robočoji narady z monitoryngu škil'nych pidručnykiv istoriji Ukrajiny (Kyjiv, 18. žovtnja 2008 roku). Kyjiv 2009. 
Rohdewald, Vom ukrainischen »Antemurale Christianitatis« zur politischen Nation?

Jakovenko, Natalija (Hg.): Škil’na istorija očyma istorykiv-naukovciv. Materialy Robočoji narady z monitoryngu škil'nych pidručnykiv istoriji Ukrajiny. Kyjiv 2008.

Jobst, Kerstin: Die Perle des Imperiums. Der russische Krim-Diskurs im Zarenreich. Konstanz 2007.

Kačala, Stepan: Polityka Polaków względem Rusi. Lwów 1879.

Kasianov, Georgiy / Ther, Philipp (Hgg.): A Laboratory of Transnational History. Ukraine and Recent Ukrainian Historiography. Budapest 2009.

Kołodziejczyk, Dariusz: Das Krimkhanat als Gleichgewichtsfaktor in Osteuropa (17.-18. Jh.). In: Klein, Denise (Hg.): The Crimean Khanate between East and West (15th-18th Century). Wiesbaden 2012, 47-58.

Kołodziejczyk, Dariusz: Ottoman-Polish Diplomatic Relations (15th-18th Century). An Annotated Edition of 'Ahdnames and other Documents. Leiden, Boston, Köln 2000.

Kołodziejczyk, Dariusz: The Crimean Khanate and Poland-Lithuania. International Diplomacy on the European Periphery (15th-18th Century). A Study of Peace Treaties Followed by Annotated Documents. Leiden, Boston 2011.

Leveau, Remy / Hunter, Shireen T.: Islam in France. In: Hunter, Shireen T. (Hg.): Islam, Europe's Second Religion. The New Social, Cultural, and Political Landscape. Westport CT 2002, 3-28.

Lypyns'kyj, V'jačeslav: Relihija i cerkva v istoriji Ukrajiny. Philadelphia 1925. Majboroda, Oleksandr: Istorija ukrajins'ko-kryms'kotatars'ych vidnosyn jak skladova ukrajin'skoji nacional'noji svidomosti. In: Kuras, Ivan u. a. (Hgg.): Problemy intehraciji kryms'kych repatriantiv v ukrajins'ke suspil'stvo. Materialy Vseukrajins'koj naukovo-praktyčnoji konferenciji. Kyjiv 2004. Ohne Paginierung unter: http://cidct.info/uk/publications/Panchuk/13.html (11.1.2014).

Maréchal, Brigitte u. a. (Hgg.): Muslims in the Enlarged Europe. Religion and Society. Leiden, Boston 2003. 
Rohdewald, Vom ukrainischen »Antemurale Christianitatis« zur politischen Nation?

Nečytajlo, Anastasija: Nacional'na identyčnist' u hlobal'nomu informacijnomu suspil'stvi. In: Stratehični prioriteti (2013), H. 4 (29), 56-63.

Petrauskas, Zenonas: Issues of Citizenship in the New Constitutions. In: Council of Europe / European Commission for Democracy through Law (Hgg.): Citizenship and State Succession. Strasbourg 1998, 26-38.

Popovyč, Myroslav: Narys istoriji kul'tury Ukrajiny. Rekomendovano Ministerstvom osvity Ukrajiny, 2. Aufl. Kyjiv 2001.

Pritsak, Omeljan: Das erste türkisch-ukrainische Bündnis (1648). In: Oriens 6/2 (1953), 266-298.

Pritsak, Omeljan: Moscow, the Golden Horde, and the Kazan Khanate from a Polycultural Point of View Author. In: Slavic Review 26 (1967) 4, 577-583. Pritsak, Omeljan: The Origin of Rus'. In: Russian Review 36 (1977) 3, 249-273. Pritsak, Omeljan: The Ukraine and the Dialectics of Nation-Building. In: Slavic Review (1963), 224-255.

Prügl, Elisabeth / Tiehl, Markus: Understanding Diversity in the European Integration Project. In: Prügl, Elisabeth / Tiehl, Markus (Hgg.): Diversity in the European Union. New York 2009, 3-20.

Rechel, Bernd: The «Bulgarian Ethnic Model〉- Reality or Ideology? In: Europe-Asia Studies 59 (2007), H. 7, 1201-1215.

Rechel, Bernd: The Long Way Back to Europe. Minority Protection in Bulgaria. Stuttgart 2008.

Rohdewald, Stefan: Die »Bewegung für Rechte und Freiheiten« und das »Bulgarische Ethnische Modell«: Funktionen und Grenzen eines politischen Legitimationsdiskurses unter Bulgaren und bulgarischen Türken. In: Boeckh, Katrin u. a (Hgg.): Staatsbürgerschaft und Teilhabe: Bürgerliche, politische und soziale Rechte im östlichen Europa. München 2014, 161-175.

Rohdewald, Stefan: »Freiheit (...) ungeschmälert durch Unterschiede der Sprache und der Religion.«Handeln für eine societas civilis in staatspolitischen Krisen auf dem Gebiet der heutigen Ukraine im Vergleich: 1658, 1919 und 2004. In: Lukanjuk, Serhij / Söller, Carola / Wünsch, Thomas (Hgg.): Uk- 
Rohdewald, Vom ukrainischen »Antemurale Christianitatis« zur politischen Nation?

rajina ta rozvytok hromadjans'koho suspil'stva pislja 2004 roku. Materialy ukrajins'ko-nimec'koji naukovoji konferenciji/ Die Ukraine und die Entwicklung ihrer Zivilgesellschaft nach 2004. Beiträge zu einer ukrainisch-deutschen Tagung. Ternopil' 2010, 13-25.

Rohdewald, Stefan / Frick, David / Wiederkehr, Stefan (Hgg.): Litauen und Ruthenien. Studien zu einer transkulturellen Kommunikationsregion (15.-18. Jahrhundert) / Lithuania and Ruthenia. Studies of a Transcultural Communication Zone (15th-18th Centuries). Wiesbaden 2007.

Rohdewald, Stefan: Multiple Europäizitäten: Orthodoxie und Islam in politischen öffentlichen Diskursen in Bulgarien nach 1989. In: Ivanišević, Alois (Hg.): Re-Sakralisierung des öffentlichen Raums in Südosteuropa nach der Wende 1989? Frankfurt am Main u. a. 2012, 99-114.

Rohdewald, Stefan: Post-Soviet Remembrance of the Holocaust and National Memories of the Second World War in Russia, Ukraine and Lithuania. In: Forum For Modern Language Studies (Special Issue: Representations of the Past in European Memorials, hg. v. Bill Niven) 44 (2008) 2, 173-184.

Srodecki, Paul: Antemurale Christianitatis. In: Bahlcke, Joachim / Rohdewald, Stefan / Wünsch, Thomas (Hgg.): Religiöse Erinnerungsorte in Ostmitteleuropa. Konstitution und Konkurrenz im nationen- und epochenübergreifenden Zugriff. Berlin 2013, 804-822.

Wöller, Burkhard Johannes: »Europa« als historisches Argument. Fortschrittsnarrative, Zivilisierungsmissionen und Bollwerkmythen als diskursive Strategien polnischer und ukrainischer Nationalhistoriker im habsburgischen Galizien. Diss. Universität Wien 2013.

Yarosh, Oleg / Brylov, Denis: Muslim Communities and Islamic Network Institutions in Ukraine: Contesting Authorities in Shaping of Islamic Localities. In: Górak-Sosnowska, Katarzyna (Hg.): Muslims in Poland and Eastern Europe Widening the European Discourse on Islam. Warszawa 2011, $252-265$. 
Rohdewald, Vom ukrainischen »Antemurale Christianitatis« zur politischen Nation?

Zaklyns'kyj, Kornylo: Znošenja cîsarja Rudolfa II. z kozakamy y ych učast' v vôjnî uhorsko-tureckôj v r. 1594 i 1595. In: Spravozdanje dyrekciî c. k. hymnaziy akademyčnoy vo L’vovî na rîk škîl’nyj 1881/2 (1882), 1-38.

Zernij, Julija: Istoryčna pam'jat' jak ob'jekt deržavnoji polityky. In: Stratehični prioriteti (2007), H. 1 (2), 71-76.

\section{Internetseiten}

http://www.president.gov.ua/content/constitution.html (06.01.2014)

http://qirimmuftiyat.org.ua (13.01.2014)

http://dcmk.org (13.01.2014)

http://www.islamyat.org (13.01.2014)

http://umma.in.ua (13.01.2014)

http://muftiyat.com.ua (13.01.2014)

http://qtmm.org (11.01.2014)

http://cidct.info/press/2008/20082112.html (11.01.2014)

http://qtmm.org/крымскотатарское-национальное-движение (11.01.2014) http://qtmm.org/депутат-верховной-рады-украины-мустафа-джемилев (11.01.2014)

https://www.facebook.com/media/set/?set=a.192693170815335.46916.11517

9595233360\&type $=1(11.01 .2014)$

http://www.arraid.org/ua (24.01.2014)

http://cidct.info/uk/publications/index.html (11.01.2014)

http://www.niss.gov.ua/catalogue/30/ (14.03.2014)

http://www.memory.gov.ua (14.03.2014)

http://www.niss.gov.ua/articles/327/ (14.03.2014)

http://zn.ua/UKRAINE/bolee-40-tysyach-zhiteley-kryma-proveli-akciyu-za-

celostnost-ukrainy-i-protiv-referenduma-141117_html (14.03.2014) 
Rohdewald, Vom ukrainischen »Antemurale Christianitatis« zur politischen Nation?

http://www.unian.net/politics/896577-voyna-s-ukrainoy-budet-nachalom-

kontsa-rossii-i-privedet-k-raspadu-rf-djemilev.html (14.03.2014)

http://podrobnosti.ua/power/2014/03/16/964961.html (14.03.2014)

http://zn.ua/POLITICS/medzhlis-otkazalsya-priznavat-vhozhdenie-kryma-v-

sostav-rossii-141401_.html (14.03.2014)

http://news.kremlin.ru/news/20603 (18.03.2014).

\section{Abstract}

\section{Stefan Rohdewald}

From the Ukrainian »Antemurale Christianitatis « to the Political Nation: Historical Images of Ukraine and the Muslim Krimtatars

Numerous states of Europe as well as the European Union itself have been challenged to change their political identity, which was often defined in the past by ethnic or religious identity, in order to offer all their citizens an acceptable civic political identity. In this article the author will discuss the case of Ukraine, which since its 1991 independence has confronted such complex identity-political challenges as the integration of a large Russian-speaking population, in relation to visions of and historiographical approaches to its Muslim population. The demand for memory politics consciously directed by the state had the objective of consolidating a political nation that incorporated Tatar history into Ukrainian history, in order to overcome the conception of a Ukrainian Christian Antemurale directed against so-called Asiatic Hordes. This letter had been worked out by the Ukrainian Institute of National Memory in cooperation with numerous academics, but was never implemented. This testifies to the resistance that a non-ethnic-national historical interpretation of Ukrainian society still faces. 


\section{Ljudmyla Boyarova}

\section{Zur religiösen Lexik in der modernen ukrainischen Standardsprache}

Der Inhalt und die Entwicklung des religiösen Wortschatzes in jeder Sprache sind konfessionell bedingt. Den größten Anteil am religiösen Leben in der Ukraine hat seit jeher die Orthodoxie als eine der Hauptrichtungen des Christentums. In den letzten Jahren erlebt die Ukrainische Griechisch-Katholische Kirche eine Renaissance, die Anzahl ihrer Gemeinden hat fast das Vorkriegsniveau erreicht. Eine dynamische Entwicklung erlebt auch die Römisch-Katholische Kirche. Es gibt protestantische Kirchen und verschiedene unabhängige christlich-protestantische Bewegungen. Nicht-christliche Konfessionen sind in der Ukraine wenig verbreitet. Der Informationsbericht des Kulturministeriums der Ukraine "Über den Zustand und die Tendenzen der Entwicklung der Situation im religiösen Bereich und in den Beziehungen zwischen Staat und Kirche in der Ukraine« stellte zum 1. Januar 2013 fest: »Die Verteilung der religiösen Organisationen je nach der Konfession zeugt davon, dass christliche Denominationen in der Ukraine klar überwiegen. Orthodoxe, katholische und protestantische Gemeinden machen etwa 94 Prozent von deren Gesamtzahl aus. « ${ }^{1}$ Und tatsächlich gehören die Ukrainer überwiegend dem Christentum an.

Die ukrainische konfessionelle Landschaft kann in der Zukunft möglicherweise noch bunter werden, aber die Struktur des religiösen Wortschatzes in der modernen ukrainischen Sprache wird dies nicht wesentlich ändern. Heute funktioniert der christliche Wortschatz als ein strukturiertes Untersystem in der ukrainischen Standardsprache. Er spiegelt die Mentalität der ethnischen Ukrainer und ihre religiöse Weltanschauung wider. Das kann man jedoch

1 Інформаційний звіт Міністерства культури України »Про стан і тенденції розвитку релігійної ситуації та державно-конфесійних відносин в Україні«. 
Boyarova, Zur religiösen Lexik in der modernen ukrainischen Standardsprache

nicht über Wörter sagen, die in der ukrainischen Sprache bekannte Begriffe aus anderen, nicht christlichen Konfessionen benennen. Diese Wörter sind durch Kontakte mit anderen Völkern und Kulturen im Ukrainischen übernommen worden und entstanden nicht zur Bezeichnung religiöser Begriffe bei den ethnischen Ukrainern. Das Ukrainische verfügt über eine begrenzte Zahl solcher Wörter; sie sind nicht systemhaft in die Sprache eingebunden, so dass die Sprachträger nicht über das gesamte Wissen über die Begriffe in anderen Konfessionen verfügen.

Ihrem Inhalt nach ist der religiöse Wortschatz in der ukrainischen Sprache christlich. Er ist Gegenstand dieses Beitrags. In der wissenschaftlichen Literatur wurde die Meinung geäußert, dass »der Stil, der in sprachwissenschaftlichen Abhandlungen als konfessionell bezeichnet wird, [...] als christlicher Stil des religiösen Metastils bezeichnet werden muss. Dazu sollen alle Texte mit Bezug zum christlichen sakralen Bereich gezählt werden . $^{2}$

Die vollwertige Entwicklung der Sprache wird vor allem durch ihr Funktionieren in allen Bereichen des menschlichen Lebens realisiert. Da das geistliche Leben eines Volkes insbesondere mit Religion verbunden ist, spiegeln sich die religiöse Weltanschauung und die Wahrnehmung der Welt durch die Gläubigen in der Sprache wider. In der ukrainischen Sprache hat sich seit langem ein Stil entwickelt, der im kirchlich-religiösen Leben der Ukrainer verwendet und in der wissenschaftlichen Literatur meistens als Konfessionsstil bezeichnet wird. In der Sowjetzeit ist der Konfessionsstil vom stilistischen System der ukrainischen Standardsprache ab Mitte der 1930er Jahre in der Ost- und in der Zentralukraine und später in der Westukraine ausgeschlossen worden. Das war durch außersprachliche Faktoren bedingt, unter anderem durch die antireligiöse Politik der sowjetischen Regierung und die Ideologisierung der Sprache. Es ist ein Beispiel dafür, wie die Sprache zum Objekt der Politik wird.

2 Грималовський: Мова української духовної поезії XVIII - початку XIX століття, 6. 
Boyarova, Zur religiösen Lexik in der modernen ukrainischen Standardsprache

Das durch die Sowjetmacht realisierte breit angelegte soziale Experiment hat sich auch auf die Sprache jeder Nation und jedes Volkes in der Sowjetunion ausgewirkt. Das Ukrainische war hier keine Ausnahme. Jurij Ševeljov hat nach seinen Forschungen über die Sprachpolitik in verschiedenen, von Ukrainern bewohnten Gebieten - also auch in verschiedenen Staaten - in der ersten Hälfte des 20. Jahrhunderts deren Besonderheiten in der Sowjetunion so formuliert: "Die staatlichen Eingriffe in die Gesetze der Sprache waren eine sowjetische Erfindung und ein Novum. Das haben weder die Polen, noch die Rumänen noch die Tschechen gemacht, auch die zaristische Verwaltung vor der Revolution in Russland hat so etwas nicht praktiziert. Sie haben sich alle auf äußerlichen Druck beschränkt, indem sie den öffentlichen Gebrauch des Ukrainischen ganz oder teilweise verboten, die Staatssprache über das Bildungssystem aufzwangen, die Ukrainer durch Kultur und Karrieremöglichkeiten gelockt haben, sie in nicht-ukrainische Gebiete um- und gleichzeitig Vertreter der Titularnation auf dem ukrainischen Territorium angesiedelt haben usw. Parallel zu diesen 〈klassischen〉 Methoden etabliert das sowjetische System die Kontrolle über die Struktur der ukrainischen Sprache [...]. Der Kampf wurde nicht nur in der Mentalität des Menschen, sondern auch in der Sprache selbst ausgetragen. « $^{3}$ Die Sprachpolitik in der Sowjetukraine betraf nicht nur das stilistische System der ukrainischen Sprache (wie bereits erwähnt, wurde der Konfessionsstil aus dem Stilsystem ausgeschlossen), sondern auch die Kodifizierung des religiösen Wortschatzes in lexikographischen Werken. Als Folge gab es in der Sowjetukraine kein Wörterbuch der Religionslexik, und in den allgemeinen Wörterbüchern wird dieser Wortschatz nur in einem sehr eingeschränkten Umfang wiedergegeben. Die Deutung der kodifizierten Wörter, die religiöse Begriffe benennen, war meistens oberflächlich und ideologisiert. Der ukrainische religiöse Wortschatz war folglich kein Gegenstand der wissenschaftli-

3 Шевельов: Українська мова в першій половині двадцятого століття (19001941): Стан і статус, 263-264.

DigiOst 3 | 425 
Boyarova, Zur religiösen Lexik in der modernen ukrainischen Standardsprache

chen Forschung in der Sowjetukraine, er wurde von Wissenschaftlern in der Diaspora untersucht. In diesem Zusammenhang sind insbesondere die in München veröffentlichten Arbeiten von Oleksa Horbač zu nennen. ${ }^{4}$ Diese Zeit der wissenschaftlichen Erforschung des Konfessionsstils und der Religionslexik wird oft als »Diaspora-Zeit« bezeichnet.

Ab Anfang der 1990er Jahre ändert sich die Sprachpolitik in der unabhängigen Ukraine, und die Wissenschaftler betrachten den Konfessionsstil als Bestandteil des stilistischen Systems der ukrainischen Standardsprache. Der religiöse Wortschatz wurde zunehmend in den Wörterbüchern aufgenommen und die ukrainische Sprachwissenschaft legte zu diesem Thema eine Reihe von Untersuchungen vor. Gegenstand dieser Forschungen ist entweder die christliche Lexik insgesamt oder die orthodoxe Lexik. Das ist damit zu erklären, dass die Sprachwissenschaft Systemerscheinungen einer Sprache untersucht, wozu auch die ukrainische christliche Lexik gehört. Den religiösen Wortschatz nicht christlicher Konfessionen analysiert die Forschung nicht als in der ukrainischen Sprache etabliertes System, sondern als vereinzelte Sprachgegebenheiten, die als Folge von verschiedenen Ursachen entstanden sind. Im letzten Jahrzehnt des 20. Jahrhunderts wird der religiöse Wortschatz nicht nur von Gelehrten der Theologie (z. B. von Mychajlo Petrovyč), sondern auch von Sprachwissenschaftlern, für die dieses Untersystem der ukrainischen Lexik Gegenstand ihrer wissenschaftlichen Interessen ist, untersucht. Im ersten Jahrzehnt nach der Unabhängigkeit der Ukraine wurden einige Doktorarbeiten zur Thematik des ukrainischen religiösen Wortschatzes verfasst. ${ }^{5} 1998$ fand in L'viv eine wissenschaftliche Konferenz unter dem Titel »Moderne ukrai-

4 Горбач: 3 історії української церковномузичної термінології; Горбач: Українська народня релігійно-християнська термінологія й лексика.

5 Бібла: Склад, джерела і шляхи формування української церковної термінології (назви церковних чинів та посад); Бочарова: Лексико-семантичні та граматичні параметри назв релігійних свят у сучасній українській мові; Піддубна: Формування номенклатури назв релігійних споруд в українській мові.

DigiOst 3 | 426 
Boyarova, Zur religiösen Lexik in der modernen ukrainischen Standardsprache

nische theologische Terminologie - von historischen Traditionen zu neuen Konzepten " statt, deren Beiträge veröffentlicht wurden. Die Beiträge der im Jahr 2000 in Kiev stattfindenden internationalen wissenschaftlichen Konferenz über "Das Christentum und die ukrainische Sprache « wurden im Verlag der Theologischen Akademie in L'viv publiziert. ${ }^{6}$ Der Band umfasst über 60 wissenschaftliche Beiträge, die sich verschiedenen Fragen der Herausbildung und Entwicklung des ukrainischen christlichen Wortschatzes und seinem Einfluss auf die Standardsprache widmen. In weniger als zehn Jahren wurden insgesamt relativ viele theoretische Analysen über die Eigenschaften dieses lexikalischen Untersystems des Ukrainischen vorgelegt. Die Forschungen dazu gehen aber weiter, und es wurden neue Doktorarbeiten vorgelegt, die sich der Herausbildung des ukrainischen religiösen Wortschatzes widmeten. ${ }^{7}$

Bis heute wurde der ukrainische religiöse Wortschatz in einer Reihe von wissenschaftlichen Abhandlungen unter verschiedenen Gesichtspunkten, aber auch unter Einzelaspekten analysiert. Das ermöglicht die hier vorliegende Auswertung von Forschungsergebnissen und die Präsentation der Besonderheiten von religiösem Wortschatz als lexikalisches Untersystem der ukrainischen Standardsprache. In diesem Beitrag wird die religiöse Lexik unter den Aspekten Bestand, Systemcharakter und Wörterbuchkodifizierung analysiert. Als Basis für diese Darstellung dienen die bisher bestehenden Forschungsergebnisse und eigene Untersuchungen dieses Spezialwortschatzes.

6 Християнство й українська мова.

7 Пуряєва: Формування української церковно-обрядової термінології (назви богослужбових предметів); Осінчук: Історія богослужбово-обрядової лексики української мови. 
Boyarova, Zur religiösen Lexik in der modernen ukrainischen Standardsprache

\section{Bestand}

Der untersuchte Wortschatz bildet sowohl nach seiner Semantik als auch nach seiner Form keine einheitliche Gruppe. Die religiöse Weltanschauung wird im Ukrainischen durch verbale Mittel ausgedrückt, das heißt durch Wörter (synthetische Nominationen) und Wortverbindungen (analytische Nominationen), die nach verschiedenen Parametern charakterisiert werden können. Man kann sie beispielsweise nach dem Bezug der einzelnen sprachlichen Einheiten zur jeweiligen Konfession gruppieren. In der wissenschaftlichen Literatur ist die Klassifikation des russischen religiösen Wortschatzes von Timofeev bekannt, der ihr eben dieses Kriterium zugrunde legt. ${ }^{8}$ Diese Klassifikation kann auch für den ukrainischen religiösen Wortschatz angewendet werden. Somit setzt sich dieser aus folgenden Einheiten zusammen:

- allgemeine religiöse sprachliche Einheiten, die Begriffe benennen, die in allen monotheistischen Religionen oder zumindest in einem großen Teil davon Verwendung finden (zum Beispiel: Бог, ві́pa, гріх, добро́, душа́, моли́тва usw.);

- sprachliche Einheiten, die allen wichtigsten christlichen Konfessionen gemeinsam sind und in diesen verwendet werden (zum Beispiel: Сва́нгеліє, Госпо́дня Моли́тва, псалм, Святи́й Дух, Свяще́нне Писа́ння, Спаси́тель, хрест, Хре́щення);

- sprachliche Einheiten, die mit einzelnen christlichen Konfessionen verbunden sind (zum Beispiel: ака́фicт, іконоста́с, кардина́л, конгрега́ція, ме́са, па́стор, Типіко́н).

8 Тимофеев: Религиозная лексика русского языка как выражение христианского мировоззрения.

DigiOst 3 | 428 
Boyarova, Zur religiösen Lexik in der modernen ukrainischen Standardsprache

\section{Systemcharakter}

Der Systemcharakter des religiösen Wortschatzes ist dadurch bedingt, dass in jeder Religion das System von religiösen Begriffen nur durch das System von sprachlichen Einheiten wiedergegeben werden kann, die diese Begriffe benennen. Der ukrainische religiöse Wortschatz wurde im Laufe von vielen Jahren im Sprachumfeld der Ukrainer mit Hilfe von denselben Paradigmen strukturiert und systematisiert, die auch für die Gesamtsprache gelten. Der religiöse Wortschatz wird durch Hypero-Hyponymie (Art-Gattungs-Relation) sowie durch Synonymie und Antonymie strukturiert. Diese Sprachphänomene sind sowohl für den Wortschatz der ukrainischen Standardsprache als auch für jedes ihrer Untersysteme charakteristisch. Der religiöse Wortschatz ist eines davon.

1. Ein Beweis für die systemhaften Beziehungen innerhalb jedes Spezialwortschatzes sind hypero-hyponyme Paradigmen, in denen die Art-Gattungs-Relation zum Ausdruck kommt. Das Hyperonym drückt eine Art, das Hyponym eine Gattung aus. Die sprachlichen Einheiten, die Unterbegriffe benennen, sind Hyponyme in Bezug auf Oberbegriffe (Hyperonyme). Um ein Hyperonym herum entsteht ein Mikrofeld der Hyponyme. Die Bedeutung der Hyponyme weist mehr Merkmale als die Bedeutung eines Hyponyms auf, da ihre Semantik durch neue Elemente erweitert wird. Die Anzahl der Unterbegriffe im hypero-hyponymen Paradigma kann variieren, zum Beispiel: ${ }^{9}$

мáнтія - архиєре́йська ма́нтія, черне́цька ма́нтія;

опівні́чниця - неді́льна опівні́чниця, повсякде́нна опівні́чниця, субо́тня опівні́чниця;

9 Hier und im Folgenden werden Beispiele aus dem Werk von Natalija Purjajeva »Словник церковно-обрядової термінології« verwendet. 
Boyarova, Zur religiösen Lexik in der modernen ukrainischen Standardsprache

часи́ - велико́дні часи́, великопі́сні часи́, повсякде́нні часи́, ца́рські часи́; моле́бень - зага́льний моле́бень, моле́бень до Пресвято́ї Богоро́диці, подя́чний моле́бень, прива́тний моле́бень, проха́льний моле́бень;

іко́на - анало́йна іко́на, виносна́ іко́на, іменна́ іко́на, запресто́льна іко́на, нагру́дна іко́на, хра́мова іко́на;

проки́мен - вели́кий проки́мен, проки́мен вечі́рні, проки́мен дня, проки́мен Літургїї, проки́мен неді́лі, проки́мен свя́та, проки́мен у́трені.

In solchen Paradigmen kann die Anzahl der Hyponyme viel größer sein. So werden 19 Нyponyme zum Нyperonym »богослужіння« angeführt, zum Hyperonym »молитва« sind es 23 Hyponyme.

Ein Oberbegriff kann hypero-hyponyme Paradigmen nach verschiedenen Klassifizierungsmerkmalen bilden. Dadurch ist es möglich, die Struktur des Begriffs zu erweitern und die in der Semantik des Hyperonyms nicht enthaltenen Bedeutungen der "unteren Ebene « zu erschließen. Der Oberbegriff »літургія« hat folgende Semantik: »bedeutendster Gottesdienst des Tages, bei dem das Sakrament der Eucharistie gespendet wird $\aleph^{10}$. Die Bedeutung dieser semantischen Einheit kann präzisiert werden:

a. abhängig davon, wer die Liturgie zelebriert: архиєре́йська Літургі́я, ієре́йська Літургі́я, собо́рна Літургі́я;

b. abhängig vom Anlass: заупокі́йна Літургі́я, Літургі́я Напередосвя́чених Дарі́;

c. abhängig vom Teil der Liturgie: Літургі́я ві́рних, Літургі́я оголо́шених.

Bei hypero-hyponymen Paradigmen kann zwischen verschiedenen Gruppen sprachlicher Einheiten mit Reihen- oder Zweigstrukturen unterschieden werden. In Falle einer Reihenstruktur werden die Glieder eines Paradigmas

10 Пуряєва: Словник церковно-обрядової термінології, 70.

DigiOst 3 | 430 
Boyarova, Zur religiösen Lexik in der modernen ukrainischen Standardsprache

nacheinander konkretisiert; dabei sind die Einheiten der ersten Ebene Oberbegriffe für die nächste Ebene. Zum Beispiel:

освя́чення - осви́чення антимі́нса, осви́чення води́, освя́чення лози́, осви́чення Святи́х Дарі́в, освя́чення хра́му.

Als zweite Ebene der Konkretisierung treten folgende Paradigmen auf: освя́чення води́ - богоя́вленське освя́чення води́, вели́ке освя́чення води́, коро́тке освя́чення води́, мале́ освя́чення води́; освя́чення хра́му - вели́ке освя́чення хра́му, мале́ освя́чення хра́му.

Zweigstrukturen sind jene Strukturen, bei denen einem Hyperonym mehrere nach verschiedenen Merkmalen gegliederte hyponyme Untergruppen zugeordnet sind. Im christlichen Wortschatz hat der Hyperonym "nict « folgende Bedeutungen: »1. Vollständige oder eingeschränkte Enthaltung von Nahrung generell bzw. von bestimmten Speisen, was ein äußerlicher Ausdruck für Buße ist, sowie ein Mittel zur Vorbereitung für wichtige Ereignisse im geistigen Leben. 2. Die durch die Kirche festgelegte Zeit des Tages, der Woche oder des Jahres, in der eine solche Enthaltung vorgeschrieben ist $« .{ }^{11}$ Man kann ihn nach folgenden Merkmalen konkretisieren:

a. abhängig von dem darauffolgenden Fest: піст - Апо́стольський піст, Вели́кий піст, Різдвя́ний піст, Успі́нський піст;

b. abhängig von der Anzahl der Fasttage: піст - багатоде́нний піст, одноде́нний піст;

c. abhängig vom Zeitraum: піст - євхаристійний піст, піст Страсно́го ти́жня.

11 Пуряєва: Словник церковно-обрядової термінології, 96. 
Boyarova, Zur religiösen Lexik in der modernen ukrainischen Standardsprache

Im ukrainischen christlichen Wortschatz sind hypero-hyponyme Gruppen mit Reihenstruktur und nur einer Konkretisierungsebene breiter vertreten als die anderen.

Die logisch-semantische Hierarchie des untersuchten Wortschatzes wird in zwei Arten von Verbindungen zwischen Hyponymen und Hyperonymen realisiert: in eigentlich semantischen und in formal-semantischen. Für eigentlich semantische hyponyme Verbindungen ist nur semantische Nähe charakteristisch, die Ober- und Unterbegriffe haben hier keine gemeinsamen formalen Elemente, beispielsweise im Wortstamm: свяще́нно-богослужбо́ва кни́га - Сва́нгеліє, Апо́стол, Псалти́р, Паремі́йник. Im religiösen Wortschatz ist dieser Paradigmentyp kaum verbreitet, dafür kann eine große Anzahl von formal-semantischen hypero-hyponymen Paradigmen mit einer gemeinsamen Komponente festgestellt werden. Diese Komponente beinhaltet das Oberbegriff-Sem ${ }^{12}$ und wird am häufigsten durch ein Substantiv ausgedrückt: вечі́рня вели́ка вечі́рня, мала́ вечі́рня, повсякде́нна вечі́рня. Die hypero-hyponymen Beziehungen solchen Typs bilden um einen Oberbegriff ziemlich viele Gruppen von Unterbegriffen, zum Beispiel:

єкте́нія - вели́ка єкте́нія, єкте́нія за оголо́шених, заупокійна єкте́нія, мала́ єкте́нія, ми́рна єкте́нія, подя́чна єкте́нія, потрійна єкте́нія, проха́льна єкте́нія; та́їнство - багаторазо́ве та́їнство, необов'язко́ве та́їнство, обов'язко́ве та́їнство, Та́їнство Вінча́ння, Та́їнство Єлеоосвя́чення, Та́їнство Миропома́зання, Та́їнство Поку́ти, Та́їнство Хре́щення.

Zwischen den Hyponymen können auch Beziehungen der Antonymie bestehen: ві́дпуст: вели́кий ві́дпуст - мали́й ві́дпуст; обі́тниці: вели́кі обітниці - малі́

12 Sem ist die kleinste Begriffskomponente in der Bedeutung einer sprachlichen Einheit. 
Boyarova, Zur religiösen Lexik in der modernen ukrainischen Standardsprache

обі́тниці; повече́р'я: вели́ке повече́р'я - мале́ повече́р'я; поклін: вели́кий поклі́н - мали́й поклі́н.

Hypero-Hyponymien gehören zu den wichtigsten Kategorien zur Bildung des christlichen Wortschatzes. "Das sind die grundlegenden semantischen Beziehungen, die den Wortbestand der Sprache strukturieren. ${ }^{13}$ Die Beziehungen zwischen Ober- und Unterbegriffen, also auch zwischen den sprachlichen Einheiten, die diese benennen, spiegeln im Bewusstsein des Menschen das Wesen der Phänomene und Gegenstände in seiner Welt, unter anderem im religiösen Bereich seines Lebens, wider. Die Hypero-Hyponymie bedingt den hierarchischen Charakter der inneren Struktur des ukrainischen christlichen Wortschatzes.

2. Der religiöse Wortschatz wird von zahlreichen synonymen Paradigmen systematisiert, deren Entstehen verschiedene Gründe hat. In der Sprachwissenschaft werden Synonyme als sprachliche Einheiten bezeichnet, die »bei vollständigem oder nicht vollständigem formalen Unterschied identische oder fast identische Bedeutungen haben (mit möglichen Unterschieden in stilistischen und grammatischen Merkmalen sowie in der Valenz) « ${ }^{14}$ In der wissenschaftlichen Literatur gibt es verschiedene Meinungen über die Synonymie im Bereich des Spezialwortschatzes. Es wird als ein positives, negatives oder als ein auch für diesen Wortschatz typisches Sprachphänomen bewertet. Das letztere überzeugt am meisten, weil die Synonyme in der Speziallexik unabhängig von den Wünschen der Wissenschaftler entstehen. Sie ist ja Bestandteil des Wortschatzes der Standardsprache, ihr Untersystem und entwickelt sich nach denselben Gesetzen wie alle anderen Wörter. Wie beim allgemeinen Wortschatz bezeichnen die

13 Українська мова, 319.

14 Ebenda, 607.

DigiOst 3 | 433 
Boyarova, Zur religiösen Lexik in der modernen ukrainischen Standardsprache

Synonyme im religiösen Wortschatz den Inhalt des Begriffes und ergänzen sich gegenseitig.

Die Verbreitung der Synonymie ist durch die Entwicklung des religiösen Wortschatzes bedingt; als Folge sind neue eigene Wörter entstanden, aber auch fremdsprachliche Entlehnungen, zu denen die Ukrainer eigene Entsprechungen erfunden haben. Die Entstehung eines Synonyms ist immer ein Versuch des Sprechenden, den jeweiligen Begriff genau zu benennen. Die Synonyme sind während der gesamten Entwicklung des religiösen Wortschatzes entstanden und wurden noch aus der ältesten Zeit geerbt. Einige Beispiele dafür sind: іко́на - о́браз; поку́тник - ка́яник; священноді́я - тайнодія; спові́дник духівни́к; Типіко́н - Ти́пік - Уста́в.

Von allen lexikalischen Paradigmen ist im ukrainischen christlichen Wortschatz eben die Synonymie am besten erforscht. Allerdings vertreten hier die Wissenschaftler unterschiedliche Meinungen. In den ziemlich detaillierten Abhandlungen von Hanna Nakonečna, ${ }^{15}$ Jurij Osinčuk $^{16}$ und Natalja Purjajeva ${ }^{17}$ werden die synonymen Beziehungen bei der Sprachanalyse unterschiedlich behandelt. Gegenstand der Diskussion sind die Fragen nach der Trennung von Synonymen und Varianten sowie nach den Typen von Synonymen und Varianten. Gleichzeitig sind sich die Forscher über die absoluten Synonyme im religiösen Wortschatz einig darüber, dass dieser Typ der Synonyme ziemlich verbreitet ist.

Die Analyse zeigt, dass der ukrainische christliche Wortschatz recht viele Synonyme und Varianten von Wörtern und Wortverbindungen aufweist. In diesem Beitrag wird folgende Gliederung vorgeschlagen: Bei den Synonymen wird zwischen absoluten und stilistischen Synonymen unterschieden; bei den

15 Наконечна: Про синонімію в богословській термінології.

16 Осінчук: Історія богослужбово-обрядової лексики української мови.

17 Пуряєва: Формування української церковно-обрядової термінології (назви богослужбових предметів).

\begin{tabular}{l|l} 
DigiOst 3 & 434
\end{tabular} 
Boyarova, Zur religiösen Lexik in der modernen ukrainischen Standardsprache

Varianten zwischen Betonungsvarianten und phonematischen, wortbildenden sowie kombinierten Varianten.

Die absoluten Synonyme sind sprachliche Einheiten, die "absolut gleichwertig und insgesamt identisch im Gebrauch sind, das heißt in stilistischer Verwendung, emotional-expressiven Merkmalen, Häufigkeit, Valenz usw. «. ${ }^{18}$ Die absoluten Synonyme (Dubletten) bilden im ukrainischen christlichen Wortschatz lexikalische Paradigmen, die oft aus zwei sprachlichen Einheiten bestehen: ${ }^{19}$ літургійний жест - молито́вний жест; моле́бень - пара́клис; поти́р - ча́ша. Es gibt auch recht viele synonyme Paradigmen mit mehreren absoluten Synonymen; diese können eine unterschiedliche Struktur aufweisen: агіа́сма - свяче́на вода́ - свята́ вода́; богослужі́ння - літургі́я - відпра́ва; вінча́ти - дава́ти шлюб - шлюбува́ти; го́рнє мі́сце - ви́шнє мі́сце - го́рній престо́л; трики́рій - трисві́чник - трираме́нний свічни́к.

Nakonečna hat die Meinung vertreten, dass »diese Dubletten zu einem gewissen Maße nützlich sind, denn jede genetisch unterschiedliche Einheit hat ihre Vor- und Nachteile, was eine maximale Genauigkeit beim Gebrauch im entsprechenden Kontext ermöglicht. Außerdem sind Dubletten auch für die Stilistik eines Textes von Nutzen, denn dadurch können Wiederholungen vermieden werden $«{ }^{20}$ In der Standardsprache sind Wörter mit identischer Bedeutung und Verwendung ziemlich selten, für den Spezialwortschatz ist dagegen die absolute Synonymie typisch. Es kann also hier eine Besonderheit der synonymen Beziehungen im religiösen Wortschatz im Vergleich zum allgemeinen Wortschatz festgestellt werden.

Sprachliche Einheiten sollen als stilistische Synonyme betrachtet werden, wenn sie sich in den synonymen Paradigmen durch Gebrauch und emotio-

18 Українська мова, 610.

19 In Purjajevas »Словник церковно-обрядової термінології« sind alle absoluten Synonyme mit dem Eintrag »Те саме, що " gekennzeichnet.

20 Наконечна: Українська богословська термінологія: характеристика системи, 87. 
Boyarova, Zur religiösen Lexik in der modernen ukrainischen Standardsprache

nal-expressive Wertung unterscheiden. Im religiösen Wortschatz können je nach Gebrauch folgende synonyme Wörter und Wortverbindungen vorkommen: Gebrauch im Gottesdienst (neutral und feierlich-gehoben); Gebrauch in der Sprache der Gläubigen (umgangssprachlich); gebräuchliche und veraltete Wörter und Wortverbindungen. Von der Bedeutung her sind das gleichbedeutende sprachliche Einheiten.

Im untersuchten Wortschatz können folgende synonyme Gegenpaare ausgegliedert werden:

- feierlich-gehobene Bedeutung - neutrale Bedeutung: Сві́тла середа́ Велико́дня середа́;

- feierlich-gehobene oder neutrale Bedeutung - umgangssprachliche Bedeutung: Навечі́p'я Богоя́влення - umgangssprachlich Голо́дна Кутя́; запасні́ Святі́ Дари́ - umgangssprachlich запа́си; у́треня з покло́нами - umgangssprachlich покло́ни;

- moderne Bedeutung - veraltete Bedeutung: дзвін - veraltet ка́мпан; нагру́дна іко́на - veraltet напе́рсна іко́на.

Ein synonymes Paradigma kann ziemlich oft aus mehreren Teilgliedern bestehen: Вели́кий Четве́р - Страсни́й четве́р - umgangssprachlich Чи́стий четве́р; Навечі́p'я Різдва́ Христо́вого - Святи́й вечі́p - umgangssprachlich Бага́тий ве́чір; хрести́льна соро́чка - кри́жмо - veraltet анаво́лій - umgangssprachlich ри́зка; хреще́на ма́ти - veraltet восприє́мниця - umgangssprachlich нана́шка. Die große Anzahl der stilistischen Synonyme im religiösen Wortschatz unterscheidet ihn von der Speziallexik in anderen Bereichen.

Die angeführten Sprachbeispiele zeigen, dass synonyme Paradigmen der religiösen Begriffe aus 1. Wörtern, 2. aus Wortverbindungen; und 3. aus Wörtern und Wortverbindungen bestehen können. Im untersuchten Wortschatz sind alle drei Paradigmentypen verbreitet; einige davon bestehen unverändert seit mehreren Jahrhunderten. Solche beständigen synonymen Beziehungen 
Boyarova, Zur religiösen Lexik in der modernen ukrainischen Standardsprache

sind ein Beweis dafür, dass der ukrainische christliche Wortschatz seit jeher als System organisiert wurde. Darauf weist unter anderem Osinčuk hin, der den religiösen Wortschatz unter historischen Aspekten untersucht hat: »Der liturgisch-rituelle Wortschatz war im Ukrainischen von Anfang an als System organisiert. Die Einheit der semantischen Organisation des ukrainischen liturgischen Wortschatzes basiert auf spezifischen hyponymen und synonymen Paradigmenkorrelationen. $\aleph^{21}$ Mit der Zeit können Synonyme in den passiven Wortschatz wechseln, was für ihre Einstufung als veraltete sprachliche Einheiten spricht und uns über die Entwicklung des religiösen Wortschatzes als Ganzes und der stilistischen Synonymie reden lässt.

Im untersuchten Wortschatz gibt es sprachliche Einheiten mit gemeinsamem Wortstamm und gleicher Bedeutung, die sich in der Form leicht unterscheiden. Man muss sie als Varianten qualifizieren und von den Synonymen trennen. Man kann diese Typen von Varianten sprachlicher Einheiten abhängig von der Änderung ihrer Form folgendermaßen einteilen:

- Betonungsvarianten (Neutralisierung der Betonung als Mittel zur Unterscheidung von Wörtern): ві́вта́p; ли́ті́я; ка́пту́р; о́бру́си;

- phonematische Varianten (die Phoneme behalten ihre physiologisch-akustische Merkmale, büßen aber ihre phonologischen Gegensätze ein und üben ihre bedeutungsunterscheidende Funktion nicht mehr aus): ака́фист und ака́тист; єпити́мія und єпіти́мія; єпитрахи́ль und єпітрахи́ль; капета́сма und капета́зма; Місяцесло́в und Місяцеслі́в; Молитвосло́в und Молитвослі́в; плащани́ця und плащени́ця; протоієре́й und протоєре́й;

- wortbildende Varianten (die sprachlichen Einheiten sind identisch in ihrer Bedeutung, unterscheiden sich aber durch verschiedene Affixe bzw. durch ihr Vorkommen oder Fehlen): висвя́чувати und посвя́чувати, освя́чувати; молито́вниця und молито́вня; свічконо́сець und свічконо́с; Синак-

21 Осінчук: Історія богослужбово-обрядової лексики української мови, 17. 
Boyarova, Zur religiösen Lexik in der modernen ukrainischen Standardsprache

cáp und Синакса́рій; у́треня und зау́треня; хрести́льниця und хрести́льня; хреще́ник und хреще́нець; Часосло́в und Часосло́вець;

- kombinierte Varianten (Modifikation der Form findet auf verschiedenen sprachlichen Ebenen statt): всенічни́к und всено́чник; ка́федра und кате́дра (auf der Betonungs- und phonematischen Ebene); іпако́й und іпако́ï (auf der phonetischen und grammatischen Ebene); мирува́льник und ми́рник, свічни́к und підсві́чник (Betonung und Wortbildung); нарука́вник und нарука́вниця (Wortbildung und Grammatik).

Variabel können nicht nur Wörter, sondern auch attributive Elemente in den Wortverbindungen sein: Квітоно́сна неді́ля und Цвітоно́сна неді́ля; То́мина неді́ля und Фо́мина неді́ля; Успі́нський піст und Успе́нський піст.

Im analysierten Wortschatz gibt es auch syntaktische Varianten. Das heißt, derselbe Begriff wird durch Wortverbindungen mit unterschiedlicher Struktur, aber gemeinsamen Stammelementen bezeichnet: заупокійний тропа́p und тропа́р за упокій; ли́тійна стихи́ра und стихи́ра на ли́тії. Zu diesem Variabilitätstyp gehören auch zwei Namen von Begriffen, von denen der eine durch Wortverbindung, der andere durch ein Wort bezeichnet wird: освя́чення хра́му und храмоосвя́чення; рукопокла́дення und покла́дення рук; тропа́p кано́ну und тропа́p; церко́вне свя́то und свя́то; Та́їнство Соборува́ння und Соборува́ння.

Im religiösen Wortschatz können große lexikalische Paradigmen mit hypero-hyponymen und synonymen Beziehungen ausgegliedert werden, bei denen einige sprachlichen Einheiten formelle Modifikationen aufweisen (in Klammern werden zu dem jeweiligen Hyponym Synonyme und ihre Varianten angegeben): ти́ждень - Ве́рбний ти́ждень (Квітоно́сний тиждень und Цвітоно́сний ти́ждень, Кві́тний ти́ждень und Цві́тний ти́ждень, ти́ждень Вáïй) - М'ясопу́сний ти́ждень (М'ясопу́ст) - Похва́льний ти́ждень - Сві́тлий ти́ждень (Пасха́льний ти́ждень, Велико́дній ти́ждень) - Сиропу́сний ти́ждень (Си́рний ти́ждень, Сироїдний ти́ждень, Масни́й ти́ждень, Масни́ця, 
Boyarova, Zur religiösen Lexik in der modernen ukrainischen Standardsprache

Ма́сляна) - Страсни́й ти́ждень (Вели́кий ти́ждень) - То́мин тиждень und Фо́мин ти́ждень - Хрестопокло́нний ти́ждень (Середохре́сний ти́ждень) церко́вний ти́ждень - зага́льниця (всеїдний ти́ждень, суці́льний ти́ждень, всеїдна седми́ця).

3. Der Wortschatz wird auch durch die Antonymie strukturiert. Die Antonymie ist ein sprachliches Universalphänomen, das ein wichtiges Merkmal des Sprachsystems ist und auf wesentlichen Besonderheiten der Wirklichkeit basiert, die sich in Gegenbegriffen in der Logik und antonymen Bedeutungen in der Sprache manifestieren. In der wissenschaftlichen Literatur hat sich die Meinung etabliert, dass Antonyme sprachliche Einheiten sind, die »eng durch bestimmte semantische Gemeinsamkeit verbunden sind und sich auf derselben Basis durch maximal gegensätzliche Bedeutungen unterscheiden.$_{.}^{22}$ Die wohl bekanntesten und am meisten gebrauchten Antonyme im religiösen Wortschatz sind »Paradies « und »Hölle«. Im religiösen Wortschatz gibt es jedoch relativ viele Gegensatzpaare: ві́рник - атеї́ст; по́вний кано́н - непо́вний кано́н; вели́ка єкте́нія - мала́ єкте́нія; вели́кий вхід - мали́й вхід.

Die Semantik der sprachlichen Einheiten ist entscheidend für deren Antonymie. In der Bedeutung jedes Teilglieds eines Gegensatzpaares muss neben den gegensätzlichen Semen auch ein gemeinsames Sem vorhanden sein. Zum Beispiel: рухо́ме церко́вне свя́то (ein Kirchenfest ohne festes Datum) - нерухо́ме церко́вне сви́то (ein Kirchenfest mit festem Datum). Das gemeinsame Sem für dieses Paar ist das »Kirchenfest«, der Gegensatz wird durch die Seme »festes Datum« und »kein festes (bewegliches) Datum« ausgedrückt. Die Antonyme im religiösen Wortschatz sind meistens semantisch einfach und werden durch ein Sem gegenübergestellt.

In der wissenschaftlichen Literatur werden die Gegensatzpaare im Spezialwortschatz nach mehreren Parametern betrachtet:

22 Українська мова, 28.

DigiOst 3 | 439 
Boyarova, Zur religiösen Lexik in der modernen ukrainischen Standardsprache

- nach semantischen Beziehungen: konträre, komplementäre oder kontradiktorische Antonyme;

- nach gemeinsamer Semantik: volle und nicht volle Antonyme. ${ }^{23}$

Als konträr werden jene Antonyme bezeichnet, bei denen die Unterbegriffe zusammen nur ein Teil des gemeinsamen Oberbegriffes bilden und dazwischen noch eine oder mehrere Abstufungen oder Zwischenstufen (Mesonyme) möglich sind. Für den ukrainischen christlichen Wortschatz können folgende konträre Antonyme als Beispiele gelten: рясофóp - малосхи́мник - великосхи́мник; повсякде́нний антифо́н - неді́льний антифо́н - святко́вий антифо́н; мали́й поклі́н - сере́дній поклі́н - вели́кий поклі́н. Die Paradigmen der konträren Antonyme sind im religiösen Wortschatz ziemlich verbreitet und werden zur Präzisierung der christlichen Begriffe verwendet.

Komplementäre Antonyme sind sprachliche Einheiten, bei denen zwei Unterbegriffe zusammen den gesamten Oberbegriff bilden. Komplementäre Antonyme ergänzen sich gegenseitig und bilden zusammen den Oberbegriff, dazwischen sind keine Abstufungen möglich. Als morphologische Form für komplementäre Antonyme treten sehr oft die von verschiedenen Wortstämmen gebildeten Substantive oder Adjektive (als alleinstehende Wörter oder als Elemente einer Wortverbindung) auf: пра́ведний - грішний; мале́ ко́піє - вели́ке ко́піє; ранко́ве богослужінння - вечі́рнє богослужі́ння.

Bei kontradiktorischen Antonymen bilden zwei Unterbegriffe ebenfalls den gesamten Umfang des Oberbegriffs, dazwischen gibt es keine Abstufung. Einer der Antonyme im Gegensatzpaar verneint das Sem in der semantischen Struktur des zweiten Antonyms. Einige Beispiele für kontradiktorische Antonyme im ukrainischen christlichen Wortschatz sind: літургійний день - алітургійний день und нелітургійний день; обов'язко́ве та́їнство - необов'язко́ве та́їнство.

23 Михайлова: Семантичні відношення в українській науково-технічній термінології, 13. 
Boyarova, Zur religiösen Lexik in der modernen ukrainischen Standardsprache

Im religiösen Wortschatz sind komplementäre und konträre Antonyme am meisten verbreitet, kontradiktorische Antonyme werden dagegen viel seltener gebraucht.

Nach gemeinsamer Semantik können volle und nicht volle Antonyme vorkommen. Bei den vollen Antonymen sind die Teilglieder des Gegensatzpaars in allen Bedeutungen antonym: одноразо́ве таиінство - багаторазо́ве таиїнтво; мале́ освя́чення хра́му - вели́ке освя́чення хра́му. Im untersuchten Wortschatz gibt es keine nicht vollen Gegensatzpaare, weil die Gegensatzrelation zwischen monosemen Wortverbindungen hergestellt wird. Semantische und strukturelle Merkmale der Teilglieder von Gegensatzpaaren sind untereinander verflochten und gegenseitig bedingt.

Der Großteil der Antonyme im ukrainischen christlichen Wortschatz hat meistens eine zweigliedrige Struktur und besteht aus einem Substantiv als Oberbegriff und antonymen attributiven Elementen. Elemente, die in solchen Wortverbindungen gegenübergestellt werden, kann man in zwei Gruppen aufteilen:

1. in Attribute, die antonyme Verbindungen sowohl im allgemeinen Wortschatz als auch in der Speziallexik haben: вели́ка - мала́ (єкте́нія); по́вний непо́вний (кано́н);

2. in Attribute, die nur im ukrainischen christlichen Wortschatz als Antonyme vorkommen: коро́ткий - по́вний (апра́кос); неді́льний - повсякде́нний (антифо́н).

Die Antonymie von sprachlichen Einheiten, die in der Standardsprache nicht als Antonyme auftreten, kann nur festgestellt werden, wenn man die Bedeutung der von ihnen benannten Begriffe kennt. Die Existenz von solchen Antonymen zeugt von einer relativen Autonomie des untersuchten Wortschatzes vom lexikalischen System der Standardsprache.

Als Besonderheit des ukrainischen christlichen Wortschatzes können Gegensatzpaare bei den christlichen Festen betrachtet werden. Sie entstehen durch die Gegenüberstellung der Festtage ein und desselben Heiligen zu ver- 
Boyarova, Zur religiösen Lexik in der modernen ukrainischen Standardsprache

schiedenen Jahreszeiten: весняни́й Лука́ - осі́нній Лука́, зимо́вий Микола́й - лі́тній Микола́й.

Im System der Ausdrucksmittel ist den Antonymen eine wichtige Funktion vorbehalten; sie stellen Begriffe gegenüber oder verbinden sie manchmal auch. Sie erschließen den Inhalt verschiedener Begriffe und helfen, Phänomene und Ereignisse des religiösen Lebens zu unterscheiden.

\section{Die Kodifizierung in Wörterbüchern}

Eine aktuelle Frage für die ukrainische Lexikographie ist die Kodifizierung des ukrainischen religiösen Wortschatzes in Wörterbüchern. Das Wörterbuch ist eine der Formen für die Speicherung und die Systematisierung von Informationen über die Welt, es ist gleichsam eine Datenbank für das kollektive Wissen der Muttersprachler. Wie bereits erwähnt, wurde in der Sowjetukraine kein einziges Wörterbuch des ukrainischen religiösen Wortschatzes herausgegeben. Erst ab Anfang der 1990er Jahre hat man mit der Kodifizierung dieses Wortschatzes in diversen Wörterbüchern begonnen, ${ }^{24}$ ihre Präsenz in den Universalwörterbüchern ist seither deutlich gestiegen. Das populärste und vollständigste Wörterbuch ist für heute das »Словник церковно-обрядової термінології« von Natalja Purjajeva (2001). Ein lexikographisches Werk muss das Sprachbewusstsein der Muttersprachler modellieren, die Diskrepanz zwischen dem individuellen und kollektiven Wissen eines Menschen überbrücken. Deswegen ist der Autor eines Wörterbuchs Träger des kollektiven Wissens, was ihm eine hohe Verantwortung abverlangt. Purjajeva schreibt im Vorwort:

24 Дещиця: Малий український церковно-історичний словник; Герасимчук: Англо-український та українсько-англійський словник релігійної термінології; Мирончук: Короткий російсько-український словник церковно-релігійної лексики.

DigiOst 3 | 442 
Boyarova, Zur religiösen Lexik in der modernen ukrainischen Standardsprache

»Wir möchten betonen, dass die linguistische Einschätzung der angeführten [...] Fakten insofern objektiv (wie übrigens auch subjektiv) ist, als die Meinung eines Autors objektiv (oder subjektiv) sein kann. «25 Man kann mit gutem Grund behaupten, dass Purjajeva in ihrem Wörterbuch den von ihr ausgewählten ukrainischen religiösen Wortschatz objektiv dargestellt hat. Der Autorin ist es gelungen, den Wortschatz als strukturierte Gesamtheit von sprachlichen Einheiten darzustellen, die für die Ukrainer wichtige Begriffe im sakralen Bereich benennen. Dieses Wörterbuch ist heute die Grundlage für die wissenschaftliche Erforschung des ukrainischen religiösen Wortschatzes, unter anderem auch für die Analyse im vorliegenden Beitrag. Purjajeva weist im Vorwort darauf hin, dass das Wörterbuch als Sprachwerk verfasst wurde, das »die nach dem heutigen Stand im Bereich der kirchlichen Riten gesamte existierende (festgehaltene) Terminologie festhält, die den phonetischen, morphologischen, lexikalischen, orthographischen sowie anderen Besonderheiten und Gesetzen der modernen ukrainischen Standardsprache nicht widerspricht « ${ }^{26}$ Der religiöse Wortschatz wird in Spezialtexten (in liturgischen Büchern), in Dokumenten, welche die Gottesdienste reglementieren, in den kirchlichen und religiösen Periodika sowie in der mündlichen Fachsprache verwendet. Purjajeva betont, dass das Wörterbuch »nicht als Normwörterbuch, also nicht als solcher, der zu diesem oder jenem Gebrauch eines Begriffes verpflichtet, verfasst wurde «. ${ }^{27}$ Die Autorin definiert als Aufgabe für ihr Wörterbuch die lexikographische Beschreibung des modernen ukrainischen kirchlich-rituellen Wortschatzes mit Elementen einer linguistischen Wertung. Heute besteht der Bedarf eben an einem Normwörterbuch des ukrainischen religiösen Wortschatzes. Die Entwicklung von Normen für diesen Spezialwortschatz ist ein langer und komplizierter Prozess, der sowohl von inneren Faktoren des religiösen Lebens als auch von äußeren,

25 Пуряєва: Словник церковно-обрядової термінології, 12.

26 Ebenda.

27 Пуряєва: Словник церковно-обрядової термінології, 11. 
Boyarova, Zur religiösen Lexik in der modernen ukrainischen Standardsprache

unter anderem politischen, Elementen beeinflusst wurde. Es bedarf auch eines ausführlicheren Wörterbuchs für den ukrainischen christlichen Wortschatz, weil das Wörterbuch von Purjajeva Wörter und Wortverbindungen führt, die im modernen ostchristlichen Ritus verwendet werden. Viele Namen für Begriffe in anderen christlichen Konfessionen fehlen hier also; nur Begriffe, die für alle Christen gemeinsam sind, kommen in diesem Wörterbuch vor. Die Verfasserin des »Словник церковно-обрядової термінології» behandelt bevorzugt die sprachlichen Einheiten, die konkrete Begriffe des religiösen Kults benennen, allerdings gibt es auch viele sprachliche Einheiten, die abstrakte Begriffe aus dem religiösen Bereich bezeichnen und die ein gläubiger Mensch kennen und verstehen muss. Eine der noch bestehenden Aufgaben der ukrainischen Lexikographie ist es, ein großes Normwörterbuch für die ukrainische christliche Lexik zu verfassen. Der im linguistischen Wörterbuch aufgelistete Wortschatz muss explizit und implizit das kollektive Wissen über das religiöse Leben der Muttersprachler widerspiegeln.

Eine besondere Rolle kommt dem Kodifizieren des religiösen Wortschatzes in den Universalwörterbüchern zu. Moderne Bedeutungswörterbücher für eine große Leserschaft sollen nicht nur allgemein bekannte Wörter beinhalten, sondern auch jenen Teil des Spezialwortschatzes, der wichtige Begriffe benennt und den ein gebildeter Mensch im 21. Jahrhundert kennen sollte. Heute entwickelt sich in der Ukraine ein neuer soziokultureller Persönlichkeitstyp, bei dem christliche Religiosität ein natürlicher Bestandteil der Weltanschauung ist. Eine besondere Rolle spielt heute nicht nur die Anzahl der kodifizierten Wörter im religiösen Bereich, sondern auch die richtige Deutung eines jeden solchen Wortes. 
Boyarova, Zur religiösen Lexik in der modernen ukrainischen Standardsprache

\section{Schlussfolgerung}

Die in diesem Beitrag unternommene Sprachanalyse lässt folgende Schlüsse ziehen:

1. Die sprachlichen Einheiten im ukrainischen religiösen Wortschatz funktionieren nicht isoliert, sondern die von ihnen benannten Begriffe sind untereinander durch diverse logische Verbindungen verknüpft. Diese können nur durch eine strukturierte und systematisierte Gesamtheit der verbalen Mittel der jeweiligen Sprache wiedergegeben werden. Dieser Spezialwortschatz von einem ziemlich großen Umfang ist ein Untersystem des Wortschatzes der ukrainischen Standardsprache, für die Hypero-Hyponymie, Synonymie und Antonymie typisch sind, was die Entwicklung von hypero-hyponymen, synonymen und antonymen Beziehungen zwischen den sprachlichen Einheiten, die religiöse Begriffe und Kultgegenstände benennen, grundsätzlich voraussetzt. Im untersuchten Sprachmaterial können sowohl gemeinsame Züge für diese Sprachphänomene in allen Untersystemen des Wortschatzes der Standardsprache, als auch Besonderheiten des Aufbaus von hypero-hyponymen, synonymen und antonymen Paradigmen festgestellt werden. Das Organisationsniveau von Paradigmen, die den religiösen Wortschatz systematisieren, ist ziemlich hoch; dadurch ist es möglich, für deren Analyse den wissenschaftlichen Apparat der modernen Linguistik anzuwenden, wie dies im vorliegenden Beitrag durchgeführt wurde.

2. Der religiöse Wortschatz ist nicht statisch. Er entwickelt sich, seine Entwicklung hat aber bestimmte Besonderheiten im Vergleich zu anderen Untersystemen der ukrainischen Sprache, in denen Evolution durch das Ersetzen der alten sprachlichen Einheiten durch neue erfolgt. In der religiösen Sprache führt das Auftreten von neuen sprachlichen Einheiten nicht zur Verdrängung der alten, wenn sie in den liturgischen Büchern festgehalten wurden. Kein Wort kann aus dem Gebrauch verschwinden, wenn es im wichtigsten sakralen Text - der Bibel - steht. Eine solche sprachliche Einheit kann zum passiven 
Boyarova, Zur religiösen Lexik in der modernen ukrainischen Standardsprache

Wortschatz wechseln, wenn sie in der neuen Fassung des sakralen Textes fehlt, zum Beispiel, wenn eine neue Übersetzung oder Fassung der Bibel erscheint. Eine größere Dynamik kann in der Semantik und in der Form von solchen sprachlichen Einheiten beobachtet werden, die keine Basisbegriffe aus dem religiösen Leben der Ukrainer bezeichnen.

3. Wenn in der heutigen globalisierten Welt der Einfluss des Englischen zunimmt und der Prozess des Eindringens von Anglizismen in andere Sprachen nicht kontrolliert werden kann, fällt nur ein Untersystem im Wortschaft jeder entwickelten Sprache nicht unter den Einfluss der globalen Sprache, nämlich der religiöse Wortschatz, der für solche Neuerungen verschlossen bleibt. Das beweist auch die Analyse von hypero-hyponymen, synonymen und antonymen Paradigmen im ukrainischen religiösen Wortschatz.

4. Der moderne ukrainische christliche Wortschatz als entwickeltes und strukturiertes Untersystem der Sprache bedarf einer vollständigen und bindenden Kodifizierung. Diese Aufgabe kann sich je nach der Sprachpolitik ändern, die Inhalte und der Auftrag der Kodifizierung können demzufolge variieren. Die Eingriffe der Politik in das natürliche Leben der Sprache in der Sowjetzeit hat die Kodifizierung der religiösen sprachlichen Einheiten qualitativ und quantitativ entstellt; die Folgen sind bis heute spürbar. Der Wortschatz, der seit mehreren Jahrhunderten die religiöse Weltanschauung von ethnischen Ukrainern widerspiegelt, sollte aber weiter nach modernen lexikographischen Leitlinien beschrieben und theoretisch unter verschiedenen Aspekten erschlossen werden.

\section{Literatur}

Бібла, Світлана: Склад, джерела і шляхи формування української церковної термінології (назви церковних чинів та посад). Автореферат. Київ 1997. 
Boyarova, Zur religiösen Lexik in der modernen ukrainischen Standardsprache

Бочарова, Ірина: Лексико-семантичні та граматичні параметри назв релігійних свят у сучасній українській мові. Автореферат. Київ 1999.

Герасимчук, Лесь: Англо-український та українсько-англійський словник релігійної термінології. Київ 1997.

Горбач, Олекса: 3 історії української церковномузичної термінології. Мюнхен 1965.

Горбач, Олекса: Українська народня релігійно-християнська термінологія й лексика. In: Наукові записки Українського Вільного Університету. Філософський факультет 13 (1988), 99-146.

Грималовський, Ігор: Мова української духовної поезії XVIII - початку XIX століття. Автореферат. Чернівці 2006.

Дещиця, Михайло: Малий український церковно-історичний словник. Львів 1994.

Інформаційний звіт Міністерства культури України »Про стан і тенденції розвитку релігійної ситуації та державно-конфесійних відносин в Україні« (Короткий виклад), 11. 04. 2013, unter: http://mincult.kmu. gov.ua/mincult/uk/publish/article/327651;jsessionid=C576ABCB3D48CB 82182949A7237D6CDE (08.04.2014).

Мирончук, Олександр: Короткий російсько-український словник церковно-релігійної лексики. Київ 2010.

Михайлова, Тетяна: Семантичні відношення в українській науково-технічній термінології. Автореферат. Харків 2002.

Наконечна, Ганна: Про синонімію в богословській термінології. In: Бюлетень Інституту богословської термінології та перекладів 2 (1998), 16-27.

Наконечна, Ганна: Українська богословська термінологія: характеристика системи. In: Християнство й українська мова. Львів 2000, 79-92.

Осінчук, Юрій: Історія богослужбово-обрядової лексики української мови. Автореферат. Київ 2009.

Піддубна, Наталія: Формування номенклатури назв релігійних споруд в українській мові. Автореферат. Харків 2000. 
Boyarova, Zur religiösen Lexik in der modernen ukrainischen Standardsprache

Пуряєва, Наталія: Словник церковно-обрядової термінології. Львів 2001. Пуряєва, Наталія: Формування української церковно-обрядової термінології (назви богослужбових предметів). Автореферат. Київ 2001.

Тимофеев, Кирилл: Религиозная лексика русского языка как выражение христианского мировоззрения. Новосибирск 2001, unter http://www. philology.ru/linguistics2/timofeev-01.htm (08.04.2014).

Українська мова. Енциклопедія. Київ 2007.

Християнство й українська мова. Львів 2000.

Шевельов, Юрій: Українська мова в першій половині двадцятого століття (1900-1941): Стан і статус. In: Шевельов, Юрій: Вибрані праці. Київ 2008, 26-279.

\section{Abstract}

\section{Ljudmyla Boyarova}

Religious Vocabulary in Modern Ukrainian Language

The present article analyzes modern Ukrainian's multi-faceted religious vocabulary. The vocabulary's content is Christian, since most Ukrainians adhere to the Christian confession. Through general purpose vocabulary and its common and distinctive features, I examine Ukrainian religious vocabulary as a research object in linguistics, its structure and system organization (hyper/hyponyms, synonyms, antonyms) and lexicographic codification. Linguistic analysis demonstrates that the religious vocabulary in modern Ukrainian represents a structured and arranged set of nominations and clearly reflects the system of religious concepts. The article also raises questions about extralinguistic factors that contribute to language development, its study and codification when it becomes a political object. 


\section{Autorenverzeichnis}

Boeckh, Katrin

Boyarova, Ljudmyla

Buchholz, Martin-Paul

Fenno, Iryna

Frey, Miriam

Gatskov, Maxim

Gatskova, Ksenija

Jelensky, Viktor

Juraš, Andrij

Liubaščenko, Viktorija

Lysenko, Oleksandr

Marynovyč, Myroslav

Popova, Olga

Rešetnikov, Jurij

Rohdewald, Stefan

Šlichta, Natalja

Söller, Carola

Turij, Oleh

Vološyn, Yuriy

Wünsch, Thomas
München/Regensburg

Charkiv

Mainz

Kiev

Regensburg

Regensburg

Regensburg

Kiev/L'viv

L'viv

L'viv

Kiev

L'viv

Regensburg

Kiev

Gießen

Kiev

Berlin/Passau

L'viv

Poltava

Passau 
Katrin Boeckh - 978-3-86688-505-9 


\section{Abkürzungen}

ark.

arkuš (ukr. Blatt)

d.

delo (russ. Sache, hier: Angelegenheit)

f. fond (russ., ukr. Archivfond)

1.

list' (russ. Blatt)

o.

opis' (russ. Beschreibung, Verzeichnis)

opys (ukr. Beschreibung, Verzeichnis)

spr.

sprava (ukr. Sache, hier: Angelegenheit)

ROK

Russische Orthodoxe Kirche

$\mathrm{UAOK}$

Ukrainische Autokephale Kirche

UGKK

Ukrainische Griechisch-Katholische Kirche

UOK-KP

Ukrainische Orthodoxe Kirche des Kiever Patriarchats

UOK (MP) Ukrainische Orthodoxe Kirche unter Jurisdiktion des Moskauer Patriarchats 
Katrin Boeckh - 978-3-86688-505-9 


\section{Register}

\section{Orte, Landschaften, Länder}

A

Ägypten 60

Argentinien 60

Armenien 284

Australien / Australia 140

B

Belaja Krinica 41

Belarus 44, 319, 323. Siehe auch Weißrussland

Belgien 214

Berlin 240, 242, 244

Brest 22, 324

Brest-Litovsk 249

Brüssel $\quad 70,71,78,79,80,82,85,87$

Bukowina 25, 29, 37, 388

Bulgarien 133, 214

C

Čerkasy 51, 170, 191, 208

Černigov 220. Siehe auch Černihiv

Černihiv 51, 59, 60, 170, 191, 208, 244, 291, 335. Siehe auch Černigov

Černivci $51,170,191,208,289$

Charkiv 51, 171, 191, 208, 219, 236, 326. Siehe auch Charkov

Charkov 220. Siehe auch Charkiv

DigiOst 3 | 453 
Chełm 23, 237, 238, 242

Cherson 51, 60, 171, 191, 208, 219, 220, 223

Chmel'nyc'kyj $\quad 51,170,191,208,224,236,326$

Czyżki 314

D

Deutschland / Germany 28, 140, 214, 236, 240

Dnipropetrovs'k $\quad 51,171,191,208,222,223$

Donbass 222, 225

Donec'k 51, 171, 191, 208, 223, 225, 236, 262

Drohobyč 256, 289

Dukla 313, 317, 327, 328

Dymytriv 223

E

Ekaterinoslav 219, 220

Europa / Europe 1, 2, 5, 6, 8, 65, 66, 67, 69, 70, 71, 72, 73, 74, 75, 79, 81, 82, $83,85,86,87,88,89,92,98,139,141,142,145,146,150$

F

Florenz 324

Frankreich / France 98, 101, 140, 214

G

Galizien $21,22,24,27,29,30,31,32,37,38,116,120,124,125,127,222$, $225,239,249,258,271,286,316,388$

Griechenland 133, 214

$\mathrm{H}$

Hrodno 238

DigiOst 3 | 454 
Register / Orte, Landschaften, Länder

\section{I}

Indien 319

Israel 60

Italien / Italy 140

Ivano-Frankivs'k $\quad 51,170,191,208,224,251,259,260,290$

J

Japan 319

K

Kanada / Canada 140

Karpaten 25, 26

Karpaten-Ukraine 249, 251, 286, 291. Siehe auch Transkarpatien / Transkarpat'ska oblast' / Zakarpatt’ja

Kaukasus 16

Kiev $15,16,41,51,58,68,71,82,90,111,129,130,131,132,170,191,208$, $211,219,220,221,244,284,289,292,297,304,335,343,380,387,427$

Kiever Rus' $15,16,17,18,70$. Siehe auch Rus'

Kirovohrad 51, 60, 170, 191, 208, 236

Kleinrussland 335

Konstantinopel $15,110,129,130,132$

Krakau 313, 314, 355

Kremenec' 238

Krim 1, 15, 41, 51, 60, 170, 191, 208, 213. Siehe auch Krym

Kroatien 214

Krosno 313, 322, 323

Krym 171. Siehe auch Krim

Kyjiv 170. Siehe auch Kiev

DigiOst 3 | 455 
L

Lemberg $249,251,256,260,261,262,266,267,270,272,284,285,287$, 289, 292, 304, 313, 314, 315, 316, 318, 321, 322, 323, 325, 326, 327, 328, 329, 380, 388. Siehe auch L'viv

Lemken-Land 238

Lissabon 78

Litauen $316,318,319,323$

Lublin 237

Luc'k 239

Luhans'k 51, 60, 171, 191, 208, 236

L'viv 22, 37, 51, 126, 134, 168, 170, 191, 208, 224, 290, 325, 426, 427. Siehe auch Lemberg

$\mathbf{M}$

Mazedonien 132

Mohyliv-Podils'kyj 60

Moldau, Fürstentum 323

Moldova 319, 323

Montenegro 133

Moskau 110, 111, 121, 128, 130, 132, 213, 215, 235, 238, 239, 250, 255, 257, $282,283,286,302,304,359$

Mukačevo 249, 251

Mykolajiv 51, 60, 171, 191, 208, 236

$\mathrm{N}$

Nordamerika 381. Siehe auch Kanada / Canada; USA

$\mathrm{O}$

Odessa $51,171,191,208$

Österreich-Ungarn $24,25,28,31,206$

DigiOst 3 | 456 
Ostgalizien 237,238

$\mathbf{P}$

Peremyšl 133. Siehe auch Przemyśl

Petrograd 279

Pinsk 238, 239, 241, 243

Počajiv 243, 244

Podlachien 237, 238, 242, 262

Podolien 26, 219, 220

Polen 24, 28, 122, 123, 133, 190, 206, 214, 238, 314, 316, 318, 319, 322, 323, $325,327,329,330,343,347,348,349,350,351,352,353,354,355,356$, $357,358,360,362,363,364,365,369$

Polessien 238, 239

Poltava 51, 60, 170, 191, 208, 220, 236, 289, 333, 334, 335, 336

Posen 314

Pryluky 244

Przemyśl 22, 133, 327. Siehe auch Peremyšl

$\mathbf{R}$

Riga 320

Rivne 51, 170, 191, 208, 226, 289

Rom 21, 71, 110, 252, 316, 318, 320, 324, 327

RSFSR 159, 160. Siehe auch Russische Föderative Sowjetrepublik

Rumänien 28, 44, 214, 348

Rus' $15,16,17,42,43,70,111,129,130,213,215,222,249,257$. Siehe auch Kiever Rus'

Russische Föderative Sowjetrepublik 284. Siehe auch RSFSR

Russisches Reich 333, 335, 343, 344 
Russland $23,24,28,32,44,65,66,67,68,70,82,87,130,132,133,159$, $172,182,206,214,225,235,263,270,296,300,319,333,334,338,339$, $340,342,344,375,381$

Ruthenien $319,322,329,330$

Rzeczpospolita 20,376

$S$

Sambir 256

San-Land 238

Schweden $333,336,340$

Schweiz 60

Sevastopol' $51,58,191$

Sibirien 321

Sloboden-Ukraine 219

Slowakei $31,60,214,348$

Sowjetukraine $118,253,255,425,426,442$. Siehe auch Ukrainische SSR Sowjetunion / Soviet Union 2, 27, 28, 29, 34, 35, 37, 66, 69, 76, 103, 107, $115,120,123,139,153,156,159,160,161,169,177,181,236,240,251$, $253,278,279,281,282,284,285,286,292,293,294,303,333,349,358$, $363,364,381,425$. Siehe auch UdSSR

Strasbourg 70,71, 75, 79

Südkorea 381

Sumy $51,170,191,208,236$

$\mathrm{T}$

Taurien 219, 220

Ternopil' 51, 60, 170, 191, 208, 224, 251, 252, 262, 272, 290

Transkarpatien / Transkarpat'ska oblast' 21, 24, 27, 29, 31, 32, 37, 38, 41, $51,116,122,125,222,225,226,378,383,388$. Siehe auch Karpaten-Ukraine / Zakarpatt'ja

DigiOst 3 | 458 
Register / Orte, Landschaften, Länder

Tschechien 348

Tschechoslowakei 28,31

$\mathrm{U}$

UdSSR 153, 160, 249, 254, 264, 282, 283, 284, 286. Siehe auch Sowjetunion / Soviet Union

Ukrainische Sowjetrepublik 160, 161, 249, 251, 252, 270, 294. Siehe auch Sowjetukraine

Uman 289

Ungarn $24,25,28,31,44,213,214$

United Kingdom (UK) 140

USA 101,140

V

Vatikan $2,125,133,249,250,317$

Vinnycja 51, 60, 170, 191, 236

Volyn' 60, 170, 191, 208. Siehe auch Wolhynien

Vorošylovhrad 262

W

Warschau $134,238,242,321$

Weißrussland 239, 284. Siehe auch Belarus

Wilna 238

Wolhynien $22,23,24,26,29,37,51,219,220,224,226,237,238,239,388$.

Siehe auch Volyn'

$\mathrm{Z}$

Zakarpatt'ja / Zakarpats'ka oblast' 170, 191, 208, 290. Siehe auch Transkarpatien / Transkarpat'ska oblast' / Karpaten-Ukraine

Zaporižžja $51,60,171,191,208,222,223$

DigiOst 3 | 459 
Register / Personenregister

Zbruč 108

Žytomyr 51, 170, 191, 208, 220, 244, 320, 321, 328

\section{Personenregister}

A

Adalbert, Heiliger 323

Aleksander von Sanok 322

Aleksij II. 129, 130

Aleksij (Simanskij) 263, 273

Antonius (Marčenko) 239

Askold 15

August III. 316

Azarov, Mykola 56

B

Barroso, José Manuel 73

Bathóry, Stephan 20

Benedikt XIV. 316

Bernardino von Siena 314,323

Bohatyrova, Rajisa 56

Brežnev, Leonid 39

C

Chmel'nyc'kyj, Bohdan 23, 376, 379

Chodčenko, Pavlo 284

Chruščev, Nikita 39, 288, 292

Clemens XII. 316, 318

DigiOst 3 | 460 


\section{Register / Personenregister}

D

Dargel, Paul 244

Dionysios (Valedyns'kyj) 238, 242

Dir 15

$\mathrm{E}$

Engels, Friedrich 177

F

Felici, Angelo 318

Feodosij (I. I. Procjuk) 291

Filaret (Denysenko) 83, 121, 132, 253, 254, 257, 359, 360

Franz von Assisi 321, 323

Franz Xaver 319,321

Füle, Štefan 80

G

Gorbačev, Michail 117, 293

$\mathrm{H}$

Hejmo, Konrad 354, 355

Heydrich, Reinhard 240

Hilarion 242

Hitler, Adolf 238

Hovorun, Kyrylo 110

Hruševs'kyj, Mychajlo 19

Hryhorij (Zakaljaka) 255, 256, 270

Huzar, Ljubomyr $\quad 109,127,131$ 


\section{I}

Igor, Fürst 15

Ihor (Huba) 243

Ilias, Heiliger 15

Innozenz VIII. 315

Ioann (Sokolov) 291

Isakowicz-Zaleski, Tadeusz $\quad 355,367$

Iskra, Ivan $337,341,342$

J

Jadwiga, Heilige 323

Jakunin, Gleb 359

Janukovyč, Viktor $5,7,43,49,78,86,110,111,128,215,216,217,223$, $299,301,302,362$

Jarema, Volodymyr 359

Jaropolk 15

Jaworski, Marian 321, 322, 327

Johannes Paul II. 8, 71, 134, 293, 313, 317, 319, 322, 325, 354. Siehe auch Wojtyła, Karol

Johannes Sacranus von Auschwitz 324

Johannes von Capestrano 314,323

Johannes von Dukla $8,313,314,315,316,317,318,319,320,321,322$, $323,325,326,327,328,329,330$

Johannes von Komorowo 315, 316, 318, 326

Józewski, Henryk 237

Jurij (Korenistov) 243

Juščenko, Viktor $5,43,68,73,128,129,298,299$

K

Karl XII. 333, 337, 343

DigiOst 3 | 462 


\section{Register / Personenregister}

Karpov, Georgij Grigor'evic 283, 284, 285, 288

Katharina II. 376

Kirill 111, 125, 127, 130, 215, 216

Koch, Erich 241, 244

Kočubej, Vasyl' 337, 341, 342

Kolesnyk, Mykola 294

Kopysteryński, Dobrosław 325, 328

Kostel'nyk, Havryjil 258, 259, 261, 262, 263

Kravčuk, Leonid 67, 296

Kučerjavyj, P. L. 285

Kučma, Leonid $\quad 43,67,71,76,109,297$

Kuroedov, Vladimir Alekseevič 288, 292, 293

$\mathrm{L}$

Lenin, Vladimir Il'ič $\quad 177,288$

Lewada, Juri $161,162,164,169$

Lutkovs'ka, Valerija 58, 59

M

Makarij (Oksijuk) 262, 263, 271, 272

Marx, Karl 176, 177

Mazepa, Ivan 334, 336, 337, 342, 343, 346

Mokrzycki, Mieczysław 325

Molotov, Vjačeslav 284

Moroz, Oleksandr 128

Moškola, Mychajlo 56

Mstyslav 243, 244

Mychajil (Mel'nyk) 256 
$\mathrm{N}$

Nikanor (Abramovyč) 243

Nikolaj (N. V. Kutepov) 288, 291

Nikolaus II. 338, 340, 344

Nikolaus (Jaruševič) 239

Nowak, Edward 327

Nusenkis, Viktor 223

Nykon (Petin) 262

$\mathrm{O}$

Oleksandr (Hromads'kyj) 241, 242

Oleksandr (Inozemcev) 238

Oleksij (Hromads'kyj) 238, 239, 243, 244

Oleśnicki, Zbigniew 314

Ol'ga 15,16

Orłowa, Hedwig/Jadwiga 326

Otto I. 16

$\mathbf{P}$

Palladij (Kamins'kyj) 272

Pantelejmon (Rožnovs'kyj) 239

Pantelejmon Rudyk (M. Rybačuk) 242, 243

Pavlovskij, Ivan 333, 337, 338

Peter I. 260, 333, 334, 336, 337, 338, 339, 340, 343, 344

Pius XII. 324

Poljanskij, Ivan Vasilevič 283

Polykarp (Sikors'kyj) 239, 241

Popov, Heorhij 299

Próchnicki, Jan Andrzej 316

Purwiński, Jan 320 
Putin, Vladimir 111

$\mathbf{R}$

Renan, Ernest 218

Rosenberg, Alfred 241

$S$

Sahan, Oleksandr 299

Sawa (Bischof) 358

Šeptyc'kyj, Andrej 243, 257

Serafim (Ljade) 242

Sergij I. (Stragorodskij) 235, 236

Ševčuk, Svjatoslav 57

Sigismund III. Wasa 20

Simon (Ivanivs'kyj) 239

Sol'čanyk, Bohdan 10

Stalin, Iosif $\quad 116,238,252,260,282,288$

Stanislaus, Heiliger 323

Stanisław August 316

Stanisław Leszczyński 337

Stolypin, Petr 376

Szyrokoradiuk, Stanisław 321,325

$\mathrm{T}$

Tietmar von Merseburg 16

Tokarczuk, Ignacy 327

Trofimiak, Marcjan 322

Tymošenko, Julija $\quad 73,86,190,227,299$ 


\section{Register / Sachregister}

V

Vlasovs'kyj, Ivan 238

Volodymyr 42, 130, 131, 132

Vyšnevskij, A. A. 285

W

Weber, Max 175, 376

Wielgus, Stanisław 355, 360

Wojtyła, Karol 355. Siehe auch Johannes Paul II.

Wyszyński, Stefan 350

$\mathrm{Z}$

Zinčenko, A. 297

Zosima (Sokur) 215

Zygmunt III. Wasa 316

\section{Sachregister}

A

Adventismus 377

Adventisten des Siebten Tages $\quad 60,378,382,383,387,388,389$

Allukrainischer Orthodoxer Kirchenrat 242, 243

All-Ukrainischer Rat der Kirchen und Religiösen Organisationen (Vse-

ukrajins'ka Rada Cerkov i relihijnych orhanizacij, VRCiRO) 45, 56, 61, $66,76,77,79,80,81,82,87,88,89,94,102,109,110,216,226,227,297$, 298, 299, 300, 301, 304, 360, 361, 362, 385

Altorthodoxie 41

Arianismus 16

Armenier $16,319,321,323,324,327,329$

DigiOst 3 | 466 
Register / Sachregister

Armenische Kirche 168, 226

Aserbaidschaner 41

Assimilierungspolitik 120

Assoziierungsabkommen $\quad 67,71,80,82,83,85,87,88,227$

Atheismus 28, 35

Atheisten 129

B

Baptismus 377

Baptisten 35, 378, 379, 382, 386

Baptistische Gemeinden 25

Baptistische Kirchen 34

Buddhismus 99

Buddhisten 380

C

Calvinische Gemeinden 19, 25

Charismatische Bewegungen $379,382,383,386,387,388$

Chasaren 16

Christuskirche 378

D

Demokratisierung $73,85,86,89,99$

Department für Religionen und Nationalitäten 56

Desäkularisierung 181

Deutsche Evangelisch-Lutherische Kirche 378

Deutsche Lutheraner 41

Dissidenten 117

Doppelglauben 17,18

Doppelkonfessionalität 23,24

DigiOst 3 | 467 
Register / Sachregister

E

EBRD $139,142,143,144,146$

Economic Reforms 139, 143, 144, 146, 147, 148, 149, 150, 151

Entsäkularisierung $7,213,221,222,223,224,225$

Erinnerungsorte $335,336,339$

EU $67,68,71,72,73,79,80,81,82,83,85,86,87,88,89$. Siehe auch Europäische Union

Euro-Majdan 1, 2, 5, 9, 10, 49, 109, 174, 386

europäische Integration $68,79,81,83,89,100$

Europäische Union 82, 94. Siehe auch EU

Europa-Politik 65, 67, 78

European Values Survey (EVS) 155, 156, 157, 158, 162, 163, 164, 166, 171, 183

Evangelisch-Augsburgische Kirche 353, 358, 364

Evangeliumschristen-Baptisten 378, 379, 386

Evangeliumskirche 379

G

Gemeinschaft Evangelischer Kirchen in Europa (GEKE) 75

Gesamtukrainischer Verband der Evangeliumschristen-Baptisten 378

Gewissensfreiheit $\quad 49,50,51,52,53,54,55,56,57,58,59,61,215,228$

Glasnost' 161

Glaubensfreiheit $50,57,58,116$

Glaubensgemeinschaften 3,7

Griechisch-Katholische Kirche 21, 22, 23, 25, 26, 27, 30, 32, 38, 39, 43, 44.

Siehe auch Ukrainische Griechisch-Katholische Kirche (UGKK)

Großer Nordischer Krieg (1700-1721) 333

$\mathrm{H}$

Heidentum $15,17,18$

DigiOst 3 | 468 
Register / Sachregister

Hitler-Stalin-Pakt 238

Homosexualität 84

Homo sovieticus 178, 179. Siehe auch Sowjetmenschen

I

Institut für Nationales Gedenken (Instytut Pamięci Narodowej, IPN) 348, $354,355,357,358,364$

Institut für Nationales Gedenken (Ukrajins'kyj instytut nacional'noï pam-jati, UINP) 348

Integration $68,71,79,81,83,87,88$

Islam 16

ISSP $155,166,169,170,211$

$\mathrm{J}$

Judaismus 16

Juden $41,51,213,219,226,245,380$

Judentum 99

Jüdische messianische Gemeinden 60

K

Katholiken 51, 108, 123, 134

Katholizismus 23, 44, 375

KGB 282, 292, 293, 351, 358, 359, 360

Kirche

Altgläubige 283

armenisch-gregorianisch 283

griechisch-katholisch 283

katholisch 283

Lutheraner 283, 383

protestantisch 295

DigiOst 3 | 469 
Register / Sachregister

Kirchenunion $19,21,22,25,26,30,32$

Kirchenverfolgung 281, 285, 288

Koreanische Baptisten 41

Kosaken 23, 120, 272, 322, 326, 327

Kreml' 235, 239

Krimtataren 9

Krishna-Anhänger 380

L

Lebendige Kirche 33

Life in Transition Survey (LiTS) 143, 144, 145, 146

Life satisfaction $140,143,146,147,148,149,150,151$

Litauer 327

Lustration $352,353,354,355,356,364$

Lutherische Gemeinden 19, 25

M

Manichäismus 16

Mennoniten 383

Militanter Atheismus 235

Minderheit

slowakische 41

ungarische 41

Monokonfessionalität $\quad 15,16,17,18,20,38,39,42$

Mormonen 380

Muslime $9,41,51,81,226$

$\mathrm{N}$

Nestorianismus 16

Neuapostolische Kirche 378

DigiOst 3 | 470 


\section{Register / Sachregister}

Neurussland 220

NKGB. Siehe KGB

NKVD. Siehe KGB

Normen 3, 147, 189, 190, 192, 202, 204, 205, 208, 209, 210. Siehe auch Werte / Values

$\mathrm{O}$

Orangene Revolution 2, 65, 68, 77, 109

Orthodoxe $22,108,127,129,130,213,216,223,225,226,241,242,249$, $250,254,255,260,261,264,268,272,273,314,321,324,336,351$

Orthodoxe Kirche 24, 35, 38, 39

Orthodoxie $15,18,19,20,23,25,26,27,30,31,33,35,37,38,39,40,44$, $46,51,99,120,121,126,127,128,130,131,132,159,182,219,222,235$, $237,238,241,243,249,250,251,254,258,260,263,264,265,271,273$, $274,320,324,331,375,423$

Osmanen 322,327

$\mathbf{P}$

Papst 252, 254, 257

Paulikianismus 16

Perestrojka 107, 117, 160, 178, 293

Pfingstbewegung 377,378

Pfingstkirche »Neues Leben» 60

Pfingstler 25, 28, 34, 382, 383, 386, 388

Polen 213, 219

Polykonfessionalität $19,25,28,33,41,99$

Presbyterianer 378

Priesterlose 41

Protestanten $51,108,213,226,376,377,379,380,381,383,384,385,387$, 388,389 
Register / Sachregister

Protestantische Gemeinden 19, 41

Protestantische Kirchen 29, 34, 375, 378, 384

Protestantismus $19,21,25,26,27,39,44,375,376,377,378,379,380,382$, $383,384,385,388,389,392$

Q

Quality of life 140

$\mathbf{R}$

Rat für die Angelegenheiten der Religiösen Kulte 254, 278, 283, 284, 292, 293, 294, 295, 296, 297, 351

Rat für die Angelegenheiten der Russischen Orthodoxen Kirche 254, 255, 262, 266, 272, 282, 284, 288, 291, 292

Rat für Religiöse Angelegenheiten 254, 266

Razumkov-Zentrum 52, 53, 54, 69, 76, 94, 102, 155, 156, 157, 158, 162 , $163,170,217,380$

Reformatorische Kirche 44

Regionale Mentalität 189

Religion

buddhistische 283

jüdische 283

muslimische 283, 295

Religionsfreiheit $107,117,126,213,214,215,217$

Religiosität 206, 207, 208, 209, 224

Renovabis 110

Römisch-Katholische Kirche $\quad 20,34,41,44,122,126,226,239,258,379$, 423

Rumänen 213

Russen 327, 336, 344

Russische Föderation 99

DigiOst 3 | 472 
Russische Orthodoxe Kirche (ROK) 29, 30, 33, 34, 38, 39, 41, 70, 73, 74, $75,79,93,99,116,117,120,121,125,159,216,219,225,235,236,239$, $241,243,250,251,253,254,255,256,258,259,260,261,262,264,265$, $266,269,270,272,273,281,282,284,285,287,288,289,290,291,292$, $303,334,336,349,350,351,359$

Ruthenen $219,314,319,323,324,327$

S

Schlacht von Poltava 333, 334, 335, 337, 338, 339, 340, 343, 344, 345

Schwedische Lutheraner 41

Sowjetmenschen 177. Siehe auch Homo sovieticus

Sowjetvolk 117

sozinianische Gemeinden 19

Sprachpolitik $\quad 425,426,446$

Sri Chinmoy 60

Staatskomitee für Nationalitäten und Religionen $\quad 56,102,118,361,377$, 378,386

Staatskomitee für Religiöse Angelegenheiten 76, 77, 277, 378

Standardsprache $\quad 423,424,426,427,429,433,435,441,443,445$

$\mathrm{T}$

Tataren $41,213,322$

$\mathrm{U}$

Ukrainische Autokephale Orthodoxe Kirche (UAOK) 28, 29, 33, 34, 36, 43, $75,116,117,120,213,241,242,243,244,249,264,295,349,353,359$

Ukrainische Autonome Orthodoxe Kirche 241, 243, 244

Ukrainische Griechisch-Katholische Kirche (UGKK) 28, 34, 38, 39, 40, 54, $55,57,60,73,81,82,102,109,110,116,117,123,124,125,126,131,132$, $133,159,171,213,216,219,223,224,225,226,227,239,243,249,250$, 


\section{Register / Sachregister}

251, 252, 256, 271, 272, 273, 295, 379, 423. Siehe auch Griechisch-Katholische Kirche und Unierte Kirche

Ukrainische nationale Bewegung 334

Ukrainische Orthodoxe Kirche 54, 71, 122, 126, 128

Ukrainische Orthodoxe Kirche des Kiever Patriarchats (UOK-KP) 54, 55, $75,81,111,121,127,131,168,213,216,224,226,227,264,360$

Ukrainische Orthodoxe Kirche unter Jurisdiktion des Moskauer Patriarchats (UOK [MP]) 43, 45, 54, 55, 70, 71, 75, 79, 81, 86, 110, 117, 121, 122, 129, $131,168,213,216,217,224,226,227,241,242,244,251$

Ungarische Reformatorische Gemeinde 388

Ungarische Reformatorische Kirche 41

Unierte Kirche 22, 24. Siehe auch Ukrainische Griechisch-Katholische Kirche (UGKK)

Union 20, 21, 22, 23, 25

Kirchenunion von Užhorod 76, 124

Unitarische Gemeinden 19, 25

V

Volksreligiosität 177

W

Wahre Orthodoxe Kirche 41

Werte / Values $2,3,6,7,9,36,69,72,73,74,80,81,83,84,88,89,116$, $147,160,173,180,189,190,191,192,193,194,202,203,204,205,206$, $208,209,210,224$

World Christian database 144,146

World Values Survey (WVS) $\quad 155,156,157,163,164,166,171,183$

$\mathrm{Z}$

Zeugen Jehovas 34, 60, 292

\begin{tabular}{l|l} 
DigiOst 3 & 474
\end{tabular} 


\section{Register / Sachregister}

Zweiter Weltkrieg $34,36,38,116,118,120,159,235,249,251,252,253$, 281

Zweites Vatikanisches Konzil 134 


\section{ostdok}

Osteuropa-Dokumente

online

\section{口的语口 \\ Fin \\ .

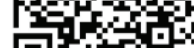 \\ aristis:}

ISBN: 978-3-86688-504-2 (print)

ISBN: 978-3-86688-505-9 (eBook)

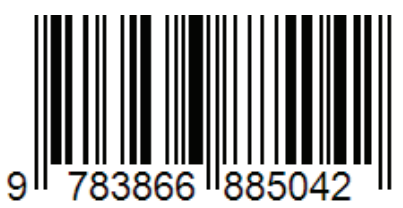

10 Institut für Ost- und Südosteuropaforschung

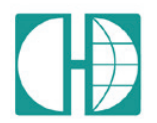

\section{HERDER-INSTITUT}

für historische Ostmitteleuropaforschung

INSTITUT DER LEIBNIZ-GEMEINSCHAFT
COLLEGIUM CAROLINUM

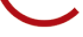

BS: Bayerische BS - StaatsBibliothek 